GÖTTINGER SCHRIFTEN ZUR INTERNETFORSCHUNG

Hg.: S. Hagenhoff, D. Hogrefe, E. Mittler, M. Schumann, G. Spindler, V. Wittke

\title{
Verfassungsrechtliche Anforderungen an Sperrmaßnahmen von kinderpornographischen Inhalten im Internet
}

Unter besonderer Berücksichtigung des Zugangserschwerungsgesetzes

Alexandra Heliosch 

Alexandra Heliosch

Verfassungsrechtliche Anforderungen an Sperrmaßnahmen von kinderpornographischen Inhalten im Internet

This work is licensed under the Creative Commons License 3.0 "by-nd", allowing you to download, distribute and print the document in a few copies for private or educational use, given that the document stays unchanged and the creator is mentioned. You are not allowed to sell copies of the free version.

SORMERIGHISRESERVED 
erschienen als Band 10 in der Reihe „Göttinger Schriften zur Internetforschung“ im Universitätsverlag Göttingen 2012 
Alexandra Heliosch

Verfassungsrechtliche

Anforderungen an

Sperrmaßnahmen von

kinderpornographischen

Inhalten im Internet

Unter besonderer Berücksichtigung des Zugangserschwerungsgesetzes

Göttinger Schriften zur

Internetforschung, Band 10

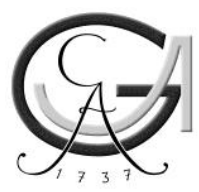

Universitätsverlag Göttingen 2012 


\section{Bibliographische Information der Deutschen Nationalbibliothek}

Die Deutsche Nationalbibliothek verzeichnet diese Publikation in der Deutschen Nationalbibliographie; detaillierte bibliographische Daten sind im Internet über $<$ http://dnb.ddb.de $>$ abrufbar.

\section{Reihe}

Band 10 der Reihe „Göttinger Schriften zur Internetforschung“ in der qualitätsgeprüften Sparte des Universitätsverlags Göttingen.

Herausgeber der Reihe: Svenja Hagenhoff, Dieter Hogrefe, Elmar Mittler, Matthias Schumann, Gerald Spindler und Volker Wittke.

\section{Anschrift der Autorin}

Alexandra Heliosch

e-mail: alexandra-anna.heliosch@jura.uni-goettingen.de

Dieses Buch ist auch als freie Onlineversion über die Homepage des Verlags sowie über den OPAC der Niedersächsischen Staats- und Universitätsbibliothek (http://www.sub.uni-goettingen.de) erreichbar und darf gelesen, heruntergeladen sowie als Privatkopie ausgedruckt werden. Es gelten die Lizenzbestimmungen der Onlineversion. Es ist nicht gestattet, Kopien oder gedruckte Fassungen der freien Onlineversion zu veräußern.

Satz und Layout: Alexandra Heliosch

Umschlaggestaltung: Martin Kasper und Margo Bargheer

(C) 2012 Universitätsverlag Göttingen

http://univerlag.uni-goettingen.de

ISBN: 978-3-86395-057-6

ISSN: 1863-0944 


\section{Vorwort}

Die vorliegende Arbeit wurde im Juli 2011 von der juristischen Fakultät der Georg-August-Universität Göttingen als Dissertation angenommen. Literatur und Rechtsprechung wurden im Wesentlichen bis Mai 2012 berücksichtigt.

Obgleich viele Menschen zum Gelingen dieser Arbeit beigetragen haben und Euch allen mein herzlichster Dank gebührt, kann ich an dieser Stelle nur einige Wenige besonders hervorheben.

Zunächst danke ich daher meinem Doktorvater, Prof. Dr. Gerald Spindler, für die Betreuung der Dissertation sowie für all die konstruktiven Anregungen und Ratschläge, die er mir während meiner Arbeit als wissenschaftliche Mitarbeiterin an seinem Lehrstuhl entgegenbrachte. Auch danke ich Prof. Dr. Langenfeld für die zügige Erstellung des Zweitgutachtens sowie Dr. Erdemir, der mein Interesse am Jugendschutz auf eine sehr einprägsame und angenehme Weise weckte.

Mareike, Danke, dass Du immer ein offenes Ohr für meine Sorgen hattest und Dir sowie Euch, Clemens und Vera, danke ich, dass Ihr Euch durch hunderte Seiten Formatierung und Rechtschreibung gequält habt, damit das Werk tatsächlich vollendet wird. Danken möchte ich auch denjenigen, die während meiner Lehrstuhlzeit von bloßen „Kürzel-Kollegen“ (Allen voran KB [Kathrin Brandt], sowie AS [Alin Seegel], Flo [Ingrid Rosine Floerke] und JuNi [Judith Nink]) zu guten Freunden wurden und neben fachlichen Diskussionen auch stets nette und aufmunternde Worte für mich fanden.

Besonderer Anerkennung bedürfen daneben auch all jene, die während der Entstehungsphase dieser Arbeit an meiner Seite standen, nie an mir gezweifelt haben, mich bedingungslos geliebt und unterstützt, finanziell entlastet und wenn nötig auch auf den Boden der Realität zurückgebracht haben: Zunächst mein Freund Julius, der - trotz seiner eigenen Dissertation - stets hilfsbereit war, mir jede erdenkliche Unterstützung entgegenbrachte und auch vor berechtigter Kritik - auch in Gewissheit meiner Reaktion darauf - nicht zurückschreckte. Sowie meine gesamte Familie, meine Tante und Patentante, Onkel, Cousin und Cousinen sowie Großeltern, vielen Dank, dass es Euch gibt.

Nicht zuletzt gebührt mein aufrichtigster Dank meinen Eltern, die meine gesamte Ausbildung ermöglicht haben und mir in allen Lebenslagen stets die nötige Sicherheit und Kraft geben und natürlich Dir, „Chrissi“, weil ich erst durch Dich, überhaupt ICH bin... Euch ist dieses Buch gewidmet. 



\section{Inhaltsverzeichnis}

VORWORT V

INHALTSVERZEICHNIS VII

LITERATUR XV

1. TEIL EINLEITUNG............................................................ 1

2. TEIL VERFASSUNGSRECHTLICHER UND TECHNISCHER HINTERGRUND ............................................................. 5

A. VERFASSUNGSRECHTLICHE EINFLÜSSE UND GEFÄHRDUNGSBEREICH

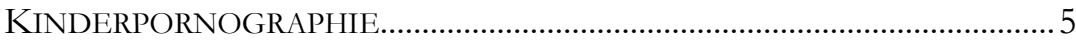

I. Schutzpflichtenlehre................................................................................... 5

1. Herleitung einer Schutzpflicht für den Jugendschutz aus der Schrankenregelung des Art. 5 Abs. 2, Var. 2 GG 8

2. Herleitung einer Schutzpflicht für den Jugendschutzes anhand des Allgemeinen Persönlichkeitsrechts gem. Art. 2 Abs. 1 GG i.V.m. Art. 1 Abs. 1 GG

a) Schutzbereichsverständnis des Bundesverfassungsgerichts...12

b) Systematik des Art. 2 Abs. 1 GG i.V.m. Art. 1 Abs. 2 GG ..13

c) Abgrenzungsschwierigkeiten................................................14

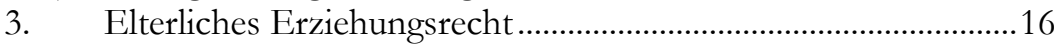

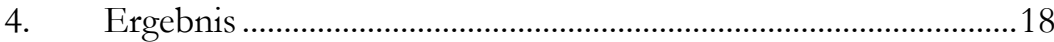

II. Kinderpornographische Angebote - Jugendschutzrelevanter

Gefährdungsbereich im Internet .....................................................18

1. Die Verbreitung von Kinderpornographie im Internet ..............18

a) Inhalt kinderpornographischer Produktionen..........................18

b) Internet als Verbreitungsweg von Kinderpornographie........22

c) Risiken der Verbreitung von Kinderpornographie.................29

(aa) Unmittelbare Gefahr: Körperliche Beeinträchtigung der

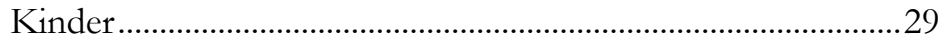

(bb) Unmittelbare Gefahr: Beeinträchtigung sexueller Selbstbestimmung ..................................................................... 30

(cc) Unmittelbare Gefahr: Geistig-seelische Nachwirkungen ........31

(dd) Mittelbare Gefahr: Konsum und geistig-seelische Beeinträchtigung .................................................................... 32

(ee) Mittelbare Gefahr: Nachahmung und erneute

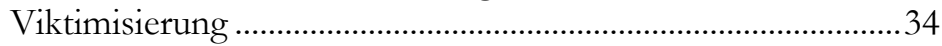

2. Schlussfolgerung für die staatliche Schutzpflicht .........................35

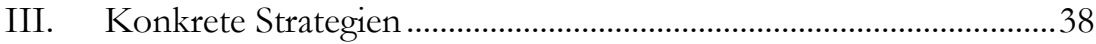

1. Gesetzliche Rahmenbedingungen mit Sanktionswirkung..........38

a) Strafrechtliche Ausgestaltung...................................................39

b) Spezialgesetzliche Ausgestaltung ...........................................44

2. Bemühungen im Bereich der Kriminalpolizei ............................45 
3. Rechtsrahmen für technische Präventivmaßnahmen .................47

IV. Ergebnis und Ausblick ...................................................................49

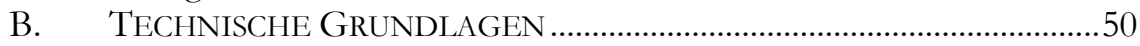

I. Systematische Einordnung der Datenübertragung im Internet .........50

1. Funktionen einzelner Schichten ....................................................5 52

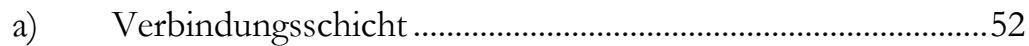

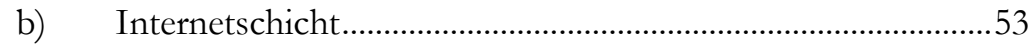

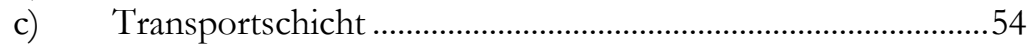

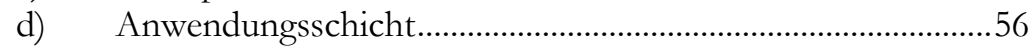

2. Technische Sperrmethoden .......................................................59

a) DNS-Server-Sperrung .............................................................59

b) Sperrung durch IP-Blocking am Router.................................60

c) Sperrung durch Proxy-Server................................................61

II. Zwischenergebnis: Technische Lösungsansätze .............................64

C. ERGEBNIS TEIL 2 UND AUSBLICK ........................................................65

3. TEIL VERFASSUNGSMÄßIGE ANALYSE ............................. 67

A. VORFRAGEN EINES GESETZLICHEN SPERRANSATZES ......................67

I. Zweck einer gesetzlichen Sperrverpflichtung/Kombination aus

Jugendschutz und Gefahrenabwehr .................................................68

II. Der Adressat der Sperrmaßnahme .................................................. 70

1. Rechtsstellung Staat $\mathrm{zu}$ Access-Providern....................................72

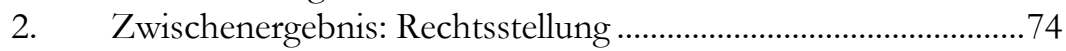

III. Grundsatz der Verhältnismäßigkeit...............................................74

IV. Ergebnis: Vorfragen........................................................................76

B. ENTGEGENSTEHENDE GRUNDRECHTE DER ACCESS-PROVIDER .. 76

I. Berufsfreiheit Art. 12 Abs. 1 GG ...........................................................76

1. Eingriff in den Schutzbereich .....................................................76

2. Verfassungsrechtliche Rechtfertigung............................................79

a) Legitimität des gesetzlichen Sperransatzes..............................81

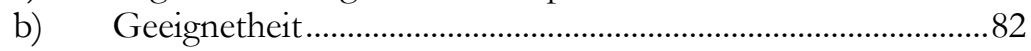

(aa) Ungeeignetheit wegen minimaler Erschwerung des

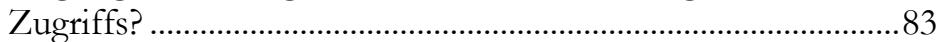

(1) Technische Sperrmethoden- Umgehungsmöglichkeiten ....84

(a) DNS-Sperrmethode: Umgehungsmöglichkeiten .........84

(b) IP-Sperrmethode: Umgehungsmöglichkeiten..............87

(c) Proxy-Sperrmethode: Umgehungsmöglichkeiten ........88

(2) Konsequenz: Minimale Erschwerung des Zugriffs ............. 90

(bb) Ungeeignetheit wegen befürchteten Overblocking? ................96

(cc) Ungeeignetheit wegen mangelnder Verhinderung mittelbarer Auswirkungen 
(dd) Schlussfolgerungen für die Geeignetheit einer gesetzlichen Sperrmaßnahme ........................................................................104

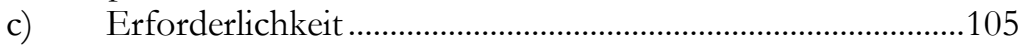

(aa) Technische Ausgestaltung der Löschung..................................106

(bb) Mildere Maßnahme....................................................................107

(cc) Gleiche Geeignetheit - Abhängigkeit vom Adressaten.........109

(1) Überblick über Bemühungen zur zeitnahen Löschung.....113

(2) Tatsächliche Löscherfolge .....................................................116

(3) Grundsätzliche Verfassungswidrigkeit eines Sperransatzes?

(4) Bestätigung durch den Grundsatz der Subsidiarität ..........121

(a) Nichtstörereigenschaft der Access-Provider..............122

(b) Zwischenergebnis: ..........................................................125

(dd) Unzulässigkeit der Sperrung wegen Auslandsbezug der

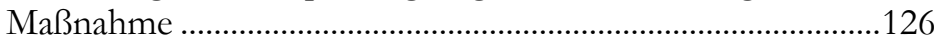

(a) Herkunftslandprinzip ..................................................127

(b) Anwendbarkeit deutschen Rechts auf Nicht-EU-Inhalte

(c) Zwischenergebnis...............................................................132

(ee) Weitere Mittel................................................................................132

(a) Nutzerseitige Filterung..................................................132

(b) Stärkung der Medienkompetenz …………………........134

(c) Selbstregulierung der Provider........................................134

(ff) Ergebnis: Erforderlichkeit.......................................................135

d) Verhältnismäßigkeit im engeren Sinne - Angemessenheit..135

(aa) Angemessenheit der Inanspruchnahme als solche .................138

(1) Abwägungsrelevanter Belang: Intensität der beruflichen Beeinträchtigung.......................................................................138

(2) Abwägungsrelevanter Belang: Inanspruchnahme für staatliche Zwecke ........................................................................140

(3) Zweck-Mittel-Relation..........................................................142

(bb) Angemessenheit der Inanspruchnahme ohne staatliche Entschädigung? ..........................................................................144

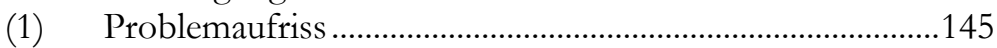

(2) Generelle Entschädigungslosigkeit bei Inanspruchnahme von Privaten zur Gefahrenabwehr .......................................148

(3) Unzumutbarkeit bei Berücksichtigung der wirtschaftlichen

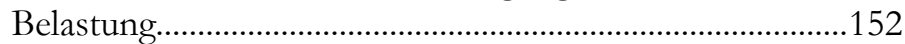

(4) Folgerungen für die Normierung .........................................154

(5) Das BVerfG-Urteil zur Vorratsdatenspeicherung Endgültige Abkehr vom Entschädigungserfordernis? ......156 
e) Zwischenergebnis: Verhältnismäßigkeit im engeren Sinne:

Angemessenheit des Eingriffs in Art. 12 Abs. 1 GG ............160

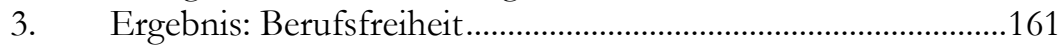

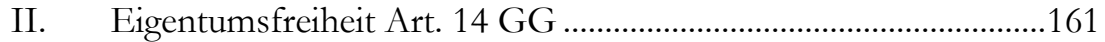

1. Eingriff in den Schutzbereich ...................................................161

2. Verfassungsrechtliche Rechtfertigung - Speziell

Verhältnismäßigkeit im engeren Sinne/Angemessenheit ........163

3. Ergebnis: Eigentumsfreiheit ....................................................166

III. Kommunikationsgrundrechte des Art. 5 Abs. 1: Meinungs- und

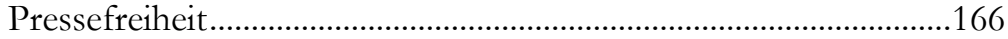

IV. Wissenschaftsfreiheit Art. 5 Abs. 3 Satz 1, Var. 2 GG .................169

1. Eingriff in den Schutzbereich.....................................................169

2. Verfassungsrechtliche Rechtfertigung - Speziell

Verhältnismäßigkeit im engeren Sinne/Angemessenheit ........170

a) Abwägungsrelevanter Belang: Abstrakte Wertigkeit ............172

b) Abwägungsrelevanter Belang: Konkrete Wertigkeit..............173

c) Abwägungsrelevanter Belang: Overblocking und Zweck-

Mittel-Relation .......................................................................174

d) Herstellung einer praktischen Konkordanz..........................175

3. Ergebnis: Wissenschaftsfreiheit...................................................177

V. Ergebnis: Tangierte Individualinteressen der Access-Provider ...178

C. ENTGEGENSTEHENDE GRUNDRECHTE DER NUTZER ....................178

I. Informationsfreiheit Art. 5 Abs. 1 Satz 1, Alt. 2 GG ........................178

1. Eingriff in den Schutzbereich ....................................................178

2. Verfassungsrechtliche Rechtfertigung - Speziell

Verhältnismäßigkeit im engeren Sinne/Angemessenheit ........183

a) Sperrung ausschließlich kinderpornographischer Inhalte....186

(aa) Abwägungsrelevanter Belang: Abstrakte und konkrete

Wertigkeit .............................................................................186

(bb) Abwägungsergebnis ...............................................................189

b) Overblocking - Mitsperrung legaler Inhalte -

Verfahrensrechtliche Kompensation zur Sicherung der

Grundrechtspositionen

(aa) Abwägungsrelevanter Belang: Intensität und Zweck-Mittel-

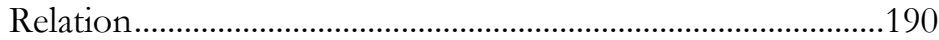

(bb) Abwägungsergebnis ...............................................................193

c) Verfahrensrechtliche Sicherung als Mittel des verfassungsrechtlichen Konkordanz

3. Ergebnis: Informationsfreiheit ...................................................197

II. Fernmeldegeheimnis Art. 10 Abs. 1, Var. 3 GG...........................198

1. Eröffnung des Schutzbereiches................................................198 
a) Schutzwirkung des Fernmeldegeheimnisses für Internetinhalte 199

b) Schutzbereichsrelevanz der Sperrmaßnahmen.......................203

(aa) IP-Sperrmethode: IP-Adresse als Umstand der Kommunikation

(1) Erhebung der IP-Adressen als Notwendigkeit zur Datenübertragung sowie zur Sperrung....

(2) IP-Adresse als schutzbereichsrelevanter näherer Umstand der Kommunikation?.

(a) IP-Adresse als personenbezogenes Verkehrsdatum? 205

(b) Personenbezug auch Nutzerbezug? 210

(bb) Proxy-Sperrmethode als schutzbereichsrelevanter Umstand der Kommunikation 213

(cc) DNS-Sperrmethode als schutzbereichsrelevanter Umstand der Kommunikation .214

2. Eingriff in den Schutzbereich..................................................216

a) Kenntnis der Provider ausreichend? .......................................216

b) Tatsächliche Kenntnisnahme? ..............................................220

(aa) Kein Eingriff bei bloßer Verhinderung des Datenübertragungsvorgangs .......................................................220

(bb) Intensität des Eingriffs entscheidend .....................................221

3. Ergebnis: Fernmeldegeheimnis ..................................................225

III. „Computergrundrecht“" Art. 2 Abs. 1 i.V.m. Art. 1 Abs. 1 GG..225

D. ENTGEGENSTEHENDE GRUNDRECHTE DER ANBIETER................227

I. Meinungsfreiheit Art. 5 Abs. 1, Satz 1, Alt. 1 GG ............................228

1. Eingriff in den Schutzbereich.................................................228

2. Verfassungsmäßige Rechtfertigung ..........................................229

II. Ergebnis: Meinungsfreiheit.........................................................233

E. GESAMTWÜRDIGUNG: ENTGEGENSTEHENDE GRUNDRECHTE...233

F. EINZUHALTENDE VERFASSUNGSPRINZIPIEN.................................234

I. Einhaltung des Bestimmtheitsgebots Art. 20 Abs. 3 GG ..................234

II. Einhaltung des Wesentlichkeitsgrundsatzes Art. 20 Abs. 3 GG.236

III. Einhaltung des Zitiergebots Art. 19 Abs. 1 Satz 2 GG ................238

IV. Widerspruch zum Zensurverbot Art. 5 Abs. 1 Satz 3 GG ..........240

G. ERGEBNIS: VERFASSUNGSMÄßIGE ANALYSE ..................................247

\section{TEIL FALLBEISPIEL -}

ZUGANGSERSCHWERUNGSGESETZ ................................. 249

A. Historische ENTWICKLUNG DES ZuGERSCHWG .........................250

B. REGELUNGSMECHANISMEN DES ZUGERSCHWG ............................2256

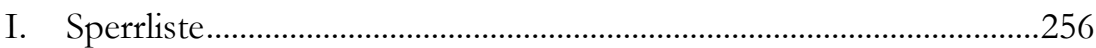

II. Zugangserschwerung gem. \ 2 Abs. 1 ZugErschwG ........................258 
III. Ergänzende Regelungen...................................................................259

C. GRÜNDE DES SCHEITERNS DES ZUGERSCHWG...............................260

I. Formelle Probleme …………………………….........................261

1. Fehlende Gesetzgebungskompetenz .........................................261

a) Kompetenz aus dem Recht der Wirtschaft Art. 74 Abs. 1 Nr.

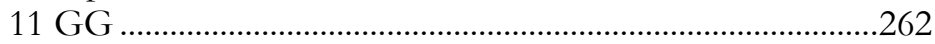

b) Kompetenz aus dem Strafrecht Art. 74 Abs. 1 Nr. 1 GG ..267

c) Kompetenz aus dem Recht der Telekommunikation Art. 73

Abs. 1 Nr. 7 Var. 2 GG ............................................................26

d) Kompetenz aus der Zusammenarbeit im Bereich der Kriminalpolizei Art. 73 Abs.1 Nr. 10 GG................................269

e) Kompetenz aus dem Jugendschutz im Rahmen der öffentlichen Fürsorge Art. 74 Abs. 1 Nr. 7 GG ....................271

(aa) Jugendschutz als Teilbereich der öffentliche Fürsorge...........272

(bb) Einschränkung des Kompetenztitels wegen „Erforderlichkeit“

(cc) Mangelnde Erforderlichkeit wegen Bestehen eines Staatsvertrages?.........................................................................227

(dd) Mangelnde Erforderlichkeit wegen Zersplitterung der Kompetenzen?............................................................................2.

f) Ergebnis: Bundeskompetenz …………………...........................28

2. Weitere formelle Probleme im Überblick: ZugErschwG und sein mangelhaftes Gesetzgebungsverfahren ...............................280

a) Verstoß gegen Geschäftsordnung und Verfassungswidrigkeit

(aa) Mangelnde erste Lesung: Kein evidenter Verfassungsverstoß....

(bb) Versagung der Anhörung als Verfassungsverstoß...................283

(cc) Ergebnis: Geschäftsordnungsverstoß.........................................286

b) Fehlende Verwaltungskompetenz ……………………….......286

(aa) Zentralstelle nach Art. 87 Abs. 1 Satz 2 GG..........................287

(bb) Generalklausel für die Bundesverwaltungskompetenz Art. 87 Abs. 3 GG

3. Ergebnis: Formelle Probleme .....................................................294

II. Materielle Probleme .........................................................................294

1. Entscheidungskompetenz der Access-Provider über die vorzunehmende Sperrmethode - verfassungsrechtlich tragbar?

a) Overblocking .......................................................................29

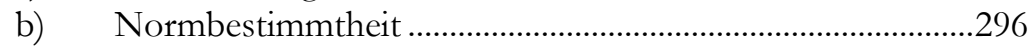

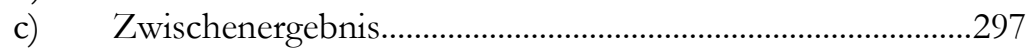

2. „Löschen vor Sperren“ ausreichend umgesetzt? ........................298 
a) Absicherung der Subsidiarität ..................................................298

b) Lehren für ein Löschgesetz ..................................................301

3. Umleitung auf Stoppschild als wesentliches Merkmal des

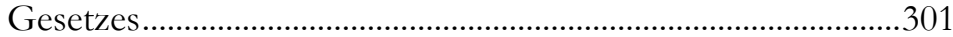

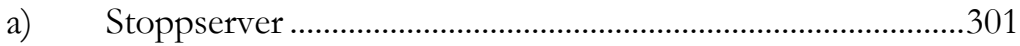

b) Lehren für ein Löschgesetz ..................................................303

4. Expertengremium als Ersatz für Richtervorbehalt?...................304

a) Richtervorbehalt als verfahrensrechtliche Kompensation ...304

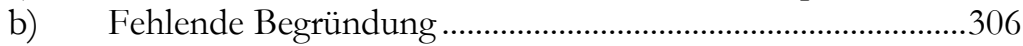

c) Besetzung des Gremiums .......................................................307

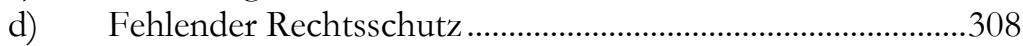

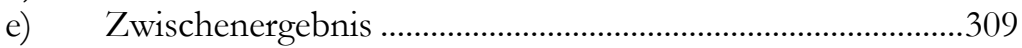

f) Lehren für ein Löschgesetz ...................................................309

5. Kompensation sonstiger Forderungen ........................................310

a) Entschädigungspflicht ..........................................................310

b) Lehren für ein Löschgesetz ................................................311

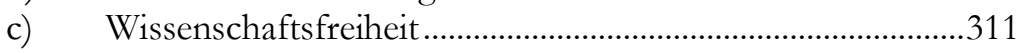

d) Lehren für ein Löschgesetz ..................................................313

6. Befürchtung der Ausweitung des Gesetzes.................................313

a) Sperrinfrastruktur universell einsetzbar.................................313

b) Lehren für ein Löschgesetz ..................................................315

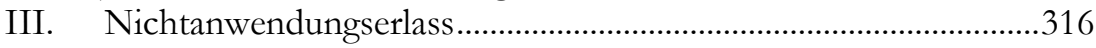

1. Rechtliche Würdigung ….............................................................316

a) Verstoß gegen Rechtsstaatsprinzip ........................................317

b) Gewaltenteilungsgrundsatz...................................................319

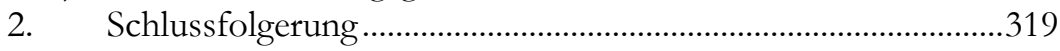

D. FAZIT: ZUGANGSERSCHWERUNGSGESETZ UND GRÜNDE DES

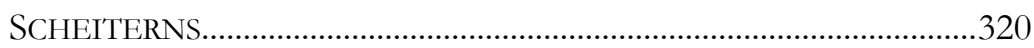

5. TEIL EUROPÄISCHE ENTWICKLUNG …...............................321

A. VOM RiCHTLINIENVORSCHLAG ZUR RICHTLINIE...........................321

I. Ausgangslage - Richtlinienvorschlag vom 29.3.2010.....................321

II. Rechtssetzungsverfahren: Die Beratungen zum

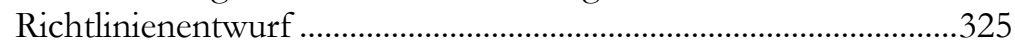

III. Die endgültige Richtlinienfassung vom 13.12.2011 ......................331

B. FOLGERUNGEN FÜR DIE INNERSTAATLICHE UMSETZUNG ............334

I. Keine Vorwirkung des bloßen Richtlinienvorschlags ......................334

1. Frustrationsverbot nach Inkrafttreten der Richtlinie.................334

2. Keine Vorverlagerung der Rechtswirkung ..................................336

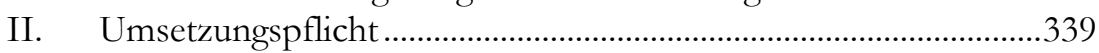

1. Keine unmittelbare Rechtswirkung einer Richtlinie .................339 
2. Erschwerte Umsetzung durch Diskrepanz zum deutschen Recht

a) Anknüpfung der Löschung an strafbewehrte „Kinder-“ Pornographieinhalte

(aa) Löschvorgabe: \184b StGB

(bb) Beibehaltung der Anknüpfung vorzugswürdig.

(cc) Unterschiedliches Verständnis: Kind und

Kinderpornographie

(1) Rahmenbeschluss 2004/68/JI gleiche Problematik ...........343

(2) Probleme für das Löschgesetz …………………………........344

(dd) Tatmodalitäten der Kinderpornographie ..................................345

b) Fiktivpornographische Darstellungen ......................................346

III. Schlussfolgerung.................................................................................347

C. EUROPÄISCHES VORGEHEN AM BEISPIEL FRANKREICHS ................347

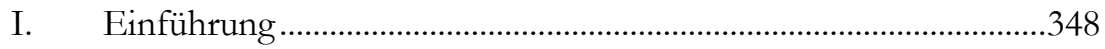

1. Ermächtigungsgrundlage nach französischen Recht ..................348

2. Conseil Constitutionnel im Kontext jüngerer

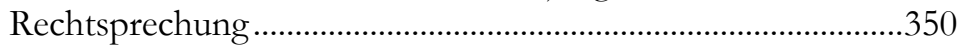

a) Conseil Constitutionnel-Entscheidung vom 10.3.2011 ........350

b) Conseil Constitutionnel-Entscheidung im Falle Hadopi......353

c) Kontext beider Entscheidungen...............................................356

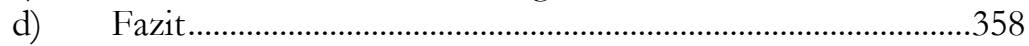

II. Art. 4 Loppsi 2 im Vergleich zum deutschen Recht ......................358

1. Rechtsgrundlage im Vergleich .....................................................358

a) Anknüpfung an strafrechtliches Verständnis .........................358

b) Konsequenz für europäischen Umsetzungsbedarf................359

c) Verfahren im Vergleich ................................................................360

d) Kreis der Verpflichteten im Vergleich......................................361

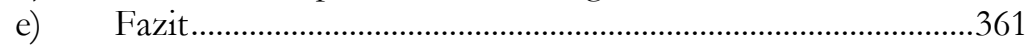

2. Verfassungsmäßigkeit der Norm nach deutschem Recht? .......362

a) Mangelnde Erforderlichkeit.....................................................362

b) Verhältnismäßigkeit im engeren Sinn - Angemessenheit ....363

c) Kommunikationsgrundrechte - fehlender

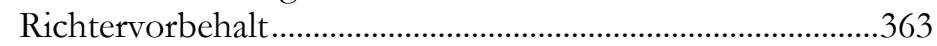

d) Einhaltung rechtsstaatlicher Prinzipien ....................................364

e) Entschädigungspflicht..............................................................364

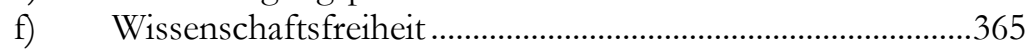

g) Mangelnde Gesetzesstruktur .................................................366

h) Europäische Vorgaben............................................................366

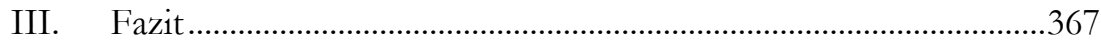

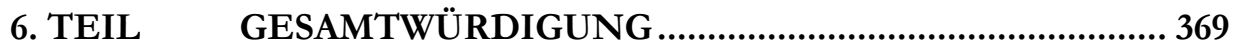




\section{Literatur}

Adolf, Marian/Mahrt, Merja/Rhomberg, Marcus: Medienwirkung interdisziplinär: Anmerkungen zum dynamisch-transaktionalen Ansatz, Festschrift für Klaus Schönbach, Wiesbaden 2009, S. 15

Albers, Marion: Gleichheit und Verhältnismäßigkeit, JuS 2008, 945

— : Informationelle Selbstbestimmung, Baden-Baden 2005

Altenhain, Karsten/Liesching, Marc/Ritz-Timme, Stefanie/Gabriel, Peter: Kriterien der Scheinminderjährigkeit im Rahmen des Strafverbots der Jugendpornographie, BPJM-Aktuell 2/2009

Altvater, Gerhard: Verfassungswidrigkeit des Gewaltbegriffs in StGB \ 240 in der Auslegung der herrschenden Rechtsprechung, NStZ 1995, 278

Amann, Gabriele/Wipplinger, Rudolf: Sexueller Missbrauch: Überblick zu Forschung, Beratung und Therapie, 3. Auflage, Tübingen 2005

Arnauld, Andreas von: Die Freiheitsrechte und ihre Schranken, Baden-Baden 1999

Arndt, Hans-Wolfgang: Steuerliches Diskriminierungsverbot und nichtharmonisierte Umsatzsteuer - zur Beschränkung des steuerlichen Erfindungsrechts der Mitgliedstaaten durch EG-Gemeinschaftsrecht, DStR 1989, 471

Baacke, Dieter: Handbuch Medien - Medienkompetenz: Modelle und Projekte, Bonn 1999

Bachmair, Ben: Gewaltdarstellungen - Schlüsse zur Definition von Subjektivität, tv-diskurs 4/1999, 63

Bachof, Otto: Beurteilungsspielraum, Ermessen und unbestimmter Rechtsbegriff im Verwaltungsrecht, JZ 1955, 97

Bader, Johann/ Ronellenfitsch, Michael: Verwaltungsverfahrensgesetz Kommentar, München 2010 
Bandehzadeh, Mona: Jugendschutz im Rundfunk und in den Telemedien, Frankfurt am Main 2007

Bange, Dirk/Deegener, Günther: Sexueller Missbrauch an Kindern, Weinheim 1996

Bär, Wolfgang: Auslesen der SIM-Karte bei beschlagnahmtem Mobiltelefon, MMR 2005, 523

— : Handbuch zur EDV-Beweissicherung, Stuttgart 2007

Bauer, Hartmut: Zum Gesetzesvorbehalt für die Handlungsform des Verwaltungsakts, NVwZ 1987, 112

Baum, Christoph Georg: Jugendmedienschutz als Staatsaufgabe, Baden-Baden 2007

Becker, Bernd: Öffentliche Verwaltung, Percha am Starnberger See, 1989

Beckmann, Kirsten: Verantwortlichkeit von Online-Diensteanbietern in Europa und Vereinigten Staaten von Amerika - Ein rechtsvergleichendes Thema am Beispiel der Ehrverletzungsdelikte in Deutschland, den USA und England mit europarechtlichem Ausblick, Münster 2001

Beisel, Daniel/Heinrich, Bernd: Die Strafbarkeit der Ausstrahlung jugendgefährdender Fernsehsendungen, NJW 1996, 491

Bender, Mark: Rechtmäßigkeit der „Deep Packet Inspection“, abrufbar unter: http://kobra.bibliothek.uni-kassel.de/bitstream/urn:nbn:de:hebis:342009113031192/5/BednerDeepPacketInspection.pdf

Berg, Stefan/Rosenbach, Marcel: Schwarz-Gelb rückt von Internetsperren ab, Spiegel Online v. 8.2.2010, abrufbar unter:

http://www.spiegel.de/politik/deutschland/0,1518,676669,00.html

Berger, Christian: Jugendschutz im Internet: ,geschlossene Benutzergruppen“ nach \4 Abs. 2 Satz 2 JMStV, MMR 2003, 773 
Berka, Walter: Konkretisierung und Schranken der Grundrechte, ZÖR 1999, 31

Beste, Hubert: Privatisierung des Staates, Opladen 1996

Bettermann, Karl August: Bundeskompetenz für Jugendschutz, AöR 83 (1958), 91

Billmeier, Eva: Die Düsseldorfer Sperrungsverfügung: Ein Beispiel für verfassungs- und gefahrenabwehrrechtliche Probleme der Inhaltsregulierung in der Informationsgesellschaft, Berlin 2007

Bizer, Johann: IP-Adressen sind Verkehrsdaten, DuD 2007, 602

— : Forschungsfreiheit und informationelle Selbstbestimmung, Baden-Baden 1992

Bleckmann, Albert: Die Grundrechte im Europäischen Gemeinschaftsrecht, EuGRZ 1981, 257

Bleich, Holger: Gefährliche Symbolpolitik, c’t 06/2010, S. 67

Bleisteiner, Stephan: Rechtliche Verantwortlichkeit im Internet unter besonderer Berücksichtigung des Telemediengesetzes und des MediendiensteStaatsvertrags, Köln 1999

Blumenthal, Sebastian/Buschmann, Marco/Höferlin, Manuel/Schulz, Jimmy: Argumentationshilfe „Netzsperren“, 2010, abrufbar unter: http://judithskudelny.de/files/33904/Netzsperren_Papier_Fraktion.pdf

Böckenförde, Ernst-Wolfgang: Grundrechte als Grundsatznormen - Zur gegenwärtigen Lage der Grundrechtsdogmatik, Der Staat 29 (1990), 1

— : Elternrecht - Recht des Kindes - Recht des Staates, Essener Gespräche zum Thema Staat und Kirche, Bd. 14 (1980), S. 54

— : Die Organisationsgewalt im Bereich der Regierung, Berlin 1998 
Böckenförde, Thomas: Die Ermittlung im Netz - Möglichkeiten und Grenzen neuer Erscheinungsformen strafprozessualer Ermittlungstätigkeit, Tübingen 2003

— : Auf dem Weg zur elektronischen Privatsphäre, JZ 2008, 925

Borrmann, Alexandra: Der Schutz der Berufsfreiheit im deutschen Verfassungsrecht und im europäischen Gemeinschaftsrecht: eine rechtsvergleichende Studie, Berlin 2002

Bottke, Wilfried: Zum Rechtsgut der $\int S 174$ ff. StGB, Festschrift für Harro Otto, Köln 2007, S. 535

Brandenburg, Christoph/Lammeyer, Philipp: Steht der Kommission für Jugendmedienschutz ein Beurteilungsspielraum zu?, ZUM 2010, 655

Brandner, Thilo: Parlamentarische Gesetzgebung in Krisensituationen, NVwZ 2009, 211

Braun, Frank: Die Finanzierung polizeilicher Aufgabenwahrnehmung im Lichte eines gewandelten Polizeiverständnisses, Stuttgart 2009

— : Verfassungswidrigkeit der entschädigungslosen Indienstnahme von Telekommunikationsunternehmen zur Auslandskopfüberwachung, jurisPRITR 2/2008 Anm. 4

— : Die entschädigungslose Indienstnahme Privater am Beispiel der sog. Vorratsdatenspeicherung, K\&R 2009, 386

Breitfeld, Anja: Berufsfreiheit und Eigentumsgarantie als Schranke des Rechts auf informationelle Selbstbestimmung, Berlin 1992

Bremer, Karsten: Radikal-politische Inhalte im Internet - ein Umdenken erforderlich?, MMR 2002, 147

— : Strafbare Internet-Inhalte in internationaler Hinsicht - Ist der Nationalstaat wirklich überholt?, Frankfurt am Main 2001 
Breyer, Patrick: Die Haftung für Mitbenutzer von Telekommunikationsanschlüssen, NJOZ 2010, 1085

Britz, Gabriele: Vertraulichkeit und Integrität informationstechnischer Systeme, DöV 2008, 411

Brodowski, Dominik: Strafrechtsrelevante Entwicklungen in der Europäischen Union - ein Überblick, ZIS 2010, 376

— : Strafrechtsrelevante Entwicklungen in der Europäischen Union - ein Überblick, ZIS 2010, 749

— : Strafrechtsrelevante Entwicklungen in der Europäischen Union - ein Überblick, ZIS 2011, 940

Bröhl, Georg M.: Rechtliche Rahmenbedingungen für neue Informations- und Kommunikationsdienste, CR 1997, 73

Brosius, Hans-Bernd/Rössler, Patrick: Die soziale Realität in einfacher Pornographie und Softsex-Filmen - Ein Beitrag zur PornographieDiskussion, RuF 47 (1999), 25

Bumke, Christian: Der Grundrechtsvorbehalt - Untersuchungen über die Begrenzung und Ausgestaltung der Grundrechte, Baden-Baden 1998

Burgi, Martin: Der Beliehene - ein Klassiker im modernen Verwaltungsrecht, Festschrift für Hartmut Maurer, München 2001, S. 581

— : Funktionale Privatisierung und Verwaltungshilfe - Staatsaufgabendogmatik Phänomenologie - Verfassungsrecht, Tübingen 1999

— : Die Enteignung durch „teilweisen“ Rechtsentzug als Prüfstein für die Eigentumsdogmatik, NVwZ 1994, 527

— : Das Grundrecht der freien Persönlichkeitsentfaltung durch einfaches Gesetz, ZfG 1994, 341 
Buron, Marie-Anne: Frankreich: LOPPSI 2 - Gesetz verabschiedet, MMR Aktuell 2011, 313762

— : Frankreich: Conseil Constitutionnel entscheidet über LOPPSI 2, MMR Aktuell 2011, 316290

Calliess, Christian/ Ruffert, Matthias: EUV/AEUV - Das Verfassungsrecht der Europäischen Union mit Europäischer Grundrechtecharta Kommentar, 4. Auflage, München 2011

Charlton, Michael/Hoffmann-Riem, Wolfgang/Neumann-Braun, Klaus/Aufenanger, Stefan: Fernsehwerbung und Kinder, Bd. 2: Rezeptionsanalyse und rechtliche Rahmenbedingungen, Opladen 1995

Classen, Claus Dieter: Wissenschaftsfreiheit außerhalb der Hochschule - Zur Bedeutung von Artikel 5 Absatz 3 Grundgesetz für außeruniversitäre Forschung und Forschungsförderung, Tübingen 1994

Cole, Mark D.: Zum Beurteilungsspielraum der KJM bei der Bewertung von Jugendmedienschutzfragen, ZUM 2010, 929

Däubler, Wolfgang/Klebe, Thomas/Wedde, Peter/Weichert, Thilo: Bundesdatenschutzgesetz - Kompaktkommentar zum BDSG, 3. Auflage, Frankfurt am Main 2010

Danwitz, Thomas v.: Rechtswirkungen von Richtlinien in der neueren Rechtsprechung des EuGH, JZ 2007, 697

Degen, Rolf: Medienwirkung: Der große Bluff, Psychologie Heute, 15/1988, S. 20

Degen, Thomas A.: Freiwillige Selbstkontrolle der Access-Provider - Ein Beitrag zur Gewährleistung einer gemeinwohlverträglichen Informationsfreiheit, Stuttgart 2007

Degenhart, Christoph: Verfassungsfragen des Jugendschutzes beim Film, UFITA 2009, 331 
Delbrück, Jost: Direkter Satellitenrundfunk und nationaler Regelungsvorbehalt - Umfang und Grenzen des transnationalen freien Informationsflusses nach Völkerrecht des Rechts der Europäischen Gemeinschaften und des Grundgesetzes der Bundesrepublik Deutschland, Frankfurt am Main 1982

Denninger, Erhard/Hoffmann-Riem, Wolfgang/ Schneider, HansPeter/Stein, Ekkehart: Kommentar zum Grundgesetz für die Bundesrepublik Deutschland, Bd. 1: Art. 1-17, 3. Auflage, Neuwied Stand 2001; Bd. 2: Art. 18-80a, 3. Auflage, Neuwied Stand 2001

Dessecker, Axel: Veränderungen im Sexualstrafrecht - Eine vorläufige Bewertung aktueller Reformbemühungen, NStZ 1998,1

Deutscher Richterbund: Stellungnahme zum Vorschlag für eine Richtlinie zur Bekämpfung des sexuellen Missbrauchs und der sexuellen Ausbeutung von Kindern sowie der Kinderpornographie und zur Aufhebung des Rahmenbeschlusses 2004/68/JI des Rates, abrufbar unter: http:/ /www.drb.de/cms/index.php?id $=708 \& \mathrm{~L}=0$

Di Fabio, Udo: Privatisierung und Staatsvorbehalt - Zum dogmatischen Schlüsselbegriff der öffentlichen Aufgabe, JZ 1999, 585

Diamond, Milton/Jozifkova, Eva/Weiss, Petr: Pornography and Sex Crimes in the Czech Republic, Archives of Sexual Behavior Online, November 2010, abrufbar unter: http://www.springerlink.com/content/v046j3g178147772/fulltext.pdf

Dickhuth, Moritz: Jugendschutzprogramme gemäß \ $11 \mathrm{JMStV}$ - Eine kritische Analyse, Ilmenau 2010

Dieterich, Thomas/Müller-Glöge, Rudi: Erfurter Kommentar zum Arbeitsrecht, 12. Auflage, München 2012

Dietlein, Johannes: Die Lehre von den grundrechtlichen Schutzpflichten, Berlin 1992

Dietlein, Johannes/Heinemann, Jan: Ordnungsrecht und Internetkriminalität, K\&R 2004, 418 
Dirnberger, Franz: Recht auf Naturgenuß und Eingriffsregelung - Zugleich ein Beitrag zur Bedeutung grundrechtlicher Achtungs- und Schutzpflichten für das subjektiv-öffentliche Recht, Berlin 1991

Dittler, Ullrich/Hoyer, Michael: Zwischen Medienerwerb und Mediensucht Chancen und Gefahren des Aufwachsens in digitalen Erlebniswelten aus medienpsychologischer und medienpädagogischer Sicht, München 2010

Dolzer, Rudolf/Kahl, Wolfgang/Waldhoff, Christian/Graßhof, Karin: Bonner Kommentar zum Grundgesetz, Bd. 1: Einleitung - Art. 5, Heidelberg Stand 2/2012; Bd. 2: Art. 6- 14, Heidelberg Stand 4/2009; Bd. 4: Art. 15 19, Heidelberg Stand 2/2012; Bd. 6: Art. 50 - 74, Heidelberg Stand $8 / 2012$

Döring, Martin/Günter, Thomas: Jugendmedienschutz: Alterskontrollierte geschlossene Benutzergruppen im Internet gem. \ 4 Abs. 2 Satz 2 JMStV, MMR 2004, 231

Dornseif, Maximilian: Government mandated blocking of foreign Web content, abrufbar unter: http://md.hudora.de/publications/200306-giblocking/200306-gi-blocking.pdf

Dörr, Dieter: Die neuere Rechtsprechung des Bundesverfassungsgerichts zur Eigentumsgarantie des Art. 14 GG, NJW 1988, 1049

Dreier, Horst: Dimensionen der Grundrechte, Hannover 1993

—: Grundgesetz-Kommentar, Bd. 1: Präambel, Art. 1-19, 2. Auflage 2004; Bd. 2: Art. 20-82, 2. Auflage 2006; Bd. 3: Art. 83-146, 2. Auflage 2008

Durer, Wolfgang: Fernmeldegeheimnis und informationelle Selbstbestimmung als Schranken urheberrechtlicher Sperrverfügungen im Internet, ZUM 2010, 833

Dustmann, Andreas: Die privilegierten Provider, Baden-Baden 2001 
Duttge, Gunnar/Hörnle, Tatjana/Renzikowski, Joachim: Das Gesetz zur Änderung der Vorschriften über die Straftaten gegen die sexuelle Selbstbestimmung, NJW 2004, 1065

Ebenroth, Carsten Thomas/Fischer, Rafael/Sorek, Christoph: Deutsche StraBenbenutzungsgebühr und EG-Recht, BB 1989, 1566

Eberle, Carl-Eugen/Rudolf, Walter/Wasserburg, Klaus: Mainzer Rechtshandbuch der neuen Medien, Heidelberg 2003

Eckhardt, Jens: Anmerkung zu Urteil des LG Berlin vom 6.9.2007, 23 S 3/07, K\&R 2007, 602

Eckhardt, Jens/Schütze, Marc: Vorratsdatenspeicherung nach BVerfG: „Nach dem Gesetz ist vor dem Gesetz...“, CR 2010, 225

Edelmann, Benjamin: „Web Sites Sharing IP Adresses“: Prevalence and Significance, Publikation der Harvard Law School, abrufbar unter: http://cyber.law.harvard.edu/archived_content/people/edelman/ipsharing/

Eifert, Martin/ Hoffmann-Riem, Wolfgang: Innovation, Recht und öffentliche Kommunikation, Berlin 2011

Elicker, Michael: Der Grundsatz der Lastengleichheit als Schranke der Sonderabgaben, Inpflichtnahmen und Dienstleistungspflichten, NVwZ 2003, 304

Emmerich, Volker: Energierechtskompetenz des Bundesgesetzgebers, BB 1972, 457

Engel, Christoph: Die Internet-Service-Provider als Geiseln deutscher Ordnungsbehörden, MMR-Beil. 4/2003, 1

Engel, David: Jugendliche im Web 2.0 - Chancen und Risiken von Medienkompetenz, Kiel 2010 
Engels, Stefan: Kinder- und Jugendschutz in der Verfassung. Verankerung, Funktion und Verhältnis zum Elternrecht, AöR 122 (1997), 212

Epping, Volker/Hillgruber, Christian: Grundgesetz Kommentar, München 2009

Erdemir, Murad: Filmzensur und Filmverbot - Eine Untersuchung zu den verfassungsrechtlichen Anforderungen an die strafrechtliche Filmkontrolle im Erwachsenenbereich, Marburg 2000

— : Jugendschutzprogramme und geschlossene Benutzergruppen - Zu den Anforderungen an die Verbreitung entwicklungsbeeinträchtigender und jugendgefährdender Inhalte im Internet, CR 2005, 275

— : Die JMStV-Novelle: Ein Angriff auf die Grundsatzentscheidung für freie Kommunikation?, K\&R 2010, Editorial Heft 5

— : Neue Paradigmen der Pornografie? - Ein unbestimmter Rechtsbegriff auf dem Prüfstand, MMR 2003, 628

Erichsen, Hans-Uwe: Grundrechtliche Schutzpflichten in der Rechtsprechung des Bundesverfassungsgerichts, JURA 1997, 85

Erichsen, Hans-Uwe/ Ehlers, Dirk: Allgemeines Verwaltungsrecht, 14. Auflage 2010

Ertel, Henner: Erotika und Pornographie - Repräsentative Befragung und psychologische Langzeitstudie zu Konsum und Wirkung, München 1990

Eschenbach, Jürgen: Die ausgleichspflichtige Inhaltsbestimmung, JURA, 1998, 401

European Financial Coalition: Studie: „14 months on: A combined report from the European Financial Coalition 2009-2010," abrufbar unter: http://ceop.police.uk/Documents/EFC\%20Strat\%20Asses2010_080910 b\%20FINAL.pdf 
Faber, Tim: Jugendschutz im Internet - Klassische und neue Regulierungsansätze zum Jugendmedienschutz im Internet, Berlin 2005

Federrath, Hannes: Zur Kontrollierbarkeit des Internet, ZUM 1999, 177

Federrath, Hannes/ Golembiewski, Claudia: Speicherung von Nutzerdaten durch Anonymisierungsdienste im Internet - Welche strafprozessualen Vorschriften zur Überwachung der Telekommunikation sind auf Anonymisierungsdienste anwendbar?, DuD 2004, 486

Fiedler, Christoph: Die formale Seite der Äußerungsfreiheit, Berlin 1999

— : Meinungsfreiheit in einer vernetzten Welt - Staatliche Inhaltskontrolle, gesetzliche Providerhaftung und die Inhaltsneutralität des Internets, Baden-Baden 2002

Fisahn, Andreas/Mushoff, Tobias: Vorwirkung und unmittelbare Wirkung Europäischer Richtlinien, EuR 2005, 222

Fischer, Thomas: Strafgesetzbuch und Nebengesetze Kommentar, 59. Auflage, München 2012

Folkers, Susanne: Die Reform der Notzuchttatbestände in den Jahren 1997 und 1998, NJW 2000, 3317

Fowles, Jib: The Case for Television Violence, 1999

Frenz, Walter/Wimmers, Kristina: Vorwirkung von Richtlinien - die AbfallRRL, UPR 2009, 425

Frenzel, Eike Michael: Das Gesetzgebungsverfahren - Grundlagen, Problemfälle und neue Entwicklungen, JuS 2010, 119

Frey, Dieter: Netzsperren: Werden Access-Provider die neuen Gatekeeper des Rechts?, MMR 2009, 221

Frey, Dieter/ Rudolph, Matthias: Jugendschutzprogramme - Bedarf es der Novellierung des JMStV, CR 2008, 403 
— : Das Zugangserschwerungsgesetz: Schnellschuss mit Risiken und Nebenwirkungen, CR 2009, 644

— : Rechtsgutachten BVDW „Zur Evaluierung des Haftungsregimes für Host- und Access-Provider im Bereich der Telemedien“, 2008

— : Der Jugendmedienschutzstaatsvertrag im Lichte des Gemeinschaftsrechts, ZUM 2008, 564

Frey, Dieter/ Rudolph, Matthias/ Oster, Jan: Internetsperren und der Schutz der Kommunikation im Internet, MMR-Beilage 3/2012

Friedrich, Dirk: Die Verpflichtung privater Telekommunikationsunternehmen, die staatliche Überwachung und Aufzeichnung der Telekommunikation zu ermöglichen, Aachen 2001

Gabriel, Ulrich/Cornels, Lars C.: Webtracking und Datenschutz - ein „hidden problem", MMR 11/2008, XIV

Gärditz, Klaus Ferdinand: Strafprozeß und Prävention: Entwurf einer verfassungsrechtlichen Zuständigkeits- und Funktionenordnung, Tübingen 2003

Geiger, Christophe: Honourable Attempt but (ultimately) Disproportionately Offensive against Peer-to-Peer on the Internet (HADOPI) - A Critical Analysis of the Recent Anti-File-Sharing Legislation in France, IIC 2011, 457

— : Hadopi, ou quand la répression devient pédagogique, Recueil Dalloz Sirey 2011, 773

Geiger, Rudolf: EUV/ EGV: Vertrag über die Europäische Union und Vertrag zur Gründung der Europäischen Gemeinschaft, 4. Auflage, München 2004

Geis, Max-Emanuel: Josefine Mutzenbacher und die Kontrolle der Verwaltung, NVwZ 1992, 25 
Gentz, Manfred: Zur Verhältnismäßigkeit von Grundrechtseingriffen, NJW 1968, 1600

Geppert, Martin: Beck'scher TKG-Kommentar, 3. Auflage, München 2006

Gercke, Björn: Rechtliche Probleme durch den Einsatz des IMSI-Catchers, MMR 2003, 453

Gercke, Marco: Impact of the Lisbon Treaty on Fighting Cybercrime in the EU, CRi 2010, 75

— : Die Bekämpfung der Internetkriminalität als Herausforderungen für die Strafverfolgungsbehörden, MMR 2008, 291

— : Defizite des „Schriften“-Erfordernisses in Internet-bezogenen Sexualund Pornographiedelikten, CR 2010, 798

— : Die Entwicklung des Internetstrafrechts im Jahr 2008, ZUM 2009, 526

— : Die Entwicklung des Internetstrafrechts 2009/2010, ZUM 2010, 633

— : Die Entwicklung des Internetstrafrechts 2009/2010, ZUM 2011, 609

Gerhardt, Michael: Normkonkretisierende Verwaltungsvorschriften, NJW 1989, 2233

Germann, Michael: Gefahrenabwehr und Strafverfolgung im Internet, Berlin 2000

Gersdorf, Hubertus: Privatisierung öffentlicher Aufgaben - Gestaltungsmöglichkeiten, Grenzen, Regelungsbedarf, JZ 2008, 831

Gola, Peter/Schomerus, Rudolf: Bundesdatenschutzgesetz: BDSG Kommentar, 10. Auflage, München 2010

Gounalakis, Georgios/Rhode, Lars: Das Informations- und Kommunikationsdienstegesetz, K\&R 1998, 321 
Grabitz, Eberhard: Der Grundsatz der Verhältnismäßigkeit in der Rechtsprechung des Bundesverfassungsgerichts, AöR 98 (1973), 568

— : Stillhalte-Verpflichtungen vor dem Binnenmarkt, Kehl am Rhein 1988

Graf, Jürgen Peter: Strafprozessordnung mit Gerichtsverfassungsgesetz und Nebengesetzen, München 2010

Greiner, Arved: Die Verhinderung verbotener Internetinhalte im Wege polizeilicher Gefahrenabwehr, Hamburg 2001

Greve, Holger/Schärdel, Florian: Zwischenruf - Internetsperren wegen Urheberrechtsverstößen - Three strikes and You're out, ZRP 2009, 54

Grimm, Jürgen: Das Verhältnis von Gewalt und Medien oder welchen Einfluß hat das Fernsehen auf Jugendliche und Erwachsene?, Der Bundesminister des Innern, Bonn 1996

Grimm, Petra/Rhein, Stefanie/ Claussen-Muradian, Elisabeth: Gewalt im Web 2.0 - Der Umgang Jugendlicher mit gewalthaltigen Inhalten und Cyber-Mobbing sowie die rechtliche Einordnung der Problematik, Berlin 2008

Grimm, Petra/Rhein, Stefanie/Müller, Michael: Porno im Web 2.0 - Die Bedeutung sexualisierter Web-Inhalte in der Lebenswelt von Jugendlichen, Berlin 2010

Gröpl, Christoph: Verzicht auf die „Erste Lesung“ bei Änderungen von Gesetzesentwürfen, LKV 2004, 438

Gronen, Vera I.: Die Vorwirkung von EG-Richtlinien: die Auswirkungen europäisches Richtlinien auf die nationale Legislative und Judikative im Zeitraum zwischen Richtlinienvorschlag und Ablauf der Umsetzungsfrist, Baden-Baden 2006

Grzeszick, Bernd: Verfassungs- und unionsrechtliche Bewertung des Entwurfs des Ersten Glückspieländerungsstaatsvertrages - Gutachterliche 
Analyse 2011 abrufbar unter: http://www.lawblog.de/wpcontent/uploads/2011/06/110610a-Gutachten-Prof.-Grzeszick$\mathrm{Gl} \% \mathrm{C} 3 \% \mathrm{BC} \% \mathrm{C} 3 \% 84 \mathrm{ndStV} 1 . \mathrm{pdf}$

Günther, Ralf: Zur strafprozessualen Erhebung von Telekommunikationsdaten - Verpflichtung zur Sachverhaltsaufklärung oder verfassungsrechtlich unkalkulierbares Wagnis?, NStZ 2005, 485

Gusy, Christoph: Gewährleistung der Vertraulichkeit und Integrität informationstechnischer Systeme, DuD 2009, 33

— : Administrativer Vollzugsauftrag und justizielle Kontrolldichte im Recht der Technik, DVBl 1987, 497

— : Die Zentralstellenkompetenz des Bundes, DVBl. 1993, 1117

— : Grundlagen der Richtervorbehalte nach $\ 100$ b stopp, GA 2003, 672

— : Zum Richtervorbehalt nach GG Art. 13 Abs. 2, JZ 2001, 1033

— : Grundgesetzliche Anforderungen an Durchsuchungsbeschlüsse i.S.d. Art. 13 II GG, NStZ 2010, 353

Halves, Kirsten: Zur Neuordnung des Jugendmedienschutzes im Bereich der Telemedien - Die KJM und das Prinzip der regulierten Selbstregulierung, Berlin 2007

Harms, Sven: Ist das „bloße“ Anschauen von kinderpornographischen Bildern im Internet nach geltendem Recht strafbar?, NStZ 2003, 646

Härting, Niko: Datenschutz im Internet, CR 2008, 743

— : Kommunikationsfreiheit im Netz - „Internet Freedom“ im lichte des Art. 5 GG, K\&R 2012, 264

Hartmann, Bernd J.: Grundwissen Öffentliches Recht, JuS 2008, 593 
Hartstein, Reinhard/Ring, Wolf Dieter/Kreile, Johannes/ Dörr, Dieter/ Stettner, Rupert: Rundfunkstaatsvertrag - Kommentar zum Staatsvertrag der Länder zur Neuordnung des Rundfunkwesens, Ordner III: Jugendmedienschutz-Staatsvertrag, Baden-Baden Stand 2008

Hausschild, Joern: Beschlagnahme einer SIM-Karte als Eingriff in das Fernmeldegeheimnis, NStZ 2005, 339

Hawellek, Christian: EuGH: IP-Adressen sind personenbezogene Daten, ZDAktuell 2011, 129

Heckmann, Dirk: Juris-Praxis Kommentar Internetrecht, 3. Auflage, Saarbrücken 2011

— : Rechtspflichten zur Gewährleistung von IT-Sicherheit im Unternehmen, MMR 2006, 280

Heermann, Peter/ Ohly, Ansgar: Verantwortlichkeit im Netz: wer haftet wofür?, Stuttgart 2003

Heinrich, Manfred: Neue Medien und klassisches Strafrecht - \184b IV StGB im Lichte der Internetdelinquenz, NStZ 2005, 361

Heintschel-Heinegg, Bernd v.: Strafgesetzbuch Kommentar, München 2010

Heinz, Kersten/Schmitt, Klaus: Vorrang des Primärrechtsschutzes und ausgleichspflichtige Inhaltsbestimmung des Eigentums - Tendenzen und Wandlungen des Eigentumsschutzes auf Grund der neueren Rechtsprechung, NVwZ 1992, 513

Hering, Eugen: Die verfassungsrechtlichen Grundlagen der Sozialhilfe und ihre Grenzen, DöV 1975, 8

Herzig, Bardo: Medienkompetenz und Web 2.0, Wiesbaden 2010

Herzog, Roman: Der Verfassungsauftrag zum Schutze des ungeborenen Lebens, JR 1969, 441 
— : Gesetzgebung und Einzelfallgerechtigkeit, NJW 1999, 25

Heß, Reinhold: Grundrechtskonkurrenzen: Zugleich ein Beitrag zur Normstruktur der Freiheitsrechte, Berlin 2000

Hesse, Konrad: Grundzüge des Verfassungsrechts der Bundesrepublik Deutschland, 20. Auflage, Heidelberg 1999

Heynckes, Heinz-Willi: Das Ausschussverfahren nach der Geschäftsordnung des Deutschen Bundestages, ZParl 2008, 459

Hilker, Judith: Grundrechte im deutschen Frühkonstitutionalismus, Berlin 2005

Hill, Andreas/Briken, Peer/Berner, Wolfgang: Pornographie und sexuelle Gewalt im Internet, Bundesgesundheitsblatt 2007, S. 90

Hirsch, Burkhard: Das Grundrecht auf Gewährleistung der Vertraulichkeit und Integrität informationstechnischer Systeme, NJOZ 2008, 1907

Hirschberg, Lothar: Der Grundsatz der Verhältnismäßigkeit, Göttingen 1981

Hoenike, Mark/Boes, Axel: Hotspot-Verträge im Bereich der Wireless Local Area Networks (WLAN), MMR 2003, 457

Hoeren, Thomas: Recht der Access Provider, München 2004

— : Vorschlag für eine EU-Richtlinie über E-Commerce - Eine erste kritische Analyse, MMR 1999, 192

— : Das Telemediengesetz, NJW 2007, 801

Hoeren, Thomas / Sieber, Ulrich: Handbuch Multimedia-Recht - Rechtsfragen des elektronischen Geschäftsverkehrs, 29. Ergänzungslieferung, München $8 / 2011$ 
Hoffmann, Christian: Die Verletzung der Vertraulichkeit informationstechnischer Systeme durch Google Street View, CR 2010, 514

Hoffmann-Riem, Wolfgang: Grundrechtsanwendung unter Rationalitätsanspruch, Der Staat 43 (2004), 214

— : Der grundrechtliche Schutz der Vertraulichkeit und Integrität eigengenutzter informationstechnischer Systeme, JZ 2008, 1009

- : Kommunikationsfreiheiten - Kommentierungen zu Art. 5 Abs. 1 und 2 sowie Art. 8 GG, Baden-Baden 2002

— : Übergang der Polizeigewalt auf Private?, ZRP 1977, 277

Hoffmann-Riem, Wolfgang/Schmidt-Aßmann, Eberhard/Voßkuhle, Andreas: Grundlagen des Verwaltungsrechts, Bd. I: Methoden, Maßstäbe, Aufgaben, Organisationen, München 2006

Höfinger, Frank Michael: Zur Übermittlung von Inhaberdaten dynamischer IP-Adressen an die Staatsanwaltschaft in Ermittlungsverfahren wegen Urheberrechtsverletzungen, ZUM 2009, 75

Höhne, Focke: Der (Nicht-) Vollzug des Zugangserschwerungsgesetzes Rechtliche Problemstellungen und Ausblick, jurisPR ITR 24/2010, Anm. 2

Höhne, Focke/Dienst, Sebastian: Das Gesetz zur Erschwerung des Zugangs zu kinderpornographischen Inhalten in Kommunikationsnetzen $(\mathrm{Zu}-$ gangserschwerungsgesetz - ZugErschwG), jurisPR-ITR 13/2009 Anm. 6

Holst, Christian: Sicherheit und Bedrohung-Determinanten subjektiver Sicherheit in der Bundesrepublik zu Beginn der neunziger Jahre, Hamburg 1998

Holtz, Günter: Aus der Rechtsprechung des Bundesgerichtshofs in Strafsachen, MDR 1978, 804 
Holznagel, Bernd: Verantwortlichkeiten im Internet und Free Speech am Beispiel der Haftung für illegale und jugendgefährdende Inhalte, ZUM 2000, 1007

Holznagel, Bernd/Schumacher, Pascal: Netzpolitik Reloaded, ZRP 2011, 74

Holznagel, Daniel: Zur Providerhaftung - Notice and Take-Down in $\ 512$ U.S. Copyright Act, GRUR-Int. 2007, 971

Holfnagel, Bernd/Kussel, Stephanie: Jugendmedienschutz und Selbstregulierung im Internet, RdJB 2002, 295

Holzner, Stefan: Private Nutzung von E-Mail und Internet am Arbeitsplatz, BB 2009, 2148

Hopf, Kristina: Der Jugendmedienschutz-Staatsvertrag, K\&R 2011, 6

— : Jugendschutz im Rundfunk und das verfassungsrechtliche Zensurverbot des Art. 5 Abs. 1 Satz 3 GG, ZUM 2000, 739

Hopf, Kristina/Braml, Birgit: Virtuelle Kinderpornographie vor dem Hintergrund des Online-Spiels Second Life, ZUM 2007, 354

Horn, Albrecht: Vereinte Nationen - Akteure und Entscheidungsprozesse, Berlin 2007

Hornig, Michael: Möglichkeiten des Ordnungsrechts bei der Bekämpfung rechtsextremistischer Inhalte im Internet, ZUM 2001, 846

Hörnle, Tatjana: Sexueller Missbrauch von Kindern: Reges Interesse in der Politik und den Sozialwissenschaften; unzureichende Schutzzweckdiskussion in der Strafrechtswissenschaft, Festschrift für Ulrich Eisenberg, München 2009, S. 321

- : Pornographische Schriften im Internet: Die Verbotsnormen im deutschen Strafrecht und ihre Reichweite, NJW 2002, 1008 
— : Die Umsetzung des Rahmenbeschlusses zur Bekämpfung der sexuellen Ausbeutung von Kindern und der Kinderpornographie, NJW 2008, 3521

— : Begriff des Eindringens bei sexuellem Missbrauch, NStZ 2000, 310

Hornung, Gerrit/ Schnabel, Christoph: Verfassungsrechtlich nicht schlechthin verboten - Das Urteil des Bundesverfassungsgerichts in Sachen Vorratsdatenspeicherung, DVBl. 2010, 824

Hufeld, Ulrich: Die Vertretung der Behörde, Tübingen 2003

Hüper, Melanie: Zensur und neue Kommunikationstechnologien, Aachen 2004

Internet Watch Foundation: Annual and Charity Report 2009, abrufbar unter: http://www.iwf.org.uk/assets/media/annualreports/IWF\%202009\%20A nnual $\% 20$ and $\% 20$ Charity $\% 20$ Report.pdf

Ipsen, Knut: Privatisierung öffentlicher Aufgaben, Köln 1994

— : Völkerrecht, 5. Auflage, München 2004

Isensee, Josef/Axer, Peter: Jugendschutz im Fernsehen, München 1998

Isensee, Josef/Kirchhof, Paul: Handbuch des Staatsrechts, Bd. II: Demokratische Willensbildung - die Staatsorgane des Bundes, 2. Auflage 1994; Bd. III: Handeln des Staates, 2. Auflage 1996; Demokratie - Bundesorgane, 3. Auflage 2005; Bd. IV: Finanzverfassung - Bundesstaatliche Ordnung, 2. Auflage 1999; Bd. V: Allgemeine Grundrechtslehren, 2. Auflage 2002; Rechtsquellen, Organisation, Finanzen, 3. Auflage 2007; Bd. VI: Freiheitsrechte, 1. Auflage 1989; Freiheitsrechte, 2. Auflage 2001

Jaeckel, Liv: Schutzpflichten im deutschen und europäischen Recht - Eine Untersuchung der deutschen Grundrechte, der Menschenrechte und Grundfreiheiten der EMRK sowie der Grundrechte und Grundfreiheiten der Europäischen Gemeinschaft, Baden-Baden 2001 
Jahraus, Oliver/Maass, Henrike: Jugendgefährdung durch Medienrechtliche Rahmenbedingungen einer Indizierung von Medien im Lichte der Erkenntnisse der Medienwirkungsforschung, UFITA 2008, 369

Jakobs, Michael Ch.: Der Grundsatz der Verhältnismäßigkeit - Mit einer exemplarischen Darstellung seiner Geltung im Atomrecht, Köln 1985

Jan, Pascal: Le Procès Constitutionnel, 2. Auflage, Paris 2010

Janssen, Dirk Thorsten: Regulierung abweichenden Verhaltens im Internet Eine Untersuchung verschiedener Regulierungsansätze unter besonderer Berücksichtigung der deutschen Rechtsordnung, Baden-Baden 2003

Jarass, Hans D.: Grundrechte als Wertentscheidungen bzw. objektivrechtliche Prinzipien in der Rechtsprechung des Bundesverfassungsgerichts, AöR 110 (1985), 363

_ : Bindungswirkung von Verwaltungsvorschriften, JuS 1999, 105

— : Die Freiheit der Massenmedien - zur staatlichen Einwirkung auf Presse, Rundfunk, Film und andere Medien, Baden-Baden 1978

— : Das allgemeine Persönlichkeitsrecht im Grundgesetz, NJW 1989, 857

Jarass, Hans D./Pieroth, Bodo: Grundgesetz- Kommentar, 11. Auflage, München 2011

Jeand'Heur, Bernd: Verfassungsrechtliche Schutzgebote zum Wohl des Kindes und staatliche Interventionspflichten aus der Garantienorm des Art. 6 Abs. 2 Satz 2 GG, Hamburg 1993

Joecks, Wolfgang/Miebach, Klaus: Münchener Kommentar zum Strafgesetzbuch, Bd. 3: \\80-184g StGB, 2. Auflage, München 2012/ Bd. 1: \\ 1-37 StGB, 2011

Joerden, Jan C./Szwarc, Andrzey J.: Europäisierung des Strafrechts in Polen und Deutschland - rechtsstaatliche Grundlagen, Berlin 2010 
Kahl, Jonas: Die verfassungsrechtliche Zulässigkeit von Internet-Sperren, SächsVBl. 2010, 180

Kapries, Uwe: Die Schranken der Grundrechte des Art. 5 Abs. 1 GG, Berlin 2005

Karg, Moritz: IP-Adressen sind personenbezogene Verkehrsdaten MMRAktuell 2011, 315811

Karger, Sandro/Gaycken, Michael: Entnetzung statt Vernetzung, MMR 2011, 3

Kempen, Bernhard/Hillgruber, Christian: Völkerrecht, München 2007

Kichling, Michael: Die Neuregelung zur Auslandskopfüberwachung gemäß \4 TKÜV auf dem verfassungsrechtlichen Prüfstand, 2006, abrufbar unter: http://www.mpicc.de/de/data/pdf/auslandskopf_publ-1.pdf

Kiefer, Günther: Regelungsbedarf und Gestaltungsspielräume bei der Beleihung, LKRZ 2009, 441

Kindt, Anne: Grundrechtsschutz für Raubkopierer und Musikpiraten, MMR 2009, 147

Kirchberg-Lennartz, Barbara/Weber, Jürgen: Ist die IP-Adresse ein personenbezogenes Datum?, DuD 2010, 479

Kischel, Uwe: Wann ist die Inhaltsbestimmung ausgleichspflichtig?, JZ 2003, 604

Klapper, Joseph T.: The Effects of Mass Communication, 14. pr., New York 1974

Klein, Eckart: Objektive Wirkung von Richtlinien, Festschrift für Ulrich Everling, Baden-Baden 1995, Bd. 1, S.641

— : Grundrechtliche Schutzpflicht des Staates, NJW 1989, 1633 
Kloepfer, Michael: Informationsrecht, München 2002

— : Der Vorbehalt des Gesetzes im Wandel, JZ 1984, 685

Knoll, Joachim H.: Pornographie, Jugendliche, Fernsehen - Prolegomena zur Wirkungsforschung, tv-diskurs 1/2001, 54

Knothe, Matthias: (Rundfunk-)Staatsverträge - Faktische Gesetzgebung der Regierung unter Ausschluss der Parlamente, ZRP 2010, 181

Koch, Arnd: Zur Strafbarkeit der Auschwitzlüge im Internet, JuS 2002, 124

Koch, Frank A.: Zivilrechtliche Anbieterhaftung für Inhalte in Kommunikationsnetzen, CR 1997, 193

— : Internet-Recht - Praxishandbuch zu Dienstenutzung, Verträgen, Rechtsschutz und Wettbewerb, Haftung, Arbeitsrecht und Datenschutz im Internet, zu Links, Peer-to-Peer-Netzen und Domain-Recht mit Musterverträgen, 2. Auflage, München 2005

Koch, Oliver: Der Grundsatz der Verhältnismäßigkeit in der Rechtsprechung des Gerichtshofs der Europäischen Gemeinschaften, Berlin 2003

Köcher, Jan K.: Personenbezug von IP-Adressen - Ein Streitfall an der Nahtstelle zwischen Persönlichkeit und Informationsgesellschaft, PIK 2010, 205

Kockott, Götz/Fahrner-Tutsek, Eva-Maria: Sexualstörungen, Stuttgart 2004

Koenig, Christian/Koch, Alexander/ Braun, Jens-Daniel: Die Telekommunikationsüberwachungsverordnung - Neue Belastungen für Internet Service Provider und Mobilfunknetzbetreiber?, K\&R 2002, 289

Köhne, Michael: Verbot von „Killerspielen“?, ZRP 2009, 155 
Köhntopp, Kristian/ Köhntopp, Marit/Seeger, Martin: Sperrungen im Internet, $K \& R$ 1998, 25

Köhntopp, Marit/Köhntopp, Kristian: Datenspuren im Internet, CR 2000, 248

König, Michael: Die Privatisierung im Landesorganisationsrecht, DÖV 1999, 322

König, Sabine: Kinderpornographie im Internet - Eine Untersuchung der deutschen Rechtslage unter besonderer Berücksichtigung des internationalen Strafrechts, Hamburg 2004

Koreng, Ansgar: Zugangserschwerungsgesetz, JURA 2010, 931

— : Zensur im Internet - Der verfassungsrechtliche Schutz der digitalen Massenkommunikation, Baden-Baden 2010

Köttgen, Arnold: Das Bundesverfassungsgericht und die Organisation der öffentlichen Verwaltung, AöR 90 (1965), 205

Kratzmann, Horst: Grundrechte - Rechte auf Leistungen, Bern 1974

Kreft, Michael: Der Nichtanwendungserlass - Akzeptanz und Bindungswirkung der Finanzrechtsprechung in der Finanzverwaltung, Pfaffenweiler 1989

Krings, Günter: Grund und Grenzen grundrechtlicher Schutzansprüche - Die subjektiv-rechtliche Rekonstruktion der grundrechtlichen Schutzpflichten und ihre Auswirkungen auf die verfassungsrechtliche Fundierung des Verbrauchervertragsrechts, Berlin 2003

Krüger, Astrid: Die Bindung der Verwaltung an die höchstrichterliche Rechtsprechung, München 1987

Kube, Hanno/ Schütze, Marc: Die Kosten der TK-Überwachung, CR 2003, 663 
Kugelmann, Dieter: Polizei- und Ordnungsrecht, 2. Auflage, Berlin 2011

Kühling, Jürgen: Die Kommunikationsfreiheit als europäisches Gemeinschaftsgrundrecht, Berlin 1999

— : Vorwirkungen von EG-Richtlinien bei der Anwendung nationalen Rechts - Interpretationsfreiheit für Judikative und Exekutive, DVBl. 2006, 857

Kuhn, Axel: Vernetzte Medien - Nutzung und Rezeption am Beispiel World of Warcraft, Konstanz 2009

Kuhn, Berthold: Entwicklungspolitik zwischen Markt und Staat - Möglichkeiten und Grenzen zivilrechtlicher Organisationen, Frankfurt am Main 2005

Kühne, Hans-Heiner: Strafbarkeit der Zugangsvermittlung von pornographischen Informationen im Internet, NJW 1999, 188

Kunczik, Michael: Befunde der Wirkungsforschung und deren Relevanz für die altersbezogenen Kennzeichnung von Video- und Computerspielen, Hamburg 2007

— : Normativ vorgehen! - Was kann der Jugendschutz mit der Wirkungsforschung anfangen, tv-diskurs 2000, 38

Kunig, Philip/Uerpmann, Robert: Der Fall des Postschiffes Lotus, JURA 1994, 186

Kurose, James F./ Ross, Keith W.: Computernetzwerke - Der Top-Down Ansatz, 4. Auflage, München 2008

Lackner, Karl/ Kühl, Kristian: Strafgesetzbuch Kommentar, 27. Auflage, München 2011

Lämmerzahl, Torsten: Die Beteiligung Privater an der Erledigung öffentlicher Aufgaben - Eine Untersuchung ihrer verfassungs- und verwaltungsrechtlichen Möglichkeiten und Grenzen, Berlin 2007 
Lamprecht, Rolf: Obiter dictum - Arabeske oder Ballast?, NJW 1998, 1039

Landmann, Dieter: Die Ausstrahlung jugendgefährdender Fernsehsendungen - strafbar?, NJW 1996, 3309

Laubenthal, Klause: Sexualstraftaten - Die Delikte gegen die sexuelle Selbstbestimmung, Berlin 2000

Laufhütte, Heinrich: Viertes Gesetz zur Reform des Strafrechts, JZ 1974, 46

Leisner, Walter: Die allgemeine Bindung der Finanzverwaltung an die Rechtsprechung, Wiesbaden 1980

— : Eigentümer als Beruf, JZ 1972, 33

— : Rechtswirkungen von Reformankündigungen im Koalitionsvertrag, NJW 2010, 823

Lenz, Carl Otto/Borchardt, Klaus-Dieter: Lissabon, 5. Auflage, Köln 2010

Lerche, Peter: Fragen des Verhältnisses zwischen Berufs- und Eigentumsfreiheit, Festschrift für Reiner Schmidt, München 2006, S. 377

— : Übermaß und Verfassungsrecht - Zur Bindung des Grundgesetzes an die Grundsätze der Verhältnismäßigkeit und der Erforderlichkeit, Köln 1961

— : Aktuelle Grundfragen der Informationsfreiheit, JURA 1995, 561

Leutheusser-Schnarrenberger, Sabine: Für ein freies Internet ohne Zensur und Missbrauch, K\&R Die erste Seite 2010, Nr. 1

Liesching, Marc: Das neue Strafverbot jugendpornographischer Schriften nach $\$ 184$ c StGB, JMS-Report 5/2008, 2

—: Anmerkung zum Beschluss des BVerfG vom 6.12.2008 - Strafbarkeit wegen des Verbreitens von jugendpornografischen Filmen bei „scheinjugendlichen“ Darstellern, MMR 2009, 179 
— : Das neue Jugendschutzgesetz, NJW 2002, 3281

— : Zur Gesetzgebungskompetenz der Bundesländer für den Bereich Jugendschutz in Rundfunk und Telemedien, ZUM 2002, 868

Liesching, Marc/ Schuster, Susanne: Jugendschutzrecht Kommentar, 5. Auflage, München 2011

Lindemann, Michael/ Wachsmuth, Ingmarie: BGH v. 27.6.2011 - 1 StR 66/01, Kinderpornographie im Internet, JR 2002, 204

Linz, Stefan: Medienkompetenz und Jugendschutz - Jugendliche beurteilen Gewalt im Film, tv-diskurs 14/2010, 46

Lisken, Hans F./Denninger, Erhard: Handbuch des Polizeirechts - Gefahrenabwehr, Strafverfolgung, Rechtsschutz, 4. Auflage, München 2007

Löffler, Martin: Handbuch des Presserechts, 5. Auflage, München 2005

Löwer, Wolfgang: Ausländisches Werbefernsehen und Deutsches Verfassungsrecht, JZ 1981, 730

Mankowski, Peter: Die Düsseldorfer Sperrungsverfügung - alles andere als rheinischer Karneval, MMR 2002, 277

Manssen, Gerrit: Telekommunikations- und Multimediarecht - ergänzbarer Kommentar zum Telekommunikationsgesetz, MediendiensteStaatsvertrag, Teledienstegesetz, Teledienstedatenschutzgesetz, Signaturgesetz, Berlin 1999

— : Das Telekommunikationsgesetz (TKG) als Herausforderungen für die Verfassungs- und Verwaltungsdogmatik, ArchivPT 1998, 236

Mantz, Reto: Rechtsfragen offener Netze - rechtliche Gestaltung und Haftung des Access-Providers in zugangsoffenen (Funk)Netzen, Karlsruhe 2008 
Marberth-Kubicki, Annette: Der Beginn der Internet-Zensur, NJW 2009, 1792

Maunz, Theodor: Medienfreiheit und Jugendschutz, Festschrift für Klaus Obermayer, München 1986, S. 85

Maunz, Theodor/Dürig, Günter: Grundgesetz Kommentar, Bd. I: Texte Art. 5, Bd. II: Art. 6-15, Bd. III: Art. 16 - 22, Bd. IV: Art. 23 - 53a, Bd. V: Art. 54 - 85, Bd. VI: Art. 86 - 106a, München, Stand 10/2011

Maurer, Hartmut: Allgemeines Verwaltungsrecht, 18. Auflage München 2011

Mayer, Patrick G.: Das Internet im öffentlichen Recht unter Berücksichtigung europarechtlicher und völkerrechtlicher Vorgaben, Berlin 1999

Maywald, Jörn: Misshandlung, Vernachlässigung und sexueller Missbrauch Eine Übersicht aus sozialwissenschaftlicher Perspektive, FPR 2003, 299

Meier, Bernd-Dieter/Hüneke, Arnd: Forschungsbericht „Herstellung und Verbreitung von Kinderpornographie über das Internet“, Hannover 2011

Meirowitz, Karel: Gewaltdarstellungen auf Videokassetten, Berlin 1993

Merten, Detlef/Papier, Hans-Jürgen: Handbuch der Grundrechte in Deutschland und Europa, Bd. 2: Grundrechte in Deutschland, Heidelberg 2006

Meßerschmidt, Klaus: Begründen Richtlinienvorschläge der EG-Kommission eine Stillhaltepflicht für den deutschen Gesetzgeber, ZG 1993, 11

Meyerdierks, Per: Sind IP-Adressen personenbezogene Daten?, MMR 2009, 8

Mochalski, Klaus/ Schulze, Hendrik: Deep Packet Inspection - Technology, Applications \& Net Neutrality, 2009, abrufbar unter: http://www.ipoque.com/sites/default/files/mediafiles/documents/white -paper-deep-packet-inspection.pdf 
Moos, Flemming/Gosche, Anna: Anmerkung zum Urteil des LG Hamburg vom 12.11.2008 (308 O 548/08) - keine Haftung des Access-Providers für Urheberrechtsverletzung seines Kunden, K\&R 2009, 275

Mühlenbruch, Ferdinand: Außenwirksame Normkonkretisierung durch Technische Anleitungen, Baden-Baden 1992

Müller, Dagmar: Die Gesetzgebungskompetenz im Berufsbildungsrecht, RdJB 1994, 467

— : Strafrecht, Jugendschutz und Freiheit der Kunst, JZ 1970, 87

Münch, Ingo v./Kunig, Philip: Grundgesetz-Kommentar, Bd. 1: Art. 1 - 69, Bd. 2: Art. 70 - 146, 6. Auflage, München 2012

Mynarik, Nadine: Jugendschutz in Rundfunk und Telemedien - Freiwillige Selbstkontrolle und Co-Regulierung nach dem JugendmedienschutzStaatsvertrag, Baden-Baden 2006

Nastelski, Karl: Unbestimmte Rechtsbegriffe, Generalklauseln und Revision, GRUR 1968, 545

Nérisson, Sylvie: Frankreich - Die erste Stufe der Internetsperre bei OnlineUrheberrechtsverletzungen soll Ende Juni eintreten, GRUR-Int. 2010, 637

Neumann, Andreas: Ordnungsrechtliche Sperrungsverfügungen und die Informationsfreiheit nach Art. 5 Abs. 1 S. 1, 2. Alt. GG, 2002, abrufbar unter: http://www.artikel5.de/artikel/sperrunginffreiheit.html

Nietsch, Thomas: Zur Ermittlung dynamischer IP-Adressen durch Drittunternehmen, K\&R 2011, 101

Nikles, Bruno W./Roll, Sigmar/ Spürck, Dieter/Erdemir, Murad/ Gutknecht, Sebastian: Jugendschutzrecht - JuschG, JMStV, StGB und weitere Bestimmungen Kommentar, 3. Aufl. 2011 
Nünke, Anja: Verwaltungshilfe und Inpflichtnahme des Sicherheitsgewerbes Kooperative Sicherheitsgewährleistung von Staat und Privat, Hamburg 2005

Oberländer, Stefanie: Gemeinsame Richtlinien der Landesmedienanstalten als normkonkretisierende Verwaltungsvorschriften, ZUM 2001, 487

Orantek, Kerstin: Die Vorratsdatenspeicherung in Deutschland, NJ 2010, 193

Ory, Stephan: Jugendschutz in Neuen Medien, ZUM 1986, 123

Ossenbühl, Fritz: Schule im Rechtsstaat, DöV 1977, 801

Ostendorf, Heribert: Mögliche Wirkungen von Pornographie, tv-diskurs 21/2002, 76

Ott, Sieghart: Kunstfreiheit und Filmbewertung, JuS 1968, 459

Pahlen-Brandt, Ingrid: Zur Personenbezogenheit von IP-Adressen, K\&R 2008, 288

Pany, Thomas: Heise, Beitrag v. 28.5.2009, „Loppsi und der Franzosentrojaner", abrufbar unter: http://www.heise.de/tp/artikel/30/30416/1.html

Pecher, Christian Matthias: Verfassungsimmanente Schranken von Grundrechten, Münster 2002

Peterson, Larry L./ Davie, Bruce S.: Computernetze - Eine systematische Einführung, 4. Auflage, Heidelberg 2008

Pfitzmann, Andreas/ Köpsell, Stefan/Kriegelstein, Thomas: Sperrungsverfügungen gegen Access-Provider - Technisches Gutachten, abrufbar unter: http://www.eco.de/dokumente/20080428_technisches_Gutachten_Sperr vervuegungen.pdf

Pieroth, Bodo/ Schlink, Bernhard/ Kniesel, Michael: Polizei- und Ordnungsrecht - mit Versammlungsrecht, 6. Auflage, München 2010 
Pietzcker, Jost: Drittwirkung - Schutzpflicht - Eingriff, Festschrift für Günter Dürig, München 1990, S. 345

Plewa, Dietrich: Die Verfassungsmäßigkeit der Indienstnahme Privater für Verwaltungsaufgaben am Beispiel des Gesetzes über Mindestvorräte an Erdölerzeugnisses, Speyer 1978

Poscher, Ralf: Grundrechte als Abwehrrechte, Tübingen 2003

Posser, Herbert/ Wolff, Heinrich Amadeus: Verwaltungsgerichtsordnung Kommentar, München 2008

Raabe, Oliver: Abgrenzungsprobleme bei der rechtlichen Einordnung von Anonymisierungsdiensten im Internet, CR 2003, 268

Rau, Marco/ Behrens, Martin: Catch me if you can ...Anonymisierungsdienste und die Haftung für mittelbare Rechtsverletzungen, K\&R 2009, 766

Rehart, Konstantin: Sperren oder Löschen? Oder beides? - Das nächste Kapitel, MMR-Aktuell 2010, 303415

Reinbacher, Tobias/ Wincierz, Andrej: Kritische Würdigung des Gesetzentwurfs zur Bekämpfung von Kinder- und Jugendpornographie, ZRP 2007, 195

Reinwald, Gerhard: Jugendmedienschutz im Telekommunikationsbereich in Bundeskompetenz?, ZUM 2002, 119

Remmert, Barbara: Private Dienstleistungen in staatlichen Verwaltungsverfahren - Eine rechts- und verwaltungswissenschaftliche Untersuchung zur privaten Entscheidungsvorbereitung, Tübingen 2003

Rensen, Hartmut/Brink, Stefan: Linien der Rechtsprechung des Bundesverfassungsgerichts, Berlin 2009

Renzikowski, Joachim: Videofilm-Kopien keine Druckwerke im Sinne des Pressegesetzes, NStZ 2000, 28 
Reuter, Thomas: Die Verhältnismäßigkeit im engeren Sinne - das unbekannte Wesen, JURA 2009, 511

Richter-Appelt, Hertha: Sexuelle Traumatisierung und körperliche Misshandlung, 1994

Riesenhuber, Karl: Europäische Methodenlehre, 2. Auflage, München 2010

Ring, Wolf-Dieter: Jugendschutz im Spannungsfeld zwischen Selbstregulierung der Medien und staatlicher Kontrolle, AfP 2004, 9

Ritlewski, Kristoff M.: Virtuelle Kinderpornographie in Second Life, K\&R 2008, 94

Robbers, Gerhard: Sicherheit als Menschenrecht - Aspekte der Geschichte, Begründung und Wirkung einer Grundrechtsfunktion, Baden-Baden 1987

Röder, Ralf: Nach der letzten Änderung des $₫ 184 \mathrm{~b}$ StGB: Ist das Verbreiten sog. „Posing“-Fotos weiterhin straflos, NStZ 2010, 113

Rohn, Stephan/ Sannwald, Rüdiger: Die Ergebnisse der Gemeinsamen Verfassungskommission, ZRP 1994, 65

Roll, Hans-Achim: Geschäftsordnung des Deutschen Bundestages - Kommentar, Baden-Baden 2001

Roßnagel, Alexander: Handbuch Datenschutzrecht: die neuen Grundlagen für Wirtschaft und Verwaltung, München 2003

— : Recht der Multimedia-Dienste, München, Stand 2005

Roters, Gunnar/Brosius, Hans-Bernd: Mediensozialisation und Medienverantwortung, Baden-Baden 1999

Rybak, Hubertus/Hoffmann, Hans: Verteilung der Gesetzgebungsrechte zwischen Bund und Ländern nach der Reform des Grundgesetzes, NVwZ 1995, 230 
Sachs, Michael: Grundgesetz - Kommentar, 6. Auflage, München 2011

Sachs, Ulrich: Datenschutzrechtliche Bestimmbarkeit von IP-Adressen, CR 2010, 547

Säcker, Franz Jürgen/ Rixecker, Roland: Münchener Kommentar zum BGB,

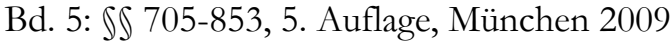

Sänger, Renate: Kinderpornografie und Frühprostitution, KJuG 1994, 43

Sankol, Barry: Herausgabe dynamischer IP-Adressen nur bei Verdacht auf schwere Straftat, K\&R 2008, 469

Schaar, Peter: Datenschutz im Internet, München 2002

Schäfer, Kerstin: Der kriminologische Hintergrund des (Jugend-) Medienschutz im Hinblick auf mediale Gewaltdarstellungen, Hamburg 2008

Schenke, Wolf-Rüdiger: Polizei- und Ordnungsrecht, 7. Auflage, Heidelberg 2011

Scherff, Jürgen: Grundkurs Computernetzwerke - Eine kompakte Einführung in Netzwerk- und Internet-Technologien, 2. Auflage, Wiesbaden 2010

Scheurle, Klaus-Dieter/Mayen, Thomas: Telekommunikationsgesetz - Kommentar, 2. Auflage, München 2008

Schewerda, Martin: Verteilung der Verwaltungskompetenzen zwischen Bund und Ländern nach dem Grundgesetz, Aachen 2008

Schirrmacher, Thomas: Internetpornografie, Holzgerlingen 2008

Schliesky, Utz: Die Vorwirkung von gemeinschaftsrechtlichen Richtlinien, DVB1. 2003, 631 
Schlink, Bernhard: Freiheit durch Eingriffsabwehr - Rekonstruktion der klassischen Grundrechtsfunktion, EUGRZ 1984, 457

Schlüter, Wilfried: Das Obiter Dictum - die Grenzen höchstrichterlicher Entscheidungsbegründung, dargestellt an Beispielen aus der Rechtsprechung des Bundesarbeitsgerichts, München 1973

Schmehl, Arndt: Die erneuerte Erforderlichkeitsklausel im Art. 72 Abs. 2 GG, DöV 1996, 724

Schmidl, Michael: Aspekte des Rechts der IT-Sicherheit, NJW 2010, 476

Schmidt, Stephan: Abhängigkeit der Störerhaftung eines Access-Providers von technischen Möglichkeiten und der Zumutbarkeit einer Sperrung, jurisPRITR 16/2009, Anm. 2

— : Die Rechtmäßigkeit staatlicher Gefahrenabwehrmaßnahmen im Internet unter besonderer Berücksichtigung des Europäischen Gemeinschaftsrechts, 2006

Schmidt, Walter: Die Freiheit vor dem Gesetz, AöR 91 (1966), 42

Schmidt-Aßmann, Eberhard: Besonderes Verwaltungsrecht, 14. Auflage, Berlin 2008

Schmidt-Bleibtreu, Bruno/Hofmann, Hans/Hopfauf, Axel: Grundgesetz Kommentar zum Grundgesetz, 12. Auflage, Köln 2011

Schmidt-Preuß, Matthias: Die verfassungsrechtlichen Anforderungen an die Entschädigung für Leistungen der telekommunikations-Überwachung und der Auskunftserteilung Kurzgutachten im Auftrag des Bundesverbands Informationswirtschaft, Telekommunikation und neue Medien e.V. (BITKOM), abrufbar unter: http://www.sfu.ca/cprost/prepaid/relateddocs/Germany/SchmidtPreuB_and_German_Constitution.pdf

— : Kurzgutachten über „Die verfassungsrechtlichen Anforderungen an die Entschädigung für Leistungen der Telekommunikations-Überwachung und der Auskunftserteilung“, abrufbar unter: 
http://www.sfu.ca/cprost/prepaid/relateddocs/Germany/SchmidtPreuB_and_German_Constitution.pdf

Schmitz, Florian/Laun, Stefan: Die Haftung kommerzieller Meinungsportale im Internet, MMR 2005, 208

Schnabel, Christoph: Das Zugangserschwerungsgesetz - Zum Access-

Blocking als ultima ratio des Jugendschutzes, JZ 2009, 996

— : Porn not found - Die Arcor-Sperre, K\&R 2008, 26

— : Die Nichtanwendung des Zugangserschwerungsgesetzes - Ein ,juristisch interessantes Konstrukt" oder ein gezielter Verfassungsverstoß?, K\&R 2011, 175

— : Böse Zensur, guter Filter? - Urheberrechtliche Filterpflichten für AccessProvider, MMR 2008, 281

— : Sperrungsverfügungen gegen Access-Provider - Technische Möglichkeiten und rechtliche Zulässigkeit anhand eines praktischen Beispiels, 2002, abrufbar unter:

http://www.eulisp.de/tl_files/eulisp\%20abschlussarbeiten/schnabel_chri stoph.pdf

Schneider, Gerhard: Die Wirksamkeit der Sperrung von Internet-Zugriffen, MMR 1999, 571

—: Sperren und Filtern im Internet, MMR 2004, 18

Schneider, Hans-Peter/Zeh, Wolfgang: Parlamentsrecht und Parlamentspraxis, Berlin 1989

Schoch, Friedrich: Gewährleistungsverwaltung: Stärkung der Privatrechtsgesellschaft, NVwZ 2008, 241

Schoch, Friedrich/ Schmidt-Aßmann, Eberhard/Pietzner, Rainer: Verwaltungsgerichtsordnung - Kommentar, München Stand 9/2011 
Schönke, Adolf/Schröder, Horst: Strafgesetzbuch Kommentar, 28. Auflage München 2010

Scholz, Rupert: Sitzblockade und Verfassung - Zur neuen Entscheidung des BVerfG, NStZ 1995, 421

Schorb, Bernd/ Anfang, Günther/Demmler, Kathrin: Grundbegriffe Medienpädagogik, München 2009

Schöttle, Hendrik: Sperrungsverfügungen im Internet: Machbar und verhältnismäßig?, K\&R 2007, 366

Schreibauer, Marcus: Das Pornographieverbot des $₫ 184$ StGB - Grundlagen, Tatbestandsprobleme, Reformvorschläge, Regensburg 1999

Schricker, Gerhard/Loewenheim, Ulrich: Urheberrecht Kommentar, 4. Auflage, München 2010

Schroeder, Friedrich-Christian: Gesetzestechnische Mängel im Gesetz zur Umsetzung des EU-Rahmenbeschlusses zur Bekämpfung der sexuellen Ausbeutung von Kindern und Kinderpornographie, GA 2009, 213

— : Strafrechtsänderungsgesetz - Kinderpornographie, NJW 1993, 2581

— : Pornographieverbot als Darstellerschutz, ZRP 1990, 299

Schüle, Adolf: Koalitionsvereinbarungen im Lichte des Verfassungsrechts, Tübingen 1964

Schulz, Wolfgang: Jugendschutz bei Tele- und Mediendiensten, MMR 1998, 182

Schulze, Reiner/Zuleeg, Manfred/Kadelbach, Stefan: Europarecht: Handbuch für die deutsche Rechtspraxis, 2. Auflage, Baden-Baden 2010

Schwarz, Thomas: Die Zitiergebote im Grundgesetz, Baden-Baden 2002 
Schwerin, Thomas: Der Deutsche Bundestag als Geschäftsordnungsgeber, Berlin 1998

Seewald, Otfried: Zum Verfassungsrecht auf Gesundheit, Köln 1981

Selg, Herbert: Psychologische Wirkungsforschung über die Gewalt in Medien, tv-diskurs 2/1997, 50

Selmer, Peter/Brodersen, Carsten/Nicolaysen, Gert: Straßenbenutzungsabgaben für den Schwerverkehr - verfassungs- und europarechtliche Probleme, Baden-Baden 1989

Sick, Brigitte/ Renzikowski, Joachim: Der Schutz der sexuellen Selbstbestimmung, Festschrift für Friedrich-Christian Schroeder, Heidelberg 2006, S. 603

Sieber, Ulrich: Strafrechtliche Verantwortlichkeit für den Datenverkehr in internationalen Computernetzen, JZ 1996, 494

— : Sperrverpflichtungen gegen Kinderpornografie im Internet, JZ 2009, 653

— : Verantwortlichkeit im Internet, München 1999

— : Die Bekämpfung von Hass im Internet - Technische, rechtliche und strategische Grundlagen für ein Präventionskonzept, ZRP 2001, 97

Sieber, Ulrich/Höfinger, Frank Michael: Drittauskunftsansprüche nach \101a UrhG gegen Internetprovider zur Verfolgung von Urheberrechtsverletzungen, MMR 2004, 575

Sieber, Ulrich/Nolde, Malaika: Sperrverfügungen im Internet - Nationale Rechtsdurchsetzung im globalen Cyberspace?, Berlin 2008

Sievers, Malte: Der Schutz der Kommunikation im Internet durch Art. 10 des Grundgesetzes, Baden-Baden 2003

Simitis, Spiros: Bundesdatenschutzgesetz, 7. Auflage, Baden-Baden 2011 
Six, Ulrike/Gleich, Uli/ Gimmler, Roland: Kommunikationspsychologie, Erotik und Pornographie in den Medien, Weinheim 2007

Solmecke, Christian/Sebastian, Maik/ Sahuc, Francois-Xavier: Experiment Internetsperre: Das erste Jahr des Hadopi-Gesetzes, MMR-Aktuell 2011, 316298

Sottet, Marianne: Frankreich: Nationalversammlung verabschiedet Entwurf des „Loppsi-2“ Gesetzes, MMR- Aktuell 2010, 301044

— : Frankreich: Senat verabschiedet zweiten Entwurf des „Loppsi-2“ Gesetzes, MMR-Aktuell 2010, 309015

Spies, Axel: Frankreich: Eins, zwei, drei, das Internet ist weg - oder doch nicht?, MMR 2009, 437

Spindler, Gerald: Europäisches Urheberrecht in der Informationsgesellschaft, GRUR 2002, 105

— : Die Verantwortlichkeit der Provider für Sich-zu-Eigen-gemachte Inhalte und für beaufsichtige Nutzer, MMR 2004, 440

— : Unterlassungsansprüche gegen Provider: keine Anwendung der wettbewerbsrechtlichen Verkehrspflicht, MMR 2008, 167

— : IT-Sicherheit - Rechtliche Defizite und rechtspolitische Alternativen, MMR 2008, 7

— : E-Commerce in Europa - Die E-Commerce-Richtlinie in ihrer endgültigen Fassung, MMR-Beil. 7/2000, S. 4

— : Das Gesetz zum elektronischen Geschäftsverkehr - Verantwortlichkeit der Diensteanbieter und Herkunftslandprinzip, NJW 2002, 921

— : Herkunftslandprinzip und Kollisionsrecht - Binnenmarktintegration ohne Harmonisierung? Die Folgen der Richtlinie im elektronischen Geschäftsverkehr für das Kollisionsrecht, RabelsZ 66 (2002), 633 
— : Der neue Vorschlag einer E-Commerce-Richtlinie, ZUM 1999, 775

Spindler, Gerald/Schmitz, Peter/Geis, Ivo: Teledienstegesetz, Teledienstedatenschutzgesetz, Signaturgesetz - TDG Kommentar, München 2004

Spindler, Gerald/ Schuster, Fabian: Recht der elektronischen Medien Kommentar 2. Auflage, München 2011; 1. Auflage 2008

Spindler, Gerald/ Volkmann, Christian: Die öffentlich-rechtliche Störerhaftung der Access-Provider, K\&R 2002, 398

Spindler, Wolfgang: Der Nichtanwendungserlass im Steuerrecht, DStR 2007, 1061

Spoenle, Jan: Netzsperren und Stolperfallen, jurisAnwZert ITR 17/2009, Anm. 2

Stadler, Thomas: Haftung für Informationen im Internet, 2. Auflage, Berlin 2005

— : Sperrungsverfügung gegen Access-Provider, MMR 2002, 343

— : Kein erschwerter Zugang, MMR 2009, 581

Steiner, Udo: Fragen der Beleihungsdogmatik aus österreichischer und deutscher Sicht, Festschrift für Friedrich Koja, Wien 1998, S. 603

Stelkens, Paul/Bonk, Heiz Joachim/Sachs, Michael: Verwaltungsverfahrensgesetz Kommentar, 7. Auflage, München 2008

Stelkens, Ulrich: Die Stellung des Beliehenen innerhalb der Verwaltungsorganisation - dargestellt am Beispiel der Beleihung nach $\$ 44$ III BHO/LHO, NVwZ 2004, 304

Stern, Klaus: Die Grundrechte und ihre Schranken, Festschrift 50 Jahre Bundesverfassungsgericht, Tübingen 2001, Bd. 2, S. 1 
— : Das Staatsrecht der Bundesrepublik Deutschland, Bd. 2: Staatsorgane, Staatsfunktionen, München 1980; Bd. 3/1: Grundlagen und Geschichte, München 1988; Bd. 3/2: Allgemeine Lehren der Grundrechte, München 1994; Bd. 4/1: Die einzelnen Grundrechte, München 2006

Stober, Rolf: Handbuch des Wirtschaftsverwaltungs- und Umweltrechts, Stuttgart 1989

— : Staatliches Gewaltmonopol und privates Sicherheitsgewerbe - Plädoyer für eine Police-Private-Partnership, NJW 1997, 889

Stramm, Marc/ Wegener, Christoph: Neue Anforderungen an eine anlasslose Speicherung von Vorratsdaten, MMR 2011, 9

Streinz, Rudolf: EUV/AEUV: Vertrag über die Europäische Union und Vertrag zur Gründung der Europäischen Gemeinschaft, 2. Auflage, München 2012

Stumpf, Roman: Jugendschutz oder Geschmackszensur - Die Indizierung von Medien nach dem Jugendschutzgesetz - eine verwaltungs- und verfassungsrechtliche Untersuchung unter Berücksichtigung europarechtlicher und völkerrechtlicher Bezüge, Berlin 2009

Süme, Oliver J.: Kinderpornografie: Access-Sperren als Ausweg?, MMR 2009, 1

Sydow, Gernot: Die Richtlinie als Instrument zur Entlastung des europäischen Gesetzgebers - Zur unmittelbaren Anwendbarkeit verfahrensrechtlicher Richtlinien im europäischen Verwaltungsverbund, JZ 2009, 373

Taeger, Jürgen/Gabel, Detlev: Kommentar zum BDSG und zu den Datenschutzvorschriften des TKG und TMG, Frankfurt am Main 2010

Taeger, Jürgen/ Wiebe, Andreas: Inside the cloud - Neue Herausforderungen für das Informationsrecht, 2009

Tanenbaum, Andrew S.: Computernetzwerke, 4. Auflage, München 2009 
Taubert, Jan Hendrik: Bundeskompetenz für Jugendschutz, Norderstedt 2003

Tellschaft, Jasmin: Medienkompetenz - Grundfragen, Chancen und Grenzen medienpädagogischen Konzeptes und sich daraus ergebende Herausforderungen an die Praxis, Kiel 2010

Tiedemann, Jens: Die Auslandskopf-Überwachung nach der TKÜV 2005, CR 2005, 858

Timofeeva, Yulia: Censorship in Cyberspace - new regulatory strategies in the digital age on the example of freedom of expression, 2006

Tinnefeld, Marie-Theres: Stopp-Schilder im Internet, DuD 2010, 15

Ukrow, Jörg: Jugendschutzrecht, München 2004

Umbach, Dieter C./Clemens, Thomas: Grundgesetz - Mitarbeiterkommentar und Handbuch, Bd. 1: Art. 1-37, Bd. 2: Art. 38-146, Heidelberg 2002

Unruh, Peter: Zur Dogmatik der grundrechtlichen Schutzpflichten, Berlin 1996

v. Eimeren, Birgit/ Frees, Beate: Der Internetnutzer 2009 - multimedial und total vernetzt? - Ergebnisse der ARD/ZDF-Onlinestduie 2009, Media Perspektiven 7-8/2010, S. 334

v. Hammerstein, Christian: Kostentragung für staatliche Überwachungsmaßnahmen nach der TKG-Novelle, MMR 2004, 222

v. Mangoldt, Hermann/ Klein, Friedrich/Starck, Christian: Kommentar zum Grundgesetz, Bd. 1: Präambel, Art. 1 bis 19; Bd. 2: Art. 20 bis 82;Bd. 3: Art. 83 bis 146; 6. Auflage, München 2010

Vassilaki, Irini E.: Anmerkung zu OVG Münster, Beschl. v. 19.3.2003 - 8 B 2567/02, CR 2003, 367 
Venske, Sven, Die Personenbezogenheit der IP-Adresse - Lange Diskutiert und immer noch umstritten?, ZD 2011, 114

Vlachopoulos, Spyridon: Kunstfreiheit und Jugendschutz, Berlin 1996

Volkmann, Christian: Der Störer im Internet, München 2005

Volkmann, Uwe: Verfassungsmäßigkeit der Vorschriften des Verfassungsschutzgesetzes von Nordrhein-Westfalen zur Online Durchsuchung und zur Internet-Aufklärung, DVB1. 2008, 590

Vormbaum, Thomas: Neues aus der Bauhütte des Rechts, oder: Geist und Buchstabe, JZ 2008, 244

Voßkuhle, Andreas: Der Grundsatz der Verhältnismäßigkeit, JuS 2007, 429

Waechter, Kay: Bereitstellungspflicht für Fernmeldeanlagenbetreiber, VerwArch 1996, 68

Wehr, Christina/Uijca, Matei: „Alles muss raus!“, MMR 2010, 667

Weichert, Thilo: Der Personenbezug von Geodaten, DuD 2007, 113

Weides, Peter: Der Jugendmedienschutz im Filmbereich, NJW 1987, 224

Weigend, Thomas: Strafrechtliche Pornographieverbote in Europa, ZUM 1994, 133

Weiß, Wolfgang: Zur Wirkung von Richtlinien vor Ablauf der Umsetzungsfrist, DVBl. 1998, 568

— : Privatisierung und Staatsaufgaben - Privatisierungsentscheidungen im Lichte einer grundrechtlichen Staatsaufgabenlehre unter dem Grundgesetz, Tübingen 2002

Welz, Wolfgang: Ressortverantwortung im Leistungsstaat - Zur Organisation, Koordination und Kontrolle der selbständigen Bundesoberbehörden un- 
ter besonderer Berücksichtigung des Bundesamtes für Wirtschaft, BadenBaden 1988

Westphal, Dietrich: Die neue EG-Richtlinie zur Vorratsdatenspeicherung, EuZW 2006, 555

— : Leitplanken für die Vorratsdatenspeicherung - Abrücken von „Solange“, EuZW 2010, 494

Wetzels, Peter: Gewalterfahrungen in der Kindheit, Baden-Baden 1997

Wienstroth, Henning: Internetregulierung im Lichte des Zensurverbots, Bucerius Law Journal 2009, 98

Wilske, Stephan/ Schiller, Teresa: International Jurisdiction in Cyberspace: Which States May Regulate the Internet, Federal Communications Law Journal 1997, 139

Wissenschaftlicher Dienst des Deutschen Bundestages: Sperrverfügung gegen Internet-Provider, Berlin 2009, WD 10-3000-010/2009, abrufbar unter: http://www.ffh.de/downloads/Sperrungsverfuegung_im_Internet.pdf

Witt, Inken: Regulierte Selbstregulierung, Baden-Baden 2008

Wolak Janis/Mitchell, Kimberly J./ Finkelhor, David: Internet Sex Crimes Against Minors, abrufbar unter: http://www.missingkids.com/en_US/publications/NC32.pdf

— : Child-Pornography Possessors Arrested in Internet-Realted Crimes, abrufbar unter:

http://www.missingkids.com/en_US/publications/NC144.pdf

Wolff, Heinrich Amadeus: Vorratsdatenspeicherung - Der Gesetzgeber gefangen zwischen Europarecht und Verfassung?, NVwZ 2010, 751

Wuermeling, Ulrich/ Felixberger, Stefan: Fernmeldegeheimnis und Datenschutz im Telekommunikationsgesetz, CR 1997, 230 
Wuttke, Gisela: Pornographie an Kindern, Opladen 2003

Zimmermann, Andreas: Polizeiliche Gefahrenabwehr und das Internet, NJW 1999,3145 


\section{Teil Einleitung}

Das Internet ist zu einem nicht mehr wegzudenkenden Medium geworden, welches nahezu lückenlos die vielfältigen Anforderungen des Menschen im Multimediazeitalter befriedigt. Insbesondere für die Politik und die Rechtwissenschaft ist es schwer, dass fortwährende Entwicklungstempo in politisch und rechtlich verträglicher Weise an die wandelnden Bedürfnisse anzupassen. Während die ersten rechtlichen Herausforderungen des Internets in das geltende Recht integriert und damit eine gewisse Grundstruktur zur Nutzung des Mediums vorgegeben wurde, ${ }^{1}$ finden sich nunmehr Stimmen, die auch eine rechtliche Struktur auf inhaltlicher Ebene fordern. Denn die nahezu lückenlose Abdeckung der Haushalte mit einem Internetanschluss ${ }^{2}$, der steigende Einsatz mobiler internetfähiger Geräte und die

1 Beispielhaft seien hier die Grundstrukturen, im Speziellen die Haftungsprivilegierungen der Internetprovider für Internetinhalte im Rahmen des TMG, die Lizenzfreistellung für den Vertrieb von Onlinediensten, die Ausweitung der strafrechtlichen Verbotstatbestandes auf den Onlinebereich sowie grundlegende Schutzstandards auf Länderebene durch den JMStV, genannt.

2 Repräsentative Studie im Auftrag von ARD und ZDF zur Entwicklung der Onlinenutzung in Deutschland, „ARD/ZDF-Onlinestudie 2010“, abrufbar unter: http://www.ard-zdfonlinestudie.de (zuletzt abgerufen 20.5.2012). Danach liegt die Anzahl der regelmäßigen Onlinenutzer bei ca. 50 Millionen und bedeutet damit eine vergleichbare Ausbreitung wie die des Fernsehens. Ausführliche Analyse und Auswertung der Studie bei v. Eimeren/Frees, Media Perspektiven 7-8/2010, S. 334. 
anonyme Benutzung des Internets, begründen die Gefahr einer weitreichenden Verbreitung sowie Konfrontation mit rechtlich unzulässigen Onlineinhalten.

Das erste gezielte Gesetzesvorhaben zu inhaltsregulierenden Maßnahmen wurde mit Nachdruck von der ehemaligen Bundesfamilienministerin Ursula von der Leyen verfolgt und richtete sich gegen kinderpornographische Onlineinhalte. Das so genannte ,Zugangserschwerungsgesetz ${ }^{\text {“3 }}$ sollte ein regulatorisches Grundkonzept zur Verhinderung der Gefahren kinderpornographischer Onlineinhalte darstellen, indem es dem Staat direkte Eingriffsbefugnisse zur Sperrung der Seiten über die Access-Provider gewährte. Schon kurz nach Bekanntwerden der gesetzlichen Initiative löste dieses national eine heftige Diskussion aus, welche durch Schlagwörter wie „Löschen statt Sperren“ und „Löschen vor Sperren“ bestimmt wurde und nicht zuletzt durch den provokanten Beinamen der nationalen Initiatorin „Zensursula“ einen einprägsamen Bezugspunkt bekam. Die Diskussion hatte erheblichen Einfluss auf den politischen Entscheidungsprozess, was letztlich dazu führte, dass sich das Zugangserschwerungsgesetz zu einem geschichtlich einmaligen ,gesetzlichen Phantom“ entwickelte.

Auch auf europäischer Ebene steht die Unterbindung von Kinderpornographie im Mittelpunkt der Regulierungsbemühungen. Die europäische Debatte war dabei ebenfalls vom Für und Wider hinsichtlich der Berechtigung zu technischen Maßnahmen wie der Löschung und Sperrung kinderpornographischer Webinhalte geprägt. Aufgrund der Richtlinie (2011/93/EU) ${ }^{4}$ wurde nunmehr aber ein Konsens herausgearbeitet, der ein deutliches Zeichen für die Notwendigkeit auch einer technischen Verfolgung von Kinderpornographie im Internet setzt.

Bei aller Einigkeit darüber, dass die Verhinderung des Zugangs zu kinderpornographischen Onlineinhalten ein legitimes Regulierungsziel darstellt, sind dabei die verfassungsrechtlichen Grenzen zu beachten. Denn mit inhaltsregulierenden Maßnahmen ist stets die Gefahr einer „Zensur“ beziehungsweise der „Verletzung der Unantastbarkeit“ des Internets und folglich des Eingriffs in die Grundrechte beteiligter sowie unbeteiligter Personenkreise verbunden. Den Schwerpunkt der Untersuchung werden dementsprechend die verfassungsrechtlichen Anforderungen an die Statuierung einer Sperrung kinderpornographischer Webinhalte bilden. Dazu sollen zunächst die verfassungsrechtliche Stellung des Jugendschutzes sowie die technischen Möglichkeiten einer Inhaltssperre dargestellt werden. AnschlieBend an die Herausarbeitung der allgemeinen verfassungsrechtlichen Anforderungen wird deren Einhaltung in dem Zugangserschwerungsgesetz untersucht. Ferner werden die europäischen Harmonisierungsbemühungen erläutert und deren mögliche Auswirkungen auf die nationale Gesetzeslage aufgezeigt. Abschließend widmet sich die Ausarbeitung einer rechtsvergleichenden Betrachtung zum in Frank-

3 Gesetz zur Erschwerung des Zugangs zu kinderpornographischen Inhalten in Kommunikationsnetzen (Zugangserschwerungsgesetz - ZugErschwG), BGBl. I 2010, S. 78.

4 ABl. 2011 Nr. L 18/, S. 7. 
reich im Jahr 2011 in Kraft getretenen „Loi d'orientation et de programmation pour la performance de la sécurité intérieure“ (so genanntes „Loppsi 2“-Gesetz), welches in Art. 4 ebenfalls eine legislatorische Verpflichtung der Access-Provider zur Sperrung kinderpornographischer Webangebote beinhaltet. 



\section{Teil Verfassungsrechtlicher und technischer Hintergrund}

\section{A. Verfassungsrechtliche Einflüsse und Gefährdungsbereich Kinderpornographie}

I. Schutzpflichtenlehre

Dem Jugendschutz wird in der heutigen Gesellschaft ein extrem hoher Stellenwert eingeräumt, der gesetzlich fixiert in viele Bereiche - hier seien exemplarisch nur das Familienrecht ${ }^{5}$, das besondere Verwaltungsrecht $t^{6}$, das Strafrecht ${ }^{7}$ und auch das Jugendmedienschutzrecht ${ }^{8}$ angeführt - ausstrahlt. Unter Jugendschutz wird überwiegend die Gesamtheit der rechtlich begründeten Maßnahmen zum Schutze

5 Beispiele: Unterhaltsverpflichtung, \S 1570, 1601 ff. BGB, S\$ 1615a ff.; Verpflichtung zur elterliche Sorge gem. \1626 ff. etc.; spezielle verfahrensrechtliche Voraussetzungen des Vormundschafts- sowie Familiengerichts \S 1712, 1773, 1837 BGB.

6 Jugendschutzrechtliche Vorschriften nach dem JuSchG, wie Jugendschutz in der Öffentlichkeit, $\$ 4$ ff. JuSchG, gewerbsrechtliche Schutznormen, z.B. \33c GewO.

7 Als jugendschützende Normen sind hier vor allem enumerativ $\$ \int 86,86 \mathrm{a}, 90 \mathrm{bis} 90 \mathrm{~b}, 130,130 \mathrm{a}$, 131 StGB aber auch $\iint 184$ ff. StGB zu nennen. Daneben die Tatbestände die sich mit der Verhinderungen von Sexualstraftaten an Kindern und Jugendlichen widmen, $\int \mathbb{1}$ 174, 176 ff., $\ 180$, 182 StGB.

8 JMStV, JuSchG, RStV. 
externer Gefahren für das körperliche, geistige und seelische Wohl von Kindern und Jugendlichen verstanden. ${ }^{9}$ Unzweifelhaft ist es der Gesellschaft daran gelegen, die Konstellation des Jugendschutzes in staatliche Hände zu legen und einen dahingehenden Schutzauftrag und damit letztlich das Wohl der Kinder und Jugendlichen gesetzlich abgesichert zu wissen. Die ungestörte Entwicklung von Kindern und Jugendlichen - erklärtes Ziel des Jugendschutzes - wird indes auch als ein verfassungsrechtlich bedeutsames Interesse anerkannt. ${ }^{10}$ Einigkeit herrscht darüber, dass es insbesondere auch staatliche Aufgabe sei, neben den Eltern, die Verwirklichung des Jugendschutzes zu leisten und zu sichern. Daher hat auch das Bundesverfassungsgericht den Jugendschutz objektiv als ein „Ziel von bedeutsamen Rang und als ein wichtiges Gemeinschaftsanliegen" ${ }^{\text {"11 }}$ charakterisiert.

Maßgeblich für eine generelle Annahme einer staatlichen Schutzwirkung für die Jugend ist die Anlehnung an die dogmatische Rechtsfigur der Schutzpflicht. Grundrechte haben - dem klassischen Verständnis folgend ${ }^{12}$ - zunächst eine negatorische Wirkung und sind vorrangig Abwehrrechte des Bürgers gegen den Staat. ${ }^{13}$ Das Abwehrrecht setzt die Freiheit des Bürgers als dem Staat vorgegeben voraus und zielt darauf ab, sie vor ungerechtfertigten Eingriffen des Staates zu bewahren. ${ }^{14}$ Zur Sicherung der persönlichen Freiheit ist die Funktion der Grundrechte als Abwehrrechte allein jedoch nicht ausreichend. ${ }^{15}$ Die Schutzpflichtenlehre kehrt die Wirkweise der Grundrechte daher gewissermaßen um: Grundrechte haben danach nicht nur eine abwehrrechtliche Dimensionen, sondern fungieren

9 Engels, AöR 122 (1997), 212 (215) unter Verweis auf die Formulierung der $\int 1$ JÖSchG, nunmehr abgelöst durch das Jugendschutzgesetz (JuSchG) vom 23.7.2002, siehe BGBl. I 2002, S. 2730; überblicksartig zur Neuordnung des Jugendschutzes, Liesching, NJW 2002, 3281.

10 Grundlegend BVerfGE 30, 336 (347); BVerfGE 77, 346 (356); BVerwGE 77, 75 (82), auch BGHSt 37, 55; Degenhart in: Bonner Kommentar, Art. 5 Abs. 1 GG, Rn. 131 ff.; Engels, AöR 122 (1997), 212 (214); Bandehzadeh, Jugendschutz im Rundfunk und in den Telemedien, 2007, S. 25 ff.; entschieden gegen die Anerkennung eines Verfassungsguts ,Jugendschutz“; Maunz in: FS für Obermayer, 1986, S. 85 (92 f.); F. Müller, Freiheit der Kunst, 1969, S. 108, 122, ders., JZ 1970, 87 (91). kritisch aber im Ergebnis zustimmend Geis, NVwZ 1992, 25 (26 f.).

11 BVerfGE 30, 336 (348); BVerfGE 77, 346 (356); BVerfGE 83, 130 (139).

12 Hierzu Dreier in: Dreier, Vorb. Art. 1 GG, Rn. 84; zusammenfassend zum klassischen Verständnis der Grundrechte Scblink, EUGRZ 1984, 457.

13 BVerfGE 7, 198 (204 ff.); BVerfGE 20, 150 (154 ff.); BVerfGE 21, 362 (368 ff.); BVerfGE 50, 290 (336 f.); BVerfGE 61, 82 (100); BVerfGE 68, 193 (205); Starck in: v. Mangold/Klein/Starck, Art. 1 GG, Rn. 110 ff.; Jarass in: Jarass/Pieroth, Vorb. vor Art. 1 GG, Rn. 2, 3; Dreier in: Dreier, Vorb. Art. 1 GG, Rn. 84; Klein, NJW 1989, 1633; Kratzmann, Grundrechte - Recht auf Leistungen, 1974, S. 1 ff.; kurz auch Holznagel/ Schumacher, ZRP 2011, 74 (75).

14 Isensee in: Isensee/Kirchhof, Hdb. StaatsR, 2002, Bd. V, \ 111, Rn. 2; vgl. Dreier in: Dreier, Vorb. Art. 1 GG, Rn. 84 f.

15 Jaeckel, Schutzpflichten, 2001, S. 38. 
gleichzeitig als staatliche Schutzpflichten. ${ }^{16}$ Im Kern verpflichtet die Schutzpflicht den Staat dazu auch die Unversehrtheit der grundrechtlichen Güter zwischen Privaten zu bewahren und geeignete Maßnahmen zu treffen, um Rechtsverletzungen zu vermeiden. ${ }^{17}$ Eine Notwendigkeit staatlicher Schutzverpflichtungen eröffnet sich insbesondere dann, wenn die typische Abwehrfunktion der Grundrechte versagt, namentlich die Gefährdung des Individuums durch ein Unterlassen beziehungsweise ein Nichteinschreiten des Staates nicht behoben werden kann, vielmehr erst ein Tätigwerden des zuständigen Staatsorgans die Gefährdungslage zu relativieren vermag. ${ }^{18}$

Als Gegenstand staatlicher Schutzpflichten kommen nach der Schutzpflichtenlehre sämtliche in den Freiheitsrechten normierten Güter in Betracht, ${ }^{19}$ wobei das Objekt der Schutzpflicht in seinem Inhalt und der thematischen Reichweite dem Schutzbereich des korrespondierenden Abwehrrechts angeglichen ist. ${ }^{20}$ Die dogmatische Basis der Schutzpflichten bildet die Prämisse des Bundesverfassungsgerichts, dass sich die Grundrechte nicht in der subjektiv-abwehrrechtlichen Dimension des Einzelnen gegen den Staat erschöpfen, sondern auch eine objektive Werteordnung enthalten, deren Verwirklichung durch aktives Handeln ständige Aufgabe der staatlichen Gewalt ist und in alle Bereiche des Rechts ausstrahlt. ${ }^{21}$ Damit leite sich aus der „dem jeweils betroffenen Einzelgrundrecht innewohnenden objektiven Wertentscheidung" ${ }^{\text {"22 }}$ auch die Akzentuierung staatlicher Schutzpflichten ab. Das Bundesverfassungsgericht geht indes davon aus, dass die Schutzverpflichtung des Staates umso dringlicher sei, ,je höher der Rang des in Frage ste-

Beispielhaft BVerfGE 39, 1; BVerfGE 46, 160; BVerfGE 49, 89; BVerfGE 53, 30; BVerfGE 56, 54; BVerfGE 77, 170 (180 f.); BVerfGE 77, 381 (391 f.); BVerfGE 88, 203.

17 Vgl. Dreier in: Dreier, Vorb. Art. 1 GG, Rn. 101.

18 Klein, NJW 1989, $1633 \mathrm{f}$.

19 So die Prognose des abweichenden Sondervotums Rupp- von Brünneck/Simon in: BVerfGE 39, 68 (73); Dirnberger, Recht auf Naturgenuß und Eingriffsregelung, 1991, S. 112 ff.; Dietlein, Schutzpflichten, 1992, S. 74 ff.; Auch Gleichheitsrechte, die im Folgenden nicht Inhalt der Untersuchung sind, können staatliche Schutzpflichten begründen, dies gebietet gerade die Herleitung aus der objektiven Werteordnung, hierzu Dietlein, Schutzpflichten, 1992, S. 84 ff.; anders Isensee in: Isensee/Kirchhof, Hdb. StaatsR, 2002, Bd. V, \$111, Rn. 96.

20 Umfassend BVerfGE 46, 160 (164); BVerfGE 39, 1 (47); BVerfGE 53, 30 (57 ff.).

21 BVerfGE 7, 198 (205); BVerfGE 39, 1 (41 ff.); BVerfGE 49, 89 (141 f.); BVerfGE 88, 203 (251 ff.); BVerfGE 56, 54 (73); andere Termini aber im Kern die gleiche Aussage einer objektivrechtlichen Dimension der Grundrechte bei BVerfGE 50, 290 (337).

22 BVerfGE 39, 1 (41 ff.); zusammenfassend zum Thema der staatlichen Schutzpflicht Isensee in: Isensee/Kirchhof, Hdb. StaatsR, 2002, Bd. V, \111, Rn. 80; Jaeckel, Schutzpflichten, 2001, S. 46 f.; Calliess in: Merten/Papier, Hdb. Grundrechte, 2006, Bd. II, \44; Klein, NJW 1989, 1633; Weiß, Privatisierung, 2002, S. $156 \mathrm{ff}$. 
2. Teil Verfassungsrechtlicher und technischer Hintergrund

henden Rechtsguts innerhalb der Wertordnung des Grundgesetzes anzusetzen ist." ${ }^{\text {"23 } 3}$

In Anbetracht der Tragweite dieser fundamentalen Wertentscheidung ist es naheliegend, dass Rechtsprechung, wie auch Literatur, der Herleitung einer staatlichen Schutzverpflichtung nicht ohne Kritik gegenüberstehen. Weitgehende Einigkeit besteht mittlerweile zumindest hinsichtlich der Existenz der verfassungsrechtlichen Schutzpflicht, ${ }^{24}$ allein die vom Gericht vorgenommene dogmatische Herleitung ist auf zunehmende Kritik gestoßen. ${ }^{25}$ In Übereinstimmung mit dem Bundesverfassungsgericht ${ }^{26}$ ist nachfolgend anzunehmen, dass jedem Freiheitsrecht auch gleichzeitig eine Verpflichtung des Staates zukommt es in seinem Bestand zu bewahren. Daran schließt sich folglich die Frage an, an welcher Stelle dem Jugendschutz Verfassungsrang zugesprochen werden kann, so dass dieser eine positivrechtliche Handlungsverpflichtung des Staates zur Abwehr kind- und jugendgefährdender Bereiche statuiert.

\section{Herleitung einer Schutzpflicht für den Jugendschutz aus der Schrankenregelung des Art. 5} Abs. 2, Var. 2 GG

Der Jugendschutz ist in der Verfassung nicht als selbstständiges Verfassungsgut normiert, sondern lediglich als Schranke einzelner Grundrechte erwähnt. Eine detaillierte Erwähnung erhält der Jugendschutz beispielsweise im Rahmen eines qualifizierten Gesetzesvorbehalts in Art. 5 Abs. 2, Var. 2 GG. Die verfassungsrechtliche Formulierung gestattet dem Gesetzgeber die Kommunikationsgrund-

23 BVerfGE 39, 1 (42).

24 Isensee in: Isensee/Kirchhof, Hdb. StaatsR, 2002, Bd. V, J 111, Rn. 80; Erichsen, JURA 1997, 85; Stern in: Isensee/Kirchhof, Hdb. StaatsR, 2002, Bd. V, \ 109, Rn. 59; Altenhain in: Roßnagel, Recht der Multimedia-Dienste, 2005, Einl. GjS, Rn. 23; Jarass, AöR 110 (1985), 363 (378); Jarass in: Jarass/Pieroth, Vorb. vor Art. 1 GG, Rn. 6 ff.; Jaeckel, Schutzpflichten, 2001, S. 46 ff.; kritisch Jeand Heur, Verfassungsrechtliche Schutzgebote, 1993, S. 59 ff.; Pietzcker in: FS für Dürig, 1990, S. 345 (356 ff.); Kratzmann, Grundrechte - Rechte auf Leistungen, 1974, S. 63 ff.

25 Diese Zweifel Gründen zum Teil auf einem staats- und verfassungsrechtlich fundierten Misstrauen hinsichtlich einer Ausdehnung der objektiven Grundrechtsdimension, hierzu Böckenförde, Der Staat 29 (1990), 1 ff.; Dreier, Dimensionen der Grundrechte, 1993, S. 53; zusammenfassend Jaeckel, Schutzpflichten, 2001, S. 51 ff.; teilweise Akzeptanz hinsichtlich dem Konstrukt der Schutzpflichten, jedoch den Rückgriff auf die objektive Werteordnung verneinend, Dietlein, Schutzpflichten, 1992, S. 52 ff.; Bumke, Der Grundrechtsvorbehalt, 1998, S. 75 ff.; Robbers, Sicherheit als Menschenrecht, 1987, S. 186 ff.; überblickartig zum Meinungsstand Calliess in: Merten/Papier, Hdb. Grundrechte, 2006, Bd. II, \44, Rn. 4 ff., 8 ff.; Dirnberger, Recht auf Naturgenuß und Eingriffsregelung, 1991, S. 112 ff.

26 BVerfGE 39, 1; BVerfGE 46, 160; BVerfGE 49, 89; BVerfGE 53, 30; BVerfGE 56, 54; BVerfGE 77, 170; BVerfGE 77, 381; BVerfGE 88, 203. 
rechte des Art. 5 Abs. 1 GG durch „Bestimmungen zum Schutze der Jugend“ einzuschränken.

Teilweise wird versucht die Schranke des Art. 5 Abs. 2, Var. 2 GG zur Begründung eines des Verfassungsrangs des Jugendschutzes mit korrespondierender staatlicher Schutzverpflichtung heranzuziehen. ${ }^{27}$ Die Schrankenbestimmungen erschöpfen sich danach nicht lediglich darin, die Abwehrrechte der Bürger zu beschränken und Eingriffe des Staates zuzulassen; vielmehr begründen sie auch eigene Handlungspflichten der Staatsgewalt, da sie ausdrücklich Aufgabenzuweisungen normieren. ${ }^{28}$ Es sei schon vom Wortlaut her „nicht zu übersehen“, dass auch die Beschränkungen von Grundrechten unmittelbar durch die Verfassung nicht nur „negativ rechtsbegrenzende Wirkung“ hätten, sondern auf der anderen Seite „positive, begünstigende Rechtswirkungen nämlich zugunsten der Rechtsgüter, die die Schrankenregelungen tatbestandsmäßig ausfüllen“, enthielten. ${ }^{29}$

Obgleich die Argumentation dem ersten Anschein konsequent erscheint, sprechen gegen die systematische Hochstufung der Schrankenbestimmung zum Verfassungsrang mit korrespondierender Schutzverpflichtung jedoch bereits zwei wesentliche Argumente: Bereits in methodischer Hinsicht ist es nicht ersichtlich, warum aus den Schrankenbestimmungen der Grundrechte das „Postulat staatlicher Aktivität" 30 folgen soll. Nach dem allgemeinen Rechtsverständnis bilden die Grundrechte Befugnisnormen zum Eingriff in den jeweiligen Schutzbereich durch die Staatsgewalt. ${ }^{31}$ Im Umkehrschluss von einer solchen Befugnis auf eine korrespondierende Verpflichtung zu schließen erscheint systematisch unzulänglich. Zwar hebt der Gesetzgeber die Wichtigkeit des Jugendschutzes gerade durch die Formulierung des qualifizierten Gesetzesvorbehalts hervor, indem ,gesetzliche Bestimmungen zum Schutze der Jugend" immerhin in der Lage sind, die für die Demokratie „schlechthin konstituierenden“32 Kommunikationsgrundrechte des Art. 5 Abs. 1 GG zu beschränken, ${ }^{33}$ jedoch ist damit nicht gleichzeitig auch die generelle Handlungsverpflichtung bezüglich des Jugendschutzes verbunden. Indem der Staat durch Gesetzesvorbehalte lediglich eine Ermächtigungsgrundlage

27 Mynarik, Jugendschutz in Rundfunk und Telemedien, 2006, S. 37 f. Für ein extensives Schrankenverständnis beim Recht auf Leben aus Art. 2 Abs. 2 S.1 GG, Herzog, JR 1969, 441 (443); Seewald, Verfassungsrecht auf Gesundheit, 1981, S. 79 ff.

28 Jaeckel, Schutzpflichten, 2001, S. 48; Seewald, Verfassungsrecht auf Gesundheit, 1981, S. 80; dem zustimmend Dietlein, Schutzpflichten, 1992, S. 32 f.

29 Seewald, Verfassungsrecht auf Gesundheit, 1981, S. 80.

30 Unruh, Dogmatik der Schutzpflichten, 1996, S. 49; ähnlich auch Baum, Jugendmedienschutz als Staatsaufgabe, 2007, S. $118 \mathrm{mwN}$.

31 Hierzu bereits oben 2. Teil A. I.

32 BVerfGE 20, 56 (97) im Anschluss an BVerfGE 5, 85 (134 f.); BVerfGE 7, 198 (208); BVerfGE 101, 361 (389).

33 Engels, AöR 122 (1997), 212 (244). 
zum Handeln erhält und gerade nicht auch diesbezüglich verpflichtet wird, steht es ihm verfassungsrechtlich frei, ob er einfach-gesetzliche Schutzaktivitäten zugunsten der jeweils genannten Rechtsgüter ergreift oder auf ein Eingreifen verzichtet. ${ }^{34}$ Darüber hinaus ließen sich derart „,funktional aufgeladene Gesetzesvorbehalte“35 zu leicht zur Beschränkung beliebiger grundrechtlicher Freiheiten heranziehen. Ein solches Vorgehen legt die Befürchtung nahe, dass dieses zu einer Verselbstständigung ,verfassungsimmanenter Schranken“ vorbehaltlos gewährleisteter Freiheitsgarantien führt und damit die verfassungsrechtlich vorgegebene Grundkonzeption der Wertigkeit der Grundrechte - die sich eben auch in deren Beschränkungsmöglichkeit widerspiegelt - aus den Angeln hebt. ${ }^{36}$ Im Ergebnis würde diese Sichtweise damit gleichbedeutend mit einer Aushöhlung der Schrankensystematik sein und kann damit rechtsdogmatisch nicht hingenommen werden. 37

\section{Herleitung einer Schutzpflicht für den Jugendschutzes anband des Allgemeinen Persönlich-} keitsrechts gem. Art. 2 Abs. 1 GG i.V.m. Art. 1 Abs. 1 GG

Das Bundesverfassungsgericht äußerte sich erstmalig in der JosepfineMutzenbacher Entscheidung ${ }^{38}$ zur Rechtsstellung des Jugendschutzes. Danach genieße der Jugendschutz, ,vor allem aufgrund des in Art. 6 Abs. 2 S. 1 GG verbrieften elterlichen Erziehungsrechts Verfassungsrang“. „Verfassungsrang kommt dem Kinder- und Jugendschutz daneben aus Art. 1 Abs. 1 GG in Verbindung mit Art. 2 Abs. 1 GG zu."

Das vom Bundesverfassungsgericht zur Begründung des Jugendschutzes herangezogene Allgemeine Persönlichkeitsrecht wurde durch Rechtfortbildung allmählich aus Art. 2 Abs. 1 GG unter Heranziehung des Art. 1 Abs. 1 GG heraus-

34 Baum, Jugendmedienschutz als Staatsaufgabe, 2007, S. 118; ähnlich auch Jaeckel, Schutzpflichten, 2001, S. 45, die aber lediglich von einen ,zufälligen“ Ergebnis spricht.

35 Baum, Jugendmedienschutz als Staatsaufgabe, 2007, S. 119.

36 Krings, Schutzansprüche, 2003, S. 140 f., 149, geht hier noch weiter und äußert die Befürchtung, dass eine derartige Vorgehensweise zu einer „Verfassungsimmanenten Universalschranke der Grundrechte" avanciert. I.E auch Baum, Jugendmedienschutz als Staatsaufgabe, 2007, S. 119; Jaeckel, Schutzpflichten, 2001, S. 44 f.

37 Baum, Jugendmedienschutz als Staatsaufgabe, 2007, S. 119 bezugnehmend auf Krings, Schutzansprüche, 2003, S. 140 f. Im Ergebnis so auch Jarass in: Jarass/Pieroth, Art. 5 GG, Rn. 61; Bethge in: Sachs, Art. 5 GG, Rn. 160; Stumpf, Jugendschutz oder Geschmackszensur, 2009, S. 83; Bandehzadeh, Jugendschutz im Rundfunk und in den Telemedien, 2007, S. 25; Engels, AöR 122 (1997), 212; Vlachopoulos, Kunstfreiheit und Jugendschutz, 1996, S. 143; anders Schulze-Fielitz in: Dreier, Art. 5 Abs.1, 2 GG, Rn. 147, jedoch ohne Begründung.

38 BVerfGE 83, 130 (139). 
gebildet ${ }^{39}$ und als „unbenanntes“ Freiheitsrecht anerkannt. ${ }^{40}$ Vom sachlichen Schutzbereich des Allgemeinen Persönlichkeitsrechts sind grundlegend drei gewichtige Entfaltungsweisen des Individuums umfasst: Die Selbstbewahrung, die Selbstdarstellung und den beiden Komponenten vorgelagerte Grundbedingungen, insbesondere das Selbstbestimmungsrecht. ${ }^{41}$ Inhaltlich sollen die genannten Fallgruppen nahezu alle Voraussetzungen an die verfassungsrechtliche Befähigung zum Person-Sein - so eine treffende Schutzbereichscharakterisierung von Jarass ${ }^{42}$ - umfassen.

Person-Sein meint dem anerkannten Rechtsprechungsverständnis nach, alle Faktoren, die der umfassenden, eigenverantwortlichen und selbstbestimmten Individualitätsbildung und dem Selbstverständnis der Position des Individuums im gesellschaftlichen Gesamtgefüge dienen. ${ }^{43}$ Damit muss auch die freie Individualitätsfindung und -bildung Minderjähriger ebenso erfasst sein, wie personelle Entfaltung Erwachsener. Dementsprechend ist jedenfalls in den Bereichen, in denen es um Gefahren geht, die speziell dadurch bedingt sind, dass die Persönlichkeit oder die Physis noch nicht so weit entwickelt sind und damit sehr leicht negativen Einfluss auf das Individuum genommen werden kann, das Allgemeine Persönlichkeitsrecht als verfassungsrechtlicher Ausgangspunkt für den Kinder- und Jugendschutz einschlägig.

BGHZ 24, 72 (81); BGHZ 27, 284 (287); BVerfGE 54, 148 (153); BVerfGE 35, 202 (219 ff.); BVerfGE 72, 155 (170); BVerfGE 79, 256 (270); BVerfGE 82, 236 (269); BVerfGE 90, 263 (270); BVerfGE 101, 361 (380 ff.); BVerfGE 114, 339 (346 f.).

40 BVerfGE 54, 148 (153); BVerfGE 72, 155 (170); grundlegend zu unbenannten Freiheitsrechten W. Schmidt, AöR 91 (1966), 42 (77 f.); Burgi, ZfG 1994, 341 (363); siehe auch Murswiek in: Sachs, Art. 2 GG, Rn. 64; Starck in: v. Mangoldt/Klein/Starck, Art. 2 Abs. 1 GG, Rn.14; Dreier in: Dreier, Art. 2 Abs. 1 GG, Rn. 68 ff.

41 Dreier in: Dreier, Art. 2 Abs. 1 GG, Rn. 68 ff.; den sachlichen Schutzbereich ausweitend, aber inhaltlich ähnlich Di Fabio in: Maunz/Dürig, Art. 2 Abs. 1 GG, Rn. 148 mit weiteren Fallgruppen.

42 Jarass, NJW 1989, 857 (859).

43 So vereinfacht dargestellt. Die bekanntesten gerichtlichen Ausprägungen der grundrechtlichen Gewährleistung sind in diesem Zusammenhang das Recht am eigenen Bild: BVerfGE 35, 202 (220); BVerfGE 87, 334 (340); BVerfGE 97, 228 (268 f.); BVerfGE 101, 361 (381) sowie das Recht am eigenen Wort: BVerfGE 34, 238 (246); BVerfGE 54, 208, (217 f.); BVerfGE 99, 185 (193 ff.). Zudem die Rechte auf Berichtigung und Gegendarstellung: BVerfGE 63, 131 (142 f.); BVerfGE 97, 125 (148 f.) und das Recht auf informationelle Selbstbestimmung: grundlegend BVerfGE 65, 1 (41 ff.); auch BVerfGE 78, 77 (84); BVerfGE 96, 171 (181); BVerfGE 115, 320 (341 f.); BVerfGE 118, 168 (187 f.). Ferner auch das „neue“ Recht auf Vertraulichkeit und Integrität informationstechnischer Systeme, als Sonderform des Rechts auf Selbstbestimmung, dazu BVerfGE 120, 274. 
Es ist aber nicht von der Hand zu weisen, dass in der Entwicklung der Individualität und des Selbstverständnisses von Kindern und Jugendlichen, diese anderen Gefahren ausgesetzt sind, als erwachsene Personen. Die Unterschiede werden bereits in der Physis, der seelisch-geistigen Integrität, wie auch der Rezeption der Umwelt und ihrer Einflüsse deutlich. ${ }^{44}$ Hiermit verbunden sind auch geringere selbstständige Abwehrmechanismen, welchen verfassungsrechtlich durch das Institut des Rechts auf Person-Sein nicht hinreichend Schutz gewährt sein könnte, obschon diese zumindest nicht minder schützenswert sind. ${ }^{45}$

Von dieser Prämisse ausgehend, vertritt eine im Vordringen befindliche Ansicht, dass der Jugendschutz sich nicht aus dem Recht auf Person-Sein als ein Teil des Allgemeinen Persönlichkeitsrechts ergibt. Vielmehr sei als besondere dogmatische Ausprägung des Allgemeinen Persönlichkeitsrechts das Recht auf PersonWerden zum Schutze vor altersspezifischen Gefahren herzuleiten. ${ }^{46}$ Inhaltlich schütze dieses den vorgelagerten Prozess der Entwicklung der Persönlichkeit und wandle sich mit deren Abschluss in das Recht auf Person-Sein. ${ }^{47}$ Die Differenzierung zwischen Person-Sein und Person-Werden beuge darüber hinaus verfassungsrechtlichen Bedenken vor. ${ }^{48}$

a) Schutzbereichsverständnis des Bundesverfassungsgerichts

Diese Ansicht ist aber bereits aus rechtsprechungsanalytischen Gesichtspunkten nicht ohne Weiteres gerechtfertigt: Die Rechtsprechung folgt dem Ansatz, dass gerade auch die Persönlichkeitsentwicklung verfassungsrechtlichen Schutz über Art. 2 Abs. 1 GG i.V.m. Art. 1 Abs. 1 GG genießt, ohne dass es der Kreation einer gesonderten Grundrechtsfigur bedürfe. Neben Konstellationen, in denen die bereits entwickelte Persönlichkeit in zwischenmenschliche Interaktionen und innerpersonale Bewusstseinserweiterungen tritt, schützt Art. 2 Abs. 1 GG i.V.m. Art. 1 Abs. 1 GG auch die erstmalige Ausprägung der Persönlichkeit. Insbesondere in der Abstammungsentscheidung ${ }^{49}$ hat das Bundesverfassungsgericht betont, dass die Kenntnis der eigenen Herkunft „unabhängig vom Stand des biologischen Wissens über die Erbanlagen wichtige Anknüpfungspunkte für das Verständnis und die Entfaltung der eigenen Individualität" ${ }^{\star 50}$ biete. Schließlich betont das Bun-

44 Engels, AöR 122 (1997), 212 (223 ff.).

45 Auf eine detaillierte Aufzählung spezifischer Gefahren, die den Entwicklungsprozess eines Kindes zum erwachsenen Menschen prägen, wird hier willentlich verzichtet; deren Existenz aber vorausgesetzt. Die Einbeziehung medienvermittelter Gefahren auf die kindliche Persönlichkeitsentfaltung wird aber unter S. 32 ff. eingehend behandelt.

46 Engels, Fernsehwerbung, 1997, S. 68 f.

47 Engels, Fernsehwerbung, 1997, S. 68 f.; ders., AöR 122 (1997), 212 (226 f.).

48 So Engels, Fernsehwerbung, 1997, S. 68 f.; ders., AöR 122 (1997), 212 (226 f.).

49 BVerfGE 79, 256.

50 BVerfGE 79, 256 (268 f.). 
desverfassungsgericht weiter, dass es „existenzielle Notwendigkeit“ sei, auch das in der Entwicklung stehende Individuum, letztlich den heranwachsenden Menschen, in dessen Heranwachsen zu schützen. Noch deutlicher bringt das Bundesverfassungsgericht seine Auffassung in der Sexualkundeentscheidung ${ }^{51}$ zum Ausdruck. Hiernach sei „Er [der Jugendliche] vielmehr von vorneherein und mit zunehmenden Alter in immer stärkerem Maße eine eigene durch Art. 2 Abs. 1 i.V.m. Art. 1 Abs. 1 GG geschützte Persönlichkeit“،

Die Auffassung, das Allgemeine Persönlichkeitsrecht müsse um den Bestand des Person-Werdens weiterentwickelt werden, verkennt diese vom Bundesverfassungsgericht entwickelten Prinzipien, die keineswegs Anlass dazu geben zwischen der kindlichen Persönlichkeit und der bereits voll entwickelten Persönlichkeit im Schutzbereich des Allgemeinen Persönlichkeitsrechts zu unterscheiden und damit eine Differenzierung zwischen dem Recht auf Person-Werden und Recht auf Person-Sein rechtfertigen würde.

b) Systematik des Art. 2 Abs. 1 GG i.V.m. Art. 1 Abs. 2 GG

Die verfassungsgerichtliche Vorgehensweise der Konstruktion eines eigenständigen Rechts auf Person-Werden findet überdies auch im Rahmen einer systematischen Auslegung des Art. 2 Abs. 1 GG i.V.m. Art. 1 Abs. 1 GG keinen Zuspruch. Die tatbestandliche Reichweite eines Grundrechts muss sich im Ausgangspunkt an der systematischen Vorgabe des Normtextes orientieren. Daher müsste bereits im Normgefüge des Art. 2 Abs. 1 GG i.V.m. Art. 1 Abs. 1 GG eine Differenzierungsmöglichkeit für die gebotene Unterscheidung zwischen dem Recht auf Person-Werden und dem Recht auf Peron-Sein, angelegt sein. Zieht man ausschließlich die Grundpfeiler des Allgemeinen Persönlichkeitsrechts zur Betrachtung heran, so erscheint eine derartige Unterscheidung aber gerade systemwidrig: Das Allgemeine Persönlichkeitsrecht gründet im Kern auf zwei verfassungsrechtlichen Grundelementen, der Allgemeinen Handlungsfreiheit und der Menschenwürdegarantie. ${ }^{52}$ Die allgemeine Handlungsfreiheit hat sich schon früh als „Handlungsfrei-

51 BVerfGE 47, 46.

52 Dogmatisch ist die Heranziehung der Menschenwürdegarantie nicht gleichlautend mit einer gleichrangigen Selbstständigkeit derselben, innerhalb der Grundgewährleistung des Persönlichkeitsrechts. Vielmehr stützt sich das Allgemeine Persönlichkeitsrecht nach überwiegender Auffassung allein auf Art. 2 Abs. 1 GG, da die von Verfassungswegen durchaus zulässigen grundrechtlichen Einschränkungen (sog. Schrankentrias, s. BVerfGE 97, 228 (269); BVerfGE 99, 185 (195 f.); BVerfGE 114, 339 (347); BVerfGE 120, 180 (201 f.)), mit einer anderweitigen Auslegung nicht vereinbar wären, vgl. Heß, Grundrechtskonkurrenzen, 2000, S. 219; Jarass in: Jarass/Pieroth, Art. 2 GG, Rn. 38; di Fabio in: Maunz/Dürig, Art. 2 GG, Rn. 128. Der Menschenwürdegehalt des Allgemeinen Persönlichkeitsrechts wird aber als objektiv-rechtliche Interpretationsrichtlinie verstanden, die dem Bereich der ,engeren persönlichen, freilich nicht auf rein geistige und sittliche Entfaltung beschränkten Lebenssphäre“ inhaltliche Konturen verleiht, 
heit im umfassenden Sinne“ - ohne Rücksicht auf sozialethische Gesichtspunkte und ungeachtet personaler Willkür und Reifegrade - gerichtlich durchsetzt. ${ }^{53}$ Auch für den Menschenwürdegehalt gem. Art. 1 Abs. 1 GG ist es nach allgemeiner Auffassung ,nicht entscheidend, ob der Träger sich dieser Würde bewußt ist oder sie selbst zu wahren weiß ${ }^{\text {“54, }}$, vielmehr ist anerkannt, dass „die von Anfang an im menschlichen Sein angelegten potentiellen Fähigkeiten genügen, um die Menschenwürde zu begründen". ${ }^{55}$ Anhand der hier zitierten Sentenzen, wird deutlich, dass sich die dem Allgemeinen Persönlichkeitsrecht zugrundeliegenden Grundrechte nicht ausschließlich auf den Schutz von bereits körperlich, wie geistig entwickelten Individuen beschränken, sondern auch die Sicherung der persönlichen Lebenssphäre und die Erhaltung ihrer Grundbedingungen allgemein gewährleisten. ${ }^{56}$ Folglich spricht auch eine systematische Auslegung des Allgemeinen Persönlichkeitsrechts gegen eine Differenzierung zwischen dem Recht auf PersonWerden und Recht auf Person-Sein.

\section{c) Abgrenzungsschwierigkeiten}

Zudem erscheint die in der Literatur vorgenommene Differenzierung gerade in Anbetracht unausweichlicher Abgrenzungsschwierigkeiten nicht vorzugswürdig. Es ist kaum möglich, nachvollziehbare Kriterien anzustellen, ab welchen Zeitpunkt das Recht auf Person-Werden verwirkt ist und sich in ein Recht auf PersonSein wandelt. So sind Abgrenzungskriterien, wie eine physische Entwicklung oder ein emotionaler Reifegrad, mangels messbarer Ergebnisse, nicht in der Lage gefes-

Starck in: v. Mangoldt/Klein/Starck, Art. 2 Abs. 1 GG, Rn. 17; kurz auch „Recht auf freie Entfaltung der Persönlichkeit“" genannt, kritisch zu dieser einschränkenden Schutzbereichsformulierung: Murswiek in: Sachs, Art. 2 GG, Rn. 46.

53 BVerfGE 6, 32 (36 ff.); BVerfGE 54, 143 (146); BVerfG 75, 108 (154 f.); BVerfGE 80, 137 (152); BVerfGE 90, 145 (171); BVerfGE 97, 332 (340 f.); BVerfGE 113, 88 (103); BVerfGE 114, 371 (383 f.); Murswiek in: Sachs, Art. 2 GG, Rn. 42 ff.; kritisch zu dieser Rechtsprechung vgl. Sondervotum Grimm, BVerfGE 80, 137 (164 ff.), der nur solches Verhalten als grundrechtlich geschützt anerkennt, dass eine gesteigerte, dem Schutzgut der übrigen Grundrechte vergleichbare Relevanz für die Persönlichkeitsentfaltung hat, da sonst eine „Banalisierung der Grundrechte“ drohe; ähnlich auch Hoffmann-Riem, Der Staat 43 (2004), 214; gegen das weite Schutzbereichsverständnis insb. auch Peters in: FS für Laun, 1953, S. 669, der auch nur solche Handlungsweisen vom Schutzbereich betroffen sieht, die angelehnt an den Wortlaut des Art. 2 Abs. 1 GG iVm. Art. 1 Abs. 1 GG den „Kernbezirk des Persönlichen“ schützen, sog. Persönlichkeitsrechtskerntheorie.

54 BVerfGE 39, 1 (41).

55 BVerfGE 39, 1 (41); iE. auch BVerfGE 88, 203 (252). So iE. auch die Literatur: Jarass in: Jarass/Pieroth, Art. 1 GG, Rn. 6; Starck in: v. Mangold/Klein/Starck, Art. 1 Abs. 1 GG, Rn. 18 ff.; Hillgruber in: Epping/Hillgruber, Art. 1 GG, Rn. 3 f.

56 Isensee/Axer, Jugendschutz im Fernsehen, 1998, S. 73. 
tigte Konturen für eine gehaltvolle Differenzierung der Rechtsfiguren herbeizuführen. ${ }^{57}$ Auch das Alter allein kann nicht ausschlaggebend dafür sein, von einem Recht auf Person-Werden und einem Recht auf Person-Sein zu sprechen. Zumal es bereits rechtsgebietsübergreifend unterschiedliche Konstellationen der altersgemäßen Beurteilung gibt; Beispielsweise Geschäftsfähigkeitsprinzipien des Bürgerlichen Gesetzbuches wonach das Recht auf Person-Sein erst mit Volljährigkeit gem. $\ 2$ BGB zum Tragen kommt, oder individuelle Reifegrade und Einsichtsfähigkeiten, wie es z.B. im Jugendstrafrecht unter dem Begriff des Heranwachsenden gem. IS 1 Abs. 2, 105 JGG. Um solche Probleme zu vermeiden bietet sich ein einheitliches Schutzbereichsverständnis an, welches den Jugendschutz unabhängig von etwaigen Differenzierungen aus dem Allgemeinen Persönlichkeitsrecht an sich ableitet. Schließlich ändert sich bei Ablehnung der Rechtsfigur des PersonWerden auch nicht die daraus resultierende rechtliche Folge: Letztlich ist die Diskussion um ein Recht auf Person-Werden und ein Recht an Person-Sein rein dogmatischer Natur. Der Schutzbereich des Allgemeinen Persönlichkeitsrechts, welches auch den Ausgangspunkt des Jugendschutzes enthält, ist an die verfassungsrechtlichen Vorgaben der Schrankenbestimmungen geknüpft. In dem Bereich in dem es um besonders sensible Gefahren geht, die spezifisch auf den geringeren Stand der Entwicklung beziehungsweise die geringe körperliche und seelische Reife zurückzuführen sind, können die Schrankenbestimmungen intensiver und detaillierter ausgestaltet sein und somit die Voraussetzungen an die Verfassungsmäßigkeit des Eingriffs höher ansetzen, als bei einem erwachsenen Grundrechtsträger, der starken staatlichen Schutzmechanismen gerade nicht bedarf.

Nach dem hier entwickelten Verständnis muss also gelten: Der Schutzbereich des allgemeinen Persönlichkeitsrechts - explizit des Rechts auf Person-Sein erfasst mit seinen Ausprägungen im Wesentlichen neben der Entfaltung der ausgereiften Persönlichkeit, auch schon den vorgelagerten Prozess der körperlichen, wie seelischen Entwicklung zu einem eigenverantwortlichen und selbstbestimmt handelnden Individuum. ${ }^{58}$ Soweit im Rahmen des verfassungsrechtlichen Schutzbereichs des allgemeinen Persönlichkeitsrechts speziell die ungestörte körperliche wie geistige Entwicklung der Persönlichkeit von Kindern und Jugendlichen im Mittelpunkt steht, dient das Allgemeine Persönlichkeitsrecht des Art. 2 Abs. 1 GG i.V.m. Art. 1 Abs. 1 GG zwangsläufig auch dem Jugendschutz und kann zur Begründung des Verfassungsrangs herangezogen werden. Die oben genannte Schutzpflichtenlehre verpflichtet den Staat folglich dazu sämtliche gesellschaftlichen Gefährdungspotenziale, die negative Auswirkungen auf die körperliche und

57 Desgleichen erkennen auch die Vertreter dieses Grundrechtsverständnisses an, dass sich „kaum jemals valide Kriterien dafür finden [ließen], wann und warum das Person-Werden beendet" ist, so Engels, Fernsehwerbung, 1997, S. 70.

58 iE. Witt, Regulierte Selbstregulierung, 2008, S. 139. 
geistige Entfaltung von Kindern und Jugendlichen haben können, zu regulieren und inhaltlich zu begrenzt. Mögliche altersspezifische Differenzierungen der gebotenen Schutzverpflichtung sind nicht durch eine verfassungsrechtliche Konstruktion eines dogmatischen Rechts auf Person-Werden vorzunehmen, sondern anhand gezielter Steuerungsmechanismen etwa auf einfach-gesetzlicher Basis.

\section{Elterliches Erziehungsrecht}

Nach Aussage des Bundesverfassungsgerichts leitet sich der Jugendschutz und damit auch die staatliche Pflicht zur Wahrung desselben neben Art. 2 Abs. 1 GG i.V.m. Art. 1 Abs. 1 GG auch aus dem Elternrecht des Art. 6 Abs. 2 GG ab. ${ }^{59}$

Entsprechend Art. 6 Abs. 2 GG ist „Pflege und Erziehung der Kinder (...) das natürliche Recht der Eltern und die zuvörderst ihnen obliegende Pflicht. Über ihre Betätigung wacht die staatliche Gemeinschaft". Dem Elternrecht kommt damit ein Doppelcharakter zu. ${ }^{60}$ Zunächst gewährt Art. 6 Abs. 2 GG den Eltern das subjektive Recht selbstbestimmt und eigenhändig für die Erziehung ihrer Kinder zu sorgen und staatliche Übergriffe auf die grundrechtlich verbürgten Rechte abzuwehren. ${ }^{61}$ Nach dem Bundesverfassungsgericht geht der Verfassungsgeber hierbei von der Idealvorstellung aus, dass „diejenigen, die einem Kind das Leben geben, von Natur aus bereit und berufen sind, die Verantwortung für seine Pflege und Erziehung zu übernehmen". ${ }^{62}$ Eltern können demnach am gewissenhaftesten entscheiden, was für ihr Kind körperlich sowie seelisch am besten ist, welche Sorge und Verantwortung für die weitere Entwicklung des Kindes notwendig und welche Erziehungsziele im Einzelfall angebracht erscheinen. Sofern sie erzieherisch tätig werden, hat die staatliche Gemeinschaft das Handeln der Eltern zu respektieren. ${ }^{63}$ Der Verfassungsgeber statuiert folglich das subjektive Recht auf staatlich unabhängige Erziehung durch die Eltern. ${ }^{64}$

Dem ersten Anschein nach könnte die verfassungsrechtliche Ausgestaltung des Elternrechts auf einen Konflikt mit einer staatlichen Jugendschutzverpflichtung hindeuten. Staatlicher Jugendschutz - egal ob hinsichtlich der Vermeidung körperlicher oder geistiger Gefahren - greift nämlich zwangsläufig in die den Eltern zugewiesenen Erziehungsrechte ein. Jedoch wird der Erziehungsauftrag schon dem Wortlaut des Grundrechts entsprechend nur „zuvörderst“ folglich

59 BVerfGE 83, 130 (139).

60 Pieroth in: Jarass/Pieroth, Art. 6 GG, Rn. 36 ff.

61 Vgl. BVerfGE 7, 320 (323); BVerfGE 59, 360 (376); Zacher in: Isensee/Kirchhof, Hdb. StaatsR, 1989, Bd. VI, \133, Rn. 44 ff.

62 BVerfGE 24, 119 (150).

63 Isensee in: Isensee/Kirchhof, Hdb. StaatsR, 2002, Bd. V, \115, Rn. 177; Ossenbübl, DöV 1977, 801 (806).

64 Vgl. BVerfGE 7, 320 (323); BVerfGE 59, 360 (376); BVerfGE 24, 119 (150); Zacher in: Isensee/Kirchhof, Hdb. StaatsR, 1989, Bd. VI, \133, Rn. 44 ff.; Ossenbübl, DöV 1977, 801 (807). 
vorrangig den Eltern gewährt. Neben dem subjektiv-rechtlichen Verbot staatlicher Eingriffe in das Elternrecht normiert Art. 6 Abs. 2 GG gerade auch die objektivrechtliche Pflicht des Staates die Ausübung des Elternrechts bei gesellschaftlichen und sonstigen Gefährdungen des Kindeswohls zu überwachen, mithin bei solchen, zu deren Abwehr die Eltern nicht oder zumindest allein nicht in der Lage sind. ${ }^{65}$ Das so verstandene staatliche Wächteramt ${ }^{66}$ ermächtigt und verpflichtet den Staat dazu, bei Missachtung, Missbrauch oder bloßem Unvermögen der Eltern, geeignete Maßnahmen zum Schutz der Kinder zu ergreifen. ${ }^{67}$

Dem Sinn und Zweck des Art. 6 Abs. 2 GG folgend, regelt das Elternrecht folglich die Verteilung der Verantwortungsbereiche von Eltern und Staat in Bezug auf Kinder und Jugendliche, verleiht überdies aber keine eigenen Rechte. ${ }^{68}$ Solange die Eltern für den tatsächlichen Schutz ihres Kindes einstehen können, solange habe der Staat das Verhalten der Eltern zu respektieren. Wenn allerdings Gefährdungsbereiche betroffen sind, die der erzieherische Auftrag nicht selbstbestimmt relativieren kann, lebt die staatliche Schutzverpflichtung auf. ${ }^{69}$ In einem familienübergreifenden intensiven Gefährdungsbereichen, bei dem ein schlichtes Unvermögen der Eltern zur Abwendung der Gefahren vorliegt, ${ }^{70}$ bedarf es daher ein-

65 Jestaedt in: Bonner Kommentar, Art. 6 Abs. 2 und 3 GG, Rn. 10; Engels, AöR 122 (1997), 212 (236); Hoffmann-Riem/Scbul in: Charlton/Hoffmann-Riem/Neumann-Braun/Aufenanger, Fernsehwerbung und Kinder, 1995, Bd. 2, S. 321.

66 BVerfGE 24, 119 (144); BVerfGE 55, 171 (179); BVerfGE 107, 104 (117), Böckenförde, Elternrecht, 1980, S. 73; weitergehend Jeand'Heur, Verfassungsrechtliche Schutzgebote, 1993, S. 81 ff., der Art. 6 Abs. 2 S. 2 GG als „Garantienorm“ versteht. Die Garantiefunktion des Wächtermats verpflichte den Staat neben einer Abwehr von Gefährdungen des Kindeswohls, auch zur Kompensation aller gesellschaftlich zu erwarteten Negativentwicklungen, durch geeignete Leistungen und Schutzmaßnahmen, mit denen die Belange von Kindern gefördert und die Ermöglichungsbedingungen zur Wahrnehmung des Elternrechts verbessert bzw. wiederhergestellt werden können; kritisch zu dieser weiten Interpretation Engels, AöR 122 (1997), 212 (242); Baum, Jugendmedienschutz als Staatsaufgabe, 2007, S. 214; Jestaedt in: Bonner Kommentar, Art. 6 Abs. 2 und 3 GG, Rn. 10; Hoffmann-Riem/Schulz in: Charlton/Hoffmann-Riem/Neumann-Braun/Aufenanger, Fernsehwerbung und Kinder, 1995, Bd. 2, S. 321.

67 Engels, AöR 122 (1997), 212 (241); zu den Rechten der Kinder im Verhältnis zu ihren Eltern aus Art. 6 GG, BGH, NJW 2008, 1287.

68 Halves, Neuordnung des Jugendmedienschutzes, 2007, S. 27.

69 Bandehzadeh, Jugendschutz im Rundfunk und in den Telemedien, 2007, S. 32, bezugnehmend auf Schul, MMR 1998, 182 (183).

70 Zur Einbeziehung des elterlichen Unvermögens zur Gewährleistung eines umfassenden Kindesschutzes im Rahmen der Schutzpflicht bei Art. 6 GG, Vlachopoulos, Kunstfreiheit und Jugendschutz, 1996, S. 150. 
heitlicher Schutzstandards die offenkundig nur von einer übergeordneten Instanz - dem Staat - gesamtverbindlich realisiert werden können. ${ }^{71}$

\section{Ergebnis}

Der Kinder- und Jugendschutz lässt sich verfassungsrechtlich vorrangig aus dem Allgemeinen Persönlichkeitsrecht im Sinne des. Art. 2 Abs. 1 GG i.V.m. Art. 1 Abs. 1 GG ableiten. Dieses schützt die freiheitliche Entwicklung des Menschen umfassend. Soweit es um den Schutz von Gefahren geht, die an den geringeren Stand der körperlichen oder psychologischen Entwicklung des Kindes ansetzen, folgt aus Art. 2. Abs. 1 GG i.V.m. Art. 1 Abs. 1 GG eine spezielle Gewährleistung des Jugendschutzes. Aufgrund des damit einhergehenden Verfassungsrangs des Jugendschutzes ist der Staat über die Schutzpflichtenlehre verpflichtet Gefahren für die grundrechtliche Gewährleistung mit dem ihm zur Verfügung stehenden Mitteln abzuwehren.

II. Kinderpornographische Angebote - Jugendschutzrelevanter Gefährdungsbereich im Internet

Bedingt durch die globale Verbreitung, die fortschreitende technische Entwicklung und die freiheitliche, sendezeitunabhängige Gestaltung, hat das Internet in Bezug auf jugendschutzrelevante Belange ein weites Gefährdungspotential, das nicht hinreichend durch Inanspruchnahme der Elternverantwortung abgewehrt werden kann. ${ }^{72}$ Die Berührungspunkte des Internets zum Jugendschutz sind vielfältig. Einen speziellen Gefährdungsbereich stellt die Verbreitung kinderpornographischer Inhalte im Internet dar. Im Folgenden soll untersucht werden, welche spezifischen Gefahren für Kinder und Jugendliche hiermit verbunden sind und wie der Staat seiner verfassungsrechtlichen Schutzverpflichtung konkret nachgeht.

\section{Die Verbreitung von Kinderpornographie im Internet}

a) Inhalt kinderpornographischer Produktionen

Um den Gefährdungsbereich der internetbasierten Verbreitung von Kinderpornographie zu erfassen, ist es zunächst notwendig die inhaltlich Dimension eines kinderpornographischen Angebots zu bestimmen. Eine Annäherung kann unter Zugrundelegung des Straftatbestandes des Verbots der Verbreitung kinderpornographischer Schriften ${ }^{73}$ gemäß $\ 184 b$ StGB erfolgen. Nach der dortigen Legaldefinition werden solche Angebote als kinderpornographisch verstanden, die „sexu-

71 So iE. BVerfGE 24, 119 (144), BVerfGE 59, 260 (276, 282); BVerfGE 72, 155 (172).

72 Umfassend Faber, Jugendschutz im Internet, 2005, S. 115 ff.

73 Zum Schriftenbegriff zugleich unter: 2. Teil A. III. 1. a). 
elle Handlungen von, an oder vor Kindern gemäß \ 176 Abs. 1 StGB zum Gegenstand haben." ${ }^{\text {"74 }}$

Damit wird der Begriff der Kinderpornographie inhaltlich bereits weitestgehend eingegrenzt. Das Objekt der visualisierten sexuellen Handlungen muss ein Kind, das heißt eine Person unter 14 Jahren sein. ${ }^{75}$ Mithin kann die dargestellte Person zwar als älter ausgegeben werden, wenn sie objektiv betrachtet die Altersgrenze von 14 Jahren noch nicht überschritten hat, gilt sie als Kind im Sinne der Kinderpornographie. ${ }^{76}$ Liegt der Darstellung im Gegenteil dazu eine sexuelle Handlung mit einer Person über 14 Jahren vor, führt dieses nicht zwangsläufig zur Verneinung des Vorliegens von Kinderpornographie, vielmehr ist in einem solchen Fall auf „die Sicht eines objektiven Betrachters“ abzustellen. ${ }^{77}$ Ist die Inszenierung explizit darauf ausgerichtet den Anschein der Kindlichkeit zu erwecken (Scheinkindlichkeit) und stellt sich die Kindlichkeit des Darstellers als „eindeutig“ und „offensichtlich“ für den objektiven Betrachter heraus, so kann die Darstellung als kinderpornographisch eingestuft werden. ${ }^{78}$ Dies kann etwa durch entsprechende Angaben des Alters im Rahmen der Beschriftung der Darstellung, mittels bewusst kindlicher Aufmachung der Darsteller, wie Kleidung, Körperhaltung oder Kinderzimmerambiente oder über eine enge Einbindung der Darstellung in einen pädophilen Kontext realisiert werden. ${ }^{79}$ Es darf jedoch nicht allein auf den Kontext der Darstellung abgestellt werden, darüber hinaus müssen der betreffenden Person selbst unmittelbar anhaftende Züge zugesprochen werden, die auf ein kindliches Alter hindeuten. ${ }^{80}$ Basiert der Eindruck der Kindlichkeit lediglich auf einer Fehlvorstellung des Betrachters, ohne dass die Inszenierung eindeutig in die

74 Die Vorschrift wurde eingeführt durch das SexualÄndG v. 27.12.2003 unter Übernahme des wesentlichen Regelungsgehalts von $\int 184$ III bis V a.F. Durch das Gesetz zur Umsetzung des Rahmenbeschlusses des Rates der EU zur Bekämpfung der sexuellen Ausbeutung von Kindern und der Kinderpornographie v. 31.10.2008 wurde der Wortlaut des Abs.1 geändert und an \ 176 StGB angepasst.

75 So die strafrechtliche Definition des Kindes in $\$ 176 \mathrm{StGB}$.

76 BGH, MMR 2001, 676 (678); Hörnle in: Münch. Komm. StGB, §184b StGB, Rn. 12; Perron/Eisele in: Schönke/Schröder, \ 184b StGB, Rn. 3b; a.A. Lindemann/Wachsmuth, JR 2002, 204 (209).

77 So BGH, MMR 2001, 676 (678) mit Anm. Gercke; Hörnle in: LK-StGB, \ 184b, Rn. 12, Fischer, \184b StGB, Rn. 6; Schreibauer, Das Pornographieverbot das \184 StGB, 1999, S.143.

78 BGH, MMR 2001, 676 (678) mit Anm. Gercke; BGH, NStZ 2000, 305 (307); So zumindest zur Scheinjugendlichkeit iSd. \ 184c StGB, BGH, MMR 2009, 178 mit Anm. Liesching, explizit auf \ 184b StGB bezogen, VGH, MMR 2001, 678 (678) mit Anm. Gercke; Fischer, \ 184b StGB, Rn. 6; Schreibauer, Das Pornographieverbot des \ 184 StGB, 1999, S. 143 f.; so schon Laufhütte, JZ 1974, 46 (49).

79 Reinbacher/Winciers, ZRP 2007, 195 (197).

80 Kritisch zur Einbeziehung äußerlicher Merkmale, Liesching, JMS-Report 5/2008, 2 (3). 
Richtung der Kindlichkeit geht, so schließt dies eine kinderpornographische Darstellung gemäß \ $184 \mathrm{~b}$ StGB aus. ${ }^{81}$

Anders als noch der frühere Gesetzeswortlaut ${ }^{82}$ forderte, ist es zudem für die Einordnung eines Angebots als kinderpornographisch nicht mehr notwendig, dass der Darstellung tatsächlich ein sexueller Missbrauch von Kindern im Sinne des $\int 176 \mathrm{StGB} z u$ Grunde liegt. Auch ist es nicht ausschlaggebend, dass die darstellenden Kinder zur Vornahme sexueller Handlung entsprechend $\iint 176$ Abs. 4 Nr. 2 StGB „bestimmt“ worden sind. ${ }^{83}$ Damit reichen - im Gegensatz zu dem in $\int 176$ StGB geforderten Missbrauch - bereits weniger intensive Handlungen, die beispielsweise gänzlich auf einen Körperkontakt der kindlichen Protagonisten verzichten aus. ${ }^{84}$ Dazu zählen beispielsweise Darstellungen, die nackte Kinder in provozierenden, die Geschlechtsteile extrem betonenden, Posen zeigen. ${ }^{85}$ Bloße Nacktaufnahmen von Kindern hingegen werden nicht vom Kinderpornographiebegriff umfasst, ${ }^{86}$ vielmehr ist zusätzlich notwendig, dass die Abbildung selbst als

81 Fischer, \184b StGB, Rn. 6; Schreibaner, Das Pornographieverbot des $\ 184$ StGB, 1999, S. 144; Oftmals kann es im Bereich der Scheinkindlichkeit auch Überschneidungen zur Jugendpornographie geben, wenn die kindlich dargestellte Person objektiv das 14. Lebensjahr überschritten hat, jedoch selbst noch minderjährig ist. Hier ist dann der nunmehr eingeführte Straftatbestand der Jugendpornographie des $₫ 184$ c StGB erfüllt, so dass eine Bezugnahme zur Kinderpornographie nicht mehr notwendig erscheint, hierzu Liesching, JMS-Report 5/2008, 2 ff.; zu dem „neuen“ $\int 184 c$ StGB basierend auf dem Umsetzungsgesetz des Rahmenbeschlusses zur Bekämpfung der sexuellen Ausbeutung von Kindern und der Kinderpornographie mit Gesetz v. 31.10.2008, BGBl. I 2008, S. 2149, Hörnle, NJW 2008, 3521.

82 Neuformulierung des $\int 184 \mathrm{~b}$ StGB eingeführt durch das Umsetzungsgesetz des Rahmenbeschlusses zur Bekämpfung der sexuellen Ausbeutung von Kindern und der Kinderpornographie mit Gesetz v. 31.10.2008, BGBl. I 2008, S. 2149; anders noch BGHSt 50, 370 zur alten Gesetzesfassung.

83 Ob diese weniger eingreifende Handlung gegenüber dem sexuellen Missbrauch des Kindes, vom alten Gesetzeswortlaut umfasst war, war sehr umstritten. Durch das jetzige Ausreichen einer sexuellen Handlung ist dieser Streit indes obsolet geworden, zur früheren Problematik, König, Kinderpornographie im Internet, 2004, S. 146; Ren₹ikowski, NStZ 2000, 28; andeutend auch Fischer, §184b StGB, Rn. 4.

84 BGH, NStZ 2003, 662; Hörnle in: Münch. Komm. StGB, \184b StGB, Rn. 16; Perron/Eisele in: Schönke/Schröder, \184b StGB, Rn. 3a.

85 So die Gesetzesmaterialien BT-Drs. 16/3439, S. 9, BT-Drs. 16/9646, S. 7; zum Einbezug des Posing in Abgrenzung zum alten Wortlaut unter die neue Gesetzesfassung, Röder, NStZ 2010, 113.

86 BGH, NStZ 1998, 351; Röder, NStZ 2010, 113 (117); Ring, AfP 2004, 9 (11); Hörnle in: Münch. Komm. StGB, \184b StGB, Rn. 17; Hörnle, NJW 2008, 3521 (3525); König, Kinderpornographie im Internet, 2004, Rn. 190. 
pornographisch einzustufen ist. ${ }^{87}$ Pornographisch ist nicht gleichbedeutend mit einer sexuellen Darstellung, ${ }^{88}$ sondern eine weitaus detailliertere Darstellung der Sexualität hinzukommen. Nach der Rechtsprechung des Bundesgerichtshofs muss die Darstellung „unter Ausklammerung sonstiger menschlicher Bezüge sexuelle Vorgänge in grob aufdringlicher, anreißerischer Weise in den Vordergrund rücken und ausschließlich oder überwiegend auf die Erregung sexueller Reize abzielen“. 89 Nicht ausreichend ist die reine Einbeziehung der Kinder in einen sexuellen Kontext. ${ }^{90}$ Es ist somit eine dezidierte und einzelfallabhängige Prüfung der Voraussetzungen der Kinderpornographie unter Heranziehung der herrschenden Moralvorstellungen notwendig. ${ }^{91}$

Bei den einzelnen dargestellten sexuellen Handlungen muss es sich um sexuelle Handlungen „von“ Kindern handeln. Dies meint alle Handlungen, die das dargestellte Kind selbst vornimmt, wobei grundsätzlich unerheblich ist, ob die sexuelle Handlung am Körper einer anderen Person, an sich selbst oder gänzlich ohne körperlichen Kontakt ausgeübt wird. ${ }^{92}$ Sexuelle Handlungen mit pornographischem Charakter, die ,an“ einem Kind im Sinne der Kinderpornographie vorgenommen werden, bedürfen grundsätzlich des körperlichen Kontaktes. ${ }^{93} \mathrm{Ob}$ insoweit auch sexuelle Handlungen erfasst werden, die die betroffene minderjährige Person „an sich selbst“ vornimmt, ist letztlich unerheblich, da insofern bereits

87 Fischer, \184b StGB, Rn. 3.

88 Hörnle in: Münch. Komm. StGB, \184 StGB, Rn. 17.

89 So grundlegend BGHSt 32, 40 - Fanny Hill; dem folgend u.a. BGHSt 23, 40 (43); BGH, UFITA 1980, 208; BGH, NJW 1990, 3026; KG, NStZ 2009, 446; Leckner/Perron/Eisele in: Schönke/Schröder, \184 StGB, Rn. 4; zur inhaltlichen Differenzierung u.a. ausführlich Erdemir, Filmzensur und Filmverbot, 2000, S. 143; Schreibaner, Das Pornographieverbot des $\$ 184$ StGB, 1999, S. 116.

90 Vgl. BGH, Urt. v. 21.04.1978 - 2 StR 739/77, abgedruckt bei Holť, MDR 1978, 804: „Hätte der Gesetzgeber den Begriff in den einzelnen Absätzen der Vorschrift [zum einfachen Pornographieverbot des $₫ 184$ StGB und $\ 184$ Abs. 3 a.F. (Kinderpornographie)] einen jeweils verschiedenen Sinn geben wollen, so hätte er sein ungewöhnliches Vorgehen im Gesetzeswortlaut zum Ausdruck bringen müssen. Wie den Gesetzesmaterialien zu entnehmen ist, bestand eine solche Absicht aber nicht“; in die Richtung jedoch mit einer Wortlautauslegung Hörnle, NJW 2008, 3521 (3525): „Wäre der pornographische Charakter [bei sexuellen Kinderdarstellungen] irrelevant, müsste dort statt „,pornographische Schrift (\$11 III)“, „Schrift (\$11 III) stehen.“.

91 In die Richtung Liesching, JMS-Report 5/2008, 2 (3); Scbmitt in: Eberle/Rudolf/Wasserburg, Rechtshandbuch, 2003, Kap. XI, Rn. 71; Erdemir, MMR 2003, 628 (631).

92 Liescbing, JMS-Report 5/2008, 2 (3); damit reicht ein bloßes Posieren aus, solange es als pornographische eingestuft werden kann, hierzu Röder, NStZ 2010, 113 (114 ff.).

93 BGH, NStZ 2006, 394; BGH, NStZ 1992, 433; Hörnle in: Münch. Komm. StGB, \184g StGB, Rn. 9; Perron/Eisele in: Schönke/Schröder, \184g StGB, Rn. 18. 
eine sexuelle Handlung „von“ einer Person unter 14 Jahren vorliegt. ${ }^{94}$ Weiterhin gelten als kinderpornographisch auch Darstellungen, die sexuelle Handlungen „vor" Personen unter 14 Jahren zum Gegenstand haben. Nach der Legaldefinition des $\$ 184 \mathrm{~g}$ Nr. 2 StGB sind darunter nur solche sexuelle Handlungen zu verstehen, „die vor einem anderen vorgenommen werden, der den Vorgang wahrnimmt". Insoweit genügt die sinnliche, etwa optische oder akustische, Wahrnehmung des äußeren Geschehensablaufs, ohne dass der kindliche Protagonist den sexuellen Charakter der Handlung erkannt haben muss. ${ }^{95}$ Auch ist die räumliche Anwesenheit des Kindes nicht erforderlich, vielmehr genügt z.B. die simultane Übertragung des Geschehens über das Internet. ${ }^{96}$

b) Internet als Verbreitungsweg von Kinderpornographie

Das Internet als Tatmittel der Verbreitung von Kinderpornographie nimmt weltweit eine zentrale Rolle ein. ${ }^{97}$ Es hat gegenüber der Verbreitung im Offlinebereich den enormen Vorteil, dass, mit Ausnahme der Herstellung, der gesamte Vertrieb über ein einziges Medium geleitet und dadurch anonym und weitestgehend „sicher" an den Nutzer gebracht werden kann. Gleichzeitig kann das Internet auch als Austauschmedium fungieren und dazu verwendet werden, Neu- wie Altproduktion technisch modifiziert und in besserer Qualität zur Verfügung zu stellen, was absatzfördernd für die kommerziellen Händler wirken kann. ${ }^{98}$

Es verwundert daher nicht, dass die Verbreitung von Kinderpornographie im Internet seit Jahren einen gewichtigen Faktor des allgemeinen Vertriebes darstellt. Eine amerikanische Studie belegt, dass von 2.500 untersuchten und geahndeten Fällen von internetbasierter Verbreitung von sexuellen Bildern, annähernd 1.700

94 So Liesching, JMS-Report 5/2008, 2 (3) in Bezug auf $\$ 184 c$ StGB. Zu alledem Perron/Eisele in: Schönke/Schröder, \ 184b StGB, Rn. 3 a ff.

95 BT-Drs. 6/3521, S. 24; Fischer, \184g StGB, Rn. 8; Hörnle in: Münch. Komm. StGB, \184g StGB, Rn. 11; Perron/Eisele in: Schönke/Schröder, \184g StGB, Rn. 21.

96 BGH, CR 2010, 62.

97 Hierzu Begr. zum Entwurf eines Gesetzes zur Bekämpfung der Kinderpornographie in Kommunikationsnetzen BT-Drs. 16/12850, S. 5; Detaillierte Ergebnisse und Analyse der Verbreitung im Internet in der Studie der European Financial Coalition against commercial sexual exploitation of childern online (EFC), „14 months on: A combined report from the European Financial Coalition 2009-2010," abrufbar unter:

http://ceop.police.uk/Documents/EFC\%20Strat\%20Asses2010_080910b\%20FINAL.pdf

(zuletzt abgerufen 20.5.2011); Meier/Hüneke, Forschungsbericht „Herstellung und Verbreitung von Kinderpornographie über das Internet“", 2011.

98 Schirmacher, Internetpornografie, 2008, S. 111. 
dem Bereich der Kinderpornographie zuzuordnen sind. ${ }^{99}$ Schätzungen zur Folge sollen weltweit 182.000 Webangebote mit pädophilem Inhalt existieren, die inhaltlich zu 80 Prozent Kinder im Altersbereich zwischen 6 und 12 Jahren visualisieren und inhaltlich übereinstimmend Genitalien oder explizite sexuelle Handlungen und größtenteils Nötigung eines Kindes zum Oral-, Anal- oder Vaginalverkehr darstellen. ${ }^{100}$ Auch in Deutschland verzeichnet die jährlich erscheinende Kriminalitätsstatistik seit Jahren einen enormen Anstieg an Besitz, Beschaffung und Verbreitung von Kinderpornographie in der Rubrik der „Straftaten mit dem Tatmittel Internet" ${ }^{101}$ So stieg der Prozentsatz der Besitzverschaffung an kinderpornographischen Inhalten in den Jahren 2006 auf 2007 um mehr als 111\%.102 Zwar verringerte sich dieser bisweilen höchste Verbreitungssatz im Jahr 2010 drastisch, ist mit 3.160 erfassten und über das bloße Versuchsstadium hinausgehenden Strafverstößen allein im innerstaatlichen Bereich, jedoch weiterhin im höheren Fallbereich angesiedelt. ${ }^{103}$ Im Jahresbericht 2009 der Internet Watch Foundation waren 8.884 solcher Webseiten weltweit gelistet, die kinderpornographisches Material im Wege einer organisierten und gegen Entgelt angeboten Vertriebsweise anboten. ${ }^{104}$ Kommerzielle Angebote bieten dem Nutzer inhaltlich wechselnde

99 Resultate bei Wolak/Mitchell/Finkelhor, Internet Sex Crimes Against Minors, S. 9 ff., abrufbar unter: http://www.missingkids.com/en_US/publications/NC32.pdf (zuletzt abgerufen 20.5.2012).

100 Wolak/Mitchell/Finkelhor, Internet Sex Crimes Against Minors, S. 9 ff., abrufbar unter: http://www.missingkids.com/en_US/publications/NC32.pdf (zuletzt abgerufen 20.5.2012); dies. Child-Pornography Possessors Arrested in Internet-Realted Crimes, VIII 1, S. 19 f.; ähnliche Ergebnisse auch bei Internet Watch Foundation, Jahresbericht 2009, S. 8, abrufbar unter: http://www.iwf.org.uk/assets/media/annual-

reports/IWF\%202009\%20Annual\%20and\%20Charity\%20Report.pdf

(zuletzt abgerufen 20.5.2012).

101 Die Rubrik wurde 2004 als selbstständige Kategorie innerhalb der jährlich erscheinenden Kriminalitätsstatistik aufgenommen, Statistiken herausgegeben vom Bundeskriminalamt auf Grundlage des $\ 2$ Abs. 6 Nr. 2 BKAG, abrufbar unter: http://www.bka.de/pks/.

102 BT-Drs 16/12850, S. 5.

103 So die detaillierte Aufstellung zur Kriminalitätsstatistik 2010, abrufbar unter: http://www.bka.de/pks/pks2010/download/pks2010_imk_kurzbericht.pdf (zuletzt abgerufen 20.5.2012).

104 Die IWF ist eine 1996 gegründete und von der EU-Kommission unterstütze britische Organisation, die jährlich das Aufkommen der kriminellen Inhalte im Internet statistisch auswertet. In Zusammenarbeit mit der britischen Regierung und weltweit aktiven Interessenverbänden, arbeitet die IWF auch stark im Bereich der Bekämpfung der onlinebasierten Verbreitung von Kinderpornographie. Zahlen entnommen aus dem Jahresbericht 2009, Internet Watch Foundation 2009 Annual And Charity Report, S. 14 ff.: abrufbar unter: 
Darstellungen in Video und Fotoformat und zeigen Kinder in jeglichen Altersbereichen. Daneben bieten sie regelmäßig auch so genannte „Sammlerstücke“, das heißt Angebote die bereits seit Jahren denselben Inhalt wiedergeben, jedoch aufgrund ihrer sexuellen Ausrichtung oder besonderen Darstellungsweise als besonders ,begehrt" gelten. ${ }^{105}$

Detaillierte wissenschaftliche Erkenntnisse über die tatsächliche Verbreitung von kindepornographischem Material im Internet, die über bloße Schätzungen hinausgehen, gibt es allerdings nur wenige. In dem Zusammenhang sind besonders die repräsentativen Studien der European Financial Coalition against commercial sexual exploitation of children online (EFC) ${ }^{106}$ sowie der jüngere Forschungsbericht der Leibniz Universität Hannover, ${ }^{107}$ zu nennen.

Im Rahmen der internetbasierten Verbreitung ist danach eine Zweiteilung des zu erkennen: Kommerzielle kinderpornographische Angebote werden vermehrt im World Wide Web verbreitet, nichtkommerzielle Angebote hingegen im individual-technischen Tauschbörden, Chatrooms oder geschlossenen Benutzergrup-

http://www.iwf.org.uk/assets/media/annual-

reports/IWF\%202009\%20Annual\%20and\%20Charity\%20Report.pdf

(zuletzt abgerufen 20.5.2012).

105 Internet Watch Foundation 2009 Annual And Charity Report, S. 16, abrufbar unter:

http://www.iwf.org.uk/assets/media/annual-

reports/IWF\%202009\%20Annual\%20and\%20Charity\%20Report.pdf

(zuletzt abgerufen 20.5.2012).

106 European Financial Coalition (EFC) ist eine von der EU-Kommission geförderte Organisation aus Internetkonzernen, internationalen Polizeibehörden und zivilrechtlichen Organisationen, die Statistiken und eigene Forschungen im Bereich der sexuellen Ausbeutung von Kindern im Internet durchführt. Die EFC ist beim „Child Exploitation and Online Protection“-Center der britischen Polizei angesiedelt, Statistiken und nähere Erläuterung des Aufgabenbereichs abrufbar unter: http://www.ceop.police.uk/efc/. Studie, „14 months on: A combined report from the European Financial Coalition 2009-2010“, abrufbar unter:

http://ceop.police.uk/Documents/EFC\%20Strat\%20Asses2010_080910b\%20FINAL.pdf

(zuletzt abgerufen 20.5.2012).

107 Forschungsbericht der Universität Hannover, gefördert von dem Bündnis White-IT, das in Zusammenarbeit mit der u.a Niedersächsischen Ärztekammer, Internetinteressenverbänden wie eco, BITKOM und BVDW unter Schirmherrschaft des niedersächsischen Innenministers Schünemann im Juli 2009 gegründet wurde. Im Mittelpunkt der Tätigkeit steht eine umfassende empirisch-kriminologische Bestandsaufnahme der tatsächlichen Ausgangsbedingungen für die Entwicklung und Präzisierung der Instrumente gegen die Verbreitung kinderpornographischen Materials, im Einzelnen Meier/Hüneke, Forschungsbericht „Herstellung und Verbreitung von Kinderpornographie über das Internet“, 2011. 
pen. Letztere Verbreitungsart macht quantitativ den Schwerpunkt der internetbasierten Verbreitung von Kinderpornographie aus. ${ }^{108}$

Der erste Vertriebsbereich innerhalb des Internetdienstes World Wide Web bildet den Hauptanwendungsfall der organisierten und kommerzialisierten Verbreitung. Das World Wide Web ist technisch betrachtet das netzarchitektonische Rahmenwerk, welches dem Nutzer den Zugriff auf graphisch dargestellte Dokumente (Webseiten) erlaubt. ${ }^{109}$ Nach den Ergebnissen der Studie des EFC sind die gewerbsmäßige Verbreitung von kinderpornographischem Material sowie die über Webseiten erzielten Gewinne jedoch rückläufig. ${ }^{110}$ Inhaltlich handelt sich vorrangig um den Vertrieb ,älterer“ Angebote, die immer wieder neu verbreitet werden. Die der siebenteiligen Fallstudie zugrundeliegenden Ergebnisse belegen, dass Erlöse von 8500 Euro bis zu 1,4 Millionen Euro auf eine Forschungsdauer von 7 Jahren mit der organisierten Verbreitung von Kinderpornographie erwirtschaftet wurden. ${ }^{111}$ Den Erkenntnissen des EFC zur Folge neigt die konkrete Ausgestaltung des kommerzialisierten Vertriebes aufgrund der gesellschaftlichen Diskussion und aktiven Strafverfolgung zu einem ,,versteckten“ Bezahlsystem. Webseiten auf denen kinderpornographisches Material offenkundig gegen Entgelt angeboten wird, werden aus dem Gesamtbestand der Webseiten immer mehr zurückgedrängt und auf ein verdecktes Entgeltsystem verlagert. Das versteckte Bezahlsystem basiert darauf, dass die Händler den Nutzern der einschlägigen Szene über scheinbar harmlose Webseiten rechtlich unbedenkliche Waren oder Software gegen Entgelt

EFC, „14 months on: A combined report from the European Financial Coalition 2009-2010“, S.

7 abrufbar unter:

http://ceop.police.uk/Documents/EFC\%20Strat\%20Asses2010_080910b\%20FINAL.pdf

(zuletzt abgerufen 20.5.2012); Meier/Hüneke, Forschungsbericht „Herstellung und Verbreitung von Kinderpornographie über das Internet", 2011, S. 96.

109 Der Internetdienst WWW wird umgangssprachlich oftmals mit dem Internet gleich gesetzt, hierzu detailliert Tanenbaum, Computernetzwerke, 2009, S. 664 f.; Peterson/Davie, Computernetze, 2008, S. 660.

110 EFC, „14 months on: A combined report from the European Financial Coalition 2009-2010“, S. 7, abrufbar unter:

http://ceop.police.uk/Documents/EFC\%20Strat\%20Asses2010_080910b\%20FINAL.pdf (zuletzt abgerufen 20.5.2012); darauf verweisend auch Meier/Hüneke, Forschungsbericht „Herstellung und Verbreitung von Kinderpornographie über das Internet“, 2011, S. 17.

111 Die Ergebnisse sind im Verhältnis zu Betrugstatbestanden im Internet als gering zu bezeichnen, hierbei werden jährlich 5,4 Mio Euro erwirtschaftet. Dazu EFC, „14 months on: A combined report from the European Financial Coalition 2009-2010“, S. 7, abrufbar unter: http://ceop.police.uk/Documents/EFC\%20Strat\%20Asses2010_080910b\%20FINAL.pdf (zuletzt abgerufen 20.5.2012), Untersuchungen beruhen auf den Zeitraum von 2000 bis 2007. Hierzu auch Meier/Hïneke, Forschungsbericht „Herstellung und Verbreitung von Kinderpornographie über das Internet“, 2011, S. 17. 
anbieten. Anstatt der eigentlichen Ware erhält der Nutzer für das bezahlte Entgelt eine Art „Membership-ID“ sowie die entsprechende Domain der Webseite übermittelt, die ihnen nachfolgend den uneingeschränkten Zugriff zum kinderpornographischen Material gewährt. ${ }^{112}$

Neben der entgeltlichen Verbreitung über Webangebote ist zunehmend auch eine Kommerzialisierung des individuellen Internetbereichs zu verzeichnen. Hierbei ist besonders die Verbreitung in Newsgroups entscheidend. Gegen die Zahlung einer „Mitgliedsgebühr“ wird der Zugang zum „persönlichen“ Bereich gewährt, in welchem die angemeldeten Mitglieder die Möglichkeit erhalten einen individuellen Austausch des Materials vorzunehmen. ${ }^{113}$ Die innerhalb der Fallstudie ermittelten Mitgliedsbeiträge lagen im Bereich zwischen 79,95 US-Dollar bis 99,95 US-Dollar. ${ }^{114}$

Im Allgemeinen kam die EFC zu dem Ergebnis, dass der größte Bereich der internetvermittelten Kinderpornographie jedoch den individualtechnischen Bereich des Internets betrifft und nicht im Rahmen einer organisierten und kommerziellen Verbreitungsstruktur vorgenommen wird. Den Untersuchungen zur Folge, waren lediglich 4 von 10 Webseiten mit kinderpornographischem Material tatsächlich kommerziell ausgerichtet. Die neuen Verbreitungsstrategien konzentrieren sich zunehmend auf die nicht gewerbliche, kostenlose Weiterverbreitung an einen kleinen Konsumentenkreis durch beispielsweise Gründungen von einschlägigen Gruppen in sozialen Netzwerken, die nicht den kommerzialisierten Einnahmecharakter in Vordergrund stellen, sondern auf die sexuelle Stimulation und Weitergabe des Materials an sich ausgerichtet sind. ${ }^{115}$ Soweit es um kommerzielle Angebote handelt, werden diese vielfach aus osteuropäischen Staaten bezogen, nichtkommerzielle Angebote lassen sich hingegen nicht auf einen bestimmten Bezugsort minimierten. Nach Auffassung der EFC gründe die Verlagerung der Verbreitung

112 EFC, „14 months on: A combined report from the European Financial Coalition 2009-2010“, S.18 ff., abrufbar unter:

http://ceop.police.uk/Documents/EFC\%20Strat\%20Asses2010_080910b\%20FINAL.pdf (zuletzt abgerufen 20.5.2012).

113 EFC, „14 months on: A combined report from the European Financial Coalition 20092010“, S. 7, abrufbar unter:

http://ceop.police.uk/Documents/EFC\%20Strat\%20Asses2010_080910b\%20FINAL.pdf (zuletzt abgerufen 20.5.2012).

114 Die repräsentativen Zahlen liegen damit im Bereich der vorherigen Schätzungen des BKA, hierzu BKA; Ausschussdrucksache 16 (9) 1549, S. 1.

115 EFC, „14 months on: A combined report from the European Financial Coalition 2009-2010“, abrufbar unter:

http://ceop.police.uk/Documents/EFC\%20Strat\%20Asses2010_080910b\%20FINAL.pdf. Auf die Verlagerungseffekte weist auch der Aufhebungsgesetzentwurf der FDP zum ZugErschwG hin, BT-Drs. 17/646, S. 4 (zum ZugErschwG nachfolgend 4. Teil ). 
auf den Bereich des individualtechnischen Internets auf verschiedenen Faktoren. Neben hohen strafrechtlichen Risiken, die im Falle einer Ermittlung der Verbreiter drohen, sei vor allem entscheidend, dass ein klare „Überschwemmung des Marktes" durch unentgeltliche Angebote in Peer-to-Peer Netzwerken ersichtlich sei und daher der wirtschaftliche Faktor durch die mit der Verbreitung drohenden Risiken überlagert wird. ${ }^{116}$

Auch der Forschungsbericht der Universität Hannover kam zu ähnlichen Ergebnissen. Über eine kriminalanalytische Vorgehensweise, die auf Expertenbefragungen, Auswertung von Strafakten sowie Stichprobenerhebungen gründet, wurde versucht, die Ausgangshypothese, wonach es sich bei Kinderpornographie um einen internetbasierten kommerziellen Markt handle, der durch das Wechselspiel von Angebot und Nachfrage und die Produktion eines Gutes „Kinderpornographie“ gekennzeichnet sei, wissenschaftlich zu belegen. ${ }^{117}$ Der Forschungsbericht kommt dabei zu dem Ergebnis, dass der „Markt Kinderpornographie“, der von Nachfrage und Angebote gelenkt wird, im klassischen Sinne nicht auf den Bereich der internetverbreiteten Kinderpornographie übertragbar ist. Maßgebliches Instrument des klassischen Markgeschehens ist die „Knappheit“ der nachgefragten Ressource. ${ }^{118}$ Angesichts der Fülle an Angeboten und der vielfältigen Verbreitung kinderpornographischen Materials in Peer-to-Peer-Netzwerken, spreche „vieles gegen einen Markt" det. Klassische Verbreitung sei danach die Weitergabe in Tauschbörsen, welche in der Regel durch gegenseitiges Zurverfügungstellen von Dateien stattfindet. Hier wird Kinderpornographie als „öffentliches Gut“ verteilt. ${ }^{119}$ Außerdem sei eine große Dunkelziffer zu verzeichnen, die das klassische Markverhalten wesentlich beeinflusst. Allerdings ist aus dem Forschungsbericht feststellbar, dass es durchaus möglich ist, mit Kinderpornographie im Internet auch kommerziell Geld zu verdienen. Die Anbieter die Kinderpornographie im Internet gewerblich verbreiten müssen sich darauf konzentrieren, ständig neue Kunden zu gewinnen oder neuwertiges Material anzubieten, das sich gegenüber anderen, insbesondere unentgelt-

116 EFC, „14 months on: A combined report from the European Financial Coalition 20092010“, S. 5, 17 ff., abrufbar unter:

http://ceop.police.uk/Documents/EFC\%20Strat\%20Asses2010_080910b\%20FINAL.pdf. Dazu kritisch Meier/Hüneke, Forschungsbericht „Herstellung und Verbreitung von Kinderpornographie über das Internet", 2011, S. 18.

117 Zur methodischen Vorgehensweise, Meier/Hüneke, Forschungsbericht „Herstellung und Verbreitung von Kinderpornographie über das Internet", 2011, S. 44.

118 Meier/Hüneke, Forschungsbericht „Herstellung und Verbreitung von Kinderpornographie über das Internet“, 2011, S. 98.

119 Meier/Hüneke, Forschungsbericht „Herstellung und Verbreitung von Kinderpornographie über das Internet“, 2011, S. 97. 
lichen Angebote, abhebt. ${ }^{120}$ Soweit Kinderpornographie im World Wide Web verbreitet wird, kommt der Bericht zu dem Ergebnis, dass es sich die Verbreitung überwiegend jedoch auf Material bezieht, dass zuvor aus anderen Quellen bezogen wurde; nicht feststellbar war indes, dass eine gezielte Produktion neuer kinderpornographischer Angebote stattfindet, um diese gegen Entgelt als Neuware anbieten zu können. ${ }^{121}$ Durch die Tatsache, dass sich praktisch jeder Nutzer auch zum Anbieter aufschwingen kann, wenn er seine bezogenen Inhalte gegen Entgelt anderen zur Verfügung stellt, kann es im Bereich der kommerziellen Kinderpornographie im allgemeinen zu einer „exponentiellen Verbreitungswirkung“ kommen.

Obgleich die angeführten Studien einen gegenwärtigen Wandel im der Bereich der internetbasierten Verbreitung von Kinderpornographie belegen, zeigen die hier zugrunde gelegten Zahlen jedoch, dass der Gesamtbereich des Internets einen enormen Verbreitungspfad für kinderpornographische Inhalte einnimmt. Auch wenn sich die kommerzielle Ausrichtung der Vertriebskette im World Wide Web immer mehr verringert, gänzlich wegzudenken aus dem Vertriebsweg ist der Bereich des World Wide Web nach den heutigen Stand wohl nicht. ${ }^{122}$ So kann die offensichtliche Dezimierung gewerblicher Kinderpornographieangebote nicht allein auf den Gebrauch neuer Verbreitungstechnologien des Internets zurückgeführt werden; möglich ist auch, dass detaillierte Strafverfolgungsmaßnahmen zu einer Verringerung des bisherigen Verbreitungsweges im World Wide Web beigetragen haben. Daneben ist es denkbar, dass unterschiedliche Definitionsmerkmale innerhalb der Einordnung eines Angebotes als kinderpornographisch während der statistischen Erhebungen verwendet wurden, die sich in einer Verringerung der Verbreitungszahlen im World Wide Web wiederspiegeln. ${ }^{123}$ Festzustellen bleibt demnach, dass ungeachtet der einzelnen Ausgestaltung des Verbreitungsweges innerhalb der speziellen Dienste des Internets, das Internet im Allgemeinen als Verbreitungsmedium für Kinderpornographie fungiert und einen hohen Stellenwert im Rahmen der Verbreitung einnimmt.

120 Meier/Hüneke, Forschungsbericht „Herstellung und Verbreitung von Kinderpornographie über das Internet", 2011, S. 97.

121 Meier/Hüneke, Forschungsbericht „Herstellung und Verbreitung von Kinderpornographie über das Internet", 2011, S. 68 ff., 98.

122 Dies wird auch in der Studie des EFC angemerkt, „European Financial Coalition Against Commercial Sexual Exploitation of children online“, S. 12, abrufbar unter:

http://www.ceop.police.uk/Documents/EFC\%20Strat\%20Asses2010_080910b\%20FINAL.pdf (zuletzt abgerufen 20.5.2012).

123 EFC, „14 months on: A combined report from the European Financial Coalition 2009-2010“,

S. 5, 17 ff., abrufbar unter:

http://ceop.police.uk/Documents/EFC\%20Strat\%20Asses2010_080910b\%20FINAL.pdf

(zuletzt abgerufen 20.5.2012). 
c) Risiken der Verbreitung von Kinderpornographie

Mit der weitreichenden Verbreitung des Internets kommt es auch zu vielfältigen Berührungspunkten mit internetbasierter Kinderpornographie. Die Möglichkeit des „ungehinderten Konsum“ eröffnet viele Risiken, welche der Staat aufgrund seiner verfassungsrechtlichen Schutzverpflichtung über die Eindämmung von Kinderpornographie relativeren muss. Dabei lässt sich zwischen unmittelbaren Gefahren, die aus der dargestellten Handlung an sich und mittelbaren Folgen, die aus der Verbreitung des Materials resultieren, unterscheiden.

(aa) Unmittelbare Gefahr: Körperliche Beeinträchtigung der Kinder

Kinderpornographische Produktionen haben eine direkte Auswirkung auf die dargestellten Personen. Das Filmen und die Zurschaustellung sexueller Szenen mit Kindern, wird oftmals dramaturgisch um den Einsatz willensbeugender Mittel ergänzt, um die ohnehin nicht stark ausgeprägte Fähigkeit zu selbstbestimmten Entscheidungen der Kinder zielorientiert aufzuheben. ${ }^{124}$ Die Herstellung kinderpornographischen Materials ist damit eng mit dem strafrechtlich geahndeten Kindesmissbrauch im Sinne des $₫ 176$ StGB und den dahinterstehenden Schutzintentionen verbunden. Obgleich für das Vorliegen von Kinderpornographie i.S.d. \184b StGB auch schon unter der Strafbarkeitsschwelle des $₫ 176$ StGB befindliche Handlungen ausreichen, so sind auch die Handlungen i.S.d. \184b StGB größtenteils mit anzüglichen Handlungen und willensbeugenden Maßnahmen verbunden..$^{125}$

Die möglichen Folgen einer sexuellen Ausbeutung von Kindern sind vielfältig und haben nachhaltige Wirkungen. So beeinflussen die sexuellen Handlungen die körperliche Integrität der involvierten Kinder. Die körperliche Entwicklung, wie auch das physische Entwicklungsstadium von Geschlechtsorgangen ist bei Kindern im Altersbereich bis 14 Jahren von Natur aus nicht so weit fortgeschritten, wie bei erwachsenen Personen. Sexuelle Körperkontakte mit Erwachsenen hinterlassen bei Kindern viel schneller und intensiver körperliche Blessuren und nachhaltige gesundheitliche Schäden, als dies bei Interaktion zweier Erwachsener der Fall wäre. ${ }^{126}$ Dies ist insbesondere dann der Fall, wenn es um Handlungen mit beträchtlicher Eingriffsintensität und Körperkontakt geht, etwa Beischlafhandlungen oder Gewalteinwirkungen zur sexuellen Nötigung im Bereich des Oral- oder Analverkehrs. ${ }^{127}$ Die körperlichen Beeinträchtigungen reichen von geringen ober-

124 In diesem Zusammenhang zum Straftatbestand des $₫ 182$ StGB, Hörnle, NJW 2008, 3521 (3522).

125 BGHSt 45, 131 (132); Hörnle, NStZ 2000, 310; Sick/Renzilkowski in: FS für Schroeder, 2006, S. 603 (606 f.); Fischer, $₫ 176$ StGB, Rn. 2.

126 So Hörnle in: FS für Eisenberg, 2009, S. 321 (336).

127 In die Richtung Schroeder, NJW 1993, 2581, auf die Gefährdung des körperlichen Unversehrtheit im Bereich des sexuellen Missbrauchs hinweisend auch Hörnle in: FS für Eisenberg, 2009, S. 321 (336). 
flächlichen Abschürfungen, Blutergüssen, Knochenbrüchen bis hin zu starken inneren Verletzungen mit dauerhaft bleibenden Folgen. Auch spätere Beeinträchtigungen der Gebärfähigkeit können auf einen frühen Missbrauch mit starker vaginaler Eingriffsintensität zurückgeführt werden. ${ }^{128}$ Daneben finden sich auch körperliche Folgen, wie die Ansteckung mit sexuellen Infektionskrankheiten oder ungewollte Schwangerschaften. ${ }^{129}$

(bb) Unmittelbare Gefahr: Beeinträchtigung sexueller Selbstbestimmung

Die Einbeziehung von Kindern in die pornographische Produktion kann über die Beeinträchtigungen der körperlichen Unversehrtheit hinaus auch das sexuelle Selbstbestimmungsrecht der involvierten Kinder beeinträchtigen. ${ }^{130}$ Angelehnt an das zu befürchtende Machtungleichgewicht zwischen Kind und erwachsenem Gegenüber, kann der „Missbrauchende“ das sexuelle Selbstbestimmungsrecht des Kindes dadurch beeinträchtigen, dass er seine körperliche sowie intellektuelle Überlegenheit zur Verfolgung sexueller Ziele einsetzt, um damit bewusst den Willen des Kindes zur Vornahme bestimmter Handlungen zu brechen. ${ }^{131}$ Problematisch ist in diesem Zusammenhang, dass die Gefahr der Beeinträchtigung der sexuellen Selbstbestimmung durch kinderpornographische Produktionen daran ansetzt, dass dem kindlichen Protagonisten tatsächlich auch die Fähigkeit zu autonomen Entscheidungen im Bezug auf die eigene Sexualität zuzusprechen ist. Dies kann aber insbesondere bei sehr jungen Kindern oder Säuglingen in Abrede gestellt werden, da diesen die entsprechende Einsichts- und Steuerungsfähigkeit, mithin die „Selbstbestimmungsfähigkeit“ fehlen könnte. ${ }^{132}$ Eine solche Betrachtung verkennt jedoch, dass das sexuelle Selbstbestimmungsrecht als Teil des Allgemeinen Persönlichkeitsrechts des Art. 2 Abs. 1 GG i.V.m. Art. 1 Abs. 1 GG zwei wesentliche Komponenten unterscheidet: Einerseits das Recht auf aktive Gestaltung der eigenen Sexualität, welches nur denjenigen zugesprochen werden kann, die auch die notwendige Einsichtsfähigkeit zur Vornahme der Gestaltung aufweisen, damit bei Kindern grundsätzlich noch nicht angelegt sein kann. Andererseits aber auch das „(Abwehr)recht des Einzelnen“ nicht gegen seinen Willen zum Objekt sexuellen Begehrens gemacht zu werden, welches unabhängig geistig-

128 Richter-Appelt, Sexuelle Traumatisierung und körperliche Misshandlung, 1994, S. 116; Wetrels, Gewalterfahrungen in der Kindheit, 1997, passim; Wuttke, Pornographie an Kindern, 2003, S. 98 ff.; Maywald, FPR 2003, 299 (302) allgemein zu körperlichen Misshandlungen auch ohne Sexualbezug.

129 Ziegler in: v. Heintschel-Heinegg, \176a StGB, Rn. 18 ff.; Fischer, \176a StGB, Rn. 20.

130 Hörnle in: LK-StGB, \174 StGB, Rn. 1; Ren₹ikoowski in: Münch. Komm. StGB, Vor. \174 ff. StGB, Rn. 7 ff., $\ 174$ StGB, Rn. 1 ff.; in die Richtung auch BT-Drs. 6/3521, S. 20.

131 Zum Selbstbestimmungsdiskurs Hörnle in: FS für Eisenberg, 2009, S. 321 (333 ff.) mwN.

132 Differenzierend zur Verneinung der sexuellen Selbstbestimmungsrechts bei Kleinkindern, Perron/Eisele in: Schönke/Schröder, Vor. \174 StGB, Rn. 1. 
personeller noch altersabhängiger Konstitution jedem zugesprochen werden kann. ${ }^{133}$ Damit greift in Bezug auf Kinder als Darsteller pornographischer Produktionen die letztere abwehrrechtliche Dimension des Selbstbestimmungsrechts ein. Auch wenn das Kind seine Einwilligung zur Vornahme und Aufzeichnung der sexueller Handlungen erteilt hat, wird ihre Wirksamkeit im Verhältnis von Kindern zu Erwachsenen generell abzulehnen sein, da hier die Belange des allgemeinen Kindesschutzes aufgrund bestehender Machtverhältnisse die individuelle Übereinkunft regelmäßig überwiegen. ${ }^{134}$

(cc) Unmittelbare Gefahr: Geistig-seelische Nachwirkungen

Von Kinderpornographie können auch Gefahren für die geistig-personelle Entwicklung, zum Teil sogar für die Gesamtentwicklung des Kindes ausgehen. ${ }^{135}$ Bedingt durch den Umstand, dass kinderpornographischen Produktionen ein reeller Missbrauch, zumindest jedoch zwangsweise verwirklichte sexuelle Handlungen mit Kindern zugrundeliegen, können neben einer geistig-personellen Fehlentwicklung mit kurz- und langfristige auftretenden psychische Problemen, teilweise auch das Risiko diagnostizierbarer psychiatrischer Symptome drohen. ${ }^{136}$ Denkbar sind überdies nachweisbare „hirnorganische Veränderungen“, die zur Störung des individuellen sowie gemeinschaftlichen Verhaltens und sogar zu Störungen partnerschaftlichen Bindungsverhaltens führen können. ${ }^{137}$ Überdies können anfänglich scheinbar symptomfreie kindliche Opfer in ihrer späteren Gesamtentwicklung Spätfolgen aufweisen. ${ }^{138}$ Dabei kann die Intensität der Beeinträchtigung von der Art der sexuellen Handlung bestimmt sein. Größere Risiken für die geistig-personelle Gesamtentwicklung sind etwa dann anzunehmen, wenn die

133 Perron/Eisele in: Schönke/Schröder, Vor. \174 StGB, Rn. 1; Hörnle in: FS für Eisenberg, 2009, S. 321 (334 f.), in die Richtung des auch Kindern zustehenden Selbstbestimmungsrechts schon BVerfGE 47, 46.

134 Bottke in: FS für Otto, 2007, S. 535 (537 f.); Renzilkowski in: Münch. Komm. StGB, \174 StGB, Rn. 24; Fischer, $₫ 182$ StGB, Rn. 2.

135 Demnach wird die Störung der Gesamtentwicklung auch als Schutzgut iSd. Straftaten in Zusammenhang mit Kindesmissbrauch anerkannt: BGHSt 1, 168 (175); BGHSt 15, 118 (121); BGHSt 45, 131 (132); BGHSt 53, 118; BGH, NStZ 2007, 700; Perron/Eisele in: Schönke/Schröder, $₫ 176$ StGB, Rn. 1.

$136 \mathrm{Zu}$ dem gesamten Komplex Hörnle in: FS für Eisenberg, 2009, S. 321 (328); KendallTackett/Williams/Finkelhor in: Amann/Wipplinger, Sexueller Missbrauch, 2005, S. 183 ff.; RichterAppelt/Moldzio in: Kockott/Fahrner, Sexualstörungen, 2004, S. 86 ff.

137 Bange/Deegener, Sexueller Missbrauch an Kindern, 1996, S. 198 ff.

138 So Hörnle in: FS für Eisenberg, 2009, S. 321 (328). 
Handlungen eine starke Eingriffsintensität aufweisen und von willensbeugenden Mittel, wie Gewalteinfluss dominiert sind. ${ }^{139}$

(dd) Mittelbare Gefahr: Konsum und geistig-seelische Beeinträchtigung

Ausgangspunkt ist die Annahme, dass Pornographie einen großen Einfluss auf die Emotionen des Menschen hat. Da ihr vordergründiger Zweck darin liegt, sexuelle Erregung auszulösen, sind bei pornographischen Angeboten unmittelbare psychologische und physische Wirkungen denkbar. ${ }^{140}$ Neben sexueller Stimulierung kann der Konsum spezieller pornographischer Angebote jedoch auch negativen Einfluss auf die geistig-seelische Entwicklung des Rezipienten sowie akute, zum Teil auch anhaltende Bewusstseinsveränderungen der Psyche nach sich ziehen. ${ }^{141}$ Die einzelnen Erkenntnisse basieren auf Feldversuchen, Studien und theoretischen Denkmodellen des sozialpädagogischen Bereichs der so genannten Medienwirkungsforschung. ${ }^{142}$ Von der Betrachtung beispielsweise pädophilpornographischer Angebote kann die Möglichkeit ausgehen, dass Kinder, Heranwachsende, teilweise sogar erwachsene Personen, in ihrer ,,seelischen Entwicklung und sozialen Orientierung beeinträchtigt werden, wenn ihnen dieses Material infolge einer breiten Streuung leichter zugänglich gemacht wird“.143 Eine große Anzahl an Studienleistungen, die sich explizit auf den Wirkzusammenhang zwischen kinderpornographischen Angeboten und geistig-personeller Entwicklung beziehen, gibt es allerdings nicht. Der Mangel an empirischen Daten, ist damit begründet, dass es ethisch kaum vertretbar erscheint zu experimentellen Zwecken missbrauchsartige Darstellungen von Kindern zu konsumieren, um eventuelle Folgen nachzuweisen. ${ }^{144}$ Daher beziehen sich die meisten Studien auf den einem Einfluss einfacher Pornographie auf die Persönlichkeitsentwicklung von erwach-

139 Vergleichbar den körperlichen Folgen, hierzu oben 2. Teil A. II. 1. c) (aa) . Zusammenfassend zu geistigen Spätfolgen, Bange/Deegener, Sexueller Missbrauch an Kindern, 1996, S. 198 ff.

140 Grimm/Rhein/Müller, Porno im Web 2.0, 2010, S. 16.

141 Mynarik, Jugendschutz in Rundfunk und Telemedien, 2006, S. 39; Schäfer, Der kriminologische Hintergrund des (Jugend-)Medienschutz im Hinblick auf mediale Gewaltdarstellungen, 2008, S. 5 .

142 Vgl. Enquete-Kommission Zukunft der Medien, BT-Drs. 13/11001, S. 15 ff.; Lukesch in: Dittler/Hoyer, Zwischen Medienerwerb und Mediensucht, 2010, S. 177; Köhne, ZRP 2009, 155 (156); Adolf/Mahrt/Rhomberg in: FS für Schönbach, 2009, S. 15 ff.; Kubn, Vernetzte Medien, 2009, S. 100 ff.; Jahraus/Maass, UFITA 2008, 369.

143 BT-Drs. 6/1552, S. 34. Ausführlich Darstellung des Forschungsstandes: Bandehzadeh, Jugendschutz im Rundfunk und in den Telemedien, 2007, S. 17 ff.

144 Knoll, tv-diskurs 1/2001, 54 (57); Lukesch in: Roters/Brosius, Mediensozialisation und Medienverantwortung, 1999, S. 72; in die Richtung auch Meier/Hüneke, Forschungsbericht „Herstellung und Verbreitung von Kinderpornographie über das Internet“", 2011, S. 30. 
senen Probanden. ${ }^{145}$ Vereinzelt finden sich auch Untersuchungen, die speziell Auswirkungen auf den mit Minderjährigen Konsumenten dokumentieren. ${ }^{146}$ Im Einzelnen kommen die Forschungen überwiegend zur Annahme, dass von dem Konsum eines pornographischen Angebotes negative Einflüsse auf die personelle Entwicklung ausgehen. Dies wurde insbesondere dann beobachtet, wenn die konsumierten sexuellen Handlungen nicht im gegenseitigen Einvernehmen der Beteiligten dargestellt wurden, beispielsweise bei Vergewaltigungsszenen oder sonstigen verharmlosenden Darstellungen sexueller Nötigung. ${ }^{147}$ Durch die Vermittlung solcher Erscheinungsformen, wie auch einer immerwährenden sexuellen Bereitschaft der Beteiligten sowie einer Überbetonung der männlichen Potenz, können Wirklichkeitsverzerrungen beim Zuschauer hervorgerufen werden, die eine Herausbildung einer ,aggressionsbehafteten Sexualmoral“ zur Folge haben. ${ }^{148}$ Anfänglich starke sexuelle Erregung des Rezipienten oder negative Gefühlsempfindungen, wie Ekel und Abneigung, können bei wiederholtem Pornographiekonsum zunehmend abflachen, was zu einer Desensibilisierung mit vermehrter sexueller Gewalt in der Realität führe. ${ }^{149}$ Aufgrund der Tatsache, dass es sich hier um Bewusstseinsforschungen handelt, die nicht auf messbaren Erkenntnissen basieren, finden sich auch völlig gegenteilige Ergebnisse. So wird vereinzelt auch vertreten, dass der Konsums pornographischer Darstellungen gerade auch positive Empfindungen beim Rezipienten hervorgerufen kann. Neben der Theorie, dass der Konsument durch die Rezeption des Angebotes einer „psychosozialen-Reinigung“ unterzogen werde, deren Folge eine Verminderung der Aggressionsbereitschaft im gewalthaften wie im intim-sexuellen Bereich sei ${ }^{150}$ und der Auffassung, dass eine Übernahme der gesehenen Verhaltensmuster nur dann anzunehmen sei, wenn die darstellte Handlung mit positiven sexuellen Empfindungen in Verbindung gebracht wird und auch nur solche ins Konsumentenverhalten übertragen werden, finden sich auch Ansätze, die einen Wirkungszusammenhang zwischen konsu-

145

146 Medien, 1996, S. 83 ff, jedoch zur Wirkung von Gewaltdarstellungen auf Jugendliche und Kinder.

147 2006, S. 46 f.; so auch v. Gottberg, tv-diskurs 12/2001, 46.

148 chologie, Erotik und Pornographie in den Medien, 2007, S. 454.

149 hirnaktivität bei wiederholtem Pornographiekonsum im häuslichen Bereich gemessen wurden.

150 So etwa die sog. Katharsistheorie, hierzu Bachmair, tv-diskurs 4/1999, S. 63 f.; Meirowitz, Gewaltdarstellungen auf Videokassetten, 1993, S. 69 f, Selg, tv-diskurs 2/1997, 50. 
mierter Pornographie und der Bewusstseinsentwicklung des Rezipienten gänzlich ausschließen. ${ }^{151}$

(ee) Mittelbare Gefahr: Nachahmung und erneute Viktimisierung

Daneben wird eine kriminalitätssteigernde, desorientierte Wirkung von der ungehinderten Rezeption kinderpornographischer Angebote erwartet. ${ }^{152}$ Die Möglichkeit des ungehinderten Konsums kinderpornographischer Angebote, kann, wie auch bei einfach pornographischen Angeboten, als primäre Wirkung sexuell stimulierend auf den Betrachter wirken. ${ }^{153}$ Das Internet hat dabei die Besonderheit, dass der pädophil-geneigte Nutzer auf der Suche nach einer sexuellen Stimulation stets unter dem Deckmantel der internetvermittelten Anonymität vorgehen kann; so muss man nicht wie noch vor wenigen Jahren den Weg in die Öffentlichkeit wagen, um in entsprechenden Etablissements Befriedigung zu erfahren, vielmehr kann mittels Internet lange in dubiosen Bereichen seiner Neigung nachgegangen werden, ohne sich in der Gesellschaft outen zu müssen. ${ }^{154}$ Als Nebenfolge des stimulierenden, anonymen und ungehinderten Konsums entsprechender Inhalte über das Internet, kann die emotionale Hemmschwelle des Rezipienten zum reellen Missbrauch zunehmend sinken. ${ }^{155}$ Durch den ungehinderten Konsum pädophiler Pornographie können beim Konsumenten Wirklichkeitsverzerrungen stattfinden, die in der fälschlichen Annahme gründen, der kindliche Protagonist wünsche sich die sexuelle Handlung. ${ }^{156}$ Dieser Normalisierungseffekt gründet vermehrt in der Annahme, Kindesmissbrauch sei nicht etwas Abstoßendes und Verwerfliches, sondern erfahre - mittels ungehinderter Verbreitung - zunehmend an

151 Sog. Theorie von der Wirkungslosigkeit, dazu Fowles, The Case for Television Violence, 1999 , S. 1; Degen, Psychologie Heute, 15/1988, S. 20; Klapper, The Effects of Mass Communication, 1974, S.18, früher auch Kunc:ilk, tv-diskurs 2000, 38 (39), nunmehr aber selbst von einen Wirkungszusammenhang ausgehend, vgl. Kunczike, Befunde der Wirkungsforschung, 2007, S. 1 ff.

152 So begründet von Sänger, KJuG 1994, 43; daran anknüpfend Schreibauer, Das Pornographieverbot des $\int 184$ StGB, 1999, S. 40 f.; Laubenthal, Sexualstraftaten, 2000, Rn. 704; König, Kinderpornographie im Internet, 2004, Rn. 101.

153 Sänger, KJuG 1994, 43; zusammenfassend König, Kinderpornographie im Internet, 2004, Rn. 104 ff.; Aufhebungsgesetzentwurf der FDP zum ZugErschwG, BT-Drs. 17/646, S. 3.

154 In die Richtung auch Heinrich, NStZ 2005, 361 (363).

155 König, Kinderpornographie im Internet, 2004, Rn. 110.

156 Schreibauer, Das Pornographieverbot des $\int 184$ StGB, 1999, S. 40; zum Einsatz der Kinderpornographie als Ersatz für reellen Missbrauch, Diamond/Jozifkova/Weiss in: Archives of Sexual Behavior, 2010, abrufbar unter:

http://www.springerlink.com/content/v046j3g178147772/fulltext.pdf

(zuletzt abgerufen 20.5.2012). 
gesellschaftlicher Akzeptanz. ${ }^{157}$ Kumulativ zur sinkenden Hemmschwelle kann speziell das Internet zur gezielten Kontaktaufnahme mit Gleichgesinnten, aber auch mit potentiellen Missbrauchsopfern zugleich genutzt werden. ${ }^{158}$ Denn die Bandbreite des Internets im Bereich des individuellen Austausches, forciert nicht nur einen direkten Austausch entsprechender Produkte, sondern eröffnet dem Nutzer auch den Einblick in ein tiefgründiges Milieu, dem potentielle Weiterleitungen zu entsprechenden Vermittlern nicht abgesprochen werden können. ${ }^{159}$ Darüber hinaus wird vielfach vom ungehinderten Konsum internetvermittelter Kinderpornographie die Gefahr einer kriminalitätssteigernden Wirkung aufgrund ökonomischer Gesichtspunkte angenommen. Ausgehend von der Annahme eines internetbasierten „Marktes für Kinderpornographie“ im Internet, kann die erhöhte Nachfrage nach kinderpornographischem Material zur Nachahmung anregen. ${ }^{160}$ Die Weitergabe kinderpornographischen Materials im Weg eines kommerziellen Vertriebssystems fördert die Produktion neuen Materials, das wiederrum zu erneuten Kindesmissbrauch führt. ${ }^{161}$

Durch die ungehinderte Verbreitung kinderpornographischer Angebote droht auch die Gefahr erneuter Viktimisierung der Opfer. In der Regel sind bei kinderpornographischen Abbildungen auch die Gesichter der kindlichen Protagonisten erkennbar. ${ }^{162}$ Die ungehinderte Weitergabe der Bilder begründet damit eine wiederholte öffentliche Zur-Schaustellung der abgelichteten Kinder und kann Persönlichkeitsrechte weit über den Missbrauchszeitpunkt hinaus verletzten. ${ }^{163}$

\section{Schlussfolgerung für die staatliche Schut:pflicht}

Die Aufzählung der potentiellen Risiken verdeutlicht die Weitläufigkeit des Schutzbedürfnisses. In der Konsequenz ist der Staat von Verfassungswegen in Ausgestaltung der Pflicht zum Jugendschutz berufen, innerhalb des rechtlich

BT-Drs. 12/3001, S. 5, ähnlich Schreibauer, Das Pornographieverbot des \ 184 StGB, 1999, S. 76; jetzt auch Aufhebungsgesetzentwurf der FDP zum ZugErschwG, BT-Drs. 17/646, S. 3.

158 Hill/Bringen/Berner, Bundesgesundheitsblatt 2007: Pornographie und sexuelle Gewalt im Internet, S. 90 (91).

159 So u.a. die den Erfahrungen des BKA im internationalen Bereich der Bekämpfung von Kinderpornographie, hierzu Pressemitteilung des BKA v. 30.9.2009, „Bundeskriminalamt zerschlägt Kinderpornografie-Ring“, abrufbar unter: http://www.bka.de/.

160 Hierzu Heinrich, NStZ 2005, 361 (362); Duttge/Hörnle/Renqikowski, NJW 2004, 1065 (1070).

161 BT-Drs. 12/3001, S. 5, in diese Richtung auch Duttge/Hörnle/Renzikowski, NJW 2004, 1065 (1070); Harms, NStZ 2003, 646 (647); Heinrich, NStZ 2005, 361 (363). Zur Kritik an der Theorie in Anbetracht der neusten Studien nachfolgend unter 2. Teil A. II. 2. sowie 3. Teil B. I. 2. b) (bb)

162 Meier/Hüneke, Forschungsbericht „Herstellung und Verbreitung von Kinderpornographie über das Internet“, 2011, S. 100.

163 Sieber, JZ 2009, 653; Aufhebungsgesetzentwurf der FDP zum ZugErschwG, BT-Drs. 17 /646, S. 3 . 
Möglichen und Zumutbaren geeignete Maßnahmen zu ergreifen, um die befürchteten Folgen bestmöglich einzudämmen. Problematisch in dem Zusammenhang ist, dass die von Kinderpornographie resultierenden Gefährdungen nur auf Annahmen und theoretischen Vermutungen basieren und nicht auf fundierte wissenschaftliche Erkenntnisse zurückzuführen sind. So muss eine geistig-personelle Beeinträchtigung der kindlichen Opfer bei Vornahme sexueller Handlungen auch bei schwersten Formen des Missbrauchs nicht zwangsläufig auftreten; im gleichen Zuge ist nicht mit Gewissheit festzustellen, dass eine kriminalitätssteigernde Wirkung vom Konsum kinderpornographischer Inhalte ausgeht. In Ermangelung weitreichender Feldversuche kann auch nicht abschließend geklärt werden, ob der Konsum kinderpornographischer Angebote auf den Rezipienten tatsächlich negativen Einfluss habe sowie ein bestimmtes Konsumentenverhalten zu späteren Missbrauchs führe. ${ }^{164}$ Besonders in Anbetracht neuster Studien zum Marktgeschehen im Kinderpornographiebereich erscheint es schwierig, weiterhin von der These auszugehen, dass zum Stillen der Nachfrage, weitere Missbrauchshandlungen begangen werden. Vielmehr zeigt die Studie, dass weder ein klassisches, von Nachfrage und Angebot geprägtes Markgeschehen vorliegt, noch aufgrund mangelnder Versuchskonzepte nachzuweisen ist, dass gegen Entgelt eingestellte Angebote zur Förderung eines Missbrauchs führen. ${ }^{165}$

Die von der Verbreitung von Kinderpornographie ausgehenden Gefahren sind folglich nicht hinreichend gesichert. Die Konsequenz für den Staat ist jedoch keineswegs, dass er von seiner verfassungsrechtlichen Schutzpflicht befreit wird, vielmehr müssen im Fall der „Ungewissheit“ eines tatsächlichen Vorliegens von Risiken, gesetzgeberische Handlungsbemühungen erlaubt sein, die auf eine Abwehr der latenten Gefahr abzielen.166 Soweit die Annahme einer möglichen Gefährdung nicht hinreichend widerlegt ist, ist der Staat aufgrund des hohen Schadens, der durch Kinderpornographie zu befürchten ist und der erklärten gesetzgeberischen Intention eines „umfassenden Jugendschutzes“, frei, entsprechende Maßnahmen zur Abwehr der latenten Gefahren einzuleiten. Obgleich fundierte wissenschaftliche Untersuchungen des Bereichs der internetbasierten Verbreitung von Kinderpornographie teilweise in der Lage sind, bestimmte Annahmen zu hinterfragen, ist nach derzeitigen Erkenntnisstand keine völlige Abkehr von der Vermutung ersichtlich, dass die ungehinderte Verbreitung von Kinderpornographie völlig risikolos für die Konsumenten sowie die an der Produktion beteiligten Protagonisten ist. Letztlich weisen auch die vereinzelten wissenschaftlichen Stu-

164 So Heinrich, NStZ 2005, 361 (362). Zu den einzelnen Einwirkungen auf die geistig-personelle Entwicklung des minderjährigen Rezipienten, Sänger, KJuG 1994, 43; zusammenfassend Scbreibauer, Das Pornographieverbot des $₫ 184$ StGB, 1999, S. 40 f.

165 Meier/Hüneke, Forschungsbericht „Herstellung und Verbreitung von Kinderpornographie über das Internet", 2011, S. 97 f.

166 BT-Drs. 6/3521, S. 35. 
dien darauf hin, dass mangels breit eingesetzter verdeckter Ermittler schlicht „,nicht festgestellt" werden kann, dass eine Produktion für die gegen Entgelt angebotenen Kinderpornographieinhalte stattgefunden habe. ${ }^{167}$ Einen wissenschaftlichen Beleg für das Gegenteil können diese Studien damit nicht liefern. Infolgedessen ist der Staat mit dem ihm zur Verfügung stehenden Mitteln zum Einschreiten berechtigt. Welche gesetzlichen Mittel der Staat zur Abwehr der Eingriffe wählt, bleibt ihm überlassen, solange der Staat überhaupt tätig wird und das gewählte Mittel rechtlich zulässig und zur Erreichung des Schutzziels objektiv dienlich ist. ${ }^{168}$ Der hieraus gefolgerte gesetzgeberische Gestaltungs- und Beurteilungsspielraum muss sich aber an dem Rang des hinter der Schutzpflicht stehenden Rechtsguts orientieren. ${ }^{169}$ Aufgrund der hohen Stellung des Jugendschutzes als „Ziel von bedeutsamen Rang und als ein wichtiges Gemeinschaftsanliegen " 170 sind auch besonders einschneidende Maßnahmen vom legislatorischen Spielraum umfasst. Überträgt man die so verstandene Einschätzungsprärogative ${ }^{171}$ des Gesetzgebers auf die Verhinderung der Verbreitung von kinderpornographischem Material, bedeutet dies, dass der Staat einerseits genug repressive Instrumente zur Bekämpfung der bestehenden Beeinträchtigungen der körperlichen und seelischen Integrität der Opfer bereitstellen muss. Andererseits auch präventive Regelungsmechanismen, die zur Abwehr zukünftiger Gefahren, wie einer mittelbaren Förderung von Kindesmissbrauch durch Nachahmungseffekte oder geistig-personeller Beeinträchtigungen der Entwicklung durch die ungehinderte Rezeptionsmöglichkeit beitragen. ${ }^{172}$

Vorrangige Mittel zur Bekämpfung bestehender Beeinträchtigungen, welche mit einem reellen sexuellen Missbrauch des kindlichen Protagonisten verbunden sind, sind repressive Befugnisse die eine gezielte Täterermittlung mit Identifizierungsmaßnahmen von Opfern und Produzenten erlauben sowie eine internationale Strafverfolgung, um auch global mögliche Täter einer entsprechenden Strafe

167 Meier/Hüneke, Forschungsbericht „Herstellung und Verbreitung von Kinderpornographie über das Internet“, 2011, S. 96 f.; EFC, „14 months on: A combined report from the European Financial Coalition 2009-2010“, S. 7 abrufbar unter:

http://ceop.police.uk/Documents/EFC\%20Strat\%20Asses2010_080910b\%20FINAL.pdf (zuletzt abgerufen 20.5.2012).

168 Damit ist die Schutzverpflichtung lediglich durch das sog. Untermaßverbot begrenzt, hierzu BVerfGE 92, 26 (46); BVerfGE 77, 170 (214), BVerfGE 77, 381 (405); BVerfGE 88, 203 (254f. 262); BVerfGE 96, 409 (412); Gržeszick in: Maunz/Dürig, Art. 20 GG, Rn. 126; Scbulze-Fielitz in: Dreier, Art. 20 GG, 223.

169 Greiner, Die Verhinderung verbotener Internetinhalte, 2001, S. 39.

170 BVerfGE 30, 336 (348) ; BVerfGE 77, 346 (356); BVerfGE 83, 130 (139).

171 BVerfGE 77, 84 (104); BVerfGE 90, 145 (173 ff.); BVerfGE 109, 279 (336 ff.).

172 Allgemein dazu Greiner, Die Verhinderung verbotener Internetinhalte, 2001, S. 39. 
zuzuführen. ${ }^{173}$ Maßnahmen zur gezielten Verhinderung der onlinebasierten Verbreitung von Kinderpornographie zielen im Gegensatz dazu auf die präventive Abwehr zukünftiger Gefahren, die mit kinderpornographischen Produktionen einhergehen, ab: Denn die Unterbindung des Vertriebsweges Internet kann nicht zu einem unmittelbaren Opferschutz beitragen, da die Verbreitung nicht zwangsläufig auch die Herstellung des kinderpornographischen Materials indiziert. ${ }^{174}$ Gesetzliche Maßnahmen zur Unterdrückung der Verbreitung sind daher vorrangig auf eine „Austrocknung“ des Marktes der Kinderpornographie ausgerichtet und sollen vor allem der latenten Nachahmungsgefahr reellen Missbrauchs bei ungehinderter Verbreitung kinderpornographischer Angebote, entgegenwirken. ${ }^{175}$ Im Rahmen der präventiven Handlungsbefugnisse kann auch die gesetzgeberische Pflicht zur Schaffung geeigneter Rechtsgrundlagen für das Einschreiten der Exekutivbehörden bestehen, da präventive Maßnahmen der Exekutive zum Jugendschutz oftmals Eingriffe in Rechte Dritter begründen und nach dem Vorbehalts des Gesetzes ${ }^{176}$ einer gesetzlichen Legitimation bedürfen. ${ }^{177}$

\section{Konkrete Strategien}

\section{Gesetzliche Rahmenbedingungen mit Sanktionswirkung}

Die konkrete gesetzliche Umsetzung der Jugendschutzverpflichtung im Bereich der Abwehr kinderpornographischer Gefahren beruht auf einem absolut wirkenden Gesamtkonzept, welches den unmittelbaren sexuellen Missbrauch, wie auch die Herstellung, Verbreitung und den Besitz von Kinderpornographie mit umfassenden Sanktionen belegt.

173 Sieber, Ausschussdrucksache 16 (9) 1559, S. 3.

174 Schroeder, ZRP 1990, 299 (300); ders. NJW 1993, 2581 (2583), hierzu auch die obige Studie des EFC, S. 5, abrufbar unter: „14 months on: A combined report from the European Financial Coalition 2009-2010“, abrufbar unter: http://ceop.police.uk/Documents/EFC\%20Strat\%20Asses2010_080910b\%20FINAL.pdf (zuletzt abgerufen 20.5.2012), die zumindest von der Annahme ausgehen, dass in osteuropäischen Ländern eine organisierte Produktion zur Marktabdeckung ,im kleinen Kreis“ stattfindet.

175 IE. auch BGHSt 45, 41 (43); Fischer, \ 184b StGB, Rn. 2; Ziegler in: v. Heintschel-Heinegg, 』184b StGB, Rn. 2; Schroeder, ZRP 1990, 299 (300); Hörnle, NJW 2002, 1008; Weigend, ZUM 1994, 133 (140).

176 Herzog/Grzeszile in: Maunz/Dürig, Art. 20 GG, Rn. 75; Ossenbühl in: Isensee/Kirchhof, Hdb. StaatsR, 2007, Bd. V, 2007, J 101, Rn. 11 ff.; grundsätzlich Voßkuble, JuS 2007, 118; Bauer, NVwZ 1987, 112.

177 Dietlein, Schutzpflichten, 1992, S. 113; Isensee in: Isensee/Kirchhof, Hdb. StaatsR, 2002, Bd. V, \ $111, \mathrm{Rn} .137 \mathrm{ff}$. 
a) Strafrechtliche Ausgestaltung

Im Strafrecht stehen im Bezug auf die unmittelbaren Gefahren sexuellen Missbrauchs die $\iint 176$ bis 176b StGB im Vordergrund. Entsprechend \ 176 Abs. 1 StGB ist die Vornahme sexueller Handlungen an einer Person unter 14 Jahre (Kind) oder die Vornahme einer sexuellen Handlung an sich vor dem Kind mit Freiheitsstrafe von sechs Monaten bis zu zehn Jahren bestraft. Über $\int 176$ Abs. 2 StGB, wird ebenso bestraft, wer ein Kind dazu bestimmt, sexuelle Handlungen an einem Dritten vorzunehmen oder von einem Dritten vornehmen zu lassen. Über \176a, b StGB wird das Strafmaß auf Freiheitsstrafe nicht unter einem Jahr erhöht, wenn der Täter der Tat nach \176 StGB innerhalb der letzten fünf Jahre bereits aufgrund dergleichen strafbaren Handlung rechtskräftig verurteilt wurde. Über den Qualifikationstatbestand des $\int 176 \mathrm{~b}$ StGB, ist das Strafmaß auf lebenslange Freiheitsstrafe oder Freiheitsstrafe nicht unter 10 Jahren erhöht, wenn der Täter durch den sexuellen Missbrauch nach $\iint 176$, a StGB den Tod des Kindes wenigstens leichtfertig verursacht. Die Tatbestände der $\iint 176-176 b$ StGB knüpfen an das Vorliegen eines tatbestandlichen Missbrauchs an und zielen damit auf einen unmittelbaren Opferschutz ab. ${ }^{178}$

Im Mittelpunkt der Unterbindung der Gefahren, die speziell mit der Verbreitung kinderpornographischen Materials einhergehen, steht die Norm des $\int 184 \mathrm{~b}$ StGB. Die Strafvorschrift soll einem mittelbaren Kindesmissbrauch ${ }^{179}$ durch Unterdrückung der Nachahmungseffekte, die mit einem unbeeinträchtigten Marktgeschehen der Kinderpornographie einhergehen, unterbinden. Zur Realisierung normiert der Gesetzgeber ein absolutes Verbreitungs- und Herstellungsverbot kinderpornographischen Materials. Verstöße werden mit Freiheitsstrafe von 3 Monaten bis 5 Jahren, bei gewerbs- und bandenmäßigem Vorgehen mit Freiheitsstrafe zwischen 6 Monaten und 10 Jahren bestraft. ${ }^{180}$ Auch der Besitz kinderpornographischen Materials, die Besitzverschaffung für einen anderen sowie ein da-

178 Auf eine Ausführung der einzelnen Tatmodalitäten wird hier verzichtet. Ausführlich hierzu: Perron/Eisele in: Schönke/Schröder, \176 StGB, Rn. 2 ff.; Ziegler in: v. Heintschel-Heinegg, \176 StGB, Rn. 9 ff.; zu einzelnen Tathandlungen, die den Tatbestand des $\int 176$ StGB erfüllen, u.a. BGH, NStZ-RR 2009, 262 - Körperkontakt als Ejakulation auf das Kind; kein sexueller Missbrauch bei Stillen eines 6jährigen Kindes mit zärtlicher Umarmung, OLG Oldenburg, NStZ-RR 2010, 240 (241).

179 Missbrauch wird hier „untechnisch“ für jegliche Formen sexueller Handlungen an, vor und mit Kindern verstanden und soll nicht gleichbedeutend mit den erhöhten Anforderungen des $\ 176$ StGB sein. Sollte letzteres ausdrücklich gewollt sein, so wird speziell darauf hingewiesen.

180 Der Strafrahmen wurde durch das 6. StrRÄndG v. 26.8.1998, BGBl. I 1998, S. 164 erhöht, hierzu überblicksartig, Dessecker, NStZ 1998, 1; Folkers, NJW 2000, 3317. 
hingehender Versuch, werden mit Freiheitsstrafe bis zu zwei Jahren oder Geldstrafe bestraft. ${ }^{181}$

Inhaltlich muss kinderpornographisches Material eine sexuelle Handlung von, an oder vor einem Kind zum Gegenstand haben. Damit knüpft das absolute Herstellungs- und Verbreitungsverbot von Kinderpornographie nicht an die Erfüllung eines tatbestandlichen Missbrauchs gemäß \176 StGB an. Folglich reichen zur Bejahung der Darstellung einer sexuellen Handlung im Sinne des \184 b StGB bereits weniger beschwerliche Handlungen gegenüber $\int 176 \mathrm{StGB}$ aus. So muss das Objekt der kinderpornographischen Produktion nicht zwangsläufig objektiv ein Kind (Person unter 14 Jahren) sein. Vielmehr genügt hier die so genannte Scheinkindlichkeit. ${ }^{182}$ Auch muss bei sexuellen Handlungen des Kindes an einen Dritten, kein „bestimmen“ zur Tat durch den Erwachsenen vorliegen, wie dieses in $\int 176$ Abs. 2 StGB gefordert wird, wonach der Täter ausdrücklich oder zumindest konkludent den Willen des Kindes durch eine entsprechende physische Einwirkung beeinflusst und dadurch den Entschluss zur Vornahme der sexuellen Handlung zumindest mitverursacht haben muss. ${ }^{183}$ Als sexuelle Handlungen i.S.d. $\int 184 \mathrm{~b}$ StGB gelten auch Handlungen von Kindern an sich selbst oder vor oder an einen Dritten, hinsichtlich derer, eine „Bestimmung“ des Kindes nach \176 Abs. 2 StGB zu verneinen wäre, etwa bei mittelbarer Beeinflussung des Kindes zur Vornahme der Handlung über eine dritte (dem Kind vertraute) Person. ${ }^{184}$

Problematisch erscheint, dass $\int 184 b$ StGB f lediglich die Verbreitung von kinderpornographischen Schriften sanktioniert. Die gesetzliche Formulierung lässt vermuten, dass sich der Tatbestand gar nicht auf eine Sanktionswirkung hinsichtlich der Verbreitung im Internet bezieht. Diese dem ersten Anschein nach missverständliche Formulierung erhält jedoch im gesetzessystematischen Kontext die notwendigen Konturen: Wegen der Gleichstellungsklausel des Schriftenbegriffs in $\int 11$ Abs. 3 StGB beanspruchen die Regelungen, die ein Verbreitungsverbot in Schriften normieren auch im Rahmen der Verbreitung entsprechender Darstellungen über das Internet Rechtswirkung: Gemäß \11 Abs. 3 StGB wird unter dem strafrechtlichen Schriftenbegriff nicht nur die Zusammenstellung von „Zeichen,

181 Zu den einzelnen Tathandlungen: Perron/Eisele in: Schönke/Schröder, \184b StGB, Rn. 2 ff.; Lackner/Kühl, \184b StGB, Rn. 3; Ziegler in: v. Heintschel-Heinegg, \184b StGB, Rn. 7 ff.; noch zum früheren Gesetzeswortlaut, König, Kinderpornographie im Internet, 2004, Rn. 209 ff.; Schreibauer, Das Pornographieverbot des $₫ 184$ StGB, 1999, S. 291.

182 BGH, MMR 2009, 178 mit Anm. Liesching; Röder, NStZ 2010, 113; Liesching, JMS-Report 5/2008, 2.

183 BT-Drs. 16/9646, S. 34; Fischer, \176 StGB, Rn. 10; Perron/Eisele in: Schönke/Schröder, \ 176 StGB, Rn. 8; Renqikowski in: Münch. Komm. StGB, \176 StGB, Rn. 26 ff.

184 Fischer, \176 Rn. 7; Hörnle in: LK-StGB, \176 StGB, Rn. 16. Laubenthal, Sexualstraftaten, 2000, S. 357 . 
die äußerlich wahrnehmbar sind und mittelbar Gedankeninhalte verkörpern“185 verstanden, sondern auch „Ton- und Bildträger, Datenspeicher, Abbildungen und andere Darstellungen“. ${ }^{186}$ Nach gefestigter Auffassung, die elektronische Weitergabe von Dateien über das Internet als „Datenspeicher“ unter den Schriftenbegriff des $₫ 11$ Abs. 3 StGB zu fassen, da bei der Betrachtung des jeweiligen Internetinhalts zumindest eine Zwischenspeicherung der Datei im Arbeitsspeicher (Browsercache) des Computers erfolgt. ${ }^{187}$ Nicht notwendig ist, dass der Betrachter sich der Abspeicherung der Dateien im Arbeitsspeicher auf der Festplatte bewusst ist: Es reicht bereits das bloße Betrachten entsprechender Webseiten auf dem Bildschirm aus. ${ }^{188}$

In Umsetzung der Vorgaben des europäischen Rahmenbeschlusses 2004/68/JI des Rates der Europäischen Union vom 22.12.2003 zur Bekämpfung der sexuellen Ausbeutung von Kindern und der Kinderpornographie ${ }^{189}$ wurden im strafrechtlichen Sanktionsbereich Angleichungen vorgenommen, die auf eine Harmonisierung des Jugendschutzes auf europäischer Ebene zielten: ${ }^{190}$ Aufgrund einer unterschiedlichen Definition des „Kindes“ wurde der Straftatbestand der Jugendpornographie in $\ 184 \mathrm{c}$ StGB eingeführt. Entsprechend den Begriffsbestimmungen des Rahmenbeschlusses, gilt nach Art. 1 lit. a als „Kind im Sinne der Kinderpornographie“, ,jede Person unter achtzehn Jahren“. Nach geltendem deutschem Recht, ist „Kind“ gemäß \176 StGB jedoch eine Person unter 14 Jahren. Im Zuge der Verpflichtung zur europäischen Angleichung schuf der Gesetzgeber daher einen eigenen Straftatbestand, der die Jugendpornographie sanktioniert. Die Tatmodalitäten entsprechen dabei dem Straftatbestand der Kinderpornographie, wobei das Tatobjekt eine Person zwischen 14 und 18 Jahren sein muss. Zudem weist der Straftatbestand einen geringeren Strafrahmen gegenüber

BGHSt 13, 375; Schreibauer, Das Pornographieverbot des $₫ 184$ StGB, 1999, S. 174; Fischer, $₫ 11$ StGB, Rn. 34.

186 So explizit der Wortlaut des $₫ 11$ Abs. 3 StGB.

187 BGH, MMR 2001, 676 (677); im Ansatz auch schon BT-Drs. 13/7385, S. 36; Bröbl, CR 1997, 73 (77); Gounalakis/Rhode, K\&R 1998, 321 (330); Sieber, JZ 1996, 494 (495), ausführlich zum Meinungsstand Harms, NStZ 2003, 646. So zumindest für die Tatmodalität des Sich-Besitzverschaffens über den Arbeitsspeicher iSd. $\int$ 184b Abs. 4 StGB, OLG Hamburg, ITRB 2010, 124 in Anlehnung an OLG Schleswig, NStZRR 2007, 41, LG Karlsruhe, Urt. v. 24.4.2004 - 3 Qs 24/04 nV. (Weiterführung von BGH, MMR 2001, 676), die hier vergleichend herangezogen werden kann.

189 Abl. 2004 Nr. L 13, S. 44.

190 Zur Umsetzung Hörnle, NJW 2008, 3521; Schroeder, GA 2009, 213; Reinbacher/Wincierz, ZRP 2007, 195; Gercke, ZUM 2009, 526; Perron/Eisele in: Schönke/Schröder, Vorb. \ 174 ff. StGB, Rn. 11. 
der Kinderpornographie nach $₫ 184 b$ StGB auf. ${ }^{191}$ Die Schaffung einer separaten Strafnorm und nicht etwa die Anhebung der Altersgrenze im Rahmen des $\ 184 \mathrm{~b}$ StGB, sollte den europäischen Vorgaben genügen, gleichzeitig aber signalisieren, dass die innerstaatliche Differenzierung zwischen Kindern und Jugendlichen nicht aufgehoben werden sollte. ${ }^{192}$ Daneben basiert auch die oben bereits erläuterte „Abschwächung“ des Tatbestandes des $\ 184 \mathrm{~b}$ StGB auf der Umsetzung des Rahmenbeschlusses: ${ }^{193}$ Entsprechend Art. 1 lit. b der Begriffsbestimmungen umfasst Kinderpornographie auch das ,aufreizende Zur-Schau-Stellen der Genitalien oder der Schamgegend von Kindern". Der frühere Verbotstatbestand der Kinderpornographie knüpfte noch an die Tatmodalitäten des tatsächlichen Missbrauchs nach $\$ 176 \mathrm{StGB}$ an, so dass ein bloßes ,zur Schau stellen“ nicht ausreichte, um den Tatbestand zu erfüllen. In Umsetzung des Rahmenbeschlusses werden jetzt auch sexueller Kontakte unterhalb der Schwelle des Missbrauchs, vom Straftatbestand der Kinderpornographie eigenständig erfasst ist.

Grundsätzlich sind auch virtuelle Darstellungen, das heißt Abbildungen bei denen nicht reelle Kinder, sondern virtuell dargestellte Gestalten mit kindlichen Zügen, elektronisch simulierte sexuelle Handlungen vornehmen, ${ }^{194}$ von $\ 184 \mathrm{~b}$ StGB umfasst. Ausgehend von der Annahme, dass das strafrechtliche Verbot vorrangig dem mittelbaren Opferschutz dient, sprechen bereits teleologische Erwägungen für die Einbeziehung. ${ }^{195}$ Eine Unterbindung virtueller Kinderpornographie kann typischerweise keinen unmittelbaren Opferschutz herbeiführen, da hinter fiktivpornographischen Produktionen keine reellen kindlichen Protagonisten stehen, die sexuellen Handlungen mittels Zwangs- und Gewaltausübung ausgesetzt sind. Fiktive Darstellungen können, wenn sie ,gut gemacht" sind, beim Betrachter in gleicher Weise Nachahmungseffekte auslösen und teilweise sogar anregender sein und daher ,gefährlicher“, als die optische und akustische Wieder-

191 Hierzu ausführlich Liesching, JMS-Report 5/2008, 2; zur Änderung explizit im Bezug auf Posing Röder, NStZ 2010, 113; allgemein zu dem Umsetzungsgesetz Hörnle, NJW 2008, 3521.

192 Daher ist der vorliegenden Arbeit ist weiterhin die Definition eines Kindes nach $\int 176 \mathrm{StGB}$ ausschlaggebend für das Vorliegen von Kinderpornographie. Im gleichen Zuge zur Einführung des $\int 184$ c StGB wurde auch $\ 182$ StGB hinzugefügt, der den sexuellen Missbrauch von jugendlichen unter Strafe stellt. Zum gesamten Komplex Hörnle, NJW 2008, 3521; Spürck/Erdemir in: Nikles/Roll/Spürck/Erdemir/Gutknecht, Jugendschutzrecht, \184 c StGB, Rn. 1 ff.; Erdemir in: Spindler/Schuster, Recht der elektronischen Medien, 2011, \4 JMStV, Rn. 33.

193 Überblicksartig etwa Vormbaum, JZ 2008, 244; Röder, NStZ 2010, 113.

194 Definitionsversuch unter Heranziehung der gesetzgeberischen Erläuterungen zu „virtuelle Darstellungen“ iSd. JMStV, Amtl. Begr. JMStV abgedruckt bei Hartstein/Kreile/Ring/Dörr/Stettner, JMStV, C 1.3, S. 7.

195 In die Richtung auch Fischer, $\mathbb{1}$ 184b StGB, Rn. 5; Perron/Eisele in: Schönke/Schröder, $\ 184 \mathrm{~b}$ StGB, Rn. 3b; Hopf/Braml, ZUM 2007, 354 (359) in Bezug auf kindliche Avatarfiguren beim Online-Spiel Second-Life; Ritlewski, K\&R 2008, 94. 
gabe eines realen Geschehens. ${ }^{196}$ Zudem kann die bewusste Einsetzung fiktiver Bilder zur Verführung von Minderjährigen benutzt werden. Mit virtuellen Bildern kann dem Kind eine spezielle „Natürlichkeit und Harmlosigkeit“ des sexuellen Umgangs von Erwachsenen mit Kindern suggeriert werden, die pädophile Nutzer dazu gebrauchen können „Kinder für den beabsichtigten Missbrauch gefügig zu machen“. ${ }^{197}$ Vor allem sprechen aber systematische Gründe für die Einbeziehung der virtuellen Kinderpornographie in den Straftatbestand des $\int 184 \mathrm{~b}$ StGB. Entsprechend \ 184b Abs. 2 sowie Abs. 4 StGB ist das sich beziehungsweise einem anderen Besitzverschaffen von kinderpornographischen Schriften unter Strafe gestellt, die ein wirkliches oder wirklichkeitsnahes Geschehen wiedergegeben (sog. Realpornographie). ${ }^{198}$ Die gesetzliche Beschränkung schließt eine Strafbarkeit dann aus, wenn das beschaffte Material lediglich „Fiktivpornographie“ darstellt (wirkliches Geschehen); oder für den objektiven Betrachter nicht sicher auszuschließen ist, dass der Abbildung ein echter Missbrauch zu Grunde liegt (wirklichkeitsnahes Geschehen). ${ }^{199}$ Die tatbestandliche Eingrenzung der Tathandlung des Besitzes auf Realpornographie, soll eine unangemessene Strafbarkeit ausschließen. ${ }^{200}$ Im Umkehrschluss führe die mangelnde Begrenzung des Herstellungs- und Verbreitungsverbots in $\ 184 \mathrm{~b}$ Abs. 1 StGB auf ein wirkliches oder wirklichkeitsnahes Geschehen dazu den Tatalternativen auch den Bereich der virtuellen Kinderpornographie zuzuordnen. ${ }^{201}$

196 Hopf/Braml, ZUM 2007, 354 (359) in Bezugnahme auf Fischer, $₫ 184 b$ StGB, Rn. 2.

197 Fischer, \184b StGB, Rn. 2; Perron/Eisele in: Schönke/Schröder, \184b StGB, Rn. 3b; Ritlewski, K\&R 2008, 94; zusammenfassend Hopf/Braml, ZUM 2007, 354 (359) mwN.

198 Hierzu BT-Drs. 12/4883, S. 8; BT-Drs. 13/7385, S. 60, 72.

199 Hörnle in: Münch. Komm. StGB, \184b StGB, Rn. 27; Laubenthal, Sexualstraftaten, 2000, Rn. 874; Schreibauer, Das Pornographieverbot des $₫ 184$ StGB, 1999, S. 141.

200 Die Bestrafung des bloßen Besitzes von Material das offenkundig, fiktionaler Natur ist, etwa Comics, computeranimierte Filme, Gedichte oder Tonbandaufnahmen, wäre schon verfassungsrechtlichen Bedenken in Bezug auf das Allgemeinen Persönlichkeitsrechts sowie die Eigentumsfreiheit des Inhabers ausgesetzt. BT-Drs. 12/4883, S. 8 entgegen BT-Drs. 12/3001, S. 3. In diese Richtung, Schreibauer, Das Pornographieverbot des $₫ 184$ StGB, 1999, S. 142; BT-Drs. 12/4883, S. 8, beide ohne nähere Begründung.

201 So Perron/Eisele in: Schönke/Schröder, \184b StGB, Rn. 11; nach Fischer, $\ 184 b$ StGB, Rn. 6 spricht auch das Gesamtkonzept eines umfassenden Kindesschutz für die Einbeziehung der Fiktivkinderpornographie. Wenn aufgrund des umfassenden Kindesschutz letztlich auch Scheinkindlichkeit der Protagonisten ausreicht, so muss im Umkehrschluss auch Fiktivkinderpornographie ausreichen, da auch hierbei objektiv betrachtet keine Kinder unter 14 Jahren sexuell ausgebeutet und zur Schau gestellt werden. 
b) Spezialgesetzliche Ausgestaltung

In Korrespondenz zu strafrechtlichen Sanktionen wird auch ein landesrechtliches Schutzkonzepts verfolgt, dass die Verbreitung von Kinderpornographie mit rechtlichen Sanktionen belegt. Im Mittelpunkt steht hier der Jugendmedienschutzstaatsvertrag (JMStV). Dieser bildet ein gesamtlandesrechtliches Regelungskonstrukt, das sich entsprechend der Zweckbestimmung in $\$ 1 \mathrm{JMStV}$, der Schaffung eines einheitlichen Rechtsrahmens für den Jugendschutz in elektronischen Medien verschrieben hat. ${ }^{202}$ Die Legislative hat durch $\$ \int 4$ und $5 \mathrm{JMStV}$ definiert, welche Darstellungen als jugendgefährdend im Rechtssinne gelten und nicht frei über elektronische Medien verbreitet werden dürfen und diese Wertung mit Restriktionen verbunden. Unbeschadet einer strafrechtlichen Verantwortlichkeit sind danach in $₫ 4$ Abs. $1 \mathrm{~S}$. $1 \mathrm{JMStV}$ absolut unzulässige Angebote verankert. ${ }^{203}$ Hierbei bilden die $\int 4$ Abs. 1 Nr. 1 bis 6 und Nr. 10 mit dem Strafgesetzbuch korrespondierende Verbote. ${ }^{204}$ Entsprechend $\ 4$ Abs. 1 Nr. 10 JMStV gilt die Kinderpornographie als absolut unzulässiges Angebot. Danach sind Angebote unzulässig, die „den sexuellen Missbrauch von Kindern oder Jugendlichen (...) zum Gegenstand haben." Hinsichtlich des Tatbestandes weicht die Norm damit von der nach dem Umsetzungsgesetz ${ }^{205}$ geltenden strafrechtlichen Fassung des $\int 184 \mathrm{~b}$ StGB ab, da diese die tatbestandliche Anknüpfung an einen reellen Missbrauch im Sinne des $\int 176$ StGB aufgegeben hat. ${ }^{206}$ Eine inhaltliche Angleichung an die Strafrechtsdogmatik ist im Rahmen des JMStV bislang nicht erfolgt. ${ }^{207}$ \$ 4 Abs. 1 S. 1 Nr. 9

202 Gilt demnach auch für den elektronischen Bereich des Internets. Insbesondere WWWAngebote, Mobilfunkinhalte, Angebote zur Nutzung anderer Netze, wie bspw. Intranet oder sonstige Benutzergruppen, hierzu Liesching/Schuster,Jugendschutzrecht, $\ 2$ JMStV, Rn. 1.

203 Gem. $\int 4$ Abs. 1 S. 2 JMStV besteht für die Angebote des $\ 4$ Abs. 1 Nr. 1 bis 6 die Ausnahme der Sozialadäquanz. Danach ist eine Verbreitung unter bestimmten engen Voraussetzungen ausnahmsweise zulässig. Angebote der Nr. 1-4 und Nr. 6 sind zulässig, sofern dies zum Zwecke der staatsbürgerlichen Aufklärung, der Abwehr verfassungswidriger Bestrebungen, der Kunst, Wissenschaft, Forschung und Lehre, der Berichterstattung über Vorgänge der Zeitgeschehens oder der Geschichte oder zu ähnlichen Zwecken erforderlich ist, vgl. \86 Abs. 3 StGB. In den Fällen des Nr. 5, wenn die Verbreitung der Berichterstattung über Vorgänge des Zeitgeschehens oder der Geschichte dient, vgl. \131 Abs. 3 StGB.

204 Namentlich $\int 86 \mathrm{a}$ StGB - Verwenden von Kennzeichen verfassungswidriger Organisationen, \130 StGB - Volksverhetzung, \131 StGB - Gewaltdarstellungen, \130a StGB - Anleitung zu Straftaten sowie $\$ \int 184 \mathrm{a} f$. StGB - Harte Pornographie.

205 Gesetz zur Umsetzung des „Rahmenbeschlusses des Rates der Europäischen Union zur Bekämpfung der sexuellen Ausbeutung von Kindern und Jugendlichen und der Kinderpornographie“"vom 31.03.2008, BGBl. I 2008, S. 2149; hierzu bereits oben unter S. 18 ff.

206 Hierzu Liesching/Schuster, Jugendschutzrecht, \4 JMStV, Rn. 10 ff.

207 In einem Entwurf zur Novelle des JMStV war die Angleichung vorgesehen, der jedoch kurz vor in Kraft treten gescheitert ist. Der gescheiterte JMStV-Entwurf basierte auf einer Evaluation der 
JMStV benennt zudem explizit Darstellungen von „Kinder[n] oder Jugendliche[n] in unnatürlich geschlechtsbetonter Körperhaltung" als eigenständigen Verbotstatbestand auf. Hierbei handelt es sich um „erotographische“ Inhalte unterhalb der Schwelle der Pornographie. ${ }^{208}$ Letztlich korrespondiert das Verbot, mit dem strafrechtlichen Verbot des $₫ 184 \mathrm{~b}$ StGB, der auch das „Posing“ beinhaltet.209 Auch führt $\ 4$ Abs. 1 Satz 1 Nr. 9 und 10 JMStV explizit virtuelle Darstellungen auf. Im Ergebnis stellen die Anforderungen des $₫ 4$ Abs. 1 S. $1 \mathrm{JMStV}$ in Bezug auf Kinderpornographie und die strafrechtliche Verbotsnorm des $\$ 184 \mathrm{~b}$ StGB eine rechtliche Kongruenz dar. Verstöße gegen das Verbreitungsverbot sind unbeschadet strafrechtlicher Verantwortlichkeit als Ordnungswidrigkeit gem. \24 Abs. 1 Nr. 1j JMStV zu ahnden.

\section{Bemübungen im Bereich der Kriminalpolizei}

Neben einem sanktionsrechtlichen Rechtsrahmen umfasst das vom Gesetzgeber verfolgte Gesamtkonzept zur Vorbeugung der sexuellen Ausbeutung von Kindern im Bereich der Kinderpornographie auch eine flächendeckende Unterstützung durch Kriminalbehörden. Hierfür unterhält das Bundeskriminalamt als Zentralstelle der Polizeidienststellen von Bund und Ländern eine „Zentralstelle Kinderpornographie“, deren vordergründige Aufgabe die „Identifizierung von Täter und Opfern im Rahmen der Auswertung im In- und Ausland sichergestellter Dateien, die sexuelle Missbrauchshandlungen an Kindern zeigen" ist. ${ }^{210}$ Der Schwerpunkt der Arbeit der Zentralstelle liegt auf der Durchsuchung und gezielten Lokalisierung neuen Bildmaterials im Gesamtbestand des Internets, um Täter zeitnah einer Bestrafung aus $₫ 176$ StGB sowie $₫ 184 b$ StGB zuzuführen. Sollten bei Recher-

\footnotetext{
bisherigen Gesetzesfassung aus dem Jahr 2008. Nach vorangegangenen Debatten wurde die Gesetzesfassung im Rahmen des 14. Rundfunkänderungsstaatsvertrages überarbeitet und mit zahlreichen Ergänzungen und Änderungen versehen. Zu den einzelnen Novellierungen überblicksartig Erdemir, K\&R 5/2010, Editorial. Nachdem sich gegen die geplanten Neuregelungen zahlreiche Kritik aus der Gesellschaft sowie den beteiligten Verbänden äußerte, wurde die Fassung noch einmal überarbeitet und letztlich durch die Ministerpräsidenten im Juni 2010 ratifiziert. Obgleich die ausstandende Zustimmung aller Bundesländer „als reine Formsache“ galt, verweigerte der nordrhein-westfälische Landtag am 16.12.2010 aufgrund „rechtlicher Bedenken“ überraschend die Zustimmung zum 14. RÄStV und damit auch zum JMStV. Der bisher geltende Staatsvertrag bleibt somit weiterhin uneingeschränkt in Kraft, ausführlich Hopf, K\&R 2011, 6 . Entwurfsfassung abrufbar unter:

http://www.telemedicus.info/uploads/Medien/Entwurf_JMStV_Stand_25-03-2010.pdf (zuletzt abgerufen 20.5.2012).

208 Amtl. Begründung JMStV abgedruckt in: Hartstein/Ring/Kreile/Dörr/Stettner, JMStV, C 1.3, S. 7.

209 Hierzu oben S. 18 ff. Durch die explizite Einbeziehung von Kindern und Jugendlichen entspricht das Schutzkonzept des JMStV auch den Vorgaben des Rahmenbeschlusses der EU.

BKA, Stellungnahme der Experten, Ausschussdrucksache 16 (9) 1549, S. 2.
}

210 
chen des BKA kinderpornographische Inhalte gesichtet werden, die sich auf deutschen Servern befinden, so leitet das BKA die entsprechenden strafrechtlichen Maßnahmen gegen die Anbieter ein und wirkt auf eine unverzügliche Löschung des inkriminierten Inhalts durch den jeweiligen Provider (Internetdiensteanbieter) hin. Im Bereich der Bekämpfung von Kinderpornographie arbeitet das BKA eng mit Nicht-Regierungs-Organisationen $(\mathrm{NGO})^{211}$ zusammen. Neben entsprechenden transnational tätigen Opferschutzorganisationen, wie beispielsweise INHOPE, ${ }^{212}$ bei denen Präventivmaßnahmen zum Schutze der Kinder vor sexueller Gewalt sowie Opferbetreuung im Vordergrund stehen, wird zur gezielten Strafverfolgung auch die Zusammenarbeit mit Kreditkartenunternehmen und Firmen forciert, die für die Abwicklung des internetvermittelten Zahlungsverkehrs zuständig sind. Durch die Einbeziehung soll eine möglichst genaue Identifizierung von Nutzern kommerziell betriebener kinderpornografischer Webseiten erreicht werden. ${ }^{213} \mathrm{Zu}$ Ermittlungszwecken unterhält das BKA zudem eine nationale Bilddatenbank. Kinderpornographisches Bildmaterial mit bereits identifizierten Tätern, kann zur Aufdeckung neuer Straftaten beitragen, indem vergleichbare Vorgehensweisen der Täter analysiert werden. ${ }^{214}$ Bedingt durch die globale Verbreitung des Internets, erstrecken sich die Bemühungen der Kriminalpolizei auch auf die internationale Ebene. Ausländische Kriminalbehörden können zur Bekämpfung von Kinderpornographie über eine internationale geführte Bilddatenbank, die seit März 2009 in Betrieb ist, gezielt Anhaltspunkte zur Aufklärung von Straftaten sammeln. Daneben sind auch überstaatliche Koordinationsbemühungen unter Einbeziehung von Interpol im Präventionsbereich zu verzeichnen, wie etwa gezielte fallbezogene Abwehrmaßnahmen. Verstärkt werden auch regelmäßige Fachgremien und Expertentagungen gefördert, die einen umfangreichen Erfah-

211 Zur Begriffserläuterung im europäischen Kontext, Horn, Vereinte Nationen, 2007, S. 39; Kubn, Entwicklungspolitik, 2005, S. 56 ff. Es handelt sich dabei um internationale privatrechtliche Organisationen, die zwar nicht durch eine öffentliches Mandat legitimiert sind, jedoch die universelle Gesellschaftsinteressen vertreten und insbesondere auf transnationaler Ebene Einfluss auf den politischen Meinungsprozess haben, Anzahl und Hintergrundinformationen Bundeszentrale für politische Bildung, abrufbar unter:

http://www.bpb.de/wissen/3UD6BP,0,0,NichtRegierungsorganisationen_\%28NGOs\%29.html (zuletzt abgerufen 20.5.2012).

212 InHope bildet ein weltweitaktives Netzwerk, in dem sich Internet-Beschwerdestellen aus 29 Ländern zusammengeschlossen haben, um gemeinsam Hinweisen auf Täter und Beteiligte u.a. kinderpornographischer Inhalte an die Strafverfolgungsbehörden weiterzureichen, hierzu Süme, MMR 2009, 1, Erdemir in: Eifert/Hoffmann-Riem, Innovation, Recht und öffentliche Kommunikation, 2011, S. 27 (38).

213 BKA, Ausschussdrucksache 16 (9) 1549, S. $2,3$.

214 Ausführlich BKA, Ausschussdrucksache 16 (9) 1549, S. $2,3$. 
rungsaustausch mit den Kriminalitätserfahrungen im globalen Cyberspace ermöglichen sollen. ${ }^{215}$

\section{Rechtsrahmen für technische Präventivmaßnahmen}

Neben der Strafandrohung sowie internationalen Strafdurchsetzung mithilfe der Kriminalpolizei, wird immer wieder auch die Möglichkeit einer direkten technischen Einflussnahme auf den Kommunikationsprozess im Internet diskutiert, welche effektiv zur Eindämmung der Kinderpornographie führen kann: Die Entfernung oder zumindest die technische Unterdrückung des Zugriffs auf entsprechendes Material.

Einen diesbezüglichen Rechtsrahmen hat der Landesgesetzgeber über das im JMStV verfolgte Schutzkonzept bereits geschaffen. Sollte ein Verstoß gegen das absolute Verbreitungsverbot des $\int 4$ Abs. 1 Satz 1 Nr. 10 JMStV vorliegen, 216 kann die zuständige Behörde entsprechend \20 Abs. 4 i.V.m. \59 Abs. 2 bis 4 $\mathrm{RStV}$ einzelfallbezogene Verwaltungsakte mit dem Inhalt der Verpflichtung der jeweiligen Diensteanbieter zur Sperrung und Untersagung des Angebotes erlassen. ${ }^{217}$ Den technischen Gestaltungsrahmen zur Vornahme der Verpflichtung hat der Gesetzgeber technologieneutral formuliert. So muss die vorgenommene inhaltsbeschränkende Maßnahme (Sperrung oder Untersagung) lediglich „technisch möglich und zumutbar“ sein. ${ }^{218}$ Welche technischen Mittel der Diensteanbieter zur Erfüllung der Verpflichtung im Einzelnen hat, bleibt anhand der gesetzlichen Formulierung offen und muss vom jeweiligen Diensteanbieter selbst ermittelt werden.

Das im JMStV zugrunde gelegte Konzept technischer Maßnahmen mit dem Ziel der Herausnahme der kinderpornographischen Angebote aus dem Gesamtbestand des Internets, basiert auf einer einzelfallbezogenen Vorgehensweise, die die Entscheidung, ob ein bestimmtes Angebot den Anforderungen der Kinderporno-

215 Zum gesamten Komplex BKA, Stellungnahme der Experten, Ausschussdrucksache 16 (9) 1549, S. 3; Bemühungen auch den Pressemitteilungen des BKA zu entnehmen abrufbar unter: http://www.bka.de/ (zuletzt abgerufen 20.5.2012), z.B. PM v. 7.5.2010 „Internationaler Fahndungserfolg im Kampf gegen sexuellen Missbrauch und Kinderpornographie; PM v. 30.9.2010, „Bundeskriminalamt zerschlägt Kinderpornographie-Ring“.

216 Der technische Rechtsrahmen nach dem JMStV ist keineswegs nur auf den Bereich der Kinderpornographie beschränkt, sondern findet bei sämtlichen Verstößen gegen Regelungen des JMStV Anwendung. Aufgrund des Schwerpunkts der Arbeit wird die Darstellung lediglich auf den Bereich der Kinderpornographie fokussiert.

217 Zur Aussichtsrechtlichen Generalklausel u.a. Liesching/Schuster, Jugendschutzrecht, \20 JMStV, Rn. 1 ff.; speziell in Bezug auf inhaltsbeschränkende Maßnahmen, Sieber/Nolde, Sperrverfügungen im Internet, 2008, S. 91 ff.; ebenfalls Frey/Rudolph, Rechtsgutachten BVDW, 2008, Rn. 35.

218 So der Wortlaut $₫ 59$ Abs. 4 Satz 1 RStV aE. 
graphie entspricht und daher aus dem Internet herauszunehmen ist, ins Ermessen der zuständigen Behörde, der KJM²19, stellt.

In Anbetracht der weitreichenden Gefahren der ungehinderten Verbreitung von Kinderpornographie und der erklärten gesetzgeberischen Intention „gegen die sexuelle Ausbeutung von Kindern im Internet muss mit allen Mitteln vorgegangen werden", 220 kommen jedoch immer wieder Forderungen auf, die gesetzlichen Handlungsbefugnisse zur Vornahme technischer Eingriffe speziell auf den Bereich der Kinderpornographie auszuweiten und nicht lediglich als Nebenmaterie innerhalb eines jugendschützenden Gesamtkonzepts zu verwirklichen. ${ }^{221}$

Nachdem anfänglich Selbstverpflichtungsvereinbarungen der Diensteanbieter zur Vornahme von gezielten technischen Sperrungen kinderpornographischer Inhalte favorisiert wurden, 222 wurde kurze Zeit darauf die Möglichkeit eines einheitlichen Sperrgesetzes diskutiert. Wesentlicher Vorteil gegenüber dem bereits im JMStV angelegten Konzept wäre danach die einheitliche Verpflichtung aller Diensteanbieter zur Vornahme technischer inhaltsbeschränkender Maßnahmen zur Unterbindung der von kinderpornographischen Material ausgehenden Gefahren. Ein diesbezüglicher Umsetzungsversuch wurde durch das Gesetz zur Erschwerung des Zugangs zu kinderpornographischen Inhalten in Kommunikationsnetzen (sog. Zugangserschwerungsgesetz - ZugErschwG) ${ }^{223}$ tatsächlich unternommen.224 Die gesetzliche Verpflichtung der Diensteanbieter zur Vornahme von Sperrungen war ähnlich konzipiert, wie die Verpflichtung nach dem JMStV. Die technische Ausgestaltung der Sperrung blieb auch hier den Diensteanbietern überlassen. Allerdings nannte das Gesetz eine Mindestanforderung an die technische Umsetzung der Sperrung: Die Sperrung hatte zumindest auf der Ebene der vollqualifizierten Domainnamen zu erfolgen. Was darunter zu verstehen war, ließ das

219 Gem. $\int 14 \mathrm{JMStV}$ handelt es sich bei der KJM (Kommission für Jugendmedienschutz) um ein Hilfsorgan der Landesmedienanstalten bei der Aufgabenerfüllung (vgl. auch $₫ 35$ Abs. 1 S. 1 Nr. 4, S. 2 RStV). Zur KJM ebenfalls Sieber/Nolde, Sperrverfügungen im Internet, 2008, S. 58.

220 So die Begr. BT-Drs. 16/12850, S. 5.

221 Die Debatte wurde insbesondere durch die damals amtierende Bundesfamilienministerien Ursula von der Leyen initiiert, zu den vorherigen Diskussionen vgl. Zusammenfassung bei BT-Drs. 16/12850, S. 5; Marbeth-Kubicki, NJW 2009, 1792.

222 So hatten sich Anfang 2008, die fünf größten Zugangsanbieter mit dem BKA auf Selbstverpflichtung zur Vornahme von Sperrungen kinderpornographischen Onlinematerials verständigt, hierzu BT-Drs. 16/12850, S. 12; zusammenfassend Marbeth-Kubicki, NJW 2009, 1792; Süme, MMR 2009, 1.

223 BGBl. I 2010, S. 78.

224 BT-Drs. 16/12850, Gesetz zur Bekämpfung der Kinderpornographie in Kommunikationsnetzen (nachfolgend Vorgänger ZugErschwG), BT-Drs. 16/13411 (ZugErschwG). Zu den einzelnen Problemen der Umsetzung, sowie zur rechtlichen Ausgestaltung, vgl. Teil 3 der Ausarbeitung, S. $34 \mathrm{ff}$. 
Gesetz jedoch offen. Wesentlicher Unterschied des ZugErschwG zum JMSTV war die ausdrückliche Beschränkung der Sperrverpflichtung auf kinderpornographische Inhalte nach $\$ 184 \mathrm{~b}$ StGB sowie die gesetzliche Ausgestaltung als unmittelbarer gesetzlicher Verpflichtung, im Gegensatz zu einer einzelfallbezogenen Verwaltungsaktsbefugnis der Exekutivbehörde. ${ }^{225}$ Obgleich das Gesetz dem ersten Anschein nach ein legislatorisches Gesamtkonzept zur Sperrung kinderpornographischer Inhalte darstellen sollte, ist es kurz nach seinem Inkrafttreten Anfang 2010 überraschend ,ausgesetzt“ worden und wurde daraufhin „,nicht angewendet", ehe des schließlich aufgehoben wurde. 226

IV. Ergebnis und Ausblick

Die oberen Ausführungen zeigen, dass die ungehinderte Verbreitung von Kinderpornographie im Internet einen erhöhten Gefährdungsbereich für Kinder- und Jugendliche eröffnet.

Aufgrund der Überschneidung zwischen der Produktion des kinderpornographischen Angebotes und einer tatsächlichen Vornahme sexueller Handlungen der kindlichen Protagonisten sind Beeinträchtigungen der körperlichen und geistigen Integrität sowie des sexuellen Selbstbestimmungsrechts von Kindern möglich. Die anschließende Verbreitung des Materials und der ungehinderte Umlauf solcher Angebote im Internet, können negative Beeinträchtigungen der Persönlichkeitsentwicklung von Kindern sowie die latente Gefahr der mittelbaren Förderung zukünftigen Kindesmissbrauchs durch Nachahmungseffekte beim Rezipienten begründen. Schon die Annahme etwaiger Gefahren verpflichtet den Staat aufgrund seiner verfassungsrechtlichen Schutzpflicht zum Jugendschutz zur Schaffung eines geeigneten Rechtsrahmens, der diese Gefahren bestmöglich relativiert. Aufgrund der starken Intensität der Gefährdung, kann der Gesetzgeber auch besonders intensive Maßnahmen zur Abwehr der Gefahren gesetzlich statuieren. Der Gesetzgeber wählte ein Gesamtkonzept, das sowohl repressive Komponenten, wie auch präventive technische Eingriffsbefugnisse beinhaltet. Daneben sind auch Bemühungen der Kriminalpolizei zu verzeichnen, die vor allem auf die globale Eindämmung der Kinderpornographie durch Einbeziehung privater Organisationen ausgerichtet sind.

Im Folgenden sollen die gesetzlichen Umsetzungsmechanismen, die dem Rechtsrahmen für technische Eingriffe in dem Kommunikationsprozess zugrundliegen untersucht werden. Hierfür ist es notwendig zunächst die technischen Grundlagen des Eingriffs in den Internetbestand zu erläutern. Die Darstellung beschränkt sich hierbei auch diejenigen Grundlagen, die für das weitere verfas-

225 Hierzu Volkmann in: Spindler/Schuster, Recht der elektronischen Medien, 2011, Vorb. ZugErschwG, Rn. 4.

226 An dieser Stelle sollen diese Andeutungen genügen. Auf die einzelnen Punkte wird unter detailliert eingegangen. 
sungsrechtliche Vorgehen notwendig sind, setzt jedoch ein gewisses technisches Grundverständnis für den Prozess der Datenverarbeitung im Internet voraus.

\section{B. Technische Grundlagen}

Im Rahmen der technischen Realisierung der Zugriffserschwerung bezüglich kinderpornographischer Onlineinhalte kommen vor allen drei verschiedene technische Sperrvarianten in Betracht: ${ }^{27}$ Der Ausschluss von Domainnamen im Domain Server (DNS Sperre), die Möglichkeit des Ausschlusses der angesteuerten IP-Adresse durch entsprechende Konfiguration des Routers (IP-Blocking), sowie die Filterung illegaler Inhalte durch Verwendung eines Proxy-Servers (ProxyServer-Sperren).

\section{Systematische Einordnung der Datenübertragung im Internet}

Zur Systematisierung technischer Vorgänge während der Datenübertragung im Internet bedient sich die Informatik eines theoretischen Denkansatzes: Der Datentransport wird aufgegliedert und einem theoretischen Schichtenmodell zugeordnet. Die Datenübertragung wird dabei im Rahmen jeder Schicht in einzelne Schritte unterteilt, innerhalb derer, so genannte Protokolle (Protocol) für die Umsetzung der verschiedenen Funktionen der Datenübertragung- und Verarbeitung

227 Die Auswahl der nachstehenden Sperrmethoden lehnt an die Vorgaben der „Düsseldorfer Sperrverfügungen“ aus dem Jahr 2002 an. Die damalige Bezirksregierung Düsseldorf hatte gem. dem damals geltenden $₫ 18$ Abs. 2 u. $3 \mathrm{MDStV}$ - in ihrer Eigenschaft als Aufsichtsbehörde - zur Bekämpfung rechtsradikaler und jugendgefährdender Webseiten, gegen alle in NordrheinWestfalen ansässigen Access-Provider, Sperrverfügungen zur Verhinderung des Zugriffs auf die entsprechenden Seiten erlassen. Die fraglichen Webseiten hatten stark nationalsozialistischen Charakter und boten u.a Adolf Hitlers „Mein Kampf“ sowie diverse volksverhetzende Computerspiele zum unentgeltlichen Download an. Zudem wurde die Vorherrschaft der „Weißen Rasse" propagiert und zum Boykott jüdischer Lebensmittelprodukte aufgerufen. Die Webseiten waren speziell kinderfreundlich und trugen damit stark jugendgefährdenden Charakter. Aufgrund der US-amerikanischen Herkunft der Webseiten handelte, war ein vorrangiges Vorgehen gegen die betreffenden Content-Provider nicht möglich, so dass die Sperranordnungen an die des Zugangs vermittelnden Access-Provider gerichtet waren. Musteranordnung mit einer Auflistung der hier gewählten Sperrmethoden gegen Oberon.net GmbH abrufbar unter:

http://www.artikel5.de/rohetexte/sperrverfueg.pdf, S. 7 (zuletzt abgerufen 20.5.2012), zusammenfassend Koreng, Zensur im Internet, 2010, S. 121, Mankowski, MMR 2002, 277; intensive Auseinandersetzung bei Billmeier, Die Düsseldorfer Sperrungsverfügung, 2007. 
zuständig sind.228 In der Praxis haben sich zum Verständnis des komplexen Ablaufs im Wesentlichen zwei theoretische Schichten-Modelle durchgesetzt: Das ISO/OSI-Referenzmodell und das TCP/IP-Modell. ${ }^{229}$

Das TCP/IP-Modell bildet die vereinfachte Version der komplexen Netzarchitektur. Es stellt die Basis der Kommunikation im Internet dar und genügt als Grundmodell zum Verständnis der juristischen Auseinandersetzung mit Sperrmethoden. ${ }^{230}$

Das TCP/IP-Modell basiert auf einem vierteiligen Schichtenmodell, welches die Verarbeitung und Darstellung der angefragten Information erläutert. Netzarchitektonisch differenziert man hierbei zwischen der Anwendungs-, Transport-, Internet-, sowie Verbindungsschicht. ${ }^{231}$

Vereinfacht betrachtet, erfordert das dem TCP/IP-Protokoll zugrundeliegende Modell, dass die Daten vom sendenden Rechner, etwa durch Eingabe eines Wortes in die Tastatur (z. B. Kinderpornographie), in einzelne Datenpakete fragmentiert, nacheinander - angefangen bei der Anwendungsschicht - über die einzelnen Schichten hinweg, bis zur niedrigsten Schicht - der Verbindungsschicht - weitergegeben und dort in Form elektromagnetischer Impulse in die niedrigste Schicht des an der Kommunikation beteiligten Empfängers (etwa des Webservers, der die angeforderten kinderpornographischen Webseiten beherbergt ${ }^{232}$ übermittelt werden. An dieser Stelle wird der Datenverarbeitungsprozess praktisch entgegensetzt wieder eingeleitet, bis die Darstellung und Weiterverarbeitung der Daten auf der Anwendungsschicht des Empfängers vorgenommen werden kann. ${ }^{233}$

Darstellend Pfitzmann/Köpsell/Kriegelstein, Sperrverfügungen gegen Access-Provider - Technisches Gutachten, S. 12; gleiche schematische Darstellung bereits bei Sieber, Verantwortlichkeit im Internet, 1999, Rn. 38.

Das ISO/OSI-Referenzmodell basiert auf einem 7 Schichten-Modell, die einzelnen durchlaufen werden und damit letztlich technisch den Datenübertragungsvorgang durch Verarbeitung kleinster Impulse „Bits“ zu letztlich auf den Rechner sichtbaren Informationen ermöglichen. Ausführliche Erläuterung jeder einzelnen Schicht und ihrer spezifischen Funktion für die Datenübertragung bei Sieber, Verantwortlichkeit im Internet, 1999, Rn. 24 ff.; Schematische Aufbereitung derselben, Rn. 34; Informationstechnische Zusammenfassung: Peterson/Davie, Computernetze, 2008, S. 27. Ebenso Sievers, Der Schutz der Kommunikation im Internet, 2003, S. 38 ff.

230 Sieber/Nolde, Sperrverfügungen im Internet, 2008, S. 37; Sieber, Verantwortlichkeit im Internet, 1999, Rn. 37 ff.

231 Sieber, Verantwortlichkeit im Internet, 1999, Rn. 34; darauf bezugnehmend Sieber/Nolde, Sperrverfügungen im Internet, 2008, S. 37; ausführlich auch Peterson/Davie, Computernetze, 2008, S. 28 ff., der jede Schicht einzeln und detailliert erläutert.

232 Als Webserver bezeichnet man Computersysteme, die World Wide Web-Seiten anbieten, Sieber, Verantwortlichkeit im Internet, 1999, Rn. 43.

233 Mantr, Rechtsfragen offener Netze, 2008, S. 23. 
Obgleich es sich bei der netzarchitektonischen Analyse der Datenübertragung im Internet um ein kompliziertes und stark technisiertes Konstrukt handelt, dass ein detailliertes technisches Grundverständnis voraussetzt, ist es für die juristische Argumentation hinsichtlich einzelner Sperrmethoden unabdingbare Voraussetzung. Wie die Analyse zeigen wird, setzten die durchführbaren Sperrmethoden an bestimmten Schichten des TCP/IP-Modells an und basieren damit auf einem unmittelbaren Eingriff in die Funktionsweise der dort befindlichen Protokolle. Demnach müssen nachfolgend zunächst die Funktionen der einzelnen Schickten grob skizziert werden, ehe sich die Bearbeitung einer Erläuterung der tatsächlichen Funktionsweise der Sperrmethoden widmen kann.

\section{Funktionen einzelner Schichten}

a) Verbindungsschicht

Auf der untersten Ebene des gestuften Datentransfers ist die Verbindungschicht angesiedelt. Diese dient dem Verbindungsaufbau zwischen zwei miteinander kommunizierenden Rechnern. Für den eigentlichen Übertragungsvorgang wird die Information (z.B. die Anfrage zum Erhalt einer bestimmten Webseite (sog. Request)) in Form der kleinsten Informationseinheiten der so genannten Bits in das Netzwerk eingespeist. Hierfür können verschiedene physikalische Medien eingesetzt werden, welche die Bitströme in Form von elektromagnetischen, optischen oder elektrischen Impulsen in den Kommunikationsprozess über Kupfer-, Glasfaserkabel, Funknetze und Laserstrahlen in den Kommunikationsvorgang einbringen. ${ }^{234}$ Für die Herstellung eines Verbindungsaufbaus ist auf beiden Seiten der Kommunikationspartner eine entsprechende Hard- beziehungsweise Software notwendig, die mittels verschiedener Protokolle verbunden wird. ${ }^{235}$

Die Verbindungsschicht dient als Zuleitung für die - vom TCP/IP-Modell ausgehend - oberhalb angesiedelten Ebenen, insbesondere als Leitung für die unmittelbar darüber liegende Internetschicht. ${ }^{236}$

234 Tanenbaum, Computernetzwerke, 2009, S. 110 ff., S. 113 (Kupfer), S. 116 (Glasfaser), S. 124 (Funk); schematische Darstellung des Übertragungsvorgangs im Allgemeinen Sieber, Verantwortlichkeit im Internet, 1999, Rn. 34; Sieber/Nolde, Sperrverfügungen im Internet, 2008, S. 37; Schneider, MMR 1999, 571.

235 Etwa ein Router, Modem o.̈. Auf der Verbindungsschicht sind u.a. folgende Protokolle aktiv: das Point to Point Protocol (PPP), das Password Authentication Protocol (PAP) sowie das Address Resolution Protocol, ausführlich und in Abgrenzung zueinander Pfitzmann/Köpsell/Kriegelstein, Sperrverfügungen gegen Access-Provider - Technisches Gutachten, S. 13 .

236 Tanenbaum, Computernetzwerke, 2009, S. 55. 
b) Internetschicht

Die sich anschließende Internetschicht hat die grundlegende Aufgabe, Datenpakete vom Quellhost (Absender) zum Zielhost (Empfänger) zu übertragen. Diese Aufgabe wird innerhalb der Internetschicht von dem ersten wichtigen Basisprotokoll des TCP/IP-Modells dem Internet Protocol (IP = Datenübertragungsprotokoll) vorgenommen. IP übernimmt die Einspeisung der Daten in ein beliebiges Netzwerk und ist damit für den Austausch der Daten zuständig. ${ }^{237}$ Die Internetschicht bildet einen verbindunglosen Dienst. Die Eigenart eines verbindungslosen Dienstes ist davon bestimmt, dass IP die einzelnen Datenpakte nicht als zusammenhängendes Datengeflecht begreift. Für den Transport an den Empfänger speist IP die Datenpakete daher weder gebündelt noch aufeinander aufbauend in die nächstgelegene Schicht ein, sondern einzeln und unabhängig voneinander in verschiedene über Netzwerkknoten (sog. Router) verbundene Teilnetze. ${ }^{238}$ Die aus der Verbindungsschicht ankommenden Bitdatenströmen werden von IP in einzelne Datenpakete, so genannte Datagramme fragmentiert und separat über mehrere Knoten zum Empfänger weitergeleitet. Hierfür wählt das Protokoll für jedes Datagramm einzeln die beste verfügbare Transportroute vom Sender durch das Internet zum bestimmungsgemäßen Empfänger. Zu diesem Zweck berechnet IP die frei verfügbaren Leitungen anhand verschiedenster statischer und dynamischer Algorithmen, die Entfernung, Kapazität und Überlastungswahrscheinlichkeit der einzelnen Leitungen mit einbeziehen. ${ }^{239}$ Diese als Routing ${ }^{240}$ bezeichnete Datenübertragungstechnik ermöglicht, dass die über das Internet übermittelten Nachrichten möglichst nie vollständig an einem Übertragungsknoten (Router) gelangen, so dass diese auch nicht ohne Weiteres bereits während des Transports unbefugt ausgelesen werden können. ${ }^{241}$

Neben der beschriebenen Weiterleitungsfunktion ist insbesondere auch die Adressierung der Datagramme durch IP eine wichtige Schlüsselposition innerhalb

237 Sieber/Nolde, Sperrverfügungen im Internet, 2008, S. 38; Faber, Jugendschutz im Internet, 2005, S. 50 .

238 Tanenbaum, Computernetzwerke, 2009, S. 383.

239 Pfitzmann/Köpsell/Kriegelstein, Sperrverfügungen gegen Access-Provider - Technisches Gutachten, S. 14; Sieber, Verantwortlichkeit im Internet, 1999, Rn. 48; Tanenbaum, Computernetzwerke, 2009, S. 518 .

240 Pfitrmann/Köpsell/Kriegelstein, Sperrverfügungen gegen Access-Provider - Technisches Gutachten, S. 14; Mantz, Rechtsfragen offener Netze, 2008, S. 24, Peterson/Davie, Computernetze, 2008, S. 268; wobei dem Routing mathematische Algorithmen zur Berechnung der einzelnen Teilstrecken zugrundeliegen, auf die an dieser Stelle nicht näher einzugehen ist, im Einzelnen Tanenbaum, Computernetzwerke, 2009, S. 388 ff. mit ausführlicher Erläuterung der einzelnen Routingmechanismen; Sievers, Der Schutz der Kommunikation im Internet, 2003, S. 46.

241 Sieber, Verantwortlichkeit im Internet, 1999, Rn. 48; Mantz, Rechtsfragen offener Netze, 2008, S. 24. 
der netzarchitektonischen Datenübertragung. Der Bedienfreundlichkeit des Internets ist es geschuldet, dass die jeweilige Information über das Internet auch tatsächlich zum bestimmungsgemäßen Empfänger gelangt. Schickt der Nutzer beispielsweise eine Anfrage bezüglich des Erhalts einer bestimmten Webseite los, muss gewährleistet werden, dass der die Seite beinhaltete Webserver auch tatsächlich angesprochen wird und die Rückantwort in Form der Applikation der angeforderten Seite garantiert. Über IP werden die einzelnen Datenpakete daher praktisch „adressiert“. Das heißt IP erweitert die Datagramme um einen so genannten IP-Header. Dieser enthält die nummerische Zahlenfolge des Quell- und Zielhosts (absendender und empfangender Rechner), die als IP-Adresse bezeichnet wird. ${ }^{242}$ IP-Adressen sind eindeutig zugeordnete nummerische Dezimalzahlenfolgen, anhand derer jeder Router und jeder Computer (damit auch Webserver) der an das Internet angeschlossen und Teil des Netzwerks bildet, individualisiert und zugeordnet werden kann. ${ }^{243}$ Gelangen die von IP verschickten Datagramme an einen Router, so liest dieser die im IP-Header befindliche IP-Adresse des Zielhosts ab und kann so autonom über eine etwaige Weiterleitung des Datenpakets entscheiden. ${ }^{244}$

\section{c) Transportschicht}

Erst in der nachfolgenden Transportschicht wird eine zuverlässige und zielgerechte Kommunikation durch Zustellung der einzelnen Datenpakete ermöglicht. ${ }^{245}$ Damit kann die Transportschicht als Mittelpunkt der gesamten Protokollhierarchie bezeichnet werden. ${ }^{246}$ Wesentlich hierfür ist das dem TCP/IP-Modell namensgebende zweite wichtige Basisprotokoll, das Transmission Control Protocol $(\text { TCP }=\text { Übertragungssteuerungsprotokoll })^{247}$. Da die vorherige Internetschicht als verbindungsloser Dienst fungiert, die Daten damit als zusammenhanglose Teile und nicht als Gesamtgeflecht betrachtet, ist nicht sichergestellt, dass die weitergegebenen Datenpakete in der richtigen Reihenfolge und tatsächlich an den richtigen

242 Sieber, Verantwortlichkeit im Internet, 1999, Rn. 47.

243 Kirchberg-Lennarty/Weber, DuD 2010, 479; Sachs, CR 2010, 547; Degen, Freiwillige Selbstkontrolle, 2007, S. 146; Pfitżmann/Köpsell/Kriegelstein, Sperrverfügungen gegen Access-Provider - Technisches Gutachten, S. 14; Sieber, Verantwortlichkeit im Internet, 1999, Rn. 47, die für den Nutzer umständliche IP-Adresse wird umgewandelt in eine leicht zu merkende Domain, hierzu anschließend unter 2. Teil B. I. 2. a) . Der nummerische Aufbau einer IP-Adresse entspricht einer 32 Bit Länge, die üblicherweise als Dezimaldarstellung geschrieben wird, ausführlich Tanenbaum, Computernetzwerke, 2009, S. 480.

244 Sieber, Verantwortlichkeit im Internet, 1999, Rn. 147.

245 Sieber in: Hoeren/Sieber, Hdb. Multimedia-Recht, Teil 1, Rn. 45 ff.

246 Tanenbaum, Computernetzwerke, 2009, S. 520.

247 Auch als Ende-zu-Ende-Protokoll bezeichnet, Peterson/Davie, Computernetzwerke, 2008, S. 333; ausführlich Tanenbaum, Computernetzwerke, 2009, S. 580 ff. 
Adressaten zugestellt werden. Für eine fehlerfreie Darstellung der Daten beim entsprechenden Anwender, ist die Reihenfolge sowie die Adressierung der Daten jedoch unabdingbar. An dieser Stelle setzt das verbindungsorientierte TCP innerhalb der Transportschicht an. Es hat die grundlegende Aufgabe eine Fehler- und Flusskontrolle für die aus der Internetschicht übernommenen Daten zu gewährleisten. Hierfür fordert es während der Datenübertragung abhandengekommene Daten erneut an oder ordnet fälschlich zusammengesetzte Datenfolgen in der vorgesehenen Reihenfolge wieder zusammen. ${ }^{248}$ TCP formt dafür die ankommenden Datenpakete in einzelne Segmente und spezifiziert diese: So werden die Datensegmente mit der Quelle und dem Ziel der übermittelten Daten, einer so genannten Port-Nummern-Kennung sowie einer durchlaufenden Nummerierung versehen, so dass die Datenpakete auch bei etwaigen Netzstörungen entsprechend der Spezifizierung von TCP wieder zusammengesetzt und erneut versendet werden können. Ausschlaggebend für die anschließende Weiterverarbeitung auf der Anwendungsschicht - also für die Analysierung des Inhalts und Darstellung desgleichen beim Anwender - ist die Unterlegung der Datenpakete mit entsprechenden Port-Nummern durch das Protokoll TCP. Die Portnummern sind standardisiert, das heißt alltäglichen Anwendungen wie etwa E-Mail, Newsdienst oder Webserver sind bestimmte Port-Kennnummern zugeordnet. Auf der Anwendungsschicht ankommende Datensegmente können anhand der Port-Nummern richtig interpretiert und leicht in den gewünschten Dienst umwandelt werden. ${ }^{249}$ Kennzeichnendes Element des TCP ist demnach die Betrachtung des Datenverkehrs als Gesamtgeflecht, so dass die grundlegende Überwachungsfunktion der Flusskontrolle und die anschließende Möglichkeit der Zuordnung des jeweiligen

Dies geschieht anhand bestimmter Algorithmen auf die hier jedoch nicht näher eingegangen wird, hierzu Tanenbaum, Computernetzwerke, 2009, S. 584 ff.

Die Liste der reservierten Ports findet sich bei der Internet Assigned Numbers Authority (iana), einer Organisation, die für die Vergabe von IP-Adressen, TOP-Level-Domains und IPProtokollnummern zuständig ist, sowie die Zuordnung von Ports regelt, abrufbar unter www.iana.org: Die bekanntesten Dienste die bestimmten Postnummern zugeordnet werden, sind der nachfolgenden Tabelle zu entnehmen:

\begin{tabular}{|l|l|}
\hline Port & Zuordnung zum Dienst \\
\hline 21 & Datenübertragung \\
\hline 25 & E-Mail Dienst \\
\hline 79 & Informationen nachschlagen \\
\hline 80 & Wort Wide Web \\
\hline 110 & Fernzugriff auf E-Mails \\
\hline 119 & Newsdienst \\
\hline
\end{tabular}


2. Teil Verfassungsrechtlicher und technischer Hintergrund

Dienstes auf der Anwendungsschicht anhand der zugewiesenen PortKennnummern.

d) Anwendungsschicht

Die höchste Ebene, die Anwendungsschicht, ist als diejenige Schicht zu begreifen, die der Bearbeitung der Daten durch den Nutzer dient. Die darunterliegenden Schichten stellen lediglich den zuverlässigen Transport von Daten sicher. Sie errichten demzufolge das Fundament für die anschließende Applikation, ohne jedoch selbst Aufgaben für den Anwender auszuführen. Erst auf der Anwendungsschicht stehen dem Nutzer spezielle Dienste zur Verfügung, welche mittels Protokollen Befehle ausführen, die auf jedem Computer auf die gleiche Weise wiedergegeben und bearbeitet werden können. Damit kommen die netzarchitektonischen Funktionen der Anwendungsschicht der vom Nutzer verstandenen Funktion des Internets als Informations- und Unterhaltungsmedium am nächsten. ${ }^{250}$

Auf der Anwendungsschicht befinden sich die für den gängigen Gebrauch des Internets erforderlichen Protokolle. Neben dem http-Anwendungsprotokolls, dass für den Nutzer den Dienst des World Wide Web, der die klassischen Funktionen der Bereitstellung, Betrachtung und Veränderung von Webseiten ermöglicht, ist für das Verständnis einzelner Sperrmethoden schwerpunktmäßig das Anwendungsprotokoll des Domain Name Service Protocol (DNS) interessant. ${ }^{251}$

Das DNS dient vorrangig dazu, das Internet benutzerfreundlich zu gestalten. ${ }^{252} \mathrm{Während} \mathrm{nummerische} \mathrm{IP-Adressen} \mathrm{für} \mathrm{die} \mathrm{netzarchitektonische} \mathrm{Weiterga-}$ be der Daten unabdingbar sind, basieren sie jedoch auf für den User umständlich zu merkenden Zahlenfolgen. Daher ist es für die Benutzung des Internets durch den informatisch-nicht-versierten Nutzer notwendig, die IP-Adressen in leichter zu verwendende Zeichenketten, die einprägsamen Begriffen entsprechen, umzudeuten. Dies stellt die Hauptaufgabe des Anwendungsprotokolls Domain Name Systems dar. ${ }^{253} \mathrm{Im}$ Wesenskern ist DNS die Erfindung eines hierarchischen Be-

250 Sieber/Nolde, Sperrverfügungen im Internet, 2008, S. 39.

251 Zum architektonischen Rahmenwerk des World Wide Web, das oftmals missverständlich mit "Internet“ umschreiben wird, Tanenbaum, Computernetzwerke, 2009, S. 664 f.; Peterson/Davie, Computernetze, 2008, S. 660. Das Internet ist ein Gesamtgefecht von verschiedenen Netzwerken, das viele Dienste vereint. Die Möglichkeit des „Surfens im World Wide Web“ ist nur eine davon, daneben ist besonders auch der E-Mail Dienst praxisrelevant, der aber netzarchitektonisch nicht dem WWW, sondern einem selbstständigen Dienst auf der Anwendungsschicht zuzuordnen ist.

252 Sievers, Der Schutz der Kommunikation im Internet, 2003, S. 54 mit einer ausführlichen Erläuterung des Aufbaus einer Domainadresse.

253 Köhntopp/Köhntopp, CR 2000, 248; Koreng, Zensur im Internet, 2010, S. 135; Scherff, Computernetzwerke, 2010, S. 330 f.; Sieber/Nolde, Sperrverfügungen im Internet, 2008, S. 47; Semken in: Heermann/Ohly, Verantwortlichkeit im Netz, 2003, S. 9 (29). 
nennungsschemas sowie eines zur Implementierung dieses Schemas notwendigen Datenbanksystems. ${ }^{254}$ DNS stellt damit keine Anwendung dar, mit welcher der Benutzer direkt interagiert, stattdessen bedient das DNS selbst die zentrale Internetfunktion der Übersetzung von Internetadressen (Host/Domainnamen) in die zu Grunde liegenden IP-Adressen. ${ }^{255}$

Das zur Übersetzung benötigte Datenbanksystem bilden die DNS-Server, die dezentral im Internet verteilt und zumeist von dem Zugangsdiensteanbieter (Access-Provider) betrieben werden. ${ }^{256}$ Wesentlicher Vorteil der dezentralen Verteilung der DNS-Server ist, dass nicht alle DNS-Umwandlungsmechanismen von Internetadressen (auch als Domain bezeichnet z.B. http://www.jura.unigoettingen.de) zu IP-Adressen über eine zentrale Plattform vorgenommen werden, so dass die Angreifbarkeit und Belastbarkeit des Systems minimiert und gleichzeitig die Funktionalität des Systems gestärkt werden können. ${ }^{257}$ Die dezentral agierenden DNS-Server speichern in einer täglich aktualisierten Datenbank alle weltweit verfügbaren Internetadressen (Domains). ${ }^{258}$ Der gewünschte Verbindungsaufbau zur entsprechenden Domain wird mittels Eingabe einer so genannten Uniform Resource Locator (URL), ${ }^{259}$ in das Browserfenster ${ }^{260}$, z. B.

Tanenbaum, Computernetzwerke, 2009, S. 631; Sievers, Der Schutz der Kommunikation im Internet, 2003, S. 54.

255 Kurose/Ross, Computernetzwerke, 2008, S. 162.

256 Stadler, MMR 2002, 343 (345).

257 Kurose/Ross, Computernetzwerke, 2008, S. 164; andeutend auch Koreng, Zensur im Internet, 2010, S. 135.

258 Bei der Größe und globalen Verbreitung des Internets ist es unmissverständlich, dass die Vergabe der Domainadressen anhand eines gut organisierten und strukturierten Vergabesystems stattfinden muss. Um Überschneidungen und Leerräume zu vermeiden, fungiert als internationale Vergabestelle die Internet Corporation for Assigned Names and Numbers (ICANN) eine usamerikatische, rechtlich nicht verbindliche Organisation. Die Vergabe der Domains erfolgt anhand eines hierarchischen Aufbaus, man unterscheidet im Bereich der TOP Level Domains (Domänen erster Ebene) zwei Bereiche Generic (Allgemeines) und Countries (Länder). Unter die allgemeinen Domänen fallen etwa die Endung ,..com“ (commercial) oder „..org“ (nicht gewinnorientierte Organistationen). Bei den Länderdomänen ist für jedes Land eine eigene Endung, z.B. ,.de“ Deutschland, reserviert.

259 Die URL besteht aus einem dreiteiligen Aufbau: Den ersten Teil bildet das benutzte Protokoll, bei Webseiten ist dies das Hypertext Transfer Protocol (http), anschließend folgt die eigentliche Adresse, wobei grundsätzlich die allgemeine bzw. länderspezifische Top-Level-Domain z.B. „.de“, an letzter Stelle steht und den geographischen Zuordnungspunkt (de = Deutschland) bildet. Der eigentliche Domainname ist eine frei wählbare Second-Level-Domain z.B. Universitätsname ,jura.uni-goettingen“ oder Unternehmensname z.B. adidas.com, Degen, Freiwillige Selbstkontrolle, 2007, S. 155 bei Fn. 96; Peterson/Davie, Computernetze, 2008, S. 668, ausführlich Tanenbaum, Computernetzwerke, 2009, S. 668, 675 f. 
www.jura.uni-goettingen.de, durch den Nutzer selbst vorgenommen. Das DNS wandelt diese URL anschließend in die netzarchitektonisch notwendige IPAdresse um, hier im Beispiel die IP-Adresse der Juristischen Fakultät der Universität Göttingen 134.76.9.7, um anschließend die entsprechende Webseite zu beziehen. ${ }^{261}$ Verantwortlich für die Umwandlung des Domainnamens zu einer IPAdresse ist innerhalb des DNS der so genannte Resolver, welcher einen Bestandteil des jeweils installierten Betriebssystems darstellt. Zur Umwandlung des eingegebenen Domainnamens in die korrespondierende IP-Adresse bedient sich der Resolver zweier unterschiedlicher Betriebsarten: rekursiv oder iterativ. ${ }^{262}$ Im rekursiven Abfragemodus (Recursive Query) kontaktiert der Resolver, falls er die angeforderte Information nicht selbst vorliegen hat, den ihm zugeordneten DNSServer und überlässt den Auflösungsvorgang demselben. Dieser kontaktiert dann schrittweise andere DNS-Server bis er die zugeordnete IP-Adresse erfolgreich übermitteln kann. Im iterativen Abfragemodus (Iterative Query) übernimmt der Resolver selbst die schrittweise Verarbeitung des Domainnamens zur IP-Adresse und bezieht demnach selbst vom kontaktierten DNS-Server den gewünschten Eintrag. Sollte eine URL vom Nutzer falsch eingegeben worden sein oder nach Auflösung durch DNS keiner IP-Adresse zugeordnet werden können, übermittelt DNS statt der vom Nutzer angeforderten Webseite lediglich eine Fehlermeldung auf die Benutzeroberfläche des anwendenden Computers. ${ }^{263}$ In der Praxis genügt also die Eingabe eines in einer URL eingebetteten Domainnamens, um die DNSÜbersetzungsmechanismen zu starten und die entsprechende Applikation auf der Benutzeroberfläche zur Weiterverarbeitung zu erhalten.

260 Als Browser wird ein Programm bezeichnet, das dazu benutzt wird, Webseiten anzuzeigen. Hierfür bezieht der Browser die angeforderte Seite, interpretiert den Text und die vorhandenen Formatierbefehle und zeigt diese graphisch auf dem Bildschirm des Nutzers an. Die gängigen Webbrowser sind Microsoft Internet Explorer, Mozilla Firefox und Google Chrome (Safari bei Macintosh- Benutzung), erläuternd Tanenbaum, Computernetzwerke, 2009, S. 665.

261 LG Kiel, ZUM 2008, 246.

262 Die schrittweise Verarbeitung in die entsprechende IP-Adresse ist ein komplexer mathematischer Vorgang auf den an dieser Stelle nicht einzugehen ist, nähere Erläuterung bei Peterson/Davie, Computernetze, 2008, S. 673 f.; systematische Erläuterung ebenfalls bei Kurose/Ross, Computernetzwerke, 2008, S. 166 f.; Scherff, Computernetzwerke, 2010, S. 332.

263 Zusammenfassend mit weiteren technischen Details Pfitzmann/Köpsell/Kriegelstein, Sperrverfügungen gegen Access-Provider Technisches Gutachten, S. 16 abrufbar unter: http://www.eco.de/dokumente/20080428_technisches_Gutachten_Sperrvervuegungen.pdf (zuletzt abgerufen 20.5.2012); technisch genau aufgearbeitet bei Peterson/Davie, Computernetze, 2008, S. 673. 


\section{Technische Sperrmethoden}

Voranzustellen ist, dass jede Sperrmethode eine vorherige Sichtung des Internetinhalts voraussetzt, um eine gezielte Einordnung bestimmter Inhalte auf ihre Sperrwürdigkeit hin vornehmen zu können. Im Falle der Sperrung kinderpornographischer Inhalte ist es folglich notwendig, Webinhalte auf das Vorliegen der Tatbestandsmerkmale des $₫ 184 \mathrm{~b}$ StGB zu untersuchen und entsprechend gefundene Seiten schematisch aufzulisten. Gleichzeitig erfordert die Vorgehensweise eine regelmäßige Kontrolle der gelisteten Angebote auf das fortbestehenden der Sperrvoraussetzungen sowie ein regelmäßiges Update auch bezüglich neuer, vormals völlig unbedenklicher Inhalte. Die einzelnen Sperrmethoden sind zwar nach erfolgreicher Implementierung auf eine automatische Sichtung der Inhalte und entsprechende Verwerfung des Zugriffs ausgerichtet, der technisch automatisierte Vorgang setzt jedoch stets an einen Abgleich vormalig gelisteter Kriterien an. Die Effektivität der technischen Sperrmöglichkeiten ist damit maßgeblich von einer manuellen Entscheidung abhängig, die schon aufgrund der teilweise problematischen „Grauzonen“ zur Ermittlung der Tatbestandsmäßigkeit 264 der Kinderpornographie, der ständigen Kontroll- und Aktualisierungspflicht und vor allem wegen der Menge der im World Wide Web verbreiteten Dateninhalte nicht nur auf technische, sondern auch auf tatsächliche Probleme stößt, auf die im Rahmen der rechtlichen Bewertung vielerorts zurückzukommen sein wird.

\section{a) DNS-Server-Sperrung}

Die DNS-Methode verhindert den Abruf einer angeforderten Webseite beim Nutzer. Die Funktionsweise der DNS-Sperrmethode setzt an den Domain-NameService an und beruht auf der Möglichkeit der Einwirkung auf die DNSFunktionalität hinsichtlich der Umwandlung der URL in die zugehörige IPAdresse innerhalb der Anwendungsschicht. ${ }^{265}$ Hierfür müssen lediglich Softwareeinstellungen am DNS-Server vorgenommen werden, welche die entsprechenden Einträge im DNS-Server dergestalt verändern, dass die vom Nutzer eingegebene URL über den Resolver nicht in die entsprechende numerische IPAdresse umgewandelt und damit die aufgerufene Seite auf der Benutzeroberfläche

264 So beispielsweise die Beurteilung der Tatbestandsmäßigkeit, obgleich lediglich „Scheinkindlichkeit" vorliegt, sowie die oftmals schwierige Frage, ob Fiktivpornographie den Straftatbestand erfüllt, hierzu oben 2. Teil A. II. 1. a) .

265 Zur Funktionsweise auch Pfitzmann/Köpsell/Kriegelstein, Sperrverfügungen gegen Access-Provider - Technisches Gutachten, S. 52 ff., abrufbar unter:

http://www.eco.de/dokumente/20080428_technisches_Gutachten_Sperrvervuegungen.pdf (zuletzt abgerufen 20.5.2012); Degen, Freiwillige Selbstkontrolle, 2007, S. 155; Billmeier, Die Düsseldorfer Sperrungsverfügung, 2007, S. 205; ausführlich auch zu den rechtlichen Problemen der Sperrmethode, Sieber, Ausschussdrucksache 16 (9) 1559; Sieber/Nolde, Sperrverfügungen im Internet, 2008, S. 50 f. 
des Anwenders nicht angezeigt werden kann. Notwendig hierfür ist zunächst eine Auflistung aller zu sperrenden Domains, etwa solche mit kinderpornographischem Charakter. Sollte der Nutzer versuchen auf eine ,gelistete“ Domain durch Eingabe derselben in das Browserfenster oder durch die Suche via Suchmaschine zuzugreifen, so bewirkt eine implementierte Abgleichfunktion, dass durch Veränderung des Umwandlungsmechanismus der Anwender anstelle der angeforderten Webseite nur eine Fehlermeldung eine Information über einen Verbindungsabbruch oder die Umleitung der Anfrage zu einer vordefinierten Seite, die einen Hinweis zu der vorgenommen Sperrmaßnahme enthält (als eine Art StoppServer/ bzw. interaktives Stoppschild) erhält. ${ }^{266}$ Für den Nutzer des Internets ist diese Veränderung erst sichtbar, wenn die Manipulation am DNSUmwandlungsmechanismus bereits vorgenommen wurde und zu entsprechenden Veränderung des angefragten Inhalts auf der Applikationsebene führte.

\section{b) Sperrung durch IP-Blocking am Router}

Die Sperrmethode beruht auf dem Prinzip der Unterbindung der Weiterleitung der Datenpakete an den Netzknotenpunkten, den so genannten Routern innerhalb der Internetschicht. ${ }^{267}$ Zur Erläuterung der Funktionsweise des IP-Blockings müssen an dieser Stelle wiederholt die technischen Vorgänge innerhalb der Internetschicht betrachtet werden: Über das Basisprotokoll IP werden die zu Datagrammen fragmentierten Datenpakete über mehrere Netzwerkknoten (Router), die die einzelnen Teilnetze miteinander verknüpfen, an den Zielhost (Empfänger) transportiert. Hierfür wird das angefragte Ziel von IP ermittelt und die einzelnen Datagramme durch Anreicherung des Datenpakets mit der entsprechenden IP-Adresse des Zielhosts im so genannten IP-Header praktisch „adressiert“. An dieser Stelle setzt nun der auf der IP-Blocking basierende Sperrmechanismus an. Beim Ankommen des Datagramms am Router soll die autonome Weiterleitung der Daten an den entsprechenden Zielhost unterdrückt werden. Hierzu muss am Router ein technischer Mechanismus implementiert werden, der die Speicherung der zu sperrenden IP-Adresse auf der Routersoftware zur Folge hat. Diese Konfiguration

266 Etwa „Host not found“, „Could not connect“, oder die Umleitung zu einer Webseite, die ein entsprechendes „Stoppschild“ enthält, wie dies etwa von \4 ZugErschwG gefordert wird, hierzu Sieber/Nolde, Sperrverfügungen im Internet, 2008, S. 47. Zudem Rosenkranそ, jurPC Web-Dok. 16/03, Abs. 20; Dornseif, Government mandated blocking of foreign Web content, Topic 2.2.2 abrufbar unter: http://md.hudora.de/publications/200306-gi-blocking/200306-gi-blocking.pdf (zuletzt abgerufen 20.5.2012).

267 Schneider, MMR 1999, 571 (572 f.); Köhntopp/Köhntopp/Seeger, K\&R 1998, 25 (28); Degen, Freiwillige Selbstkontrolle, 2007, S. 150; Schnabel, K\&R 2008, 26 (28); Schöttle, K\&R 2007, 366 (367); Dorsreif, , "Government mandated blocking of foreign Web content“ Topic 2.1.1, abrufbar unter: http://md.hudora.de/publications/200306-gi-blocking/200306-gi-blocking.pdf (zuletzt abgerufen 20.5.2012); überblicksartig LG Hamburg, ZUM 2010, 902 (905). 
bewirkt, dass beim Eintreffen eines Datagramms am manipulierten Router, dieser den um die IP-Zieladresse angereicherten IP-Header des Datagramms ausliest, die dort befindliche Zieladresse mit der zu sperrenden IP-Adresse abgleicht und bei Übereinstimmung die Weileitung an dieselbe negiert. Die angeforderte Webseite kann dadurch nicht beim Benutzer appliziert werden. ${ }^{268}$ Auf der Benutzeroberfläche erscheint anstelle der angefragten Webseite wiederrum lediglich die Applikation eines Verbindungsabbruchs wie „Could not connect" oder der Hinweis auf eine Unauffindbarkeit der angeforderten Webseite „Page not found“.269 Möglich ist auch hierbei, anstelle der Negierung des Zugriffs, eine Weiterleitung an eine vordefinierte Webseite zu verknüpfen, die den Nutzer über die Vornahme der Sperrung informiert. ${ }^{270}$

\section{c) Sperrung durch Proxy-Server}

In der Theorie sollen Proxy-Server eine inhaltsbezogene Filterung von Webinhalten ermöglichen und lediglich den Zugriff auf gänzlich legale oder zumindest legale Teile der angeforderten Webseiten gewähren. ${ }^{271}$ In der netzarchitektonischen Betrachtung setzt diese Sperrmethode auf der Anwendungsschicht innerhalb des TCP/IP-Modells an. Zur Unterbindung des Zugriffs auf illegale Webseiten kann auf dieser Ebene ein Proxy-Server implementiert werden, der Nutzeranfragen zu bestimmten Inhalten unterbindet.

Zunächst bedarf es daher der Implementierung des vorgenannten ProxyServers der die Datenverbindung unterbricht und als zwischengeschaltetes Element alle Nutzeranfragen durch ein vorkonfiguriertes System leitet. ${ }^{272}$ Generell bedienen sich die meisten Browsersysteme bereits der Möglichkeit der Informationsbeschaffung über den „Umweg“ des Einsatzes eines Proxy-Servers. Diese als Proxy-Cache-Technologie bekannte Funktion ist jedoch von der Zwischenschal-

268 Zur IP-Sperrmethode u.a. Stadler, Haftung für Informationen im Internet, 2005, Rn. 128; Semken in: Heermann/Ohly, Verantwortlichkeit im Netz, 2003, S. 13; Koreng, Zensur im Internet, 2010, S. 137; Schnabel, K\&R 2008, 26 (28); Schneider, MMR 1999, 571 (572).

269 Ausführlich auch unter Berücksichtigung der Kosten Sieber/Nolde, Sperrverfügungen im Internet, 2008, S. $185 \mathrm{ff}$.

270 Allgemein Rosenkranz, jurPC Web-Dok. 16/03, Abs. 20; Dornseif, Government mandated blocking of foreign Web content, Topic 2.2.2 abrufbar unter:

http://md.hudora.de/publications/200306-gi-blocking/200306-gi-blocking.pdf (zuletzt abgerufen 20.5.2012).

271 Hierzu u.a. Beckmann, Verantwortlichkeit von Online-Diensteanbietern in Europa und Vereinigten Staaten, 2001, S. 48; Stadler, Haftung für Informationen im Internet, 2005, Rn. 131 f.; Sieber, Verantwortlichkeit im Internet, 1999, Rn. 150 ff.; Schneider, MMR 1999, 571 (574); ders., MMR 2004, 18 (21); Rosenkran₹, jurPC Web-Dok. 16/2003, Abs. 21.

272 Zur Proxy-Sperre als Filtermechanismus Billmeier, Die Düsseldorfer Sperrungsverfügung, 2007, S. 205; Sieber, CR 19997, 653 (659), andeutend auch Schnabel, JZ 2009, 996. 
tung eines „Sperrproxy“ zu unterscheiden. Grundsätzlich fungieren die kommerziell angeboten Proxy-Cache-Systeme in erster Linie als eine Art „Überlastungsminimierer", um unnötigen Netzkapazitätsverlusten entgegenzuwirken, etwa für den Fall, dass die gleichen Informationen zum wiederholten Male, beispielsweise die gleiche URL mehrmals in den Browser vom Nutzer eingegeben wird. ${ }^{273}$ Der Grundidee des Proxy-Caching folgend, ist die Einsparung der Netzkapazitäten simpel umsetzbar: Jede Anfrage bezüglich des Erhalts einer Webseite setzt auf der Applikationsebene den DNS-Umsetzungsmechanismus in Gang der über den iterativen beziehungsweise rekursiven Modus, die eingegebene URL in die zugehörige IP-Adresse umwandelt, was erhebliche Netzkapazitäten verbraucht. ${ }^{274} \mathrm{Um}$ eine Entlastung der Netzkapazitäten zu erreichen, speichert der Proxy-Server das Umwandlungsergebnis in seinem Cache (Erinnerungsspeicher). Bei erneuter Anfrage einer beliebigen Webseite, durchsucht der Proxy zunächst seinen eigenen Cachespeicher auf eventuelle Übereinstimmung mit der angeforderten Webseite und übermittelt beim positiven Ergebnis die entsprechende Webseite direkt aus seinem Cache an den Nutzer. ${ }^{275}$ Der Benutzer kann über das BrowserOptionsmenü selbst einstellen, dass statt des für die URL zuständigen Servers zunächst der implementierte Proxy befragt wird, ob dieser die gewünschte Information in seinem Cache bereits vorrätig hat um diese anschließend weiterzuleiten. ${ }^{276}$

Die Zwischenschaltung eines Proxy-Server mit den Ziel der Sperrung bestimmter Inhalte basiert grundlegend auf dem oben beschriebenen Prinzip, wonach die Datenübertragung zunächst unterbrochen und anschließend über einen Proxy weitergeleitet wird, anders als beim Proxy-Caching kann der Einsatz eines Proxy zur Realisierung der Sperrmethode, aber nicht nutzerseitig bestimmt werden. Vielmehr wird jede Anfrage zwangsweise über das implementierte Computersystem geleitet. Dieser bedient sich einer Software im Inneren des Proxy, die einen vorkonfigurierten Filtermechanismus enthält. Der Filtermechanismus führt bei jedem Nutzervorgang eine inhaltsbezogene Analyse des angefragten Content anhand vorgegebener Filterkriterien durch und leitet lediglich diejenigen Anfragen

273 Peterson/Davie, Computernetze, 2008, S. 666.

274 Hierzu oben 2. Teil B. I. 2. a) .

275 Kurose/Ross, Computernetzwerke, 2008, S. 169; Tanenbaum, Computernetzwerke, 2009, S. 172 f.; wesentlicher Nachteil dieser Methode ist die mangelnde Aktualität der angeforderten Seiten, da beim Benutzer lediglich eine abgelegte Webseite appliziert wird. Der Proxy-Cache Mechanismus kommt damit nur bei solchen Seiten in Einsatz, die keine aktuellen, sich wandelnden Inhalte beherbergen. Zudem muss der Cache-Speicher regelmäßig geleert und mit neuen Inhalten gefüllt werden, darauf weist Tanenbaum, Computernetzwerke, 2009, S. 713 hin.

276 Tanenbaum, Computernetzwerke, 2009, S. 712 f. 
weiter, deren Inhalte keine Übereinstimmung beziehungsweise keinerlei verwerfliche Inhalte aufweisen. ${ }^{277}$

Bereits an dieser Stelle setzt das erste technische Problem des Sperrmechanismus an; namentlich die technische Realisierbarkeit, der Isolation einzelner Inhalte aus einer Vielzahl der durchgeleiteten Daten. Denkbar sind hier zwei verschiedene Systeme: Einerseits die automatische Bewertung von Inhalten auf Basis formaler Merkmale - etwa Schlüsselbegriffen oder Abbildungen - andererseits eine pauschale Filterung von Inhalten anhand der ihnen zu Grunde liegenden IP- oder URL-Adressen. ${ }^{278}$

Bei der ersten Filtermethode gleicht eine im Proxy implementierte Software die angeforderten Webseiten auf Vorkommen bestimmter Signalwörter oder Abbildungen $\mathrm{ab}$, die im Vorhinein manuell als unzulässig eingestuft und in einer aktualisierungsbedürftigen Sperrliste aufzuführen sind. Ermittelt der Proxy innerhalb der angerufenen Webseite ein in der Sperrliste enthaltenes Wort oder eine Bilddatei, so stuft er die Seite als unzulässig ein und verweigert den Zugriff, in dem er den Request (Anfrage) unterbricht. Beim Anwender wird anstatt der angeforderten Webseite lediglich eine Fehlermeldung angezeigt. Auch besteht die Möglichkeit einen gleichzeitigen Weiterleitungsmechanismus zu implementieren, der die verworfene Nutzeranfrage auf eine vordefinierte Seite weiterleitet, die Informationen über die Verbindungsunterdrückung trägt. ${ }^{279}$

Bei der zweiten Methode muss der Proxy über das Auslesen des IP-Headers der ankommenden Datenpakete, die angefragte Webseite mit den in der Sperrliste befindlichen Adressen abgleichen und lediglich die unbedenklichen Datenpakete zur vollständigen Anzeige weiterleiten. ${ }^{280}$ Bei der IP-Filterung filtert der Proxy die gesamte IP-Information des Headers und gleicht diese mit der implementierten Kriterien der internen Sperrliste ab. Bei der URL-Filterung hingegen ist die Vorgehensweise technisch diffiziler. Um die URL-Adresse, die es zu verwerfen gilt, aus der gesamten Anfrage herauszufiltern muss der Proxy zunächst das gesamte Datenpaket „untersuchen“, um an die angesteuerte URL-Information zu gelan-

277 Hierzu u.a. Beckmann, Verantwortlichkeit von Online-Diensteanbietern in Europa und Vereinigten Staaten, 2001, S. 48; Stadler, Haftung für Informationen im Internet, 2005, Rn. 131 f.: Schneider MMR 1999, 571 (574); Rosenkranz, jurPC Web-Dok. 16/2003, Abs. 21.

278 Zum gesamten Komplex Köhntopp/Köhntopp/Seeger, K\&R 1998, 25 (27); Kloepfer, Informationsrecht, 2002, \5 Rn. 61.

279 Pfitzmann/Köpsell/Kriegelstein, Sperrverfügungen gegen Access-Provider Technisches Gutachten, S. 39, abrufbar unter:

http://www.eco.de/dokumente/20080428_technisches_Gutachten_Sperrvervuegungen.pdf (zuletzt abgerufen 20.5.2012); zur Filterung anhand von Signalwörter, Faber, Jugendschutz im Internet, 2005, S. 61 ff.; Bandehzadeh, Jugendschutz im Rundfunk und in den Telemedien, 2007, S. 177; Dickhuth, Jugendschutzprogramme, 2010, S. 41.

280 Sieber, Verantwortlichkeit im Internet, 1999, Rn. 152. 
gen. Hierfür wird ein Mechanismus implementiert, der die angeforderte Information in mehrere Elemente aufspartet: So kann aus der Headerinformation der so genannten GET-Request, ${ }^{281}$ also der URL-Adressen typische http://-Anfang herausgefiltert, abgeglichen und die Anfrage auf eine bestimmte URL verworfen werden, ohne das andere unter derselben IP-Adresse befindliche Inhalte gleichzeitig mitgeperrt werden. ${ }^{282}$ Auch diese Methode setzt allerdings eine vorherige manuelle Bewertung und tägliche Aktualisierung einzelner Seiten voraus.

\section{Zwischenergebnis: Technische Lösungsansätze}

Die Vornahme einer Sperrung beruht auf einer direkten Einflussnahme in den Datenverarbeitungsprozess im Internet. Die automatisierten Vorgänge im Internet werden dahingehend abwandelt, als die abgefragte Information beim Nutzer nicht wie angefordert dargestellt, sondern lediglich eine Benachrichtigung über einen Verbindungsabbruch erfolgt. Anstelle der Verwerfung des Zugriffs kann gleichzeitig auch eine Umleitung der Nutzeranfrage auf eine vordefinierte Webseite (interaktives Stoppschild) erfolgen, die als Informationsportal über Grund und Art der vorgenommen Sperrung Auskunft erteilt. ${ }^{283}$

281 Semken in: Heermann/Ohly, Verantwortlichkeit im Netz, 2003, S. 9 (19); Degen, Freiwillige Selbstkontrolle, 2007, S. 168.

282 Zum typischen Problem des Overblocking, d.h. der technisch bedingten Mitsperrung weiterer Angebote, unter 3. Teil B. I. 2. b) (bb) .

283 Daneben kommen auch hybride Sperransätze sowie gebündelte Filtermethoden (Deep Packet Inspection) in Betracht. Dahinter verbergen sich aber nur Methoden, die eine technische Kombination der Ansätze darstellen, um die Erfolgswahrscheinlichkeit des Erschwerungserfolges zu vergrößern. Zu hybriden Sperrtechniken, Pfitżmann/Köpsell/Kriegelstein, Sperrverfügungen gegen Access-Provider - Technisches Gutachten, S. 55 ff., abrufbar unter:

http://www.eco.de/dokumente/20080428_technisches_Gutachten_Sperrvervuegungen.pdf (zuletzt abgerufen 20.5.2012); Sieber/Nolde, Sperrverfügungen im Internet, 2008, S. 188 ff.; Koreng, Zensur im Internet, 2010, S. 141; zur Deep Packet Inspection überblicksartig, Töniges, „Im Rausch der Tiefe“ Beitrag v. 21.3.2009, Deutschlandfunk, abrufbar unter: http://www.dradio.de/dlf/sendungen/computer/938186/ (zuletzt abgerufen 20.5.2012); Mochalski/Schulze, Deep Packet Inspection, White Paper, abrufbar unter: http://www.ipoque.com/userfiles/file/DPI-Whitepaper.pdf (zuletzt abgerufen 20.5.2012), Koreng, Zensur im Internet, 2010, S. 140; Bender, Rechtmäßigkeit der Deep Packet Inspection, abrufbar unter:

http://kobra.bibliothek.uni-kassel.de/bitstream/urn:nbn:de:hebis:34-

2009113031192/5/BednerDeepPacketInspection.pdf (zuletzt abgerufen 20.5.2012). 


\section{Ergebnis Teil 2 und Ausblick}

Der Jugendschutz lässt sich verfassungsrechtlich vorrangig aus dem Allgemeinen Persönlichkeitsrecht im Sinne des. Art. 2 Abs. 1 GG i.V.m. Art. 1 Abs. 1 GG ableiten. Nach der Schutzpflichtenlehre ist der Staat verpflichtet, für das Freiheitsrecht bestehende Risiken mit den ihm zur Verfügung stehenden Mitteln abzuwehren. Einen wesentlichen Gefährdungsbereich eröffnet die ungehinderte Verbreitung von Kinderpornographie im Internet. Um die möglichen Risiken einzudämmen hat der Gesetzgeber bereits zahlreiche Versuche unternommen und neben strafrechtlichen und spezialrechtlichen Sanktionen auch den Exekutivbehörden Befugnisse eingeräumt, welche darauf gerichtet sind entsprechende Inhalte aus dem Internet zu beseitigen oder zumindest den Zugriff auf diese zu unterbinden. Schwerpunktmäßig wird diesbezüglich die Sperrung des Inhaltes, das heißt die Erschwerung der Erreichbarkeit untersucht. Auf Grundlage des technischen Verständnisses soll sich die Bearbeitung nachfolgend der verfassungsmäßigen Analyse von gesetzlichen Sperrverpflichtungen widmen. Ausgehend von der Annahme, dass mit der legislatorisch angeordneten Sperrung von Internetinhalten auch Grundrechte Dritter betroffen sind, sind die spezifischen Anforderungen an die Verfassungsmäßigkeit jugendschutzmotivierter Sperrungen herauszuarbeiten. Dabei wird insbesondere auf die technischen Umgehungsmöglichkeiten und deren Einfluss für die rechtliche Beurteilung von Sperrverpflichtungen eingegangen sowie auf den verfassungsmäßigen Auftrag des Staates hinsichtlich der Wahrung der Jugend zurückzukommen sein. 



\section{Teil Verfassungsmäßige Analyse}

Im Folgenden soll die Verfassungsmäßigkeit einer gesetzlichen Sperrverpflichtung untersucht werden. Dabei konzentriert sich die Darstellung auf grundrechtlich abgesicherte Belange von Access-Providern sowie Nutzern, die einer gesetzlichen Normierung einer Sperrverpflichtung für kinderpornographische Inhalte entgegenstehen. Zudem werden auch die allgemeinen Verfassungsprinzipien berücksichtigt und entsprechend ausgewertet. Aus den jeweiligen verfassungsrechtlichen Gewährleistungen ergeben sich spezifische Anforderungen an eine verfassungsrechtlich verträgliche Formulierung einer Sperrverpflichtung, die anschließend zusammenzufassen gilt.

\section{A. Vorfragen eines gesetzlichen Sperransatzes}

Die rechtliche Analyse eines gesetzlichen Sperransatzes zur Unterbindung von Webinhalten setzt zunächst eine Auseinandersetzung mit wesentlichen Vorfragen voraus, welche die Basis für die später notwendige Abwägung in Hinblick auf die tangierten Grundrechtspositionen bildet. Grundlage der nachfolgenden Auseinandersetzung ist die gesetzliche Normierung einer Sperrpflicht. ${ }^{284}$ Danach soll der Adressat der Maßnahme ${ }^{285}$ infolge einer unmittelbar gegen ihn wirkenden Nor-

284 Angelehnt an die Formulierung des vom Gesetzgeber präferierten Ansatzes im Zugangserschwerungsgesetz, dazu ausführlich 4. Teil B. I. .

285 Das heißt die Access-Provider, zur Erläuterung des Adressaten später unter 3. Teil A. II. 
mierung verpflichtet werden, entsprechende technische Vorkehrungen zu treffen, die auf die Sperrung eines als kinderpornographisch eingestuften Webinhalts im Sinne des \184b StGB, ausgerichtet sind. Im Unterschied zu \20 JMStV i.V.m. \ 59 Abs. 1 bis 3 RStV handelt es sich hierbei nicht um eine einzelfallbezogene Ermächtigung einer Behörde zur Erteilung einzelner Verwaltungsakte, sondern um eine abstrakt-generelle Pflicht, der alle Normadressaten gleichzeitig unterstehen. Die Sperrpflicht wird ausgelöst, soweit die Provider Kenntnis von den zu sperrenden Inhalten bekommen. Hierfür muss eine Behörde die sperrungswürdigen Inhalte zusammenfassen und entsprechend an alle Provider weiterleiten. ${ }^{286}$ Für die nachfolgende Analyse ist zunächst überblicksartig zu klären, welchen Zweck der Gesetzgeber mit einer solchen gesetzlichen Sperrverpflichtung verfolgt und wer als Normadressat eines legislatorischen Sperransatzes in Betracht kommt. Zudem soll bereits an dieser Stelle auf den verfassungsrechtlichen Grundsatz der Verhältnismäßigkeit eingegangen werden, dieser gibt im Wesentlichen die Anforderungen für die weitere Prüfung vor.

I. Zweck einer gesetzlichen Sperrverpflichtung/ Kombination aus Jugendschutz und Gefahrenabwehr

Zweck einer gesetzlichen Sperrpflicht kann unterschiedlicher Natur sein. Im Ergebnis soll der Zugriff auf die Inhalte des Gesamtbestandes des World Wide Web erschwert werden, um die Gefahren eines ungehinderten Zugriffs einzudämmen. Geht es um die Sperrung von speziell kinderpornographischen Angeboten, so ist die Zielrichtung zweigeteilt: Im Rahmen seiner Einschätzungsprärogative geht der Gesetzgeber davon aus, dass der ungehinderten Verbreitung von Kinderpornographie Risiken zugrundeliegen, die er über legislatorische Mechanismen zu relativieren habe. Nicht nur die Tatsache, dass den Abbildungen oftmals ein tatbestandlicher Missbrauch im Sinne des $₫ 176$ StGB zu Grunde liegt, sondern auch die Rezeptionsmöglichkeit der Bilder bergen das Risiko einer erneuten Viktimisierung der darstellten Opfer sowie eine latente Nachahmungsgefahr, die bis hin zur sexuellen Ausbeutung von Kindern für zukünftige Produktionen reichen kann. ${ }^{287}$ Daneben ist nicht auszuschließen, dass kinderpornographische Darstellungen bewusst eingesetzt werden, um entsprechende Verhaltensweisen bei Kindern als „,normal“" zu suggerieren und Hemmschwellen zur Vornahme sexueller Handlun-

286 Demnach ist die Bezeichnung einer ,unmittelbaren Sperrverpflichtung“ rechtsdogmatisch nicht ganz sauber. Die konkrete Pflicht wird erst über die Weiterleitung der Sperrliste, demnach durch einen Verwaltungsakt i.S.d. \ 35 VwVfG begründet. Von einem Verwaltungsakt ausgehend auch Volkmann in: Spindler/Schuster, Recht der elektronischen Medien, 2011, § 1 ZugErschwG, Rn. 3.

$287 \mathrm{Zu}$ den wissenschaftlichen Analysen zur Verbreitung internetvermittelter Kinderpornographie, oben 2. Teil A. II. 1. b) . 
gen senken. 288 Über die Unterbindung der Rezeptionsmöglichkeit wird versucht den Risiken entgegenzutreten. Ist der Nutzer im Zugriff auf den Webinhalt erschwert, ist nicht auszuschließen, dass er von einer Betrachtung absieht, weil es ihm entweder nicht möglich ist, sich Umgehungsanleitungen des Sperrmechanismus zu besorgen und den verdeckten Inhalt zum Vorschein zu bringen oder weil aufgrund der erhöhten Anforderungen von einem Zugriffsversuch abgesehen wird. Gleichzeitig können Sperrungen auch ein nach außen hin sichtbares Zeichen der gesellschaftlichen Ächtung von Kinderpornographie signalisieren. ${ }^{289}$

Der hinter solchen inhaltsbeschränkenden Sperrungen stehende übergeordnete Zweck ist damit zunächst im Jugendschutz zu sehen: Einerseits in Ausformung eines mittelbaren Opferschutzes durch Einschränkung der Nachfragestimulierung und der Verleitung zum zukünftigen Kindesmissbrauch über die Behinderung des Vertriebs und Konsums derartiger Angebote im Onlinebereich. Andererseits in unmittelbarer Ausprägung durch die Verhinderung von menschenwürdeverachtenden „Zur-Schau-Stellung“ der abgebildeten kindlichen Protagonisten. ${ }^{290}$

Daneben ergibt sich aus der Rechtsgebietszugehörigkeit der Sperrungen eine weitere gesetzgeberische Zielrichtung, die durch den Sperransatz verwirklicht werden soll. Sperrungen kinderpornographischer Internetinhalte sind einfachgesetzlich dem präventiven Bereich der öffentlich-rechtlichen Gefahrenabwehr zuzuordnen. ${ }^{291}$ Bei Vorliegen von Gefahren für die öffentliche Sicherheit und Ordnung wird der Staat verpflichtet entsprechende Maßnahmen zu ergreifen um diese Gefahren abzuwehren. Als Gefahr, die präventives staatliches Einschreiten mittels Sperrverpflichtung rechtfertigt kommt bereits die bloße Möglichkeit der Vorhaltung jugendschutzrechtlich relevanter Inhalte im Internet in Betracht. ${ }^{292}$ Grundsätzlich begründet schon das Vorhalten kinderpornographischer Inhalte die hin-

288 Sieber, JZ 2009, 653; Osterheider, Ausschussdrucksache, 16 (9) 1544, S. 1, darauf bezugnehmend, Heckmann, Stellungnahme der Sachverständigen im Rechtsausschuss v. 8.11.2010, S. 6, abrufbar unter:

http://www.bundestag.de/bundestag/ausschuesse17/a06/anhoerungen/archiv/03_Zugangsers chwerung/04_Stellungnahmen/Stellungnahme_Heckmann.pdf (zuletzt abgerufen 20.5.2012); Aufhebungsgesetzentwurf der FDP zum ZugErschwG, BT-Drs. 17 /646, S. 3.

289 Kubnen, Ausschussdrucksache 16 (9) 1545, S. 1; Höbne/Dienst, jurisPR ITR 13/2009, Anm. 6; so auch schon die Eckpunkte der Bundesministeriums für Familie, Senioren, Frauen und Jugend „Zur Bekämpfung von Kinderpornographie im Internet“ v. 25.3.2009, S. 1, abrufbar unter: http://www.bmfsfj.de/RedaktionBMFSFJ/Abteilung5/Pdf-Anlagen/kinderpornografie-

kabinett-eckpunkte,property $=$ pdf,bereich $=$ bmfsf ,sprache $=$ de, $r w b=$ true.pdf (zuletzt abgerufen 20.5.2012).

290 Sieber, Ausschussdrucksache 16 (9) 1559, S. 7.

291 Volkmann, Der Störer im Internet, 2005, S. 193 ff.

292 So Volkmann, Der Störer im Internet, 2005, S. 193 ff.; Greiner, Die Verhinderung verbotener Internetinhalte, 2001, S. 95 ff. 
reichende Wahrscheinlichkeit, dass ohne staatliches Einschreiten ein Verstoß gegen gesetzliche Bestimmungen zum Schutze der Jugend, speziell das landesrechtliche Verbreitungsverbot des $\int 4$ Abs. 1 Satz. 1 JMStV oder gegen absolute Verbreitungs-, Herstellungs- und Besitzvorbote des $₫ 184 \mathrm{~b}$ StGB erfolgt, so dass die „Rechtsordnung“ im Sinne der „öffentlichen Sicherheit“ als gefährdet angesehen werden kann. ${ }^{293}$ Wird der Zugriff auf den kinderpornographischen Inhalt durch eine Sperrmaßnahme erschwert, kann der Nutzer in Folge der verminderten Zugriffsmöglichkeiten nicht gegen geltende Verbotstatbestände verstoßen. Folglich dient der Sperransatz damit auch einem Zweck der Allgemeinheit. ${ }^{294}$

Zusammenfassend dienen gesetzliche Sperrverpflichtungen bezüglich kinderpornographischer Internetinhalte damit zwei Schutzzwecken. Zuvorderst soll der Zugang zu einem bestimmten Webcontent unterbunden werden, um präventiven Rechtsverstößen zu entgegen. Daneben sollen auch die mittelbaren Auswirkungen unterbunden werden, die von einer ungehinderten Verbreitung des Inhaltes erwartet werden. In der Konsequenz überschneiden sich Schutzziele des präventiven Jugendschutzes mit Interessen der Allgemeinheit an der Aufrechterhaltung der Staatssicherheit sowie der Wahrung der Rechtsordnung. ${ }^{295}$

\section{Der Adressat der Sperrmaßnahme}

Der Adressatenkreis einer gesetzlichen Sperrverpflichtung wird schon über die technische Ausgestaltung der Sperrung selbst begrenzt. Die Sperrung eines Webinhalts setzt einen direkten Eingriff in den technischen Vorgang der Datenübertragung im Internet voraus. Der Staat selbst kann diesen Eingriff aus rein tatsächlichen Gründen nicht vornehmen, da er weder die kommunikationsspezifische Infrastruktur des Internets bereitstellt noch diese eigenhändig betreibt. Folglich mangelt es dem Staat an den technischen Handlungsapparaten, die Voraussetzung für einen Eingriff in den Kommunikationsprozess wären.

Den technischen Anknüpfungspunkt für einen inhaltsbeschränkenden Eingriff in den Kommunikationsprozess bilden die Kommunikationsleitungen sowie Verbindungsdienste, wie Router, Proxy- und DNS-Server, die für die Eingliederung der Teilnehmer am Netzwerk Internet und einer stabilen Datenübertragung innerhalb desselben ausschlaggebend sind. Diese werden von speziellen Diensteanbietern in der Regel gegen Entgelt bereitgestellt und unterhalten. Es handelt

293 Greiner, Die Verhinderung verbotener Internetinhalte, 2001, S. 95 f.

294 Zu alledem Billmeier, Die Düsseldorfer Sperrungsverfügung, 2007, S. 245.

295 Der Gesetzgeber hält das von kinderpornographischen Inhalten ausgehende Gefährdungspotential für so groß, dass es eine Maßnahme rechtfertigen vermag, die nicht nur darauf gerichtet ist, vorrangig die beteiligten Kindern und Jugendlichen vor erneuter Stigmatisierung und mittelbaren Missbrauch zu schützen, sondern erkennt in der völligen Unzugänglichkeit auch den Schutz der Allgemeinheit vor einer Konfrontation mit den Bildern sowie einer Wahrung der Rechtsordnung als schützenswert an, so Billmeier, Die Düsseldorfer Sperrungsverfügung, 2007, S. 245. 
sich hierbei um so genannte Zugangsdiensteanbieter oder Access-Provider. Sie ermöglichen ihren Kunden über bestimmte Einwahlknoten (Router) einen individuellen Zugriff auf das Netzwerk und sind damit der erste technische Berührungspunkt des Nutzers mit dem Internet. ${ }^{296}$ Der Begriff Access-Providing umschreibt die Art der Dienstleistung der Zugangsdiensteanbieter: Die Bereitstellung des Zugangs, die Übernahme der mit dem Datenverkehr verbundenen Übermittlungstätigkeit und die Bereitstellung der technisch notwendigen Protokolle. ${ }^{297}$ Die verschiedenen Dienstleitungen ermöglichen in Addition praktisch die Nutzung des Internets durch den User im Rahmen seiner klassischen Funktion als Informations- und Unterhaltungsmedium. ${ }^{298}$

Die technische Umsetzung der Sperrung setzt nunmehr an der Funktion der Access-Provider im Gesamtgefüge des Internets an: Mangels eigener Handlungsapparate muss der Staat die technische Ausführung gesetzlicher Sperrverpflichtungen durch die Access-Provider vornehmen lassen, da diese unmittelbar am Kommunikationsprozess beteiligt sind und Zugriff auf die zur Sperrung benötigte Infrastruktur haben. Der Staat „bedient“ sich daher praktisch an der von den Access-Providern bereitgestellten und unterhaltenen Infrastruktur, indem er ihnen gesetzlich die Pflicht auferlegt in bestimmte Bereiche der Datenübertragung, die direkt mit den bereitgehaltenen technischen Gegebenheiten zusammenhängen, einzuwirken und Sperrmechanismen zu implementieren. ${ }^{299}$ Objektiv ist es somit nicht der Staat selbst der sperrt, sondern ein Privatrechtssubjekt, das direkten Einfluss auf den Datenübertragungsprozess im Internet hat. Bei näherer Betrachtung der vorliegenden Konstellation bedient sich der Staat der privaten AccessProvider nicht nur um die eigentlichen technischen Sperrungen vorzunehmen, sondern um damit gleichzeitig auch eine öffentliche Aufgabenerfüllung wahrzunehmen, mithin einen effektiven Jugendschutz und Gefahrenabwehr im Internet. ${ }^{300}$ Rechtlich eingeordnet stellt ein „sich-bedienen“ im vorliegenden Bereich einen Fall der „funktionalen Privatisierung“ dar. ${ }^{301}$ Charakteristisch für die funktionale Privatisierung ist, dass nicht die Staatsaufgabe, also die Abwehr der kinder-

296 Stadler, Haftung für Informationen im Internet, 2005, Rn. 11; Degen, Freiwillige Selbstkontrolle, 2007, S. 48; Schaar, Datenschutz im Internet, 2002, Rn. 22; Dustmann, Die privilegierten Provider, 2001, S. 31; Hoffmann in: Spindler/Schuster, Recht der elektronischen Medien, 2011, \8 TMG, Rn. 17. Gängige Access-Provider sind u.a. T-Online, Arcor, Freenet, Kabel Deutschland oder $1 \& 1$.

297 Degen, Freiwillige Selbstkontrolle, 2007, S. 50.

298 So ebenfalls Degen, Freiwillige Selbstkontrolle, 2007, S. 50.

299 Die rechtliche Einordnung des „Sich-Bedienens“ zugleich unter 3. Teil A. II. 1.

300 Zu alledem Volkmann, Der Störer im Internet, 2005, S. 213 ff.; Zimmermann, NJW 1999, 3145 (3149); Frey/Rudolph, Rechtsgutachten BVDW, 2008, Rn. 118 ff.

301 In Gerstorf, JZ 2008, 831 (832); Schoch, NVwZ 2008, 241 (246); speziell in Bezug auf AccessProvider bei Sperranordnungen auch Koreng, Zensur im Internet, 2010, S. 143. 
pornographischen Gefahren als solche privatisiert wird, sondern nur ihr planmäBiger Vollzug. Die funktionale Privatisierung belässt die Aufgabenzuständigkeit und damit die Aufgabenverantwortlichkeit beim Hoheitsträger; lediglich die Durchführung der Aufgabe wird einem Privaten übertragen. ${ }^{302}$ Das in die Pflicht genommene Privatrechtssubjekt wird folglich für den Staat zur Erfüllung präventiver Gefahrenabwehr tätig. ${ }^{303}$

\section{Rechtsstellung Staat zu Access-Providern}

Fraglich ist, welche Rechtsstellung den Access-Providern im Verhältnis zum selbst nicht handeln könnenden Staat zuzusprechen ist: In Betracht kommt eine Rechtsstellung als Verwaltungshelfer oder als Beliehene des Staates. Im Unterschied zueinander zeichnet sich der Beliehene dadurch aus, dass er vom Staat mit der selbstständigen Wahrnehmung hoheitlicher Aufgaben betraut ist. ${ }^{304}$ Wesentliches Merkmal der eigenständigen Aufgabenwahrnehmung ist eine eigene Verwaltungsaktbefugnis des handelnden Privatrechtssubjekts. ${ }^{305}$ Der Private kann - wie die staatlichen Exekutivbehörden - rechtsverbindlich unmittelbar geltende Verfügungen gegenüber Dritten erlassen und bei Nichtbefolgung Sanktionen anordnen. Notwendig zur Rechtsstellung als Beliehener ist ein formeller Beleihungsakt, der durch ein formelles Gesetz festzulegen ist. ${ }^{306} \mathrm{Im}$ Gegensatz dazu wird der Verwaltungshelfer nicht selbstständig tätig, seine hoheitlichen Befugnisse sind auf die

Di Fabio, JZ 1999, 585 (588); Gersdorf, JZ 2008, 831 (832); Schoch, NVwZ 2008, 241 (246). Die „funktionale Privatisierung“ ist nicht die einzige Möglichkeit Private Rechtssubjekte mit staatlichen Aufgaben zu versehen. Neben der funktionalen, gibt es auch die materiell (auch Aufgabenprivatisierung genannt) und die formelle Privatisierung (auch Organisationsprivatisierung genannt). Bei der materiellen Privatisierung wird die Staatsaufgabe als solche privatisiert, das private Rechtssubjekt erbringt die Aufgabe eigenständig und muss auch die finanziellen Verbindlichkeiten, die sich aus der Aufgabe ergeben selbst tragen. Der Staat muss lediglich im Rahmen der Gemeinwohlverträglichkeit der Aufgabenverteilung unterstützend tätig werden Lämmerzabl, Die Beteiligung Privater an der Erledigung öffentlicher Aufgaben, 2007, S. 97; König, DöV 1999, 322 (324); bei der formellen Privatisierung hingegen erfolgt allein ein Wechsel der Rechtsform in der die betreffende Aufgabe wahrgenommen wird. Die Aufgabe selbst bleibt weiterhin staatlich, nur ihr organisatorisches Verfahren wird von einem Privaten übernommen, ausführlich, Schuppert in: Hoffmann-Riem/Schmidt-Aßmann/Voßkuhle, Grundlagen des Verwaltungsrechts, 2006, Bd. I, $\int 16$ Rn. 83.

303 Gersdorf, JZ 2008, 831 (832); Koreng, Zensur im Internet, 2010, S. 144, allgemein zu den daran geknüpften rechtlichen Folgen etwa im Staatshaftungsrecht, Papier in: Münch. Komm. BGB, $\int 839$ BGB, Rn. 135 f.

304 Burgi: FS für Maurer, 2001, S. 581 (585); Steiner, FS für Koja, 1998, S. 603; Stelkens, NVwZ 2004, 304 (305).

305 Kiefer, LKRZ 2009, 441.

306 Schoch, NVwZ 2008, 241 (246); Stelkens, NVwZ 2004, 304 (305 f.); Gersdorf, JZ 2008, 831 (832). 
Vorbereitung oder die tatsächliche Durchführung der Staatsaufgabe beschränkt; die eigentliche Entscheidungskompetenz verbleibt bei der Behörde. ${ }^{307}$

Nimmt ein Access-Provider auf staatliche Veranlassung eine technische Sperrung bestimmter Internetseiten vor, so steht ihm regelmäßig kein eigenes Ermessen hinsichtlich der Vornahme - des „ob“ er überhaupt tätig werden soll - zu; vielmehr führt er nur eine gesetzliche Handlungsverpflichtung aus, dessen Adressatenkreis er unmittelbar unterfällt. Die Einordnung des Onlineangebotes als kinderpornographisch im Sinne des $₫ 184 \mathrm{~b}$ StGB und die daraus resultierende Notwendigkeit der Sperrung, muss schon aufgrund des hierfür notwendigen juristischen Sachverstands bei einer staatlichen Behörde verbleiben. ${ }^{308}$ Die hoheitlichen Befugnisse des Access-Providers erstrecken sich lediglich auf die Durchführung der Staatsaufgabe, folglich der Implementierung einer technischen Sperrmaßnahme ohne eigene Entscheidungskompetenz. Damit ist der Access-Provider bei der staatlichen Veranlassung zur Sperrung als Verwaltungshelfer einzuordnen. ${ }^{309}$

Ohne eine entsprechende gesetzliche Beschränkung innerhalb der Formulierung der Sperrverpflichtung könnte dem Access-Provider aber in Bezug auf die Wahl der vorzunehmenden Sperrmethode - mithin das „wie“ der Vornahme der Sperrung - ein gewisser Entscheidungsspielraum zuzubilligen sein. Der AccessProvider könnte in einem solchen Fall selbstbestimmt entscheiden, ob er beispielsweise zwangsweise alle Anfragen über einen implementierten Proxy leitet, einzelne IP-Adressen unterbindet oder bereits an den zumeist selbst betriebenen DNS-Server Konfigurationen vornimmt, die eine Zugriffsverweigerungen zum angefragten Content zur Folge haben. Obgleich sich gerade diese Selbstständigkeit entscheidend auf die betroffenen Grundrechte, insbesondere der Nutzer auswir-

307 So ausdrücklich Remmert, Private Dienstleistungen in staatlichen Verwaltungsverfahren, 2003, S. 217 ff.; Hufeld, Die Vertretung der Behörde, 2003, S. 21 ff.; Maurer, Allg. Verwaltungsrecht, \23, Rn. 60. Allgemein zur Abgrenzung der beiden Rechtsinstitute, Stober, Hdb. Wirtschaftsverwaltungs- und Umweltrechts, 1989, S. 915 ff.; Nünke, Verwaltungshilfe und Inpflichtnahme, 2005, S. 9.

308 Strikt davon zu unterscheiden sind privat veranlasste Sperrungen durch Access-Provider, wie dies etwa in der sog. „Arcor-Sperre“ der Fall war, hierzu u.a. Schnabel, K\&R 2008, 26. Hier geht es rechtlich betrachtet im Wesentlichen um privatrechtliche Unterlassungsansprüche aus $\ 1004$ BGB im Bereich des Wettbewerbsrechts. Zu den Rechtsproblemen, etwa Koreng, Zensur im Internet, 2010, S. 164 ff., mit besonderer Berücksichtigung des Zensurverbots, S. 211 ff.

309 In die Richtung auch Koreng, Zensur im Internet, 2010, S. 144; offen gelassen Sieber/Nolde, Sperrverfügungen im Internet, 2008, S. 60: Unabhängig einer präzisen Einordnung sind die Access-Provider „Werkzeug und Erfüllungsgehilfen der öffentlichen Hand“ zu betrachten. In die Richtung auch Boecker, Stellungnahme der Sachverständigen im Rechtsausschuss v. 8.11.2010, S. 4, abrufbar unter: http://www.bundestag.de/bundestag/ausschuesse17/a06/anhoerungen/archiv/03_Zugangsers chwerung/04_Stellungnahmen/Stellungnahme_Boecker.pdf (zuletzt abgerufen 20.5.2012). 
ken, da - wie zugleich zu zeigen sein wird - jede Sperrmethode mit verschiedener Eingriffsintensität verbunden sein kann. ${ }^{310}$ An der Einordnung als Verwaltungshelfer vermag die Entscheidungskompetenz jedoch nichts zu ändern, da sie sich nur auf einen organisatorischen Nebenbereich erstreckt und nicht den Kern der Staatsaufgabe ausmacht. Auch im Falle einer mangelnden gesetzlichen Beschränkung der technischen Ausführungshandlung würde der Access-Provider als Verwaltungshelfer einzustufen sein.

\section{Zwischenergebnis: Rechtsstellung}

Im Ergebnis fungieren die Access-Provider bei der Erfüllung der staatlichen Handlungsverpflichtung damit nur als Diener des Staates, wobei die eigentliche Sperrung stets eine staatliche Aufgabenerfüllung bleibt. ${ }^{311}$ Aufgrund ihres direkten Einflussbereichs und einer grundsätzlichen technischen Versiertheit, die der Dienstleistung des Access-Providings anhaftet, sind die Zugangsdiensteanbieter die Adressaten einer gesetzlichen Handlungsverpflichtung zur Vornahme von Sperrungen onlineverbreiteter Inhalte. 312

\section{Grundsatz der Verhältnismäßigkeit}

Aus dem Umstand, dass es sich bei gesetzlichen Sperrverpflichtungen um eine Maßnahme der staatlichen Gefahrenabwehr handelt folgt, dass sich die Maßnahme am rechtsstaatlichen Grundsatz der Verhältnismäßigkeit orientieren muss. ${ }^{313}$ Durch die Beachtung dieses rechtsstaatlichen Grundprinzips, soll im Spannungsverhältnis zwischen notwendigen staatlichen Maßnahmen einerseits und subjektiven Freiheitsrechten des Bürgers andererseits, ein adäquater Ausgleich geschaffen

310 Dazu ausführlich unten 3. Teil B. .

311 IE. auch Sieber/Nolde, Sperrverfügungen im Internet, 2008, S. 60.

312 Die Frage der Vereinbarkeit einer solchen Inanspruchnahme mit dem medienspezifischen Haftungssystem des $\iint 7 \mathrm{ff}$. TMG wird in der Arbeit bewusst offengelassen. Die Prüfung konzentriert sich vielmehr rein auf die verfassungsmäßige Vereinbarkeit. Zur Einordnung in das Haftungsregime Frey/Rudolph, Rechtsgutachten BVDW, 2008 mwN.

313 Gilt damit rechtsgebietsübergreifend, u.a. BVerfGE 19, 342 (347 f.) - im Bezug auf das Strafprozessrecht; BVerfGE 43, 242 - Hochschulrecht; BVerfG, NVwZ 2006, 1282 - Disziplinarverfahren; BGH, NStZ, 2009, 324 - Strafrecht; BVerfGE 44, 353 - Gesundheitswesen; allgemein zum Verhältnismäßigkeitsgrundsatz und seinen rechtlichen Ausgestaltungen: Grz̨eszick in: Maunz/Dürig, Art. 20 GG, Rn. 106 ff.; Huster/Rux in: Epping/Hillgruber, Art. 20 GG, Rn. 167 ff.; Stern in: Isensee/Kirchhof, Hdb. StaatsR, 2002, Bd. V, \ 20 IV, Rn. 7b; Hirschberg, Der Grundsatz der Verhältnismäßigkeit, 1981, S. 26 ff.; grundlegend Voßkuble, JuS 2007, 429. Der Grundsatz der Verhältnismäßigkeit wird in erster Linie aus dem Rechtsstaatsprinzip des Art. 20 Abs. 3 GG abgeleitet. 
werden. ${ }^{314}$ Ausgehend von dem Gedanken, dass die Freiheit des Einzelnen im Rechtsstaat ein oberstes Gut darstellt und vor unnötigen und übermäßigen staatlichen Eingriffen zu bewahren ist, ist die Eingriffsbefugnis der öffentlichen Gewalt in der Freiheitsphäre des Bürgers zurückgedrängt und nur insoweit zulässig, als der Eingriff zum Schutz öffentlicher Interessen unerlässlich ist und das gewählte Eingriffsmittel zum angestrebten Erfolg in einem vernünftigen Verhältnis steht. ${ }^{315}$ Zur Konkretisierung der Anforderungen müssen staatliche Maßnahmen - der üblichen Terminologie folgend - einen legitimen Zweck verfolgen, geeignet, erforderlich und letztlich verhältnismäßig im engeren Sinne, sprich angemessen, in Bezug auf den zu erzielenden Zweck sein. Ob staatliches Handeln dann den Verhältnismäßigkeitsanforderungen ,im engeren Sinne“ genügt, ist anhand einer Zweck-Mittel-Relation zu bestimmen, welche die Schwere und das Gewicht des Eingriffs sowie die Dringlichkeit der ihn rechtfertigenden Gründe ins Verhältnis zur Zumutbarkeit der Maßnahme für den betroffenen Adressaten sowie damit einhergehender Beeinträchtigung von Grundrechten Dritter setzt. ${ }^{316}$

Freilich kann man in Anbetracht dessen die Frage aufwerfen, ob die Sperrungen - wie in der weiteren Prüfung angelegt - zu Recht an dem Grundsatz der Verhältnismäßigkeit gemessen werden, obgleich der eigentliche Sperrvorgang von einem Privatrechtssubjekt vorgenommen wird und gerade nicht von einer staatlichen Stelle. Ausdrücklich ist nur staatliches Handeln dem Grundsatz der Verhältnismäßigkeit unterworfen, nicht jedoch unmittelbar der einzelne Private. ${ }^{317}$ Aus der Herleitung der Rechtsstellung der Access-Provider im Verhältnis zum Staat bei Ausführung der staatlichen Sperrverpflichtung folgt allerdings, dass die Access-Provider rechtlich stets als Privatrechtssubjekte zu behandeln sind. Zwar sind die Access-Provider während der Sperrmaßnahme faktisch in eine staatliche Aufgabe eingegliedert, rechtlich betrachtet ist diese Eingliederung nicht gleichbedeutend mit einer Übertragung von Hoheitsgewalt, sondern beschränkt sich rein auf den organisatorisch technischen Bereich. Im Ergebnis muss sich die Bindungswirkung an den Verhältnismäßigkeitsgrundsatz, die grundsätzlich nur staatlichen

314 Gržeszick in: Maunz/Dürig, Art. 20 GG, Rn. 108; Huster/Rux in: Epping/Hillgruber, Art. 20 GG, Rn. 167 f.; Billmeier, Die Düsseldorfer Sperrungsverfügung, 2007, S. 111.

315 BVerfG, NJW 1974, 227.

316 Die hier angesprochene Angemessenheit der Maßnahme wird auch als Verhältnismäßigkeit im engeren Sinne verstanden, ständ. Rspr. u.a. BVerfGE 90, 145; BVerfGE 109, 279; BVerfGE 113, $148 \mathrm{mwN}$.

317 So die Grundaussage der mittelbaren Drittwirkung von Grundrechten, BVerfGE 7, 198 (205); BVerfGE 25, 256 (263); BVerfGE 34, 269 (280); Starck in: v. Mangoldt/Klein/Starck, Art. 1 GG, Rn. 303 ff.; Zur ausschließlichen Bindung des Staates an den Verhältnismäßigkeitsgrundsatz, Schulze-Fielitz in: Dreier, Art. 20 GG, Rn. 187; Sommermann in: v. Mangoldt/Klein/Starck, Art. 20 GG, Rn. 316. 
Stellen abverlangt wird, auch explizit auf die durch die von Access-Providern vorzunehmenden Sperrmaßnahmen erstrecken. ${ }^{318}$

IV. Ergebnis: Vorfragen

Zur Erfüllung der staatlichen Aufgabe bedient sich der Staat der Zugangsanbieter (Access-Provider). Zweck einer Sperrung kinderpornographischer Angebote ist zum einen die verfassungsrechtlich gebotene Realisierung eines effektiven Jugendschutzes, gleichzeitig verfolgt der Gesetzgeber mit einem Sperransatz auch objektiv-rechtliche Belange der Allgemeinheit, indem er durch die Unterdrückung des Zugriffs grundsätzlich die Aufrechterhaltung der Staatssicherheit sowie der Rechtsordnung forciert. Bei der Vornahme der Sperrmaßnahme sind AccessProvider als staatliche Verwaltungshelfer einzuordnen, die keine eignen Hoheitsbefugnisse genießen. Folglich sind die internetbasierten Sperrmaßnahmen, wie sämtliches staatliches Handeln am Grundsatz der Verhältnismäßigkeit zu messen.

\section{B. Entgegenstehende Grundrechte der Access-Provider}

Grundlage einer verfassungsmäßigen Auseinandersetzung mit einer gesetzlichen Sperrverpflichtung ist der Umstand, dass sie grundrechtlich geschützte Positionen Dritter berühren. Bereits die Tatsache, dass der Staat die Sperrung nicht selbst vornehmen kann, sondern sich der am Kommunikationsprozess beteiligten Access-Provider bedient, deutet darauf hin, dass zumindest grundrechtlich verbürgte Rechte der in Anspruch genommenen Access-Provider entgegenstehen. Die nachfolgende verfassungsmäßige Analyse widmet sich scherpunktmäßig den Grundrechten, die im Rahmen der politischen und gesellschaftlichen Auseinandersetzung kontrovers diskutiert werden. ${ }^{319}$

\section{Berufsfreiheit Art. 12 Abs. 1 GG}

\section{Eingriff in den Schutabereich}

Die Berufsfreiheit umfasst in ihrem persönlichen Schutzbereich grundsätzlich nur deutsche Staatsbürger im Sinne des Art. 116 GG, das heißt nur diejenigen, denen die deutsche Staatsangehörigkeit zukommt. Auswärtige natürliche Personen können sich nach einhelliger Auffassung ebenfalls auf den Schutzbereich berufen,

318 IE. auch Sieber/Nolde, Sperrverfügungen im Internet, 2008, S. 60; Koreng, Zensur im Internet, 2010, S. 143.

319 Hinsichtlich einer eigehenden Prüfung der Verfassungsmäßigkeit von Sperrmaßnahme sei auf die ausführliche Bearbeitung von Sieber/Nolde, Sperrverfügungen im Internet, 2008, hingewiesen. Auch Grundlage dieses Werkes, werden entsprechend weniger diskutierte Grundrechte lediglich vereinfacht wiedergegeben. 
soweit sie im Geltungsbereich der EU gemeldet sind. ${ }^{320}$ Außerhalb der EU lebenden Bürgern bleibt ein direkter Schutz über Art. 12 GG verwehrt. Diese können sich bei Einschränkungen der Berufsfreiheit jedoch auf die Allgemeine Handlungsfreiheit des Art. 2 Abs. 1GG berufen. ${ }^{321}$ Grundrechtsträger können neben natürlichen Personen auch inländische beziehungsweise europäische juristische Personen des Privatrechts sein, soweit die Tätigkeit ihrem Wesen nach grundsätzlich auch von einer juristischen Person ausgeübt werden kann. ${ }^{322}$

Die Tätigkeit der Access-Provider, also die Bereitstellung der zum Kommunikationsaufbau im Internet notwendigen Infrastruktur, das Ermöglichen eines Verbindungsaufbaus sowie der Kommunikation, sind Tätigkeiten die typischerweise von einer juristischen Person ausgeübt werden. Eine gesetzliche Verpflichtung, die sich an alle inländischen Access-Provider richtet, würde daher unproblematisch in den persönlichen Schutzbereich des Grundrechts fallen.

Den Ausgangspunkt für die Bestimmung des sachlichen Schutzbereiches bildet allgemein der „Beruf“. Darunter wird jede auf Dauer angelegte wirtschaftliche Tätigkeit verstanden, die zur Schaffung und Erhaltung einer Lebensgrundlage dient. ${ }^{323}$ Die Tätigkeit der Access-Provider stellt unter Zugrundelegung der Definition einen Beruf im Sinne des Art. 12 Abs. 1 GG dar. Die Bereitstellung der zur Nutzung des Internets benötigten Infrastruktur wird überwiegend im Rahmen einer gewerblich strukturierten entgeltlichen Dienstleistung erbracht, die sich nicht in einem einmaligen Erwerbsakt erschöpft. ${ }^{324}$

Beim Schutzbereich des Art. 12 Abs. 1 GG handelt es sich zwar um ein einheitliches Berufs-Grundrecht, der Schutzbereich wird aber in das Recht auf Berufsausübungsfreiheit und Berufswahlfreiheit untergliedert. ${ }^{325}$ Die Berufswahlfreiheit schützt zum einen die Wahl des Berufes, also die Entscheidung überhaupt einen Beruf zu ergreifen, zum anderen die zwanglose Wahl einen bestimmten Beruf vorzunehmen und gegebenenfalls zu wechseln. ${ }^{326}$ Die Berufsausübungsfrei(321); BVerfGE 111, 10 (28); Scholz in: Maunz/Dürig, Art. 12 GG, Rn. 29 mwN.; Jarass in: Jarass/Pieroth, Art. 12 GG, Rn. 4.

324 2007, S. 256; Sieber/Nolde, Sperrverfügungen im Internet, 2008, S. 61; Spoenle, jurisAnwZert ITR 17/2009, Anm. 2; iE. wohl auch Kabl, SächsVBl. 2010, 180 (190), der allerdings ohne den Schutzbereich zu eröffnen gleich in die verfassungsmäßige Rechtfertigung einsteigt.

Breuer in: Isensee/Kirchhof, Hdb. StaatsR, 2001, Bd. VI, \147, Rn. 21.

BVerfGE 78, 179 (196 f.); BVerfGE 104, 337 (346); BVerwGE 59, 284 (294).

BVerfGE 21, 362 (369); BVerfGE 61, 82 (101); BVerfGE 68, 193 (206).

BVerfGE 7, 277 (397); BVerfGE 102, 197 (212); BVerfGE 105, 252 (265); BVerfGE 110, 304

BVerfGE 7, 377 (402); BVerfGE 95, 193 (214); Breuer in: Isensee/Kirchhof, Hdb. StaatsR, 2001, Bd. VI, \147, Rn. 32; Borrmann, Schutz der Berufsfreiheit, 2002, S. 70 f.

BVerfGE 58, 358 (364); BVerfGE 68, 256 (267); BVerfGE 87, 287 (316); BVerfGE 43, 291 (363). 
heit wiederum umfasst die gesamte berufliche Tätigkeit, das heißt sämtliche mit der Ausübung einhergehenden Modalitäten, wie Mittel, Art und Umfang sowie die gegenständliche Ausgestaltung der beruflichen Tätigkeit..327

Durch eine gesetzliche Verpflichtung der Access-Provider zur Vornahme von Sperrungen kinderpornographischer Inhalte wird die gegenständliche Ausgestaltung der beruflichen Tätigkeit des „Access-Providings“ beeinflusst. Durch eine gesetzliche Sperrverpflichtung wird das berufliche Tätigkeitsfeld der Provider um gefahrenabwehrrechtliche Aspekte erweitert und den Adressaten damit eine zusätzliche Leistung abverlangt, die vom normalen Geschäftsverkehr abweicht. Die gesetzliche Sperrverpflichtung gestaltet damit bestimmte Modalitäten der beruflichen Tätigkeit des Access-Providings aus und ist nicht etwa auf die vorgelagerte Entscheidung, wie die Aufnahme einer bestimmten beruflichen Tätigkeit, ausgerichtet. ${ }^{328}$ Folglich würde es sich bei einer gesetzlichen Sperrverpflichtung um eine Berufsausübungsregelung handeln. ${ }^{329}$

Die alleinige Einordnung in den Schutzbereich reicht indes nicht aus, um auch einen Eingriff in denselben anzunehmen. Für das Vorliegen eines tatsächlichen Eingriffs in die Berufsausübung der Access-Provider im Sinne des Art. 12 Abs. 1 GG ist es ferner notwendig, dass die staatliche Maßnahme gerade eine „objektiv berufsregelnde Tendenz“ aufweist. ${ }^{330} \mathrm{Da}$ viele legislatorische Beschränkungen Rückwirkungen auf den Beruf des Normadressaten zulassen und deshalb eine uferlose Ausweitung des Grundrechtsschutzes drohen würde, ${ }^{331}$ wird für die Bejahung eines tatsächlichen Eingriffscharakters einer Regelung zusätzlich verlangt,

327 Breuer in: Isensee/Kirchhof, Hdb. StaatsR, 2001, Bd. VI, \147, Rn. 57; Jarass in: Jarass/Pieroth, Art. 12 GG, Rn. 8.

328 Sieber/Nolde, Sperrverfügungen im Internet, 2008, S. 62 mwN und einer Abgrenzung zur Berufswahlfreiheit anhand der Berufsbildlehre, wonach die abverlangte Tätigkeit, soweit sie eine sozial abgrenzbare Aktivität mit eignen charakteristischen Gepräge darstellt, einen selbstständigen Eingriff in die Berufswahlfreiheit begründen kann. Die bloße Verpflichtung zur Übernahme von Aufgaben die über die Zugangsgewährung hinausgehen und möglicherweise im Rahmen der Datenverarbeitung einen Eingriff in Schichten notwendig machen, die ansonsten außerhalb des Tätigkeitsgebiets der Access-Provider angesiedelt sind, begründet jedoch noch nicht, dass nach den Charakteristika und dem Gesamtgefüge nach, eine selbstständige Berufswahlregelung vorliegt. Zur Berufsbildlehre, BVerfGE 13, 97 (196), BVerfGE 16,147 (163 f.); BVerfGE 25, 236 (247); iE. auch Kabl, SächsVBl. 2010, 180 (185) jedoch ohne Begründung.

329 IE. ebenso Kabl, SächsVBl. 2010, 180 (185); Schnabel, Sperrungsverfügungen gegen AccessProvider, 2002, S. 62, abrufbar unter:

http://www.eulisp.de/tl_files/eulisp\%20abschlussarbeiten/schnabel_christoph.pdf, (zuletzt abgerufen 20.5.2012); Sieber/Nolde, Sperrverfügungen im Internet, 2008, S. 62.

330 BVerfGE 13, 181 (186); BVerfGE 97, 228 (254); BVerfGE 98, 228 (254); BVerfGE 98, 218 (258); BVerfGE 110, 274 (288); BVerfGE 111, 191 (213).

331 BVerfGE 97, 228 (253 f.). 
dass diese „im Schwerpunkt die Tätigkeiten betreffen [sollen], die typischerweise beruflich ausgeübt werden“, 332 etwa Rahmenbedingungen der beruflichen Tätigkeit gestaltet werden oder die gesetzliche Intention in ihren tatsächlichen Auswirkungen im engen Zusammenhang mit der Ausübung des Berufes steht. ${ }^{33}$

Eine solche berufsregelnde Tendenz liegt bei einer gesetzlichen Sperrverpflichtung vor: Access-Providern wird eine Sperrverpflichtung aufgedrängt, die primär gefahrenabwehrrechtliche Ziele verfolgt und eine Zugriffssperrung, also eine Einschränkung des Zugangs zum Internet abverlangt. Diese Verpflichtung stellt damit gerade das Gegenteil der sonstigen beruflichen Ausgestaltung dar, welche nicht auf die Verhinderung, sondern auf die Gewährung des Zugriffs gerichtet ist. Sie ist daraus folgernd explizit darauf ausgerichtet die Rahmenbedingungen der beruflichen Tätigkeit zu ändern. ${ }^{334}$ Damit liegt einer gesetzlichen Sperrverpflichtung eine berufsregelnde Tendenz zugrunde, die nach verfassungsrechtlichem Verständnis einen Eingriff in den Schutzbereich der Berufsausübungsfreiheit begründet.

\section{Verfassungsrechtliche Rechtfertigung}

Allein der Umstand, dass verfassungsrechtlich geschützte Interessen durch eine staatliche Maßnahme berührt werden, noch nicht die Verfassungswidrigkeit eines Gesetzes. Vielmehr muss es dem Staat zugebilligt werden, im Spannungsverhältnis zwischen notwendigen staatlichen Maßnahmen zum Schutze verfassungsrechtlich fundierter Rechtsgüter einerseits und subjektiven Freiheitsrechten des Bürgers andererseits, einen adäquaten Ausgleich zu schaffen, bei dem unter bestimmten Voraussetzungen auch die Freiheitsrechte des Einzelnen gegenüber der staatlichen Vollzugsgewalt zurücktreten müssen. ${ }^{335}$

An die Verfassungsverträglichkeit einer Beschränkung von Freiheitsrechten des Einzelnen setzt das Grundgesetz selbst spezifische Anforderungen, die für jedes Grundrecht verfassungsrechtlich normiert und damit rechtsstaatlich überprüfbar sind (sog. Schranken). ${ }^{336}$ Der Schranken-Systematik folgend unterscheidet das Grundgesetz Grundrechte mit so genanntem einfachem Gesetzesvorbehalt, diese sind schon durch ein verfassungsgemäßes Gesetz im materiellen Sinn ein-

BVerfGE 97, 228 (254).

333

BVerfGE 111, 191 (213).

334

So Sieber/Nolde, Sperrverfügungen im Internet, 2008, S. 62; Degen, Freiwillige Selbstkontrolle, 2007, S. 292; iE auch schon Germann, Gefahrenabwehr im Internet, 2000, S. 405.

335 Billmeier, Die Düsseldorfer Sperrungsverfügung, 2007, S. 111.

336 Grundlegend zur Beschränkbarkeit von Grundrechten Stern in: FS 50 Jahre Bundesverfassungsgericht, 2001, Bd. 2, S. 1; Berka, ZÖR 1999, 31; Arnauld, Die Freiheitsrechte und ihre Schranken, 1999, passim. 
schränkbar. ${ }^{337}$ Daneben wird bestimmten Grundrechten eine Einschränkungsmöglichkeit erst über die spezifischen Voraussetzungen eines qualifizierten Gesetzesvorbehalts gewährt. Beispielsweise muss der Gesetzgeber bei der allgemeinen Einschränkung der Meinungsfreiheit darauf achten, dass es sich um ein ,allgemeines" Gesetz, dass nicht schlechthin die Meinungsfreiheit beschränken möchte. Daneben existieren auch Grundrechte die objektiv betrachtet keine Schranke aufweisen. Wie beispielsweise die Kunstfreiheit aus Art. 5 Abs. 3 GG. Diese vermeintlich „schrankenlos gewährleisteten Grundrechte“ lassen sich indes nur über so genanntes kollidierendes Verfassungsrecht, also andere Rechte mit Verfassungsrang, einschränken. 338

Innerhalb der verfassungsrechtlichen Rechtfertigung kommt neben der grundsätzlichen Einschränkungsmöglichkeit des Grundrechts dem Grundsatz der Verhältnismäßigkeit eine überragende Bedeutung zu. ${ }^{339}$ Wenngleich lediglich das gesetzlich favorisierte Ziel eines Rechtsgüterschutzes ausreichen würde, um Grundrechtseinschränkungen beliebiger Art zu rechtfertigen, könnte die Wichtigkeit der Grundrechte durch die bloße Beschränkungsmöglichkeit ausgehöhlt werden. Um dieses zu vermeiden, ist auch das zum Schutze der verfassungsrechtlich fundierten Rechtsgüter staatlich eingesetzte Mittel, bestimmten Grenzen unterworfen. ${ }^{340}$ Danach ist trotz des objektiven Erfüllens der Schrankenvoraussetzung, der Eingriff nur dann verfassungsrechtlich gerechtfertigt, wenn dieser sich im Rahmen des durch die so genannten Schranken-Schranken eröffneten Spielraums bewegt, letztlich die charakteristischen Anforderungen der Verhältnismäßigkeit erfüllt. ${ }^{341}$ Die einem bestimmten Rechtsgüterschutz dienende gesetzliche Regelung, die gleichzeitig in verfassungsrechtlich abgesicherte Rechte Dritter eingreift, muss demnach einem legitimen Zweck dienen, im Hinblick auf die Erreichung dieses Zwecks geeignet, erforderlich und angemessen sein. ${ }^{342}$

337 Exemplarisch ist hier beispielweise Art. 2 Abs. 1 GG zu nennen. Die Beschränkung der Allgemeinen Handlungsfreiheit kann bereits „durch oder aufgrund“ eines Gesetzes erfolgen. Gleiches bspw. auch in Bezug auf die Beschränkung von Art. 11 GG.

338 Pernice in: Dreier, Art. 5 GG, Rn. 39; Jarass in: Jarass/Pieroth, Art. 5 GG, Rn. 131. Grundsätzlich ist hier eine Schrankenübertragung der Schranken aus Art. 5 Abs. 2 GG bzw. Art. 2 Abs. 1 GG abzulehnen. BVerfGE 47, 327 (369); Scholz in: Maunz/Dürig, Art. 5 GG, Rn. 184 mwN.; Bethge in: Sachs, Art. 5 GG, Rn. 223; Pernice in: Dreier, Art. 5 GG, Rn. 33; grundlegend Pecher, Verfassungsimmanente Schranken, 2002, passim.

339 Grundlegend Lang in: Epping/Hillgruber, Art. 2 GG, Rn. 25.

340 Grabitz, AöR 98 (1973), 568 (586 ff.); Starck in: v. Mangoldt/Klein/Starck, Art. 1 GG, Rn. 277; Koch, Der Grundsatz der Verhältnismäßigkeit, 2003, S. 35 ff.

341 Ständ. Rspr. u.a. BVerfGE 75, 108 (154 f.); BVerfGE 80, 137 (153).

342 Zum Verhältnismäßigkeitsgrundsatz u.a. BVerfGE 19, 342 (347 f.); BVerfGE 43, 242; BVerfG, NVwZ 2006, 1282; BGH, NStZ, 2009, 324; BVerfGE 44, 353; zur rechtlichen Ausgestaltung 
Grundsätzlich unterliegen Eingriffe in die Berufsfreiheit einem einfachen Gesetzesvorbehalt. ${ }^{343}$ Diese dürfen folglich bereits durch einfache Gesetze eingeschränkt werden. Abstrakt betrachtet wäre eine gesetzliche Sperrverpflichtung objektiv in der Lage die Berufsfreiheit zu beschränken. Ein Eingriff in die Berufsfreiheit wäre aber nur dann verfassungsrechtlich gerechtfertigt, soweit das einschränkende Gesetz, hier also die gesetzliche Sperrverpflichtung, den Anforderungen an den Verhältnismäßigkeitsgrundsatz genügen würde. ${ }^{344}$

\section{a) Legitimität des gesetzlichen Sperransatzes}

Wie vorangestellt dient eine gesetzlich angeordnete technische Sperrmaßnahme zwei unterschiedlichen Schutzzwecken. ${ }^{345}$

Zum einen soll aktiv der Zugang zu bestimmten Inhalten unterbunden werden, um die Rechtsordnung vor Verstößen zu wahren, die mit der Rezeption des Inhaltes begründet würden. Im vorliegenden Fall handelt es sich damit speziell um Rechtsverstöße, die den Straftatbestand des $\ 184 b$ StGB erfüllen. Über die technische Zugriffserschwerung sollen mittelbar auch die Auswirkungen unterbunden werden, die mit der ungehinderten Rezeption und Verbreitung solcher Inhalte einhergehen. Durch die Verhinderung der Rezeptionsmöglichkeit sollen Persönlichkeitsrechte der dargestellten Kinder geschützt werden, indem eine erneute Zur-Schau-Stellung der kindlichen Protagonisten verhindert wird. ${ }^{346}$ Langfristig soll die Unterdrückung einer latenten Nachahmungsgefahr zukünftiger Produktionen minimiert und damit mittelbar auch auf die Verhinderung der sexuellen Ausbeutung der kindlichen Protagonisten hingewirkt werden. Über eine Zugriffs-

grundlegend, Stern in: Isensee/Kirchhof, Hdb. StaatsR, 2002, Bd. V, \20 IV, Rn. 7b; Hirschberg, Der Grundsatz der Verhältnismäßigkeit, 1981, S. 26 ff.; Voßkuble, JuS 2007, 429.

343 BVerfGE 7, 398 (402 f.); BVerfGE 84, 133 (148); Manssen in: v. Mangoldt/Klein/Starck, Art. 12 GG, Rn. 108.

Das einschränkende Gesetz muss folglich selbst verfassungsgemäß sein, dass heißt formell und materille verfassungsrechtliche legitimiert. Nachfolgend soll sich die Prüfung auf die materielle Verfassungsmäßigkeit beschränken, entsprechende formelle Voraussetzungen werden innerhalb des konkreten Fallbeispiels des Zugangserschwerungsgesetzes behandelt. Dazu 4. Teil .

Dieses wurde bereits oben unter 3. Teil A. I. dargestellt.

Sieber, Ausschussdrucksache 16 (9) 1550, S. 7; Hoffmann-Holland, Stellungnahme der Sachverständigen im Rechtsausschuss v. 8.11.2010, S. 8; abrufbar unter:

http://www.bundestag.de/bundestag/ausschuesse17/a06/anhoerungen/archiv/03_Zugangsers chwerung/04_Stellungnahmen/Stellungnahme_Hoffmann-Holland.pdf, in die Richtung auch EFC, EFC, „14 months on: A combined report from the European Financial Coalition 20092010“, S. 17 abrufbar unter:

http://ceop.police.uk/Documents/EFC\%20Strat\%20Asses2010_080910b\%20FINAL.pdf (zuletzt abgerufen 20.5.2012). 
erschwerung wird zudem auch ein nach außen hin sichtbares Zeichen der gesellschaftlichen Ächtung von Kinderpornographie gesetzt. ${ }^{347}$

Da eine gesetzliche Sperrverpflichtung die Erreichbarkeit des kinderpornographischen Contents unabhängig vom Alter potentieller Zielgruppen beschränken, folgt ihre Legitimität neben der verfassungsrechtlichen Gewährleistung des Jugendschutzes auch aus verfassungsrechtlichen Grundwerten der Allgemeinheit, wie der Aufrechterhaltung der öffentlichen Sicherheit und Ordnung und der Gewährleistung der Rechtsordnung. Damit stehen die Schutzzwecke im Einklang mit wesentlichen Wertentscheidungen des Grundgesetzes, so dass an der grundsätzlichen Legitimität der Zielsetzung keine Zweifel bestehen. ${ }^{348}$

\section{b) Geeignetheit}

Weitaus problematischer gestaltet sich die Geeignetheit eines gesetzlichen Sperransatzes. Eine staatliche Maßnahme ist als geeignet im verfassungsrechtlichen Sinne anzusehen, wenn sie den legitimen Zweck erreicht oder zumindest fördert. ${ }^{349}$ Übertragen auf die Sperrverpflichtung bedeutet das, dass diese dann geeignet ist, wenn durch sie die Erreichbarkeit des kinderpornographischen Content tatsächlich eingeschränkt und die langfristigen Risiken einer ungehinderten Verbreitung kinderpornographischer Inhalte minimiert werden. ${ }^{350}$ Die Rechtsprechung greift zur Bestimmung einer Geeignetheit speziell im Bereich der internetbasierten Sperrungen auf das oftmals zitierte Beispiel des „Schritt[s] in die richtige Richtung““351 und des ,wirksamen Beitrag[s] zur Gefahrenabwehr“352 zurück.

Kubnen, Ausschussdrucksache 16 (9) 1545, S. 1; Höhne/Dienst, jurisPR ITR 13/2009, Anm. 6; so auch schon die Eckpunkte der Bundesministeriums für Familie, Senioren, Frauen und Jugend „Zur Bekämpfung von Kinderpornographie im Internet“ v. 25.3.2009, S. 1, abrufbar unter: http://www.bmfsfj.de/RedaktionBMFSFJ/Abteilung5/Pdf-Anlagen/kinderpornografie-

kabinett-eckpunkte,property $=$ pdf,bereich $=$ bmfsfj, sprache $=\mathrm{de}, \mathrm{rwb}=$ true.pdf $\quad$ (zuletzt abgerufen 20.5.2012).

348 IE. Billmeier, Die Düsseldorfer Sperrungsverfügung, 2007, S. 245

349 Ständ. Rspr. u.a. BVerfGE 96, 10 (23); BVerfGE 30, 292 (316); BVerfGE 33, 171 (187); BVerfGE 67, 157 (173); BVerfGE 90, 145 (172); BVerfGE 110, 141 (164).

350 OVG Münster, K\&R 2003, 303; LG Hamburg, K\&R 2009, 272 (274); LG Hamburg, NJOZ 2010, 443 (444); so zur Geeignetheit auch Hornig, ZUM 2001, 846 (852); Zimmermann, NJW 1999, 2145 (3150); Volkmann, Der Störer im Internet, 2005, S. 232; Spindler/Volkmann, K\&R 2002, 398 (406).

351 OVG Münster, MMR 2003, 348 (351); VG Gelsenkirchen, Beschl. v. 18.12.2002 - 1 L 2528/02 n.v., VG Düsseldorf, MMR 2003, 205 m. Anm. Stadler, kritisch als Banalisierung der Geeignetheitsprüfung zur „dogmatischen Pflichtübung“ bezeichnend, Engel, MMR-Beilage 4/2003, 1 (24). 
Die Anforderungen an die Geeignetheit einer gesetzlichen Maßnahme sind damit von Verfassungswegen relativ gering. Dem Gesetzgeber wird bei der Beurteilung der Geeignetheit in ständiger Rechtsprechung ein weiter Gestaltungsspielraum zugebilligt. Die so genannte Einschätzungsprärogative ${ }^{353}$ erlaubt es dem Rechtsetzungsorgan auch solche legislatorischen Mittel einzusetzen, mit denen der bezweckte Rechtsgüterschutz zwar nicht hinreichend verwirklicht, jedoch nicht offensichtlich hinter dem bezweckten Erfolg zurückbleibt. ${ }^{354}$ Der Gesetzgeber ist regelmäßig nicht verpflichtet für die Richtigkeit der Annahme und Beurteilung der Eignung des gewählten Mittels einen Nachweis zu erbringen. ${ }^{355}$ Wenn er im Rahmen seiner Einschätzungsprärogative die Wahrscheinlichkeit annimmt, dass das gewählte Mittel den bezweckten Rechtsgüterschutz zumindest nicht offensichtlich ausschließt und auch kein wissenschaftlicher Beweis für das Gegenteil erbracht wird, dann steht der Geeignetheit aus verfassungsrechtlichen Gründen nichts entgegen. 356

\section{(aa) Ungeeignetheit wegen minimaler Erschwerung des Zugriffs?}

In der jüngsten gesellschaftlichen Auseinandersetzung wird oftmals betont, dass jeglichen technischen Sperransätzen grundsätzlich die Geeignetheit abzusprechen ist, da aufgrund von Umgehungsmaßnahmen nie wirklich erreicht werden kann, dass der Nutzer im Zugriff auf einen bestimmten Webcontent tatsächlich erschwert werde. ${ }^{357}$ In den instanzgerichtlichen Entscheidungen zu Sperrmaßnah-

352 VG Köln, MMR 2005, 399 (402), dies auch anführend, Sieber/Nolde, Sperrverfügungen im Internet, 2008, S. 180; Volkmann, Der Störer im Internet, 2005, S. 231; in die gleiche Richtung bereits Spindler/Volkmann, K\&R 2002, 398 (406). BVerfGE 77, 84 (104); BVerfGE 90, 145 (173 ff.); BVerfGE 109, 279 (336 ff.). BVerfGE 25, 1 (12 f.); BVerfGE 30, 250 (263); BVerfGE39, 210 (230 ff.); BVerfGE 98, 265 (309); BVerfGE 104, 337 (347); BVerfGE 106, 62 (150). BVerfGE 16, 147 (183); BVerfGE 30, 292 (316); BVerfGE 33, 171 (187); BVerfGE 67, (151 ff.); BVerfGE 96, 10 (23 ff.). Zu alledem Hoffmann-Holland, Stellungnahme der Sachverständigen im Rechtsausschuss v. 8.11.2010, S. 3, abrufbar unter: http://www.bundestag.de/bundestag/ausschuesse17/a06/anhoerungen/archiv/03_Zugangsers chwerung/04_Stellungnahmen/Stellungnahme_Hoffmann-Holland.pdf (zuletzt abgerufen 20.5.2012).

$356 \mathrm{Zu}$ den geringen Anforderungen an die Geeignetheitsprüfung, BGH, NJW 2008, 822 (828); IE. Sieber/Nolde, Sperrverfügungen im Internet, 2008, S. 192.

357 So bspw. Stadler, Internet-Law, Beitrag v. 4.11.2010, „Warum das Zugangserschwerungsgesetz verfassungswidrig ist“, abrufbar unter: http://www.internet-law.de/2010/11/netzsperrenwarum-das-zugangserschwerungsgesetz-verfassungswidrig-ist.html (zuletzt abgerufen 20.5.2012); so auch die Begründung der Verfassungsbeschwerde des AK-Zensur, die allerdings vom BVerfGE aufgrund mangels Begründung nicht zur Entscheidung angenommen wurde, hierzu akzensur, Beitrag v. 23.2.2011, abrufbar unter: 
men wird die Eignung einer unterschiedlich beurteilt. ${ }^{358}$ Empirische wissenschaftliche Studien, die als Beleg für die tatsächliche Wirksamkeit hinsichtlich einer verminderten Zugriffsmöglichkeit herangezogen werden können, bestehen insoweit nicht. Infolgedessen ist zu untersuchen, welche technischen Möglichkeiten zur Umgehung von Sperrmaßnahmen vorhanden sind und ob dieses in der Konsequenz zur Annahme der offensichtlichen Ungeeignetheit des Sperransatzes führen.

(1) Technische Sperrmethoden- Umgehungsmöglichkeiten

\section{(a) DNS-Sperrmethode: Umgehungsmöglichkeiten}

Die einfachste Umgehungsvariante der DNS-Sperre ist, dass der Internetnutzer die entsprechende nummerische Abfolge der IP-Adresse des zu kontaktierenden Servers, der die illegale Webseite betreibt, kennt und diese an Stelle der URL in den Browser eingibt. Wird anstelle der URL die betreffende IP-Adresse eingegeben, so entfällt die Auslösung des funktionalen DNS-Umwandlungsmechanismus. Unabhängig etwaiger Manipulationen am Domain-Name-System auf der Anwendungsschicht, wird der entsprechende Inhalt der Webseite beim Anfragenden ohne Umleitung direkt auf der Benutzeroberfläche angezeigt. ${ }^{359}$ Die der Domain zugehörigen IP-Adressen können mit Hilfe gängiger Suchmaschinen, die auf die entsprechende Auskunftswebseiten verweisen, abgefragt und direkt eingegeben werden. ${ }^{360}$ Sollte die entsprechende IP-Adresse der illegalen Webseite nicht ermittelbar sein, beispielsweise weil der tatsächliche Domain-Name unbekannt oder nicht über die entsprechenden Auskunftswebseiten einsehbar ist, so besteht daneben die Möglichkeit der Konfiguration eines alternativen DNS-Servers, welcher

http://ak-zensur.de/2011/02/verfassungsbeschwerde.html; Nichtannahmebeschluss des BVerfG, 1 BvR 508/11 v. 29.3.2011; schon in die gleiche Richtung Krempel in: Telepolis Beitrag v. 22.1.2001, „Netzsperre für Fritzchen Doof“, abrufbar unter:

http://www.heise.de/tp/artikel/11/11175/1.html (zuletzt abgerufen 20.5.2012).

358 Gegen die Eignung LG Hamburg, MMR 2010, 488, hierzu Rehart, MMR-Aktuell 2010, 303415: LG München I, CR 2009, 816; LG Hamburg, NJOZ 2010, 443, hierzu auch Moos/Gosche, K\&R 2009, 275; LG Kiel, MMR 2008, 123. Dafür OVG Münster, MMR 2003, 348 (351); VG Köln, MMR 2005, 399 (402).

359 LG Hamburg, ZUM 2009, 587 (590); Stadler, Haftung für Informationen im Internet, 2005, Rn. 130; Billmeier, Die Düsseldorfer Sperrungsverfügung, 2007, S. 205; Koreng, Zensur im Internet, 2010, S. 135; Stadler, MMR 2002, 343 (345); Engel, MMR Beil. 4/2003, 1 (26).

360 So zum Beispiel die Website „Auskunft zu IP-Adressen und Domain-Namen“ abrufbar unter: http://ipnr.rehbein.net/l, die einen Service bieten, bei dem sowohl von einer IP-Adresse auf die entsprechende Domain, wie auch von der Domain auf die entsprechende IP verwiesen wird. 
den DNS-Umwandlungsmechanismus ohne Beschränkung in Gang setzt. ${ }^{361}$ Technisch besteht keine Verpflichtung den vom jeweiligen Zugangsdiensteanbieter, z.B. T-Online - im Sperrfall verfälschten - DNS-Server zu benutzen, vielmehr bietet das Internet entsprechende Anleitungen zur Einrichtung eines Sekundärservers an, die auch für den technisch nicht versierten User leicht nachvollziehbar sind. 362

Zudem scheitert die Effektivität der DNS-Sperre, soweit die gesperrten Seiten einer „Spiegelung“ (Mirroring) 363 unterzogen wurden. Danach unterscheiden sich die abgerufenen Webseiten inhaltlich nicht von ihrem originären Abbild. Sie entsprechen inhaltlich den angefragten (kinderpornographischen) Inhalten, netzarchitektonisch betrachtet unterscheiden sich diese Mirror-Sides jedoch über die zugrundeliegende IP-Adresse grundlegend von der Ursprungsseite. Obgleich Manipulationen am automatischen Umwandlungsmechanismus von Domain zur IPAdresse am DNS-Server vorgenommen werden, die zur eingegebenen Domain zugehörige IP-Adresse daher nicht ermittelt werden kann, bleiben inhaltlich gleichgeartete Seiten aufgrund anderslautender IP-Adresse mühelos abrufbar. Die identischen Abbildungen gesperrter Seiten können entweder durch Aktivisten eines zensurfreien Internets selbst erstellt und verbreitet werden, ${ }^{364}$ naheliegender ist jedoch, dass eine automatische Spiegelung während des Suchvorgangs mittels Suchmaschine geschieht. Hierbei ist zu unterscheiden: Nicht jeder Suchvorgang über eine Suchmaschine führt dazu, dass quasi „automatisch“ eine Spiegelung der aufgerufenen Webseiten vollzogen wird. 365 Werden entsprechende Seiten mittels Suchmaschine abgerufen, erfolgt keine Spiegelung und damit auch keine Umgehung der DNS-Sperre. In diesem Fall wird über die Suchmaschine hinweg der

361 Aufgrund des dezentralen Aufbaus des DNS gibt es viele alternative Server, die verwendet werden können, auf diese Umgehungsmethode hinweisend LG Kiel, ZUM 2008, 246 (249); Koreng, Zensur im Internet, 2010, S. 135. Nennenswert ist in dem Zusammenhang etwa der öffentliche DNS-Server 8.8.8.8 von Google der seit Dezember 2009 kostenlos angeboten wird, hierzu Beitrag „Öffentlicher DNS-Server von Google“, bei heise-online von 4.12.2009, abrufbar unter: http://www.heise.de/ix/meldung/Oeffentlicher-DNS-Server-von-Google-876709.html (zuletzt abgerufen 20.5.2012).

362 Darauf hinweisend Sieber, Stellungnahme der Experten, Ausschussdrucksache 16 (9) 1559, S. 8; Wie bspw. die Anleitung des Chaos Computer Clubs abrufbar unter: http://www.ccc.de/censorship/dns-howto/ (zuletzt abgerufen 20.5.2012).

363 Tanenbaum, Computernetzwerke, 2009, S. 715.

364 Pfitzmann/Köpsell/Kriegelstein, Sperrverfügungen gegen Access-Provider - Technisches Gutachten, S. 53, abrufbar unter: http://www.eco.de/dokumente/20080428_technisches_Gutachten_Sperrvervuegungen.pdf (zuletzt abgerufen 20.5.2012).

365 Fälschlicherweise von dieser Annahme wohl ausgehend Vassilaki, CR 2003, 367 (368), jedoch ohne Begründung. 
gleiche Umwandlungsmechanismus in Gang gesetzt wird, wie bei direkter Eingabe der bekannten Domain im Browser. ${ }^{366}$ Einige Suchmaschinen bieten daneben jedoch die Möglichkeit einer quasi automatischen Zwischenspeicherung des Inhalts, die so genannte „Cache“-Version an. Caching wird als simple Methode zur Leistungsverbesserung im Internet benutzt. ${ }^{367}$ Die hinter dem Caching stehende Funktion ist relativ einfach: Erhält ein DNS-Server bei der Anfrage bezüglich der zugehörigen IP-Adresse eine Antwort, kann er die Übersetzung bei sich zwischenspeichern. Beim wiederholten Zugriffsversuch des Nutzers auf dieselbe Seite muss nicht mehr im iterative oder rekursiven Modus stufenweise die zugehörige IPAdresse zur eingegebenen Domain ermittelt, sondern kann direkt die "gecachte Version“ der Seite angezeigt werden, was den Verbrauch wertvoller Netzkapazitäten freihält. ${ }^{368}$ Netzwerkarchitektonisch bedeutet die Anzeige einer gecachten Seite, dass auf der Anwenderschicht eine von der Originaladresse abweichende IPAdresse eingesetzt wird. Manipulationen des DNS-Servers bezüglich der originären Domain haben daher keinen Einfluss auf den angeforderten Content. ${ }^{369}$

Überdies können sich Inhalte, die unter einem bestimmten Domainnamen zur Verfügung stehen, ständig verändern. Die zugehörige Domainadresse kann beispielsweise aufgegeben oder verkauft werden. In diesem Fall ist die Manipulation des Umwandlungsmechanismus ineffektiv, da die unterdrückte Umwandlung auf eine Webseite ausgerichtet ist, die gar nicht mehr funktioniert.

Zudem besteht wegen der globale Verbreitung des internetbasierten Datenverkehrs auch die Möglichkeit einer Ausweichabfrage: Obgleich alle inländischen Zugangsanbieter zur Vornahme einer DNS-Sperre verpflichtet sein könnten und diese zielorientiert auch innerhalb der von ihnen betriebenen DNS-Server implementieren würden, so haben die Internetnutzer stets die Möglichkeit beim Erhalt einer bestimmten Webseite auf ausländische DNS-Server auszuweichen, welche für den fraglichen Content gerade keinen Sperrmechanismus vorsehen. ${ }^{370}$

366 Sieber/Nolde, Sperrverfügungen im Internet, 2008, S. 184.

367 Tanenbaum, Computernetzwerke, 2009, S. 712.

368 Kurose/Ross, Computernetzwerke, 2008, S. 169; Pfitzmann/Köpsell/Kriegelstein, Sperrverfügungen gegen Access-Provider Technisches Gutachten, S. 27, 53 abrufbar unter: http://www.eco.de/dokumente/20080428_technisches_Gutachten_Sperrvervuegungen.pdf (zuletzt abgerufen 20.5.2012); Sieber/Nolde, Sperrverfügungen im Internet, 2008, S. 184; allgemein zum technischen Ablauf des Caching, Tanenbaum, Computernetzwerke, 2009, S. 712.

369 Pfitzmann/Köpsell/Kriegelstein, Sperrverfügungen gegen Access-Provider Technisches Gutachten, S. 27, abrufbar unter: http://www.eco.de/dokumente/20080428_technisches_Gutachten_Sperrvervuegungen.pdf (zuletzt abgerufen 20.5.2012), hin.

370 Diese Feststellung beinhaltet weitere mit der Nutzung eines ausländischen Zugangsanbieters einhergehende Probleme, wie die Unterwerfung unter mitunter geringere Schutzstandarts auch 


\section{(b) IP-Sperrmethode: Umgehungsmöglichkeiten}

Die obige Beschreibung der Datenübertragung innerhalb des TCP/IP-Modells verdeutlicht bereits die technische Ungenauigkeit dieses Sperransatzes. Das auf der übergeordneten Transportschicht befindliche TCP-Basisprotokoll hat die grundlegende Aufgabe, eine Daten- sowie Flusskontrolle der aus der Internetschicht übernommenen Daten aufrechtzuerhalten. Sollte das IP-Blocking am Router die Weiterleitung der Daten unterbrechen, so verzeichnet TCP innerhalb seiner Steuerungssoftware einen technischen Defekt während der Datenübertragung und versucht diesen durch die Berechnung alternativer Wege zu kompensieren. Dadurch entsteht quasi automatisch eine Umgehung der Sperrmaßnahme. ${ }^{371}$ Notwendig für eine hinreichende Sperrung der Seite wäre es demnach, eine Software am Router zu implementieren, die zwischen einem Sperr- und Störfall differenziert und lediglich im Störfall den Datenflussmechanismus durch Rückanforderung der abhanden gekommenen Datenpakete in Gang setzt. Ob ein solcher aufwendiger Unterscheidungsalgorithmus tatsächlich kreierbar ist, erscheint technisch betrachtet problematisch, da hierdurch erheblich auf die Funktionsweise der Datenübertragung im Internet Einfluss genommen und gleichsam auch Angriffspunkte für etwaige Manipulationsvorgänge im Datenverarbeitungsprozess geschaffen würden. So könnten technisch versierte Nutzer beispielsweise die Benachrichtigung über einen Sperrfall durch Implementierung einer Gegensoftware netzarchitektonisch in einem Störfall verwandeln, mit der Folge, dass TCP wieder in den Beseitigungsmodus zurückversetzt wird. Letztlich würde das einen Zirkelschluss in der Funktionsweise bedeuten und im Bezug auf die Funktionalität des Sperransatzes wenig weiterhelfen.

Überdies können die Betreiber eines mittels IP-Blocking gesperrten Servers technisch leicht umsetzbar die Netzadresse ihres Servers ändern. Die Änderung betrifft in diesem Fall lediglich eine Änderung der zur Domain zugehörigen IPAdresse, die Domain selbst kann beibehalten und entsprechend dem DNSUmwandlungsmechanismus in die neu zugeordnete IP-Adresse umgewandelt werden. Bestehende Blockaden der alten IP-Adressen wären hierdurch problemlos umgangen. ${ }^{372}$ Neben der oben bereits erläuterten Möglichkeit der Vervielfältigung der rechtswidrigen Inhalte mittels Mirror-Sides, kommt beim IP-Blocking insbesondere der Einsatz von Anonymisierungsdiensten als Umgehungsalternative

im datenschutzrechtlichen Bereich, darauf bezugnehmend Sieber/Nolde, Sperrverfügungen im Internet, 2008, S. 184.

371 Janssen, Regulierung abweichenden Verhaltens im Internet, 2003, S. 24 darauf bezugnehmend Degen, Freiwillige Selbstkontrolle, 2007, S. 152.

372 Greiner, Die Verhinderung verbotener Internetinhalte, 2001, S. 48; Sieber, Verantwortlichkeit im Internet, 1999, Rn. 173; Federrath, ZUM 1999, 177 (180). 
im Betracht. ${ }^{373}$ Grundsätzlich dienen Anonymisierungsdienste dazu, Datenspuren im Internet, die einen Rückschluss auf die Identifikation des Nutzers ermöglichen, zu minimieren. ${ }^{374}$ Hierfür verbergen Anonymisierungsdienste die Herkunft des Internetnutzers, indem die Verwendung einer fremden IP-Adresse ermöglicht und der Webserver nicht direkt, sondern gerade durch Umleitung über eine Zwischenstation angefordert wird. ${ }^{375}$ Technisch betrachtet agieren die meisten Anonymisierungsdienste als Proxy-Server. ${ }^{376}$ Hierbei handelt es sich um Computersysteme, die durch Kopplung von Software- und Hardwarekomponenten eine Teilunterbrechung des Datenstroms zwischen Sender und Empfänger bewirken und damit faktisch einen Zwischenschalter bilden, auf welchen Nutzeranfragen automatisch umgeleitet werden. ${ }^{377}$ Netzarchitektonisch bewirken diese Zwischenschalter, dass identische Inhalte unter einer anderen IP-Adresse abrufbar sind, folglich der IPAngaben des Anonymisierungsdienstes. ${ }^{378} \mathrm{Da}$ die IP-Blockierungsmethode jedoch nur eine spezifische IP-Adresse, mithin die des illegalen Content tragenden Servers sperren kann, sind die Seiten mittels Einsatz von derartigen Anonymisierungsdiensten weiterhin zugänglich. Eine tatsächliche Effektivität der IPSperrmethode, könnte nur dann ganzheitlich angenommen werden können, wenn auch alle web-basierten Anonymisierungsdienste gleichzeitig gesperrt werden würden, was wohl angesichts der täglich zu ändernden Angebote im Netz nicht durchzusetzen wäre. ${ }^{379}$

\section{(c) Proxy-Sperrmethode: Umgebungsmöglichkeiten}

Neben den allgemeinen Umgehungsmechanismen, wie nutzerseitigen Replikationen entsprechender Inhalte unter anderen Adressen, sowie der Informationsbeschaffung entsprechender Seiten über ausländische Server sind bei der Eigenart der Proxy-Server-Sperre spezifische Umgehungsmöglichkeiten denkbar, die mit geringen technischen Aufwand effektiv Sperrmechanismus aushebeln können.

373 Schöttle, K\&R 20007, 366 (368); Rau/Behrens, K\&R 2009, 766; allgemein zur technischen Ausgestaltung von Anonymisierungsdiensten Pfitzmann/Köpsell/Kriegelstein, Sperrverfügungen gegen Access-Provider Technisches Gutachten, S. 39, abrufbar unter:

http://www.eco.de/dokumente/20080428_technisches_Gutachten_Sperrvervuegungen.pdf

(zuletzt abgerufen 20.5.2012); Sievers, Der Schutz der Kommunikation im Internet, 2003, S. 78 ff.

374 Grafin: Beck'scher TKG-Komm., \113a TKG, Rn. 29.

375 Spindler/Nink in: Spindler/Schuster, Recht der elektronischen Medien, 2011, \13 TMG, Rn. 12; Raabe, CR 2003, 268 (269).

376 Schöttle, K\&R 2007, 366 (368).

377 Sieber, Verantwortlichkeit im Internet, 1999, Rn. 181; Köhntopp/Köhntopp, CR 2000, 248; Raabe, CR 2003, 268 (269) Federrath/Golembiewski, DuD 2004, 486; Schneider, MMR 2004, 18 (21).

378 Hierzu ein Beispiel bei Schöttle, K\&R 2007, 366 (368).

379 Darauf weist auch Schöttle, K\&R 2007, 366 (368) hin. 
Die Filterung anhand von bestimmten Signalwörtern (Keyword-Blocking) lässt sich am einfachsten bereits dadurch entgehen, dass bestimmte Seiten ohne erläuternde Beschriftungen angeboten werden. Durch die bloße Visualisierung entsprechender Bilder - von einem stärkeren Effekt auf den Betrachter ganz abgesehen kann der Filtermechanismus nicht mehr zwischen bedenklichen und unbedenklichen Inhalten trennen und leitet die komplette Abfrage zur Abbildung des Inhalts weiter. ${ }^{380}$ Auch die Erweiterung des Filtermechanismus um eine Software, welche die inkriminierten Abbildungen anhand der Dateistruktur und dem Quellcode erkennt und entsprechend herausfiltert, kann durch bildliche Abstrahierungen oder Umbenennen der Bilddateien, die Einfluss auf Dateistruktur und Quellcode haben, umgangen werden und nicht mehr zur zielgenauen Lokalisierung des Inhalts führen. ${ }^{381}$ Zudem kann auch die Filterung von Textdaten nur über ein sehr grobes Raster vorgenommen werden. Eine Filterung bestimmter Begrifflichkeiten scheitert, wenn bewusst Synonyme oder umgangssprachliche Erklärungen an Stelle der gängigen Schlüsselbegriffe eingesetzt werden. Auch können die meisten textbasierten Filtersysteme relativ einfach durch die Benutzung einer nicht gängigen Sprache zur Erläuterung der Abbildung umgangen werden. Für eine kontextbezogene und wortanalytische Filterung mit sprachenübergreifenden Charakter sind bislang keine technischen Filtermöglichkeiten bekannt. ${ }^{382}$

Überdies versagt eine Filterung der Seiten, wenn Verschlüsselungstechniken bei der Datenübertragung verwendet werden. Sollte der Filtermechanismus nicht auf einer Inhaltsfilterung beruhen, sondern auf die Filterung bestimmter IP- oder URL-Adressen ausgerichtet sein, können auch hier Anonymisierungsdienste zur Umgehung der Proxy-Methode eingesetzt werden. Durch das Aufrufen der gewünschten Seite über einen Anonymisierungsdienst verändert sich die IP-Adresse der angefragten Seiten in die IP-Adresse des verwendeten Anonymisierungsdienstes. Liest der Proxy-Server die im IP-Header der ankommenden Datenpakete gespeicherten Informationen bezüglich der zu sperrenden IP-Adressen aus, wird

Holznagel/Kussel, RdJB 2002, 295 (303).

381 Sieber, Verantwortlichkeit im Internet, 1999, Rn. 165.

382

Sieber, Verantwortlichkeit im Internet, 1999, Rn. 106 bei Fn. 126, der zutreffend darauf hinweist, dass auch schon bloße maschinelle Umschreibungen, wie die Verwendung von Abkürzungen s4all, oder die Umschreibung von „Sex“ durch „Verkehr“ oder das bloße Hinzufügen von Bindestrichen ausgehebelt werden; im Bereich des Jugendmedienschutzes sollen die gesetzlich als Anbieterverpflichtung normierten Jugendschutzsysteme nach $\int 5 \mathrm{iVm}$. $\int 11 \mathrm{JMStV}$ auf die gleiche Weise eingesetzt werden, um einen altersgerechten Zugang zu Telemedienangeboten zu gewährleisten, hierzu Erdemir, CR 2005, 275; Frey/Rudolph, CR 2008, 403; Dickhuth, Jugendschutzprogramme, 2010, S. $41 \mathrm{ff}$. 
er die IP-Adresse mangels Übereinstimmung mit der implementierten Sperrliste nicht verwerfen. 383

Eine alternative Verschlüsselungstechnik mit dem Ziel der Umgehung einer IP-bezogenen Proxy-Sperrung ist das so genannte Tunneling. ${ }^{384}$ Tunneling bildet eine netzwerkarchitektonische Methode Datenpakete innerhalb einer bestimmten Netzwerkschicht in ein anderes Datenpaket einzubetten. Hierdurch kann das einzelne Datenpaket in einer Art „Tunnel“ praktisch „,verdeckt" durch die Netzwerkschichten hinweg transportiert werden. ${ }^{385}$ In Bezug auf die Umgehung des ProxySperrmechanismus der auf das Filtern einer bestimmten IP-Adresse gerichtet ist, bietet sich eine Tunneling-Software an, die auf der Internetschicht von IP bearbeiteten Daten in andere aus der gleichen Schicht kommenden Datenpakete verpackt. Das so getunnelte IP-Protokoll verhindert, dass die IP-Adresse der angerufenen Seite vom auf der Anwendungsschicht befindlichen Proxy-Server ausgelesen werden kann. Im Einzelnen wird beim Ankommen des Datenpakets am Proxy-Server die IP-Headerinformationen des Datenpakets vom Proxy ausgelesen. Der tatsächlich angesteuerte Dateninhalt ist jedoch nicht im Datensatz des Headers vorhanden, sondern im Inneren des Datenpakets integriert. Mangels Übereinstimmung der Headerinformation mit der implementierten Sperrliste, verwirft der Proxy die angeforderte Seite nicht, sondern entlässt die Anfrage zur Anzeige auf der Anwendungsschicht. Hier greift nunmehr der entgegengesetzte Teil der Tunneling-Software ein, der eine Entschlüsselung des innenliegenden Datenpakets vornimmt, dieses konvertiert und im ursprünglichen Format zur Applikation auf der Benutzeroberfläche entlässt. ${ }^{386}$

(2) Konsequenz: Minimale Erschwerung des Zugriffs

Mithin ist festzustellen, dass tatsächlich Umgehungsmöglichkeiten bestehen und den Erhalt des ,gesperrten“ Webcontent über Umwege ermöglichen.

Wie die obige Darstellung zeigt, können bereits über die Benutzung gängiger Suchmaschinen zahlreiche technische Umgehungsanleitungen heruntergeladen und entsprechend angewendet werden. Die Recherche mittels Suchmaschine zählt

383 Degen, Freiwillige Selbstkontrolle, 2007, S. 166; Dustmann, Die privilegierten Provider, 2001, S. 28; Koch, Internet-Recht, 2005, S. 201.

384 Zum Begriff und Funktionsweise des Tunneling, Peterson/Davie, Computernetze, 2008, S. 325, speziell in Bezug auf die gängige IP-Version 4; Pfitżmann/Köpsell/Kriegelstein, Sperrverfügungen gegen Access-Provider Technisches Gutachten, S. 20 (Begriff), S. 50 (Funktionsweise) abrufbar unter:

http://www.eco.de/dokumente/20080428_technisches_Gutachten_Sperrvervuegungen.pdf (zuletzt abgerufen 20.5.2012).

385 Sieber, Verantwortlichkeit im Internet, 1999, Rn. 177.

386 Pfitzmann/Köpsell/Kriegelstein, Sperrverfügungen gegen Access-Provider Technisches Gutachten, S. 50. 
gegenwärtig wohl zu den Standardfähigkeiten eines jeden Internetnutzers. Zumindest die Eingabe des entsprechenden Suchbegriffs, der auf den Erhalt einer Umgehungsanleitung, wie beispielsweise dem Gebrauch eines externen oder ausländischen DNS-Servers gerichtet ist und sich damit zum Umgehen der DNS-Sperre eignet, ist jedem durchschnittlich begabten Nutzer des Internets zuzutrauen. Auch die Suche nach der entsprechenden IP-Adresse, um diese anstelle der Domainbezeichnung in das Browserfenster einzugeben, kann über entsprechende Eingabe eines Suchbegriffs leicht ermittelt werden. 387

In die gleiche Richtung geht indes auch die Argumentation der jüngeren Rechtsprechung. Das LG Hamburg ${ }^{388}$ beispielsweise führte einen entsprechenden Selbstversuch zur Umgehung der DNS-Sperre durch und kam zu dem Ergebnis, dass „es dem Gericht in wenigen Minuten gelungen sei, eine Internetseite mit einer Anleitung zur Umgehung mit den verfügbaren Name-Servern zu finden. Den Nutzern (...) würde es im Zweifel noch schneller gelingen“, so dass die grundsätzliche Eignung der Sperre abzulehnen sei. Gleichsam meinte auch das LG Kiel, ${ }^{389}$ DNS-Sperren seien ,nahezu wirkungslos“ und würden die Nutzung der rechtswidrigen Seiten nicht spürbar beeinträchtigen. In einer anderen Entscheidung führte das LG Hamburg ${ }^{390}$ erneut aus, dass Zugangssperren „keine brauchbare Erschwerung" begründen würden, da sie nur solche Personen abhalten, die sich ohnehin nicht für die verdeckte Information interessieren.

Eine so starre Ablehnung der Zwecktauglichkeit technischer Sperrmethoden ist jedoch nicht zwingend: Maßgeblich kommt es bei der Beurteilung der Geeignetheit einer technischen Sperrmaßnahme darauf an, welche Anforderungen an den Grad der zu erreichenden Zugriffserschwerung sowie an die Fähigkeiten des jeweiligen Nutzers zu legen sind. So kann die vom Sperransatz bezweckte Verhinderung der Erreichbarkeit eines rechtswidrigen Inhaltes sowohl als eine erfolgsabhängige totale Abschottung jedes technisch versierten Nutzers vor rechtswidrigen Inhalten verstanden werden, in gleicher Weise auch als eine erfolgsunabhängige bloße zeitliche Behinderung des zufälligen Zugriffs eines technisch durchschnittlich begabten Nutzers. ${ }^{391}$ Gerade diese unterschiedliche Betrachtung des MaßAnm. 2. Die Ansicht wird erneut im vergleichbaren Fall vom LG Hamburg, MMR 2010, 488 bestätigt. Kritisch Schnabel, JZ 2009, 996; Schmidt, jurisPR ITR 16/2009, Anm. 2; Moos/Gosche, K\&R 2009, 275; Höhne, jurisPR ITR 24/2010, Anm. 2.

389 LG Kiel, MMR 2008, 123.

390 LG Hamburg, MMR 2010, 488.

391 Degen, Freiwillige Selbstkontrolle, 2007, S. 227 und Koreng, Zensur im Internet, 2010, S. 147 präferieren hier eine Unterscheidung zwischen dem kriminell geneigten Nutzer, der tatsächlich auf den Erhalt entsprechender Webseiten aus ist und dem „,normalen“ Durchschnittsnutzer, der rein zufällig auf die illegalen Inhalte stößt. 
stabs, führt zu unterschiedlichen Anforderungen an die Eignung der technischen Sperrmaßnahmen: Zur totalen Abschottung aller technisch versierten Nutzer eignen sich letztlich nur Maßnahmen, die keinen Raum für technische Umgehungsmethoden lassen; praktisch einer vollständigen Beseitigung der Gefahrenlage gleichkommen und damit beim technischen Mittel der Sperre niemals gegeben wären. Zur bloßen Behinderung des Zugriffs reichen bereits technische Alternativen aus, die dem durchschnittlichen Internetnutzer den zufälligen Zugriff auf die gewählten Inhalte zumindest zeitlich erschweren. ${ }^{392}$

Betrachtet man die technischen Eigenarten des Internets, so deuten gewichtige Gründe darauf hin, die Sperrung als eine erfolgsunabhängige zeitliche Erschwerung der zufälligen Erreichbarkeit zu begreifen und damit bereits die minimale Zugriffserschwerung des durchschnittlich begabten Nutzers als zweckdienlich anzuerkennen: Dem Internet als technisches und globales Geflecht ist es anheim, dass ständig neue Möglichkeiten und Alternativen technischer Umgehungsmechanismen und Verbreitungsmethoden bekannt werden, die Maßnahmen zur Verhinderung der Erreichbarkeit zielorientiert beschränken. ${ }^{393}$ Daneben ist auch der technische Fortschritt ausschlaggebend dafür, dass sich kaum konstante Mechanismen entwickeln lassen, die auf eine konsequente Unerreichbarkeit bestimmter Webinhalte abzielen. Auch wenn eine gegenwärtige technische Sperrmethode im Zeitpunkt ihrer Erfindung den Zugriff auf einen bestimmten Webcontent nahezu vollständig verhindert, kann nicht ausgeschlossen werden, dass zeitnah die technischen Sicherheitsvorkehrungen durch andere Technologien überholt und aufgehoben werden. ${ }^{394}$ Folglich wird man zugestehen müssen, dass die weiten technischen Möglichkeiten dazu führen, dass derjenige der gezielt auf einen bestimmten Webcontent zugriffen möchte über entsprechende Anstrengungen letztlich sämtliche technischen Zugriffsbarrieren überwinden kann. 395

Besonders bei technischen Sachverhalten ist es insofern notwendig, die Anforderungen an die Wirksamkeit der Sperrmaßnahme nicht zu hoch anzusetzen. ${ }^{396}$ Es genügt bereits, wenn der zufällige Zugriffsversuch eines technisch durchschnittlichen begabten Internetnutzers durch die Sperrmaßnahme ,in zeitlich und

392 In Bezug auf den durchschnittlichen Jugendlichen, Altenhain in: Hoeren/Sieber, Hdb. Multimedia-Recht, Teil 20, Rn. 188; dem anschließend VG Köln, MMR 2005, 399 (402), ebenfalls folgend, Sieber/Nolde, Sperrverfügungen im Internet, 2008, S. 178.

393 Volkmann, Der Störer im Internet, 2005, S. 231.

394 So die übertragbare Argumentation aus dem Urheberrecht zu ,wirksamen technischen Maßnahmen“ iSd. \ 95 a UrhG, Götting in: Schricker/Loewenheim, Vorb. zu \95a ff. UrhG, Rn. 21; in die Richtung der Annahme, dass bereits auf den Durchschnittsnutzer abzustellen ist, VG Köln, MMR 2005, 399 (402).

395 In die Richtung und deshalb IE. gegen die Geeignetheit gesetzlicher Sperrmaßnahmen, Koreng, Zensur im Internet, 2010, S. 147.

396 BVerfGE 90, 145 (172); BVerfGE 110, 141 (164); BVerfG, MMR 2010, 48. 
technischer Hinsicht“ beschränkt wird. ${ }^{397}$ Der mit dem Sperransatz verfolgte Zweck einer präventiven Gefahrenabwehr würde ins Leere laufen, wenn die Anforderungen an die Wirksamkeit der technischen Maßnahme zu hoch anzusetzen wären. ${ }^{398}$

Vor diesem Hintergrund ist damit auch die minimale Zugriffserschwerung noch als geeignetes gesetzgeberisches Mittel anzusehen und demnach auch bei Sperrungen trotz zahlreichem Umgehungspotential nicht abzusprechen. ${ }^{399}$

Der zufällige Zugriffsversuch auf kinderpornographische Webinhalte kann infolge einer Sperrung unterbunden werden, obgleich ein hohes Umgehungspotential vorliegt. Maßgeblich für die Annahme ist die Tatsache, dass sich der Sperrmechanismus erst beim Nutzer bemerkbar macht, wenn dieser bereits erfolgreich implementiert und dem Nutzer tatsächlich ein Zugriffsversuch auf den inkriminierten Inhalt verwehrt wurde. Erst dann erhält der Anwender entweder einen Hinweis auf einen Verbindungsabbruch oder auf die Nichtauffindbarkeit der Seite. $\mathrm{Ob}$ dieses bereits ausreicht, um den Durchschnittsnutzer beim zufälligen Zugriffsversuch zur relativ einfachen Umgehung mittels Suchmaschinen zu animieren, erscheint fraglich. Allein ein "Could not connect"- Hinweis" während des alltäglichen Surfvorgangs wird aus dem Blickwinkel des Nutzers der zufällig auf eine bestehende Sperrmaßnahme trifft, zunächst wohl darauf hindeuten, dass kommunikationstechnische Probleme, wie eine fehlerhafte Internetverbindung, eine mangelnde Softwareeinstellung am Webserver, der Einsatz einer Firewall oder sonstige technischen Feheinstellungen am Computersystem bestehen und deshalb den Zugang zum angefragten Content negieren. ${ }^{400}$ Keineswegs wird derjenige, der zufällig über den Einsatz einer Suchmaschine oder per Verlinkung auf einen technischen Verbindungsabbruch trifft, dahinter eine staatliche Sperrmaßnahme vermuten, die möglicherweise kinderpornographische Inhalte verdeckt und die es über gängige Umgehungssoftware zu umgehen gilt. Auch wenn zumindest

VG Düsseldorf, MMR 2005, 794 (798), darauf bezugnehmend Sieber/Nolde, Sperrverfügungen im Internet, 2008, S. 179; Altenhain in: Hoeren/Sieber, Hdb. Multimedia-Recht, Teil 20, Rn. 188; iE. wohl auch Schnabel, Sperrungsverfügungen gegen Access-Provider, 2002, S. 85. So die übertragbare Argumentation aus dem Urheberrecht zu ,wirksamen technischen Maßnahmen“ iSd. \95 a UrhG, Götting in: Schricker/Loewenheim, Vorb. Zu \95a ff. UrhG Rn. 21 mwN.

399 IE. u.a. Dietlein/Heinemann, K\&R 2004, 418 (423); ausführlich Sieber/Nolde, Sperrverfügungen im Internet, 2008, S. 178; Heckmann, Stellungnahme der Sachverständigen im Rechtsausschuss v. 8.11.2010, S. 11, abrufbar unter: abrufbar unter: http://www.bundestag.de/bundestag/ausschuesse17/a06/anhoerungen/archiv/03_Zugangsers chwerung/04_Stellungnahmen/Stellungnahme_Heckmann.pdf (zuletzt abgerufen 20.5.2012).

400 Ebenso Mankowski, MMR 2002, 277 (278); dagegen Engel, MMR-Beil. 4/2003, 1 (24 f.); Degen, Freiwillige Selbstkontrolle, 2007, S. 157 ff.; Semken in: Heermann/Ohly, Verantwortlichkeit im Netz, 2003, S. 9 (24); Koreng, Zensur im Internet, 2010, S. 149. 
beim gezielten Zugriffsversuch auf kinderpornographische Inhalte eine dahingehende Vermutung naheliegt, bleibt dies lediglich eine Unterstellung, die keinesfalls anhand fundierter wissenschaftlicher Erkenntnisse belegt ist. ${ }^{401}$

Neben der Problematik der faktischen Unkenntnis einer Sperrmaßnahme ist die Umgehung von IP-Blocking oder Proxy-Sperren nur über den Rückgriff auf einen Anonymisierungsdienst oder eine Tunneling-Software denkbar. ${ }^{402}$ Es kann bezweifelt werden, ob dem gewöhnlichen Durchschnittsnutzer des Internets der Einsatz einer Verschlüsselungssoftware unterstellt werden kann. Zwar gibt es im Internet viele Anbieter die unentgeltlich Anonymisierungs- und Tunnelingdienste vertreiben, ${ }^{403}$ diese müssen jedoch vom Nutzer gezielt gesucht, die Software entsprechend runtergeladen und zur bewussten Umgehung des IP-Blocking oder Proxy-Sperransatzes eingesetzt werden. Nach den gegenwärtigen Fähigkeiten des durchschnittlichen Nutzers zu urteilen, drängt sich der Einsatz eines solchen Computerprogramms nicht augenscheinlich auf. ${ }^{404}$ Zunächst müsste der Nutzer das Vorliegen einer Sperrmaßnahme erkennen und anschließend herausfinden, um welche spezielle Sperrmaßnahme es sich handelt, damit die richtige Verschlüsselungssoftware runtergeladen werden kann. Bereits hierdurch treten wesentliche zeitliche Verzögerungen des Zugriffs eintreten und begründen die faktische Erschwerung, die vom gesetzgeberischen Schutzziel erreicht werden soll.

Was anderes muss aber dann gelten, wenn nicht nur ein Hinweis auf einen Verbindungsabbruch oder eine Unerreichbarkeit der angeforderten Webseite gesendet wird, sondern eine Umleitung auf eine eigens vorgesehene Sperrseite (,Stoppschild“) erfolgt, die einen Hinweis zur Sperrung der Seite erhält. ${ }^{405}$ In diesem Fall wird auch der technisch durchschnittlich begabte Nutzer, der zufällig auf einen kinderpornographischen Internet trifft, gerade in die Richtung eines bestehenden Sperrmechanismus gelenkt. Der mit der Umleitungsseite verfolgte Zweck einer „nutzerseitigen Abschreckung“ wird dabei in das ungewollte Gegenteil einer

401 Sämtliche Gutachten befassen sich mit der Frage der Umgehungsmöglichkeiten. Entsprechende Feldversuche, die gesicherte Erkenntnisse zur der Zahl bewusster und unbewusster Zugriffsversuche liefern würden finden sich hingegen nicht. Maßgeblich ist die Ermangelung an wissenschaftlich zuverlässigen Zahlen mit der hohen Dunkelziffer der KinderpornographieKonsumenten verbunden. Hierzu Meier/Hüneke, Forschungsbericht „Herstellung und Verbreitung von Kinderpornographie über das Internet", 2011, S. 96 ff.

402 Zur Umgehung der IP-Sperrmethode unten 3. Teil B. I. 2. b) (aa) (1) (b) .

403 Z.B. http://www.anonymizer.com/; http://anonymouse.org/;

http://blog.gjl-network.net/archives/166-google-chrome-chrome-privacy-guard-cpg.html. Zur technischen Funktionsweise Sievers, Der Schutz der Kommunikation im Internet, 2003, S. 78.

404 IE. Sieber/Nolde, Sperrverfügungen im Internet, 2008, S. 191; anders Schöttle, K\&R 2007, 366 (368), der unterstellt, „dass jeder Durchschnittsnutzer mit einem Anonymizer umgehen kann“.

405 Dieses wurde im Rahmen der Diskussion um ein einheitliches Sperrgesetz sogar gesetzlich in $₫ 4$ ZugErschwG fixiert. Hierzu später 4. Teil C. II. 3. 
augenscheinlichen Fixierung auf die Sperrmethode verkehrt. ${ }^{406}$ In einem solchen Fall kann wohl auch der technisch nicht versierte Nutzer, der auf das Bestehen eines Sperrmechanismus hingewiesen wird, leicht über gängige Suchmaschinen eine Umgehung des Mechanismus erreichen, wodurch die Maßnahme an Effektivität verliert. Zudem kann der explizite Hinweis auf die Unerreichbarkeit des angefragten Content einen „Neugiereffekt“ beim Nutzer auslösen, der ihn ebenfalls zur gezielten Suche nach einer Umgehungsmöglichkeit animiert, was der gesetzgeberischen Zielrichtung offensichtlich entgegenwirken würde. ${ }^{407}$ Gleichzeitig ist zu beachten, dass die Stopp-Server den Betreibern der kinderpornographischen Angebote praktisch als „Warnschilder“ dienen können und darauf hinweisen, dass das eigene kinderpornographische Angebot unter einer neuen Domain erneut online zustellen ist. ${ }^{408}$

Insgesamt ist folglich herauszustellen, dass je anonymisierter und der gesellschaftlichen Debatte entzogener ein gesetzlicher Sperransatz technisch durchgesetzt wird, desto mehr von einer grundsätzlichen Eignung des Ansatzes auszugehen ist. Wegen der technischen Eigenart des Internets dürfen die gestellten Anforderungen an die Verhinderung des Zugriffs nicht zu hoch angesetzt werden. Stellt man lediglich auf den durchschnittlich begabten Internetnutzer ab, der zufällig auf eine technische Sperrmaßnahme im Internet trifft, ist dieser in Folge des Mechanismus im uneingeschränkten Zugriff erschwert. Hierdurch folgt, dass das Sperrkonzept einen „wirksamen Beitrag zur präventiven Gefahrenabwehr“ leistet und nicht offensichtlich ausgeschlossen werden kann, dass der Rechtsgüterschutz durch die Maßnahme nicht erreicht werde. Allein aufgrund des enormen Umgehungspotentials ist die vorgebrachte Kritik an der grundsätzlichen Eignung der Sperrung damit verfassungsrechtlich nicht fundiert.

IE. Boecker, Stellungnahme der Sachverständigen im Rechtsausschuss v. 8.11.2010, S. 6, abrufbar unter:

http://www.bundestag.de/bundestag/ausschuesse17/a06/anhoerungen/archiv/03_Zugangsers chwerung/04_Stellungnahmen/Stellungnahme_Boecker.pdf (zuletzt abgerufen 20.5.2012); Stadler, MMR 2009, 581 (582); Sieber, JZ 2009, 653 (657).

407 In die Richtung Graf, Stellungnahme der Experten im Rechtsausschuss v. 10.11.2010, S. 4, abrufbar unter:

http://www.bundestag.de/bundestag/ausschuesse17/a06/anhoerungen/archiv/03_Zugangsers chwerung/04_Stellungnahmen/Stellungnahme_Graf.pdf (zuletzt abgerufen 20.5.2012).

408 Heckmann, Stellungnahme der Sachverständigen im Rechtsausschuss v. 8.11.2010, S. 16, abrufbar unter:

http://www.bundestag.de/bundestag/ausschuesse17/a06/anhoerungen/archiv/03_Zugangsers chwerung/04_Stellungnahmen/Stellungnahme_Heckmann.pdf (zuletzt abgerufen 20.5.2012); Stadler, MMR 2009, 581 (582). 
(bb) Ungeeignetheit wegen befürchteten Overblocking?

Neben den offenkundigen Umgehungsmöglichkeiten bergen die technischen Sperransätze auch rechtliche Probleme, die vor allem in einer mangelnden Zielgenauigkeit der Sperrung gründen und zum verfassungsrechtlich bedenklichen Overblocking-Effect führen. Möglicherweise kann bereits aufgrund dieses Phänomens einer gesetzlichen Sperrverpflichtung ihre Wirksamkeit hinsichtlich der Zielerreichung abgesprochen werden, was in der Konsequenz zur Versagung der Verhältnismäßigkeit des Eingriffs in Art. 12 Abs. 1 GG führen würde.

Als Overblocking wird in diesem Zusammenhang der Umstand bezeichnet, dass durch die erfolgreiche Implementierung eines Sperrmechanismus auch eine Vielzahl von legalen Inhalten, die mit dem „gelisteten“ Webcontent technisch verwoben sind, beispielsweise dadurch, dass sie auf einem gemeinsamen Server gespeichert sind, ebenfalls unerreichbar werden. ${ }^{409}$

Besonders häufig tritt dieser Effekt bei der DNS-Sperrmethode auf: Unter einer Domain ist nicht zwangsläufig nur eine bestimmte Internetadresse zu finden. Vielmehr können unter einer einzelnen Domain (Hauptdomain) auch viele andere Angebote, die unter so genannten Subdomains gespeichert werden, beherbergt sein. ${ }^{410}$ Bei der Implementierung des DNS-Sperrmechanismus, der die Umwandlung der vom Nutzer eingegebenen Domain in die netzwerkarchitektonische IPAdresse negiert, ist technisch immer nur die Information zur Sperrung der Hauptdomain enthalten. Versucht der Nutzer einen (womöglich legalen) Inhalt abzurufen, der zwar selbst auf einer legalen Subdomain lagert, jedoch einer ,indizierten" Hauptdomain entspringt, so verweigert der DNSUmwandlungsmechanismus auch diese Anfrage. Eine differenzierte Sperrung lediglich einzelner Subdomains, die einer übergeordneten Hauptdomain zugehören würde eine technisch ausgereifte Software erfordern, deren laufende Pflegekosten aufgrund der ständigen Aktualisierungsbedürftigkeit der Datenbankeinträge enorme Belastungen für die verpflichteten Provider nach sich ziehen würden und kaum technisch umsetzbar wären. ${ }^{411}$

Daneben trägt auch die IP-Sperrmethode die Befürchtung eines OverblockingEffects: Aufgrund der Massenattraktivität des Internets - im privaten wie geschäftsmäßigen Bereich - herrscht zwangsläufig eine Knappheit freier Internetad-

409 Sieber, JZ 2009, 653 (657); Volkmann in: Spindler/Schuster, Recht der elektronischen Medien, 2011, Vorb. ZugErschwG, Rn. 6; Sieber, Ausschussdrucksache 16 (9) 1559, S. 11; Spoenle, jurisAnwZert ITR 17/2009, Anm. 2; Tinnefeld, DuD 2010, 15 (18).

410 In die Richtung Frey/Rudolph, CR 2009, 644 (647), ausführlich Degen, Freiwillige Selbstkontrolle, 2007, S. 158.

411 Semken in: Heermann/Ohly, Verantwortlichkeit im Netz, 2003, S. 9 (23); darauf bezugnehmend auch Degen, Freiwillige Selbstkontrolle, 2007, S. 157. 
ressen. ${ }^{412}$ Annähernd jedes Unternehmen hat eine eigene Domainadresse; auch viele Private haben bereits einen eigenen Internetauftritt, der mit der Eingabe einer bestimmten Domain abrufbar ist. Um einer Ressourcenknappheit entgegenzuwirken, werden nicht nur unter einer Hauptdomain viele Subdomains untergeordnet, sondern auch unter einer einzigen IP-Adresse zahlreiche verschiedene Domainnamen gespeichert. ${ }^{413}$ Dieses so genannte virtual hosting ${ }^{414}$ ist zwar ressourcenschonend, weil nicht so viele IP-Adressen, wie Domains benötigt werden. Es hat im Bezug auf das IP-Blocking als Sperrmethode aber den Nachteil, dass nie nur eine bestimmte Webseite gesperrt werden kann, sondern gleichzeitig alle zur gleichen IP-Adresse gehörenden Angebote. Folglich bewirkt die Sperrung einer einzigen IP-Adresse im Falle des virtual hosting, dass ohne inhaltliche Spezifizierung, beispielsweise nach Legalitätskriterien, alle angeforderten Inhalte unzugänglich sind. 415 Zwar besteht die Möglichkeit die IP-Blockade inhaltlich einzugrenzen, indem die Konfiguration am Router lediglich zum Ausschluss bestimmter Portnummern oder zur Unerreichbarkeit eines für einen bestimmten Bereich von IP-

Deshalb werden die gängigen IPv4 Adressen auch immer mehr durch IPv6 Adressen ersetzt, um den Ressourcenknappheit entgegenzuwirken. Am 3.2.2011 wurden die letzten IPv4 Adressen vergeben. Hierzu Ermert in: „IPv4-Adressen: Abschiedsgrüße, Mahnungen und Pappschilder“, heise-online Meldung v. 3 2.2011, abrufbar unter:

http://www.heise.de/newsticker/meldung/IPv4-Adressen-Abschiedsgruesse-Mahnungen-undPappschilder-1183204.html (zuletzt abgerufen 20.5.2012); zu dem technischen unterschieden und den Ressourceneinsparung grundlegend Tanenbaum, Computernetzwerke, 2009, S. 508, kurzer Überblick, Kirchberg-Lennartr/Weber, DuD 2010, 479; Sachs, CR 2010, 547.

413 Hierzu Sieber/Nolde, Sperrverfügungen im Internet, 2008, S. 186 unter Verweis auf Edelmann, „Web Sites Sharing IP Adresses“: Prevalence and Significance, Publikation der Harvard Law School, abrufbar unter: http://cyber.law.harvard.edu/archived_content/people/edelman/ipsharing/ (zuletzt abgerufen 20.5.2012), wonach im Jahr 2002 mehr als 87 Prozent der aktiven Domainnamen die IP-Adresse mit anderen Domains geteilt haben.

414 Zum Begriff, Pfitzmann/Köpsell/Kriegelstein, Sperrverfügungen gegen Access-Provider Technisches Gutachten, S. 20, abrufbar unter:

http://www.eco.de/dokumente/20080428_technisches_Gutachten_Sperrvervuegungen.pdf (zuletzt abgerufen 20.5.2012); teilweise auch als ,,shared hosting“ bezeichnet, Sieber, Ausschussdrucksache 16 (9) 1559, S. 10 bei Fn. 21; Frey/Rudolph, Stellungnahme der Sachverständigen im Rechtsausschuss v. 7.11.2010, S. 5, abrufbar unter:

http://www.bundestag.de/bundestag/ausschuesse17/a06/anhoerungen/archiv/03_Zugangsers chwerung/04_Stellungnahmen/Stellungnahme_Frey.pdf (zuletzt abgerufen 20.5.2012).

415 Bleisteiner, Rechtliche Verantwortlichkeit im Internet, 1999, S. 40 mit Verweis auf die Sperrung des niederländischen Server „xs4all“ im Jahr 1996, bei dem die gesamten IP-Adresse aus dem Routertabellen entfernt wurde, hierzu auch Schneider, MMR 1999, 571 (573) mwN, zu „Kollateralschäden“, Sieber, Ausschussdrucksache 16 (9) 1559, S. 10; zu „Nebenwirkungen“ des IPBlocking, Stadler, Haftung für Informationen im Internet, 2005, Rn. 128. 
Adressen zuständigen Domain-Servers führt: Ersteres hätte jedoch zur Folge, dass beispielsweise die Sperrung des Ports 80, welcher dem Dienst World Wide Web entspricht, ${ }^{416}$ zwar den Zugriff auf alle im WWW vorhandenen kinderpornographischen Angebote verwehrt, gleichzeitig aber auch sämtliche über das WWW verbreiteten Inhalte nicht mehr abrufbar wären. Die Konfiguration der Unerreichbarkeit eines bestimmten Adressbereichs hätte zur Folge, dass der gesamte Adressbereich der Domains, die beispielsweise auf ,.de“ enden, gesperrt würde. ${ }^{417}$

Auch die technischen Ansätze, die auf eine Proxy-Sperrmethode hinauslaufen sind von einem Overblocking-Effect bedroht: Im Fall der inhaltlichen Proxyfilterung anhand von „Signalwörter“ oder „Abbildungen“ können die Filtersysteme nicht zielgenau arbeiten. So kann beispielsweise die Sperrung aller Webseiten, die das Wort „Brust“ oder die Abbildung einer Brust beinhalten, gleichsam auch die Sperrung sämtlicher aufklärerischen Webseiten, Enzyklopädien sowie Medizineinträge für den Nutzer durch Zwangsfilterung bedeuten. ${ }^{418}$ Auch eine IP-bezogene Proxyfilterungsmethode ist hinsichtlich eines Overblocking-Effects nicht anders zu beurteilen als die IP-Sperrung am Router. Ob die zur angeforderten Webseite zugehörige IP schon am Router oder erst am Proxy ermittelt und bei Übereinstimmung mit den Sperrkriterien verworfen wird, kann rechtlich betrachtet keinen Unterschied machen. Demnach droht auch bei der IP-bezogenen Sperrung am Proxy aufgrund des weit verbreiteten virtual hosting eine massive Gefahr eines Overblocking-Effects, durch unbeabsichtigte Mitsperrung aller zu einer IPAdresse gehörenden Inhalte.

Zusammenfassend lässt sich feststellen, dass eine Befürchtung eines Overblocking-Effects im Wesentlichen allen Sperrmethoden immanent ist. Rechtlich gründet die Befürchtung auf einem Konflikt zwischen der staatlichen Verpflichtung zur Vornahme von Sperrungen und einem dadurch einhergehenden Eingriff in die Grundrechte der am Kommunikationsprozess beteiligten Personen. Werden neben kinderpornographischen Inhalten auch legale Inhalte (wenn auch unbeabsichtigt) auf staatliche Veranlassung gesperrt, so führt dieses zwangläufig zu einem Konflikt mit der Informationsfreiheit des Nutzers aus Art. 5 Abs. 1 Satz 1 Var. 2 GG und dem Fernmeldegeheimnis des Art. 10 GG. Auch führt die Mitsperrung legaler Inhalte möglicherweise zu einem Konflikt mit dem Zensurverbot des Art. 5 Abs. 1 Satz 3 GG.

Mithin mögen die vorgebrachten Aspekte gewichtig in Bezug auf eine rechtliche Zulässigkeit der Sperrmethode hinsichtlich der „Angemessenheit“ einer ge-

416 Zur Portnummern-Kennung und ihrer standardisierten Zuordnung zu speziellen Diensten, oben unter Fn. 249.

417 Bleisteiner, Rechtliche Verantwortlichkeit im Internet, 1999, S. 40, ebenfalls sog. „Kollateralschäden“ Sieber/Nolde, Sperrverfügungen im Internet, 2008, S. 186; Sieber, Ausschussdrucksache 16 (9) 1559, S. 4.

418 Beispiel angelehnt an Faber, Jugendschutz im Internet, 2005, S. 63. 
setzlichen Sperrverpflichtung sein, im Sinne der eigentlichen Hinterfragung der Geeignetheit der Sperrmethoden sind diese Argumente jedoch nicht als Gegenargument anzuführen. ${ }^{419}$ Die Beurteilung der Geeignetheit einer staatlichen Sperrmaßnahme richtet sich lediglich danach, ob die gewählte Art der Sperrung zweckdienlich und wirksam in Bezug auf die Erreichung des Ziels ist. Die Wirksamkeit bestimmt sich damit ungeachtet etwaiger rechtlicher Kollateralschäden ${ }^{420}$ allein danach ob durch die Maßnahme eine allein danach, ob die Sperrmethoden einen „Schritt in die richtige Richtung“421 und einen „wirksamen Beitrag zur Gefahrenabwehr" ${ }^{\star 422}$ leisten. Ist dies der Fall, so ist von einer Geeignetheit der Maßnahme im verfassungsrechtlichen Sinne auszugehen. Folglich ist die Tatsache des massiven Overblockings kein Grund dafür, die Geeignetheit eines gesetzlichen Sperransatzes in Frage zu stellen.

(cc) Ungeeignetheit wegen mangelnder Verhinderung mittelbarer Auswirkungen

Ein technischer Sperransatz verfolgt nicht nur den Zweck einen Zugriff auf den kinderpornographischen Webcontent zu verhindern um damit präventiv vor Verstößen gegen geltende Strafrechtsnormen und andere Verbotstatbestände zu schützen, gleichzeitig soll über die Eindämmung der Zugriffsmöglichkeit auch bezweckt werden, dass die Risiken, die einer kinderpornographischen Darstellung anhaften, verringert werden.

Gerade vor dem Aspekt wird technischen Sperrmethoden eine Zweckförderung abgesprochen. Dem Sperransatz wird vorgeworfen, es handele sich lediglich

419 Heckmann, Stellungnahme der Sachverständigen im Rechtsausschuss v. 8.11.2010, S. 12, abrufbar unter:

http://www.bundestag.de/bundestag/ausschuesse17/a06/anhoerungen/archiv/03_Zugangsers chwerung/04_Stellungnahmen/Stellungnahme_Heckmann.pdf (zuletzt abgerufen 20.5.2012).

$420 \mathrm{Zu}$ diesen Problem mit dem Hinweis, dass etwa das australische Justizministerium selbst zugeben müsse, dass weniger die Hälfte der in Australien zur Sperrung vorgesehenen Inhalte tatsächlich kinderpornographisches Material enthielten, Schnabel, JZ 2009, 996 (999) bei Fn. 58: mit einem Verweis auf Borchers in: heise-online, Meldung v. 20.2.2009, „Kinderporno-Sperren“ im internationalen Vergleich“, abrufbar unter:

http:/ /www.heise.de/newsticker/meldung/Kinderporno-Sperren-im-internationalen-Vergleich199060.html (zuletzt abgerufen 20.5.2012).

421 OVG Münster, MMR 2003, 348 (351); VG Gelsenkirchen, Beschl. v. 18.12.2002 - 1 L 2528/02 n.v., VG Düsseldorf, MMR 2003, 205 m. Anm. Stadler; kritisch als Banalisierung der Geeignetheitsprüfung zur „dogmatischen Pflichtübung“ bezeichnend, Engel, MMR-Beilage 4/2003, 1 (24).

422 VG Köln, MMR 2005, 399 (402), bereits Spindler/Volkmann, K\&R 2002, 398 (406). 
um „Symbolpolitik“ die keineswegs effektiv zur Bekämpfung der mit Kinderpornographie einhergehenden Gefahren beitrage. ${ }^{423}$

Eine solche pauschale Abwertung kann gesetzlichen Sperransätzen zur Unterbindung kinderpornographischer Inhalte jedoch nicht per se unterstellt werden.

Wird die Rezeption durch einen Sperrmechanismus unterbunden, so können direkte rezeptionsbedingte Risiken, die mit der Verbreitung verbunden sind minimiert werden. Nutzer, die etwa über Suchmaschinen zufällig mit kinderpornographischen Inhalten in Berührung kommen und erstmalige sexuelle Stimulation durch die Inhalte erfahren, können durch den Sperrmechanismus von einer wiederholten, bewussten Anfrage abgehalten werden, wenn die unerkannte sexuelle Stimulation infolge einer Sperrmaßnahme erst gar nicht ,aufkeimen kann".424 Zudem ist nicht offensichtlich ausgeschlossen, dass auch der pädophil-geneigte Nutzer der gezielt nach entsprechenden Webseiten sucht, bei mehreren aufeinanderfolgenden Zugriffsverweigerungen von einer Fortsetzung der Suche Abstand nimmt. ${ }^{425}$ Liegt eine diesbezügliche Vermutung im entsprechenden Nutzerumfeld nahe, so kann diese Annahme, nicht mit der für die Ungeeignetheit notwenigen Wahrscheinlichkeit widerlegt werden.

Soweit es damit um den unmittelbaren Rechtgüterschutz geht, wie den Schutz der darstellten Kinder vor einer erneuten Zur-Schau-Stellung sowie den Gefahren, die der Nutzer infolge der Rezeption des Inhaltes ausgesetzt ist, ${ }^{426}$ kann ein gesetzlicher Sperransatz diesen Zweck damit zumindest fördern. Letztlich dürfen

${ }^{423}$ Hoffmann-Holland, Stellungnahme der Sachverständigen im Rechtsausschuss v. 8.11.2010, S. 3; Bleich in: c't, 06/2010, S. 67; ausführlich mwN. iE. jedoch selbst ablehnend Sieber/Nolde, Sperrverfügungen im Internet, 2008, S. 191, ohne den wörtlichen Vorwurf der Symbolpolitik zu äußern; andeutend Heckmann, Stellungnahme der Sachverständigen im Rechtsausschuss v. 8.11.2010, S. 12, abrufbar unter:

http://www.bundestag.de/bundestag/ausschuesse17/a06/anhoerungen/archiv/03_Zugangsers chwerung/04_Stellungnahmen/Stellungnahme_Heckmann.pdf (zuletzt abgerufen 20.5.2012), Winsemann in: telepolis Beitrag v. 12.3.2009, „Warum Netzsperren reine Symbolpolitik sind“, abrufbar unter: http://www.heise.de/tp/artikel/29/29914/1.html (zuletzt abgerufen 20.5.2012); zur Symbolpolitik des Jugendmedienschutzrechts, Faber, Jugendschutz im Internet, 2005, S. 179.

424 Osterheider, Ausschussdrucksache 16 (9) 1544; a.A. Koreng, Zensur im Internet, 2010, S. 147, der schon davon ausgeht, dass Durchschnittsnutzer beim Surfvorgang nicht zufällig auf kinderpornographisches Material stoßen wird. In die gleiche Richtung auch Schneider, MMR 2004, 18 (24); Billmeier, Die Düsseldorfer Sperrungsverfügung, 2007, S. 284 f.

425 In die Richtung Heckmann, Stellungnahme der Sachverständigen im Rechtsausschuss v. 8.11.2010, S. 12, abrufbar unter:

http://www.bundestag.de/bundestag/ausschuesse17/a06/anhoerungen/archiv/03_Zugangsers chwerung/04_Stellungnahmen/Stellungnahme_Heckmann.pdf (zuletzt abgerufen 20.5.2012).

$426 \mathrm{Zu}$ den einzelnen rezeptionsbedingten Risiken eines kinderpornographischen Inhaltes, oben 2. Teil A. II. 1. c) . 
hier auch keine anderen Maßstäbe angesetzt werden, als an die tatsächliche Verhinderung der Verstöße gegen die Rechtordnung. Soweit der zufällige Zugriff für den durchschnittlichen Nutzer erschwert ist, liegt der Sperrmaßnahme ein wirksamer Beitrag zur präventiven Abwehr der rezeptionsbedingten Gefahren zu Grunde, so dass die Maßnahme von der Einschätzungsprärogative des Gesetzgebers getragen ist.

Problematischer gestaltet sich der Umstand, ob eine erschwerte Zugriffsmöglichkeit langfristig auch dem Zweck einer sexuellen Ausbeutung von Kindern entgegenwirken kann. Maßgeblich geht die gesetzgeberische Intention einer umfassenden Zugriffsverhinderung davon aus, dass ein klassisches von Angebot und Annahme bestimmtes Marktverhalten der Verbreitung kinderpornographischen Angebote im Internet zugrundeliegt. Die ungehinderte Belassung der Inhalte im Internet, kann dazu führen, dass Kinder für Neuproduktionen sexuell ausgebeutet werden müssen, um einer Nachfrage nach Neuware gerecht zu werden. Auch können Nachahmungseffekte durch die Betrachtung eines kinderpornographischen Materials ausgelöst werden, die darauf gerichtet sind, über kommerzielle Wege das kinderpornographische Angebot zu verbreiten und Gewinne zu erwirtschaften. ${ }^{427}$

In jüngerer Zeit wird diese Annahme aber zunehmend hinterfragt. Der Europarat hat demnach auch die Empfehlung an die Mitgliedstaaten ausgesprochen, Umstände der sexuellen Ausbeutung von Kindern, die Verflechtungen einer Sexindustrie mit der organisierten Kriminalität sowie die Zusammenhänge zwischen Konsum und Verbreitung von Kinderpornographie in Kommunikationsnetzen zu erforschen. ${ }^{428}$ In dem Bereich sind aber weiterhin erhebliche wissenschaftliche Defizite zu verzeichnen. Es fehlen umfassende Grundlagenforschungen sowie über Jahre hinweg aufbereitete Studien, die hinreichend Aufschluss über die tatsächlichen Einwirkungen von einer ungehinderten Konsummöglichkeit im Inter-

So die gesetzliche Intention bei der Schaffung absoluter Herstellung- und Verbreitungsverbote von kinderpornographischen Material nach $\int 184 \mathrm{~b}$ StGB, BT-Drs. 12/3001, S. 5, in diese Richtung auch Duttge/Hörnle/Renzilkowski, NJW 2004, 1065 (1070); Harms, NStZ 2003, 646 (647); Heinrich, NStZ 2005, 361 (363). Auch die gesetzliche Intention beim Erlass des Zugangserschwerungsgesetzes nahm auch die „umfassenden Schutz vor sexueller Ausbeutung“ Bezug, BT-Drs. 16712850.

428 Empfehlung Nr. R (91) 11 zur sexuellen Ausbeutung, Pornographie und Prostitution von und Menschenhandel mit Kindern und jungen Erwachsenen, abrufbar unter: http://www.egmr.org/minkom/ch/rec2000-11.pdf (zuletzt abgerufen 20.5.2012); darauf bezugnehmend auch Meier/Hüneke, Forschungsbericht „Herstellung und Verbreitung von Kinderpornographie über das Internet“", 2011, S. 7. 
net auf die zur Erstellung des Inhaltes notwendige sexuelle Ausbeutung geben können. 429

Die eingangs bereits erwähnten Forschungsberichte der Universität Hannover sowie der European Financial Coalition against commercial sexual exploitation of children online geben jedoch eine gewisse Grundtendenz hinsichtlich eines Wirkzusammenhangs zwischen dem Angebotsverhalten im Internet und sexueller Ausbeutung wieder. ${ }^{430}$ Nach den Erkenntnissen sei ein „Markt Kinderpornographie“, der von Angebot und Nachfrage gelenkt wird, im klassischen Sinne nicht auf den Bereich der internetverbreiteten Kinderpornographie übertragbar. Maßgebliches Instrument des klassischen Markgeschehens ist die „Knappheit“ der nachgefragten Ressource. ${ }^{431}$ Angesichts der Fülle an kinderpornographischen Angeboten und der vielfältigen und vorrangig unentgeltlichen Verbreitung entsprechender Bilder in Peer-to-Peer-Netzwerken, könne sich ein klassisches Marktverhalten gar nicht entwickeln. ${ }^{432}$ Soweit Konsumenten über unentgeltliche Verbreitungssektoren an die Inhalte herankommen, werden die kommerziellen, von Angebot und Nachfrage geleiteten Angebote nicht in Anspruch genommen. Die neuen Verbreitungsstrategien konzentrieren sich zunehmend auf die nicht gewerbliche, kostenlose Weiterverbreitung an einen kleinen Konsumentenkreis durch Gründungen von einschlägigen Gruppen in sozialen Netzwerken und anderen geschlossenen Benutzergruppen. Bei der Verbreitung in solchen Kleingruppen steht die sexuelle Stimulation und Weitergabe des Materials an sich im Vordergrund und nicht ein kommerzieller Einnahmecharakter, der ausschlaggebend für eine Nachfrage nach Neuware wäre. ${ }^{433}$

429 So der niedersächsische Innenminister Scbünemann auf dem White-IT Symposium am 24/25.11.2010, wiedergegeben bei Kleintr in: Zeit-Online v. 25.11.2010, „Auf der Suche nach den Verbreitungswegen der Kinderpornographie“, abrufbar unter:

http://www.zeit.de/digital/internet/2010-11/kinderpornografie-whiteIT-schuenemann?page=1 (zuletzt abgerufen 20.5.2012). Dieses selbst herausstellend auch Meier/Hüneke, Forschungsbericht „Herstellung und Verbreitung von Kinderpornographie über das Internet“, 2011, S. 10.

430 Meier/Hüneke, Forschungsbericht „Herstellung und Verbreitung von Kinderpornographie über das Internet“, 2011; EFC, „14 months on: A combined report from the European Financial Coalition 2009-2010“, abrufbar unter:

http://ceop.police.uk/Documents/EFC\%20Strat\%20Asses2010_080910b\%20FINAL.pdf. Zu den Einzelheiten oben 2. Teil A. II. 1. b) .

431 Meier/Hüneke, Forschungsbericht „Herstellung und Verbreitung von Kinderpornographie über das Internet“, 2011, S. 98.

432 Eingehend Meier/Hüneke, Forschungsbericht „Herstellung und Verbreitung von Kinderpornographie über das Internet“", 2011, S. 37 ff.

433 EFC, „14 months on: A combined report from the European Financial Coalition 2009-2010“, abrufbar unter: 
Die Forschungsberichte sind aber in Bezug auf die Frage nach einer Eignung von Sperrmaßnahmen insofern unzureichend, als sie vorrangig auf eine Bewertung des gesamten Internetbereichs ausgerichtet ist. Für die Beurteilung der Geeignetheit von Sperrmechanismen muss vorrangig aber der Bereich der Verbreitung kinderpornographischer Angebote im Internetdienst World Wide Web betrachtet werden. Technische Sperrmethoden gleich welcher Art verhindern im Ergebnis die Anzeige der angeforderten Webseite auf der Benutzeroberfläche des Nutzers und sind damit auf eine Zugriffserschwerung im Internetdienst World Wide Web beschränkt. ${ }^{434}$

Soweit man den Fokus auf den Internetdienst des World Wide Web legt, kommen die Forschungsberichte übereinstimmend zu dem Ergebnis, dass dieser Dienst nach wie vor den Hauptanwendungsfall einer kommerziellen Verbreitung von Kinderpornographie darstellt. ${ }^{435}$ Danach tendieren vor allem „Einsteiger“ dazu, nach Kinderpornographie im World Wide Web zu suchen und entsprechend ein Entgelt für die Angebote zu entrichten. ${ }^{436}$ Anbieter die Kinderpornographie im Internet gewerblich verbreiten müssen sich darauf konzentrieren, ständig neue Kunden zu gewinnen oder neuwertiges Material anzubieten, damit sich das Angebot gegenüber anderen, insbesondere unentgeltlichen Inhalten, abhebt. ${ }^{437}$

Ausgehend von dieser Grundannahme kommen die Forschungsberichte zu dem Ergebnis, dass nicht abschließend festgestellt werden konnte, ob das Bedürfnis nach einem ,exklusiven“ Angebot auch tatsächlich zu einer Neuproduktion von kinderpornographischen Angeboten oder zumindest gewissen offenkundigen Vorbereitungshandlungen im Hinblick auf eine spätere sexuelle Ausbeutung führte. Vielmehr können diesbezüglich nur Vermutungen angestellt werden, keineswegs jedoch fundierte Ergebnisse vorgelegt werden. Für einen hinreichenden

http://ceop.police.uk/Documents/EFC\%20Strat\%20Asses2010_080910b\%20FINAL.pdf. Auf die Verlagerungseffekte weist auch der Aufhebungsgesetzentwurf der FDP zum ZugErschwG hin, BT-Drs. 17/646, S. 4.

434 Zur technischen Ausgestaltung 2. Teil B. .

435 Meier/Hüneke, Forschungsbericht „Herstellung und Verbreitung von Kinderpornographie über das Internet“, 2011, S. 98; EFC, „14 months on: A combined report from the European Financial Coalition 2009-2010“, S. 7, abrufbar unter:

http://ceop.police.uk/Documents/EFC\%20Strat\%20Asses2010_080910b\%20FINAL.pdf (zuletzt abgerufen 20.5.2012).

436 Meier/Hüneke, Forschungsbericht „Herstellung und Verbreitung von Kinderpornographie über das Internet“, 2011, S. 97; EfC, „14 months on: A combined report from the European Financial Coalition 2009-2010“, S. 18, abrufbar unter: http://ceop.police.uk/Documents/EFC\%20Strat\%20Asses2010_080910b\%20FINAL.pdf (zuletzt abgerufen 20.5.2012).

437 Meier/Hüneke, Forschungsbericht „Herstellung und Verbreitung von Kinderpornographie über das Internet", 2011, S. 97. 
Nachweis der sexuellen Ausbeutung müssten weit angelegte Versuche, etwa über den Einsatz von verdeckten Ermittlern durchgeführt werden, die gezielt über eine nach Neuwaren verlangen. ${ }^{438}$

Letztlich können auch die angeführten Forschungsberichte keine gesicherten Erkenntnisse liefern, welche der gesetzlichen Annahme Zusammenhangs zwischen Konsummöglichkeiten und sexuellen Ausbeutung hinreichend widerlegen.

Für die Geeignetheit der Sperrmaßnahme hinsichtlich der Zweckerreichung der Verhinderung der Risiken, die mit kinderpornographischen Inhalten einhergehen ist $\mathrm{zu}$ folgern, dass diese nicht in hinreichend widerlegt werden kann. Soweit die Annahme besteht, dass sich kommerzielle kinderpornographische Angebote im World Wide Web weiterhin befinden, kann die Zugriffserschwerung auf die Inhalte den langfristigen Zweck des Sperransatzes zumindest fördern.

Für die Geeignetheit des Sperransatzes spricht insbesondere auch die Grundentscheidung, die der Annahme einer Zugriffserschwerung speziell kinderpornographischer Angebote zugrundeliegt. Die Weite der dem Gesetzgeber zugebilligten Einschätzungsprärogative bezüglich der Eignung einer Maßnahme richtet sich grundsätzlich nach dem Rang, des mit der Maßnahme verfolgten Schutzgutes. ${ }^{439}$ Vorliegend will der Gesetzgeber vorrangig jugendgefährdende Risiken minimieren. Aufgrund des Verfassungsrangs des Jugendschutzes aus Art. 2 Abs. 1 i.V.m. Art. 1 Abs. 1 GG handelt es sich folglich um ein besonders hohes Rechtsgut. In Ausübung der verfassungsrechtlichen Schutzverpflichtung ist der Gesetzgeber indes auch in der Pflicht, den Jugendschutz umfassend zu wahren. Hierzu kann er sich folglich auch Schutzkonzepte bedienen, die nur eine minimale Erreichung des Rechtsschutzziels bewirken, solange die positive Wirkung für den Jugendschutz nicht hinreichend wiederlegt werden kann. Folglich wird man der Sperrung kinderpornographischer Inhalte auch vor dem Aspekt des umfassenden Schutzes vor sexueller Ausbeutung nicht ihre Geeignetheit absprechen können.

\section{(dd) Schlussfolgerungen für die Geeignetheit einer gesetzlichen Sperrmaßnahme}

In Anbetracht der geringen Anforderungen an die Eignung des gesetzgeberischen Mittels lässt sich das Sperrkonzept nicht wegen der vorstehenden Probleme verfassungsrechtlich verwerfen. Zwar weisen alle technischen Maßnahmen nur eine minimale Wirksamkeit auf, solange der Zugriff auf den Content zumindest für den zufälligen Zugriffsversuch erschwert wird, ist nicht von einer offensichtlichen Ungeeignetheit auszugehen. Auch die Einwände, dass Sperrungen nur einer bloBen Symbolpolitik folgen, können im Ergebnis nicht überzeugen. Zwar kann nicht mit hinreichender Wahrscheinlichkeit festgestellt werden, dass über eine Zugriffssperre die langfristigen Auswirkung von sexueller Ausbeutung von Kindern tat-

Meier/Hüneke, Forschungsbericht „Herstellung und Verbreitung von Kinderpornographie über das Internet", 2011, S. 68 ff., 98.

439 Greiner, Die Verhinderung verbotener Internetinhalte, 2001, S. 39. 
sächlich entgegengewirkt wird, der Gesetzgeber ist aber auch nicht verpflichtet einen entsprechenden Nachweis für diese Annahme anzuführen. Schon aufgrund des hinter der Maßnahme stehenden Intention des „umfassenden Jugendschutzes" und der sich daraus ergebenen staatlichen Schutzverpflichtung aus Art. 2 Abs. 1 i.V.m. Art. 1 Abs. 1 GG ist der Gesetzgeber befugt auch im Fall der „Ungewissheit“ des Bestehens von Risiken, gesetzgeberische Handlungsbemühungen zu ergreifen, die auf eine Abwehr der latenten Gefahr abzielen. ${ }^{440}$ Obgleich fundierte wissenschaftliche Untersuchungen des Bereichs der internetbasierten Verbreitung von Kinderpornographie teilweise in der Lage sind, bestimmte Annahmen zu hinterfragen, ist nach derzeitigen Erkenntnisstand keine völlige Abkehr von der Vermutung ersichtlich, dass die ungehinderte Verbreitung von Kinderpornographie völlig risikolos für die Konsumenten sowie die an der Produktion beteiligten Protagonisten ist.

\section{c) Erforderlichkeit}

Im verfassungsmäßigen Element der Erforderlichkeit findet das Prinzip des geringstmöglichen Eingriffs seinen Ausdruck. ${ }^{441}$ Im Gegensatz zur Geeignetheit konzentriert sich die Betrachtung hierbei nicht lediglich auf das Verhältnis der Maßnahme zum angestrebten Zweck, sondern beruht darüber hinaus auch auf dem Vergleich der zur Zweckerreichung ebenfalls denkbaren Mittel untereinander. ${ }^{42}$ Danach ist nur dasjenige staatliche Mittel rechtstaatlich erforderlich, dass bei gleicher Geeignetheit die relativ mildeste Maßnahme darstellt. ${ }^{443}$ Es darf sich keine andere Regelungsalternative finden, die den Regelungszweck in gleicher Weise erfüllt, die grundrechtlich geschützte Freiheit jedoch weniger beeinträchtigt. ${ }^{444}$

In Bezug auf gesetzliche Sperrverpflichtungen zur Unterbindung kinderpornographischer Gefahren im Internet wird vorgebracht, dass diese letztlich nur eine oberflächliche Zugriffsbarriere darstellen, keineswegs jedoch auf eine Entfernung des Inhalts „an der Quelle“, also die Löschung des Angebotes aus dem Gesamtbe-

441 Lerche, Übermaß und Verfassungsrecht, 1961, S. 19; darauf bezugnehmend Billmeier, Die Düsseldorfer Sperrungsverfügung, 2007, S. 117.

442 BVerfGE 100, 313 (375); Grzeszick in: Maunz/Dürig, Art. 20 GG, Rn. 113 f.; Hirschberg, Der Grundsatz der Verhältnismäßigkeit, 1981, S. 148.

443 (194); BVerfGE 113, 167 (234); Huster/Rux in: Epping/Hillgruber, Art. 20 GG, Rn. 183; Gržeszik in: Maunz/Dürig, Art. 20 GG, Rn. 113, 114; Sommermann in: v. Mangoldt/Klein/Starck, Art. 20 GG, Rn. 304; Jarass in: Jarass/Pieroth, Art. 20 GG, Rn. 85; Reuter, JURA 2009, 511 (513). 
stand des Internets gerichtet sind. ${ }^{445}$ Die Löschung sei aber gezielter in Hinblick auf die Unterbindung der kinderpornographischen Gefahren und stelle gegenüber der Sperrung eine weniger eingriffsintensive Maßnahme dar. ${ }^{446}$ Fraglich ist daher, ob die Löschung zu Recht als ein gezielteres und wirksameres Instrument eines präventiven technischen Schutzes im Internet angeführt wird und daher in der Lage ist dem gesetzlichen Sperransatz seine Erforderlichkeit abzusprechen.

\section{(aa) Technische Ausgestaltung der Löschung}

Unter Löschung wird eine totale, dauerhafte und ersatzlose Entfernung des Inhalts aus dem Angebot des World Wide Web verstanden. ${ }^{447}$ Im Vergleich zur Sperrung eines Inhalts ist die Entfernung technisch nicht so diffizil wie die Implementierung eines Sperrmechanismus. Für die Löschung eines Angebots ist es lediglich notwendig die Dateninhalte vom jeweiligen Speichermedium mittels Entfernung der Daten aus dem Zielverzeichnis zu löschen, das heißt die Inhalte beispielsweise von der Festplatte des ans Internet angeschlossenen Rechners zu entfernen. ${ }^{448}$

Im Vergleich zur „oberflächlich“ wirkenden Sperrung hat die Löschung den wesentlichsten technischen Vorteil, so dass der Inhalt nicht nur äußerlich ,,verdeckt", sondern tatsächlich unwiderruflich beseitigt wird. Eine Umgehung der Löschung scheidet mit den gängigen technischen Mitteln nahezu aus. Die einzige Möglichkeit einen gelöschten Inhalt erneut abrufen zu können, ist eine identische Vervielfältigung des Angebotes und eine erneute Bereitstellung des Zugriffs über den Webserver. ${ }^{449}$ Dieses ist beispielsweise über die oben beschriebene Methode

Ausdrücklich Sieber, Ausschussdrucksache 16 (9) 1559, S. 8.

446 Aus der Gesellschaft u.a. Krempl in: heise-online, Meldung v. 22.3.2010, „Löschgesetz soll Missbrauchsbilder rascher aus dem Netz Befördern“, abrufbar unter: http://www.heise.de/newsticker/meldung/Loeschgesetz-soll-Missbrauchsbilder-rascher-ausdem-Netz-befoerdern-959998.html (zuletzt abgerufen 20.5.2012); Krempel in: heise-online,, Meldung v. 16.8.2010, „Provider: „Löschen statt Sperren“ funktioniert“, abrufbar unter: http://www.heise.de/newsticker/meldung/Provider-Loeschen-statt-Sperren-funktioniert1060092.html (zuletzt abgerufen 20.5.2012); Eco, Stellungnahme der Experten, Ausschussdrucksache, 16 (9) 1542, S. 3; Kubnen, Ausschussdrucksache, 16 (9) 1545; Frey/Rudolph, Stellungnahme der Sachverständigen im Rechtsausschuss v. 7.11.2010, S. 6, abrufbar unter:

http://www.bundestag.de/bundestag/ausschuesse17/a06/anhoerungen/archiv/03_Zugangsers chwerung/04_Stellungnahmen/Stellungnahme_Frey.pdf (zuletzt abgerufen 20.5.2012); Sieber, Ausschussdrucksache 16 (9), 1559, S. 9.

447 Degen, Freiwillige Selbstkontrolle, 2007, S. 136; Koreng, Zensur im Internet, 2010, S. 119.

448 Hierfür braucht es lediglich einfacher Softwarekonfigurationen, Sieber, Verantwortlichkeit im Internet, 1999, Rn. 97 ff.

449 In die Richtung Heuner in: Taeger/Wiebe, Inside the cloud, 2009, S. 197 (120). 
des Mirroring 450 - der Spiegelung der Seite - möglich, bedarf im Falle der Löschung jedoch einer präventiven Vervielfältigung vor der Löschmaßnahme.

Anders als bei Sperrungen ist hier eine nachträglich vorgenommene Duplizierung des Inhalts undenkbar, da der Inhalt, sollte er einmal gelöscht sein, gerade unwiderruflich aus dem Datenbestand verschwunden ist. Das jeweilige Angebot kann nicht über eventuelle Umgehungsmaßnahmen im Nachhinein wieder veröffentlicht und über eine neue Domain verbreitet werden. Die Wahrscheinlichkeit einer etwaigen Duplizierung ist bei Löschungen daher relativ gering, da der derjenige der den Inhalt einstellt, letztlich in Aussicht einer möglichen Löschung präventiv und auf schnellstmöglichen Wege den von ihm eingestellten Inhalt spiegeln und unter einer anderen Adresse online stellen müsste, was wohl nicht weitläufig $\mathrm{zu}$ unterstellen ist. Zwar sind entsprechende punktuelle präventive Abhilfemaßnahmen im fraglichen Milieu immer wieder als Antwortphänomen auf die gesellschaftlichen Sperr- und Löschdiskussionen beobachtet worden, ${ }^{451}$ letztlich an der Tagesordnung eines jeden Betreibers von kinderpornographischen Angeboten dürften diese „Doppelinserate“ wohl nicht sein. ${ }^{452}$

\section{(bb) Mildere Maßnahme}

Zur rechtlichen Bestätigung der Annahme, dass die Möglichkeit der Löschung etwaigen gesetzlichen Sperrverpflichtungen ihre verfassungsmäßige Erforderlichkeit abspricht, müsste die Löschung des Inhalts zunächst ein milderes Mittel gegenüber der Sperrung darstellen. Das heißt, die durch die staatliche Maßnahme tangierten Rechtspositionen weitaus weniger beeinträchtigen, als das andere denkbare staatliche Mittel der Sperrung. ${ }^{453}$

Welche Maßnahme die involvierten Rechtspositionen weniger beeinträchtigt hängt von einer Vielzahl von Faktoren ab. So können für die Beurteilung Aspekte, wie die Eigenart der betroffenen Positionen, die Intensität der Beschränkung und die Anzahl der Betroffenen maßgeblich sein.454 In den Vergleich sind auch güns-

Tanenbaum, Computernetzwerke, 2009, S. 715.

451 Heuner in: Taeger/Wiebe, Inside the cloud, 2009, S. 197 (120).

452 Internet Watch Foundation, Jahresbericht 2009, S. 8, abrufbar unter: http://www.iwf.org.uk/assets/media/annualreports/IWF\%202009\%20Annual\%20and\%20Charity\%20Report.pdf (zuletzt abgerufen 20.5.2012).

453 Ständ. Rspr. u.a. BVerfGE 65, 1 (54); BVerfGE 67, 157 (173 ff.); BVerfGE 100, 313 (375); Grzeszick in: Maunz/Dürig, Art. 20 GG, Rn. 113; Voßkuble, JuS 2007, 429; Michael, JuS 2001, 148.

454 Schulze-Fielitz, in: Dreier, Art. 20 GG, Rn. 183; Jakobs, Der Grundsatz der Verhältnismäßigkeit, 1985, S. 68 ff. 
tige Einwirkungen auf andere Rechtspositionen sowie etwaige Nebenwirkungen der Maßnahme einzubeziehen. ${ }^{455}$

Die Löschung eines Angebotes aus dem Gesamtbestand der Internetdateien hat gegenüber der Sperrung des Inhalts zunächst den Vorteil, dass sie gezielt und global übergreifend durchführbar ist: Mittels gesetzlicher Löschverpflichtungen kann systematisch gegen diejenigen Inhalte vorgegangen werden, denen tatsächlich ein kinderpornographischer Hintergrund zu unterstellen ist. 456 Anders als die Sperrung eines Inhalts ermöglicht die Löschung eine punktuelle Entfernung einzelner Angebote, Bilder oder ganzer Webseiten, ohne gleichzeitig auch legale Teile des Webangebotes unzugänglich zu machen. Die unvermeidbare Mitsperrung einer Vielzahl legaler Inhalte, die jeder Sperrmethode anhaftet, kann durch die Löschung eines Inhaltes weitestgehend vermieden werden. ${ }^{457}$ Daraus folgt, dass zum einen die Anzahl der beeinträchtigten Grundrechtsträger bei Vornahme einer Löschung geringer gegenüber der Sperrung sein kann, zum anderen eine weitaus geringere Intensität der beeinträchtigten Grundrechtspositionen folgen kann. Technisch möglich ist es zudem gezielt über den reinen Internetdienst des World Wide Web hinausgehende Löschungen vorzunehmen. Die Maßnahme der Löschung ist damit nicht wie die Sperrung nur auf den Eingriffsbereich des Internetdienstes World Wide Web beschränkt, sondern kann auch auf eine Entfernung der betreffenden kinderpornographischen Angebote in weiteren Verbreitungssektoren, wie Chats, Newsgroups oder sozialen Netzwerken ausgedehnt werden. Dabei wird zwar nicht der unmittelbare Austausch des Materials unterbunden, es besteht allerdings die Möglichkeit einzelne Angebote, die auf dem Webserver abgelegt werden, zu entfernen. 458

Aufgrund der punktuellen Wirkweise ist die technische Möglichkeit der Löschung eines kinderpornographischen Inhalts im Vergleich zur Sperrung damit augenscheinlich ein milderes Mittel innerhalb der inhaltsbeschränkenden Maßnahmen im Internet.

Problematisch ist jedoch, dass sich die Beurteilung der Erforderlichkeit nicht mit dieser Feststellung erübrigt. Die Erforderlichkeit im Sinne der VerhältnismäBigkeit ist nicht nur an das Vorhandensein eines milderen Mittels geknüpft, das mildere Mittel muss auch die gleiche Geeignetheit aufweisen, folglich in gleicher

455 Sachs in: Sachs, Art. 20 GG, Rn. 152; Hirschberg, Der Grundsatz der Verhältnismäßigkeit, 1981, S. 65; Gentz, NJW 1968, 1600 (1604); Stern in: Isensee/Kirchhof, Hdb. StaatR, 1994, Bd. II, S. 781.

456 BT-Drs. 16/13411, S. 13.

457 Heckmann, Stellungnahme der Experten im Rechtsausschuss v. 8.11.2010, S. 13, abrufbar unter: http://www.bundestag.de/bundestag/ausschuesse17/a06/anhoerungen/archiv/03_Zugangsers chwerung/04_Stellungnahmen/Stellungnahme_Heckmann.pdf (zuletzt abgerufen 20.5.2012); Sieber, Ausschussdrucksache 16 (9) 1559, S. 9; Frey/Rudolph, CR 2009, 644 (647).

458 IE. Sieber, Ausschussdrucksache 16 (9), 1559, S. 7. 
Weise der Zweckerreichung dienlich sein, wie die andere gesetzlich denkbare Alternative. 459

(cc) Gleiche Geeignetheit - Abhängigkeit vom Adressaten

Die gleiche Geeignetheit würde der Löschung zukommen, soweit sie die Erfolgswahrscheinlichkeit gleichwertig steigert. ${ }^{400}$ In Bezug auf die Beurteilung der Erfolgswahrscheinlichkeit ist zunächst hervorzuheben, dass eine nutzerseitige Umgehung der Löschmaßnahme nahezu unmöglich ist. Weder kann der Nutzer auf einen ausländischen Anbieter ausweichen, da der Inhalt nicht nur in einem bestimmten Gebiet nicht mehr aufrufbar ist, sondern komplett aus dem weltweiten Internetbestand herausgenommen wurde. ${ }^{461}$ Es bestehen auch keine speziellen Entschlüsselungstechniken, die das gelöschte Angebot wieder im World Wide Web zugänglich machen würden. Eine der Umgehung vergleichbare Alternative den gelöschten Inhalt zu erreichen, bildet nur das erneute Hochladen desselben Inhalts. Praktisch jeder Inhalt, der auf einem lokalen Datenträger zwischengespeichert ist, kann innerhalb weniger Minuten erneut hochgeladen und auf einem Webserver bereitgestellt werden. ${ }^{462}$ Hierbei handelt es sich im Gegensatz zu den Umgehungsmöglichkeiten der Sperrung aber nicht um eine Methode, die der Nutzer des Angebotes selbstbestimmt einsetzen kann, um das Angebot trotz inhaltsbeschränkender Maßnahme zu erhalten, sondern um eine Möglichkeit über die maßgeblich der Anbieter des Angebotes bestimmt.

Legt man der Betrachtung der Geeignetheit lediglich diese Umgehungsaspekte zu Grunde, so scheint die Löschung tatsächlich milder bei gleicher, wenn nicht größerer Erfolgswahrscheinlichkeit zu sein. Ist der Inhalt aus dem Datenbestand des Internets herausgenommen, so ist eine erneute Rezeption des Inhalts verhindert. Die mit der Rezeption verbundenen Gefahren des Verstoßes gegen Straftatbestände, sowie rezeptionsbedingte Risiken einer erneuter Stigmatisierung der Opfer, der geistig-personellen Beeinträchtigung des Rezipienten sowie der etwaiger Nachahmungseffekte können bei einer systematischen und breit angelegten Herausnahme deutlich stärker minimiert und damit das gesetzgeberische Schutz-

BVerfGE 25, 1 (20); BVerfGE 30, 292 (319); BVerfGE 77, 84 (109 f.); BVerfGE 100, 313 (375).
BVerfGE 25, 1 (20); BVerfGE 30, 292 (319); BVerfGE 77, 84 (109 ff.); BVerfGE 81, 70 (91);
BVerfGE 100, 313 (375).
BVerfGE 25, 1 (20); BVerfGE 30, 292 (319); BVerfGE 92, 262 (273); Zum gesamten Komplex Sieber, Ausschussdrucksache 16 (9) 1559, S. 9; Koreng, Zensur im Internet, 2010, S. 163.

Heuner in: Taeger/Wiebe, Inside the cloud, 2009, S. 107 (120) mit Verweis auf den IWF Jahresbericht 2009, S. 8, abrufbar unter: http://www.iwf.org.uk/assets/media/annualreports/IWF\%202009\%20Annual\%20and\%20Charity\%20Report.pdf (zuletzt abgerufen 20.5.2012). 
ziel mehr fördern, als dieses bei Maßnahmen mit hohem Umgehungspotential der Fall wäre. ${ }^{463}$

Entscheidend für die Betrachtung der Erfolgswahrscheinlichkeit der Löschung ist jedoch die tatsächliche Ausgestaltung des Löschansatzes. Löschungen von Onlineinhalten können nur innerhalb eines so genannten Notice-and-take-downVerfahrens durchgesetzt werden. Der aus dem amerikanischen Recht abgeleitete (urheberrechtliche) Grundsatz ist darauf ausgerichtet, dass der Provider nach Kenntniserlangung (notice) des Rechtsverstoßes unverzüglich tägig wird und den beanstandeten Inhalt entfernt (take down). 464 Entscheidenden Einfluss auf die tatsächliche Erfolgswahrscheinlichkeit des Lösch-Ansatzes hat folglich die praktische Frage, wer im Wege des „take down“ das kinderpornographische Angebot herausnehmen kann.

Der Staat kann, in gleicher Weise wie beim Mittel der Sperrung, bereits aus tatsächlichen Gegebenheiten nicht selbstständig in den Kommunikationsprozess eingreifen und die entsprechenden kinderpornographischen Inhalte direkt herausnehmen, sondern ist auch bei der Löschung auf die Inanspruchnahme der Diensteanbieter angewiesen. 465 Bezüglich der Durchführung der Herausnahme muss sich der Staat an diejenigen Provider halten, die eine direkte Einflussmöglichkeit auf die rechtswidrigen Inhalte haben. Je näher die Beziehung eines Dienstanbieters zum jeweiligen Dateninhalt ist, desto besser sind seine Möglichkeiten direkt auf den Inhalt einzuwirken. ${ }^{466}$ Keine Probleme der Einwirkung ergeben sich indes bei denjenigen Diensteanbietern, die tatsächlich Verfügungsgewalt über den inkriminierten Inhalt haben. Nach Beanstandung können diese unmittelbar in den Kommunikationsprozess eingreifen und die Vornahme der Löschung durchführen. In der Regel sind die Inhaber der tatsächlichen Verfügungsgewalt über einen Webinhalt die verantwortlichen Content-Provider, die gerade eigene Informatio-

463 So wohl auch Erdemir in: Eifert/Hoffmann-Riem, Innovation, Recht und öffentliche Kommunikation, 2011, S. 35, der hier ergänzend darauf aufmerksam macht, dass es sich bei der Löschung jedoch nicht um ein Allheilmittel gegen rechtswidrige Inhalte handelt.

464 Begriffserläuterung, grundsätzlich aber mit urheberrechtlichen Einschlag, Holznagel, GRUR-Int. 2007, 971 (972); speziell im Bezug auf Löschungen, Sieber, Ausschussdrucksache 16 (9) 1559, S. 9; schon Sieber, ZRP 2001, 97 (99 f.); Dustmann, Die privilegierten Provider, 2001, S. 35.; siehe hierzu auch „Argumentationshilfe Netzsperren“ der FDP-Fraktion v. 5.10.2010, Beantwortung Frage 7, abrufbar unter:

http:/ jimmy-schulz.netactive.de/wp-content/uploads/2011/04/HIER-finden-Sie-liberale-

Argumente-zu-L\%C3\%B6schen-statt-Sperren1.pdf (zuletzt abgerufen 20.5.2012).

465 Ausführlich zum gesamten Kontext, Dustmann, Die privilegierten Provider, 2001, S. 35; Sieber, Verantwortlichkeit im Internet, 1999, S. 48 ff.

466 Dustmann, Die privilegierten Provider, 2001, S. 35. 
nen beziehungsweise eigene Inhalte zur Nutzung bereithalten. ${ }^{467}$ Es handelt sich hierbei regelmäßig um die Anbieter der betreffenden Webseiten. Content-Provider können im gleichen Zuge, so wie sie Inhalte einstellen, diese Inhalte aus dem Gesamtbestand des World Wide Web auch wieder herausnehmen. ${ }^{468}$

Neben Content-Providern können auch Host-Provider zur Löschung eines Inhaltes verpflichtet werden. Als Host-Provider werden diejenigen Diensteanbieter bezeichnet, die Internetinhalte zwar nicht selbst anbieten, jedoch auf ihren eigenen Servern für Dritte zugänglich machen beziehungsweise zum Abruf bereithalten. ${ }^{469}$ Aufgrund ihrer Tätigkeit als „Herr[en] des Speichermediums“470 ist es für diese Provider unproblematisch über den von ihnen betriebenen Server den beanstandeten Inhalt aus dem Zielverzeichnis zu entfernen und damit eine Löschung herbeizuführen. ${ }^{471}$ Klassischerweise können demnach auch alle Webdiensteanbieter, die ihren Kunden Speicherplatz für das Verfassen eigener Inhalte zur Verfügung stellen die auf ihren Servern lagernden kinderpornographischen Inhalte nach Beanstandung zielorientiert löschen. ${ }^{472}$

In Wirklichkeit birgt aber gerade die Anknüpfung an die Verfügungsgewalt über den inkriminierten Inhalt das wesentlichste Problem eines effektiven Vorgehens mittels Löschung um kinderpornographische Inhalte aus dem Internet zu

467 Stadler, Haftung für Informationen im Internet, 2005, Rn. 9, Hoeren in: Hoeren/Sieber, Hdb. Multimedia-Recht, Teil 18.2, Rn. 12; Hoffmann in: Spindler/Schuster, Recht der elektronischen Medien, 2011, \6 TMG, Rn. 41. \7 TMG erweitert den Begriff des Content-Providers auf denjenigen, der sich fremde Inhalte zu eigen macht, etwa wenn keine erkennbare Distanzierung von den angebotenen Inhalten vorlieget, etwa wenn z.B. ein Verweis auf der Seiten wesentlicher Bestandteil der Geschäftsidee ist, BGH, MMR 2008, 400 (402) m. Anm. Liesching/Waldenberger, LG, Köln, Urt. v. 9.4.2008 - 28 O 690/07, n.v, ein sich-zu-Eigen-machen, liegt auch vor, wenn der Anbieter sich ein uneingeschränktes und unwiderrufliches Nutzungsrecht an allen von den Kunden im Onlineportal eingestellten Beiträgen einräumen lässt, allgemein zu sich-zu-Eigenmachen iSd. \ 7 TMG, Amt. Begr. RegE zum TDG, BT-Drs. 14/6098, S. 23; Koch, CR 1997, 193 (197); Spindler, MMR 2004, 440; Schmitz/Laun, MMR 2005, 208 (210 f.); Pursch/Bär in: Sperrverfügungen gegen Access-Provider, Ausarbeitung des Wissenschaftlichen Dienstes des Deutschen Bundestages, WD 10-3000-010/2009, S. 8.

468 Als „actus contrarius“ zur Dateneinspeisung bezeichnet, Dustmann, Die privilegierten Provider, 2001, S. 35; in die gleiche Richtung Germann, Gefahrenabwehr im Internet, 2000, S. 301.

469 Frey/Rudolph, Rechtsgutachten BVDW, 2008, Rn. 65; Degen, Freiwillige Selbstkontrolle, 2007, S. 4; Pursch/Bär in: Sperrverfügungen gegen Access-Provider, Ausarbeitung des Wissenschaftlichen Dienstes des Deutschen Bundestages, WD 10-3000-010/2009, S. 8.

470 Federrath, ZUM 1999, 177.

471 Dustmann, Die privilegierten Provider, 2001, S. 36; Sieber, Verantwortlichkeit in Internet, Rn. 97.

472 Stadler, Haftung für Informationen im Internet, 2005, Rn. 10; Volkmann, Der Störer im Internet, 2005, S. 216; iE. auch Spindler, MMR 2008, 167 (168) zugl. Anm. zu OLG Frankfurt a.M., Beschl. v. 22.1.2008 - $6 \mathrm{~W} 10 / 08$. 
entfernen. Anders als etwa beim Rundfunk ist der Zugang zum Internet nicht zulassungspflichtig. Daher kann praktisch „Jedermann“ von „Überall“ Inhalte einstellen und der Öffentlichkeit zugänglich machen. ${ }^{473}$ Aufgrund der faktischen Freiheit des Internets lassen sich die Betreiber des kinderpornographischen Inhalts oftmals nur schwer lokalisieren und entsprechend mit Löschverfügungen zur Vornahme von inhaltsbeschränkenden Maßnahmen verpflichten. ${ }^{474}$ Auch die globale Verbreitung und die Tatsache, dass der Staat auf die Zusammenarbeit anderer Länder angewiesen ist, bergen die Gefahr, dass Löschungen nicht zeitnah umgesetzt und die mit dem kinderpornographischen Inhalt einhergehenden Gefahren nicht hinreichend relativiert werden. ${ }^{475}$

Betrachtet man im Verhältnis dazu die Sperrung eines Inhalts, so ist dieser Umstand weniger effektivitätsraubend. Zur Vornahme einer Sperrung muss der Staat nicht auf die global agierenden Content- und Hostprovider zurückgreifen, sondern kann die technische Maßnahme durch die inländischen Access-Provider durchführen lassen. Diese sind im Regelfall den deutschen Behörden bekannt und können bei Nichtvornahme der Sperrmaßnahme mit entsprechenden Sanktionen belegt werden.

Auf den ersten Blick würde es sich daher anbieten hinsichtlich des Adressaten einer Löschung des inkriminierten Inhalts, ebenfalls auf die inländischen AccessProvider zurückzugreifen. Diese Möglichkeit scheitert allerdings an der technischen Konstellation: Die Dienstleistung des Access-Providers liegt in der Zugangsgewährung zum Internet, durch Bereitstellung der nötigen Internetprotokolle und der zur Datenübertragung benötigten Funktionen. ${ }^{476}$ Access-Provider haben damit schon rein technisch betrachtet keinen direkten Zugriff, also keine unmittelbare Verfügungsgewalt auf die zur Löschung des Inhalts benötigten Softwarekonfigurationen. Mit der Infrastruktur der Access-Provider (Kommunikationsnetz) kommt der inkriminierte Inhalt erst in Berührung, wenn die Nutzeranfrage bearbeitet, also die Anfrage bezüglich des Erhalts eines bestimmten Inhalts vom Nutzer gestartet und vom entsprechenden Host beantwortet wurde. ${ }^{477}$ Erst an dieser Stelle im Datenübertragungsprozess wird der rechtwidrige Inhalt über die Leitungen des Access-Providers zum Nutzer transportiert. In diesem Bereich hat der Access-Provider allerdings keine technischen Möglichkeiten den Inhalt zu beseitigen. Der Access-Provider kann nur den vorgelagerten Prozess, folglich nur

473 So Degen, Freiwellige Selbstkontrolle, 2007, S. 281, jedoch in Bezug auf den Zensurbegriff.

474 BT-Drs. 16/12850, S. 5.

475 BT-Drs. 16/12850, S. 5; Sieber, JZ 2009, 653 (654); in die Richtung auch schon Faber, Jugendschutz im Internet, 2005, S. 52.

476 Hierzu bereits oben 3. Teil A. II.

477 Zum gesamten Komplex Frey/Rudolph, Rechtsgutachten BVDW, 2008, Rn. 122 sowie Volkmann, Der Störer im Internet, 2005, S. 215 f.; in die Richtung zuvor auch schon German, Gefahrenabwehr und Strafverfolgung im Internet, S.386 ff. mwN. 
die Anfrage hinsichtlich des Erhalts eines kinderpornographischen Inhaltes verwerfen oder umleiten, nicht aber die bereits rückgesandten Inhalte herausnehmen, was technisch letztlich nur die Möglichkeit der Sperrung beim Access-Providern eröffnet. ${ }^{478}$

Infolgedessen ist die Beantwortung der Frage nach einer gleichen Geeignetheit der (milderen) Löschung gegenüber der (eingriffsintensiveren) Sperrung immer im Kontext zur tatsächlichen Möglichkeit der Einflussnahme auf die Content- und Hostprovider zu sehen. Nachfolgend müssen daher die praktischen Bemühungen aufgezeigt werden, die auf eine gezielte Täterermittlung und Herausnahme des Inhaltes ausgerichtet sind und deren Erfolgschancen bewertet werden.

\section{(1) Überblick über Bemühungen zur zeitnahen Löschung}

Wie Eingangs der Bearbeitung dargestellt finden sich auch nationaler Ebene zahlreiche Bemühungen, die auf eine zeitnahe Anbieterermittlung und Löschung des Inhaltes ausgerichtet sind. So unterhält das BKA eine „Zentralstelle Kinderpornographie“, deren Schwerpunkt neben der Durchsuchung und gezielten Lokalisierung neuen Bildmaterials im Gesamtbestand des Internets auch auf die Einleitung entsprechender Maßnahmen gegen die Anbieter zur unverzüglichen Löschung des inkriminierten Inhalts gerichtet ist. ${ }^{479}$ Gleichzeitig arbeitet das BKA eng mit Nicht-Regierungs-Organisationen und privaten Beschwerdestellen wie dem internationalen Netzwerk INHOPE zusammen, um zu gewährleisten, dass ein breites Konzept zum Auffinden neuer Kinderpornographieinhalte sowie einer zeitnahen Täterermittlung und Angebotsentfernung erreicht wird. ${ }^{480}$ Jüngst wurde die enge

http://www.bundestag.de/bundestag/ausschuesse17/a06/anhoerungen/archiv/03_Zugangsers chwerung/04_Stellungnahmen/Stellungnahme_Maurer.pdf (zuletzt abgerufen 20.5.2012); hierzu auch Krempl in: heise-online, Meldung v. 16.6.2010, „Provider: Löschen statt Sperren“ funktioniert“, abrufbar unter: http://www.heise.de/newsticker/meldung/Provider-Loeschen-stattSperren-funktioniert-1060092.html (zuletzt abgerufen 20.5.2012); eco, PM v. 8.11.2010, „Russland ist Musterschüler beim Kampf gegen Internet-Kinderpornographie, abrufbar unter: http://www.eco.de/verband/202_8408.htm (zuletzt abgerufen 20.5.2012); ebenfalls eco, Newsmeldung v. 17.11.2010, Erfolge der Internet Beschwerdestelle und Mitgliedervorstellung Turtle Entertainment, abrufbar unter: http://www.eco.de/verband/202_8428.htm (zuletzt abgerufen 20.5.2012). Zur Begriffserläuterung im europäischen Kontext, Horn, Vereinte Nationen, 2007, S. 39; Kubn, Entwicklungspolitik, 2005, S. 56 ff. Es handelt sich dabei um internationale privatrechtliche Organisationen, die zwar nicht durch eine öffentliches Mandat legitimiert sind, jedoch die universelle Gesellschaftsinteressen vertreten und insbesondere auf transnationaler 
Zusammenarbeit mit nationalen privatrechtlichen Einrichtungen zusätzlich optimiert. Im März 2011 schlossen die Bundesprüfstelle für jugendgefährdende Medien sowie die deutschen INHOPE-Partnerstellen, wie der Verband der deutschen Internetwirtschaft e.V. (eco), jugendschutz.net und die Einrichtungen der freiwilligen Selbstkontrolle der Multimedia-Diensteanbieter e.V. (fsm) eine Kooperationsvereinbarung, welche die Zusammenarbeit zwischen Polizeibehörden und Beschwerdehotlines in Deutschland weiter verbessern soll, um auf diese Weise eine höhere Löschungswahrscheinlichkeit bei kinderpornographischen Inhalten im Internet zu erreichen und auch die internationale Rechtsdurchsetzung ausbauen. ${ }^{481}$ Einschlägige Hinweise auf im Ausland gehosteten Angebote sollen danach nicht nur über das BKA an die Interpol-Kontaktstellen des ausländischen Staates gemeldet werden, sondern parallel dazu auch an den am Netzwerk INHOPE angeschlossenen internationalen Beschwerdestellen zugeführt werden um mittels gleichzeitigen privaten wie behördlichen Vorgehen eine effektivere Löschung zu erwirken. Hierzu soll auch die weitere Verfügbarkeit des im Ausland gemeldeten Angebotes nach erfolgter Löschaufforderung regelmäßig überprüft und die Anbieter gegebenenfalls mit einer erneuten Aufforderung um Löschung belegt werden.

Auch auf europäischer Ebene finden sich rechtlich verbindliche wie private Kooperationsbemühungen, die auf eine bessere Zusammenarbeit der Behörden und damit auch auf eine gezielte Löschungsmöglichkeit abzielen

Hinsichtlich rechtlich verbindlicher Standards verpflichtet der geltende Rahmenbeschluss 2004/68/JI des Rates der Europäischen Union zur Bekämpfung der sexuellen Ausbeutung von Kindern und der Kinderpornographie, die Mitgliedstaaten entsprechend Erwägungsgrund 7 dazu, ein ,umfassendes Konzept “ und eine „möglichst breite justizielle Zusammenarbeit“482 aufzubauen, welche zur besseren Rechtsdurchsetzung bei Löschbemühungen hilfreich sein kann. ${ }^{483}$

Ebene Einfluss auf den politischen Meinungsprozess haben, Anzahl und Hintergrundinformationen Bundeszentrale für politische Bildung,

abrufbar unter:

http://www.bpb.de/wissen/3UD6BP,0,0,NichtRegierungsorganisationen_\%28NGOs\%29.html (zuletzt abgerufen 20.5.2012).

481 Darauf weist auch BR-Drs. 1319/11 (Aufhebungsentwurf zum Zugangserschwerungsgesetz, hierzu ausführlich unter 4. Teil A. ).

482 So Erwägungsgrund (7) abgedruckt ABl. 2004 Nr. L 13, S. 44 zum Rahmenbeschluss 2004/68/JI des Rates vom 22.12.2003 zur Bekämpfung der sexuellen Ausbeutung von Kindern und der Kinderpornographie.

483 Zum inhaltlichen Problemen in Bezug auf die Umsetzung ins deutsche Recht, Hörnle, NJW 2008, 3521; Liesching, JMS-Report 5/2008, 2; Gercke, ZUM 2009, 526 (527 ff.); Schroeder, GA 2009, 213. Umfassende kritische Stellungnahmen der Sachverständigen im Rechtsausschuss zum deutschen Umsetzungsgesetz abrufbar unter: 
Seit Ratifizierung des Lissabon-Vertrages ${ }^{484}$ ist eine solche justizielle Zusammenarbeit auch rechtlich abgesichert. Entsprechend Art. 82, 83 AEUV kann die EU innerhalb der ihr zur Verfügung stehenden Handlungsinstrumente diese Zusammenarbeit auch von den Mitgliedstaaten einfordern. Hierfür wird sie über Art. 83 AEUV ermächtigt Richtlinien zu erlassen, wenn es um Strafen und Straftaten geht die grenzüberschreitende Dimension haben und daher eine besondere Notwendigkeit einer gemeinsamen Grundlage besteht. Absatz 1 Satz 2 nennt hier explizit die Computerkriminalität als ein solches grenzüberschreitendes Problemfeld. Ein entsprechender Aktionismus hinsichtlich einer auf Art. 82 Abs. 2, 83 Abs. 1 AEUV basierten internetbezogenen Harmonisierungsinitiative ist der Entwurf einer Richtlinie zur Bekämpfung von Kinderpornographie (KOM(2010)94 endg.). ${ }^{485}$ Danach soll der bisherige Rahmenbeschluss 2004/68/JI aufheboben und die Mitgliedstaaten über die Richtlinie zur Gewährleistung wirksamer Ermittlungsmaßnahmen verpflichtet werden (Art. 14 Abs. 3 der Richtlinie). Unter anderen soll über eine Vereinheitlichung des Straftatbestandes der Kinderpornographie ein vergleichbarer Austausch sachdienlicher Daten und Erfahrungen herbeigeführt werden. Nach Erwägungsgrund 13 dient die verstärkte Zusammenarbeit ausdrücklich auch der Erleichterung der Entfernung kinderpornographischer Angebote.

Daneben finden sich im „Stockholm Programm“486 Vorgaben für eine vereinfachte Zusammenarbeit der Mitgliedstaaten zur besseren Rechtsdurchsetzung. So soll unter anderem die Informationserhebung von privaten und öffentlichen Einrichtungen eines anderen Mitgliedstaates ohne Zwangsmaßnahmen und Einschaltung von Justizbehörden des anderen Staates erfolgen sowie exterritoriale Ermittlungsmaßnahmen zugelassen. ${ }^{487}$

http://webarchiv.bundestag.de/cgi/show.php?fileToLoad=1103\&id=1118 (zuletzt abgerufen 20.5.2012).

484 ABl. 2007 Nr. C 306, S. 1.

485 Vorschlag einer Richtlinie des Europäischen Parlaments und des Rates zur Bekämpfung des sexuellen Missbrauchs und der sexuellen Ausbeutung von Kindern sowie der Kinderpornografie und zur Aufhebung des Rahmenbeschlusses 2004/68/JI des Rates, KOM (2010) 0094 endg. COD 2010/0064 abrufbar unter:

http:// eur-lex.europa.eu/LexUriServ/LexUriServ.do?uri=COM:2010:0094:FIN:DE:HTML (zuletzt abgerufen 20.5.2012). Hierzu Gercke, ZUM 2010, 633 (637); Brodowski, ZIS 2010, 376 (381); Rehart, MMR-Aktuell 2010, 303415. Zum Richtlinienvorschlag ausführlich unter 5. Teil .

Das Stockholm-Programm hat das Haager-Programm abgelöst. Hierzu Braum in: Joerden/Szwarc, Europäisierung des Strafrechts, 2010, S. 11. Wortlaut des Stockholm-Programms ist abrufbar unter: http:// eur-

lex.europa.eu/LexUriServ/LexUriServ.do?uri=OJ:C:2010:115:0001:0038:EN:PDF_ (zuletzt abgerufen 20.5.2012). Überblicksartig, Gercke, ZUM 2010, 633 (637); ders., CRi 2010, 75 (79); Brodowski, ZIS 2010, 376 (377). 
Zudem fördert die Europäische Kommission im Rahmen ihres Programms „Safer Internet“"488 auch privatrechtliche Einrichtungen bei der Bekämpfung von kinderpornographischen Inhalten. Dazu gehören insbesondere Beschwerdehotlines, die im internationalen Netzwerk INHOPE zusammengeschlossen sind und sich über eine intensive Zusammenarbeit zwischen in Behörden und Providern um die Löschung von kinderpornographischen Inhalten bemühen. 489

Auf internationaler Ebene mangelt es indes an vergleichbaren rechtlich verbindlichen Übereinkommen, die eine verbesserte Zusammenarbeit zur Lokalisierung der Verantwortlichen und Entfernung des kinderpornographischen Angebotes gewährleisten würden. Die Verbesserung der Anbieterermittlung konzentriert sich demnach hauptsächlich auf kooperative Zusammenarbeit der Staaten untereinander sowie auf die Zusammenarbeit mit internationalen Beschwerdestellen. Hierbei nimmt das Netzwerk INHOPE eine zentrale Stellung ein. Es dient als Hauptorgan für die für Koordination von Hotlines weltweit und wird auch selbstständig bei der Durchsetzung des notice-and-take-down-Verfahrens tätig, indem es eigenständig Täterermittlung betreibt und Löschaufforderungen ausspricht. 490 Seit Oktober 2010 leitet das BKA indes aufgespürte kinderpornographische Angebote die auf Servern außerhalb der EU gehostet werden nicht mehr nur an die zuständige Interpol-Kontaktstelle im Ausland weiter, sondern meldet parallel auch der jeweiligen INHOPE-Partnerstelle im jeweiligen Standortland des Anbieters, dass ein Inhalt als kinderpornographisch eingestuft wurde. Die entsprechenden Partnerstellen bemühen sich daraufhin parallel zu dem behördlichen Vorgehen um eine Aufforderung des Anbieters zur zeitnahen Löschung. 491

\section{(2) Tatsächliche Löscherfolge}

Die Bemühungen zur Lokalisierung der Verantwortlichen um diese einer zeitnahen Löschung zu unterziehen sind großflächig ausgelegt und vereinen rechtliche verbindlich Vorgaben mit freiwilligen Kontrolleinrichtungen, die in Addition eine zeitnahe Löschung herbeiführen sollen. Fraglich ist indes, welche tatsächlichen Erfolge der Löschung zu verzeichnen sind.

Im Ergebnis deuten die auf europäischer Ebene darauf hin, dass eine entsprechende Anbieterermittlung und Veranlassung zur Löschung im Regelfall erfolg-

BR-Drs. 319/11, S. 2; Safer Internet ist ein von der Europäischen Kommission gefördertes internationales Aufklärungsprogramm zum sicheren Umgang mit dem Internet, abrufbar unter: http://ec.europa.eu/information_society/activities/sip/index_en.htm.

$489 \mathrm{Zu}$ den Bemühungen im Einzelnen BR-Drs. 319/11, S. 3.

490 Ausführliche Tätigkeitsschwerpunkte abrufbar unter: http://www.inhope.org/gns/home.aspx; Erdemir in: Eifert/Hoffmann-Riem, Innovation, Recht und öffentliche Kommunikation, 2011, S. 27 (35).

491 BR-Drs. 319/11, S. 3. 
versprechend sein wird. ${ }^{492}$ So gab der Internetverband Eco 2010 insgesamt 656 Hinweise auf das Vorliegen kinderpornographische Angebote an entsprechende Beschwerdestellen weiter in europäischen Mitgliedstaaten weiter. ${ }^{493}$ Bei Inhalten die von deutschen Servern aus gehostet wurden erteilte 448 Beanstandungen an die entsprechenden Provider. Sämtliche Webseiten wurden daraufhin von entfernt. Auf internationaler Ebene war die Erfolgsquote der Löschbemühungen annähernd bei 94 Prozent. Die Dauer zwischen Beanstandung des Inhaltes beim Provider und der Vornahme einer Löschung wird dabei mit einer Woche angegeben. Handelt es sich um kinderpornographische Inhalte, die auf deutschen Server gelagert werden, so ist die Entfernung oftmals bereits innerhalb eines Werktages nach Meldung des Inhaltes an den Provider vorgenommen worden. Eine ähnliche Tendenz hinsichtlich der Erfolgsquote weisen auch die Evaluationsergebnisse des Bundeskriminalamts (BKA) auf. Im Evaluationsmonat Januar 2011 sind binnen einer Woche nach Meldung des Inhaltes an die entsprechenden Provider bereits 68 Prozent der Angebote vom Netz genommen worden; nach vier Wochen belief sich die Erfolgsquote sogar auf 99 Prozent. ${ }^{494}$ Im Einzelnen verzeichnete das BKA im Januar 2011 insgesamt 143 Fälle von kinderpornographischen Webseiten. Die meisten Beanstandungen des Inhaltes beim Provider führten innerhalb einer Woche zum gewünschten Löscherfolg. Nach zwei Wochen musste in 10 Fällen eine erneute Mitteilung an die Provider vorgenommen werden. Nur ein einziger

In die Richtung wohl Frey/Rudolph, Ausschussdrucksache 16 (9)1546, S. 14; ebenfalls Bitkom, Ausschussdrucksache 16 (9)1538, S. 7; eco, Ausschussdrucksache 16 (9) 1542, S. 4.

$493 \mathrm{Zu}$ den Zahlen eco, PM v. 18.1.2011, „Kampf gegen Kinderpornographie 2010: Erfolgsquote über 99 Prozent“, abrufbar unter: http://www.eco.de/verband/202_8727.htm (zuletzt abgerufen 20.5.2012).

494 Die Vorgabe der Erstellung einer monatlichen Evaluation entsprechender Löschversuche resultiert aus der Aussetzung des Zugangserschwerungsgesetzes. Nach Maßgabe eines Erlasses des BMJ gegenüber dem BKA soll die vormals im Gesetz angeordnete Erstellung einer Sperrliste von kinderpornographischen Inhalten und wie Weiterleitung der Sperrliste an die AccessProvider (damit auch die Sperrung) unterbleiben, Nichtanwendungserlass abrufbar unter: http://blog.odem.org/2010/02/19/Erlass-ZugErschwG.pdf. Die gewonnen Erkenntnisse sollten als Grundlage dienen, über die Notwenigkeit eines weiteren Sperrkonzepts, wie es das Zugangserschwerungsgesetz vorsah, zu entscheiden. Evaluationsergebnisse allerdings nicht veröffentlicht. Hier zitiert nach Bleich, heise-online, Meldung v. 18.3.2011, „Kampf gegen Kinderpornos: BKA Zahlen belegen den Erfolg von Löschen statt sperren“, abrufbar unter: http://www.heise.de/newsticker/meldung/Kampf-gegen-Kinderpornos-BKA-Zahlen-belegenden-Erfolg-von-loeschen-statt-sperren-1210432.html (zuletzt abgerufen 20.5.2012); Koch in: digitale linke, Beitrag v. 17.3.2011, „BKA Zahlen bestätigen Erfolg von „Löschen statt sperren“, abrufbar unter: http://blog.die-linke.de/digitalelinke/bka-zahlen-bestatigen-erfolg-von-loschenstatt-sperren/ (zuletzt abgerufen 20.5.2012). 
Provider hatte nach einem Zeitraum von vier Wochen und der viermaligen Aufforderung zur Löschung den Inhalt weiterhin zur Verfügung gestellt.

Auf internationaler Ebene ist die Löschquote ebenfalls hoch, wenngleich hier deutliche Unterschiede zur innereuropäischen Durchsetzung zu verzeichnen sind. Dem Jahresbericht 2010 des internationalen Netzwerks INHOPE, welches wohl die größte Koordinationsstelle für die internationale Durchsetzung des Löschansatzes darstellt, ist zu entnehmen, dass etwa 80 Prozent der gemeldeten Seiten innerhalb von sieben Tagen gelöscht werden konnten nachdem eine entsprechende Aufforderung an die Anbieter erfolgt ist. 50 Prozent der Seiten waren bereits nach zwei Tagen nicht mehr vorhanden. Nach 14 Tagen verblieben noch zwischen 5 und 10 Prozent der Seiten im Netz. ${ }^{495}$

\section{(3) Grundsätzliche Verfassungswidrigkeit eines Sperransatzes?}

Fraglich ist, ob die internationalen Bemühungen und die Ergebnisse einer erfolgreichen Löschung dazu führen, dass ein legislatorischer Sperransatz damit aufgrund mangelnder Erforderlichkeit verfassungswidrig ist. Grundsätzlich tendieren die angeführten Ergebnisse in die Richtung, dass die Löschung des Inhaltes nicht nur ein milderes Mittel gegenüber der Sperrung darstellt, sondern auch eine effektive Maßnahme ist, um kinderpornographische Inhalte aus dem Internet zu entfernen und dadurch den gesetzgeberischen Zweck einer Verhinderung des Zugriffs sowie der rezeptionsbedingten Risiken zu erreichen.

Die Studien sprechen zwar für eine eindeutige Tendenz für Löscherfolge, sie belegen gleichzeitig aber auch, dass trotz wirksamer Löschbemühungen weiterhin kinderpornographische Inhalte im Internet vorhanden sind. Insbesondere auf internationaler Ebene folgt das Vorgehen gegen kinderpornographische Inhalte nur aufgrund kooperativer Zusammenarbeit zwischen internationaler Kriminalbehörden und privaten Beschwerdestellen, die auf eine Verbesserung der Täterermittlung und Strafzuführung im Bereich der Verbreitung kinderpornographischen Materials ausgerichtet ist. Es handelt sich hierbei jedoch nicht um etwa dem europäischen Rechtssystem vergleichbare verbindliche Rechtsvorgaben, die effektiv auf eine verstärkte internationale Zusammenarbeit und die eindeutige Tendenz zur zeitnahen Löschung ausgerichtet sind. So zeigen die Löschergebnisse des international agierenden Netzwerks INHOPE, dass trotz laufender Löschbemühungen von behördlicher wie privater Seite, weiterhin bis zu 10 Prozent der kinderpornographischen Inhalte zur freien Verfügung im Internet verbleiben. Zudem bestehen auch auf internationaler Ebene keine global durchsetzbaren, rechtlichen Sanktionen, welche bei Zuwiderhandlungen gegen private Löschaufforderungen greifen würden. Es ist auch nicht absehbar, ob sich die positiven Ergebnisse der Lösch-

495 INHOPE Jahresreport 2010, abrufbar unter: http://www.inhope.org/gns/news-andevents/news/11-03-08/INHOPE_Annual_Report_2010_released.aspx (zuletzt abgerufen 20.5.2012). 
maßnahmen auch zukünftig verwirklichen lassen. So müssen bei der Bewertung der Effektivität einer Löschung stets die rasanten technischen Entwicklungen beachtet werden, die dem Medium Internet immanent sind. Dieses verdeutlichen bereits die monatlichen Evaluationsergebnisse des BKA. So waren im März 2010 von 179 durch das BKA gegenüber den Providern beanstandeten Fällen nach einer Woche noch 71 Prozent zur freien Verfügbarkeit. Im August 2010 hingegen waren von 104 beanstandeten Fällen nach einer Woche lediglich 14 Prozent weiterhin im Netz, wobei im Folgemonat wiederum ein Anstieg auf 54 Prozent zu verzeichnen war. ${ }^{496}$ Dieses zeigt, dass sich schon im engen Zeitrahmen die positive Tendenz praktisch ins Gegenteil verkehren kann, langfristig betrachtet kann demnach nicht mit Sicherheit davon ausgegangen werden, dass eine Löschung immer das effektivere Mittel zur Rechtsdurchsetzung sein wird.

Neben den ändernden Strukturen des Internets ist auch eine Verlagerung des Angebots zu berücksichtigen. Denn aufgrund des derzeit erfolgreichen Vorgehens, kann nicht ausgeschlossen werden, dass sich die Anbieter kinderpornographischer Webseiten speziell in Staaten ansiedeln, für welche gerade keine internationalen Vereinbarungen getroffen wurden und auch der Einfluss von privaten Beschwerdestellen relativ gering ist. Soweit eine deutliche Verlagerung in löschresistente Länder vollzogen wird, schwindet auch der Erfolgswahrscheinlichkeit eines Löschvorgehens. Es ist damit keineswegs bewiesen, dass alle Inhalte, die im Internet bestehen, sich auch tatsächlich entfernen lassen und der Löschansatz insoweit immer der effektivere Lösungsweg zur effektiven Rechtsdurchsetzung sein wird.

Die Wichtigkeit des hinter der Maßnahme stehenden Rechtsguts Jugendschutz und die hohen Risiken, die von der ungehinderten Verbreitung von kinderpornographischen Material ausgehen, müssen es dem Gesetzgeber im Rahmen seines verfassungsrechtlichen Schutzauftrages deshalb erlauben auch mehrere potentielle Mittel miteinander zu verbinden, die das Gesetzesziel im Kombination am besten herbeiführen können.

Es muss dem Gesetzgeber zugestanden sein sich auch rechtlich an die tatsächlichen Gegebenheiten zukünftig anpassen zu können. Soweit man ihm die Möglichkeit der Sperre des Inhaltes verwehrt, kann er den Schutzauftrag dann nicht mehr hinreichend nachkommen, wenn Verlagerungen auf löschresistente Gebiete stattgefunden haben und die erfolgreiche Rechtsdurchsetzung nicht mehr gewährleistet ist. Soweit man neben Löschung noch ein weiteres Handlungsinstrument zugesteht, kann der Gesetzgeber flexibler auf mögliche Veränderungen reagieren und dadurch das zu verfolgende Rechtschutzziel einer effektiven Verhinderung der Ausbreitung sexueller Angebote im Internet am besten gewährleisten. So ver-

496 Antwort zur kleinen Anfrage BT-Drs. 17/3164, der Abgeordneten Sitte sowie der Fraktion DIE LINKE an die Bundesregierung, S. 2 abrufbar unter: http://blog.die-linke.de/digitalelinke/wpcontent/uploads/Antwort-Loeschen-statt-Sperren.pdf (zuletzt abgerufen 20.5.2012). 
standen dienen Sperren zulässigerweise einer Absicherung der gesetzlichen Schutzintention und sind nicht als per se verfassungswidrig zu verwerfen.

Soweit sich der Gesetzgeber zur Formulierung mehrerer gesetzlicher Alternativen entscheidet, dürfen Sperrungen in diesem System aufgrund der bisherigen Erfahrungen zur Ermittlungsmöglichkeit von Anbietern und den geringeren Eingriffsintensität nur ultima ratio sein, um nicht verfassungsrechtlich beanstandet zu werden. ${ }^{497}$ Der verfassungsverträglichste Ansatz der Sperrung wäre demnach nur in zwei Fällen denkbar: Entweder es liegt ausnahmsweise eine Nichtermittelbarkeit der Anbieter der Inhalte vor, obgleich ein weitläufiges Bemühen stattgefunden hatte oder wenn die Sperrung der Seiten praktisch als „,sanktionsähnlicher Ansatz“ erst dann vorgenommen wird, wenn eine Löschung in „vorwerfbarer Weise“ unterlassen wurde. ${ }^{498}$ Eine solche Handhabe der Subsidiarität von Sperrungen setzt voraus, dass die betroffenen Host- beziehungsweise ContentProvider in jedem Fall erst ermittelt und zur Löschung der gespeicherten Daten aufgefordert werden müssen. Erst wenn entsprechende Versuche scheitern oder sich die Provider schlicht weigern der Löschaufforderung nachzukommen, kann die gesetzliche Verpflichtung zur Sperrung in Betracht kommen um den verfassungsrechtlichen Auftrag abzusichern.

Die hohe Eingriffsintensität der Sperrmaßnahme relativiert sich innerhalb eines solchen Vorgehens damit praktisch von selbst. Soweit die Tendenz weiterhin zu einer nahezu lückenlosen Löschung des Inhaltes geht, dann wird der Anwendungsbereich der Sperrung praktisch auch ein Minimum zurückgeführt. Besonders europäisch vorgehaltenen Inhalten wird der Auffangcharakter der Sperrung praktisch nicht in Betracht kommen, da hier neben den privaten Vorgehen auch rechtlich verbindliche Strukturen bereitstehen, die eine bessere Rechtsdurchsetzung forcieren. Im Hauptanwendungsfall werden Sperrungen daher auf Inhalte beschränkt sein, die im außereuropäischen Raum ihren Ursprung haben, da sich den Löschbemühungen hier kein rechtsverbindlicher Charakter zugrundeliegt.

Dementsprechend ist festzustellen, dass ein Subsidiaritätsverhältnis zwischen den inhaltsbeschränkenden Maßnahmen Löschen und Sperren besteht. Nur soweit der Gesetzgeber innerhalb der gesetzlichen Formulierung bereits den „Löschen vor Sperren“-Grundsatz gesetzlich fixiert ist von einer Verfassungsmäßigkeit der Sperrung zur Absicherung des Rechtsschutzziels auszugehen. ${ }^{499}$ Ein sofortiges Vorgehen mittels Sperrung beziehungswiese die alleinige Formulierung einer gesetzlichen Sperrmaßnahme wäre jedoch verfassungswidrig.

497 Sieber, Ausschussdrucksache 16 (9) 1559, S. 18.

498 So ausdrücklich Sieber, Ausschussdrucksache 16 (9) 1559, S. 18.

499 IE. ebenso Graf, Ausschussdrucksache 16 (9) 1555, S. 5; Kabl, SächsVBl. 2010, 180 (189); Erdemir in: Eifert/Hoffmann-Riem, Innovation, Recht und öffentliche Kommunikation, 2011, S. 27 (35); Sieber, Ausschussdrucksache 16 (9) 1559, S. 18. Zur Frage, ob die Verankerung des Grundsatzes im Rahmen des Zugangserschwerungsgesetzes gelungen ist 4. Teil C. II. 2. 
(4) Bestätigung durch den Grundsatz der Subsidiarität

Schließlich wird das Ergebnis der Subsidiarität der Sperrung gegenüber der Löschung von dem allgemeinen ordnungsrechtlichen Grundsatz der Subsidiarität des Nichtverantwortlichen bestätigt. Wie bereits erläutert bedient sich der Staat zur Vornahme der technischen Sperrung der direkt am Kommunikationsprozess beteiligen Access-Provider, um ihre Einflussmöglichkeit auf den Datenverarbeitungsprozess für die Erfüllung der staatlichen Aufgabe der Gefahrenabwehr im jugendschutzrelevanten Bereich auszunutzen. Die Konstellation des „SichBedienens“ stellt gleichzeitig auch eine faktische „Inanspruchnahme“ der Provider dar, die unter dem Aspekt der öffentlich-rechtlichen Störerhaftung, diskutiert wird.

Für die staatliche Inanspruchnahme eines Privaten zur Gefahrenabwehr im Rahmen der Störerhaftung ist das Vorliegen einer Gefahr maßgeblich. ${ }^{500}$ Bereits das Vorhalten inkriminierten Inhalte im Internet begründet die Gefahr, dass die Rechtsordnung durch Verstöße gegen geltende Gesetzesnormen verletzt wird. ${ }^{501}$ Überdies entfaltet auch jeder Rechtsverstoß - also jede Einstellung eines kinderpornographischen Inhaltes - gegenwärtig spürbare und in die Zukunft reichende Rechtswirkungen, die ausreichend sind um gleichzeitig auch ein präventives staatliches Handeln im Sinne der Gefahrenabwehr anzunehmen. ${ }^{502}$

Gerade diese ordnungsrechtliche Einordnung der Rechtsmaterie impliziert gleichzeitig aber auch eine Wertung in Bezug auf das Rangverhältnis der Inanspruchnahme von entsprechenden Störern, das heißt den Normadressaten der jeweiligen Maßnahme.

Der Begriff des Störers unterscheidet ordnungsrechtlich in Verhaltens-, Zustands- und Nichtstörer. Verhaltensstörer ist derjenige, der die Gefahr unmittelbar selbst verursacht hat. Zustandsstörer ist, wer die tatsächliche Sachherrschaft über die Gefahrenquelle hat und als Nichtstörer wird derjenige verstanden, der weder die Gefahr selbst verursacht, noch die tatsächliche Sachherrschaft über die Gefahrquelle innehat. ${ }^{503}$

Innerhalb der in Frage kommenden Störer ist in Übereinstimmung mit den allgemeinen Verantwortlichkeitsregelungen der \$S 7-10 des Telemediengesetzes

500 Volkmann, Der Störer im Internet, 2005, S. 195; Germann, Gefahrenabwehr im Internet, 2000, S.183 ff.; Greiner, Die Verhinderung verbotener Internetinhalte, 2001, S. 93 ff., 95.

501 Ausführlich zum gesamten Bereich der öffentlich-rechtlichen Störerhaftung: Volkmann, Der Störer im Internet, 2005, S. 194 ff.

502 Volkmann, Der Störer im Internet, 2005, S. 196 mwN.; Schoch in: Schmidt-Aßmann, Besonderes Verwaltungsrecht, Kap. 2, Rn. 65.

503 OVG Münster, NVwZ 1985, 356 mwN.; OVG Koblenz, NVwZ 1992, 499 (500); OVG Münster, NVwZ 1997, 507 (508); Schenke, Polizei- und Ordnungsrecht, 2011, Rn. 241; Pieroth/Schlink/Kniesel, Polizei- und Ordnungsrecht, 2010, S 9, Rn. 5; Denninger in: Lisken/Denninger, Hdb. PolR, 2007, Teil E, Rn. 77; Hartmann, JuS 2008, 593 (594). 
(TMG) ${ }^{504}$ einem abgestuften Verantwortlichkeitssystem zu folgen, welches stets auf die nachrangige Haftung des Nichtverantwortlichen ausgerichtet ist. ${ }^{505}$ Derjenige, der die Störung nicht selbst verursacht hat, sondern nur mittelbar an der Störung beteiligt ist, soll nur zu Verantwortung gezogen werden, wenn derjenige, der die Gefahr selbst verursacht oder Inhaber der tatsächlichen Sachherrschaft über die Gefahrenquelle ist, mit angemessenen Mitteln und im angemessenen Rahmen nicht zu ermitteln ist. 506

Die Nichtstörerhaftung bildet damit einen Ausnahmefall, der an strenge Voraussetzungen geknüpft ist. ${ }^{507} \mathrm{Um}$ das Spannungsverhältnis zwischen effektiver Gefahrenabwehr einerseits und dem ausnahmsweisen Haftung eines „nahezu“ Unbeteiligten anderseits verfassungskonform zu lösen, wird gefordert, dass die Inpflichtnahme zur Abwehr einer erheblichen gegenwärtigen Gefahr unerlässlich ist, Maßnahmen gegen Verhalts- und Zustandsstörer nicht oder nicht rechtzeitig möglich sind oder keinen Erfolg versprechen und der Nichtstörer ohne erhebliche eigene Gefährdung und ohne Verletzung höherwertiger Pflichten in Anspruch genommen wird. ${ }^{508}$ Zudem dürfen die Maßnahmen nur aufrechterhalten werden, solange die Abwehr nicht auf andere Weise möglich ist. Im Lichte dieser Grundsätze wird man den Nichtstörer im Internet nur wegen besonders schwerwiegenden Rechtsverstößen beziehungsweise zum Schutze eine besonders schutzwürdigen Rechtsgutes zur Gefahrenabwehr heranziehen können.509

\section{(a) Nichtstörereigenschaft der Access-Provider}

Access-Provider sind, soweit sie zur Vornahme von Sperrungen gesetzlich verpflichtet werden, ordnungsrechtlich als Nichtstörer einzuordnen und folglich nur unter strengen Voraussetzungen und nur subsidiär in Anspruch zu nehmen. ${ }^{510}$

504 Zum Haftungsregime des TMG mit besonderer Bezugnahme zu Access und Hostprovidern, Frey/Rudolph, Rechtsgutachten BVDW, 2008.

505 Kugelmann, Polizei- und Ordnungsrecht, 2006, S. 257; Pieroth/Schlink/Kniesel, Polizei- und Ordnungsrecht, 2010, \9, Rn. 2.

506 Storr in: Heermann/Ohly, Verantwortlichkeit im Netz, 2003, S. 103 (111) mwN.

507 Denninger in: Lisken/Denninger, Hdb. PolR, 2007, Teil E, Rn. 126; Volkmann, Der Störer im Internet, 2005, S. 220; Frey/Rudolph, Rechtsgutachten BVDW, 2008, Rn. 117 ff.

508 So die ordnungsrechtlichen Voraussetzungen an eine Nichtstörerhaftung, vgl. Landespolizeigesetze, z.B. \8 Nds-SOG, \6 NRW PolG, \7 BremPolG, \10 BayPAG.

509 Spindler in: Spindler/Schmitz/Geis, $\int 9$ TDG, Rn. 49; Volkmann, Der Störer im Internet, 2005, S. 220; dem zustimmend Frey/Rudolph, Rechtsgutachten BVDW, 2008, Rn. 124.

510 So schon Zimmermann, NJW 1999, 3145 (3148); Hornig, ZUM 2001, 846 (856); Spindler/Volkmann, K\&R 2002, 398 (404 ff.); ausführlich Volkmann, Der Störer im Internet, 2005, S. 208 ff. mwN. und einer detaillierten Auseinandersetzung mit Sonderformen der Verhaltensstörereigenschaft wie Zweckveranlasser oder latente Gefahr, jeweils zu Recht ablehnend. Dem an- 
Die Dienstleistung der Access-Provider basiert nicht auf dem unmittelbar selbstständigen Anbieten kinderpornographischer Seiten zum Abruf durch den Nutzer. Vielmehr ermöglichen sie ihren Kunden lediglich den Zugang zum Internet, indem sie die notwendige Infrastruktur zum Austausch der Daten durch die Nutzer im Internet bereitstellen. Access-Provider haben damit keinerlei Einfluss auf den Inhalt der Datenbestände regelmäßig mangelt es ihnen auch an einer Kenntnis der durch ihre Leitungen verbreiteten Inhalte. ${ }^{511}$

Die ordnungsrechtliche Störereigenschaft setzt zwar nicht an eine Kenntnis beziehungsweise an ein vorhergehendes Verschulden an, bedarf jedoch einer unmittelbaren Verursachung der Gefahr. Im Falle der Gefahren die mit der onlinebasierten Verbreitung von kinderpornographischen Material verbunden sind, wird die Gefahr frühestens mit dem Einstellen der Bilder und spätestens mit dem Ansehen der Bilder begründet, was jedoch nicht mehr dem Machtbereich Zugangsdiensteanbieter zuzuordnen ist. ${ }^{512}$

Überdies lässt sich eine unmittelbare Verursachung der Gefahr durch den Access-Provider auch nicht damit begründen, dass diese das Kommunikationsnetz bereitstellen, welches erst die Möglichkeit eröffnet gefahrtragende Inhalte einzustellen. ${ }^{513}$ Die bloße Bereitstellung eines Kommunikationsmediums über das verschiedene Datenpakete transportiert werden können wird regelmäßig nicht eine ordnungsrechtlich relevante Gefahrenschwelle überschreiten, sondern ist als rein sozialadäquat neutrale Handlung zu verstehen. ${ }^{514}$ Denn neben der Verbreitungsund Vertriebsmöglichkeit für kinderpornographische Inhalte, ist das Kommunikationsnetz primär Träger einer Vielzahl legaler Informationen, die gerade völlig

schließend Sieber/Nolde, Sperrverfügungen im Internet, 2008, S. 154 f. So jetzt auch ausdrücklich der Gesetzgeber im Rahmen des ZugErschwG, BT-Drs. 16/13411, S. 12.

511 LG Frankfurt a.M., MMR 2008, 344 (346).

512 So im Ergebnis, Volkmann, der Störer im Internet, 2005, S. 208, dem zustimmend Frey/Rudolph, Rechtsgutachten BVDW, 2008, Rn. 119.

513 Volkmann, Der Störer im Internet, 2005, S. 215; darauf bezugnehmend Frey/Rudolph, Rechtsgutachten BVDW, 2008, Rn. 122. Sinngemäß jedoch im Einzelnen für die Vorratsdatenspeicherung, Braun, K\&R 2009, 386 (390); Schnabel, MMR 2008, 281 (286); Rehart, MMR-Aktuell 2010, 303415: LG München I, CR 2009, 816 (817).

514 So auch Kübne, NJW 1999, 188 (190 bei Fn. 11); LG Frankfurt a.M., MMR 2008, 344 (346); LG Hamburg, NJOZ 2010, 443 (445); LG München I, CR 2009, 816 (817); zur Überwachung von Gefahrenquellen in Bezug auf Internetprovider Sieber, JZ 1996, 494; a.A. OLG Düsseldorf, Beschl. v. 11.5.2009 - I-20 W 146/08 n.v, für die Zurverfügungstellung eines WLAN-Netzes, da man hier einer Person ermöglicht im Zuge der Anonymität Rechtsverletzungen (Urheberrechtsverletzungen) zu begehen; dem anschließend LG Düsseldorf, NJOZ 2010, 680; LG Mannheim, MMR 2007, 537; explizit in Bezug auf Sperrverfügungen gegen Access-Provider, Frey/Rudolph, Rechtsgutachten BVDW, 2008, Rn. 124; zum Kommunikationsnetz als Gefahrenquelle allgemein, Mantz, Rechtsfragen offener Netze, 2008, S. 224 ff. 
unbedenklich sind. Zwar mag die Bereitstellung des Kommunikationsnetzes die Möglichkeit erst hervorbringen, dass auch inkriminierte Inhalte über die Leitungen gelangen, jedoch müsste sich dann jeder der in nur adäquat-kausaler Weise potentiell gefahrerhöhend tätig wird, als Zustandsstörer verantworten müssen, was letztlich zu einer nicht hinnehmbaren ausufernden Haftung führen würde. ${ }^{515}$

Auf diesem Umstand gründet auch die Haftungsfreistellung für Zugangsanbieter nach $\int 8$ TMG, der nach einhelliger Auffassung typischerweise auch AccessProvider unterfallen. ${ }^{516}$ Nach $\int 8$ TMG sind Zugangsdiensteanbieter für fremde

515 Detaillierte Herleitung und Ablehnung bei Germann, Gefahrenabwehr im Internet, 2000, S. 387 ff.; dem folgend Volkmann, Der Störer im Internet, 2005, S. 208 ff., 212 f. ergänzend auch mit Ablehnung einer Verhaltensverantwortlichkeit anhand einer latenten Gefahr, da die Figur der „latenten Gefahr“ nicht solche Fälle erfassen soll, in denen die Verantwortlichkeit bereits einer bestimmten Person - dem Content-Provider - zugerechnet werden kann in die gleiche Richtung auch Frey/Rudolph, Rechtsgutachten BVDW, 2008, Rn. 116 ff.; Degen, Freiwillige Selbstkontrolle, 2007, S. 220 ff.; VG Düsseldorf, MMR 2003, 205 (206), offen OVG Münster, MMR 2003, 348; in Bezug auf Vorratsdatenspeicheung mit vergleichbarer Argumentation, Braun, K\&R 2009, 386 (390).

516 Teilweise wird hinterfragt, ob der Access-Provider wirklich als Zugangsanbieter iSd. \8 TMG verstanden werden kann, weil der Access-Provider zwar dem weiten Verständnis des Diensteanbieters nach \ 2 S. 1 Nr. 1 TMG gerecht wird, der Anwendungsbereich des TMG nach \ 1 Abs. 1 S. 1 TMG jedoch auf elektronische Informations- und Kommunikationsdienste, soweit sie nicht dem Rundfunk nach $\int 2 \mathrm{RStV}$ einerseits, oder der Telekommunikation - in Form von telekommunikationsgestützten Diensten nach $\int 3$ Nr. 25 TKG oder reinen Telekommunikationsdiensten nach $\int 3$ Nr. 24 TKG, also solchen die ganz in der Übertragung von Signalen über Telekommunikationsnetze bestehen - andererseits (Telemedien), beschränkt ist und der AccessProvider vom Verständnis seiner Dienstleistung (Bereitstellung der zur Internetnutzung notwendigen Kommunikationsinfrastruktur) folgend, auch als reiner Anbieter von Telekommunikation verstanden werden und damit aus dem Anwendungsbereich des TMG gänzlich rauszuhalten wäre. iE. erschöpfen sich die vom Access-Provider angebotenen und unterhaltenen Dienste aber nicht lediglich in der reinen Telekommunikationsdienstleitung; neben der rein technischen Komponente der Zugangsleistung stellen Access-Provider auch ganze Komplettpakete zur Verfügung, wie die Vermittlung von Sprachdienstleistungen, E-Mail oder Suchmaschinen sowie sämtliche für die Benutzung des Netzes erforderlichen Protokollfunktionen, so dass sich ihre Dienstleistungen auch keineswegs in reiner Telekommunikation erschöpfen, in die Richtung Sieber, Verantwortlichkeit im Internet, 1999, Rn. 23; Sieber/Nolde, Sperrverfügungen im Internet, 2008, S. 125; Zu bedenken ist in diesem Zusammenhang dass Access-Providern, Wittern/Schuster in: Beck'scher TKG-Komm., \3 TKG, Rn. 49. Darüber hinaus hat der Gesetzgeber durch die Neugestaltung des TMG, trotz des missverständlichen Ausschlusses, die Veranwortlichkeitsregeln des $\int 8$ TMG gerade auch auf den Access-Providern anwenden wollen, da sonst der Regelung kaum noch eine Bedeutung zuzusprechen wäre, Klarstellend auch die Begr. RegE TMG bei BR-Drs. 556/06, S. 17; Spindler in: Spindler/ Schmitz/Geis, \ 9 TDG Rn. 14; Gersdorf in: 
Informationen, die sie in einem Kommunikationsnetz übermitteln oder zu denen sie den Zugang zur Nutzung vermitteln grundsätzlich von der Haftung freigestellt. 517 Würde man diese aber schon durch die Bereitstellung der Kommunikationsnetze als Verantwortliche ansehen, würde das der gesetzgeberischen Intention, die sich in der Formulierung des $₫ 8$ TMG niederschlägt, zuwiderlaufen.

Damit ist der Access-Provider ordnungsrechtlich betrachtet als Nichtstörer einzuordnen und darf als Ausfluss der Verhältnismäßigkeit nur unter erhöhten Voraussetzungen und nur subsidiär gegenüber den Content- und Hostprovidern in Anspruch genommen werden.

Die geforderten höheren Anforderungen sind bei gesetzlichen Sperrverpflichtung zur Unterbindung von Kinderpornographie im Internet gegeben: Die von einer Abruf- und Rezeptionsmöglichkeit der Inhalte ausgehenden Gefahren erscheinen gegenwärtig und von erheblichen Ausmaß. Zudem ist der mit der Verpflichtung der Access-Provider verfolgte Zweck gerade in einem extrem hohen Rechtsgut - dem Kindesschutz vor sexueller Ausbeutung - begründet. Damit ergeben sich aus ordnungsrechtlicher Sicht, dass nur eine ausnahmsweise subsidiäre Inanspruchnahme der Access-Provider gegenüber den primär verantwortlichen Content- und Hostprovidern möglich ist. Übertragen auf die technische Umsetzung der Inanspruchnahme bedeutet dieses in Übereinstimmung zum obigen Ergebnis, dass zunächst Löschversuche über die verantwortlichen Zustands- und Verhaltensstörer (Content- und Hostprovider) vorangehen müssen, ehe nachrangig auf den Nichtstörer erfolgreich die Vornahme einer Sperrmethode auferlegt werden kann. ${ }^{118}$

\section{(b) Zwischenergebnis:}

Im Regelfall wird eine Sperrverpflichtung der inländischen Access-Provider nicht notwendig sein, weil sich Löschersuche als mildere und effektive Maßnahme darstellen werden und damit in jedem Fall vorzugehen haben. Der Gesetzgeber ist aufgrund der Wichtigkeit des verfolgten Rechtsgutes und dem verfassungsrechtli-

Beck'scher TKG-Komm., Einl. C Rn. 18; Holžner, BB 2009, 2148; Hoeren, NJW 2007, 801 (802); a.A. Stadler, Haftung für Informationen im Internet, 2005, Rn. 36; Stadler, MMR 2002, 343 (344); zusammenfassend zum Streitstand Schmitz in: Spindler/Schuster, Recht der elektronischen Medien, 2008, \$1 TMG, Rn. 17.

517 Zur Haftungsprivilegierung für Zugangsdiensteanbieter nach $\ 8$ TMG, Spindler in: Spindler/Schmitz/Geis, \8 TDG, Rn. 4 ff.; Hoffmann in: Spindler/Schuster, Recht der elektronischen Medien, 2011, \8 TMG, Rn. 1 ff.

518 Im Ergebnis auch Volkmann, Der Störer im Internet, 2005, S. 206 ff. mwN.; Greiner, Die Verhinderung verbotener Internetinhalte, 2001, S. 120 ff.; Germann, Gefahrenabwehr im Internet, 2000, S. 386 ff. Welche weiteren Folgen aus einer Inanspruchnahme als Nichtstörer resultieren, z.B. das Erfordernis einer Entschädigungspflicht, wird später unter 3. Teil B. I. 2. d) (bb) näher behandelt. 
chen Auftrag einer umfassenden staatlichen Jugendschutzverpflichtung befugt hinsichtlich der Wahl des Mittels auch mehrere Alternativen zur Erreichung des gesetzlichen Schutzziels gemeinsam zu formulieren. Soweit es sich wie hier um Maßnahmen handelt, die auf ein rasant wechselnden Datenbestand Einfluss nehmen und die Rechtsdurchsetzung vor allem durch die Globalität der verbreiteten Angebote nicht in jedem Fall garantiert ist, muss dem Gesetzgeber zugestanden werden auch Auffangmaßnahmen zu statuieren um den Rechtsgüterschutz in jedem Fall zu erreichen.

Zur Wahrung der Verhältnismäßigkeit und aufgrund der Tatsache, dass es sich bei der Sperrung um die ausnahmsweise Inanspruchnahme eines Nichtverantwortlichen handelt, darf die Sperrung gegenüber der Löschung nur nachrangig zur Anwendung kommen lassen. Innerhalb der gesetzlichen Formulierung kann dieses dadurch erreicht werden, dass explizit eine Sperrung explizit ausgeschlossen wird, wenn die verantwortlichen Content- und Host-Provider zu ermitteln sind oder über einen sanktionsrechtlichen Ansatz, der die Sperrung im Falle greifen lässt, in dem sich die Verantwortlichen schlicht weigern die Löschmaßnahme vorzunehmen. Eine alleinige Formulierung einer Sperrverpflichtung verbietet sich aus Gründen der Erforderlichkeit.

(dd) Unzulässigkeit der Sperrung wegen Auslandsbezug der Maßnahme

Die Internationalität des Internets führt dazu, dass Webinhalte unabhängig ihres technischen Ursprungsortes weltweit aufgerufen werden können. Dieser grenzüberschreitende Charakter des Internets kann dazu führen, dass Angebote in einem Land von dem sie angeboten werden rechtlich völlig unbedenklich sind, bei einem Abruf in einem anderen Staat gegen dort geltendes Recht verstoßen können. ${ }^{519}$ Eine gesetzliche Sperrverpflichtung aller deutschen Access-Provider zur Unterbindung des Zugriffs auf sämtliche kinderpornographischen Inhalte unabhängig ihres jeweiligen Ursprungsortes, beinhaltet folglich nicht nur eine rechtliche Wertung hinsichtlich des innerstaatlich abrufbaren Angebotes (Einordnung des Angebotes als kinderpornographisch i.S.d. $\$ 184 \mathrm{~b} \mathrm{StGB}$ ), darüber hinaus impliziert die Sperrmaßnahme gleichzeitig auch eine negative Wertung über das Angebot, soweit es von einem im Ausland ansässigen Anbieter stammt. Somit haben nationale Kontrollmaßnahmen im Internet grundsätzlich auch über den nationalen Regelungskreis hinausgehende Wirkungen. ${ }^{520}$

Die tatsächlichen Gegebenheiten einer globalen Verbreitung kinderpornographischer Inhalte und die erschwerten Rechtsdurchsetzung erlauben es dem innerstaatlichen Gesetzgeber die Möglichkeit die Sperrung als streng subsidiäre Maßnahme für Unterbindung kinderpornographischer Angebote im Falle der man-

519 Engel, MMR-Beilage 4/2003, 1 (7); Bremer, MMR 2002, 147 (149).

520 Degen, Freiwillige Selbstkontrolle, 2007, S. 192; Volkmann, Der Störer im Internet, 2005, S. 201 ff. 
gelnden Löschung gesetzlich zu normieren. Die gesetzliche Sperrverpflichtung aller inländischen Provider zur Unterbindung kinderpornographischer Inhalte würde doch in ihrem Sinn entleert, soweit sie nur auf Inhalte beschränkt wäre, die auf inländischen Servern speichern. Die Löschergebnisse zeigen vielmehr, dass die schlechteste Löschquote erreicht wird, wenn die Inhalte auf ausländischen Servern lagern. Folglich ist zu untersuchen, welche europäischen oder internationalen Vorgaben bestehen, die einer gesetzlichen Sperrpflicht, die keine territoriale Beschränkung auf inländische Inhalte vorsieht, entgegenstehen könnten.

\section{(a) Herkunftslandprin $2 i p$}

In Bezug auf die kinderpornographischen Inhalte, die von Servern innerhalb der EU gehostet werden, kommt vor allem eine Unzulässigkeit wegen des Herkunftslandprinzips in Betracht. Das Herkunftslandprinzip ist in $₫ 3$ Abs. 2 TMG normiert. ${ }^{221}$ Danach wird der freie Dienstleistungsverkehr von Telemedien, die in der Bundesrepublik Deutschland geschäftsmäßig angeboten oder erbracht werden, jedoch in einem anderen Mitgliedstaat innerhalb des Geltungsbereich der ECommerce-Richtlinie niedergelassen sind, nicht eingeschränkt. Im Umkehrschluss ist demnach nur derjenige Mitgliedsstaat zu einschränkenden Maßnahmen befugt, in dessen Staatsgebiet der jeweilige Anbieter niedergelassen ist. ${ }^{522}$ Das Prinzip normiert damit den Grundsatz, dass Diensteanbieter nur ihrer eigenen Rechtsordnung unterworfen sind und ihre Inhalte nicht gleichzeitig auch an etwaige strengere Anforderungen anderer Rechtsordnungen ausrichten müssen. Damit trägt jeder Mitgliedstaat selbst dafür Sorge und Aufsicht, dass der in seinem Land ansässige Diensteanbieter den rechtlichen Anforderungen genügt. ${ }^{523}$ Andere Mitgliedstaaten dürfen, obgleich das Angebot nach innerstaatlich geltenden Rechtsvorschriften nicht zulässig wäre, keine eigenen einschränkenden Maßnahmen gegen diese Anbieter ergreifen. ${ }^{524}$

Eine gesetzliche Verpflichtung aller inländischen Access-Provider zur Vornahme von Sperrmaßnahmen bezüglich der Unterbindung kinderpornographi-

521 Das Herkunftslandprinzip beruht auf Art. 3 der Richtlinie 2000/31/EG des Europäischen Parlaments und des Rates vom 8. Juni 2000 über bestimmte rechtliche Aspekte der Dienste der Informationsgesellschaft, insbesondere des elektronischen Geschäftsverkehrs, im Binnenmarkt („Richtlinie über den elektronischen Geschäftsverkehr"), Abl. EG 2000 Nr. L 278, S. 1.

522 Der räumliche Bereich der Niederlassung umfasst jede feste Einrichtung mittels derer Telemedien geschäftsmäßig, das heißt nachhaltig und nicht nur gelegentlich angeboten werden, wobei der Serverstandort selbst keine Niederlassung begründen kann, so Begr. z. RegE zu \4 TDG, BT-Drs, 14/6098, S. 17; Hoeren, MMR 1999, 192 (195); Spindler, ZUM 1999, 775 (777); ders., MMR-Beil. 7/2000, S. 4 (5). Vgl. ebenfalls Begr. zu Art. 2 f ECRL, KOM (1998) 586 endg. 98/0325 (COD), S. 22.

523 Spindler, NJW 2002, 921 (925); ders., RabelsZ 66 (2002), 633 (638).

524 Hierzu ausführlich Greiner, Die Verhinderung verbotener Internetinhalte, 2001, S. 173 mwN. 
scher Angebote die keine territoriale Beschränkung auf den Ursprungsort des Angebotes vorsieht, führt nicht nur zu einer Unerreichbarkeit des Inhaltes aus Deutschland, sondern bedeutet gleichzeitig auch eine Zugangsbeschränkung des inkriminierten kinderpornographischen Inhalts für den in einem anderen Mitgliedstaat niedergelassenen Anbieter. Nach dem Herkunftslandprinzip hat aber nur das Land die ausschließliche Regelungs- und Aufsichtsbefugnis über das fragliche Angebot, in dessen Hoheitsgebiet der Anbieter niedergelassen ist, der das fragliche Angebot verbreitet. Ist der Anbieter nicht in Deutschland, sondern in einem anderen Mitgliedstaat niedergelassen, so würde eine Sperrverpflichtung, die den territorialen Bereich der Sperrung nicht nur auf inländische Inhalte beschränkt dem Herkunftslandprinzip widersprechen. ${ }^{525}$

$\int 3$ Abs. 3 bis 5 TMG sieht jedoch entsprechende Ausnahmen des Herkunftslandprinzips für das Straf- und Ordnungsrecht vor. Danach unterliegen die Diensteanbieter abweichend von Absatz 2 den innerstaatlichen Einschränkungen, soweit dieses dem Schutz der „öffentliche Sicherheit und Ordnung, insbesondere im Hinblick auf die Verhütung, Ermittlung, Aufklärung und Vollstreckung von

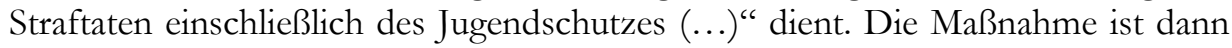
entsprechend $\int 3$ Abs. 5 Satz 1 TMG zulässig, soweit ohne entsprechendes Einschreiten eine Beeinträchtigung oder eine ernsthafte Gefahr für die genannten Schutzziele drohe würde und die innerstaatliche Maßnahme auch erforderlich und angemessen, mithin verhältnismäßig in Hinblick auf die Erreichung des Schutzziels wäre. Als prozedurale Voraussetzung sieht $\int 3$ Abs. 5 Satz 2 TMG die Pflicht zur Durchführung eines vorhergehenden Konsultationsverfahrens und Informationspflichten vor. ${ }^{526}$ Hierfür muss der Mitgliedstaat in dem der fragliche Anbieter seinen Sitz hat, zunächst erfolglos aufgefordert werden, selbst entsprechende Maßnahmen gegen den Anbieter zu ergreifen und anschließend die Kommission und den Mitgliedstaat des Sitzes des Diensteanbieters über die Absicht selbst Maßnahmen zu treffen in Kenntnis setzen.

Grundsätzlich wäre eine inländische Regelung, welche mittelbar auch Auswirkungen auf das Hoheitsgebiet anderer EU-Mitgliedstaaten aufweist, damit nicht per se mit dem Herkunftslandprinzip unvereinbar: Die Sperrverpflichtung kinderpornographischer Inhalte verfolgt das legitime Schutzziel ,Jugendschutz“ und ist damit grundsätzlich zur Durchbrechung des Herkunftslandprinzips geeignet. Daneben müsste sie die weiteren Voraussetzungen für die Ausnahme des Herkunfts-

525 Zu der Frage auch Sieber/Nolde, Sperrverfügungen im Internet, 2008, S. 147; Greiner, Die Verhinderung verbotener Internetinhalte, 2001, S. 179; Volkmann, Der Störer im Internet, 2005, S. 205; Mynarik, Jugendschutz in Rundfunk und Telemedien, 2006, S. 72 ff.

$526 \int 3$ Abs. 5 S. 2 TMG nimmt hierzu auf die Verpflichtung nach Art. 3 Abs. 4 u. 5 der Richtlinie 2000/31/EG sowie Art. 2 a Abs. 4 u. 5 der Richtlinie 89/552/EW Bezug. Zum Konsultationsverfahren Frey/Rudolph, ZUM 2008, 564, Volkmann in: Spindler/Schuster, Recht der elektronischen Medien, 2011, \ 59 RStV, Rn. 13. 
landprinzips erfüllen. Neben der Verhältnismäßigkeit der Maßnahme müssten auch entsprechend die prozeduralen Voraussetzungen eines Konsultations- und Informationsverfahren eingehalten werden. ${ }^{527}$

Daraus folgt, dass es dem Gesetzgeber nicht verwehr ist eine gesetzliche Sperrverpflichtung zu formulieren, die keine territoriale Einschränkung auf den inländischen Ursprungsort des jeweiligen Angebotes vorsieht. Eine Zulässigkeit einer derartigen Normierung setzt allerdings das Bestehen eines Ausnahmetatbestandes voraus sowie die explizite Normierung der prozeduralen Folgen der Einhaltung eines vorangehenden Konsultations- und Informationsverfahrens.

\section{(b) Anwendbarkeit deutschen Rechts auf Nicht-EU-Inhalte}

Für EU-interne Inhalte regelt das Herkunftslandprinzip, dass sich die Anbieter grundsätzlich nur an ihrer eigenen Rechtsordnung orientieren müssen und andere Mitgliedstaaten keine eigenen, einschränkenden Maßnahmen gegen diese Anbieter ergreifen dürfen. Eine entsprechende Regelung findet sich auf außer-europäischer Ebene selbstverständlich nicht. Nach geltendem völkerrechtlichem Verständnis entfaltet das Nichteinmischungsgebot (Interventionsverbot) jedoch vergleichbare Wirkungen. Danach dürfen Staaten keine Normen setzen, die ausschließlich ausländische Sachverhalte betreffen. ${ }^{528}$ Die jeweilige Regelungskompetenz eines Landes ist insofern auf das eigene Hoheitsgebiet beschränkt. ${ }^{529}$ Über Art. 25 GG entfaltet dieser allgemeine völkerrechtliche Grundsatz auch Bindungswirkung für den deutschen Gesetzgeber. ${ }^{530}$ Will ein Staat ausnahmsweise einen extraterritorialen Sachverhalt regeln, so bedarf es einer Rechtfertigung, die als so genannter genuine Link bezeichnet wird. ${ }^{531}$ Das Erfordernis eines genuine Link wird damit begründet, dass anderenfalls allein die rechtliche Missbilligung eines Verhaltens dazu führen kann, dass ein Staat seine „Verbotsgewalt“ mittelbar auch auf fremdem Staatsgebiet ausüben kann. ${ }^{532}$ Eine rechtliche Missbilligung kann aber gerade un-

Spindler, MMR Beilage 7/2000, 4 (8); Volkmann, Der Störer im Internet, 2005, S. 205; ders. in: Spindler/Schuster, Recht der elektronischen Medien, 2011, 』59 RStV, Rn. 13; Sieber/Nolde, Sperrverfügungen im Internet, 2008, S. 149 f.

528 Koenig in: v. Mangoldt/Klein/Starck, Art. 25 GG, Rn. 63; Kempen/Hillgruber, Völkerrecht, Kap. 4, Rn. 37; Hierzu auch Billmeier, Die Düsseldorfer Sperrungsverfügung, 2007, S. 78 ff.

529 Koenig Koreng, Zensur im Internet, 2010, S. 122; zum Nichteinmischungsgebot Kempen/Hillgruber, Völkerrecht, Kap. 4, Rn. 37; Ipsen, Völkerrecht, \59 Abs. 4, Rn. 53 jeweils mwN.

530 BVerfGE 15, 25 (33); BVerfGE 37, 116 (126); v. Heintschel-Heinegg in: Epping/Hillgruber, Art. 25 GG, Rn. 1; Herdegen in: Maunz/Dürig, Art. 25 GG, Rn. 3 ff.

531 Kempen/Hillgruber, Völkerrecht, Kap. 4, Rn. 37; Bremer, Strafbare Internet-Inhalte, 2001, S. 221; Koreng, Zensur im Internet, 2010, S. 122; Engel, MMR-Beil. 4/2003, 1 (8 ff.) mwN.

532 Kempen/Hillgruber, Völkerrecht, Kap. 4, Rn. 37; Koreng, Zensur im Internet, 2010, S. 125; Degen, Freiwillige Selbstkontrolle, 2007, S. 196. 
terschiedlicher Natur und Intensität sein. ${ }^{533}$ Eine Aussage, die in Deutschland beispielsweise den strafrechtlichen Charakter einer Volksverhetzung erreicht, kann in Ländern mit einer größeren Toleranzschwelle als rechtlich beanstandungslose Meinungsäußerung verstanden werden. ${ }^{534}$ Um solche Konflikte zu lösen, sollen die Staaten ihre gegenseitige Souveränität weitestgehend akzeptieren. Eine nationale Behörde darf daher nationales Recht nicht ohne sachlichen Grund auf internationalem Gebiet anwenden. Anerkannt ist in dem Zusammenhang, dass die bloße Möglichkeit zum Abruf eines Inhaltes nicht ausreicht, um die völkerrechtlich geforderte Rechtfertigung der „Einmischung“ des Landes, von dem aus der Abruf geschieht, zu rechtfertigen. ${ }^{535}$ Vielmehr bedarf es zur Vermeidung unverhältnismäßiger Eingriffe in die Internetkommunikation strengerer Voraussetzungen an den genuine link. ${ }^{536}$

Sperrverpflichtungen der inländischen Access-Provider, die mittelbar auch Bindungswirkung für andere Staaten entfalten, weisen jedoch einen ausreichenden Bezug zum Inland auf und berühren daher schon nicht den Anwendungsbereich des Nichteinmischungsgebots. ${ }^{537}$ Eine Verletzung desgleichen setzt eine inländische Regelung für einen ausschließlich ausländischen Sachverhalt voraus. ${ }^{538}$ Dies ist bei gesetzlichen Sperrverpflichtungen jedoch nicht gegeben. Denn im Falle der Sperrverpflichtungen sollen Gefahren unterbunden werden, deren negative Wirkungen explizit auf inländischem Hoheitsgebiet auftreten. Es geht demnach nicht um ein aktives Eindringen in ein fremdes Hoheitsgebiet, sondern lediglich um eine passive Folge einer innerstaatlichen Gefahrenabwehrmaßnahme. Wenn bereits eine ,greifbare ordnungsrechtliche Gefahr" auf nationalem Gebiet anzunehmen ist, kann im Umkehrschluss ausgeschlossen werden, dass ein Sachverhalt geregelt werden soll, der ausschließlich einer anderen Rechtsordnung zuzuordnen ist. ${ }^{539}$ Der Abruf einer kinderpornographischen Seite in Deutschland begründet latente Gefahren für das geistige und körperliche Wohl des Kindes. Es kann nicht

533 Kempen/Hillgruber, Völkerrecht, Kap. 4, Rn. 37; Degen, Freiwillige Selbstkontrolle, 2007, S. 196.

534 So Mayer, Das Internet im öffentlichen Recht, 1999, S. 112; hierzu auch Volkmann, Der Störer im Internet, 2005, S. 202; Koreng, Zensur im Internet, 2010, S. 122.

535 Koch, JuS 2002, 124; Determann, Kommunikationsfreiheit im Internet, S. 158; Engel, MMR-Beil. 4/2003, 1 (10); in die Richtung bereits Wilske/Schiller, Federal Communications Law Journal 1997, $139 \mathrm{f}$.

536 In die Richtung, Hornig, ZUM 2001, 846 (850); Bremer, MMR 2002, 147 (150); Engel, MMR-Beil. 4/2003, 1 (10).

537 VG Düsseldorf, CR 2005, 885 (886); Billmeier, Die Düsseldorfer Sperrungsverfügung, 2007, S. 78; Sieber/Nolde, Sperrverfügungen im Internet, 2008, S. 96.

538 Kempen/Hillgruber, Völkerrecht, Kap. 4, Rn. 37; Ipsen, Völkerrecht, \59 Abs. 4, Rn. 53 jeweils mwN.

539 IE. Volkmann, Der Störer im Internet, 2005, S. 201 mit einer detaillierten Herleitung über die Parallelen zum Strafrecht. Kritisch hierzu Koreng, Zensur im Internet, 2010, S. 124. 
ausgeschlossen werden, dass durch die Verbreitung und ungehinderte Abrufbarkeit eine erneute Stigmatisierung der beteiligten Kinder und die Gefahr einer zukünftigen sexuellen Ausbeutung von Kindern zur Herstellung kinderpornographischer Produktionen einhergeht. Maßgeblich für die Zulässigkeit einer Regelungskompetenz auf nationalem Gebiet ist demnach bereits diese latente Gefahr, die von inländischen Abrufmöglichkeit des Inhalts ausgeht, auch wenn sich die Inhalte im Ausland gehostet wurde. 540

Zwar mag dem entgegengehalten werden, dass über eine solche Sichtweise lediglich die nationale Einordnung eines Sachverhalts zum Gefahrenabwehrrecht ausschlaggebend dafür sei, den Anwendungsbereich des Nichteinmischungsgebots zu verneinen, so dass keine völkerrechtliche Rechtfertigung notwendig sei. ${ }^{541} \mathrm{Je}-$ doch wäre, obgleich man auch bei gesetzlichen Sperrverpflichtungen keine Ausnahme vom Erfordernis des genuine Link zulässt, ein sachlicher Grund für die ausnahmsweise Einmischung in fremdes Hoheitsgeit auch aufgrund weiterer Aspekte gegeben. Das passive Personalitätsprinzip erlaubt es, dass der Staat auch Eingriffe auf Rechtsgüter eigener Staatsbürger dem nationalen Hoheitsrecht unterstellt.542 Wenngleich einzelfallbezogene Sperrverfügungen zum Zwecke der Unterbindung nationalsozialistischer Äußerungen oder urheberrechtsverletzender Vervielfältigungshandlungen oftmals keinen individuellen Rechtsgüterschutz forcieren, sondern lediglich allgemeiner Inhaltsregulierung von Internet-Angeboten dienen, so sind bei gesetzlichen Sperrverpflichtungen zum Schutz vor kinderpornographischen Gefahren gerade individuelle Rechtsgüter gefährdet und sollen durch die inhaltsbeschränkenden Maßnahmen geschützt werden. ${ }^{543}$ Eine gesetzliche Regelung wäre demnach - soweit sie sich ausschließlich auf die Unterbindung von Kinderpornographie bezieht - dem Erfordernis des genuine Link gerecht und

VG Düsseldorf, CR 2005, 885 (886) m. zust. Anm. Volkmann; in die gleiche Richtung bereits Germann, Gefahrenabwehr im Internet, 2000, S. 233 ff.; Spindler/Volkmann, K\&R 2002, 398 (400); fortgeführt Volkmann, Der Störer im Internet, 2005, S. 202, 204, Herleitung über eine Parallelen zu herrschenden strafrechtlichen Prinzipien bis hin zu einer Vergleichbarkeit mit dem „Auswirkungsprinzip“ des Kartellrechts sowie des „Marktortprinzip“ im Kapital- und Wettbewerbsrecht. Sieber/Nolde, Sperrverfügungen im Internet, 2008, S. 96. Dies ablehnend Koreng, Zensur im Internet, 2010, S. 124. So Koreng, Zensur im Internet, 2010, S. 124.

542 Ambos in: Münch. Komm. StGB, Vorb. $\$ \int$ 3-7 StGB, Rn. 34; Eser in: Schönke/Schröder, \ 3 StGB, Rn. 7; in Bezug auf Eingriffsbefugnisse nach dem Strafrecht Kunig/Uerpmann, JURA 1994, 186 (192 f.) darauf bezugnehmend aus weiteren Gründen jedoch ablehnend Koreng, Zensur im Internet, 2010, S. 125. Das passive Personalitätsprinzip bildet das Gegenteil zum aktiven Personalitätsprinæip, wonach der Staat auch im Ausland seine Staatsbürger seinem Recht unterwerfen kann. Hierzu ausführlich Bremer, Strafbare Internet-Inhalte, 2001, S. 218, $222 \mathrm{mwN}$. 
würde den Konflikt mit dem Nichteinmischungsgebot lösen, soweit man überhaupt dessen Anwendungsbereich als eröffnet anerkennt. ${ }^{544}$

\section{(c) Zwischenergebnis}

Zusammenfassend ist der deutsche Gesetzgeber damit auch bei grenzüberschreitenden Inhalten befugt legislatorisch tätig zu werden, so dass eine gesetzliche Sperrverpflichtung aller deutschen Access-Provider zur Sperrung kinderpornographischer Inhalte nicht unzulässig wäre.

\section{(ee) Weitere Mittel}

Neben der Löschung eines kinderpornographischen Inhaltes kommen weitere Mittel in Betracht, die dem gesetzlichen Sperransatz die Erforderlichkeit absprechen könnten. Allerdings werden diese regelmäßig nicht als mildere Maßnahme mit gleicher Geeignetheit zu qualifizieren sein. Ihre Rolle sollte sich insofern darauf beschränken, kumulativ zur staatlichen Eingriffsbefugnissen auf dem Gesamtbestand des Internets eingesetzt zu werden um den Rechtsgüterschutz hinreichend abzusichern

\section{(a) Nutzerseitige Filterung}

Risiken der Verbreitung von Kinderpornographie können über entsprechende Filtermechanismen vom Nutzer selbst minimiert werden. Hierzu kann der Nutzer auf seinem Computer entsprechende Filter implementieren, die anhand Keywords oder Abbildungen den Datenbestand des Computers nach entsprechenden Inhalten scannen und bei Übereinstimmung mit den in der Software enthaltenen Sperrkriterien verwerfen. Entsprechende Software ist bereits zahlreich auf dem Softwaremarkt enthalten. ${ }^{545}$ Technisch basiert sie auf zwei unterschiedlichen Mechanis-

544 Dies ist freilich das ZugErschwG, das explizit eine übertragende Wirkung auf andere Sachverhalte ausschließt, so Begr. BT-Drs. 16/13411, S. 12. Anders $\ 20$ JMStV iVm. \59 RStV, der gerade eine Sperrung von Inhalten erlaubt, die auch über den Individualrechtsgüterschutz hinausgehen. Die Norm kann aber völkerrechtkonform ausgelegt werden, so dass sie nicht völkerrechtswidrig ist. Hier Koreng, Zensur im Internet, 2010, S. 127 f., 129 f.

545 Vgl. zur Filtersoftware die detaillierte Aufzählung bei Top Ten Reviews Filter-Software 2009 Internet Filter Reviews stellt einen Teil der TopTenReviews, einem us-amerikanischen Internetportal dar, das sich auf alle Fragestellungen, Produkte und Neuigkeiten im multimedialen Bereich spezialisiert hat. Unter anderen bewertet das Portal gängige Filtersoftware zur Einhaltung von Jugendschutzbestimmungen, neuste multimediale Gerätschaften und veröffentlicht regelmäßig Statistiken zu verschiedenen mit Multimedia in Zusammenhang stehenden Themen, Homepage abrufbar unter: http://www.toptenreviews.com/. 
men:546 Bei der ersten Methode wird der Zugriff auf das Internet grundsätzlich gesperrt. Ausnahmsweise „erlaubt“ die Software den Zugriff auf Internetdateien, wenn ein Zugriffsversuch auf geprüfte und für unbedenklich befundene sich um als positiv befundene Inhalte handelt (sog. White-List-Filtering). ${ }^{547}$ Der zweite Filteransatz basiert im Gegenteil auf einem grundsätzlich unbeschränkten Zugriff auf das Internet. Jedoch wird der Zugriff auf bestimmte als kinderpornographisch oder illegal eingestufte Inhalte verwehrt (sog. Black-List Filtering). ${ }^{548}$

Die entsprechende Einordnung und Bewertung des jeweiligen Angebotes als positiv (white-listed) oder negativ (black-listed) muss in beiden Fällen von einer eigenständigen Einrichtung vorgenommen werden, was in Anbetracht des hohen Datenaufkommens zu erheblichen „Erstellungs-, Aktualisierungs- und Pflegeaufwand" führt. ${ }^{549}$ Zudem mangelt es den meisten Filterprogrammen nach dem heutigen Stand der Technik an einer zuverlässigen Treffersicherheit, da eine kontextbezogene Filterungen bislang nicht möglich erscheint. ${ }^{550}$ Besonders in individualtechnischen Internetbereichen versagen solche Filtersysteme, so die die Inhalte nicht differenziert aus dem geschlossenen Bereich nicht herausfiltern können. Dadurch kann zum einen ein übermäßiger, Grundrechte beeinträchtigender Overblocking-Effect hervorgerufen werden, zum anderen kann auch der gegenteilige Effekt entstehen, dass der Zugriff auf eine Vielzahl von illegalen Inhalten nicht ausreichend unterdrückt wird, wenn die Filterkriterien nur unzureichend vorgegeben werden. ${ }^{551}$

Zudem setzt die Wirksamkeit der Verwendung eines nutzerseitigen Filterprogramms auch gleichzeitig den tatsächlichen Willen zum Einsatz des Programms auf Seiten des Nutzers voraus. Ist ein entsprechender Wille nicht vorhanden oder kommt es dem Nutzer vielmehr bewusst darauf an den Internetbestand auf kinderpornographische Inhalte hin zu untersuchen, so verlieren nutzerseitige Schutzvorkehrungen ihre Wirksamkeit. ${ }^{552}$ Folglich kann der Staat auf die Möglichkeit der Verpflichtung zu nutzerseitigen Filterprogrammen lediglich ergänzend zurückgrei-

Schneider, MMR 2004, 18, Sieber/Nolde, Sperrverfügungen im Internet, 2008, S. 196.

548 Eingehend Faber, Jugendschutz im Internet, 2005, S. 63 mwN.

Hierzu Faber, Jugendschutz im Internet, 2005, S. 63. Die innerhalb der staatlichen Sperrverpflichtung verfolgten Sperransätze basieren demnach auf einer Art Black-List-Filterung, so schon Schneider, MMR 2004, 18.

549 Sieber/Nolde, Sperrverfügungen im Internet, 2008, S. 196.

550 Eine Aufstellung mit Vor- und Nachteilen gängiger Filterschutzprograme, Faber, Jugendschutz im Internet, 2005, S. 62 ff.; detailliert Sieber/Nolde, Sperrverfügungen im Internet, 2008, S. 197 mwN.

551 In die Richtung Erdemir in: Eifert/Hoffmann-Riem, Innovation, Recht und öffentliche Kommunikation, 2011, S. 27 (31).

552 Ausdrücklich Sieber/Nolde, Sperrverfügungen im Internet, 2008, S. 196. 
fen. Ein eigenständiges Korrektiv zur Sperrverpflichtung sind solche Filtermechanismen jedoch nicht. ${ }^{553}$

\section{(b) Stärkung der Medienkompetenz.}

Überdies scheitert auch die Möglichkeit einer bewussten Stärkung der Medienkompetenz als geeignete und gegenüber der Sperrung mildere Maßnahme, um den legitimen Zweck der Erschwerung des Zugriffs auf kinderpornographisches Material als Ausdruck der Gefahrenabwehr zu erreichen. ${ }^{554}$ Unter Medienkompetenz besonders im Internetbereich wird die Fähigkeit eines selbstständigen Umgangs und der eigenverantwortlichen Erkennens von möglichen Risiken verstanden. ${ }^{555}$ Der Ansatz beruht folglich nicht auf einer Herausnahme des fraglichen Angebotes sondern auf einen gewissenhaften Umgang trotz Bestehens desselben. ${ }^{556}$ Eine gleichwertige Eignung wie eine staatlich verpflichtende Maßnahme kann die Stärkung der Medienkompetenz allerdings nicht darstellen. Sie setzt einen nutzerseitigen Willen voraus, der nicht immer unterstellt werden kann. Auch wenn ein Wille für den bewussten und besonnenen Umgang vorliegt, so variiert das letztliche Ergebnis stark vom Alter des jeweiligen Rezipienten. Zur Gewährleistung einer einheitlichen Wirksamkeit eines effektiven Schutzes vor kinderpornographischen Gefahren kann die Stärkung der allein nicht beitragen. ${ }^{557}$

\section{(c) Selbstregulierung der Provider}

Daneben kann eine gesetzliche Sperrverpflichtung auch nicht durch selbstverpflichtende Vereinbarungen der betreffenden Provider mit dem Staat ersetzt werden. ${ }^{558}$ Der Gesetzgeber kann sich keineswegs allein auf eine Selbstverpflichtung von Wirtschaftssubjekten verlassen. Schon die Geeignetheit einer solchen Vereinbarung für die Erreichung des Schutzziels ist fraglich. Zwar steht es dem Staat grundsätzlich frei auch Verträge mit öffentlich-rechtlichem Charakter einzugehen, jedoch wirken Verträge immer nur inter-partes. Sollten etwa neue Access-Provider auf den Markt kommen, sind diese von den Selbstverpflichtungsvereinbarungen

553 In die Richtung Sieber/Nolde, Sperrverfügungen im Internet, 2008, S. 196; Kabl, SächsVBl. 2010, 180 (189).

554 Hierzu Kabl, SächsVBl. 2010, 180 (189); Degen, Freiwillige Selbstkontrolle, 2007, S. 367; zur Medienkompetenz allgemein, Linz, tv-diskurs 14/2010, 46; v. Hipel in: Herzig, Medienkompetenz und Web 2.0, 2010, S. 362; Engel, Jugendliche im Web 2.0 - Chancen und Risiken von Medienkompetenz, 2010, S. 3 ff. Tellschaft, Medienkompetenz, 2010, S. 20 ff.

555 Theunert in: Schorb/Anfang/Demmler, Grundbegriffe Medienpädagogik, S. 199.

556 Baacke, Handbuch Medien, 1999, S. 31.

557 IE. auch Kabl, SächsVBl. 2010, 180 (189); Sieder/Nolde, Sperrverfügungen im Internet, 2008, S. 195.

558 ausführlich Degen, Freiwillige Selbstkontrolle, 2007, S. 353 ff. mwN, skeptisch zur Selbstkontrolle auch Sieber/Nolde, Sperrverfügungen im Internet, 2008, S. 205 ff. 
zunächst ausgeschlossen. Eine der gesetzlichen Verpflichtung entsprechende Geeignetheit kann eine Maßnahme aber nur leisten, die auch entsprechend alle Adressaten umfasst. Überdies wäre eine selbstverpflichtende vertragliche Vereinbarung auch keine mildere Maßnahme. Die befürchteten Grundrechtseinschränkungen von Nutzern und Inhaltsanbietern drohen in gleicher Weise bei einer vertraglichen Formulierung wie bei einer gesetzlichen Verpflichtung. Zudem kann hier im Unterscheid, dass der dann nur gegebene Zivilrechtsschutz und die im Zivilrecht schwächere Grundrechtsbindung der Provider unter Umständen sogar dazu führen könnte, dass die Rechte der Nutzer sogar wesentlich mehr eingeschränkt werden als bei gesetzlichen Regelungen. 559

(ff) Ergebnis: Erforderlichkeit

Im Ergebnis bleibt festzustellen, dass zur effektiven Abwehr kinderpornographischer Inhalte im Internet eine Bündelung verschiedener Maßnahmen in Betracht kommt, die in Verbindung zueinander einen effektiven Rechtsgüterschutz bewirken können. Zugleich ist jedoch kein eigenständiges Mittel ersichtlich, welches bei geringerer Eingriffsintensität denselben Wirksamkeitsgrad entfaltet wie staatlich veranlasste inhaltsbeschränkende Maßnahmen in Form von Zugriffssperren oder Löschverfügungen.

Innerhalb der in Betracht kommenden Mittel wird die Löschung im Regelfall effektiv zur Entfernung des kinderpornographischen Angebotes beitragen können und damit die Risiken einer ungehinderten Verbreitung zielorientiert unterbinden können. Auch die Löschung ist indes kein Idealmittel. Aufgrund der globalen Verbreitung der Inhalte kann nicht ausgeschlossen werden dass die Maßnahme an tatsächlichen Gegebenheiten scheitert. Soweit sich die Provider nicht ermitteln lassen oder schlicht weigern einer Löschung nachzukommen muss es dem Staat unbenommen bleiben, die Wichtigkeit des Rechtsgutes auch über die Inanspruchnahme der inländischen Access-Provider abzusichern. Hierbei muss aufgrund des Prinzips der Erforderlichkeit aber ein strenger „Löschen vor Sperren“-Ansatz verfolgt werden, der sich letztlich auch nur die Inanspruchnahme der AccessProvider als Nichtstörer bestätigt. Die alleinige Formulierung einer gesetzlichen Sperrverpflichtung scheidet hingegen aus.

d) Verhältnismäßigkeit im engeren Sinne - Angemessenheit

Die gesetzliche Sperrmaßnahme müsste auch verhältnismäßig im engeren Sinn, das heißt angemessen sein. Im Rahmen der Angemessenheit einer gesetzlichen Maßnahme erfolgt eine umfassende Zweck-Mittel-Relation, die auf eine „Gesamtabwägung zwischen der Schwere des Eingriffs und dem Gewicht sowie der Dring-

559 Eingehend Kahl, SächsVBl. 2010, 180 (189); Witt, Regulierte Selbstregulierung, 2008, S. 322 mwN. 
lichkeit der ihn rechtfertigende Gründe“ unter Beachtung der „Grenze der Zumutbarkeit" gerichtet ist. 560

Auch bei der Angemessenheit einer staatlichen Maßnahme ist letztlich die Einschätzungsprärogative des Gesetzgebers zu berücksichtigen: Eine Maßnahme ist nur dann unangemessen, wenn die Wertigkeit des mit der Regelung verfolgten Ziels gegenüber der Belastung durch den mit ihr verbundenen Eingriff außer Verhältnis steht, wenn also die mit der Maßnahme verbundenen Nachteile, die mit dergleichen verbundenen Vorteile überwiegen. ${ }^{561}$ Soweit jedoch die Maßnahme in einem angemessenen Verhältnis zur Schwere und zum Gewicht sowie zur Dringlichkeit des Eingriffs steht und die Grenze der Zumutbarkeit gewahrt bleibt, ist die damit einhergehende Einschränkung fremder Grundrechtspositionen verfassungsrechtlich zulässig. .52

Für eine umfassende Güterabwägung ist es notwendig, die konkret durch die Sperrmaßnahme betroffene Berufsausübungsfreiheit der Access-Provider gegenüber dem mit der Maßnahme verfolgten Zweck einer effektiven Gefahrenabwehr im kinderpornographischen Internetbereich gegenüberzustellen und zu bewerten.

Als Konsequenz des einheitlichen Schutzbereiches der Berufsfreiheit aus Berufswahl- sowie Berufsausübungsfreiheit ist im Rahmen der Angemessenheit des Eingriffs in Art. 12 GG nach ständiger Rechtsprechung des Bundesverfassungsgerichts die so genannte „Drei-Stufen-Theorie“ als Schranken-Schranke zu beachten. ${ }^{563}$ Danach erfolgt auf Rechtfertigungsebene eine Differenzierung zwischen der Berufsausübung- und Berufswahlfreiheit, die zu einem einheitlichen Schutzbereich zusammengezogen wurden: Staatliche Einschränkungen der Berufsausübungsfreiheit sind bereits dann zulässig, wenn vernünftige Erwägungen des Ge-

560 So ausdrücklich BVerfGE 90, 145 (173); allgemein zur Angemessenheit, Dreier in: Dreier, Vorb. Art. 12 GG, Rn. 149; Durner in: Maunz/Dürig, Art. 10 GG, Rn. 148 ff.; Axer in: Epping/Hillgruber, Art. 14 GG, Rn. 92; Hirschberg, Der Grundsatz der Verhältnismäßigkeit, 1981, S. 79, speziell auf Sperrmaßnahmen bezogen, Storr in: Heermann/Ohly, Verantwortlichkeit im Netz, 2003, S. 103 (117); Sieber/Nolde, Sperrverfügungen im Internet, 2008, S. 212; Heuner in: Taeger/Wiebe, Inside the cloud, 2009, S. 107 (120); Billmeier, Die Düsseldorfer Sperrungsverfügung, 2007, S. 118 (allgemeine Ausführungen), S. 254 ff. (in Bezug auf Sperrmaßnahmen); Greiner, Die Verhinderung verbotener Internetinhalte, 2001, S. 149, jeweils unter dem Begriff der „Zumutbarkeit" geprüft.

561 Stern in: Stern, Staatsrecht, 1994, Bd. 3/2, S. 782 f., darauf bezugnehmend Heckmann, Stellungnahme der Sachverständigen im Rechtsausschuss, v. 8.11.2010, S. 14, abrufbar unter: http://www.bundestag.de/bundestag/ausschuesse17/a06/anhoerungen/archiv/03_Zugangsers chwerung/04_Stellungnahmen/Stellungnahme_Heckmann.pdf (zuletzt abgerufen 20.5.2012).

562 BVerfGE 83, 1 (19); hierzu auch Baum, Jugendmedienschutz als Staatsaufgabe, 2007, S. 293.

563 U.a. BVerfGE 7, 377; BVerfGE 25, 1 (11 f.); hierzu allgemein Brener in: Isensee/Kirchhof, Hdb. StaatsR, 2001, Bd. VI, \148, Rn. 6 f. 
meinwohls diese als zweckmäßig erscheinen lassen (1. Stufe).564 Während für die Rechtfertigung einer Berufsausübungsregelung bereits Zweckmäßigkeitserwägungen des Gemeinwohls genügen, sind im Gegensatz dazu Einschränkungen der Berufswahlfreiheit an höhere Anforderungen gebunden. ${ }^{565}$ Hierfür bedürfte es, soweit subjektive Zulassungsbeschränkungen, welche die Aufnahme einer beruflichen Tätigkeit von persönlichen Eigenschaften des Grundrechtsträgers abhängig machen, eines Schutzes eines überragendes Gemeinschaftsgutes (2. Stufe). ${ }^{566}$ Geht es hingegen um objektive Bedingungen, die dem Einfluss des Bewerbers entzogen sind, so sind diese nur zulässig, wenn ,sie zur Abwehr nachweisbarer oder höchst wahrscheinlicher schwerer Gefahren für ein überragend wichtiges Gemeinschaftsgut zwingend geboten sind (3.Stufe). 567

In Bezug auf das mit einer gesetzlichen Sperrverpflichtung verfolgte Schutzziel handelt es sich wie bereits erläutert um eine Berufsausübungsregelung. ${ }^{568}$ Damit genügen der Stufentheorie folgend bereits einfache Gründe des Gemeinwohls, um einen Eingriff in die Berufsfreiheit zu rechtfertigen.

Die in Frage stehende Maßnahme der Sperrung kinderpornographischer Webangebote dient dem Schutz vor Risiken, die mit der ungehinderten Verbreitung von Kinderpornographischen Inhalten verbunden sind. Neben präventiven Jugendschutzbelangen der langfristigen Vorbeugung vor sexueller Ausbeutung dient die Unterdrückung des Zugriffs der Aufrechterhaltung der öffentlichen Sicherheit. Es handelt sich hierbei folglich um Schutzgüter von besonders hohem Rang. Abstrakt betrachtet genügt die Verfolgung und Wahrung der Schutzgüter zweifellos den geringen Zweckmäßigkeitserwägungen, die an die Rechtfertigung der Maßnahme zu stellen sind.

Allerdings entbindet allein die Feststellung der grundsätzlichen Tauglichkeit der gesetzlichen Maßnahme zur Rechtfertigung der Berufsausübungsbeschränkung nicht von der Notwendigkeit einer Abwägung, in welcher der staatlich verfolgte Zweck den tangierten Interessen der Provider gegenübergestellt wird, letztlich der Überprüfung der Maßnahme bezüglich ihrer Verhältnismäßigkeit im engeren Sinne. ${ }^{569}$ Die Stufentheorie gibt lediglich einen Anhaltspunkt dafür, in welcher Weise die kollidierenden Belange im Verhältnis zueinander zu gewichten und

564

565

566

567

http://www.eulisp.de/tl_files/eulisp\%20abschlussarbeiten/schnabel_christoph.pdf abgerufen 20.5.2012); Sieber/Nolde, Sperrverfügungen im Internet, 2008, S. 62.

569

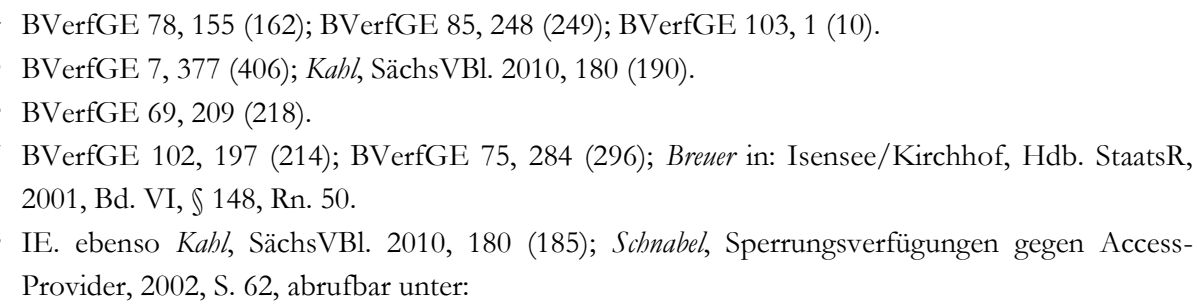

Provider, 2002, S. 62, abrufbar unter: 
inwiefern erhöhte Anforderungen an die Verfassungsmäßigkeit zu stellen sind. 570 Je tiefer in die Berufsfreiheit eingegriffen wird, umso höher muss das Gewicht des verfolgten Zwecks sein. Für die Einschränkung der Berufsausübungsfreiheit auf der 1. Stufe darf die Maßnahme den Betroffenen daher nicht „übermäßig belasten“571, wobei „Eingriffszweck und Eingriffsintensität“" in einem angemessenen Verhältnis zueinander stehen müssen. Ist damit ein intensiver, besonders empfindlicher Eingriff in die Berufsausübungsfreiheit der Provider gegeben, so können sich, obgleich „nur“ ein Eingriff auf „geringer“ Stufe vorliegt, erhöhte Anforderungen an dessen Verfassungskonformität ergeben. ${ }^{572}$

$\mathrm{Zu}$ beachten ist, dass bei der Vornahme der nachfolgenden Gewichtung zwei wesentliche Fragestellungen voneinander unterschieden werden: Zunächst die Frage danach, „ob“ bereits die Inpflichtnahme der Provider und ein damit verbundener Eingriff in die Berufsfreiheit an sich unverhältnismäßig wäre. So dann wird zu klären sein, ob das aus der Inanspruchnahme resultierende finanzielle „Sonderopfer“, welches die Provider in Folge der Sperrung erbringen müssen zu einer übermäßigen wirtschaftlich Belastung führt, die verfassungsrechtlich nur hinzunehmen sei, wenn ein angemessener finanzieller Ausgleich an die legislatorische Inanspruchnahme der Provider geknüpft wäre. ${ }^{573}$

(aa) Angemessenheit der Inanspruchnahme als solche

(1) Abwägungsrelevanter Belang: Intensität der beruflichen Beeinträchtigung

Durch die Inanspruchnahme der Provider liegt ein Eingriff in die Berufsfreiheit in Form der Beeinträchtigung der Berufsausübungsfreiheit vor. Zugangsdiensteanbieter werden durch eine gesetzliche Verpflichtung zur Errichtung einer Sperrinfrastruktur und zur Vornahme bestimmter Sperrmethoden verpflichtet. Die Inanspruchnahme erfolgt gemeinhin in Ausführung gefahrenabwehrrechtlicher Aufgaben, um Gefahren, die im Zusammenhang mit der ungehinderten Verbreitung von Kinderpornographie drohen, zu relativieren. Der mit der staatlichen Verpflichtung einhergehende Zweck folgt damit einem anerkannten Gemeinwohlinte-

570 In die Richtung wohl Jarass in: Jarass/Pieroth, Art. 12 GG, Rn. 31, 35 f.

571 BVerfGE 83, 1 (19); BVerfGE 85, 248 (259).

572 BVerfGE 61, 291 (311); BVerfGE 77, 84 (106); BVerfGE 103, 1 (10).

573 Die Notwendigkeit der Unterscheidung heben auch Kube/Scbütre, CR 2003, 663 (666), insg. immer noch grundlegend zur Thematik der entschädigungslosen Inanspruchnahme von Privaten für staatliche Zwecke, obgleich sich die Gesetzeslage seither geändert hat. Zur notwendigen Unterscheidung ebenfalls, Schmidt-Preuß, Die verfassungsrechtlichen Anforderungen an die Entschädigung, S. 13, Kurzgutachten i. A. v. Bitkom, abrufbar unter: http://www.sfu.ca/cprost/prepaid/relateddocs/Germany/SchmidtPreuB_and_German_Constitution.pdf (zuletzt abgerufen 20.5.2012); Braun, Die Finanzierung polizeilicher Aufgabenwahrnehmung, 2009, S. 368. 
resse an der Realisierung eines effektiven Jugendschutzes, der Aufrechterhaltung der staatlichen Sicherheit sowie die Erhaltung der Rechtsordnung. Letztlich verbergen sich dahinter Individualgüter der Bürger, denen der Staat in seinem Gewährleistungsauftrag vorrangig verpflichtet ist. ${ }^{574}$ Die im Falle der Sperrverpflichtung für kinderpornographischer Angebote im Raum stehenden Schutzgüter eröffnen schon aufgrund ihrer abstrakten Wertigkeit einen weiten gesetzgeberischen Gestaltungsspielraum bei der Verfolgung und dem Schutz derselben und sind demnach von Gemeinwohlaspekten getragen.

Zur Erreichung dieses Gemeinwohlinteresses werden durch eine gesetzliche Sperrverpflichtung konkret die Rahmenbedingungen des beruflichen Betätigungsfeldes der Provider erweitert. Den Access-Providern wird in Folge der staatlichen Handlungspflicht die Vornahme einer ihrem eigentlichen Tätigkeitsfeld fremden beziehungsweise gegenteiligen Aufgabe abverlangt. ${ }^{575}$ Grundsätzlich ist das berufliche Bestätigungsfeld des Access-Providings rein auf eine inhaltsunabhängige und automatisierte Leistung gerichtet. Durch die Sperrverpflichtung wird den Providern aber gerade das Spiegelbild dessen, praktisch eine am Inhalt ausgerichtete Kontrolle und Unterdrückung des durchgeleiteten Datenverkehrs abverlangt. ${ }^{576}$

Legt man den Fokus lediglich auf die vorgenannten Aspekte, so sind die Nachteile der Inanspruchnahme auf das berufliche Betätigungsfeld der Access-Provider offensichtlich. Im Ergebnis müssen diese Belange aufgrund einer geringfügigen Intensität hinter dem mit der Sperrverpflichtung verfolgten Gemeinwohlinteresse zurückbleiben.

Die Intensität der Einschränkung des beruflichen Betätigungsumfeldes ist bei der Inanspruchnahme nicht allzu hoch. Dies folgt daraus, dass die AccessProvider neben der Durchführung der Sperrung auch weiterhin ihre eigentliche Aufgabe der Zugangsvermittlung wahrnehmen können. ${ }^{577}$ Die Verpflichtung zur Vornahme eines technischen Sperrmechanismus liegt im engen Zusammenhang zu der ohnehin von ihnen bereits erbrachten technikbasierten und automatisierten Dienstleistung. Zudem genügen zur Vornahme der Sperrung bereits simple Softwarekonfigurationen innerhalb der jeweiligen Computersysteme. Diese können von Access-Providern ohne großen technischen Aufwand leicht implementiert

574 Schmidt-Preuß, Die verfassungsrechtlichen Anforderungen an die Entschädigung, S. 13, Kurzgutachten iA. V. Bitkom, abrufbar unter:

http://www.sfu.ca/cprost/prepaid/relateddocs/Germany/Schmidt-

PreuB_and_German_Constitution.pdf (zuletzt abgerufen 20.5.2012); Braun, Die Finanzierung polizeilicher Aufgabenwahrnehmung, 2009, S. 368.

575 Zum gesamten Komplex Sieber/Nolde, Sperrverfügungen im Internet, 2008, S. 62, in die Richtung auch schon Engel, MMR-Beil. 4/2003, 1 (20).

576 Ausdrücklich Sieber/Nolde, Sperrverfügungen im Internet, 2008, S. 62; in die Richtung ebenso Billmeier, Die Düsseldorfer Sperrungsverfügung, 2007, S. 256; Kabl, SächsVBl. 2010, 180 (185).

577 Sieber/Nolde, Sperrverfügungen im Internet, 2008, S. 214, 
und entsprechend zur Unterdrückung des Datenverkehrs eingesetzt werden. Die Einfachheit der technischen Implementierung erklärt sich dadurch, dass AccessProvider ohnehin die jeweiligen an der Kommunikation beteiligten Computersysteme selbst betreiben und mit den technisch-organisatorischen Gegebenheiten des Berufsfeldes vertraut sind. Eine gewisse „Technikgeneigtheit“ ist ihnen damit wesensimmanent. 578

Betrachtet man rein die Intensität der Beeinträchtigung durch die gesetzliche Sperrverpflichtung hinsichtlich der organisatorischen Ausrichtung, so ist die Beeinträchtigung damit nicht allzu hoch. In Anbetracht der Tatsache, dass zur Rechtfertigung eines Eingriffs in die Berufsausübung bereits die der 1. Stufe genügenden geringen Anforderungen des „Gemeinwohlinteresses“ ausreichen und Eingriffsintensität die im Verhältnis dazu auch hier relativ gering ist, wird allein aus dieser Betrachtung heraus keine Unangemessenheit einer gesetzlichen Sperrverpflichtung folgern.

(2) Abwägungsrelevanter Belang: Inanspruchnahme für staatliche Zwecke

Access-Provider werden innerhalb einer Sperrverpflichtung nicht nur zur technisch organisatorischen Einwirkungen auf das Datensystem verpflichtet, ihre berufliche Tätigkeit wird zudem zur Erfüllung originär staatlicher Zwecke der Gefahrenabwehr benutzt. Grundsätzlich ist aber der Staat vorrangig verpflichtet, der Staatssicherheit zu dienen und mit Hilfe eigener Handlungsapparate mögliche Gefahren abzuwehren. ${ }^{579}$

Fraglich ist daher, ob aus der Tatsache heraus, dass der Staat eben bei der Abwehr kinderpornographischer Internetgefahren das berufliche Betätigungsfeld der Provider einfordert und sich zur Erfüllung der Staatsaufgaben auf die Formulierung einer gesetzlichen Handlungsverpflichtung an Dritte beschränkt, ein nicht mehr angemessener Eingriff in die berufliche Betätigungsfreiheit der in Anspruch genommenen Provider vorliegt.

578 Darauf hinweisend, jedoch im Kontext der Vorratsdatenspeicherung, BVerfG, CR 2010, 232 (246).

579 Holst, Sicherheit und Bedrohung, 1998, S. 257 ff.; Braun, Die Finanzierung polizeilicher Aufgabenwahrnehmung, 2009, S. 223 ff. Insbesondere vor dem Hintergrund medialer Gefährdungsbereiche ist eine Verlagerung zur Entstaatlichung des staatlichen Sicherheitsmonopols bemerkbar, so dass immer mehr staatliche Aufgaben vom privaten Sicherheitsgewerbe durchgeführt werden. Insbesondere die bevorzugte Handlungsform des States ist hier nicht die staatliche Kontrolle durch Einsetzung geschulten staatlichen Personals, sondern die Inanspruchnahme Privater zum Vollzug bestimmter staatlich veranlasster Maßnahmen oder die gänzliche Überlassung der Schaffung von bestimmten Schutzstandards durch Private. Zur IT-Sicherheit beispielhaft, Heckmann, MMR 2006, 280; Spindler, MMR 2008, 7; Schmidl, NJW 2010, 476; Karger/Gaycken, MMR 2011, 3. 
Gegen eine Einbindung Privater zur Erfüllung staatlicher Aufgaben können grundsätzlich keine verfassungsrechtlich relevanten Gründe angeführt werden. ${ }^{580}$ Weder kennt das Grundgesetz selbst ein ausdrückliches Privatisierungsverbot noch ein Verbot der Übertragung einzelner originär staatlicher Aufgaben auf Private. ${ }^{581} \mathrm{Im}$ Rahmen des staatlichen Gestaltungsspielraums muss es vielmehr zugestanden werden, sämtliche Handlungsalternativen zu nutzen, um eine Sicherstellung des verfassungsmäßigen Schutzauftrages zu gewährleisten. In die gleiche Richtung tendiert indes auch die Rechtsprechung. Danach sei die Inanspruchnahme Privater zur Ausführung staatlicher Aufgaben dann nicht verfassungsrechtlich angreifbar, wenn sich die Einbeziehung auf unselbstständige Hilfstätigkeiten beschränkt und die Letztentscheidungskompetenz beziehungsweise das eingriffsrelevante Handeln selbst dem Hoheitsträger vorbehalten bleibt. ${ }^{582}$ Die Beschränkung der Handlungsbefugnisse soll einen Konflikt zwischen dem Verlust des Sicherheitsgefühls durch die private Übernahme einerseits und die grundgesetzlich geschützten Positionen der Inanspruchgenommenen andererseits wahren.

Der Befürchtung eines derartigen Konflikts kann anhand einer klaren Zuständigkeitsverteilung bei der Inanspruchnahme von Access-Providern zur Sperrung kinderpornographischer Webseiten entgegnet werden. Soweit sich die abgegebene Staatsaufgabe lediglich auf den Vollzug des staatlichen Handelns beschränkt und den Access-Providern darüber hinausgehend keine eigene Entscheidungskompetenz bezüglich der Frage nach der Notwendigkeit eines generellen Tätigwerden zuerkannt wird, können die kollidierenden Rechtspositionen hier bestmöglich in Einklang gebracht werden. Durch die Auferlegung einer gesetzlichen Handlungsverpflichtung, welche hinsichtlich Notwendigkeit und Breite des Tätigwerdens relativ begrenzt ist, werden die Rahmenbedingungen der beruflichen Tätigkeit für

580 In die Richtung BVerfGE 109, 64 (85); BVerfG, CR 2010, 232 (246). Gegen eine verfassungsrechtliche Zulässigkeit jedoch grundlegend Hoffmann-Riem, ZRP 1977, 277; Beste, Privatisierung von Staates, 1996, S. 233; Grünewald in: Ipsen, Privatisierung öffentlicher Aufgaben, 1994, S. 5 (14). Dafür u.a. Schmidt-Preuß, Die verfassungsrechtlichen Anforderungen an die Entschädigung, S. 18, Kurzgutachten i. A. v. BITKOM, abrufbar unter:

http://www.sfu.ca/cprost/prepaid/relateddocs/Germany/Schmidt-

PreuB_and_German_Constitution.pdf (zuletzt abgerufen 20.5.2012), jedoch in Bezug auf die hier übertragbare Verfassungsmäßigkeit des Eingriffs in Art. 14 GG.

581 BVerfG, CR 2010, 232 (246). Zum staatlichen Gewaltmonopol ausführlich Stober, NJW 1997, 889, zur vorliegenden Fragestellung allgemein, Braun, Die Finanzierung staatlicher Aufgabenwahrnehmung, 2009, S. 229 ff.

582 Z.B. BVerwG, NVwZ-RR 1997, 648 (650) zu den Flugsicherheitsgebühren. Beschränkt sich die Tätigkeit auf den hilfsorganisatorischen Bereich, werden die verfassungsrechtlichen Grenzen des staatlichen Gewaltmonopols, sowie der Funktionsvorbehalt zugunsten des Berufsbeamtentum nicht angetastet. Zum Gewaltmonopol hierzu Stober, NJW 1997, 889, zu den Privatisierungsgrenzen, Burgi, Funktionale Privatisierung, 1999, S. 123 ff. 
den Provider erkennbar erweitert. Er kann sich auf die ihm auferlegte Aufgabe einstellen, seine berufliche Tätigkeit selbstbestimmt danach ausrichten. Wird von staatlicher Seite eine Sperrverpflichtung abverlangt, so handelt es sich hier zwar um eine Gefahrenabwehrmaßnahme, gleichzeitig liegt aber keine völlig atypische und aus seinem sonstigen Arbeitsumfeld gänzlich herausfallende Pflicht vor. Gleichzeitig wirkt sich die strikte Eingrenzung des Betätigungsfeldes auch positiv auf das Sicherheitsgefühl der Bevölkerung aus. Soweit der Entscheidungsspielraum bei der Inanspruchnahme für staatliche Zwecke auf ein Minimum zurückgeführt wird und praktisch nur die Durchführungshandlung aus der staatlichen Hand gegeben wird, suggeriert dieses für den Bürger, dass faktisch der Staat selbst die staatliche Sicherheitsgewährleistung weiterhin bestimmt. Folglich liegt bei der Inanspruchnahme der Provider zur Sperrung kinderpornographischer Inhalte eben jene unselbstständige Situation vor, gegen die grundsätzlich keine verfassungsmäßigen Bedenken zu äußern sind.

Wenn eine generelle Inanspruchnahme Privater zur Vornahme staatlicher Aufgaben schon in einem Bereich nicht verfassungsrechtlich angreifbar ist, indem der Staat selbst auf eigene Handlungsinstrumente zurückgreifen kann (also außerhalb des Internets), so muss dieses erst recht für den Bereich des Internets gelten, in dem keine selbstständige Handlungsfähigkeit des Staates besteht. Den Diensteanbietern kommt in dem Bereich der Gefahrenabwehr im Internet damit eine besondere Schlüsselposition zu. Der Staat muss sich zur Herausnahme des Angebotes aus dem Internetbestand, der direkt am Kommunikationsprozess beteiligten Akteure bedienen und damit gleichzeitig deren Berufsausübungsfreiheit einschränken. Zwar sind Gefahrenabwehr und Strafverfolgung auch im Internet stets originär staatliche Aufgaben. Doch der Staat kann die Umsetzung dergleichen jedoch nicht „eigenhändig“ vornehmen. ${ }^{583}$ Als einzig gangbare Alternative zur Realisierung der Schutzverpflichtung sowohl in jugendschützender wie auch ordnungsrechtlicher Hinsicht ist er auf eine zwingende Mitwirkung der Provider angewiesen. ${ }^{584}$

\section{(3) Zweck-Mittel-Relation}

In die gleiche Richtung führt auch die Argumentation, wenn man die Einschränkung der Berufsfreiheit durch die Inanspruchnahme der privaten Provider als solche im Verhältnis zum verfolgten Zweck betrachtet. Die gesetzliche Sperrverpflichtung dient nicht nur abstrakt dem Gemeinwohlinteresse eines effektiven Jugendschutzes sowie einer Aufrechterhaltung der staatlichen Sicherheit, sondern

583 In die Richtung Kilching, Die Neuregelung zur Auslandskopfüberwachung, S. 19, Gutachten i. A. v. VATM, abrufbar unter: http://www.iuscrim.mpg.de/de/data/pdf/auslandskopf_publ-1.pdf (zuletzt abgerufen 20.5.2012).

584 Ähnlich jedoch zum Bereich der Vorratsdatenspeicherung, Braun, Die Finanzierung polizeilicher Aufgabenwahrnehmung, 2009, S. 348, 368. 
wird gleichzeitig in Erfüllung einer verfassungsrechtlich statuierten Schutzverpflichtung verwirklicht. Im Rahmen einer verfassungsrechtlichen Untersuchung der zur Erfüllung der Schutzpflicht vom Gesetzgeber initiierten Regelungen, muss dessen Einschätzungsprärogative hinreichend gewürdigt werden. ${ }^{585}$ So ist die vom Gesetzgeber gewählte rechtliche Ausgestaltung nur verfassungsmäßig angreifbar, wenn sich die Regelung nicht an dem Rang des hinter der Schutzpflicht stehenden Rechtsguts orientiert und die zur Erfüllung der Schutzpflicht getroffenen Maßnahmen offensichtlich hinter dem verfolgten Schutzziel zurückbleiben. ${ }^{586}$ Auf der einen Seiten wird zwar durch die Sperrverpflichtung die berufliche Tätigkeit der Provider um einen nahezu spielbildlichen Tätigkeitsbereich erweitert. Auf der anderen Seite kann aber auch keine offensichtliche Ungeeignetheit des gewählten Mittels - also der Zugangserschwerung - zur Realisierung des Jugendschutzes in Hinblick auf die Unterdrückung einer Kindesgefährdung durch kinderpornographische Internetangebote angenommen werden. Das zwangsläufig die Berufsfreiheit der Access-Provider tangiert wird, ist somit notwendiger Zwischenschritt zur Realisierung der staatlichen Schutzverpflichtung und nicht etwa nur eine freiwillige Ergänzung durch den Staat.

Auch wenn allen Sperrmethoden gemein ist, dass die letztlich nur eine minimale Erschwerung des Zugangs erreichen, so muss hier beachtet werden, dass der minimalen Wirkweise hier letztlich auch nur ein schwacher Eingriff in die Berufsfreiheit der Provider gegenübersteht.

Überdies ist ein die Einschränkung der Berufsfreiheit der Provider stets im Kontext zur Löschung des Inhalts zu betrachten. Soweit eine Löschung in Betracht kommt, ist diese schon aufgrund der Verfassungsverträglichkeit im Hinblick auf die Erforderlichkeit der Maßnahme vorrangig vorzunehmen. Das heißt die Einschränkung der Berufsfreiheit, in Form der Erweiterung der Tätigkeitsmodalitäten der Access-Provider, ist ohnehin auf den ausnahmsweisen Fall beschränkt, dass ein Vorgehen gegen die Verantwortlichen aufgrund der mangelnden Identifizierung oder Verweigerung der Löschung ausscheidet. Sobald ein Löschvorhaben scheitert, die Verantwortlichen damit nicht ermittelt werden können oder sich weigern eine Löschung durchzuführen, der rechtsverstoßende und gefahrbergründende Inhalt jedoch identifiziert wurde, muss auch eine Möglichkeit bestehen, die Gefahr über „Umwege“ zu beseitigen. Dieser Ausnahmecharakter muss auch bei der verfassungsrechtlichen Rechtfertigung entsprechend herausgestellt werden. Würde der Gesetzgeber in diesem Fall aufgrund einer Unzumutbarkeit Einschränkung der Berufsfreiheit von einer Inanspruchnahme der Provider absehen, würde dies bedeuten, dass der Staat praktisch „sehenden Auges“ einen rechtswidrigen Zustand mit hohem Gefahrpotential aufrechterhält, nur um die ohnehin nur

U.a. BVerfGE 77, 84 (104); BVerfGE 90, 145 (173 ff.); BVerfGE 109, 279 (336 ff.). 
gering beeinflusste Grundrechtsposition des Verpflichteten zu schonen. Dies kann und darf verfassungsrechtlich betrachtet nicht staatliches Anliegen sein.

Obgleich den Access-Providern daher eine staatliche Gefahrenabwehrfunktion abverlangt wird, verbirgt sich dahinter lediglich eine Erweiterung, keineswegs eine Veränderung ihrer beruflichen Dienstleistung. Die Funktionsgewährung eines kommunikativen Internetverkehrs, wird durch die zusätzliche Vornahme einer Sperrung nicht wesentlich angetastet. Im Ergebnis kann also nicht von einer solch stark in die Berufsfreiheit der Access-Provider einschneidenden Maßnahme ausgegangen werden, als diese eine Erfüllung der Schutzpflicht verfassungsrechtlich an einer Unzumutbarkeit scheitern lassen würde.

Festzustellen ist demnach, dass eine Regelung zur Sperrung kinderpornographischer Inhalte in Bezug auf die Inpflichtnahme der Provider als solche nicht unangemessen wäre.

(bb) Angemessenheit der Inanspruchnahme ohne staatliche Entschädigung?

Mag die Inanspruchnahme der Provider aus dem Blickwinkel der Heranziehung zur Erfüllung staatlicher Gefahrenabwehr verfassungsrechtlich nicht anzutasten sein, kann mitunter aber aus der damit einhergehenden wirtschaftlichen Einbuße der Provider ein unangemessener Eingriff in Art. 12 Abs. 1 GG resultieren.

Den Ausgangspunkt bildet der Umstand, dass die Inanspruchnahme der Provider zwar den für die 1. Stufe der verfassungsmäßigen Rechtfertigung notwendigen Gemeinwohlcharakter erfüllt. Jedoch wird nur eine subsidiäre rechtliche Verantwortlichkeit der Provider im Hinblick auf das Gemeinwohl begründet. ${ }^{587}$ Vorrangig zur Realisierung des Gemeinwohlinteresses sind die verantwortlichen Content- und Hostprovider mit entsprechenden Löschverfügungen zu belegen, die eine punktuelle Herausnahme des kinderpornographischen Angebotes bedeuten. Die Access-Provider werden damit als Private an der Verwirklichung einer staatlichen Aufgabe beteiligt, die ihnen ordnungsrechtlich nicht einmal zuzurechnen ist. ${ }^{588}$ Gleichzeitig folgt aus dieser atypischen Verpflichtung eine wirtschaftliche Einbuße der Provider. ${ }^{59}$ Zunächst kommen einmalige Investitionskosten auf die Access-Provider zu, die eine Vornahme der entsprechenden technischen Sperrmethode überhaupt erst ermöglichen. Nachfolgend fallen Pflege-, Wartungs-, sowie Personalkosten an, die eine systematisierte Aufrechterhaltung der Sperrinfrastruktur erlauben. Die Implementierung eines Sperrmechanismus ist damit nicht ohne einen erhöhten Kosten - sowie teilweise auch erhöhten Personalaufwand - mög-

Degen, Freiwillige Selbstkontrolle, 2007, S. 234, zur vorrangigen Haftung der Content-und Hostprovider oben unter REF_Ref325031234 \r \h 3. Teil B. I. 2. b) (cc)

588 So VG Berlin, MMR 2008, 851, zur vergleichbaren Konstellation bei der „Auslandskopfüberwachung“", mit Vorlage an das BVerfGE hinsichtlich der Vereinbarkeit einer mangelnden Kostentragungspflicht mit Art. 12 GG.

589 Zum gesamten Komplex Billmeier, Die Düsseldorfer Sperrungsverfügung, 2007, S. 257 f. 
lich. Die Höhe des tatsächlich anfallenden Kostenaufwands kann aber keineswegs pauschal bestimmt werden. Vielmehr hängt diese maßgeblich von der Art der Sperrmaßnahme ab. Während die DNS-Sperrmethode mit relativ geringen Kosten- und Zeitfaktor schnell und leicht implementiert werden kann, weil die dafür benötigte DNS-Infrastruktur in den meisten Fällen von den Access-Providern selbst betrieben wird, ${ }^{590}$ sind die Kosten bei einer Proxy-Sperrmethode wesentlich höher anzusetzen. ${ }^{591}$ Hat der Access-Provider bei der Zugangsvermittlung noch keinen Proxy installiert, muss er hinreichend qualifiziertes Personal einsetzen, welches die notwendige Einrichtung vornimmt und den regelmäßigen Aufwand der Pflege und Aktualisierung der Proxy-Einstellungen bewerkstelligt. ${ }^{592}$ Benutzt der Access-Provider hingegen selbst schon einen Proxy-Server über den sämtliche Nutzeranfragen geleitet werden entfallen die Errichtungskosten, die Pflegekosten bleiben jedoch auch hier gleichermaßen bestehen. ${ }^{593}$ Bei erhöhter Zugriffszahl des zu überprüfenden Datenbestands, kann es durchaus auch notwendig sein weitere Proxy-Server anzuschaffen und entsprechend zu unterhalten, um den zu filternden Datenbestand bestmöglich auffangen zu können. Wenngleich der finanzielle Aufwand nicht pauschal als hoch zu bezeichnen ist, bilden gesetzliche Sperrverpflichtungen in jedem Fall eine zusätzliche finanzielle Belastung, die ohne die gesetzliche Sperrverpflichtung gerade nicht angefallen wäre.

(1) Problemaufriss

Legt man den Fokus der Untersuchung auf den Ausgangspunkt für das Bedürfnis eines verfassungsrechtlichen Ausgleichs, ${ }^{594}$ so drängt sich hier vordergründig die

590 Stadler, MMR 2002, 343 (345).

591 Hierzu Heuner in: Taeger/Wiebe, Inside the Cloud, 2009, S. 107 (121).

592 Zimmermann, NJW 1999, 3145 (3151).

593 VG Köln, MMR 2005, 399 (402 f.).

594 Im Hinblick auf die Frage nach einer präzisen verfassungsrechtlichen Einordnung des Erfordernisses einer Entschädigungspflicht für die ausnahmsweise Inanspruchnahme der AccessProvider kann der Streit, ob die Diskussion im Rahmen einer Prüfung von Art. 12 GG oder Art. 14 GG zu erfolgen habe, letztlich dahinstehen, da die eigentliche Problematik im Bezug auf die Verhältnismäßigkeit des Eingriffs auf beide Schutzbereiche in der gleichen Weise Anwendung findet, so v. Hammerstein, MMR 2004, 222 (223); Friedrich, Die Verpflichtung privater Telekommunikationsunternehmen, 2001, S. 163 mwN.; Braun, Die Finanzierung polizeilicher Aufgabenwahrnehmung, 2009, S. 364; Sieber/Nolde, Sperrverfügungen im Internet, 2008, S. 64; SchmidtPreuß, Die verfassungsrechtlichen Anforderungen an die Entschädigung, S. 18, Kurzgutachten im Auftrag der BITKOM, abrufbar unter:

http://www.sfu.ca/cprost/prepaid/relateddocs/Germany/Schmidt-

PreuB_and_German_Constitution.pdf (zuletzt abgerufen 20.5.2012); Breuer in: Isensee/Kirchhof, Hdb. StaatsR, 1989, Bd. VI, \147, Rn. 100. Solange für die Erfüllung der staatlichen Pflicht eigene Sachwerte eingesetzt werden müssen, kommt neben der Beeinträchtigung 
Stellung der Access-Provider im Rahmen der Zurechnungskette der ordnungsrechtlichen Verantwortlichkeit auf. Access-Provider würden ohne einen entsprechenden Entschädigungstatbestand als Nichtstörer in Anspruch genommen, ohne eine finanzielle Entschädigung für die daraus resultierenden Kosten zu erhalten. Wäre die Sperrverpflichtung jedoch als landesrechtliche Regelung innerhalb der polizeilichen Eingriffsbefugnisse normiert, würde den Access-Providern nach den geltenden landesrechtlichen Regelungen ein Ausgleich für die Inanspruchnahme gewährt. 595

Fraglich ist demnach, ob die einfach-gesetzlichen Überlegungen gleichfalls auch im Rahmen der Betrachtung einer verfassungsmäßigen Notwendigkeit einer Entschädigungspflicht für eine selbstständig formulierte Sperrverpflichtung heranzuziehen sind.

Allein aus der Tatsache, dass einfach-gesetzlich ein Entschädigungsanspruch besteht, kann nicht verfassungsrechtlich ein generelles Bedürfnis für die Entschädigung eines Nichtstörers hergeleitet werden mit der Folge, dass immer auch eine Entschädigung zu leisten ist. Anderenfalls würde man über die Vorgaben einfachen Rechts höherrangiges Verfassungsrecht ausgestalten, was grundsätzlich abzu-

des Art. 12 GG regelmäßig auch eine gesetzliche Inhalts- und Schrankenbestimmung als eigentumsrelevante Maßnahme im Sinne des verfassungsrechtlichen Schutzes aus Art. 14 GG in Betracht. Zuweilen ist jedoch von einer Idealkonkurrenz der beiden Grundrechte im Verhältnis zueinander auszugehen; zumindest in Bezug auf die verfassungsmäßige Rechtfertigung, IE. Dörr, NJW 1988, 1049 (1051); Sieber/Nolde, Sperrverfügungen im Internet, 2008, S. 64; Braun, Die Finanzierung polizeilicher Aufgabenwahrnehmung, 2009, S. 364. Die ausnahmsweise Verpflichtung mit entsprechender Kostenlast muss in beiden Fällen durch sachgerechte Erwägungen des Gemeinwohls getragen, geeignet, erforderlich sein und innerhalb einer Gesamtabwägung zwischen der Schwere des Eingriffs und dem Gewicht und der Dringlichkeit der ihn rechtfertigenden Gründe, die Grenze der Zumutbarkeit wahren. Der Schutz des Eigentumsrechts kann in Bezug auf eine notwendige Entschädigungspflicht daher nicht weiter gehen als der des Art. 12 GG. Demnach hat die Rechtsprechung die Fragestellung bislang auch innerhalb des Art. 12 GG behandelt (BVerfGE 30, 292 (312). Auch wenn die systematischen Gewichte teilweise verschoben wurden, BVerfGE 100, 226 (241), wird auch in jüngsten Entscheidungen die Problematik erneut unter der Prüfung des Art. 12 GG verortet so BVerfG, CR 2010, 232 (245).

So z.B. $\ 80$ Abs. 1 Nds. SOG; $\ 19$ Abs. 1, 39 Abs. 1a OBN NRW; zur Entschädigung des ordnungsrechtlichen Nichtstörers Schenke, Polizei- und Ordnungsrecht, 2011, Rn. 684; zur Übertragbarkeit auf die Sperrung im Internet Frey/Rudolph, Rechtsgutachten BVDW, 2008, Rn. 116 ff.; Sieber/Nolde, Sperrverfügungen im Internet, 2008, S. 155, die aber einen analogen Rückgriff auf die Entschädigungstegelungen der ordnungsrechtlichen Landesgesetze ablehnen. In die Richtung einer Übertragbarkeit auf die Access-Provider Volkmann, Der Störer im Internet, 2005, S. 217 ff.; so auch schon Spindler/Volkmann, K\&R 2002, 398 (404); ausdrücklich dagegen Billmeier, Die Düsseldorfer Sperrungsverfügungen, 2007, S. 275. 
lehnen ist. ${ }^{596}$ Daher ist die Beantwortung der Frage nach einem verfassungsrechtlichen Entschädigungsbedürfnis damit anhand der Verfassung selbst zu messen.

Vordergründig ist dabei herauszustellen, dass das Grundgesetz selbst keinen generellen Entschädigungsanspruch kennt, somit auch nicht im Falle der Nichtstörerhaftung. ${ }^{597}$ Hiergegen sprechen schon systematische Erwägungen. Betrachtet man beispielsweise das Eigentumsrecht aus Art. 14 GG, so zeigt sich, dass die Verfassung keineswegs von einer grundsätzlichen Entschädigungspflicht ausgeht. Soweit eine zulässige Inhalts- und Schrankenbestimmung im Sinne des Art. 14 GG vorliegt, ist diese aufgrund der Sozialpflichtigkeit des Eigentums entschädigungslos hinzunehmen (Eigentum verpflichtet). ${ }^{598}$ Damit hat der Gesetzgeber das Abwägungsverhältnis im Kollisionsfall zwischen der Institutsgarantie aus Art. 14 Abs. 1 GG und der Sozialpflichtigkeit des Eigentums, zu Gunsten Ersterem entschieden. Auch zeigt sich aus der expliziten Normierung einer Entschädigungsverpflichtung für eine staatliche Enteignung, dass nur ausnahmsweise eine Entschädigung zu gewähren ist. 599

Darüber hinausgehend lässt das Grundgesetz aber Raum für eine ausnahmsweise gebotene Entschädigungspflicht. Soweit eine für sich genommen verfassungsrechtlich zulässige gesetzliche Verpflichtung in atypischen Fällen zu einer besonderen Belastung führe, kann auch ein verfassungsrechtliches Bedürfnis nach einem entsprechenden Ausgleich bestehen. ${ }^{600}$ Die gleiche Argumentation lässt sich auf die subsidiäre Beanspruchung der Access-Provider zur „Gemeinwohlbindung“

BVerfGE 20, 56 (97); BVerfGE 30, 336 (347); von einer „Spiegelung“ der verfassungsrechtlichen Anforderungen über die landesgesetzlichen Entschädigungsklauseln ausgehend, ScbmidtPreuß, Die verfassungsrechtlichen Anforderungen an die Entschädigung, S. 14, Kurzgutachten i.

A. v. Bitkom, abrufbar unter:

http://www.sfu.ca/cprost/prepaid/relateddocs/Germany/Schmidt-

PreuB_and_German_Constitution.pdf (zuletzt abgerufen 20.5.2012).

IE. wohl Depenheuer in: v. Mangoldt/Klein/Starck, Art. 14 GG, Rn. 243; a.A. Im Falle der Inanspruchnahme als Nichtstörer greife ein genereller Aufopferungsanspruch, so wohl schon BVerwG, NJW 1968, 1626 (1628); Stadler, Haftung für Informationen im Internet, 2005, Rn. 140; offengelassen Volkmann, Der Störer im Internet, 2005, S. 222; dagegen, Sieber/Nolde, Sperrverfügungen im Internet, 2008, S. 217; zum Aufopferungsentschädigungsanspruch des Nichtstörers im Einzelnen, Schenke in: Steiner, Beson. Verwaltungsrecht, Kap 2, Rn. 347, Rachor in: Lisken/Denninger, Hdb. PolR, 2007, Kap L, Rn. 32 ff. BVerfGE 100, 226 (241); Depenheuer in: v. Mangoldt/Klein/Starck, Art. 14 GG, Rn. 236; Axer in: Epping/Hillgruber, Art. 14 GG, Rn. 104. IE. Sieber/Nolde, Sperrverfügungen im Internet, 2008, S. 218. BVerfGE 103, 1 (10); BVerfGE 106, 181 (192); BVerfGE 121, 317 (346); Axer in: Epping/Hillgruber, Art. 14 GG, Rn. 104.So im Falle der Ausgleichspflichtigen Inhalts- und Schrankenbestimmung, hierzu grundlegend Heinz/Schmitt, NVwZ 1992, 513 (516 f.); Eschenbach, JURA 1998, 401; Kischel, JZ 2003, 604. 
im Rahmen der Berufsfreiheit übertragen. Diese Gemeinwohlverpflichtung müsste im Regelfall entschädigungslos hinzunehmen sein, jedenfalls soweit die Bindungswirkung nicht ausnahmsweise zu unzumutbaren finanziellen Belastungen der Provider führt. Eine solche ausnahmsweise wirtschaftliche Unzumutbarkeit für die gesetzlich verpflichteten Provider ist dann anzunehmen, wenn die mit der Erfüllung der Pflicht einhergehenden Kosten eine derart „erdrosselnde Wirkung“ auf die Provider haben, dass die berufliche Ausübungsfreiheit unter der Kostenlast erheblich leidet beziehungsweise soweit zurückgedrängt werde, dass werde, dass von der beruflichen Tätigkeit nichts mehr als reine wirtschaftliche Belastung verbleibt und der berufliche Inhalt hingegen komplett aufgehoben wird. ${ }^{601}$

(2) Generelle Entschädigungslosigkeit bei Inanspruchnahme von Privaten zur Gefahrenabwehr

Möglicherweise entbehrt die vorliegende Konstellation ausnahmsweise einer detaillierten Zumutbarkeitsprüfung soweit bereits über die Heranziehung vergleichbarer Rechtsinstitute verfassungsrechtlich eine generelle „Abwälzung“ der Kosten auf die Provider möglich ist. In einem solchen Fall wäre der Ausnahmecharakter der Entschädigung als „Wiedergutmachung“ für den intensiven Eingriff schon gar nicht gegeben und die gesetzliche Regelung auch ohne Entschädigungspflicht verfassungsrechtlich tragbar.

In der Literatur wird eine entschädigungslose Inanspruchnahme der Provider teilweise durch eine Vergleichbarkeit zum verfassungsrechtlich über Art. 105 GG legitimierten „Sonderabgabenrecht“ hergeleitet. ${ }^{602}$ Grundsätzlich wird nämlich die Allgemeinheit zur Finanzierung öffentlicher Aufgaben im Wege der Steuerlast herangezogen. ${ }^{603}$ Dies gilt insbesondere für den Bereich der Gefahrenabwehr. Die Aufrechterhaltung der öffentlichen Sicherheit und Ordnung ist, soweit die Gefahr nicht vom Pflichtigen verursacht wurde, aus staatlichen Steuermitteln zu finanzieren. ${ }^{604}$ Sonderabgaben bilden eine besondere Form dieser staatlichen Finanzierung. Sie zeichnen sich dadurch aus, dass eine bestimmte Kostenlast, die ihrem Zweck nach eine Gemeinlast ist, einer bestimmten abgrenzbaren gesellschaftli-

601 So beispielhaft die Denkmalschutzentscheidung des BVerfGE 100, 226 (240).

602 Vor allem Waechter, VerwArch 1996, 68 (77 ff.; 81 ff.); Koenig/Koch/Braun, K\&R 2002, 289 (294); grundlegend zu den Problemen der Übertragung Kube/Schütž, CR 2003, 663 (668 ff.).

603 Kichling, Die Neuregelung zur Auslandskopfüberwachung, S. 21, Gutachten i. A. v. VATM, abrufbar unter: http://www.iuscrim.mpg.de/de/data/pdf/auslandskopf_publ-1.pdf (zuletzt abgerufen 20.5.2012); hierauf weisen auch Sieber/Nolde, Sperrverfügungen im Internet, 2008, S. 218 hin.

604 Kichling, Die Neuregelung zur Auslandskopfüberwachung, S. 21, Gutachten i. A. v. VATM, abrufbar unter: http://www.iuscrim.mpg.de/de/data/pdf/auslandskopf_publ-1.pdf (zuletzt abgerufen 20.5.2012); zum ganzen Elicker, NVwZ 2003, 304. 
chen Gruppe (homogene Gruppe) zugeordnet wird. ${ }^{605}$ In Übertragung auch die Inanspruchnahme von Access-Providern wird die Vergleichbarkeit zum Abgabenrecht damit begründet, dass Access-Provider bei der Sperrverpflichtung zwar keine speziellen Zahlungen an den Staat leisten, doch entfaltet diese staatlich auferlegte Pflicht im Ergebnis eine entsprechende Wirkung. 606 Sie führen keine tatsächlichen Leistungen an die Staatskasse ab, müssen jedoch eigene Gelder in den Aufbau und die Pflege der Sperrinfrastruktur investieren, die zur Vornahme staatlicher Gefahrenabwehr verwendet wird, ohne im Gegenzug einen Ausgleich dafür zu erhalten. Nach dieser Auffassung erspare sich der Staat praktisch die Einziehung des Geldes, um dieses anschließend in staatliche Zwecke zu überführen.

Der vorgenommenen Interpretation ist jedoch nicht zuzustimmen. ${ }^{607}$ Die Auffassung einer „faktischen Abgabe“ wirkt zum einen stark konstruiert und ist zum anderen im Ergebnis auch nicht durchdacht. Denn die Rechtfertigung der Auferlegung der Kosten ist weiterhin nur dann zulässig, wenn die in Anspruch genommene Gruppe eine besondere Verantwortung, eine so genannte „Sachnähe“ zur Aufgabe aufweist, deren Erfüllung durch die Sonderabgabe finanziert wird. ${ }^{608}$

Problematisch ist hieran jedoch, dass das Zurechnungskriterium für die Rechtfertigung der Auferlegung einer Sonderabgabe inhaltlich unterschiedlich interpretiert werden kann. Legt man das Kriterium der Sachnähe inhaltlich wie beispielsweise das VG Berlin ${ }^{609}$ mit entsprechender Vorlagefrage an das Bundesverfassungsgerich ${ }^{610}$ im vergleichbaren Fall der Beanspruchung von Providern zu

605 Kube in: Epping/Hillgruber, Art. 105 GG, Rn. 16 ff.

606 Um das Beispiel Brauns aufzugreifen, könnte man erwägen, der Staat nehme die notwendigen Finanzmittel und gebe diese im gleichen Zuge wieder zur Verfügung, um bezogen auf Sperrverpflichtungen, seinem verfassungsrechtlichen Schutzauftrag nachzukommen, so Braun, Die Finanzierung polizeilicher Aufgabenwahrnehmung, 2009, S. 353 im Ergebnis aber die Sonderabgabentatbestand ablehnend. Ähnlich zuvor auch schon Kube/Schütze, CR 2003, 663 (669).

607 Ebenso u.a. Friedrich, Die Verpflichtung privater Telekommunikationsunternehmen, 2001, S. 173, der stattdessen eine unentgeltliche Inpflichtnahme als Gleichheitsproblem erörtert; ebenfalls gegen die Vergleichbarkeit zur Sonderabgabenrecht wegen Kontroverse zur Finanzverfassung, Haß in: Manssen, Telekommunikations- und Multimediarecht, \88 TKG, Rn. 41; dagegen auch Braun, Die Finanzierung polizeilicher Aufgabenwahrnehmung, 2009, S. 353, der die faktischen Vergleichbarkeit zwar anerkennt, da es im Ergebnis keinen Unterscheid machen kann, ob man selbst einen Gegenstand anschaffen muss, den der Staat nutzbar macht, oder ob man dem Staat Geld geben muss, damit er den Gegenstand selbst anschafft. Jedoch dann aus Gründen der falschen Einordnung des Merkmals der Sachnähe ablehnend, S. 379 f.

608 BVerfGE 55, 274 (308); BVerfGE 91, 186 (203); BVerfGE 92, 91 (113); BVerfGE 101, 141 (147).

609 VG Berlin, MMR 2008, 851. Hierzu Braun, jurisPR ITR 2/2008 Anm. 4.

610 Zur Antwort des Gerichts, BVerfG, MMR 2009, 606. Das BVerfG hat die vom VG Berlin gerügte Verletzung des Art. 12 GG durch den damaligen \ 110 TKG iVm. \4 Abs. 2 TKÜV 
Überwachungsmaßnahmen im Internet (Auslandskopfüberwachung) ${ }^{611}$ aus, ist Sachnähe als Verantwortungsnähe zu verstehen und im Falle der Heranziehung von Nichtstörern grundsätzlich abzulehnen: „Verantwortlich für den Inhalt der Kommunikation sind die Nutzer. Die Anknüpfung der Zurechnung an die Zurverfügungstellung einer neutralen Leistung würde (...) den Kreis der Verantwortlichen unüberschaubar weit ziehen." "612 Einem Nichtstörer kann eine so ausgelegte Sachnähe danach nie ernsthaft zugerechnet werden. Denn wie bereits erläutert halten Access-Provider lediglich die Kommunikationsplattform zur Nutzung für Dritte bereit. Der Beitrag der Access-Provider zur tatsächlichen Gefahr eines mittelbaren Kindesmissbrauchs beschränkt sich auf einen rein äquivalent-kausalen Beitrag, weshalb man den Aspekt der Sachnähe regelmäßig verneinen müsste. ${ }^{613}$

Das Kriterium der Sachnähe hat im gleichen Kontext jedoch noch eine andere Auslegungsalternative. Das Bundesverfassungsgericht billigt eine finanzielle Inanspruchnahme einer bestimmten Gruppe unter dem Gesichtspunkt der Sachnähe nämlich auch dann, wenn eine Aufgabe traditionell wahrgenommen wird beziehungsweise sich nicht als „schlechthin unternehmensfremd“ darstellt. ${ }^{614}$ Es sei demnach unerheblich, ob die Verpflichteten in irgendeiner Weise für die Gefahrentatbestände verantwortlich seien. Vielmehr komme es rein auf einen beruflichspezifischen Bezug der Verpflichteten zur individuellen Verpflichtung an. In die gleiche Richtung geht auch die jüngere Rechtsprechung, indem sie die Abwälzung der Kosten am Kriterium einer eine Art „spezifischen Befähigung“" auslegt. ${ }^{615}$ Übertragen auf die Inanspruchnahme der Provider wäre eine vorliegende Unter-

mangels Zulässigkeit der Vorlagefrage nicht entschieden. Das BVerfG dürfe über die Verfassungsmäßigkeit der vorgelegten Norm nicht entscheiden, wenn das vorlegende Gericht nicht unter Ausschöpfung der ihm verfügbaren prozessualen Mittel alle tatsächlichen Umstände aufgeklärt hatte, die für die Vorlage von Bedeutung waren. Die Vorlage nach Art. 100 Abs. 1 GG sei damit bereits Unzulässig. Das BVerfG rügte damit, dass das vorlegende VG Berlin nicht hinreichend die Höhe der tatsächlich anfallenden Kosten ermittelt, oder zumindest die ungefähre Höhe der Kosten im Vorlagebeschluss genannt hatte. Wenn diese aber ausschlaggebend für die Verfassungswidrigkeit der Norm seien, müssen diese auch substantiiert, etwa durch die Herkunft und Grundlage der Kostenschätzung dargeboten werden. Bloße Annahmen die durchschnittliche Jahresbelastung wäre hoch, reichen indes nicht aus.

611 Zur Normierung BT-Drs. 15/5199, S. 1 f., 3; grds. Tiedemann, CR 2005, 858.

612 IE. VG Berlin, MMR 2008, 851 (853); zur Sach- und Verantwortungsnähe als Kriterium der Zurechnung bereits BVerfGE 95, 173 (187), jedoch nur als Zurechnungsgrund für die Auferlegung der Kosten angewandt, nicht als Voraussetzung einer Sonderabgabenvergleichbarkeit.

613 IE. so VG Berlin, MMR 2008, 851 (853), anders wohl jetzt BVerfG, CR 2010, 232 (246).

614 BVerfGE 22, 380 (386); BVerfGE 30, 292 (324); BVerfGE 44, 103 (104), dies ebenfalls anführend Sieber/Nolde, Sperrverfügungen im Internet, 2008, S. 218.

615 In die Richtung wohl BVerfG, CR 2010, 232 (246), ohne dies aber auf die Sonderabgabendogmatik zu beziehen. 
nehmensfremdheit kaum anzunehmen und damit auch eine Zurechnung zum nichtverantwortlichen Provider nicht von Vorneherein ausgeschlossen. Durch die Verpflichtung zur Übernahme staatlichen Gefahrenabwehrhandelns entsteht lediglich eine Erweiterung, keineswegs eine Veränderung der typischen beruflichen Dienstleistung des Access-Providings. Ausgehend von der Annahme, dass den Access-Providern ohnehin eine spezifische „Technikbeherrschtheit“ zugesprochen werden kann, da sie gerade diejenigen sind, die die Kommunikationsnetze technisch betreiben, kann ihnen danach eine Sachnähe in Gestalt einer fachspezifischen besonders effektiven Aufgabenerfüllung zugesprochen werden. ${ }^{616}$

Das Zurechnungskriterium der Sachnähe zur Rechtfertigung einer staatlichen Finanzierungslast ist damit je nach vorgenommener inhaltlicher Auslegung in der Lage unterschiedliche Ergebnisse herbeizuführen. Schon diese Auslegungsoffenheit muss dazu führen, dass das Kriterium einer Sachnähe bei der Frage einer generellen Entschädigungspflicht nicht ausschlaggebend sein darf, weil es fallabhängig zu unterschiedlichen Ergebnissen führt und damit keine Rechtsicherheit für die betroffenen Provider herbeiführen kann. ${ }^{617}$

In Anerkennung der Probleme der vorstehenden Ansicht, wird daher teilweise eine generelle Überleitung der Kosten über einen „umgekehrten Gebührentatbestand" vorgenommen. ${ }^{618}$ Auch wenn man dieser Ansicht folgt, kommt man nicht umhin, einen spezifischen Zurechnungsgrund für die Kostentragungspflicht zu fordern. ${ }^{619}$ Im Falle der Nichtverantwortlichkeit wird dieser Zurechnungsgrund kaum hinreichend festzustellen sein. ${ }^{620}$ Wesensmerkmal einer Gebühr ist ein individueller Vorteil. Diese Annahme scheitert aber bei der in Inanspruchnahme von Access-Providern zur Gefahrenabwehr im Internet. Die Mitwirkung an der Sper-

In die Richtung der Auslegung des Kriteriums der Sachnähe wohl BVerfG, CR 2010, 232 (246).

Braun, Die Finanzierung polizeilicher Aufgabenwahrnehmung, 2009, S. 382; ders., K\&R 2009, 386 (390) äußert in dem Zusammenhang sogar den Vorwurf, dass Kriterien der Zurechnung einer staatlichen Finanzlast mit Kriterien der ordnungsrechtlichen Verantwortlichkeit vermischt werden und dadurch zur Kontroverse mit dem Bedürfnis nach einer gerechten Lastenverteilung geraten können.

618 Vor allem Braun, Die Finanzierung polizeilicher Aufgabenwahrnehmung, 2009, S. 382, danach liege bei der Inanspruchnahme von Providern (dort zur Vorratsdatenspeicherung) ein umgekehrter Gebührentatbestand vor. Der Staat müssen dann solche Leistungen nicht vergüten, wenn diese dem Bürger zurechenbar sind, die Verpflichtung insoweit gerechtfertigt ist, als der Bürger seine Leistung selbst mitveranlasst hat oder ihm dadurch ein zurechenbarer Vorteil entsteht. Zu den Gebührenvoraussetzungen im Einzelnen, BVerfGE 50, 217 (226); BVerfGE 91, 207 (223); BVerfGE 115 (125 (129).

619 Beispielsweise (Mit)Verantwortlichkeit für die Leistung, so Waecbter, VerwArch 1996, 68 (82); Manssen, ArchivPT 1998, 236.

620 IE. wohl auch Braun, Die Finanzierung polizeilicher Aufgabenwahrnehmung, 2009, S. 389 „Inkurs Auslandskopfpauschale" mit übertragbarer Argumentation. 
rung kinderpornographischer Inhalte bewirkt keinen messbaren Vorteil für die Provider. Vielmehr begründet gerade die Inanspruchnahme korrespondierende finanzielle Einbußen und ist damit nicht über die Konstruktion eines Gebührentatbestandes zu rechtfertigen. ${ }^{621}$

Es ist somit festzustellen, dass kein verfassungsrechtlich legitimiertes staatliches Finanzierungsinstitut in der Lage ist eine generelle „Abwälzung“ der Kosten auf die nichtverantwortlichen Access-Provider zu rechtfertigen.

Folglich bleibt es bei der grundsätzlichen Annahme, dass eine Entschädigungspflicht bei Unzumutbarkeit der wirtschaftlichen Einbußen zu gewähren ist, was letztlich anhand einer Zweck-Mittel-Relation zu bestimmen ist.

\section{(3) Unzumutbarkeit bei Berücksichtigung der wirtschaftlichen Belastung}

Für die Prüfung der Zumutbarkeit der Kostentragung muss die zu erwartende Kostenlast auf ihre Verträglichkeit mit der Berufsfreiheit hin überprüft werden. Ein Ausgleichstatbestand muss nur dann verfassungsrechtlich gefordert werden, wenn eben das Nichtvorliegen desselben zur Unzumutbarkeit beim Normadressaten und damit zur Verfassungswidrigkeit der Norm führen würde. ${ }^{622}$ Dies wäre der Fall, wenn die mit der gesetzlichen Verpflichtung einhergehende Kostenlast zu einer erdrosselnden Wirkung der gesamten beruflichen Betätigungsfreiheit der Provider führen würde.

Bei der Beurteilung einer etwaigen erdrosselnden Wirkung der Kostenlast müssen zunächst die allgemeinen Kosten berücksichtigt werden. Um der gesetzlichen Sperrverpflichtung nachzukommen, müssen die Provider eigene Sachwerte aufwenden und diese selbstbestimmt verwalten. Dies setzt nicht nur einen einmaligen Investitionsakt voraus, vielmehr ist zur fortwährenden Vornahme einer Sperrung auch stets ein konstanter Wartungs- und Personalaufwand notwendig. Regelmäßig wird daher bei der Verwirklichung einer gesetzlichen Sperrverpflichtung von einem Kostenaufkommen auszugehen sein. Mitunter kann nämlich auch die an sich kostenarme DNS-Methode zu einer enormen wirtschaftlichen Belastung führen, wenn man etwa vorrangig Provider betrachtet, die selbst keine DNSServer betreiben. In diesem Fall müssen neben den laufenden Kosten, auch die zur Domain-Umwandlung notwendigen Server angeschafft und betrieben werden. Auch Zugangsanbieter die bereits die notwenige DNS-Infrastruktur betreiben und

621 Auch eine etwaige Abwälzung der Kosten auf die Nutzer kann nicht als relevanter Vorteil für einen Gebührentatbestand herangezogen werden, BVerfGE 58, 137 (151). Ähnlich das BVerfG, CR 232 (246), jedoch zur Kostenlast bei Vorratsdatenspeicherung; in die Richtung auch BVerfGE 30, 292 (325), dass durch die Kostenabwälzung hier aber von einer Kostenneutralität ausgeht.

622 BVerfGE 58, 137 (150f.); BVerfGE 79, 174 (192); Depenheuer in: v. Mangoldt/Klein/Starck, Art. 14 GG, Rn. 214; Wieland in: Dreier, Art. 14 GG, Rn. 132; Jarass in: Jarass/Pieroth, Art. 14 GG, Rn. 40. 
folglich ohne nennenswerten finanziellen Aufwand eine DNS-Sperrung innerhalb der bestehenden Computersystems vornehmen können, werden im Falle einer Proxy-Sperrmethode dagegen zur Aufrüstung hinsichtlich Proxy und notwendiger Verbindungsleitung verpflichtet, was letztlich dann doch wieder zur Annahme einer finanziellen Belastung führen würde. ${ }^{623} \mathrm{Zu}$ beachten ist in diesem Zusammenhang auch, dass die Kostenlast unabhängig von der ultima-ratio Ausrichtung des Sperransatzes in jeden Fall auftreten wird. Obgleich der Anwendungsbereich der tatsächlichen Sperrmaßnahme selbst durch den Erfolg von Löschungen begrenzt ist, so sind die zur Sperrinfrastruktur aufzuwendenden Kosten unabhängig vom konkreten Einzelfall enthalten. Die Möglichkeit einer subsidiären Rechtsdurchsetzung setzt primär voraus, dass eine entsprechende technische Grundstruktur vorhanden ist und im Ausnahmefall angewendet werden an.

Die Annahme eines regelmäßigen Kostenaufkommens zur Realisierung der gesetzlichen Sperrverpflichtung führt indes noch nicht zu dem Schluss, dass die Kosten auch „hoch“ und erstattungsfähig, wegen „erdrosselnder Wirkung“ sind. Die Bestimmung der tatsächlich anfallenden Kostenhöhe, im Bezug auf eine untragbare finanzielle Belastung kann nur einzelfallabhängig und bei genauer Betrachtung des relativen Verhältnisses zwischen aufzubringenden infrastrukturellen Maßnahmen und damit verbundenen Kosten einerseits und den grundsätzlichen wirtschaftlichen Einnahmen der Provider andererseits erfolgen. Eine gesetzliche Sperrverpflichtung, die keinen Erstattungstatbestand vorsieht, würde als mögliche Normadressaten nämlich sämtliche Access-Provider umfassen. Mit der Zugangsvermittlung zum Internet sind jedoch nicht nur gewerbsmäßig agierende Unternehmen beschäftigt, deren Hauptbetätigungsfeld ausschließlich auf die Dienstleistung der Zugangsgewährung ausgerichtet ist, sondern auch private mittelständische Unternehmen, die losgelöst von ihrer sonstigen beruflichen Rahmen nebenbei ihren Arbeitsnehmern auch einen eigenen Internetzugang vermitteln. Genauso wie Universitäten, Schulen und staatliche Stellen, die im Rahmen ihrer beruflichen Tätigkeit auch den Zugang zum Internet gewähren. ${ }^{624}$

Marktanalytisch betrachtet ist davon auszugehen, dass Provider mit einem weiten Kundenstamm und einem beruflichen Betätigungsfeld, welches ausschließlich auf der professionellen Zugangsgewährung beruht, wegen der kontinuierlichen Kundenbindungsverträge und hoher Nutzerfrequenzen, die anfallende Kostenlast besser wirtschaftlich tragen, als Provider, die nur bestimmten Kleingruppen $\mathrm{Zu}$ gänge zum Internet vermitteln. ${ }^{625}$ Andererseits kann nicht in jedem Fall bei Klein-

${ }^{623} \mathrm{Zu}$ den unterschiedlichen finanziellen Belastungen, Billmeier, Die Düsseldorfer Sperrungsverfügung, 2007, S. $258 \mathrm{f}$.

624 überblicksartig Pursch/Bär in: Sperrverfügungen gegen Access-Provider, Ausarbeitung des Wissenschaftlichen Dienstes des Deutschen Bundestages, WD 10-3000-010/2009, S. 24.

625 In die Richtung Pursch/Bär in: Sperrverfügungen gegen Access-Provider, Ausarbeitung des Wissenschaftlichen Dienstes des Deutschen Bundestages, WD 10-3000-010/2009, S. 24. 
anbietern geschlossen werden, dass eine Kostenlast diese vollständig in ihrer beruflichen Ausgestaltung einschränkt. Auch verhältnismäßig kleine Provider, die bereits über die notwendige Infrastruktur wie DNS-Server oder Proxy verfügen, können weitaus weniger finanzielle Einbußen erfahren, als Großprovider, die lediglich unter Einsetzung eines minimalen technischen Aufwands eine breitflächige Internetnutzung ermöglichen. Zudem ist nicht immer davon auszugehen, dass die Provider für ihre Dienstleistung auch tatsächlich ein Entgelt verlangen, dass sich letztlich mit dem Kostenvolumen verrechnen lässt.

Die für eine Unangemessenheit einer gesetzlichen Sperrverpflichtung notwendige erdrosselnde Wirkung ist damit grundsätzlich abhängig von der jeweiligen Fallgruppe und kann daher nicht pauschaliert ,immer" in Erwägung gezogen werden. Vielmehr bedarf es zur Feststellung einer Unzumutbarkeit substantiiert nachweisbarer Kostenaufstellungen, die den Bedarf sowie den Gewinn der Provider miteinander ins Verhältnis setzen. Ohne eine derartige substantiierte Feststellung ist eine grundsätzliche Unzumutbarkeit abzulehnen. ${ }^{626}$

Sollte über die Maßgabe einer detaillierten Kostenaufstellung eine besonders hohe finanzielle Belastung nachweisbar sein, muss überdies betrachtet werden, ob aus dieser hohen Belastung tatsächlich eine einschneidende Beeinträchtigung der gesamten Ausübung der beruflichen Dienstleistung folgt. Werden die Kosten in dem Maße veranschlagt, als die gesamte berufliche der Fortführung der Beruflichen Tätigkeit flankieren ist eine Unzumutbarkeit im Hinblick auf die Einschränkung der Berufsfreiheit denkbar. Zwar verbietet sich verfassungsrechtlich die Annahme einer Unzumutbarkeit auf Verdacht, es kann jedoch nicht ausgeschlossen werden, dass über eine detaillierte Kostenkalkulation bei manchen Unternehmen tatsächliche eine erdrosselnde Wirkung der Kosten bescheinigt wird.

Als Ergebnis ist demnach festzuhalten: Die Heranziehung der Diensteanbieter zur Vornahme einer gefahrenabwehrrechtlich motivierten Sperrung von kinderpornographischen Webinhalten ist als solche in Hinblick auf die Berufsfreiheit prinzipiell nicht zu beanstanden. Dagegen kann eine mangelnde Normierung einer Entschädigung für die aufzubringende Sperrinfrastruktur zur Unangemessenheit der Regelung führen.

\section{(4) Folgerungen für die Normierung}

Entscheidet sich der Gesetzgeber wegen des hohen Rangs der zu schützenden Rechtsgüter für eine strikte gesetzliche Handlungsverpflichtung der AccessProvider zur Sperrung kinderpornographischer Inhalte im Internet, so werden aufgrund des abstrakt-generellen Charakters einer Norm sämtliche AccessProvider zu Normadressaten. Folglich auch diejenigen, bei denen auf Grund der geringen Zahl der Kunden im Verhältnis zur Kostenlast der Sperrverpflichtung

626 In die Richtung wohl BVerfG, CR 2010, 232 (246); hierzu ausführlich Eckhardt/Schütze, CR 2010, 225 (229). 
besonders einschneidende Beeinträchtigungen der Berufsfreiheit zu erwarten sind. Verzichtet der Gesetzgeber also auf die gleichzeitige Normierung eines Entschädigungstatbestandes würde das Gesetz im Ganzen gegen Art. 12 Abs. 1 i.V.m. Art. 3 Abs. 1 GG verstoßen, da die gesetzliche Regelung zu Ungleichbehandlung von Normadressaten führen kann. Vergleichbar mit dem vom Bundesverfassungsgericht entschiedenen Fall der Verwerfung des baden-württembergischen Nichtraucherschutzgesetzes, ist dies dann anzunehmen, wenn Gruppenangehörige „in bestimmten auch zahlenmäßig begrenzten typischen Fällen ohne zureichende Gründe verhältnismäßig stärker belastet werden als andere" $.627 \mathrm{Um}$ die gleichheitswidrigen Zustände auszuschließen wäre es ohne eine entsprechende Entschädigungspflicht allenfalls möglich von einem grundsätzlichen Überwiegen des Gemeinwohlinteresses bei gesetzlichen Sperrverpflichtungen für kinderpornographische Inhalte auszugehen. Nicht zu übersehen ist jedoch, dass sich die Frage nach einem Überwiegen von konkurrierenden Grundrechtspositionen dann nicht stellt, wenngleich bereits im Wege der praktischen Konkordanz ein schonender Ausgleich zwischen den beteiligten Interessenpositionen herbeigeführt werden kann. ${ }^{628}$ Eben eine solche ist bei der Konkurrenz zwischen dem Interesse der Allgemeinheit an einer effektiven Gefahrenabwehr und Strafverfolgung im Internet und der möglichen unzumutbaren Beeinträchtigung der Berufsfreiheit einzelner Zugangsanbieter über die explizite Normierung einer Entschädigungspflicht herbeizuführen. Der Gesetzgeber ist also gehalten, den unterschiedlichen Auswirkungen einer gesetzlichen Regelung durch Härteregelungen oder weitere Differenzierungen wie Ausgleichstatbestände Rechnung zu tragen. ${ }^{629}$

Hinsichtlich dieser Formulierung steht dem Gesetzgeber ein weites Spektrum an Umsetzungsinstrumenten zu. ${ }^{630}$ Eine Entschädigung kann pauschaliert benannt

BVerfGE 121, 317 (358), wonach in Gaststätten, ohne einen räumlich abgetrennten „Raucherraum", sowie generell in Diskotheken, ein striktes Rauchverbot galt. Im Ansatz in die gleiche Richtung bereits BVerfGE 25, 236 (251); BVerfGE 30, 292 (327); BVerfGE 59 (336); BVerfGE 68, 155 (173).

628 Das Prinzip der „praktischen Korkordanz“ verpflichtet dazu im Idealfall einen schonenden Ausgleich zwischen den Beteiligten Grundrechtspositionen zu schaffen, oder dass eine grundrechtliche Gewährleistung gegenüber der anderen ganz zurücktreten muss. Prinzip begründet von Hesse, Grundzüge des Verfassungsrechts der Bundesrepublik Deutschland, 1999, Rn. 72: zuvor schon Lerche, Übermaß und Verfassungsrecht, 1961, S. 51 ff., jedoch ohne dem Prinzip des „angemessenen Ausgleichs der kollidierenden Verfassungsgüter“ einen eigenständigen Namen zu geben. Die Notwendigkeit eines schonenden Ausgleichs ist mittlerweile in ständ. Rspr. anerkannt, u.a. BVerfGE 41, 29 (51); BVerfGE 77, 240 (255); BVerfGE 81, 298 (308); BVerfGE 83, 130 (143).

${ }^{629}$ BVerfGE 34, 71 (80); BVerfGE 121, 317 ( 358).

630 Depenheuer in: v. Mangoldt/Klein/Starck, Art. 14 GG, Rn. 237; Wieland in: Dreier, Art. 14 GG, Rn. 135; Schoch, JZ 1995, 768 (770). 
werden, muss dann aber eine annähernde Deckung der verursachten Kosten erreichen. ${ }^{631}$ Denkbar ist es aber auch die notwendige Entschädigungspflicht nur auf spezielle Härtefälle gesetzlich zu beschränken. ${ }^{632}$ Fehlt eine solche Formulierung, ist die Norm an sich verfassungswidrig.

Zusammenfassend ist festzustellen, dass grundsätzlich kein verfassungsrechtlicher Anspruch auf Entschädigung gewährt wird. Auch ist eine Norm, die eine staatliche Inanspruchnahme Privater für öffentliche Zwecke vorsieht mangels Kostentragung daher nicht per se verfassungswidrig. Ausnahmsweise kann aber gerade die mangelnde Kostentragung zur Verfassungswidrigkeit der Norm führen. Dies wäre bei der Inanspruchnahme von Access-Providern zur Vornahme technischer Sperrungen zur Gefahrenabwehr der Fall, soweit die zur Sperrung aufzuwendenden Kosten zur nachweisbaren Unzumutbarkeit in Hinblick auf die Ausübung ihrer Berufsfreiheit für einzelne Normadressaten führen würden. Um gleichheitswidrigen Zustände zu vermeiden, muss der Gesetzgeber diesem Umstand mit einer entsprechenden Normierung einer Entschädigungspflicht oder durch spezielle Härtefallklausel entgegnen, welche die unzumutbar Betroffenen entsprechend wirtschaftlich ausgleichen oder aus dem Kontext der Normadressaten herausnehmen. Erfüllt der Gesetzgeber die Anforderungen an die Formulierung der Sperrverpflichtung, so ist der Eingriff in die Berufsfreiheit der verpflichteten Provider angemessen.

(5) Das BVerfG-Urteil zur Vorratsdatenspeicherung - Endgültige Abkehr vom Entschädigungserfordernis?

Möglicherweise bedarf das gefundene Resultat in Anbetracht jüngerer höchstrichterlicher Rechtsprechung jedoch einer Korrektur. So hatte sich das Bundesverfassungsgericht mit der Frage zu beschäftigen, ob Telekommunikationsunternehmen entschädigungslos zur Vornahme einer „,anlasslosen“ Speicherung von Verkehrsdaten sog. „Vorratsdatenspeicherung“" verpflichtet werden können. ${ }^{633}$ Im Kern ging es bei der Verfassungsbeschwerde eines Telekommunikationsunternehmens, um die Verfassungsmäßigkeit der $\int \mathbb{S} 113 \mathrm{a}$ und $113 \mathrm{~b}$ TKG sowie $\$ 100 \mathrm{~g}$ StPO,

631 V. Hammerstein, MMR 2004, 222 (225) mwN.; differenzierend unter Heranziehung einer ,"modellhaften“ Vergleichbarkeit zur Entschädigung bei Enteignungen gem. Art. 14 Abs. 3, S. 3 GG, iE aber volle Entschädigung fordernd, Schmidt-Preuß, Die verfassungsrechtlichen Anforderungen an die Entschädigung, S. 19 ff., Kurzgutachten i. A. v. Bitkom, abrufbar unter: http://www.sfu.ca/cprost/prepaid/relateddocs/Germany/SchmidtPreuB_and_German_Constitution.pdf (zuletzt abgerufen 20.5.2012),

632 Depenheuer in: v. Mangoldt/Klein/Starck, Art. 14 GG, Rn. 237; Wieland in: Dreier, Art. 14 GG, Rn. 135.

633 BVerfG, CR 2010, 232 mit Anm. Heun. 
welche in Umsetzung europarechtlicher Vorgaben der Richtlinie 2006/24/EG G34 $^{634}$ den Telekommunikationsunternehmen die Pflicht auferlegen, die bei der Inanspruchnahme von Telekommunikationsdiensten anfallenden Daten der Telefon-, Email und Internetverbindungen ihrer Nutzer sechs Monate lang ohne konkreten Anlass zu speichern. Die Telekommunikationsunternehmen sollten die gespeicherten Daten im Bedarfsfall, also zu Strafverfolgungszwecken, zur Abwehr von erheblichen Gefahren für die öffentliche Sicherheit sowie zur Erfüllung des Verfassungsschutzes, an die zuständigen Behörden weiterleiten. ${ }^{635}$ Das Bundesverfassungsgericht hatte die in Frage standen Normen aufgrund Verstoßes gegen Art. 10 Abs. 1 GG für nichtig erklärt und sich dabei explizit für die Verfassungswidrigkeit der entsprechenden Normen, nicht jedoch der Vorratsdatenspeicherung als solche ausgesprochen. ${ }^{636}$

Obgleich im Fokus der gerichtlichen Auseinandersetzung die Verletzung des Fernmeldegeheimnisses durch die anlasslose Vorhaltung von Daten mit Hilfe derer Nutzerprofile erstellt werden können stand, beschäftigte sich das Gericht am Rande der Entscheidung auch mit Teilfragen des Eingriffs in Art. 12 Abs. 1 GG sowie einer Entschädigungslosigkeit für die Inanspruchnahme der Provider. Für die Frage nach der Abkehr des Entschädigungserfordernisses auch bei staatlicher Inanspruchnahme zur Sperrung kinderpornographischer Inhalte können die getätigten Ausführungen vergleichbar herangezogen werden und sind daher analysebedürftig. Die Vergleichbarkeit der beiden Fälle gründet nämlich auf den Umstand, dass beide Male ein Privater (privates Unternehmen) zur Ausführung an sich staatlicher Aufgaben beansprucht wird, weil der Staat weder selbst über die notwendigen infrastrukturellen Einrichtungen verfügt, noch unmittelbar Einfluss auf die zur Sperrung beziehungsweise zur Speicherung notwendigen Leitungen hat. Überdies liegt eine gewisse Gleichartigkeit der Fälle unter dem Aspekt vor, dass den in die Pflicht genommenen Provider in gleicherweise eine berufliche

Richtlinie des Europäischen Parlaments und des Rates v. 15.3.2006, Abl 2006 Nr. L 105, S. 54. Danach müssen die Mitgliedstaaten entsprechend dem Anwendungsbereich der Richtlinie im Wege der gemeinschaftsrechtlichen Harmonisierung sicherstellen, dass „die Daten zum Zwecke der Ermittlung, Feststellung und Verfolgung von schweren Straftaten (...) zur Verfügung stehen. In Art. 3 iVm. Art. 11 wird daher eine Vorratsspeicherungspflicht vorgesehen. Zum Regelungsinhalt im Einzelnen, Westphal, EuZW 2006, 555.

635 Grundlegende Analyse der Entscheidung des BVerfG, Eckhardt/Schütze, CR 2010, 225; Stramm/Wegener, MMR 2011, 9; Webr/Uijca, MMR 2010, 667; Orantek, NJ 2010, 193; Besprechung der Entscheidung mit Hauptaugenmerk auf den europarechtlichen Kontext, Westphal, EuZW 2010, 494; Wolff, NVwZ 2010, 751, mit dem Ergebnis, dass grds. eine anlasslose Vorratsdatenspeicherung in Umsetzung der Vorgaben der Richtlinie 2006/24/EG mit dem deutschen Recht vereinbar sei, dies jedoch nur bei entsprechender verfahrensrechtlicher Absicherung. Hierzu werden die Vorgaben der Entscheidung analysiert und bewertet.

636 BVerfG, CR 2010, 232 (234). 
Verpflichtung auferlegt wird, die im Wesentlichen eine Modifizierung ihrer sonstigen beruflichen Tätigkeit begründet. Der in Anspruch genommene Provider muss eine zum Teil „artfremde“, zumindest jedoch zusätzliche Tätigkeit vornehmen, die mangels gesetzlicher Verpflichtung so nicht angefallen wäre.

Das Bundesverfassungsgericht hatte in der Entscheidung herausgestellt, dass die Inanspruchnahme Privater zur Durchführung originär staatlicher Aufgaben, zwar einen Eingriff in Art. 12 Abs. 1 GG begründet, dieser jedoch im Ergebnis verfassungsmäßig gerechtfertigt sei. ${ }^{637}$ Gleichzeitig machte das Gericht ex obiter generelle Ausführungen zur Auferlegung der Kostentragungspflicht an die Verpflichteten. ${ }^{638}$ Unverhältnismäßig sei danach die Speicherungspflicht auch nicht „in Bezug auf die finanziellen Lasten, die den Unternehmen durch die Erfüllung der gesetzlichen Verpflichtung und den hieran knüpfenden Folgeverpflichtungen erwachsen“. Allein deshalb eine Unzumutbarkeit anzunehmen, weil „Private unzulässig mit Staatsaufgaben betraut werden würden" scheide nach Ansicht des Gerichts aus. Eine kategorische Trennung von „Staatsaufgaben“ und „privaten Aufgaben" mit der Folge der grundsätzlichen Unzulässigkeit einer Indienstnahme für Gemeinwohlzwecke von Privaten auf deren Kosten ließe sich der Verfassung nicht entnehmen. Vielmehr verweist das Gericht auf den „weiten Gestaltungsspielraum“ des Gesetzgebers hinsichtlich der Pflichten zur „Sicherstellung von Gemeinwohlbelangen“, die er „Privaten im Rahmen ihrer Berufstätigkeit auferlegt““. ${ }^{639}$ Der Gesetzgeber verlagere ,,auf diese Weise die mit der Speicherung verbundenen Kosten entsprechend auf dem relevanten Markt der Telekommunikationsdienstleitung". Dabei werden einzelnen Unternehmen nicht einzelfallbezogene Sonderopfer erbracht, sondern in ,allgemeiner Form die Rahmenbedingungen für die Erbringung der Telekommunikationsdienstleistung ausgestaltet". Folglich bestünden nach Ansicht des Bundesverfassungsgerichts gegen die Auferlegung der Kostenlast keine grundlegenden Bedenken. „Die von den Unternehmen auferlegten Pflichten stehen im engen Zusammenhang mit den von ihnen erbrachten Dienstleistungen und können als solche nur von ihnen selbst erbracht werden.“ Es sei damit nach Auffassung des Gerichts „,verfassungsrechtlich nicht zu beanstanden, wenn die Unternehmen hierfür die anfallenden Kosten grundsätzlich zu tragen" hätten.

Dem ersten Anschein nach positioniert sich das Bundesverfassungsgericht hier offensichtlich zu der Entschädigungspflicht und erteilt der Entschädigung eine generelle Absage. ${ }^{640}$ Bei genauerer Analyse der Entscheidung ist diese Folge nicht

637 BVerfG, CR 2010, 232 (245 f.) entgegen OVG Berlin Brandenburg, MMR 2010, 274, dies hatte einen Eingriff speziell in Bezug auf Die Pflicht zur Vorratsdatenspeicherung verneint, weil die verpflichteten Provider die Daten ohnehin geschäftsmäßig erheben müssten.

638 Ausführliche Analyse Eckhardt/Stütre, CR 2010, 225 (229).

639 BVerfG, CR 2010, 232 (246) mit Verweis auf BVerfGE 109, 64 (85).

640 So wohl das Verständnis von Heun, Anm. zum Urteil des BVerfG, CR 2010, 247 (248). 
zwingend. Wie Eckhardt/Stütze ${ }^{641}$ zutreffend feststellen, hat das Bundesverfassungsgericht hier lediglich „streitgegenstandsbezogen“ nur für den vorliegenden Einzelfall die Unzumutbarkeit einer Kostentragung beurteilt; keineswegs das grundsätzliche Bedürfnis nach einer Kostenlast abgelehnt. Wie das Gericht selbst wiederholt hervorhebt, mangelte es an einer detaillierten Kostenausstellung über die tatsächliche Höhe der anfallenden Investitionskosten. ${ }^{642}$ Damit lagen der Entscheidung nur abstrakte Kostenschätzungen der Provider vor. ${ }^{643}$

Auch wenn dem Bundesverfassungsgericht in der Regel auch zuerkannt wird, losgelöst vom Streitgegenstand im Rahmen eines Obiter Dictum seine generelle Rechtsauffassung zu einer verfassungsrechtlich strittigen Problematik kundzutun, ${ }^{644}$ so verzichtete das Bundesverfassungsgericht im Rahmen der Vorratsdatenspeicherung explizit auf diese Möglichkeit. ${ }^{645}$ Dies wird vor allem dadurch deutlich, dass es selbst herausstellt, dass aufgrund der mangelnden Kostendarlegung, „insofern (...) nicht weiter zu prüfen [ist], ob hinsichtlich besonderer Fallgruppen oder Sondersituationen aus dem Gesichtspunkt der Verhältnismäßigkeit Härteregelungen geboten sind. Denn jedenfalls ergibt sich hierfür aus dem Vorbringen der Beschwerdeführerin nichts. (...) Insbesondere hat sie auch (...) eine über die bei den sonstigen Telekommunikationsunternehmen hinausgehende Belastung weder für sich noch für andere Anbieter solcher Dienste hinreichend nachvollziehbar durch konkrete Zahlen belegt. Nur unter dieser Voraussetzung ließe sich aber eine Überschreitung des gesetzgeberischen Gestaltungsspielraums bei der Indienstnahme der Provider feststellen. Solange die Einschätzung des Gesetzge-

641 So auch die Interpretation von Eckhardt/Stütře, CR 2010, 225 (229 f., insb. 230). Belegen lässt sich diese Sichtweise mit der Argumentation des Gerichts, CR 2010, 232 (246): „, Dass die Kostenlasten in dieser Weise erdrosselnde Wirkung haben, ist weder substantiiert vorgebracht noch erkennbar. Insofern ist nicht weiter zu prüfen, ob hinsichtlich besonderer Fallgruppen oder Sondersituationen aus dem Gesichtspunkt der Verhältnismäßigkeit Härteregelungen geboten. sind.“ „Solange die Einschätzung des Gesetzgebers nur durch Vermutungen und Behauptungen in Frage gestellt wird, kann das BVerfG dieser Frage nicht nachgehen." (Hervorhebungen hinzugefügt).

${ }^{642}$ BVerfG, CR 2010, 232 (245, 246), „Demgegenüber sind die angegriffenen Vorschriften hinsichtlich Art. 12 Abs. 1 GG, soweit in diesem Verfabren bierfür zu entscheiden ist, keinen verfassungsrechtlichen Bedenken ausgesetzt. „Insbesondere hat (die Beschwerdeführerin) eine über die bei sonstigen Telekommunikationsunternehmen hinausgehende Belastung für sich noch für andere Anbieter solcher Dienste binreichend nachvollziehbar durch konkrete Zablen belegt.“

643 Im Falle der Auslandskopfpauschale verlangte das BVerfGE ausdrücklich eine detaillierte Kostenaufstellung und wies die Vorlagefrage zur Vereinbarkeit der Norm mangels unzureichender Tatsachenaufklärung des anfragenden Gerichts zurück, BVerfG MMR 2009, 606; Vorlagebeschluss VG Berlin, MMR 2008, 851.

644 Zur damit einhergehenden Problematik z.B. der Durchbrechung der Gewaltenteilung grundlegend, Schlïter, Das Obiter Dictum, 1973, S. 15 ff.; ebenfalls kritisch Lamprecht, NJW 1998, 1039.

645 So ausdrücklich Eckhardt/Stütze, CR 2010, 225 (229). 
bers nur durch Vermutungen und Behauptungen n Frage gestellt wird, kann das BVerfG dieser Frage nicht nachgehen. "“46 Analysiert man diese Ausführungen, so lässt sich daraus der Umkehrschluss formulieren, dass die Beurteilung einer verfassungsrechtlich gebotenen Entschädigungspflicht durchaus eine andere wäre, wenn die Beschwerdeführerin explizit eine detaillierte Kostenaufstellung vorgelegt hätte, die eine Unzumutbarkeit dargelegt. Deutlich macht das Bundesverfassungsgericht hier selbst darauf aufmerksam, dass Aspekte der wirtschaftlichen Belastung durchaus zu einer Unzumutbarkeit und damit zu einem unangemessenen Eingriff in Art. 12 Abs. 1 GG führen können.

Das Bundesverfassungsgericht statuiert in seiner Entscheidung zur Vorratsdatenspeicherung damit keineswegs eine höchstrichterliche Abkehr vom Entschädigungserfordernis. Es muss damit bei dem Ergebnis bleiben. Soweit eine gesetzliche Sperrverpflichtung nachrangig zur Löschung gesetzlich formuliert wird, ist zur Relativierung drohender gleichheitswidriger Zustände im Hinblick auf Art. 12 Abs. 1 GG i.V.m. Art. 3 GG eine staatliche Kostentragungspflicht zu formulieren.

e) Zwischenergebnis: Verhältnismäßigkeit im engeren Sinne: Angemessenheit des Eingriffs in Art. 12 Abs. 1 GG

Durch die gesetzliche Auferlegung einer Sperrverpflichtung für Access-Provider liegt grundsätzlich ein Eingriff in die Berufsausübungsfreiheit der Provider vor. Providern wird per Gesetz die Verpflichtung auferlegt gefahrenabwehrrechtlich relevante Handlungen vorzunehmen, die auf einer gegensätzlichen Berufsausübung basiert. Dieser Eingriff ist jedoch in Anbetracht des mit ihm verfolgten Zwecks nicht als unverhältnismäßig anzusehen. Er greift nicht in unzumutbarer Weise in das berufliche Betätigungsfeld ein, vielmehr wird dieses lediglich ausgestaltet, keineswegs verändert oder beschränkt. Etwas anderes ist jedoch anzunehmen, wenn die mit der gesetzlichen Verpflichtung notwendigerweise anfallenden Kosten nicht gesetzlich auf den Staat übertragen werden. Der in Anspruch genommene Access-Provider ist Nichtstörer und bietet folglich keinerlei Zurechnungsgrund für über seine Kommunikationsnetze durchgeleiteten Gefahren. Sollte die aufkommende Kostenlast zur Herstellung und Aufrechterhaltung der Sperrinfrastruktur die verpflichteten Provider so hart treffen, dass ein Nachkommen der Verpflichtung in Bezug auf ihre berufliche Tätigkeit eine erdrosselnde Wirkung hätte und dieses auch hinreichend substantiiert dargelegt werden kann, so ist an der Verfassungsmäßigkeit der Norm ohne entsprechende Kostentragungsverpflichtung des Staates zu zweifeln. Um etwaigen Ungleichbehandlungen vorzubeugen und eine praktische Konkordanz zwischen den beeinträchtigten Belangen herbeizuführen, müssen gesetzgeberische Regelungsmechanismen eine Entschädigungspflicht vorsehen. 


\section{Ergebnis: Berufsfreibeit}

Eine gesetzliche Sperrverpflichtung stellt zwar einen Eingriff in Art. 12 Abs. 1 GG dar, dieser kann jedoch verfassungsrechtlich gerechtfertigt sein. Durch die gesetzliche Sperrverpflichtung wird ein legitimer staatlicher Zweck erfüllt, der auch in Anbetracht technischer Umgehungsmaßnahmen noch als geeignet anzusehen ist. Im Rahmen der Erforderlichkeit wird im Regelfall die Löschung des Angebotes in Betracht kommen, und ist aus verfassungsrechtlichen Aspekten stets vorrangig durchzuführen. Auf Grundlage der ausdrücklichen gesetzlich festzuschreibenden Subsidiarität, wird der der tatsächliche Anwendungsbereich der Sperrung damit nur auf Ausnahmefälle begrenzt sein. In diesem Fall steht die der Maßnahme der Sperrung zum verfolgten Zweck nicht außer Verhältnis zur Einschränkung der Berufsfreiheit der Access-Provider. Diesbezüglich muss innerhalb der gesetzlichen Formulierung jedoch auch ein finanzieller Kostenausgleich festgesetzt werden.

\section{Eigentumsfreiheit Art. 14 GG}

\section{Eingriff in den Schutzbereich}

Neben dem Eingriff in Art. 12 Abs. 1 GG stellen gesetzliche Sperrverpflichtungen auch eine eigentumsrelevante Maßnahme im Sinne des Art. 14 GG dar und tangieren die Access-Provider damit auch in individualrechtlichen Eigentumsinteressen. Bezüglich der Anforderungen an personellen Schutzbereich ergeben sich bei Art. 14 GG keine spezifischen Beschränkungen. Als inländische juristische Personen ist den Access-Providern ein Schutz über Art. 14 GG grundsätzlich nicht verwehrt.

Das Eigentumsgrundrecht beinhaltet in sachlicher Hinsicht in erster Linie das subjektive Recht des Einzelnen konkrete vermögenswerte Rechtspositionen vor staatlichem Zugriff zu bewahren. Art. 14 GG will damit zuvorderst im Rahmen eines Bestandschutzes die Integrität im Hinblick auf den konkreten Vermögensbestand erhalten und den Vermögenswert vor staatlicher Kommerzialisierung schützen. ${ }^{647}$ Neben diesem abwehrrechtlichen Charakter enthält Art. 14 GG auch eine Instituts- und Bestandsgarantie. Diese verpflichtet den Gesetzgeber die typischen Grundformen und Grundstrukturen des Eigentums zu erhalten. Bei der Bestimmung von Inhalt und Schranken des Eigentums durch den Gesetzgeber muss demnach ein elementarer Grundbestand grundrechtlich geschützter Betätigung im vermögensrechtlichen Bereich verbleiben. ${ }^{648}$ Das Eigentumsrecht erstreckt sich

647 Depenheuer in: v. Mangoldt/Klein/Starck, Art. 14 GG, Rn. 86; Papier in: Maunz/Dürig, Art. 14 GG, Rn. 27. Zur Bestandsgarantie des Art. 14 GG näher, BVerfG 24, 367 (389, 400 ff.)

648 Axer in: Epping/Hillgruber, Art. 14 GG, Rn. 19; Jarass in: Jarass/Pieroth, Art. 14 GG, Rn. 4; Papier in: Maunz/Dürig, Art. 14 GG, Rn. 11. 
nicht nur auf die Verfügungsgewalt über den jeweiligen Eigentumsgegenstand als solchen, sondern auch auf die Verfügungsfreiheit und Privatnutzen, folglich das Recht, den Gegenstand nach eigenem Belieben zu nutzen und andere aus der Nutzung auszuschließen. ${ }^{649}$ Dabei beschränkt sich der Schutz nur auf alle gegenwärtigen Rechtspositionen, zukünftige Vermögensaussichten, wie Gewinn- und Umsatzchancen, bloße Erwartungen sowie Hoffnungen werden nicht vom sachlichen Schutzbereich umfasst. ${ }^{650}$

Eine Verwehrung des Grundrechtsschutzes der Access-Provider aus Art. 14 GG kann sich nicht aus dem grundrechtlichen Konkurrenzverhältnis zu dem Eingriff in Art. 12 Abs. 1 GG ergeben. ${ }^{651}$ Es besteht nämlich keine allgemeingültige Regel, wonach Art. 12 und Art. 14 in einem Exklusivitätsverhältnis zueinander stehen. ${ }^{652}$ Zwar mag dies weitestgehend der Fall sein, da die Ausrichtung des staatlichen Eingriffscharakters im Schwerpunkt der Beschränkung einer bestimmten Grundrechtspositionen zuzurechnen ist, ${ }^{653}$ doch lässt sich ein solcher Schwerpunkt indes nicht ausmachen ist von einer Idealkonkurrenz der beiden Grundrechte auszugehen.654 Zwar betont das Bundesverfassungsgericht in ständiger Rechtsprechung die Formel, wonach Art. 12 GG „den Erwerb“ und Art. 14 GG „das Erworbene“" schütze ${ }^{655}$ und leitet dadurch die Annahme eines Exklusivitätsverhältnisses selbst ein; in dem Bereich, wo ersteres jedoch eine gewerbliche Tätigkeit ist, berührt eine Beschränkung des „Erwerbs“ zwangsläufig auch das Recht am eingerichteten und ausgeübten Gewerbebetrieb, was einen anerkannten Vermögenswert, also „das Erworbene“ im Sinne des Art. 14 GG darstellt, so dass ausnahmsweise überschneidend beide Schutzbereiche eröffnet seien. ${ }^{656}$

Regelmäßig wird dies im Bereich der Providerverantwortlichkeit angenommen. Diese machen ihre subjektiven Vermögenswerte gerade zur Grundlage ihrer be-

649 BVerfGE 31, 229 (222 f.).

650 St. Rspr. BVerfGE 28, 119 (142); BVerfGE 39, 210 (237); BVerfGE 51, 193 (221 f.); BVerfGE 74, 129 (148).

651 Ausdrücklich offengelassen, ob eine Berufsausübungsregelung den Schutzbereich von Art. 14 GG eröffnen kann, BVerfGE 177, 232 (248); BVerfGE 22, 380 (386); BVerfGE 30, 297 (334).

652 IE. Plewa, Die Verfassungsmäßigkeit der Indienstnahme Privater, 1978, S. 175.

653 Auf das Exklusivitätsverhältnis lässt der einprägsame Satz des BVerfG wonach Art. 12 GG ,den Erwerb“ und Art. 14 GG „das Erworbene“ schützt deuten, z.B. BVerfGE 30, 292 (335); BVerfGE 85, 360 (383).

654 Andeutend auch BVerfGE 50, 262 So Lerche in: FS für Schmidt, 2006, S. 377 (381); Scholz in: Maunz/Dürig, Art. 12 GG, Rn. 130; Jarass in: Jarass/Pieroth, Art. 12 GG, Rn. 3; Sieber/Nolde, Sperrverfügungen im Internet, 2008, S. 65.

655 Z.B. BVerfGE 30, 292 (335); BVerfGE 85, 360 (383).

656 So schon Leisner, JZ 1972, 33 (37), dem folgend Plewa, Die Verfassungsmäßigkeit der Indienstnahme Privater, 1978, S. 176, eingehend zum gesamten Komplex, Sieber/Nolde, Sperrverfügungen im Internet, 2008, S. 65 f. mwN. 
ruflichen Tätigkeit, so dass sich Beschränkungen ihrer beruflichen Ausgestaltung gleichzeitig auch mit Beschränkungen ihres Eigentumsrechts decken. ${ }^{57}$ Bei gesetzlicher Inpflichtnahme von privaten Access-Providern ist somit die Eröffnung des Schutzbereiches nicht von vorneherein auszuschließen.

Inhaltlich liegen die Voraussetzung des Eingriffs in den Schutzbereichs des Art. 14 GG bei einer gesetzlichen Regelung zur Sperrung kinderpornographischer Webinhalte ebenfalls vor. Als Eingriff gilt eine Regelung nämlich dann, wenn diese direkt auf den Entzug oder die Beschränkung der geschützten Eigentumsposition gerichtet ist. Auch faktische und mittelbare Beeinträchtigungen stellen einen Eingriff dar, soweit ihre Intensität die freie „Auslebung“ der geschützten Eigentumsposition erheblich beeinträchtigt. ${ }^{658}$

Ein Eingriff in die Eigentumsgarantie des Art. 14 GG ist bei einer gesetzlichen Handlungsverpflichtung zur Vornahme von Sperrungen kinderpornographischer Webseiten gegeben. Dadurch werden diese faktisch gezwungen technische Einrichtungen zur Umsetzung der gesetzlichen Verpflichtung vorzuhalten, eine etwaig erforderliche Infrastruktur zu errichten und eigene Finanzmittel aufzuwenden. Sind Einrichtungen beziehungswiese Vorkehrungen bereits vorhanden, müssen sie nach den gesetzlichen Vorgaben entsprechend eingesetzt werden. Die gesetzliche Verpflichtung schränkt die Access-Provider damit unmittelbar in der Verfügungsgewalt über die Kommunikationsstrukturen ein. ${ }^{659}$ Access-Providern wird gleichzeitig auch ein besonderer Einsatz ihres Eigentums im Hinblick auf die Gefahrenabwehr abverlangt, was eine Auslebung der grundrechtlich garantieren Position beeinträchtigt. ${ }^{660}$

\section{Verfassungsrechtliche Rechtfertigung - Speziell Verbältnismäßigkeit im engeren Sin- ne/Angemessenbeit}

Die allgemeinen Voraussetzungen an die verfassungsrechtliche Rechtfertigung des Eingriffs liegen auch im Rahmen des Art. 14 GG vor. Entsprechend den obigen Ausführungen verfolgt der Gesetzgeber mit der Sperrverpflichtung einen legitimen Zweck, der geeignet und erforderlich ist das Ziel eines effektiven Jugend-

657 Breitfeld, Berufsfreiheit und Eigentumsgarantie, 1992, S. 30, dem folgend Degen, Freiwillige Selbstkontrolle, 2007, S. 294; in die Richtung auch Sieber/Nolde, Sperrverfügungen im Internet, 2008, S. 65.

658 Jarass in: Jarass/Pieroth, Art. 14 GG, Rn. 29 ff.; differenzierter mit systematischer Darstellung des wandelnden Eingriffsbegriffs, Papier in: Maunz/Dürig, Art. 14 GG, Rn. 355 ff.

659 Degen, Freiwillige Selbstkontrolle, 2007, S. 294; Sieber/Nolde, Sperrverfügungen im Internet, 2008, S. 65; dem folgend Kabl, SächsVBl. 2010, 180.

660 Sieber/Nolde, Sperrverfügungen im Internet, 2008, S. 65; Degen, Freiwillige Selbstkontrolle, 2007, S. 294. 
schutzes und der Aufrechterhaltung der Sicherheit und Ordnung zu gewährleisten. ${ }^{661}$

Letztlich können sich damit nur hinsichtlich der Verhältnismäßigkeit im engeren Sinne spezifische Unterschiede zur Rechtfertigung des Eingriffs ergeben, die auf den verfassungsrechtlichen Unterschieden der Grundrechte untereinander gründen. Die speziellen Anforderungen an die verfassungsmäßige Rechtfertigung des Eingriffs in das Eigentumsrecht richten sich nach der Einordnung der Regelung in den Kontext der möglichen Eigentumsbeschränkungen. Danach steht die spezifische Rechtfertigung in Abhängigkeit dazu, ob aus der jeweiligen Regelung eine Inhalts- und Schrankenbestimmung gemäß Art. 14 Abs. 1 GG oder eine Enteignung nach Art. 14. Abs. 3 GG zu folgern ist.

Eine Inhalts- und Schrankenbestimmung ist dann anzunehmen, wenn es sich um eine abstrakt-generelle Festlegung von Rechten und Pflichten handelt, die grundrechtliche geschützte Eigentumspositionen betreffen. ${ }^{662}$ Das Wesensmerkmal einer Enteignung ist in Abgrenzung dazu, eine konkret-individuelle, mithin final ausgerichtete Regelung, die staatlichen Zugriff auf das Eigentum des Einzelnen, der auf die vollständige oder teilweise Entziehung konkreter subjektiver Rechtspositionen gerichtet ist, erlaubt. 663

In Übertragung der Abgrenzungsmerkmale stellt eine gesetzliche Sperrverpflichtung demnach eine Inhalts- und Schrankenbestimmung dar. Sie ist eben nicht darauf gerichtet konkret und individuell über Art. 14 Abs. 1 GG geschützte Rechtspositionen vollständig oder teilweise zu entziehen, um eine bestimmter öffentliche Aufgaben zu erfüllen, vielmehr beschränkt die Regelung generell und abstrakt die Nutzungsmöglichkeiten der einzusetzenden Sachwerte der verpflichteten Provider und gestaltet diese im Rahmen eines öffentlich-rechtlichen Gefah-

661 Folglich kann auf eine wiederholende Ausführung verzichtet werden. Die oben herausgearbeiteten Voraussetzungen gelten bei sämtlichen über die Berufsfreiheit hinaus tangierten Grundrechtspositionen entsprechend.

662 BVerfGE 52, 1 (27); BVerfGE 58, 137 (144); BVerfGE 72, 66 (76).

663 Zur Abgrenzung zwischen Enteignung und Inhalts- und Schrankenbestimmung im Wandel der Rechtsprechung umfassend Papier in: Maunz/Dürig, Art. 14 GG, Rn. 523 ff.; Wendt in: Sachs, Art. 14 GG, Rn. 186; Burgi, NVwZ 1994, 527; Zur Abgrenzung der Rechtsprechung im Einzelnen: BVerfGE 100, 226. Eine Abgrenzung nach „Intensität“ oder danach, ob dem Verpflichteten ein besonderes „Sonderopfer“ abverlangt werden, wie die Rspr. früher als Abgrenzungsmerkmale zur Hilfe nahm, ist heute obsolet. Durch die strikte Trennung von abstrakt-generellen und konkret-individueller Ausrichtung, können befürchtete Vermischung vermeiden werden. Inhalts-und Schrankenbestimmungen stehen demnach im Aliudverhältnis. Daraus folgt auch, dass aus einer abstrakt-generellen Inhalts- und Schrankenbestimmung, sei sie noch so intensiv, als sie in ihrer Wirkung einer Enteignung nahekommt, nicht als solche gewertet werden kann, so begründet durch BVerfGE 5, 300 (330 ff.) fortgeführt in ständ. Rspr.; zum „Paradigmenwechsel“, Depenheuer in: v. Mangoldt/Klein/Starck, Art. 14 GG, Rn. 198. 
renabwehrauftrages neu aus. ${ }^{664}$ Auf der Rechtfertigungsebene folgt aus dieser Einordnung entsprechend Art. 14 Abs. 1 Satz 2 GG eine grundsätzliche Duldungspflicht der Eigentumsbeschränkung, soweit die Inhalts- und Schrankenbestimmung auf einem verfassungsmäßigen Gesetz beruht. Im Spannungsverhältnis zwischen der Beschränkung des Eigentums durch den Staat und dem Eigentumsrecht des Grundrechtsträgers, gibt der Verfassungsgeber die Gewichtung der tangierten Belange folglich selbst vor, in dem er explizit in Art. 14 Abs. 2 GG herausstellt, dass „Eigentum verpflichtet“ und sein „Gebrauch zugleich dem Wohle der Allgemeinheit" dienen soll. Daraus folgt, dass über eine zulässige Inhalts- und Schrankenbestimmung eine verstärkte Pflicht des Einzelnen in Hinblick auf die Einsetzung seiner Vermögenswerte zu Gemeinwohlzwecken zu erwarten ist. Einschränkungen des Eigentumsrechts sind demnach grundsätzlich hinzunehmen und die Vermögenswerte am Wohle der Allgemeinheit auszurichten. 665 Dem Gesetzgeber wird dadurch gestattet auch strak eigentumsbeschränkende Maßnahmen, die er im öffentlichen Interesse für geboten hält, regelmäßig durchzusetzen.

Der Gedanke dieser verstärkten Pflichtigkeit kann aber nicht jede Totalbegrenzung des Eigentums legitimieren. Gleichzeitig kommt durch die Hervorhebung der Sozialpflichtigkeit des Eigentums nämlich auch zum Ausdruck, dass der Eigentumsgebrauch nicht „ausschließlich“, sondern „zugleich“ dem Gemeinwohl dienen soll. 606 Der Staat ist auch im Bereich der vermögenswerten Rechte letztlich verpflichtet „die Belange des betroffenen Eigentümers mit denen der Allgemeinheit in einen gerechten Ausgleich zu bringen und einseitige Belastungen zu vermeiden." ${ }^{667}$ Ausnahmsweise kann deshalb auch bei schwerwiegenden und unzumutbaren Eingriffen in Art. 14 Abs. 1 GG eine Ausnahme von der grundsätzlich hinzunehmenden Beschränkung der Vermögenspositionen folgern und zu einer Kompensation über einen finanziellen Ausgleich verpflichten. ${ }^{668}$

In Übereinstimmung zu dem bei der Beschränkung der Berufsfreiheit herausgearbeiteten, muss auch die Einschränkung des Eigentumsrechts grundsätzlich ohne staatlichen Erstattungsanspruch hinzunehmen sein, wenn Aspekte des Ge-

664 IE. ebenso Dörr, NJW 1988, 1049 (1051); Sieber/Nolde, Sperrverfügungen im Internet, 2008, S. 64; Braun, Die Finanzierung polizeilicher Aufgabenwahrnehmung, 2009, S. 364.

665 BVerfGE 50, 290 (339); BVerfGE 79, 292 (303); BVerfGE 81, 202 (208).

666 BVerfGE 58, 137 (147); BVerfGE 100, 226; Papier in: Maunz/Dürig, Art. 14 GG, Rn. 378c; Axer in: Epping/Hillgruber, Art. 14 GG, Rn. 104; eingehend Schmidt-Preuß, Die verfassungsrechtlichen Anforderungen an die Entschädigung, S. 15, Kurzgutachten i. A. v. Bitkom, abrufbar unter:

http://www.sfu.ca/cprost/prepaid/relateddocs/Germany/Schmidt-

PreuB_and_German_Constitution.pdf (zuletzt abgerufen 20.5.2012).

667 BVerfGE 58, 137 (150).

668 So genannte ausgleichspflichtige Inhalts- und Schrankenbestimmung, begründet von BVerfGE 58, 137 (150); seither ständ. Rspr. u.a. BVerfGE 100, 226; BVerwGE 84, 361 (368). 
meinwohls die Beeinträchtigung der Grundrechtsträgers im Verhältnis erlauben. Dies hebt der Gesetzgeber bei Art. 14 Abs. 1 GG sogar explizit hervor. Soweit die Beschränkung jedoch zu einer ausnahmsweise anzunehmenden unzumutbaren Belastung der eigentumsrechtlichen Grundrechtsposition führt, ist auch hierbei ein angemessener Ausgleich als Kompensation zu fordern. Letztlich sind hier die gleichen Erwägungen anzustellen. Nur über eine marktanalytische Betrachtung kann verbindlich festgestellt werden, welcher Provider durch die Sperrmaßnahme so wesentlich beeinträchtigt ist, dass im infolge der finanziellen Bereitstellungsund Pflegelast der Infrastruktur, die Nutzung seiner Kommunikationsnetze im eigentlichen Sinn nicht mehr zuzumuten ist. Eine Auflösung zu Gunsten einer bestimmten Grundrechtsposition muss hier nicht aufgelöst werden, soweit der Gesetzgeber sich der kompensatorischen Lösung annimmt. Durch die gleichzeitig finanzielle Entlassung für die ausnahmsweise staatliche Belastung der AccessProvider folgen.

\section{Ergebnis: Eigentumsfreibeit}

Gesetzliche Sperrverpflichtungen von Access-Providern von kinderpornographischen Internetinhalten stellen eine eigentumsrelevante Maßnahme im Sinne des Art. 14 Abs. 1 GG dar. Die Verpflichtung zur Sperrung ist gleichzeitig als Inhaltsund Schrankenbestimmung auszulegen. Verfassungsrechtlich gerechtfertigt ist die Beschränkung des Eigentumsrechts in Korrespondenz zum Eingriff in Art. 12 GG, soweit der Gesetzgeber eine angemessene Entschädigung für die bei der Inanspruchnahme anfallenden Kosten normiert. Sollte der Gesetzgeber dem Ausgleichsbedürfnis nachkommen, wird die Regelung in diesem Punkt verfassungsrechtlich nicht angreifbar sein.

III. Kommunikationsgrundrechte des Art. 5 Abs. 1: Meinungs- und Pressefreiheit Obgleich der Schutzbereich der Meinungs- sowie Pressefreiheit weit auszulegen ist, ${ }^{669}$ ist dieser im Falle einer gesetzlichen Sperrverpflichtung gegenüber AccessProvidern nicht eröffnet. Die Tätigkeit der Access-Provider beruht auf einer inhaltsunabhängigen Weiterleitung der Daten. Damit vermitteln die Access-Provider lediglich den Zugang zu Inhalten Dritter und verbreiten keine eignen Meinungen. ${ }^{670} \mathrm{Um}$ Wertungswidersprüche zu vermeiden, muss in Korrespondenz zur Herleitung der Nichtstörereigenschaft der Access-Provider auch bezüglich der

669 Zur Meinungsfreiheit, BVerfGE 61, 1 (9); BVerfGE 71, 162 (179); BVerfGE85, 1 (15); BVerfGE 90, 241 (247); zur Pressefreiheit, BVerfGE 10, 118 (112); BVerfGE 12, 205 (260); BVerfGE 20, 162 (176).

670 So auch u.a Billmeier, Die Düsseldorfer Sperrverfügungen, 2007, S. 261; Sieber/Nolde, Sperrverfügungen im Internet, 2008, S. 66; Kabl, SächsVBl 2010, 180 (185); Spindler/Volkmann, K\&R 2002, 398 (406 f.); Degen, Freiwillige Selbstkontrolle, 2007, S. 274. 
Meinungs- und Pressefreiheit der gleiche Maßstab angelegt werden. Allein das Kommunikationsnetz, das faktisch die Verbindung zwischen Inhalten und Nutzern bietet, stellt keinen hinreichenden Zurechnungsgrund für die durchgeleiteten Inhalte dar. Eine Berufung auf die Meinungsfreiheit ist Access-Providern insoweit verwehrt.

Innerhalb der Kommunikationsgrundrechte ist in Bezug auf die AccessProvider auch nicht die Pressefreiheit des Art. 5 Abs. 1 Satz 2, Var. 1 GG tangiert. 671 Zwar fällt unter den verfassungsrechtlichen Schutz der Presse jede Tätigkeit, die mit Presse, also zur Verbreitung geeigneten und bestimmten Druckerzeugnissen ${ }^{672}$ in Zusammenhang steht und jedwedes mit der Ausübung der Pressetätigkeit in Verbindung stehendes Handeln. ${ }^{673}$ Jedoch wird, um den verfassungsrechtlichen Schutz nicht über Gebühr auszuweiten, der Schutzbereich darauf beschränkt, dass nur diejenigen Betätigungsfelder geschützt sind, die notwendige Bedingung des Funktionierens einer freien Presse sind. ${ }^{674}$ Presseexterne inhaltsunabhängige Tätigkeiten unterfallen daher nur ausnahmsweise einem grundrechtlichen Schutz der Presse, soweit sie eine unmittelbare Eingliederung in das Pressegeschehen erfahren und damit „typischerweise pressebezogen“ sind.675

Teilweise wird versucht über diese Rechtsprechung ${ }^{676}$ eine Vergleichbarkeit zur Tätigkeit der Access-Provider zu begründen und diese als externe Hilfstätigkeit in den Schutzumfang des Art. 5 Abs. 1 Satz 1, Var. 2 GG einzugliedern. ${ }^{677}$ Danach liege eine Vergleichbarkeit vor, da die „publizistische Leistungsfähigkeit des Internets" erst über die Access-Provider funktionieren kann, da die Anbieter von derartigen Inhalten sich „darauf verlassen können“, dass die Access-Provider ihnen die notwendige Infrastruktur anbieten um ihre Inhalte zu verbreiten. „Schwächt der Staat diese Infrastruktur, hat das Auswirkungen auf sämtliche Anbieter von Inhalten im Internet". ${ }^{\text {" } 78}$

IE. Spindler/Volkmann, K\&R 2002, 398 (406); Sieber/Nolde, Sperrverfügungen im Internet, 2008, S. 67; Heuner in: Taeger/Wiebe, Inside the cloud, 2009, S. 107 (110); Fiedler, Meinungsfreiheit in der vernetzten Welt, 2002, S. 45.

672 So BVerfGE 95, 28 (35); Zum Begriff der „Presse“ Starck in: v. Mangoldt/Klein/Starck, Art. 5 GG, Rn. 59 mwN; Jarass in: Jarass/Pieroth, Art. 5 GG, Rn. 25; Schulze-Fielitz in: Dreier, Art. 5 GG, Rn. 89 .

673 BVerfGE 10, 118 (112); BVerfGE 12, 205 (260); BVerfGE 20, 162 (176).

674 BVerfGE 66, 116 (134); BVerfGE 77, 346 (354).

675 So BVerfGE 77, 346; Schulze-Fielitz in: Dreier, Art. 5 GG, Rn. 96; Wendt in: v. Münch/Kunig, Art. 5 GG, Rn. 33; ausführlich Löffler in: Löffler, Handbuch des Presserechts, 2005, Kap. 8, Rn. $8 \mathrm{ff}$.

676 BVerfGE 77, $346 \mathrm{ff}$.

677 So vor allem Engel, MMR- Beil. 4/2003, 1 (20); iE. auch Stadler, Haftung für Informationen im Internet, 2005, S. $121 \mathrm{f}$.

678 So ausdrücklich Engel, MMR- Beil. 4/2003, 1 (20). 
Bei näherer Betrachtung kann der angeführten Ansicht aber nicht zugestimmt werden. Zunächst liefert die Auffassung keine hinreichende Begründung für die Vergleichbarkeit der Sachverhalte, sondern bemüht sich lediglich eines Hinweises auf die Notwendigkeit der vor staatlichen Eingriffen freizuhaltenden Infrastrukturbereithaltung. Letztlich leitet die Meinung eine Vergleichbarkeit allein aus einem kausalen Beitrag der Access-Provider zur Möglichkeit der Verbreitung von Onlinepresseerzeugnissen her, was zwangsläufig zu einem uferlosen Verfassungsschutz führen würde. Zuzustimmen ist der Ansicht aber insofern, als die Onlinepresse zu ihrer Verbreitung tatsächlich auf die Infrastruktur der Provider angewiesen ist; jedoch vermitteln die Access-Provider nicht nur regelmäßig Zugang zu den in Frage stehenden Presseinhalten, sondern gerade zu vielen verschiedenen Inhalten, die völlig losgelöst vom Pressebegriff an den Nutzer gelangen. ${ }^{679}$ Diese Ausgangssituation unterscheidet sich entscheidend von derjenigen, die ausschlaggebend für die Zuordnung der Tätigkeit zur Pressefreiheit war. ${ }^{680}$ Access-Providern fehlt es an einer unmittelbaren Eingliederung in die presseexterne Berufsstruktur. Auch betont das Bundesverfassungsgericht ausdrücklich, dass die Eingliederung einer inhaltsunabhängigen presseexternen Struktur nur in Ausnahmefällen den Schutzbereich berührt. ${ }^{681}$ Diese Ausnahmesituation liegt bei der Tätigkeit der Access-Provider nicht vor. Sie werden bereits hinreichend über Grundrechte abgesichert, die an der Bereitstellung der technisch-kommunikativen Datenstruktur ausgerichtet sind. Ein über Art. 12 GG sowie Art. 14 GG hinausgehe ist folglich nicht notwendig. ${ }^{682}$

Überdies ist der Ansicht auch deshalb nicht zuzustimmen, da sie über die mangelnde Vergleichbarkeit hinaus auch gleichzeitig einen verfassungsrechtlichen Schutz von onlineverbreiteter Presse voraussetzt, ohne diesen zu hinterfragen. Dieses ist aber nicht ohne weiteres möglich, zumal schon die Definition des Pressebegriffs eigentlich ein „Druckerzeugnis“, also eine körperlich fixierte Materie voraussetzt. ${ }^{683}$ Die Feststellung, dass die Ansicht ohne Problematisierung der Frage von einer Anwendbarkeit ausgeht, zeigt die mangelnde Substanz der Übertragung und befürwortet eine grundsätzliche Abkehr von der Schutzbereichseröffnung der Pressefreiheit bei Access-Providern. Zusammenfassend ist demnach

679 Ausdrücklich Heuner in: Taeger/Wiebe, Inside the cloud, 2009, S. 107 (110).

680 Sieber/Nolde, Sperrverfügungen im Internet, 2008, S. 68 ff.; Heuner in: Taeger/Wiebe, Inside the cloud, 2009, S. 107 (110).

681 BVerfGE 77, 346 (354).

682 Sieber/Nolde, Sperrverfügungen im Internet, 2008, S. 68 ff.; Heuner in: Taeger/Wiebe, Inside the cloud, 2009, S. 107 (110), Fiedler, Meinungsfreiheit in einer vernetzten Welt, 2002, S. 173; in die Richtung auch schon Spindler/Hoffmann, K\&R 2002, 398 (406 f.), jedoch differenzierter und für presseinterne Tätigkeit den Schutzbereich eröffnend.

683 Grds. von einer Körperlichkeit ausgehend und demnach nicht auf Onlinepresse anwendbar: Clemens in: Umbach/Clemens, Art. 5 GG, Rn. 408; Schultze-Fielitzin: Dreier, Art. 5 GG, Rn. 93. 
festzustellen, dass einer gesetzlichen Sperrverpflichtung nicht die Kommunikationsgrundrechte der Access-Provider entgegenstehen.

IV. Wissenschaftsfreiheit Art. 5 Abs. 3 Satz 1, Var. 2 GG

\section{Eingriff in den Scbutzbereich}

Durch eine gesetzliche Sperrverpflichtung sämtlicher Zugangsdiensteanbieter zur Sperrung kinderpornographischer Webinhalte kommt auch ein Eingriff in den Schutzbereich der Wissenschaftsfreiheit Art. 5 Abs. 3 Satz 1, Var. 2 GG in Betracht.

Der Schutzbereich der Wissenschaftsfreiheit umfasst ,jede wissenschaftliche Tätigkeit die ihrem Inhalt nach als planmäßiger Versuch zur Ermittlung der Wahrheit anzusehen ist. ${ }^{64}$ Geschützt sind die auf „wissenschaftlicher Eigengesetzlichkeit beruhenden Prozesse, Verhaltensweisen und Entscheidungen“, welche bei der „Suche nach der Erkenntnis für die Deutung und Weitergabe auschlaggebend sind" ${ }^{\text {" }}{ }^{885}$ In personeller Hinsicht unterfallen dem Schutzbereich alle an der Erkenntnisfindung beteiligten Personen, wie Hochschullehrer, Studenten und auch Mitarbeiter, soweit sie in Ausübung ihrer funktionsspezifischen wissenschaftsbezogenen Tätigkeit agieren. ${ }^{686}$ Es handelt sich bei der Wissenschaftsfreiheit damit vordergründig um eine Gewährleistung eines subjektiv-rechtlichen Abwehrrechts von allen am Wahrheitsfindungsprozess beteiligten Personen.

Ein Eingriff in den Schutzbereich der Wissenschaftsfreiheit ist dann anzunehmen, wenn die Erkenntnisfindung durch staatliche Stellen eingeschränkt wird. Damit sich die Wissenschaft ungehindert an dem für sie kennzeichnenden Bemühen um Wahrheit ausrichten kann, ist sie zu einem von staatlicher Fremdbestimmung freien Bereich erklärt worden. ${ }^{67}$ Dieser wissenschaftliche Freiraum umfasst vordergründig die Grundlagen des Erkenntnisprozesses, also die „unbegrenzte Informationsfreiheit" des Forschers und weitet diesen Schutz sowohl auf Vorarbeiten, den eigentlichen Erkenntnisfindungsprozess, als auch auf forschungstypische Begleit- und Nacharbeiten aus. ${ }^{688}$

Soweit eine gesetzliche Sperrverpflichtung keine Beschränkung des personellen Anwendungsbereichs vorsieht, werden sämtliche Zugangsdiensteanbieter erfasst. Neben gewerblich tätigen Providern, deren berufliche Hauptstruktur auf die Erbringung der Zugangsdienstleistung ausgerichtet ist, können auch nicht kommerzielle Anbieter wie Forschungseinrichtungen, Schulen und Universitäten, zum

684

BVerfGE35, 79 (113); ausführliche Herleitung, Scholz in: Maunz/Dürig, Art. 5 Abs. 3 GG, Rn. 85 ff. mwN., speziell Rn. 101.

BVerfGE 35, 79 (112 f.); BVerfGE 47, 327 (367 f.); BVerfGE 111, 333 (354).

BVerfGE 90, 1 (12).

BVerfGE 35, 79 (112); BVerfGE 47, 327 (367 f.); BVerfGE 90, 1 (12).

Bizer, Forschungsfreiheit und informationelle Selbstbestimmung, 1992, S. 47, 106. 
Kreis der Verpflichteten gehören. Vermehrt bieten aber auch Forschungseinrichtungen ihren Angehörigen einen individuellen Zugang zum Internet und treten damit vergleichsweise wie ein kommerzieller Anbieter in die Funktion eines Access-Providers ein. Gegenüber diesen Forschungsinstitutionen liegt ein Eingriff in die Wissenschaftsfreiheit vor. Durch die Vornahme des gesetzlich angeordneten Sperrmachanimus kann der internetbasierte Zugang zur Primärquellen wesentlich eingeschränkt sein. ${ }^{689}$ Die ,ungehinderte Informationsbeschaffung“, welche das wesentlichste Merkmal der Ausübung der Wissenschaftsfreiheit darstellt, wäre in einem solchen Fall wesentlich beeinträchtigt. Gerade in der heutigen Zeit ist das Internet aber ein unverzichtbarer Träger von Informationen und ist damit nicht nur für Private, sondern gerade für die Wissenschaft ein essentieller Bestandteil der Wahrheitsfindung.

\section{Verfassungsrechtliche Rechtfertigung - Speriell Verbältnismäßigkeit im engeren Sin- ne/Angemessenheit}

Voraussetzung für die verfassungsrechtliche Rechtfertigung des Eingriffs ist zunächst, dass dem Staat grundsätzlich die Möglichkeit zuzusprechen sei, die Verfolgung bestimmter legislatorischer Ziele über die Einschränkung der Wissenschaftsfreiheit zu erreichen. Betrachtet man hierfür die Systematik des Art. 5 Abs. 3 GG, so zeigt sich, dass die Wissenschaftsfreiheit ein schrankenlos gewährleistetes Grundrecht darstellt. ${ }^{690}$ Eine beispielsweise Art. 12 GG ähnliche Formulierung, durch welche die Einschränkung bereits "durch oder aufgrund eines Gesetzes“ erfolgen kann, enthält Art. 5 Abs. 3 GG nicht. Vielmehr betont der Wortlaut des Art. 5 Abs. 3 Satz 1 explizit: Wissenschaft sei frei.

Aus dieser verfassungsrechtlichen Grundwertung ist jedoch nicht grundsätzlich zu folgern, dass der Staat keine verfassungskonforme Einschränkung der Wissenschaftsfreiheit vornehmen kann. Die Annahme einer verfassungsmäßigen Rechtfertigung ist dadurch begründet, dass grundsätzlich ein Spannungsverhältnis zwischen notwendigen staatlichen Maßnahmen einerseits und subjektiven Freiheitsrechten des Bürgers andererseits entstehen kann. Es ist nicht auszuschließen, dass die wissenschaftliche Betätigung nie in einen Kollisionsfall zu Rechten anderer tritt, die der Staat durch entsprechende Maßnahmen relativieren kann. Beispielsweise liegt ein Spannungsverhältnis vor, soweit Meinungsäußerungen oder Bilder zum wissenschaftlichen Nachweis einer bestimmten Erkenntnis veröffentlicht werden. Augenscheinlich kann die Wissenschaftsfreiheit dann in einen Konflikt mit Rechten Dritter, wie der Meinungs- und Kunstfreiheit, treten. Deshalb muss es auch im Rahmen so genannter ,vorbehaltslos gewährleisteter Grundrech-

689 Ebenso Sieber/Nolde, Sperrverfügungen im Internet, 2008, S. 71; Kabl, SächsVBl. 2010, 180 (185).

690 Grundlegend BVerfGE 30, 173 (193), zur Kunstfreiheit, die ebenfalls ein schrankenlos gewährleistetes Grundrecht darstellt. Ausführlich Scholz in: Maunz/Dürig, Art. 5 Abs. 3 GG, Rn. 11 sowie 51. 
te" möglich sein, eine Einschränkung der Grundrechtsposition vorzunehmen um die berührten Belange Dritter zu verfolgen. Hierbei steht es dem Staat zu, über so genanntes kollidierendes Verfassungsrecht, also andere Rechte mit Verfassungsrang, die grundsätzlich schrankenlos gewährleisteten Grundrechte, einzuschränken. ${ }^{611}$ Das Bundesverfassungsgericht führt zur ebenfalls schrankenlos gewährleisteten Kunstfreiheit in diesem Zusammenhang aus: „Da die Kunstfreiheit keinen Vorbehalt für den einfachen Gesetzgeber enthält, darf sie weder durch die allgemeine Rechtsordnung noch durch eine unbestimmte Klausel relativiert werden, welche ohne verfassungsrechtlichen Ansatzpunkt und ohne ausreichende rechtsstaatliche Sicherung auf eine Gefährdung der für den Bestand der staatlichen Gemeinschaft notwendigen Güter abhebt. Vielmehr ist ein im Rahmen der Kunstfreiheitsgarantie zu berücksichtigender Konflikt nach Maßgabe der grundgesetzlichen Wertordnung und unter Berücksichtigung der Einheit dieses grundlegenden Wertsystems durch Verfassungsauslegung zu lösen“". ${ }^{692}$ Soweit das einschränkende Gesetz demnach zur Verfolgung eines anderen verfassungsrechtlich legitimierten Gutes eingesetzt wird, dann kann es die Beschränkung der Wissenschaftsfreiheit im Grundsatz rechtfertigen.

Eine gesetzliche Handlungsverpflichtung zur Vornahme von Sperrungen kinderpornographischer Webinhalte stellt eine Konkretisierung des Jugendschutzes sowie der Gefahrenabwehr im Internet dar. Wie bereits hergeleitet, genießen diese Werte selbst Verfassungsrang. Folglich ist die staatliche Verfolgung dieser Zwecke zumindest abstrakt in der Lage die Wissenschaft als schranklos gewährleistetes Grundrecht einzuschränken.

Materiell ist neben der notwendigen Geeignetheit und Erforderlichkeit der Maßnahme, ${ }^{693}$ bei der Einschränkung über kollidierendes Verfassungsrecht ebenfalls eine Angemessenheitsprüfung vorzunehmen, die auf einer Abwägung zwischen der Einschränkung des vorbehaltlos gewährleisteten Verfassungsguts und dem staatlich verfolgten Zweck, seiner Dringlichkeit sowie Zumutbarkeit der Beeinträchtigung, basiert. ${ }^{694}$

BVerfGE 33, 52 (71); BVerfGE 30, 173 (193); Pernice in: Dreier, Art. 5 GG, Rn. 39; Jarass in: Jarass/Pieroth, Art. 5 GG, Rn. 131. Grundsätzlich ist hier eine Schrankenübertragung der Schranken aus Art. 5 Abs. 2 GG bzw. Art. 2 Abs. 1 GG abzulehnen hierzu BVerfGE 47, 327 (369); ausführlich Scholz in: Maunz/Dürig, Art. 5 GG, Rn. 184 mwN.; Bethge in: Sachs, Art. 5 GG, Rn. 223.

692 Kabl, SächsVBl. 2010, 180 (185).

${ }^{692}$ BVerfGE 30, 173 (193).

693 Auch an dieser Stelle kann auf die allgemeingültige Prüfung innerhalb der Verletzung der Berufsfreiheit verwiesen werden. Zum legitimen Ziel, Geeignetheit und Erforderlichkeit der gesetzlichen Sperrverpflichtung oben 3. Teil B. I. 2.

694 BVerfGE 47, 327 (369 f.); BVerfGE 57, 70 (99); Oppermann in: Isensee/Kirchhof, Hdb. StaatsR, 2001, Bd. 6, \145, Rn. 27; Jarass in: Jarass/Pieroth Art. 5 GG, Rn. 131. 
a) Abwägungsrelevanter Belang: Abstrakte Wertigkeit

Die Wissenschaftsfreiheit ist schon aufgrund der Schrankendogmatik ein Grundrecht mit einem besonderen Schutzanspruch. Der Verfassungsgeber unterwirft ihre Beschränkungen einem verfassungsimmanenten Schrankenvorbehalt. Dabei ist aus der verfassungsrechtlichen Schrankensystematik allein noch nicht zu folgern, dass im Spannungsverhältnis mit anderen mit Verfassungsrang ausgestalteten Rechten, der Wissenschaftsfreiheit schlechthin Vorrang einzuräumen ist. ${ }^{695}$ Vielmehr bedarf es auch in diesem Fall einer Abwägung, die dem Gewicht der Wissenschaftsfreiheit einerseits hinreichend Rechnung trägt und andererseits das mit dem gesetzgeberischen Mittel verfolgte Ziel betrachtet. ${ }^{696}$ Im Idealfall kann der Gesetzgeber dann eine Regelung schaffen, die zwischen den mit einander kollidierenden Verfassungsgütern eine „praktische Konkordanz“ hergestellt, bei welcher ein schonender Ausgleich geschaffen wird, ohne dass eine verfassungsrechtliche Gewährleistung gegenüber der anderen ganz zurücktreten muss. ${ }^{697}$

Im vorliegenden Fall tritt die abstrakt hoch zu veranschlagende Wissenschaftsfreiheit in Kollision mit einer jugendschutz- sowie gefahrenabwehrrechtlich motivierten staatlichen Maßnahme. Auch die kollidierende Maßnahme verfolgt insofern in ihrer abstrakten Wertigkeit besonders hohe und schützenswerte Rechtsgüter. Obgleich der Jugendschutz anders als die Wissenschaftsfreiheit nicht ausdrücklich als eigenes Grundrecht konzipiert ist, leitet sich seine hohe Rangordnung an vielen Stellen der Verfassung her. So ist der Jugendschutz beispielsweise in Art. 5 Abs. 2 GG normiert und in der Lage die demokratisch wichtigen Kommunikationsrechte einzuschränken. Daneben ist der Jugendschutz anerkannterweise aus Art. 2 Abs. 1 GG i.V. m. Art. 1 Abs. 1 GG indes auch als ein eigenständiges Schutzgut mit Verfassungsrang anerkannt. Der Gesetzgeber spricht sich für einen umfassenden Schutz des Kindes aus und betont dabei dass es sich um ein besonderes Gemeinschaftsanliegen handelt. ${ }^{698}$

Auch die mit dem Sperransatz verfolgte Sicherheitsgewährung wird als hohes Gemeinschaftsgut verstanden und darf muss hinreichende Berücksichtigung erfahren. Bezüglich ihrer abstrakten Wertungen sind die tangierten Belange insofern nahezu identisch. Eine Positionierung zugunsten des Einen oder Anderen verbietet sich.

695 BVerfGE 47, 327 (369).

696 Scholz in: Maunz/Dürig, Art. 5 Abs. 3 GG, Rn. 65.

697 Begründet von Hesse, Grundzüge des Verfassungsrechts der Bundesrepublik Deutschland, 1999, Rn. 72: zuvor schon Lerche, Übermaß und Verfassungsrecht, 1961, S. 51 ff., jedoch ohne dem Prinzip des ,angemessenen Ausgleichs der kollidierenden Verfassungsgüter einen eigenständigen Namen zu geben. Die Notwendigkeit eines schonenden Ausgleichs ist mittlerweile in ständ. Rspr. anerkannt, u.a. BVerfGE 41, 29 (51); BVerfGE 77, 240 (255); BVerfGE 81, 298 (308); BVerfGE 83, 130 (143).

698 BVerfGE 30, 336 (348) ; BVerfGE 77, 346 (356); BVerfGE 83, 130 (139). 
b) Abwägungsrelevanter Belang: Konkrete Wertigkeit

$\mathrm{Zu}$ beachten ist auf Seiten der Wissenschaft, dass die Informationsrecherche vor allem über das Internet zu einen unverzichtbaren Gut für die wissenschaftliche „Erkenntnisfindung“ geworden ist. Die Primärquellen dienen nicht nur als Informationsgarant für den Forschenden, sondern können auch zur Einsichtnahme, zum Nachweis oder als Gegenbeleg des wissenschaftlichen Diskurses für alle am Forschungsprozess beteiligten Personen fungieren. ${ }^{699}$ Insbesondere dem Internet ist es dabei immanent, dass es ein von Einzigartigkeit geprägtes, zusammenhängendes Geflecht, mit einer nahezu unfassbaren Breite an Informationen und möglichen Nachweisen auf wissenschaftliche Fragen bietet. Die über das Internet beziehbaren Informationen sind insbesondere dadurch gekennzeichnet, dass sie gleichzeitig aktuell wie historisch sein können, länderübergreifende Meinungen beherbergen und wandelbar in ihrem wissenschaftlichen Gehalt sind. Eben deshalb bietet das Internet ein unverwechselbares Wissenschaftsportal, das zum Gleichgewicht von Frage und Antwort, die für den wissenschaftlichen Diskurs unabdingbarer Bestandteil sind, beiträgt, wie keine andere denkbare Informationsquelle. Nur bei freier Überlassung der benötigten Informations- und Nachweisquellen ist gewährleistet, dass auch die Erkenntnisfindung letztlich den angestrebten forschungstechnischen Fortschritt voranbringt. ${ }^{700}$

Durch einen erfolgreich implizierten Sperrmechanismus wird dieses Gleichgewicht jedoch erheblich behindert. Technische Sperrmethoden, gleich welcher spezifischen Ausgestaltung, bewirken zumindest eine Zugrifferschwerung auf den Inhalt bestimmter Webseiten.

Dabei impliziert die Tatsache, dass sich hinter dem erschwerten Zugriff strafrechtlich verbotene Angebote befinden können, noch nicht allein, dass der Wissenschaftsfreiheit gegenüber der beabsichtigten Zugriffserschwerung ein geringeres Gewicht beizumessen ist. Eine derartige Annahme die Gefahr, dass die Anforderungen an die Rechtfertigung von höherrangigen Verfassungsrecht über einfach-gesetzliche Normen unterlaufen werden könnte. ${ }^{701}$ Dieses kann nicht staatliche Intention sein. Der Gesetzgeber hebt hier durch die Schrankensystematik bereits die konkrete Wertigkeit des Grundrechts selbst hervor. Dieses könnte durch die Übertragung einfach-gesetzlicher Anforderungen faktisch ausgehöhlt werden, so dass der rechtlichen Qualifikation der „verborgenen“ Information lediglich Indizwirkung zugesprochen kann und nicht allein auch schon eine ein-

699 In die Richtung Schnabel, Sperrungsverfügungen gegen Access-Provider, 2002, S. 58, abrufbar unter: http://www.eulisp.de/tl_files/eulisp\%20abschlussarbeiten/schnabel_christoph.pdf, (zuletzt abgerufen 20.5.2012); Kahl, SächsVBl. 2010, 180 (185), jedoch ohne die eigentliche Abwägung vorzunehmen.

700 Ausführlich zur Bedeutung des Internets auch im Rahmen der Wissenschaftsfreiheit Frey/Rudolph, Ausschussdrucksache 16 (9) 1546, S. 16.

701 BVerfGE 20, 56 (97); BVerfGE 30, 336 (347). 
deutige Tendenz für das Gewichtungsverhältnis der Maßnahmen untereinander zukommen kann. ${ }^{702}$ Entscheidend muss hier aber der Aspekt sein, dass es dem wissenschaftlichen Diskurs zugebilligt werden muss gesetzlich fragliche teilweise auch strafrechtlich verbotene Inhalte zur Erkenntnisfindung zu nutzen. Insbesondere die wissenschaftliche Arbeitsweise im kriminalitätsinternen Bereich lebt von der wissenschaftlichen Auswertung von Statistiken, dem Vergleich von Fallzahlen und der Interpretation von Fallbeispielen. Hierzu gehören notwendigerweise auch entsprechende Einsichtnahmen in strafrechtliche verbotene und rechtlich zu ahndende Angebote und Internetquellen.

Auf Seiten des gesetzlich verfolgten Zwecks ist ausschlaggebend, dass es sich bei den gesperrten Inhalten im Spezialfall der Zugriffsunterdrückung um Angebote handelt, die eine besondere Verwerflichkeit, ausgehend von ihrem enormen Gefährdungspotential, aufweisen. Jede weitere Visualisierung des kinderpornographischen Materials, sei sie wissenschaftlich motiviert oder rein von „Neugieraspekten“ getragen, bedingt eine erneute Stigmatisierung und Zurschaustellung der betroffenen kindlichen Protagonisten, die letztlich in der Verletzung sensibler Persönlichkeitsrechte der darstellten Kinder mündet. Nur unter Beachtung dessen könnte demnach auch kein Abwägungsergebnis zu Gunsten eines tangierten Belanges herbeizuführen sein.

\section{c) Abwägungsrelevanter Belang: Overblocking und Zweck-Mittel-Relation}

Demgegenüber sind jedoch die Folgen zu verdeutlichen, die eben aus der Ungenauigkeit der technischen Umsetzung der Sperrmechanismen herrühren: Durch die unterschiedliche Intensität der gewählten Sperrmethode auf die Erschwerung des Zugangs, ist es zum Teil unvermeidbar, dass durch die beabsichtige Sperrung eines bestimmten (kinderpornographischen) Webcontents, eine Vielzahl mit demselben Inhalt „technisch verwobener“ Angebote gleichzeitig einer Zugriffserschwerung unterfallen (Overblocking-Effect). ${ }^{703}$ Die inhaltliche Dimension dieser „zufällig“ mitgesperrten Inhalte kann völlig losgelöst von der kinderpornographischen Ausrichtung des beabsichtigt gesperrten Contents sein. Wenngleich bei der URL-Proxy-Filtermethode nur geringe Abweichungen bezüglich des Inhalts der Sperrung vorliegen, können infolge einer DNS-Sperrung oder einer IPSperrmethode viel größere Overblocking-Effekte entstehen, die ein unbestimmbares Ausmaß an unzugänglichen Webinhalten begründen. Durch das Overblocking ist schließlich nur mit erschwerten Mitteln analysierbar, welche Inhalte tatsächlich nur erschwert zu erreichen sind und wie ihr Gehalt bezüglich einer wissenschaftli-

702 In die Richtung, jedoch in Bezug auf die Informationsfreiheit, BVerfGE 27, 71 (83 f.); Neumann, Ordnungsrechtliche Sperrungsverfügungen und die Informationsfreiheit nach Art. 5 Abs. 1 S. 1 2. Alt. GG, abrufbar unter http://www.artikel5.de/artikel/sperrunginffreiheit.html (zuletzt abgerufen 20.5.2012).

703 Zum Overblocking oben 3. Teil B. I. 2. b) (bb) . 
chen Erkenntnisfindung einzuordnen ist. Die praktische Unkenntnis der Anzahl der unzugänglichen Quellen, sowie die Unkenntnis der ,verdeckten“ Inhalte wirkt sich enorm auf die ungestörte Informationsrecherche aus, die das grundlegende Element der Wissenschaftsfreiheit darstellt. Im Rahmen der geforderten ZweckMittel-Relation ist jedoch zu beachten, dass die Mitsperrung legaler Inhalte nicht nur Nebenfolge ist, sondern zwangsläufig mit der Art des gewählten gesetzgeberischen Mittels der Sperrmethode einhergeht: Grundsätzlich ist nach dem heutigen Stand der Technik keine Sperrmethode in der Lage die legalen von den illegalen Informationen zu filtern und nur den Zugriff auf die illegalen Teile einer Information, beziehungsweise schlicht illegale Webseiten, zu verbieten. Es handelt sich beim Overblocking damit nicht um eine bewusste staatliche Beschränkung, sondern um eine technisch nicht zu umgehende Problematik, die der Sperrung als solche immanent ist. Anders ausgelegt, gründet die enorme Beschränkung der Wissenschaftsfreiheit nicht auf einer legislatorischen, sondern genauer auf einer technischen Ungenauigkeit des Sperransatzes.

Demgegenüber muss beachtet werden, dass die mit der Sperrmaßnahme verbundenen negativen Auswirkungen auf die Wissenschaftsfreiheit bereits von Verfassungswegen auf ein Minimum zurückzuführen sind. Die Sperrung unterliegt einer Subsidiaritätspflicht und kommt nur ausnahmsweise in Betracht, wenn entsprechende Löschbemühungen scheitern. Damit ist der Anwendungsbereich, in welchen es überhaupt zum vermuteten Spannungsverhältnis kommt, relativ begrenzt.

d) Herstellung einer praktischen Konkordanz

Um das ausnahmsweise befürchtete verfassungsrechtliche Spannungsverhältnis zwischen der Möglichkeit staatlicher Herausnahme inkriminierter Inhalte im Internet und einer enormen Beschränkung der Wissenschaftsfreiheit zu lösen und die konkurrierenden Grundrechtspositionen in einen verfassungsmäßig schonenden Ausgleich zu bringen, lässt sich bereits über eine einfache Begrenzung des Adressatenkreises der gesetzlichen Sperrverpflichtung erreichen: Durch die Beschränkung des persönlichen Anwendungsbereichs auf kommerzielle AccessProvider, die keinem forschenden „Gewerbe“ zuzuordnen sind, würde der darstellte Konflikt zwischen den nicht punktuell wirkenden Sperrungen und der damit einhergehenden Gefahr eines massiven Overblockings und der Beeinträchtigung der Wissenschaftsfreiheit entgegengewirkt werden. ${ }^{704}$ In der Konsequenz

So auch die Beschränkung im Rahmen der Düsseldorfer Sperrverfügungen. Hier waren Forschungseinrichtungen explizit aus dem Adressatenbereich ausgeschlossen, Zusammenfassend Koreng, Zensur im Internet, 2010, S. 121, Mankowski, MMR 2002, 277; intensive Auseinandersetzung bei Billmeier, Die Düsseldorfer Sperrungsverfügung, 2007; beispielhaft: Verfügung der Bezirksregierung Düsseldorf v. 6.2.2002 gegen Oberon.net GmbH abrufbar unter: 
müsste der sensible Bereich der Wissenschaftsfreiheit aus den beeinträchtigten Grundrechtspositionen ausgeklammert werden und sich nicht gegenüber der gesetzgeberischen Schutzintention behaupten müssen. Diese Möglichkeit bietet insofern eine grundrechtsschonende Herstellung einer praktischen Konkordanz und würde dem Charakter und der hohen Wertigkeit der schrankenlosgewährleisteten Wissenschaftsfreiheit damit am nächsten kommen.

Nicht zu verwechseln ist die hier präferierte Möglichkeit eines Ausschlusses der Forschungseinrichtungen aus dem Adressatenkreis jedoch mit einer Beschränkung der Adressaten auf rein privat-rechtliche Einrichtungen. ${ }^{705}$ Eine diesbezügliche Begrenzung hätte in Bezug auf die notwendig vorzunehmende Abwägung der kollidierenden Verfassungsgüter keinen positiven Effekt. Denn nicht nur die öffentlich-rechtlichen Forschungseinrichtungen sind Grundrechtsträger der Wissenschaftsfreiheit. Auch privat-rechtliche Einrichtungen können sich auf die Wissenschaftsfreiheit berufen. Notwendig für einen verfassungsrechtlichen Schutz ist jedoch, dass organisatorisch sichergestellt ist, dass die Wissenschaft die nötigen Freiräume erhält und die wissenschaftliche Betätigung sich ungehindert ausweiten kann. ${ }^{706}$ Die Herausnahme der öffentlich-rechtlichen Forschungseinrichtungen würde zwar in Hinblick auf diese den obigen Konflikt entkräften, der Konflikt würde aber in gleicher Weise bei den verbleibenden Normadressaten bestehen bleiben.

Die Beschränkung auf rein privat-rechtliche Forschungseinrichtungen hätte daher nicht den gewünschten Effekt der Milderung. Überdies würde sie zu gleichheitswidrigen Zuständen führen. ${ }^{707}$ Die Beschränkung des Anwendungsbereichs auf privatrechtliche, und folglich die Ausklammerung des Anwendungsbereichs hinsichtlich öffentlicher Zugangsanbieter, würde eine verfassungsrechtliche Ungleichbehandlung darstellen, die im Sinne des allgemeinen Gleichheitsgrundsatzes aus Art. 3 GG nach der „Neuen Formel“708 nur über einen „sachlichen Grund“

http://www.artikel5.de/rohetexte/sperrverfueg.pdf S. 7 (zuletzt abgerufen 20.5.2012), wobei alle ergangenen Verfügungen im Wesentlichen wortgleich waren. Zur nachfolgenden Diskussion in der Rspr. VG Köln, MMR 2005, 399; OVG Münster, NJW 2003, 2183; VG Düsseldorf, CR $2005,891$.

705 So aber die anfängliche Präferenz des Gesetzgebers bei der Schaffung des Zugangserschwerungsgesetzes. Über $\int 8$ TMG-E sollte der persönliche Anwendungsbereich der Norm nur auf privat-rechtliche Provider beschränkt sein, BT-Drs. 16/12850, S. 6.

706 Classen, Wissenschaftsfreiheit, 1994, S. $150 \mathrm{ff}$.

707 So ausdrücklich Bitkom, Ausschussdrucksache 16 (9) 1538, S. 8.

708 Dazu Bitkom, Ausschussdrucksache 16 (9) 1538, S. 8. Im Gegensatz zur früher vertretenen Willkiurformel, die für die Verletzung des Gleichheitssatzes jeden vernünftigen, sich der Sache nach ergebenden Grund für die gesetzliche Differenzierung zuließ, BVerfGE 1, 14 (52), fordert die herrschende Neuen Formel für die Verletzung des Gleichheitssatz des Art. 3 GG das „eine Gruppe von Normadressaten im Vergleich zu anderen Normadressaten anders behandelt wird, 
verfassungsmäßig zu rechtfertigen wäre. ${ }^{709}$ Augenscheinlich ist jedoch kein sachlicher Grund ersichtlich, der für den Ausschluss des öffentlichen Adressaten herangezogen werden kann. In Anbetracht des Ziels des Gesetzes - eine Einschränkung der Verbreitung kinderpornographischer Inhalte im Internet - erscheint die Beschränkung auf rein privatrechtliche Anbieter sogar kontraproduktiv: Die Erreichung dieses Ziels würde dann praktisch durch den Gesetzgeber selbst konterkariert, wenn die Sperrverpflichtung lediglich einen eingeschränkten Adressatenkreis treffen soll. Denn je weniger tatsächliche Verpflichtungen zur Sperrung vorliegen, desto mehr kinderpornographische Inhalte bleiben weiter zur freien Verfügung im Netz. Die Einschränkung des Adressatenkreises ist daher nur dann verfassungsrechtlich hinnehmbar, wenngleich mit dieser eine erhebliche Verbesserung der eingeschränkten Grundrechtspositionen zu erwarten ist. ${ }^{710}$ Dies ist hier nur dann zu erreichen, wenn sämtliche Forschungseinrichtungen aus dem Adressatenkreis der gesetzlichen Sperrverpflichtung herausgenommen werden. Ein Eingriff in die Wissenschaftsfreiheit wäre damit nur über die zusätzlichen Voraussetzungen an die Beschränkung des Adressatenkreises verfassungsrechtlich angemessen und demnach gerechtfertigt.

\section{Ergebnis: Wissenschaftsfreiheit}

Die Wissenschaftsfreiheit des Art. 5 Abs. 3 Satz 1, Var. 2 GG wird durch eine gesetzliche Sperrverpflichtung eingeschränkt, soweit auch Forschungseinrichtungen, die eine dem Access-Providing verwandte Funktion wahrnehmen vom personellen Anwendungsbereich der Norm umfasst werden. Die Unzugänglichkeit verschiedener Primärquellen als Folge der technischen Sperrmethode führt zwangsläufig zu Beschränkungen der Informationsrecherche und damit auch zu Beeinträchtigungen des gesamten wissenschaftlichen Erkenntnisprozesses. Um die negativen Auswirkungen nicht über Gebühr zu strapazieren bietet sich eine Ausnahmeregelung für Forschungseinrichtungen an, die im Wesentlichen den Konflikt zwischen der Erreichung des Rechtsgüterschutzes durch die Herausnahme des kinderpornographischen Angebotes und der technischen Unzulänglichkeit dieser Methode insbesondere in Hinblick auf die damit verbundene Einschränkung der Wissenschaftsfreiheit verfassungsrechtlich ausgleicht. Allein die Beschränkung des Adressatenkreises auf privatrechtliche Access-Provider vermag den dargelegten Konflikt nicht zu lösen. Vielmehr bedarf es einer bereits im Wort-

\footnotetext{
obwohl zwischen beiden Gruppen keine Unterschiede von solcher Art und solchen Gewicht bestehen, dass sie die ungleiche Behandlung rechtfertigen könnten, BVerfGE 55, 72 (88); demnach ist die Neue Formel als Ausfluss des Verhältnismäßigkeitsgrundsatzes zu verstehen, der eine Abwägung der geschützten Interessen verlangt, Albers, JuS 2008, 945; Kischel in: Epping/Hillgruber, Art. 3 GG, Rn. 28.

709 BVerfGE 55, 72; BVerfGE 110, 141; Kischel in: Epping/Hillgruber, Art. 3 GG, Rn. 14 ff., 30.

710 So iE. auch Frey/Rudolph, Ausschussdrucksache 16 (9) 1546, S. 25.
} 
laut der Norm angelegten Ausnahme für sämtliche Forschungseinrichtungen. Soweit eine derartige Formulierung innerhalb der gesetzlichen Sperrverpflichtung besteht, ist die Regelung angemessen und im Hinblick auf den Eingriff in Art. 5 Abs. 3 GG verfassungsmäßig.

\section{Ergebnis: Tangierte Individualinteressen der Access-Provider}

Infolge einer gesetzlichen Inanspruchnahme von Access-Providern zur Sperrung kinderpornographischer Angebote im Internet werden grundrechtlich relevante Positionen der Provider tangiert. Die dem Gesetzgeber einzuräumende Einschätzungsprärogative sowie der unerlässliche Subsidiaritätsgrundsatz sind ausschlaggebend dafür, dass eine unmittelbare gesetzliche Handlungsverpflichtung zur Vornahme von Sperrungen kinderpornographischer Webinhalte den strengen Voraussetzungen der Verhältnismäßigkeit standhält. Aus den spezifischen Schranken-Schranken der jeweils beeinträchtigten Grundrechtspositionen der AccessProvider ergeben sich überdies eigene Anforderungen an die Verfassungskonformität einer solchen gesetzlichen Regelung. So muss eine gesetzliche Verpflichtung ein angemessenes Entschädigungserfordernis für die Kostenbelastung der Provider beinhalten und zudem auch in personeller Hinsicht dahingehend beschränkt sein, als Forschungseinrichtungen aus dem Normadressatenkreis herauszufallen. In einen Konflikt zur Meinungs- und Pressefreiheit treffen die gesetzlichen Sperrverpflichtungen indes nicht.

\section{Entgegenstehende Grundrechte der Nutzer}

Insbesondere durch die Tatsache, dass sämtliche Sperrmethoden dazu führen, dass nicht nur entsprechende kinderpornographische Angebote unzugänglich werden, sondern auch der Zugriff auf viele legale Inhalte gleichzeitig erschwert wird, werden zwangsläufig auch verfassungsrechtlich relevante Individualinteressen der Nutzer beeinträchtigt.

\section{Informationsfreiheit Art. 5 Abs. 1 Satz 1, Alt. 2 GG}

\section{Eingriff in den Schutzbereich}

Die Informationsfreiheit entfaltet über Art. 5 Abs. 1 Satz 1, Alt. 2 GG verfassungsmäßigen Schutz. Danach hat jeder das Recht „sich aus allgemein zugänglichen Quellen ungehindert zu unterrichten“. Die Informationsfreiheit bildet somit das Gegengewicht zur Meinungsfreiheit: Nur wer sich ungehindert informieren kann, ist in der Lage sich auch eine eigene Meinung zu bilden und den Kommuni- 
kations- sowie Meinungsbildungsprozess voranzutreiben. ${ }^{711}$ Daher ist der Schutzbereich der Informationsfreiheit verhältnismäßig weit gefasst. Er umfasst den freien Zugang zu allen Informationsquellen, die dazu geeignet und bestimmt sind der Allgemeinheit, also einem individuell nicht bestimmbaren Personenkreis, Informationen $\mathrm{zu}$ verschaffen. ${ }^{712}$ Dabei bezieht sich der Schutz auf den gesamten Informationsprozess. Folglich ist sowohl die passive Entgegennahme der Information geschützt, als auch die aktive Beschaffung, das Aufbereiten sowie das Speichern der erhaltenen Information. ${ }^{713}$ Als Informationsquellen gelten dabei alle Informationsträger, wie beispielsweise Schriftstücke, das gesprochene Wort, Rundfunksendungen, Filme, Zeichen, Symbole und Bilder sowie das Internet, soweit dadurch Meinungen oder Nachrichten zu öffentlichen oder privaten Angelegenheiten zum Ausdruck kommen.714 Dem Erfordernis der Allgemeinzugänglichkeit kommt im Rahmen des Schutzbereiches indes doppelte Bedeutung zu. Einerseits schränkt es den Schutzbereich darauf ein, dass es sich explizit um Quellen handeln muss, die „,nach ihrer tatsächlichen Lage“715 also nach der „Art der

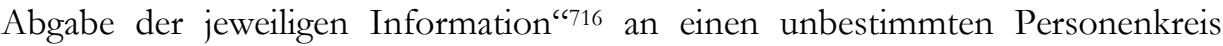
gerichtet sind. Dies nimmt folglich Individualkommunikation oder sonstige an den Einzelnen adressierte Nachrichten aus dem Schutzbereich heraus. Andererseits wird der Schutzbereich gerade durch dieses Merkmal weiter ausgebreitet. Indem als allgemein zugänglich nicht nur inländische Quellen, sondern auch ausländische Quellen gelten, deren Zugänglichkeit in Deutschland an einen unbestimmbaren Personenkreis uneingeschränkt gewährleistet ist. ${ }^{717}$ Besonders das Internet, welches über die einzelnen Landesgrenzen hinausgeht und innerhalb ist

711 BVerfGE 27, 71 (81); BVerfGE 90, 27 (32); BVerfGE 92, 126; Bethge in: Sachs, Art. 5 GG, Rn. 52; Scbulze-Fielitz in: Dreier, Art. 5 GG, Rn. 76; Hoffmann-Riem, Kommunikationsfreiheiten, 2002, S. 92; Starck in: v. Mangoldt/Klein/Starck, Art. 5 GG, Rn. 39; Herzog in: Maunz/Dürig, Art. 5 GG, Rn. 95; Klöpfer, Informationsfreiheit, \3, Rn. 75.

712 BVerfGE 103, 44 (66); BVerfGE 27, 71 (83); BVerfGE 90, 27 (32); BVerfGE 103, 44 (60).

713 BVerfGE 27, 88 (98); BVerfGE 27, 71 (82); Wendt in: v. Münch/Kunig, Art. 5 GG, Rn. 26; Schulze-Fielitz in: Dreier, Art. 5 GG, Rn. 83; ausführlich zum gesamten Komplex auch Billmeier, Die Düsseldorfer Sperrungsverfügung, 2007, S. 173 ff.

714 Starck in: v. Mangoldt/Klein/Starck, Art. 5 GG, Rn. 42; Degenhart in: Bonner Kommentar, Art. 5 GG, Rn. 320; Schulze-Fielitz in: Dreier, Art. 5 GG, Rn. 77.

715 So begründet von Lerche, JURA 1995, 561 (565); zuvor ders. in: Herzog, ev. Staatslexikon, 1987, Bd. I, Sp. 1315 „Titel:“ Informationsfreiheit“. Entsprechend auch Herzog in: Maunz/Dürig, Art. 5 GG, Rn. 89.

716 BVerfGE 27, 71 (83); BVerfGE 27, 104 (108); BVerfGE 28, 175 (188); BVerfGE 103, 44 (60).

717 BVerfGE 90, 27 (32); Löwer, JZ 1981, 730 (734); Delbrück, Satellitenrundfunk, 1982, S. 71 f.; Starck in: v. Mangoldt/Klein/Starck, Art. 5 GG, Rn. 45; Degen, Freiwillige Selbstkontrolle, 2007, S. $262 \mathrm{f}$. 
damit als Ausgangspunkt eines Schutzes aus Art. 5 Abs. 1 Satz 1, Alt. 2 GG denkbar.

In persönlicher Hinsicht finden sich innerhalb der grundrechtlichen Gewährung der Informationsfreiheit keine weitreichenden Einschränkungen. Daher kommt als Grundrechtsträger jede natürliche Person, bezogen auf mögliche Sperrverfügungen, also der durchschnittliche Internetnutzer in Betracht. Daneben können über Art. 19 Abs. 3 GG auch nicht-rechtsfähige Vereinigungen oder juristische Personen berechtigt sein, sich auf die Informationsfreiheit zu berufen. ${ }^{718}$

Bei der typischen Informationsbeschaffung des durchschnittlichen Internetnutzers über das frei zugängliche Internet handelt es sich demnach um eine grundrechtlich über die Informationsfreiheit geschützte Tätigkeit. ${ }^{719}$ Da der Internetempfang von technischen Anlagen abhängig ist, erstreckt sich der Schutz auch auf sämtliche zur Informationsbeschaffung dienenden Computer- und Netzwerksysteme. ${ }^{720}$ Nicht jedoch auf den Kommunikationsprozess als solchen, da dieser bereits als lex specialis vom Fernmeldegeheimnis geschützt wird. ${ }^{721}$ Nicht eingeschlossen ist zudem der Informationserhalt innerhalb ,geschlossener Benutzergruppen“ des Internets, da es hierbei an der Allgemeinzugänglichkeit der Quelle mangelt. ${ }^{722}$ Sämtliche, zum freien Abruf stehenden Dienste des Internets, enthalten jedoch in Bezug auf ihre Nutzer grundrechtlichen Schutz. ${ }^{723}$

Zur Bestimmung des tatsächlichen Eingriffscharakters einer gesetzlichen Maßnahme in Art. 5 Abs. 1 Satz 1, Alt. 2 GG kommt es insbesondere auf die „,ungehinderte Unterrichtung“ an. Ungehindert meint frei von bewusster rechtli-

718 Hierzu Schulze-Fielitz in: Dreier, Art. 5 GG, Rn. 87; Borrmann, Der Schutz der Berufsfreiheit, 2002, S. $54 \mathrm{mwN}$.

719 Degen, Freiwillige Selbstkontrolle, 2007, S. 262.

720 BVerfGE 90, 27 (36).

721 BVerfGE 100, 313 (360); in die Richtung Jarass in: Jarass/Pieroth, Art. 10 GG, Rn. 5.

722 Geschlossene Benutzergruppen sind individuelle Nutzerbereiche, die nur mittels einer speziellen Authentifizierung virtuelle „betreten“ werden können. Hierbei handelt es sich um „Erwachsenenbereiche" die anbieterseitig angeboten werden um etwa den jugendmedienschutzrechtlichen Anforderungen des $\ 4$ Abs. $2 \mathrm{JMStV}$ gerecht zu werden. Als anerkanntes technisches System, das einen Zugang nur für Erwachsene zum jeweiligen Telemedienangebot garantiert wurde bisher Altersverifikationssysteme (AVS) entwickelt. Den Anforderungen der gängigen Rechtspraxis entsprechend müssen die AVS danach gewährleisten, dass eine Volljährigkeitsprüfung über eine persönliche Identifizierung erfolgt und bei jedem einzelnen Nutzungsvorgang nur identifizierte und altersgeprüfte Personen Zugang zum jeweiligen Angebot erhalten, hierzu ausführlich BGH, NJW 2008, 1882 (1884). Zudem Erdemir in: Spindler/Schuster, Recht der elektronischen Medien, 2011, \4 JMStV, Rn. 53 ff.; Liesching/Schuster, Jugendschutzrecht, \4 JMStV, Rn. 64 ff.; Erdemir in: Nikles/Roll/Spürck/Erdemir/Gutknecht, Jugendschutzrecht, $\int 4$ JMStV, Rn. 30 ff.; Döring/Günter, MMR 2004, 231; Berger, MMR 2003, 773; Erdemir, CR 2005, 275, jeweils mwN.

723 Degen, Freiwillige Selbstkontrolle, 2007, S. 263. 
cher oder faktischer Verhinderung oder zumindest frei von wesentlicher Erschwerung des Informationsvorgangs oder der Informationsaufnahme. ${ }^{724}$ Auch nur kurzzeitige Informationsverzögerungen sind als Behinderung und damit als Eingriff in den Schutzbereich zu werten, jedenfalls soweit sie für den Nutzer nicht mehr als zumutbar erachtet werden. ${ }^{725}$ Die ungehinderte Unterrichtung ist somit charakteristisch für das Grundrecht: Es ist folglich in erster Linie als Abwehrrecht des Bürgers vor staatlichen Verboten oder Erlaubnisvorbehalten bei der Informationsbeschaffung anzusehen. Es verbietet gesetzliche Einschränkungen der Informationsrecherche, sowie Verbote oder tatsächliche Maßnahmen, die eine Nutzung der Informationsquelle verzögern oder unmöglich machen, beispielsweise die Informationsquelle vernichten oder den Zugang zu ihr zu sperren. ${ }^{726}$

Gesetzliche Sperrverpflichtungen der Access-Provider zur Unterbindung kinderpornographischer Inhalte stellen unter Zugrundelegung dieser Voraussetzungen einen Eingriff in den Schutzbereich der Informationsfreiheit dar: Sie hindern den Internetnutzer an einer potentiellen Informationsbeschaffung über internetbasierte Webangebote, die vom Schutzbereich als „allgemein zugängliche“ Quellen umfasst sind. Wenngleich anzunehmen ist, dass breitflächige Umgehungsmöglichkeiten bestehen, welche die technisch implementierte Zugriffserschwerung wieder relativieren können, so ist der Nutzer zumindest in der Informationsbeschaffung zeitlich beeinträchtigt beziehungsweise erschwert, da er auf die Zuhilfenahme von technischen Anleitungen oder Umgehungssoftware angewiesen ist. ${ }^{727}$

Bei einer Einordnung einer gesetzlichen Sperrmaßnahme als Eingriff in den Schutzbereich der Informationsfreiheit kommt es nicht auf eine Abgrenzung zwischen der ausdrücklichen Sperrung kinderpornographischen Materials und einer zufälligen Mitsperrung legaler Internetinhalte, die beispielsweise auf Subdomains lagern, oder über dieselbe IP-Adresse gehostet werden, an. Vielmehr ist die recht-

724 Billmeier, Die Düsseldorfer Sperrungsverfügung, 2007, S. 178; Degen, Freiwillige Selbstkontrolle, 2007, S. 264; Schulze-Fielitz in: Dreier, Art. 5 GG, Rn. 76; Jarass in: Jarass/Pieroth, Art. 5 GG, Rn. 19.

725 Schmidt-Jortzig in: Isensee/Kirchhof, Hdb. StaatsR, 2002, Bd. V, \141, Rn. 34. Jarass in: Jarass/Pieroth, Art. 5 GG, Rn. 19.

726 BVerfGE 27, 71 (85); BVerfGE 33, 52 (65); Jarass in: Jarass/Pieroth, Art. 5 GG, Rn. 19; Degen, Freiwillige Selbstkontrolle, 2007, S. 264.

727 IE. Stadler, MMR 2002, 343 (346); Sieber, Stellungnahme der Experten, Ausschussdrucksache 16 89) 1559, S. 10; Kabl, SächsVBl. 2010, 180 (187); Sieber/Nolde, Sperrverfügungen im Internet, 2008, S. 77 f.; in die Richtung der Zweiteilung Billmeier, Die Düsseldorfer Sperrungsverfügung, 2007, S. 266. Die Aussage korrespondiert mit der Geeignetheit der Maßnahme, der hier vertretenen Ansicht nach, ist dem Durchschnittsnutzer nicht zu unterstellen, dass er sämtlich Sperrmethoden ohne wesentlichen zeitlichen und technischen Aufwand umgehen kann, s. 3. Teil B. I. 2. b) (aa) (1) . In die gleiche Richtung, Billmeier, Die Düsseldorfer Sperrungsverfügung, 2007, S. 268; Degen, Freiwillige Selbstkontrolle, 2007, S. 266. 
liche Einordnung des beschränkten Inhaltes für den Schutzbereich irrelevant, da es für einen verfassungsrechtlichen Schutz auch hier nicht darauf ankommen kann, ob die Inhalte nach einfachem Recht als rechtswidrig oder rechtmäßig einzustufen sind. Eine etwaig notwendige Differenzierung ist erst auf der Ebene der verfassungsmäßigen Rechtfertigung des Eingriffs vorzunehmen und kann nicht schon bei der Eingriffsqualität zum Tragen kommen. ${ }^{728}$ Eine Ansicht die davon ausgeht, dass der Nutzer keinen verfassungsrechtlichen Anspruch auf den Erhalt strafrechtlich verwerflicher oder sonstiger gegen die Rechtsordnung verstoßender Informationen habe, ${ }^{729}$ verkennt indes die gefestigte Dogmatik zu Art. 5 Abs. 1 Satz 1, Alt. 2 GG, wonach eine strafrechtliche Ahndung der nachgefragten Information, die Anwendbarkeit des Grundrechtsschutzes nicht auszuschließen vermag. ${ }^{730}$ Anderenfalls hätte es der Staat im Widerspruch zur Zielsetzung und Systematik des Grundrechtes in der Hand, bereits den Schutzbereich der Informationsfreiheit nach Belieben zu begrenzen, ohne an die Voraussetzungen des Art. 5 Abs. 2 GG gebunden zu sein. ${ }^{731}$ Die zusätzlichen Voraussetzungen an die Verfassungsmäßigkeit der Beschränkung nach Absatz 2 wären damit gegenstandslos, was zwangsläufig der hohen Stellung der Kommunikationsgrundrechte im Gesamtgefüge des Grundgesetzes zuwiderlaufen würde. Folglich bleibt die rechtliche Wür-

728 So Sieber/Nolde, Sperrverfügungen im Internet, 2008, S. 77 ff.; Degen, Freiwillige Selbstkontrolle, 2007, S. 265; in die Richtung eines Abwägungsbedürfnisses auch Landmann, NJW 1996, 3309 (3310).

729 Ansatzweise in die Richtung die Erläuterung der Düsseldorfer Bezirksregierung, danach habe der einzelne Nutzer „keinen Anspruch (...) auf Empfang unzulässiger Angebote. Dieses gelte „erst recht dann, wenn sich die Unzulässigkeit aus einem Verstoß gegen Straftatbestände ergibt“, abrufbar unter: dies erläuternd und die Auffassung der Düsseldorfer Bezirksregierung richtigstellend: Neumann, Ordnungsrechtliche Sperrungsverfügungen und die Informationsfreiheit nach Art. 5 Abs. 1 S. 1 2. Alt. GG, abrufbar unter

http://www.artikel5.de/artikel/sperrunginffreiheit.html (zuletzt abgerufen 20.5.2012): die Formulierung deute darauf hin, dass „die Bezirksregierung insoweit methodisch korrekt den Schutzbereich der Informationsfreiheit für einschlägig, den Eingriff in das Grundrecht der Nutzer jedoch für verfassungsrechtlich gerechtfertigt hält", da Sie die Beschränkungsmöglichkeiten des Grundrechts zutreffend erkennt und wiedergibt.

730 So begründet durch BVerfGE 27, 71 (83), mit Verweis auf die Wichtigkeit der Informationsfreiheit vor dem Hintergrund der Ereignisse um die Geschehnisse des zweiten Weltkrieges, als das staatliche Diktat die Informationenbeschaffung des Bürgers steuerte. Um Lehren aus der Vergangenheit zu ziehen, darf der Schutzbereich der Informationsfreiheit nicht schon über staatliche vorgaben eingeschränkt werden.

731 BVerfGE 27, 71 (83 f.); Neumann, Ordnungsrechtliche Sperrungsverfügungen und die Informationsfreiheit nach Art. 5 Abs. 1 S. 1 2. Alt. GG, abrufbar unter http://www.artikel5.de/artikel/sperrunginffreiheit.html (zuletzt abgerufen 20.5.2012). 
digung der Information für die Eröffnung des Schutzbereichs sowie des Eingriffscharakters unbeachtlich.

Zusammenfassend bleibt festzustellen, dass die Informationsfreiheit der Nutzer durch gesetzlich initiierte Sperrmaßnahmen beeinträchtigt wird.

\section{Verfassungsrechtliche Rechtfertigung - Speziell Verbältnismäßigkeit im engeren Sin- ne/Angemessenheit}

Die Informationsfreiheit ist nicht staatlicher Lenkung entzogen. Vielmehr darf der Staat in engen Grenzen in die grundrechtlich garantierten Informationsrechte des Nutzers eingreifen. Die Zulässigkeit des Eingriffs bestimmt sich nach Art. 5 Abs. 2 GG. Danach finden die Rechte aus Absatz 1 - demnach auch die Informationsfreiheit - ihre Schranken in den Vorschriften der allgemeinen Gesetze, den gesetzlichen Bestimmungen zum Schutze der Jugend und in dem Recht der persönlichen Ehre. Die Informationsfreiheit unterliegt folglich einem qualifizierten Gesetzesvorbehalt. ${ }^{732}$

Eine gesetzlich formulierte Sperrverpflichtung aller Access-Provider zur Unterbindung kinderpornographischen Internetmaterials würde abstrakt betrachtet eine zulässige Schranke der Informationsfreiheit bilden, da sie als allgemeines Gesetz oder als Bestimmung zum Schutze der Jugend ausgelegt werden kann. Allgemeine Gesetze zeichnen sich dadurch aus, dass sie sich weder gegen eine bestimmte Meinung oder Information, noch gegen die Meinungs- oder Informationsfreiheit als solche richten, sondern auf die Wahrung eines hochrangigen Rechtsguts zielen, dessen Schutz unabhängig davon ist, ob es durch MeinungsäuBerungen oder auf andere Weise verletzt wird. ${ }^{733}$ Das Bundesverfassungsgericht formuliert in diesem Zusammenhang damit zwei kumulativ ${ }^{734}$ vorliegende Anforderungen an ein allgemeines Gesetz i.S.d. Art. 5 Abs. 2 GG. Zunächst darf es sich nicht gegen eine bestimmte Meinung oder die Meinungsbildungsprozesse als solche wenden. Weiterhin muss es dem Schutz eines intensiv und gemeinhin schützenswerten Rechtsguts dienen.

Überträgt man die Anforderungen der Rechtsprechung auf eine gesetzliche Sperrvorschrift zur Zugriffserschwerung bezüglich kinderpornographischer Inhalte würde sich ein solches Gesetz nicht gegen eine spezifische Meinung noch gegen den Meinungsbildungsprozess als solchen richten. Es bezweckt gerade keine be-

732 Herzog in: Maunz/Dürig, Art. 5 Abs. 1 GG, Rn. 249; Jarass in: Jarass/Pieroth, Vorb. Vor Art. 1 GG, Rn. 40 sowie Art. 5 GG, Rn. 55 ff.; Wendt in: v. Münch/Kunig, Art. 5 GG Rn. 67 ff.; Kapries, Die Schranken der Grundrechte, 2005, S. 36.

733 Ständ. Rspr. u.a. BVerfGE 7, 198 (209); BVerfGE 95, 220 (235); BVerfGE 113, 63 (79); BVerfGE 111, 147 (155); BVerfGE 120, 180 (200).

734 Kritisch zum kumulativen Vorliegen der Voraussetzungen, Kühling, Die Kommunikationsfreiheit als europäisches Gemeinschaftsgrundrecht, 1999, S. 231. 
stimmte Meinungsdiskriminierung, sondern zielt vordergründig auf Legitimierung technischer Eingriffsbefugnisse im Internet.

Zudem deckt sich der hinter der Sperrverpflichtung stehende Regelungszweck ebenfalls mit der weiteren Anforderung an ein allgemeines Gesetz. Eine Vorschrift, welche ausschließlich darauf ausgerichtet ist, den Zugriff auf kinderpornographische Inhalte zu unterbinden, dient unwiderleglich einem hohen Gemeinschaftsgut, explizit dem Jugendschutz und der Aufrechterhaltung der öffentlichen Sicherheit und Ordnung. Folglich genügt eine gesetzliche Sperrverpflichtung zur Erschwerung des Zugriffs auf kinderpornographische Webinhalte aufgrund ihrer Meinungsneutralität und der Verfolgung des Schutzes eines hochrangigen Rechtsguts, unproblematisch den verfassungsrechtlichen Anforderungen an ein allgemeines Gesetz. ${ }^{735}$ Somit wäre eine solche Regelung potentiell in der Lage die Informationsfreiheit zu beschränken.

Darüber hinaus folgt aus der Tatsache, dass die Sperrung kinderpornographischer Webinhalte speziell auch aus einer jugendschutzrechtlichen Motivation heraus ergeht, die Konsequenz, dass eine gesetzliche Sperrverpflichtung daneben auch als Schrankenbestimmung zum Schutze der Jugend auszulegen ist. Verfassungsrechtlich konkretisiert die Formulierung des Art. 5 Abs. 2 GG den vorrangig aus dem Allgemeinen Persönlichkeitsrecht des Art. 2 Abs. 1 i.V.m. Art. 1 Abs. 1 GG abgeleiteten staatlichen Schutzauftrag zur Unterbindung von Gefahren, die mit der entwicklungsbedingten Schutzwürdigkeit des kindlichen Individuums zusammenhängen. Bereits durch diese Formulierung hebt der Verfassungsgesetzgeber selbst hervor, dass er bei der Beschränkung der Kommunikationsgrundrechte dem Jugendschutz ein hohes Gewicht zuspricht und sich selbst verpflichtet, dieses bei Einschränkungen der Informationsfreiheit zu beachten beziehungsweise gerade deshalb Einschränkungen dergleichen vornehmen kann.

In dem Zusammenhang ist zu beachten, dass die Schranke des Jugendschutzes nicht als Universalschranke für sämtliches jugendschutzrechtlich-motiviertes staatliches Handeln zu verstehen ist. Vorrangig bezieht sich die Beschränkungsmöglichkeit der Informationsfreiheit über „Bestimmungen zum Schutze der Jugend“ nur auf den Bereich der Einschränkung der Informationsfreiheit Jugendlicher. ${ }^{736}$ Sie sichert damit verfassungsrechtlich Maßnahmen ab, die auf einen altersdifferenzierten Informationszugriff ausgerichtet sind. Dieses gründet auf dem Umstand, dass bei gesetzlichen Informationsbeschränkungen von Kindern und Jugendlichen, etwa in Form von Sendezeitbeschränkungen für gewaltbehaftete oder pornographische Rundfunkangebote, der Jugendschutz grundsätzlich die Freiheit des

735 IE. jedoch speziell zu Regelungen aus dem JMStV, bzw. früheren Mediengesetze, die speziell eine Sperrung von jugendmedienschutzrechtlich bedenklichen Inhalten enthielten, Degen, Freiwillige Selbstkontrolle, 2007, S. 107.

736 Sieber/Nolde, Sperrverfügungen im Internet, 2008, S. 72 mit Verweis auf Hoffmann-Riem in: Alternativkommentar GG, Art. 5, GG, Rn. 56. 
jugendlichen Rezipienten am Erhalt einer solchen Information überwiegen wird. Soweit altersspezifische Zugangsbeschränkungen zum Schutze der Jugend gleichzeitig aber auch die Informationsfreiheit Erwachsener beeinträchtigen, ist die Maßnahme folglich nicht allein an der Schranke des Jugendschutzes zu messen. Überdies müssen auch die Voraussetzungen an ein allgemeines Gesetz „ergänzend" herangezogen werden. ${ }^{737}$

Aufgrund der absoluten, altersunabhängigen Beschränkung der Informationsfreiheit im Bereich der gesetzlichen Sperrverpflichtungen zur Unterbindung kinderpornographischer Webinhalte bedarf es neben den Voraussetzungen der Schranke des Jugendschutzes ergänzend auch der Voraussetzungen der „allgemeinen Gesetze" um eine Beschränkung verfassungsrechtlich zu rechtfertigen. Zur verfassungsmäßigen Rechtfertigung einer Totalbeschränkung der Informationsfreiheit müssen neben den allgemeinen Voraussetzungen der Verhältnismäßigkeit wie legitimer Zweck, Geeignetheit und Erforderlichkeit der Maßnahme, letztlich auch die erhöhten Anforderungen der allgemeinen Gesetze im Rahmen der Angemessenheit der Maßnahme entsprechend herangezogen werden. Danach ist der Eingriff in die Kommunikationsrechte ergänzend an der „Wechselwirkungslehre“ zu messen. ${ }^{738}$ Diese verpflichtet dazu, dem Gewicht der Kommunikationsrechte bei der Einschränkung derselben, ebenfalls ein gewisses $\mathrm{Maß}$ an Berücksichtigung zuzubilligen. Das die Kommunikationsgrundrechte einschränkende Gesetz muss selbst im Lichte des eingeschränkten Kommunikationsgrundrechts - hier also selbst im Lichte der Informationsfreiheit - ausgelegt werden. Im Ergebnis soll damit der besonderen Stellung der Kommunikationsgrundrechte für die freiheitlich demokratische Grundordnung einerseits und dem notwendigen Staatshandeln andererseits eine besondere Berücksichtigung zuteilwerden, bei welcher im Wege der „praktischen Konkordanz" ein möglichst schonender Ausgleich aller beteiligten Grundrechtspositionen angestrebt wird. ${ }^{739}$

Bei der nachfolgenden Gegenüberstellung der Grundrechtspositionen müssen zwei Konstellationen unterschieden werden, die sich unter Beachtung der Wechselwirkungslehre im Ergebnis unterschiedlich auf die Verfassungskonformität des Eingriffs in die Informationsfreiheit der Nutzer auswirken können. Zum einen die Betrachtung der Einschränkung der Informationsfreiheit, soweit ausschließlich kinderpornographische Informationen aufgrund der Sperrung im Zugriff erschwert werden. Zum anderen die Einschränkung der Informationsfreiheit aufgrund des sperrimmanenten Overblocking-Effects.

737 Herleitung mwN. Sieber/Nolde, Sperrverfügungen im Internet, 2008, S. 74 f., jedoch explizit auf die absoluten Verbreitungsverbote des $₫ 4$ Abs. 1 JMStV bezogen.

738 BVerfGE 7, 198 (208 f.); BVerfGE 20, 162 (177); BVerfGE 59, 231 (265); BVerfGE 71, 206 (214).

739 BVerfGE 41, 29 (51); BVerfGE 77, 240 (255); BVerfGE 81, 298 (308); BVerfGE 83, 130 (143). 
a) Sperrung ausschließlich kinderpornographischer Inhalte

Im Einzelfall stehen sich bei gesetzlich vorgeschriebenen Sperrverpflichtungen zur Unterbindung kinderpornographischer Webinhalte einerseits das grundrechtlich garantierte und der Demokratie dienende Recht des Nutzers auf freie Unterrichtung aus allgemein zugänglichen Quellen und andererseits die staatliche Schutzverpflichtung zum Jugendschutz sowie die staatliche Verpflichtung zur Aufrechterhaltung der öffentlichen Sicherheit und Ordnung gegenüber.

Betrachtet man in dem Zusammenhang die widerstreitenden Interessen im Fokus nur die Sperrung von kinderpornographischen Webinhalten, so wird im Ergebnis, obgleich erhöhte Anforderungen an die Rechtfertigung zu stellen sind, das öffentliche Interesse an der Unterbindung der Weiterverbreitung des kinderpornographischen Inhalts, die Nutzerinteressen am Erhalt des jeweiligen Angebotes überwiegen und demnach verfassungsrechtlich als angemessen zu bezeichnen sein.

Die Schlussfolgerung folgt indes nicht schon aus der Tatsache, dass es sich bei kinderpornographischen Inhalten um strafrechtlich beziehungsweise jugendmedienschutzrechtlich verbotene Angebote handelt. ${ }^{740}$ Bei einer solchen Annahme würde man, die oben bereits aufgeführte Befürchtung, der Staat könne über einfaches Recht letztlich Verfassungsrecht definieren, einfach von der Ebene des Eingriffs, auf die Ebene der Rechtfertigung übertragen, ohne dieses Problem hinreichend zu würdigen. Dem Umstand der strafrechtlichen Relevanz des Angebotes kann höchstens Indizwirkung für die Beurteilung der Rechtfertigung zukommen, er allein entbindet jedoch nicht von einer Einzelfallabwägung zwischen dem Interesse an der Unterbindung der Verbreitung solcher illegalen Inhalte im Lichte der Informationsfreiheit und der Informationsfreiheit als solcher. ${ }^{741}$

\section{(aa) Abwägungsrelevanter Belang: Abstrakte und konkrete Wertigkeit}

Bei Vornahme der notwendigen Abwägung ist der Fokus zunächst auf eine abstrakte Wertigkeit der beteiligten Grundrechtsinteressen zu legen. Im Rahmen einer abstrakten Gewichtung der konkurrierenden Grundrechte ist zum einen der hohe Rang des staatlicherseits verfolgten und verfassungsrechtlich über das Allgemeine Persönlichkeitsrecht abgesicherten Jugendschutzes hervorzuheben. Das Bundesverfassungsgericht betont selbst immer wieder dessen besondere Stellung als wichtiges Gemeinschaftsanliegen. ${ }^{742}$ Im Rahmen seines verfassungsrechtlichen Schutzauftrages ist der Gesetzgeber über die ihm zugebilligte Einschätzungsprärogative auch befugt, besonders starke und intensive Beeinträchtigungen hochrangiger

740 BVerfGE 20, 56 (97); BVerfGE 30, 336 (347).

741 Billmeier, Die Düsseldorfer Sperrungsverfügung, 2007, S. 272; in die gleiche Richtung auch wenn bezogen auf die Verfassungsmäßigkeit von totalen Verboten nach \4 JMStV, Baum, Jugendmedienschutz als Staatsaufgabe, 2007, S. 295.

742 BVerfGE 30, 336 (347 f.); BVerfGE 83, 130 (139). 
Grundrechte im Sinne des Jugendschutzes vorzunehmen, solange diese nicht völlig außer Verhältnis zum angestrebten Zweck stehen. ${ }^{743}$

Dem steht abstrakt betrachtet die Informationsfreiheit des Nutzers gegenüber. Auch bei dieser handelt es sich um ein besonders sensibles und in seiner abstrakten Wertigkeit enorm hochrangiges Grundrecht. Dem Grundrecht wird in der Rechtsprechung des Bundesverfassungsgerichts und der verfassungsrechtlichen Lehre gemeinhin eine fundamentale Bedeutung für die freiheitlich-demokratische Grundordnung beigemessen. ${ }^{74}$ Dem Einzelnen wird über die Gewährung einer staatlicherseits uneingeschränkten Informationsmöglichkeit erst die Gelegenheit eröffnet am Kommunikationsprozess teilzuhaben und sich entsprechend der bezogenen Informationen Meinungen zu bilden und verbreiten zu können. Im Kollisionsfalle ist diesem Umstand entsprechend Rechnung zu tragen und die Informationsfreiheit in der Wertung grundsätzlich hoch zu veranschlagen. Vor allem gilt dies, wenn es sich um besonders einschneidende Eingriffe in den Kerngehalt des Grundrechts handelt, wenn etwa dem Nutzer sämtlicher Zugang zu bestimmten Informationen langfristig untersagt wird. ${ }^{745}$

Wenngleich damit anzunehmen ist, dass die gegenüberstehenden Belange, abstrakt betrachtet, praktisch gleichwertig sind, ist fraglich zu wessen Gunsten, der durch gesetzliche Sperrverpflichtungen hervorgerufene Konflikt aufzulösen ist oder inwiefern eine „praktische Konkordanz“ der beteiligten Grundrechtspositionen hergestellt werden kann.

Bei näherer Betrachtung wird man wohl den Jugendschutz aus gesetzesanalytischer Sicht in einer privilegierten Stellung gegenüber der Informationsfreiheit sehen müssen. Das Grundgesetz deutet dieses Ergebnis nämlich selbst durch den Schrankentatbestand des Art. 5 Abs. 2, Var. 2 GG an, indem es ,gesetzliche Bestimmungen zum Schutze der Jugend“ aus der Masse der denkbaren Kollisionsgüter der Kommunikationsfreiheiten explizit heraushebt. ${ }^{746}$ Damit wird bereits von Verfassungswegen verdeutlicht, dass dem staatlich verfolgten Jugendschutz durchaus die Möglichkeit anheim ist, die fundamental wichtige Informationsfreiheit zu beschränken. Dieses systematische Argument wird indes auch durch die Zusammenschau mit einfach-gesetzlichen Normierungen deutlich: Im konkreten Fall hat der Gesetzgeber sich bereits eindeutig im Verhältnis der Informationsfrei-

743 Sog. Untermaßverbot, ausführlich dazu BVerfGE 92, 26 (46); BVerfGE 77, 170 (214), BVerfGE 77, 381 (405); BVerfGE 88, 203 (254f. 262); BVerfGE 96, 409 (412); Gržeszick in: Maunz/Dürig, Art. 20 GG, Rn. 126; Schulze-Fielitz in: Dreier, Art. 20 GG, 223.

744 Beispielhaft Schulze-Fielitz in: Dreier, Art. 5 GG, Rn. 41, 76; Klöpfer, Informationsrecht, $\mathbb{\int} 3$ Rn. 75.

745 Baum, Jugendmedienschutz als Staatsaufgabe, 2007, S. 294, in Bezug auf die Rundfunkfreiheit.

746 BVerfGE 30, 336 (338); dies ebenfalls herausstellend Baum, Jugendmedienschutz als Staatsaufgabe, 2007, S. 294, jedoch in Bezug auf das Kollisionsverhältnis von Rundfunkfreiheit und Jugendschutz. 
heit zum konkurrierenden Jugendschutz beziehungsweise zur Aufrechterhaltung der öffentlichen Sicherheit und Ordnung positioniert. Kinderpornographische Materialien gelten als schlichtweg verboten. Ihre Zugänglichmachung ist altersunabhängig generell nicht gewährleistet und überdies mit schärfsten Sanktionen belegt. ${ }^{747}$ Dadurch zeigt der Gesetzgeber bereits die Wertung, dass die Informationsbeschaffung hinsichtlich kinderpornographischer Inhalte völlig gegenüber den bei deren Verhinderung verfolgten staatlichen Interessen zurückgedrängt wird.

Die sich dahinter verbergende einfach-gesetzliche Wertung ist auch von Verfassungswegen insbesondere unter Beachtung der Wechselwirkungslehre nicht zu beanstanden: Wie aufgezeigt birgt die ungehinderte Verbreitung kinderpornographischer Webinhalte erhebliche Risiken. Die hier in Frage stehende beschränkte Informationsfindung bezieht sich konkret auf einen Bereich von Informationen, welche sexuelle Ausbeutung von Kindern und teilweise sogar von Säuglingen visualisiert. Neben der physischen und psychischen Beeinträchtigung der kindlichen Protagonisten während der pornographischen Produktion, werden die Bilder oftmals um willensbeugende Mittel ergänzt und reichen von geringfügigen Unterwerfungshandlungen bis hin zu grausamen Vergewaltigungsszenen. Neben der inhaltlichen Dimension ist vor allem die rezeptions- sowie verbreitungsbedingte Gefahr, die von solchen Inhalten ausgeht, ausschlaggebend für das Gewichtungsverhältnis der beiden Grundrechte zueinander. Die ungehinderte Verbreitung birgt die Gefahr einer erneuten Stigmatisierung der beteiligten Kinder, mündet damit im Schutz von sensiblen persönlichkeitsrechtlichen Aspekten und bei besonders intensiven Bildern sogar im Schutz der Menschenwürde der Beteiligten. Zudem dient die Herausnahme des Angebotes aus dem verfügbaren Informationsbestand des Internets der Verhinderung einer breitflächigen Nachahmungsgefahr, die durch eine uneingeschränkte Verbreitung zu befürchten ist. ${ }^{78}$ Unter Beachtung der Wechselwirkungslehre lassen sich gehaltvolle Informationen, welche eine fundamentale Ausprägung einer freiheitlich demokratischen Grundordnung wären, der Visualisierung von Kindesmissbrauch wohl kaum entnehmen. Zwar mag auch der wissenschaftliche Diskurs zur öffentlichen Meinungsbildung beitragen, ob dieser im Falle einer ,laienhaften“ Diskussion jedoch auf die Heranziehung von onlinevermittelten Primärquellen angewiesen ist, die solche Bilder visualisieren, wird nicht ernsthaft anzunehmen sein. Wenn die Notwenigkeit der Informationsfindung schon auf professioneller Ebene des wissenschaftlichen Diskurses zu bezweifeln ist, ${ }^{749}$ so muss dies erst recht für die Informationsbeschaffung des einzelnen Privaten gelten. Folglich wird regelmäßig von einem verfassungsrechtlichen Bedürfnis nach einer Beschränkung der Informationsfreiheit, auch im Lichte der Wichtigkeit des Grundrechts auszugehen sein.

747 Ebenso Baum, Jugendmedienschutz als Staatsaufgabe, 2007, S. 294.

748 So auch Sieber, Ausschussdrucksache 16 (9) 1559, S. 7.

749 Zur Wissenschaftsfreiheit oben 3. Teil B. IV. 
Keinen wesentlichen Einfluss auf die Bewertung hat hier der Umstand, dass die Inhalte bereits straf- und spezialgesetzlich sanktionsbehaftet sind. Es muss in Anbetracht der Verbreitungszahlen auch möglich sein, auch eine über die bloße Verbotswirkung hinausgehende Durchsetzbarkeit gesetzlich abzusichern, die der Erreichung des Schutzziels eines effektiven Jugendschutzes sowie des Schutzes der Allgemeinheit dient.

In die gleiche Richtung ist das Argument anzuführen, dass gesetzlich initiierte Sperrverpflichtungen neben dem Jugendschutz gerade auch einem staatlichen Interesse an der Aufrechterhaltung der öffentlichen Sicherheit dienen und damit präventiv vor Beeinträchtigungen der Rechtsordnung schützen. Das staatliche Interesse an der Erhaltung der Rechtsordnung und Bekämpfung von Straftaten dient nicht nur der Aufrechterhaltung seiner Funktionsfähigkeit, sondern zusätzlich auch dem Erhaltung des „Rechtsfriedens“ und ist als allgemeingültiger Belang gegenüber dem individualrechtlichen Nutzerinteresse an einer unbeeinträchtigten Informationsfindung bezüglich kinderpornographischer Inhalte in der Abwägung ebenfalls überwiegend. ${ }^{750}$

(bb) Abwägungsergebnis

Im Ergebnis führen die genannten Argumente dazu, dass das Interesse des einzelnen Nutzers an dem Erhalt einer kinderpornographischen Information, hinter der staatlichen Pflicht zur Unterbindung des Inhaltes zurücktreten muss. Zusammenfassend wird bezüglich gesetzlicher Sperrverpflichtungen, die sich einzig auf die Zugriffserschwerung zu ausschließlich kinderpornographischen Inhalten beziehen, wird auch im Hinblick auf die Wechselwirkungslehre kaum ernsthaft behauptet werden können, dass die dem Eingriff entgegenstehenden Interessen der Nutzer ersichtlich schwerer wiegen als diejenigen Interessen, deren Wahrung die staatlichen Maßnahmen dienen sollen. Ein verhältnismäßiger Ausgleich, bei dem beide Grundrechtspositionen nebeneinander zur möglichst optimalen Wirksamkeit gelangen, ist in der vorstehenden Situation nicht zu erreichen und verfassungsrechtlich auch nicht wünschenswert. Daher muss die Informationsfreiheit des Nutzers vollständig bei Sperrverpflichtungen aufgrund einer gesetzlichen Regelung zurücktreten.

b) Overblocking - Mitsperrung legaler Inhalte - Verfahrensrechtliche Kompensation zur Sicherung der Grundrechtspositionen

Das vorstehende Ergebnis mag in Bezug auf die Sperrung ausschließlich kinderpornographischer Inhalte überzeugend sein, in der Realität ist es technisch jedoch nicht möglich, die Sperrmaßnahme lediglich punktuell auf einen bestimmten Webinhalt zu beschränken. Je nach Art der gewählten Maßnahme variiert das Ausmaß der von einer Sperrung betroffenen Webseiten. Gleichzeitig führt die gezielte

750 So Billmeier, Die Düsseldorfer Sperrungsverfügung, 2007, S. 271. 
Sperrung eines kinderpornographischen Inhaltes damit zum Overblocking-Effect und bewirkt, dass auch rechtlich völlig unbedenkliche Inhalte zu einer großen Zahl im Zugriff erschwert werden. Die damit einhergehende Beeinträchtigung der Informationsfreiheit des Nutzers, der von dem Erhalt legaler Informationen abgehalten wird, gestaltet sich in der verfassungsmäßigen Rechtfertigung demnach diffiziler als die Abwägung zwischen dem Jugendschutz sowie staatlichen Sicherheitsinteressen und der Informationsfreiheit bei rein kinderpornographischen Inhalten. Keineswegs kann hier schon aufgrund der obigen Ausführungen gleichfalls auf ein Überwiegen des staatlichen Verfolgungsinteresses geschlossen werden. Vielmehr muss auch bezüglich der unbeabsichtigten Mitsperrung eine selbstständige Abwägung zwischen den beteiligten Rechtspositionen im Lichte der Kommunikationsgrundrechte vorgenommen werden. Dabei ist zu hinterfragen, inwiefern ein Interessenausgleich, bei dem die beteiligten Grundrechtspositionen zu einem schonenden Ausgleich gelangen, durch die gesetzliche Sperrverpflichtung möglich erscheint.

(aa) Abwägungsrelevanter Belang: Intensität und Zweck-Mittel-Relation

Zunächst ist der Umstand hervorzuheben, dass die Informationsfreiheit durch eine gesetzliche Sperrverpflichtung in einem besonders intensiven Maße beeinträchtigt wird. Der Erhalt sämtlicher an die Sperrmaßnahme gekoppelter Informationen wird dem potentiellen Internetnutzer infolge einer staatlichen Sperrverpflichtung verwehrt. Hinsichtlich legaler Inhalte sind auf den ersten Blick keine Gründe erkennbar, die eine Beschränkung der verfassungsmäßig enorm wichtigen Informationsfreiheit insbesondere vor dem Hintergrund ihrer fundamentalen Bedeutung für die Demokratie rechtfertigen würden. Die zufällig mitgesperrten Inhalte können weder aus jugendschutzrechtlichen noch aus strafrechtlichen Gründen beanstandet werden. Vielmehr verbergen sich hinter den zugriffsverwehrten Angeboten teilweise sogar politisch wertvolle und stark zur Meinungsbildung beitragende Angebote. Das mögliche Ausmaß der Beeinträchtigung spricht indes dafür, einen Eingriff in die Informationsfreiheit daher verfassungsrechtlich nicht zu rechtfertigen und einer derartigen Regelung ihre materielle Verfassungsmäßigkeit abzusprechen. Zudem ist anzuführen, dass der starken Beschränkung der Informationsfreiheit nur eine relativ geringe Effektivität in Bezug auf das verfolgte Rechtsschutzziel gegenübersteht. Zwar können technische Sperrungen den Zugriff auf kinderpornographische Inhalte erschweren, es handelt sich aufgrund des weiten Umgehungspotentials jedoch nur um eine Maßnahme mit einer geringen Erfolgswahrscheinlichkeit. ${ }^{751}$ In Anbetracht des Stellenwertes der Informationsfreiheit für die freiheitlich demokratische Grundordnung sowie der weitrei-

751 Darauf weisen übereinstimmend viele Autoren hin, u.a.: Billmeier, Die Düsseldorfer Sperrungsverfügung, 2007, S. 273; Stadler, MMR 2009, 581 (582); Schnabel, JZ 2009, 996 (1000); andeutungswiese Höhne/Dienst, jurisPR ITR 13/2009, Anm.6. 
chenden Einschränkung des Grundrechts im Verhältnis zur relativ geringen Wirkung im Hinblick auf das verfolgte gesetzgeberische Ziel kann die Angemessenheit der Sperrung in Zweifel gezogen werden.

Eine solche Betrachtung lässt hingegen den Umstand völlig unerwähnt, dass die Mitsperrung legaler Inhalte nicht der eigentliche staatliche Zweck ist. In Wirklichkeit kommt es zu einer Zugriffserschwerung hinsichtlich legaler Inhalte gerade nur, weil eine Sperrung kinderpornographischer Inhalte veranlasst worden ist. Nach der derzeitigen technischen Realisierbarkeit ist es aber unmöglich, eine punktuell genaue und hinreichend detaillierte Filterung der Angebote auf ihre Legalität vorzunehmen. Aufgrund der technischen Defizite erscheint daher verfassungsrechtlich geboten, die Sperrmaßnahme als Ganzes zu betrachten und nicht losgelöst nach legalen und illegalen Inhalten eine Rechtfertigung vorzunehmen. Anderenfalls müsste allein wegen der vorstehenden technischen Probleme eine Angemessenheit gesetzlicher Sperrmaßnahmen in Abrede gestellt werden, was in der Konsequenz aber bedeuten würde, dass der mit der Sperrverpflichtung verfolgte staatliche Schutzzweck nicht hinsichtlich rechtlicher sondern allein wegen technischer Defizite zurücktreten müsste.

Hinsichtlich rechtlicher Gründe ist in den Abwägungsvorgang demgegenüber der Umstand einzustellen, dass die Sperrung immer im Kontext zur Löschung des Inhalts zu sehen ist. Eine Sperrmaßnahme ist verfassungsrechtlich nur dann zulässig, wenn die Maßnahme als ultima ratio nach gescheiterten Löschversuchen als einzige Alternative für eine Behebung des Rechtsverstoßes verbleibt. Das heißt vor der denkbaren Beschränkung der Informationsfreiheit muss bereits alles versucht worden sein, um die verantwortlichen Diensteanbieter ausfindig zu machen und sie zur Entfernung des Inhaltes aufzufordern. Demnach werden die Fälle der in Bezug auf die Informationsfreiheit der Nutzer fragwürdigen „Kollateralschäden“ und „Nebenwirkungen“, schon von Verfassungswegen stark zurückgedrängt. Im Hinblick auf die Zweck-Mittel Relation ist dieser Umstand entscheidend zu würdigen.

Auf der Seite der Nutzerinteressen ist der Umstand anzuführen, dass besonders die Dauer der Sperrmethode starke Auswirkungen auf das grundgesetzlich garantierte Recht des Nutzers hat. Je länger eine Sperrwirkung andauert, die sich gerade auch auf rechtmäßige Inhalte erstreckt, umso schwerer wiegt der Eingriff in die grundrechtliche Informationsfreiheit. Überdies ist das Ausmaß der Informationsbeeinträchtigung beim Nutzer kaum überschaubar und je nach Art der vorgenommenen Sperrung variabel. Wird etwa die Methode der Proxy-Server-Sperre gewählt, die anhand von URL-Adressen filtert, so kann die Beschränkung der Informationsfreiheit weitestgehend relativiert werden, da sich der Sperrmechanismus allein auf eingegebene URL-Adresse beschränkt. Soweit diese tatsächlich im Vorhinein als kinderpornographisch eingestuft wurde, ist die Wirkung der Sperrung hinreichend begrenzt. Obgleich die URL-Sperrmethode damit aufgrund ihrer Zielgenauigkeit im Idealfall in Bezug auf die Informationsfreiheit relativ zumutbar 
erscheint, ist die Beurteilung eine andere, wenn etwa die grundrechtsintensive DNS- oder IP-Sperrmethode technisch zur Realisierung der Sperrverpflichtung eingesetzt wird. Diese birgt aufgrund der breiten Streufläche der Sperrung gerade ein hohes Risiko von Overblocking und tangiert die Informationsfreiheit damit weit mehr als andere Methoden. ${ }^{752}$

Besonderes Gewicht muss zudem der Tatsache zugesprochen werden, dass der Internetnutzer der jeweiligen Sperrmaßnahme praktisch „kampflos“ ausgeliefert ist. Der Internetnutzer hat weder Einfluss auf deren Wahl sowie tatsächliche Vornahme, noch hat er Kenntnis bezüglich dergleichen sowie deren informationsbeschränkendes Ausmaß. Zum Teil wird der Nutzer ohne entsprechende Umleitung auf eine Sperrseite, 753 noch nicht einmal bemerken, dass er „Opfer“ einer grundrechtsrelevanten staatlichen Informationsbeschränkung geworden ist. Schon aufgrund der Heimlichkeit steht dem Nutzer letztlich auch keinerlei Überprüfungsmöglichkeit hinsichtlich der Richtigkeit der Einordnung eines Inhalts als kinderpornographisch und einer daran gekoppelten Beschränkung weiterer Inhalte zu. Zu bedenken ist in diesem Zusammenhang, dass aber gerade der Entscheidung darüber, wann ein Inhalt tatsächlich den Anforderungen des Straftatbestandes des $\int 184 b$ StGB genügt, oftmals eine einzelfallabhängige und von juristischen Fachwissen geprägte Entscheidungsfindung voraus geht. ${ }^{754}$

Darüber hinaus droht durch eine nachträglich bekanntgewordene Zugriffserschwerung und die Kenntnis des Nutzers, dass dieser entsprechend „Opfer“ einer staatlichen Regulierungsmaßnahme bei einem bestimmten Zugriffsversuch geworden ist, die Befürchtung eines so genannten Chilling-Effect. ${ }^{755}$ Durch die staatliche Einmischung in die Informationsrecherche im Internet und das öffentliche Bekanntwerden von Sperrmaßnahmen könnte sich der Nutzer zukünftig „abgeschreckt" fühlen seinem Surfverhalten wie gewöhnlich freien Lauf zu lassen. Stattdessen wird er nur noch begrenzt auf unbekannten Seiten surfen und vielmehr sein Surfverhalten ausschließlich auf solche Webseiten beschränken, die er tatsächlich kennt beziehungsweise als vertrauenswürdig erachtet, um nicht weiteren staatlichen Manipulationen mit eventuell strafrechtlichen Folgen ausgesetzt zu sein. Die dadurch hervorgerufene Gefahr einer Selbstzensur der Informationsgewinnung im Internet ist im Hinblick auf die Wechselwirkungslehre, also Lichte der fundamentalen Wichtigkeit der Informationsfreiheit für die Demokratische

752 Zu alldem Sieber, Ausschussdrucksache 16 (9) 1559, S. 11.

753 Wobei diese nach der hier vertretenen Ansicht sogar dazu führen kann, dass eine gesetzliche Sperrverpflichtung verfassungsrechtlich als ungeeignet zu bezeichnen ist, da der durchschnittlich begabte Internetnutzer dann offenkundig auf das Bestehen einer Sperrmaßnahme und damit auch in die Richtung der Suche nach speziellen Umgehungsmethoden gelenkt wird.

754 Sieber, Stellungnahme der Experten, Ausschussdrucksache 16 (9) 1559, S. 12.

755 Vgl. Kahl, SächsVBl. 2010, 180 (194); grds. BVerfG, JuS 2009, 664 (665); Holznagel, ZUM 2000, 1007 (1011), in Bezug auf Providerverantwortlichkeit. 
Grundordnung, nicht hinnehmbar. Die Informationssuche darf nicht unterbleiben, nur weil der Nutzer fürchten muss, staatliche Stellen könnten sich in die Kommunikation einschalten und den Zugang sperren. ${ }^{756}$

(bb) Abwägungsergebnis

Es stehen sich somit auf beiden Seiten gewichtige Argumente gegenüber, die anders als bei der bloßen Betrachtung der Sperrung kinderpornographischer Inhalte, nicht ohne Weiteres zu Gunsten der einen noch der anderen Grundrechtspositionen aufgelöst werden können.

c) Verfahrensrechtliche Sicherung als Mittel des verfassungsrechtlichen Konkordanz

Im Lichte der Wichtigkeit der Informationsfreiheit ist demnach zu hinterfragen, ob hier möglicherweise im Wege der praktischen Konkordanz ein schonender Ausgleich der beeinträchtigten Positionen herbeigeführt werden kann.

$\mathrm{Zu}$ erwägen ist die Gefahr eines massiven Overblockings im Verhältnis zur geringen Effektivität über verfahrensrechtliche Sicherungsmittel rechtsstaatlich zu begrenzen. Dadurch könnte erreicht werden, dass die staatliche Schutzverpflichtung zur Wahrung und Aufrechterhaltung der Rechtsordnung sowie zur Realisierung eines effektiven Jugendschutzes einerseits sowie die Interessen der Nutzer an der Vermeidung eines massiven Eingriffs in die fundamentalen Kommunikationsrechte andererseits, einem verfassungsrechtlich hinnehmbaren Ausgleich zuzuführen sind. Schließlich droht der Aspekt der verfassungsrechtlich bedenklichen und enormen Eingriffsintensität in die Informationsfreiheit der Nutzer aus Art. 5 Abs. 1 Satz 1, Alt. 2 GG nur in besonderen Einzelfällen, wenn Löschverfügungen nicht erfolgreich ergehen. Auch die weiteren Aspekte, die in der Gegenüberstellung der beeinträchtigten Grundrechtspositionen auf Seiten der Informationsfreiheit anzuführen sind, basieren auf Tatsachen, die sich über eine verfahrensrechtliche Sicherung bestmöglich relativieren lassen.

Als ein solches verfahrensrechtliches Sicherungsmittel kommt die Normierung eines Richtervorbehalts in Betracht. ${ }^{757}$

Das Bundesverfassungsgericht hat sich schon mehrmals bei der Diskussion um wichtige Einzelfragen der Verfassungsmäßigkeit von bestimmten Maßnahmen

756 So zumindest in Bezug auch das Fernmeldegeheimnis, BVerfGE 100, 313 (359).

757 So u.a. auch gefordert von Bäcker, Ausschussdrucksache, S. 9, ähnlich auch eco, Stellungnahme der Experten, Ausschussdrucksache 16 (9) 1542, S. 3; Frey/Rudolph, Ausschussdrucksache 16 (9) 1546, S. 15 f.; Kubnen, Ausschussdrucksache 16 (9) 1545, S. 4 jedoch ohne detaillierte Begründung. 
mit dem Richtervorbehalt befasst. ${ }^{758}$ Danach bilde dieser ein zentrales Instrument im verfahrensrechtlichen System der Grundrechtssicherung, dass von der Grundidee geprägt sei, bei besonders intensiven Grundrechtseingriffen, dem Gewicht dergleichen, durch besonders geeignete Verfahrensvorkehrungen Rechnung zu tragen. ${ }^{759}$ Die Anordnung präventiver Richtervorbehalte als Instrument der vorbeugenden Kontrolle einer Maßnahme, sei eine Regelungstechnik, welche sich im besonderen Maße dazu eigne die Verhältnismäßigkeit einer Maßnahme im Einzelfall sicherzustellen. ${ }^{760}$ Dabei ist nicht zu verwechseln, dass die verfahrensrechtliche Sicherung keineswegs materielle Mängel der gesetzlichen Sperrverpflichtung ausgleichen kann, ${ }^{761}$ dies ist mit dem Erfordernis hier auch nicht gewollt. Der Richtervorbehalt soll lediglich einen schonenden Ausgleich bezüglich miteinander konkurrierender Grundrechte darstellen.

In der Regel bestimmt das Grundgesetz selbst wann ein Richtervorbehalt als verfassungsrechtliches Sicherungsmittel einschlägig und zwingend einzuhalten ist. Geschriebene Vorbehalte finden sich in Art. 13 Abs. 2, 3 Satz 2, 4 sowie in Art. 104 Abs. 2, 3 GG. Die Rechtsprechung ist jedoch keineswegs auf die geschriebenen Vorbehalte beschränkt, sondern geht von einer allgemeinen Anwendbarkeit aus. Anerkannt und ausdrücklich herausgestellt wurde das Erfordernis eines Richtervorbehalts insbesondere im Zusammenhang der verfassungsmäßigen Rechtfertigung von Eingriffen in das Fernmeldegeheimnis nach Art. 10 Abs. 1, Var. 3 GG.762 Die Rechtsprechung weitet das Erfordernis seit dem OnlineDurchsuchungs-Urteil nunmehr auch auf das Grundrecht auf Gewährleistung der Vertraulichkeit und Integrität informationstechnischer Systeme aus. ${ }^{763}$

Den Ausführungen des Bundesverfassungsgerichts ist dabei eine gewisse Regelmäßigkeit zu entnehmen. Soweit zwei Kriterien kumulativ vorliegen, befürwortet es das Erfordernis eines Richtervorbehalts, um die Verfassungsmäßigkeit der Maßnahme im Einzelfall verfahrensrechtlich abzusichern: Zum einen muss es sich um einen besonders „,schweren Grundrechtseingriff“ handeln; zum anderen wurde der Richtervorbehalt grundsätzlich bei „Heimlichkeit“ der staatlichen Maßnahme angenommen, welche bewirkt, dass der „Betroffene selbst seine Interessen aufgrund der Heimlichkeit der Maßnahme im Vorwege nicht wahrnehmen

758 BVerfGE 51, 97; BVerfG, NJW 1981, 211; BVerfGE 120, 274; BVerfG, NJW 2010, 2864; allgemein zum Richtervorbehalt als verfassungsrechtliches Kompensat, Gusy, JZ 2001, 1033; ders., GA 2003, 673; Gusy, NStZ 2010, 353.

759 Gusy, NStZ 2010, 353 (354).

760 Durner in: Maunz/Dürig, Art. 10 GG, Rn. 153.

761 BVerfGE 110, 33 (66).

762 BVerfGE 107, 299 (325), hierzu Durner in: Maunz/Dürig, Art. 10 GG, Rn. 152 ff.; Baldus, Epping/Hillgruber, Art. 10 GG, Rn. 45; Gusy in: v. Mangoldt/Klein/Starck, Art. 10 GG, Rn. 74.

${ }^{763}$ BVerfGE 120, 274 (331), zu Einzelfall Fragen Britr, DöV 2008, 411 (415). 
kann“.764 Die Kontrolle des Richters diene insoweit einer „kompensatorischen Repräsentation" der Interessen des Betroffenen. ${ }^{765}$ Ein Richtervorbehalt gilt danach jedenfalls als verfassungsmäßig erforderlich, wenn ex ante die Notwendigkeit besteht „besonders geschützte Zonen der Privatheit“ und die „Interessen des Betroffenen verfahrensrechtlich abzusichern“.

Bemüht man sich einer Übertragung der rechtsprechungsanalytischen Vorgaben an den Richtervorbehalt auf die gesetzliche Sperrverpflichtung so fällt zunächst folgende Parallelität auf: Auch im Falle der gesetzlichen Sperrmaßnahmen kommt es zu besonders schwerwiegenden Eingriffen. Soweit eine Löschung scheitert und auf das Sperrerfordernis ultima ratio zurückgegriffen wird, ist je nach Art der Sperrmaßnahme ein besonders schwerwiegender Grundrechtseingriff in die Informationsfreiheit der Nutzer zu befürchten, da oftmals mit einer einzigen Sperrmaßnahme eine ganze Vielzahl von völlig unbedenklichen Inhalten ebenfalls unzugänglich wird. Die Sperrung dieser Inhalte ist reine Nebenfolge der jugendschutz- und gefahrenabwehrrechtlich zu vertretenden Sperrung. Hat für sich genommen aber keine staatliche Notwendigkeit.

In Bezug auf die Intensität des Grundrechtseingriffs ist die gesetzliche Sperrmaßnahme damit vergleichbar mit einem schwerwiegenden Eingriff in die Privatsphäre des Einzelnen. Zwar ist hier anders als in den entschiedenen Fällen nicht ein Grundrecht betroffen, dass direkt aus dem allgemeinen Persönlichkeitsrecht resultiert oder zumindest entsprechende Rückschlüsse auf eine Persönlichkeitsprofil zulässt, ${ }^{766}$ jedoch kommt es zur Bejahung der Notwendigkeit nicht auf eine völlige Identität, sondern lediglich auf die generelle Vergleichbarkeit der Fälle an, welche hier zweifelsohne gegeben ist: Gleichsam staatlicher Infiltration eines informationstechnischen Systems, ${ }^{767}$ werden zur Vornahme von Sperrungen ebenfalls direkte Eingriffe in den technischen Kommunikationsbestand eines informationstechnischen Systems vorgenommen und Kommunikationsdaten erhoben

\footnotetext{
764 BVerfGE 120, 274 (332).

765 BVerfGE 120, 274 (332), bezugnehmend auf SächsVerfGH, JZ 1996, 957 (964).

766 BVerfGE 120, 274.

767 So der Ausgangspunkt der Online-Durchsuchungsentscheidung BVerfGE 120, 274, wonach das nordrheinwestfälische Verfassungsschutzgesetz die Befugnisse der Verfassungsbehörden zu verschiedenen Datenerhebungen insbesondere aus informationstechnischen Systemen (Computern etc.) enthielten. Das BVerfG erklärte die Nomen für mit dem Grundgesetz unvereinbar und das Gesetz für nichtig. Ein durch die Infiltration gegebener Eingriff in das aus dem Allgemeinen Persönlichkeitsrecht abgeleitete Recht auf Gewährleistung der Vertraulichkeit und Integrität informationstechnischer Systeme, mittels derer die Nutzung des Systems überwacht und seine Speichermedien ausgelesen werden können, sei verfassungsrechtlich nur zulässig, wenn tatsächliche Anhaltspunkte einer konkreten Gefahr für ein überragend wichtiges Rechtsgut bestehen, beispielsweise eine Bedrohung von Leib, Leben und Grundlagen der Existenz des Staates bedroht sind.
} 
werden. ${ }^{768}$ Auch wenn es hier nicht um die persönlichkeitsrechtlichen Aspekte des Datenerhebung geht, so ist das Gewicht des Eingriffs in das Informationsrecht gleichwertig mit dem in das Allgemeine Persönlichkeitsrecht, da mit der Vornahme einer Sperrung eine Vielzahl von Beeinträchtigungen des Informationsbestandes einhergeht und dem Nutzer praktisch eine staatliche Maßnahme aufgedrängt wird, auf deren Vornahme er keinerlei vorhergehenden rechtlichen Einfluss hat.

Auch bezüglich des Erfordernisses der Heimlichkeit finden sich Parallelen. Dem Nutzer wird in der Regel keine Möglichkeit zu Teil, hinreichend überprüfen zu können, welche Angebote als kinderpornographisch eingestuft wurden. Noch weniger hat er eine vorhergehende Vorstellung darüber, welche legalen Inhalte an die Aussonderung des illegalen Inhaltes gekoppelt und für ihn im Zugriff ebenfalls erschwert sind. Wenn überhaupt, so bekommt der Nutzer erst nach Einordnung sowie nach Vornahme der Sperrmaßnahme mit, dass er einer staatlichen Inhaltsregulierung unterliegt und sein Surfverhalten technisch eingeschränkt wurde. Bei der bloßen Mitteilung über einen Verbindungsabbruch beispielsweise über die Meldung „could not connect" wird regelmäßig nicht zu erkennen sein, dass eine staatliche Sperrmaßnahme den Verbindungsversuch negiert.

Zur Kompensation der mangelnden Rechtsschutzmöglichkeit wegen Heimlichkeit der Maßnahme müsste demnach gefordert werden, dass die Einordnung eines Inhaltes als kinderpornographisch und die damit einhergehende Sperrung durch einen unvoreingenommenen sowie mit dem notwendigen juristischen Sachverstand ausgestatteten Richter vor „Indexierung“ des Angebotes durchgesehen wird. ${ }^{769}$ Richter können aufgrund ihrer persönlichen und sachlichen Unabhängigkeit und ihrer ausschließlichen Bindung an das Gesetz die Rechte des Betroffenen im Einzelfall am besten und sichersten wahren. ${ }^{770}$ Vor allem in einem Bereich, der die Definition von Kinderpornographie voraussetzt, ist oftmals ein weiter Entscheidungsspielraum hinsichtlich formaler Kriterien eingeräumt. Beispielsweise genügt bereits Scheinminderjährigkeit, um den Straftatbestand zu erfüllen. Das heißt es reicht bereits aus, wenn in Wirklichkeit eine Person über 14 Jahre dargestellt wird, diese anhand der äußeren Umstände der Darstellung, für den objektiven Betrachter allerdings ,kindlich“ anmutet. ${ }^{771}$ Auch ist besonders vor dem Hintergrund, dass auch fiktive Darstellungen vom Straftatbestand der Kinderporno-

$768 \mathrm{Ob}$ die Erhebung der Daten einen Eingriff in das Fernmeldegeheimnis darstellt, zugleich unter 3. Teil C. II.

769 Wie hier ebenfalls Sieber, JZ 2009, 653 (659); Heckmann, Stellungnahme der Sachverständigen im Rechtsausschuss v. 8.11.2010, S. 18, abrufbar unter:

http://www.bundestag.de/bundestag/ausschuesse17/a06/anhoerungen/archiv/03_Zugangsers chwerung/04_Stellungnahmen/Stellungnahme_Heckmann.pdf (zuletzt abgerufen 20.5.2012).

770 BVerfGE 103, 142 (151); BVerfGE 107, 299 (325); BVerfGE 120, 274 (332).

771 Zum gesamten Komplex der inhaltlichen Anforderungen an den Straftatbestand der Kinderpornographie, oben2. Teil A. II. 1. 
graphie umfasst sind, eine vorherige juristisch verständige Überprüfung der Bedürftigkeit der Sperrung erforderlich. Erst wenn die Einordnung als kinderpornographisch verfahrensrechtlich sichergestellt ist, kann das Angebot einer Sperrung unterliegen und erst dadurch ist verfassungsrechtlich zu rechtfertigen, dass vor dem Hintergrund der Wichtigkeit der Jugendschutzes und der enormen Gefährdung, welche von kinderpornographischen Inhalten ausgeht, auch völlig legale Inhalte unzugänglich werden.

Im gleichen Zusammenhang ist für einen für alle Grundrechtspositionen hinnehmbaren Interessenausgleich zu fordern, dass die Möglichkeit der Auswahl der jeweiligen Sperrmaßnahme ebenfalls gesetzlich abgesichert und von einem Richter vor Vornahme der Sperrung überprüft wird. Aufgrund der Tatsache, dass mit jeder Sperrmaßnahme unterschiedlich intensive Einschränkungen der Informationsfreiheit verbunden sind, sollte die Entscheidung über die Wahl der technischen Methode nicht der Ausführungsentscheidung der Access-Provider überlassen, sondern bereits hinreichend gesetzlich fixiert werden. Dabei muss explizit abgewogen werden, bei welcher Sperrmaßnahme vor dem Hintergrund der Gefährdung durch den Inhalt, die wenigsten grundrechtlichen Belastungen der Nutzer, beziehungsweise weiterer am Kommunikationsprozess beteiligter Akteure, ausgehen. 772

Sollten die genannten Anforderungen an die gesetzliche Regelung sowie die verfahrensrechtliche Absicherung gewährleistet sein, so können die beteiligten Grundrechtspositionen hier in einen Ausgleich gebracht und die materielle Verfassungsmäßigkeit einer gesetzlichen Sperrverpflichtung nicht beanstandet werden.

\section{Ergebnis: Informationsfreibeit}

Grundsätzlich stellt eine gesetzliche Regelung, die auf die Sperrung kinderpornographischer Inhalte im Internet ausgerichtet ist einen Eingriff in das Grundrecht der Internetnutzer aus Art. 5 Abs. 1 Satz 1, Alt. 2 GG dar. Aufgrund des subsidiären Charakters der Maßnahme kommt dieser allerdings nur in wenigen Ausnahmefällen in Betracht. Um dem Gewicht der beeinträchtigten Grundrechtspositionen gerecht zu werden, stellen sich erhöhte Anforderungen an die Verfassungsmäßigkeit, die aber unter Beachtung verfahrensrechtlicher Kompensationsmittel herbeigeführt werden kann.

$772 \mathrm{Ob}$ die vom ZugErschwG verfolgte Mindestlösung der DNS-Sperre“ ausreichend ist, wird größtenteils bezweifelt, siehe hierzu Frey/Rudolph, Stellungnahme der Sachverständigen im Rechtsauschuss v. 7.11.2010, S. 10 f.; ausführlich und in Beschränkung auf die DNS- Methode, Sieber, Stellungnahme der Experten, Ausschussdrucksache 16 (9) 1554, S. 6 ff. 
II. Fernmeldegeheimnis Art. 10 Abs. 1, Var. 3 GG

\section{Eröffnung des Schutzbereiches}

Der Schutzbereich des Fernmeldegeheimnisses gemäß Art. 10 Abs. 1, Var. 3 GG umfasst die Vertraulichkeit individueller unkörperlicher Kommunikation auf Distanz. ${ }^{773}$ Der Begriff des Fernmeldeverkehrs umfasst dabei jede Nachrichtenübermittlung unter Raumüberwindung in nicht körperlicher Weise mittels technischer Einrichtungen. ${ }^{774}$ Geschützt ist die Vertraulichkeit der Nutzung des zur Nachrichtenübermittlung eingesetzten technischen Mediums, nicht aber das Vertrauen der Kommunikationspartner zueinander. ${ }^{775}$ Risiken, welche nicht in der telekommunikativen Übermittlung gründen, sondern aus dem Einfluss- und Verantwortungsbereich eines der Kommunizierenden stammen, werden daher von der Grundrechtsnorm nicht erfasst. ${ }^{776}$ Die Schutzintention des Fernmeldegeheimnisses gründet in dem Umstand, dass die Phase der Übermittlung einer Nachricht vom Sender zum Empfänger weitestgehend dem Einfluss der beteiligten Kommunikationspartner entzogen ist, die gleichen jedoch ein Interesse daran haben, dass auch während dieser Phase, die Kommunikation vor staatlicher Einflussnahme geschützt werde. ${ }^{777}$ Damit geht von dem verwendeten Medium selbst die maßgebliche Gefahr eines Verlustes von Vertraulichkeit aus, indem es dem unkontrollierbaren Zugriff Dritter unterliegt. ${ }^{778}$ Art. 10 Abs. 1 GG soll demnach einen Ausgleich für die technisch bedingte Einbuße an Vertrautheit schaffen und will den Gefahren entgegen, die aus dem Übermittlungsvorgang entspringen. ${ }^{779}$ Über Art. 10 Abs. 1 GG sollen die an der Kommunikation Beteiligten daher so gestellt werden, wie sie bei der Kommunikation unter Anwesenden stünden. ${ }^{780}$

Inhaltlich findet der Schutzumfang des Art. 10 Abs. 1, Var. 3 GG verfassungsrechtlich in zweierlei Hinsicht seine Ausprägung: Zum einen soll sich die Vertraulichkeit auf den Inhalt innerhalb des Kommunikationsvorgangs beziehen zum

773 Hermes in: Dreier, Art. 10 GG, Rn. 15, 37; Sievers, Der Schutz der Kommunikation im Internet, 2003, S. 111, Pagenkopf in: Sachs, Art. 10 GG, Rn. 14; Jarass in: Jarass/Pieroth, Art. 10 GG, Rn. 5.

774 BVerfGE 46, 120 (128); Schmidt in: Umbach/Clemens, Art. 10 GG, Rn. 64.

775 BVerfGE 106, 28 (37); BVerfGE 120, 274 (340); BVerfG, NJW 2007, 3055.

776 BVerfGE 106, 28 (37); BVerfGE 120, 274 (340); Bock in: Beck'scher TKG-Komm., \88 TKG, Rn. 2.

777 In die Richtung Kindt, MMR 2009, 147 (150); Bäcker in: Rensen/Brink, Linien der Rechtsprechung des BVerfG, 2009, S. 99 (103); Sieber/Nolde, Sperrverfügungen im Internet, 2008, S. 79.

778 Gusy in: v. Mangoldt/Klein/Starck, Art. 10 GG, Rn. 41.

779 BVerfGE 85, 386 (396); BVerfGE 106, 28 (36); BVerfGE 107, 299 (313).

780 BVerfG WM, 2011, 211 (212). 
anderen sind auch die näheren Umstände der Kommunikation geschützt. ${ }^{781} \mathrm{Zu}$ den näheren Umständen der Kommunikation gehören alle Aspekte, die einen Rückschluss auf die Ausgestaltung der Kommunikation zulassen, insbesondere „ob, wann und wie oft zwischen welchen Personen oder Fernmeldeanschlüssen Fernmeldeverkehr stattgefunden hat oder versucht worden ist." "782 Die Kommunikationsumstände genießen einen selbstständigen Schutz, der nicht etwa lediglich von dem Schutz der Kommunikationsinhalte abgeleitet ist. ${ }^{783}$ Der Schutzcharakter des Art. 10 Abs. 1 GG wäre in Folge der Digitalisierung unzureichend gewährleistet, wenngleich diese näheren Umstände der Kommunikation nicht ebenfalls verfassungsrechtlich abgesichert wären. Denn auch Häufigkeit, Dauer und Zeitpunkt von Kommunikationsverbindungen geben Hinweise auf Art und Intensität von Beziehungen und ermöglichen auf den Inhalt bezogene Schlussfolgerungen. ${ }^{784}$ Der Schutzumfang des Fernmeldegeheimnisses erstreckt sich auf den rein infrastrukturellen Bereich der Datenübertragung und ist damit mit Beendigung der Kommunikation erloschen. ${ }^{785}$ Vor Beginn der Datenübertragung sowie nach ihrer Beendigung besteht die typische Schutzintention des Art. 10 Abs. 1, Var. 3 GG gerade nicht. Denn die Inhalte sowie die näheren Umstände der Kommunikation befinden sich hierbei im Herrschaftsbereich der jeweiligen Kommunikationspartner, wo sie über speziellere Grundrechte geschützt werden. ${ }^{786}$ Geht es allerdings um den Zugriff während des Kommunikationsvorgangs, so ist Art. 10 Abs. 1, Var. 3 GG als lex specialis heranzuziehen. ${ }^{787}$

a) Schutzwirkung des Fernmeldegeheimnisses für Internetinhalte

Vorgelagert der Frage, ob gesetzlich veranlasste Sperrverpflichtungen zur Unterbindung kinderpornographischer Inhalte im Internet den Schutzbereich des Fernmeldegeheimnisses des Art. 10 Abs. 1 GG eröffnen, ist zunächst zu erläutern, ob das Fernmeldegeheimnisses in Bezug auf Internetinhalte überhaupt Anwendung findet.

781 BVerfGE 85, 386 (396); BVerfGE 107, 299 (312); BVerfGE 100, 313 (358); BVerfGE 67, 157 (172); BVerfG, WM 2011, 211.

782 BVerfGE 67, 157 (172); BVerfGE 85, 386 (396); BVerfGE 100, 313 (358); BVerfGE 107, 299 (312 f.); BVerfGE 115, 166 (183); BVerfGE 120, 274 (307); BVerfG, CR 2010, 232 (233).

783 Bäcker in: Rensen/Brink, Linien der Rechtsprechung des BVerfG, 2009, S. 99 (103).

784 BVerfGE 67, 157 (172); BVerfGE 85, 386 (396); BVerfGE 107, 299 (329); BVerfGE 110, 33 (53); BVerfGE 115, 166 (183).

785 BVerfGE 106, 28 (38); BVerfGE 115, 166 (183 f.); Hermes in: Dreier, Art. 10 GG, Rn. 42; Gusy in: v. Mangoldt/Klein/Starck, Art. 10 GG, Rn. 24; Bizer in: Alternativkommentar GG, Art. 10 GG, Rn. 67; Hausscbild, NStZ 2005, 339; Bär, MMR 2005, 523 (524); Günther, NStZ 2005, 485 (489).

786 BVerfGE 115, 166 (183 f.).

787 BVerfGE 100, 313 (360); in die Richtung Jarass in: Jarass/Pieroth, Art. 10 GG, Rn. 5. 
Teilweise wird die Anwendbarkeit des Fernmeldegeheimnisses auf Onlinesachverhalt bestritten, weil Internetinhalte grundsätzlich keine individuelle Kommunikation garantieren, sondern vordergründig an die Allgemeinheit gerichtet sind. ${ }^{788}$ Diesen Fall umfasse der Schutzbereich des verfassungsrechtlichen Fernmeldegeheimnisses gerade nicht. Eine schützenswerte Vertraulichkeit, wie sie schon im Wortlaut des Grundrechts durch den Wortteil „Geheimnis“ gefordert wird, sei dort nicht gegeben, wo sich eine Kommunikation an eine unbestimmte Vielzahl von Adressaten richte, da Kommunikationsangebote an jedermann nicht geheim, im Sinne von vertraulich seien. ${ }^{789}$ Grundrechtlichen Schutz der Allgemeinkommunikation erhalte der Grundrechtsträger nicht aus Art. 10 Abs. 1, Var. 3 GG, sondern über entsprechende Kommunikationsfreiheiten des Art. 5 Abs. 1 GG. ${ }^{790}$ Maßgeblich für den Schutz des Art. 10 GG ist daher die Individualität der Kommunikation, also die Übermittlung von Informationen an einen oder mehrere individuelle Empfänger. ${ }^{791}$

Ziel der gesetzlichen Sperrmaßnahmen ist es, den Zugriff der Nutzer auf bestimmte an die Allgemeinheit gerichtete Webangebote zu verhindern. Würde man der vorstehenden Ansicht daher Folge leisten, so läge es nahe, die Schutzwirkung des Grundrechts auf Onlinesachverhalte zu verneinen.

Fraglich ist indes, ob die angestrebte Unterscheidung zwischen Individual- und Allgemeinkommunikation im Internet durchzuhalten ist und damit tatsächlich im Rahmen der Frage nach einer Schutzwirkung des Fernmeldegeheimnisses für Onlinesachverhalte bestimmend sein kann.

Zum Teil gehen Bemühungen dahin, einerseits die strikte Unterscheidung zwischen Allgemein- und Individualkommunikation als Ausgangspunkt des Schutzbereichs des Art. 10 Abs. 1 GG beizubehalten, andererseits Onlinesachverhalte als Teil der geschützten Individualkommunikation anzuerkennen: Die technische Funktionsweise des Internets basiere danach durchgängig auf individuellen technischen Verbindungen zwischen den jeweils verarbeitenden Computern und führe somit stets zu einer geschützten Individualkommunikation. ${ }^{792}$ Zur Herstellung einer Kommunikation im Internet sei es notwendig, eine individuell adressierte

788 Pagenkopf in: Sachs, Art. 10 GG, Rn. 14a; Durer, ZUM 2010, 833 (838 ff.), zusammenfassend mwN. Bäcker in: Rensen/Brink, Linien der Rechtsprechung des BVerfG, 2009, S. 99 (104).

789 Durer, ZUM 2010, 833 (838).

790 Albers, Informationelle Selbstbestimmung, 2005, S. 371; Gusy in: v. Mangoldt/Klein/Starck, Art. 10 GG, Rn. 42; Hermes in: Dreier, Art. 10 GG, Rn. 38, Stern in: Stern, Staatsrecht, 2006, Bd. 4/1, S. 227 f.; Bäcker in: Rensen/Brink, Linien der Rechtsprechung des BVerfG, 2009, S. 99 (104).

791 BVerfGE 115, 166 (182); Bizer in: Alternativkommentar GG, Art. 10 GG, Rn. 39.

792 Determann, Kommunikationsfreiheit im Internet, S. 462 f.; Germann, Gefahrenabwehr im Internet, 2000, S. 117; dem folgend Bäcker in: Rensen/Brink, Linien der Rechtsprechung des BVerfG, 2009, S. 99 (104); Sievers, Der Schutz der Kommunikation im Internet, 2003, S. 129 f.; Frey/Rudolph, Rechtsgutachten BVDW, 2008, Rn. 19. 
Anfrage an einen anderen Rechner zu senden, welche als eine gleichfalls individuell adressierte Antwort zurückgesandt wird. Selbst wenn die Inhalte, auf die sich die Anfrage beziehe, jedermann offen stehen, seien die Adressaten keineswegs für die Allgemeinheit bestimmt oder erkennbar. Die Ansicht wird zutreffend um das Argument ergänzt, dass die Beibehaltung der Unterscheidung zwischen einer individuellen und allgemeinen Kommunikation aus teleologischen Aspekten durchaus angebracht erscheine, da die von Art. 10 Abs. 1 GG geschützte Vertraulichkeit der Kommunikation nicht angetastet wird, wenn eine staatliche Stelle allgemein zugängliche Kommunikationsinhalte unter denselben Voraussetzungen wie jeder Dritte zur Kenntnis nimmt. ${ }^{793}$

Jedoch mündet die Beibehaltung einer Unterscheidung zwischen Individualund Massenkommunikation zwangsläufig in Abgrenzungsschwierigkeiten, die vor dem Hintergrund der technischen Ausgestaltung des Internets kaum noch trennungsscharf durchzuhalten ist. ${ }^{794}$ Insbesondere ist es nicht möglich auf der technischen Ebene einzelne Kommunikationsdienste des Internets wie beispielsweise Email oder Chatfunktion pauschaliert der Individualkommunikation und andere, wie den besonders bei Sperrverpflichtungen in Frage stehenden Dienst des World Wide Web, dem Bereich der Massenkommunikation zuzuordnen. ${ }^{795}$ Vor allem ist der Dienst des World Wide Web technisch so ausgestaltet, dass eine Vereinigung vieler individueller Aspekte über allgemein verbreitete Angebote zulässt, so dass die Trennung auf dem für die Sperrverpflichtungen relevanten Übertragungsprotokolls nicht konsequent durchgehalten werden kann. ${ }^{796}$ Daher ist es im Sinne des Grundrechtsträgers effektiver die Reichweite des Schutzbereichs in Anlehnung an die Rechtsprechung des Bundesverfassungsgerichts „entwicklungsoffen“ auszulegen. ${ }^{797}$ Danach umfasse die Schutzwirkung auch „,neuartige Übertragungstechniken mit Hilfe der verfügbaren Telekommunikationstechniken" ${ }^{\text {"798 }}$ und soll auch neuen Persönlichkeitsgefährdungen begegnen „die sich aus der gestiegenen Bedeutung der Informationstechnik für die Entfaltung des Einzelnen ergeben.“799

793 Bäcker in: Rensen/Brink, Linien der Rechtsprechung des BVerfG, 2009, S. 99 (104).

794 Hierzu Durer in: Maunz/Dürig, Art. 10 GG, Rn. 92 ff.; Bäcker in: Rensen/Brink, Linien der Rechtsprechung des BVerfG, 2009, S. 99 (104); Degenhardt, CR 2011, 231 (232).

795 In die Richtung jedoch Böckenförde, JZ 2008, 925 (937 f.), der insbesondere das World Wide Web aus dem Schutzbereich des Fernmeldegeheimnisses herausnehmen möchte.

796 Bäcker in: Rensen/Brink, Linien der Rechtsprechung des BVerfG, 2009, S. 99 (105); Gusy in: v. Mangoldt/Klein/Starck, Art. 10 GG, Rn. 43 f.; Jarass in: Jarass/Pieroth, Art. 10 GG, Rn. 6.

797 BVerfGE 46, 120 (143); BVerfGE 115, 166 (182); BVerfG, WM 2011, 211; Baldus in: Epping/Hillgruber, Art. 10 GG, Rn. 7; Gusy in: v. Mangoldt/Klein/Starck, Art. 10 GG, Rn. 40; für die Anerkennung des Schutzbereichs auch Frey/Rudolpf/Oster, MMR-Beil. 3/2012, S. 6.

798 BVerfGE 115, 166 (182).

799 BVerfGE 120, 274 (307). Für die Einbeziehung von Internetdiensten in den Schutzbereich, BVerfGE 113, 348 (383) E-Mails; BVerfGE 120, 274 (307). 
Der Schutz des Art. 10 Abs. 1 GG erfasst damit die Telekommunikation im Ganzen „einerlei welche Übermittlungsart (Kabel oder Funk, analoge oder digitale Vermittlung) und welche Ausdrucksform (Sprache, Bilder, Töne, Zeichen oder sonstige Daten) genutzt werden".800 Ausdrücklich erweitert das Bundesverfassungsgericht den Schutzbereich damit auch auf „die Kommunikationsdienste des Internets. “801 So betrachtet genießen neben den „herkömmlichen“ Kommunikationsdiensten des Internets, wie Chat sowie Email auch sämtliche anderen Internetdienste wie World, Wide, Web, on-demand-Netzwerke, Textverarbeitungsprogramme im Zweifel verfassungsrechtlichen Schutz.

Die vom Bundesverfassungsgericht vorgenommene Ausweitung des Fernmeldegeheimnisses auf sämtliche Internetdienste erscheint vorzugswürdig. Zwar mag die Unterscheidung zwischen Allgemein- und Individualkommunikation teleologisch verständlich sein, da die vom Schutzbereich umfasste „Vertraulichkeit“ schon in ihrer sprachlichen Tendenz nur innerhalb eines direkten Austausches der am Kommunikationsprozess beteiligten Akteure gewährleistet und dementsprechend auch nur dort angetastet werden kann. Die Entwicklungsoffenheit und die Vergleichbarkeit der Schutzintension bei internetvermittelter Kommunikation zur Telekommunikation rechtfertigt eine Schutzbereichseröffnung für alle Dienste des Internets. Die Risiken der aus dem Herrschaftsbereich der Kommunikationspartner entlassenen Daten stellen sich gleichsam bei individual- sowie allgemeinheitsbezogenen Kommunikationsmittel und können in Anbetracht der zunehmenden Stellung des Internets nicht jeglichen Grundrechtsschutz entbehren. Daher ist der hier vertreten Ansicht nach auf die Unterscheidung zu verzichten und sämtliche Kommunikation im Internet als vom Schutzbereich des Art. 10 Abs. 1, Var. 3 GG umfasst, anzusehen, soweit die zusätzlichen Voraussetzungen des Grundrechtsschutzes gegeben sind..$^{802}$

BVerfGE 106, 28 (36); BVerfGE 115, 166 (182); BVerfGE 120, 274 (307).

BVerfGE 113, 348 (383); BVerfGE 120, 274 (307); dem zustimmend Jarass in: Jarass/Pieroth, Art. 10 GG, Rn. 5; differenzierendLöwer in: v. Münch/Kunig, Art. 10 GG, Rn. 18; AA. Pagenkopf in: Sachs, Art. 10 GG, Rn. 14; a.A. Durer, ZUM 2010, 833 (840 f.), allein auf die Notwendigkeit einer Individualkommunikation für den Schutzbereich abstellt zu welcher er das Internet gerade nicht zählt.

802 IE. Bäcker in: Rensen/Brink, Linien der Rechtsprechung des BVerfG, 2009, S. 99 (109); Frey/Rudolph, Rechtsgutachten BVDW, 2008, Rn. 15 ff.; Heuner in: Taeger/Wiebe, Inside the cloud, 2009, S. 107 (11 ff.); wohl auch BMI u.a, Sitzung der Arbeitsgruppe „Access-Blocking“ am 12.2.2009, „Grundrechtliche, telekommunikations- und telemedienrechtliche Fragen im Zusammenhang mit der Sperrung kinderpornographischer Inhalte im Internet“ v. 19.2.2009, S. 1 ff., abrufbar unter: http://blog.odem.org/2009/02/19/finale-stellungnahme.pdf (zuletzt abgerufen 20.5.2012), jedoch ohne den Schutzbereich auf Internetinhalte zu hinterfragen. Strikte Ablehnung der weiten Auffassung Durer, ZUM 2010, 833 (838 ff.) mwN. 
b) Schutzbereichsrelevanz der Sperrmaßnahmen

(aa) IP-Sperrmethode: IP-Adresse als Umstand der Kommunikation

Die IP-Sperrmethode eröffnet den Schutzbereich des Fernmeldegeheimnisses, soweit die während des Sperrmechanismus ausgelesene IP-Adresse einen schutzbereichsrelevanten Umstand der Kommunikation darstellt.

(1) Erhebung der IP-Adressen als Notwendigkeit zur Datenübertragung sowie zur Sperrung

Zunächst ist herauszustellen, dass IP-Adressen die zentralen Verbindungsdaten der Internetkommunikation darstellen, indem sie spezielle Einzelfragen über die technische Dimension der Datenübertragung kodieren. ${ }^{803}$ Sie selbst sind jedoch nur nummerische Zahlenfolgen, die für sich genommen keine Aussage über den Inhalt noch über Umstände der Kommunikation treffen. Der netzarchitektonischen Datenverarbeitung im Internet ist es aber immanent, dass eben über die jeweilige nummerische Zahlenfolge der IP-Adresse der Datenübertragungsprozess zwischen Ziel- und Absenderhost funktioniert. Durch die spezifische IPAdressierung kann eine bestimmte Anfrage einem bestimmten Webserver zugeordnet werden und bewirkt, dass der angeforderte Inhalt letztlich auf der Bildschirmoberfläche des Nutzers angezeigt wird. ${ }^{804}$ Für die Erreichung einer Datenkommunikation sowie für die Einrichtung einer IP-Blockade ist die kurzzeitige Verwendung der in der Anfrage enthaltenden IP-Adresse notwendig, um das jeweilige Datenpaket zielorientiert zu versenden beziehungsweise verwerfen zu können. ${ }^{805}$

Die Notwendigkeit der IP-Adresse zur Realisierung der Datenübertragung im Internet bewirkt, dass eine Knappheit von freien IP-Adressen herrscht.806 Daraus ergeben sich technisch unterschiedliche IP-Adressen, die letztlich auch rechtlich unterschiedlich zu behandeln sind: Webserver, die Inhalte im Internet zur Verfügung stellen, haben in der Regel feste, so genannte statische IP-Adressen, die nicht wechseln. ${ }^{807}$ Einem bestimmten Webserver wird bei Vertragsbegründung mit dem Provider nur eine spezifische IP-Adresse zugewiesen, anhand derer sich stets eine Zuordnung zum dahinterstehenden Computersystem beispielsweise über den Abgleich der Vertragsunterlagen durch den Access-Provider herstellen lässt. ${ }^{808}$

803 Sachs, CR 2010, 547 (548); Sieber/Nolde, Sperrverfügungen im Internet, 2008, S. 83.

804 Zum Datenverarbeitungsprozess oben 2. Teil B. I.

805 Durer, ZUM 2010, 833 (848).

806 Hierzu Sieber in: Hoeren/Sieber, Hdb. Multimedia-Recht, Teil 1, Rn. 57.

807 Bär in: Bär, Hdb. EDV-Beweissicherung, 2007, Rn. 16; Graf in: Graf, StPO-Komm., \ 100a StPO, Rn. 15.

808 In Bezug auf die Personenbezogenheit i.S.d. $₫ 3$ BDSG Buchner in: Taeger/Gabel, $₫ 3$ BDSG, Rn.17; Dammann in: Simitis, \3 BDSG, Rn. 63. 
Auf Seiten des Nutzers agieren technisch so genannte Clients, die zum Abruf von Webinhalten gebraucht werden. Um IP-Adressen einzusparen, werden in der Regel von den jeweiligen Access-Providern den Clients (also den abfragenden Computersystemen) IP-Adressen lediglich für die Dauer einer Verbindung zugewiesen. Dies bedingt, dass eine einzige aus dem Adressenpool des Access-Providers stammende IP-Adresse, beliebig oft an verschiedene Nutzer zugewiesen werden kann. ${ }^{809}$ Bei einer solchen dynamischen IP-Adressierung ${ }^{810}$ tritt der Nutzer bei jeder neuen Internetnutzung nach außen unter einer anderen IP-Adresse auf. Bleibt der Nutzer mit dem Gerät länger im Netz, wird die zugewiesene IP-Adresse mindestens einmal täglich erneuert. ${ }^{811}$

(2) IP-Adresse als schutzbereichsrelevanter näherer Umstand der Kommunikation?

Fraglich ist, welche rechtliche Konsequenz aus der unterschiedlichen Vergabe von IP-Adressen für die Einordnung unter den Schutzbereich des Fernmeldegeheimnisses zu ziehen ist. Im Rahmen des Datenverarbeitungsprozesses im Internet werden IP-Adressen zunächst unabhängig einer etwaigen Differenzierung zur genauen Bezeichnung der miteinander kommunizierenden Computersysteme verwendet. Bei der IP-Sperrmethode werden von den Access-Providern, die für den Datenübertragungsvorgang ohnehin zu erfassenden IP-Adressen, von Client und Webserver durch Konfiguration am Router oder durch Filterung mittels Proxy zusätzlich auf die Übereinstimmung der angefragten IP-Adresse mit einer vorherig ,indizierten“ IP-Adresse abgeglichen. Bei Übereinstimmung wird der Verbindungsaufbau verworfen und der Datenverkehr unterbunden. Augenscheinlich bildet die jeweilige IP-Adresse, der an der Kommunikation beteiligten Rechner, nicht den eigentlichen Kommunikationsinhalt. Es kommt daher ein verfassungsrechtlicher Schutz über das Fernmeldegeheimnis als Teil der „näheren Umstände der Kommunikation " in Betracht. ${ }^{812}$

Der Schutzumfang der „näheren Umstände der Kommunikation“ wird vom Bundesverfassungsgericht gemeinhin „weit“ verstanden und umfasst grundsätz-

809 Begriffserläuterung LG Darmstadt, GRUR-RR 2006, 173; LG Köln, NSTZ 2009, 352; KirchbergLennartz/Weber, DuD 2010, 479. Die Vergabe solcher dynamischer IP-Adressen ist derzeit wohl der Regelfall. Schmitz in: Hoeren/Sieber, Hdb. Multimedia-Recht, Teil 16.2, Rn. 80; Bäcker in: Rensen/Brink, Linien der Rechtsprechung des BVerfG, 2009, S. 99 (112). Zu den entsprechenden datenschutzrechtlichen Streitfragen in Bezug auf dynamische IP-Adressen wird hier nicht eingegangen, vgl. hierzu ausführlich Meyerdierks, MMR 2009, 8 mwN.

810 Kirchberg-Lennarty/Weber, DuD 2010, 479; Sachs, CR 2010, 547 (548); Schmitz in: Hoeren/Sieber, Hdb. Multimedia-Recht, Teil 16.2, Rn. 80.

811 Meyerdierks, MMR 2009, 8 mwN.; Sachs, CR 2010, 547 (548); Schmitz in: Hoeren/Sieber, Hdb. Multimedia-Recht, Teil 16.2, Rn. 81.

812 Greiner, Die Verhinderung verbotener Internetinhalte, 2001, S. 116. 
lich alle Angaben, die Rückschlüsse auf die Kommunikationsvorgang zulassen, außerhalb der Kommunikation aber über spezielle Grundrechte abgesichert wären. 813 Die Ausweitung auf die „näheren Umstände der Kommunikation“ soll eben die aus der technischen Zwischenschaltung von Kommunikationsmitteln ergehenden Spielräume zur Rekonstruktion des Kommunikationsvorgangs kompensieren. Neben dem eigentlichen Inhalt müssen auch sämtliche technisch bedingten Rückschlussmöglichkeiten auf die Kommunikation als solche geschützt sein. Zu diesen werden gemeinhin die gesamten Verkehrsdaten gezählt, die Aufschluss über die an der Kommunikation beteiligten Personen sowie die äußeren Umstände der Kommunikation gewähren. 814

\section{(a) IP-Adresse als personenbezogenes Verkehrsdatum?}

Die IP-Adresse ist als ein personenbezogenes Verkehrsdatum zu begreifen und unterfällt demnach dem Schutz des Fernmeldegeheimnisses.

Der Begriff des Verkehrsdatums wird über die einfachgesetzliche Konkretisierung des Fernmeldegeheimnisses in $\ 88$ i.V.m. $\ 3$ Nr. 30 TKG näher ausgestaltet. Danach sind als Verkehrsdaten alle kommunikationsbezogenen Daten zu verstehen, die bei der „Erbringung eines Telekommunikationsdienstes erhoben, verarbeitet oder genutzt werden“. Über die kommunikationstechnische Verarbeitung der Verkehrsdaten wird gleichzeitig die Verwertbarkeit der Daten für Rückschlüsse auf den Kommunikationsvorgang begründet, die eine Auswertung von Häufigkeit und Dauer des Kommunikationsvorgangs erlauben. ${ }^{815}$

Die IP-Adresse wird bei der Herstellung einer Internetverbindung und der Datenübertragung zum angefragten Webserver von den jeweils an der Datenbearbeitung beteiligten Anwendungsprotokollen ausgelesen und entsprechend zur Anzeige der angeforderten Webseite genutzt. Über eine nachträgliche Analyse kann die

813 BVerfGE 67, 157 (172); BVerfGE 85, 386 (396); BVerfGE 100, 313 (358); BVerfGE 107, 299 (312 f.); BVerfGE 115, 166 (183); BVerfGE 120, 274 (307); BVerfG, CR 2010, 232 (233). BVerfGE 107, 299 (312 ff.); BVerfGE 113, 348 (365); BVerfGE 115, 166 (183); Gusy in: v. Mangoldt/Klein/Starck, Art. 10 GG, Rn. 45; Durer, ZUM 2010, 833 (842).

Abzugrenzen hiervon sind rein personenbezogene Daten, die außerhalb des eigentlichen Kommunikationsvorgangs entsprechend \95 TKG erhoben werden. Dazu zählen unter anderem so genannten Bestandsdaten, die gemäß $\int 3$ Nr. 3 TKG Daten eines Teilnehmers darstellen, die für die Begründung, inhaltliche Ausgestaltung, Änderung oder Beendigung eines Vertragsverhältnisses über Telekommunikationsdienste erhoben werden. Charakteristisch für die Bestandsdaten ist, dass diese gerade keinen Bezug zur konkreten Kommunikation aufweisen, vielmehr beziehen sich Bestandsdaten auf die vertragliche Beziehung zwischen Anbieter und Nutzer. Bei Ihrer Erhebung verwirklicht sich gerade nicht das typische Risiko, dass einer Kommunikation unter Abwesenden zugrundeliegt; folgerichtig fallen diese aus dem Schutzbereich des Fernmeldegeheimnisses heraus, hierzu Zerres in: Scheurle/Mayen, S 85, Rn. 17; Wuermeling/Felixberger, CR 1997, 230 (234); im Ergebnis OVG Münster, MMR 2009, 424. 
IP-Adressierung potentiell Aufschluss über die Häufigkeit sowie Dauer einer angesteuerten Internetverbindung geben. Notwendig hierfür ist eine Auswertung der (gespeicherten) Login-Files der Access-Provider. ${ }^{816}$ Hierüber kann anschließend theoretisch das Netzwerk herausgefiltert werden zudem der Abrufende gehört, gleichzeitig kann anhand der IP-Adresse eine Rekonstruktion des angeforderten Seitenverlaufs erfolgen, die zum Teil sogar eine spezifische Inhaltsanalyse der aufgerufenen beziehungsweise der einzelnen Zugriffsversuche dokumentiert. ${ }^{817}$ In der Folge eröffnet sich über die IP-Adresse die vom Schutzumfang des Fernmeldegeheimnisses zu kompensierende Gefahr des Verlustes der Vertraulichkeit, indem über Häufigkeit, Dauer und Zeitpunkt der getätigten Kommunikationsverbindungen, Rückschlüsse auf den Inhalt ermöglicht werden. ${ }^{818}$ Von diesen Aspekten her betrachtet wäre die IP-Adresse demnach als Verkehrsdatum und folglich als näherer Umstand der Kommunikation zu begreifen.

Jedoch unterfallen dem Schutzumfang des Fernmeldegeheimnisses nur solche Verkehrsdaten, die zugleich auch einen datenschutzrechtlichen Personenbezug aufweisen. ${ }^{819}$ Dies resultiert aus der engen Verbindung des Fernmeldegeheimnisses und des aus dem Allgemeinen Persönlichkeitsrecht abgeleiteten Rechts auf personelle Selbstbestimmung aus Art. 2 Abs. 1 i.V.m. Art. 1 Abs. 1 GG. Art. 2 Abs. 1 GG i.V.m. Art. 1 Abs. 1 GG gewährleistet in seiner Ausprägung als Recht auf informationelle Selbstbestimmung die Befugnis „,selbst über die Preisgabe und Verwendung seiner persönlichen Daten zu bestimmen. "820 Im Konkurrenzverhältnis der beiden Grundrechte zueinander betont das Bundesverfassungsgericht zwar den Anwendungsvorrang des Fernmeldegeheimnisses vor dem Recht auf informationelle Selbstbestimmung, ${ }^{821}$ es begreift die Gewährleistung des Art. 10 GG jedoch als „Sonderrecht“ gegenüber dem Recht auf informationelle Selbstbestimmung. ${ }^{822}$ Bei der grundrechtlichen Absicherung im Verhältnis der beiden

816 Sievers, Der Schutz der Kommunikation im Internet, 2003, S. 77; Sieber/Nolde, Sperrverfügungen im Internet, 2008, S. 83.

817 In die Richtung, BVerfG, CR 2010, 232 (242).

818 BVerfGE 67, 157 (172); BVerfGE 85, 386 (396); BVerfGE 107, 299 (329); BVerfGE 110, 33 (53); BVerfGE 115, 166 (183).

819 Durer, ZUM 2010, 833 (845); zum Verhältnis der beiden Grundrechte grundlegend Sievers, Der Schutz der Kommunikation, 2003, S. 134 ff.; angedeutet Sieber/Nolde, Sperrverfügungen im Internet, 2008, S. 83.

820 Begründet durch BVerfGE 65, 1.

821 BVerfG 100, 313 (358); so schon zum Verhältnis des Fernmeldegeheimnisses zum allgemeinen Persönlichkeitsrecht, BVerfGE 67, 151 (171).

822 Als „Sonderfall“ genannt bei Durner in: Maunz/Dürig, Art. 10 GG, Rn. 56; Durer, ZUM 2010, 833 (845); Sievers, Der Schutz der Kommunikation im Internet, 2003, S. 136; Böckenförde, Die Ermittlung im Netz, 2003, S. 172; Wedde in: Roßnagel, Hdb. Datenschutzrecht, 2003, Kap. 4.4, Rn. $1 \mathrm{ff}$. 
Grundrechte zueinander kommt es dabei entscheidend darauf an, welchem Grundrecht die Erlangung der Daten näher steht. ${ }^{823}$ Handelt es sich bei der Erlangung der Daten um eine spezifische Möglichkeit des Einsatzes eines Fernkommunikationsmittels, so verdrängt das Fernmeldegeheimnis im Weg der Spezialität die Grundgewährleistung des Rechts auf informationelle Selbstbestimmung. ${ }^{824}$ Die Anforderungen die für den Schutz des einen Grundrechts gelten, müssen insoweit auch für den Schutz des anderen Grundrechts gelten. ${ }^{825}$ Demnach ist der Schutzbereich des Fernmeldegeheimnisses auch nur dort gegeben, wo über erhobenen Daten, eine Individualisierung, also ein Bezug zu einer bestimmten Person hergestellt werden kann. ${ }^{826}$

Eben aus dieser Tatsache heraus gründet die weitläufige Unsicherheit der Einordnung der IP-Adresse unter dem Schutzbereichscharakter des Fernmeldegeheimnisses:

Personenbezogen im grundrechtlichen Sinne sind Verkehrsdaten nämlich nur dann, soweit sie Auskunft über persönliche und sachliche Verhältnisse einer „bestimmten oder bestimmbaren natürlichen Person" leisten können. ${ }^{827}$ Soweit sich also bereits aus der Erhebung, Verarbeitung und Nutzung des Datums Rückschlüsse auf Name und Anschrift des hinter dem Datum stehenden Anschlussinhabers herleiten lassen, genießt das Datum grundrechtlichen Schutz und darf nur über die zusätzlichen Einschränkungen des Art. 10 Abs. 2 GG, i.V.m. Art. 88, 96 TKG erhoben, gespeichert und verarbeitet werden.

In die Richtung BVerfGE 100, 313 (358 ff.).

In dem Zusammenhang ist seit der „Online-Durchsuchung“-Entscheidung, BVerfGE 120, 274 auch das Recht auf „Gewährleistung der Vertraulichkeit und Integrität informationstechnischer Systeme“ zu beachten. Dies stellt eine spezielle Ausprägung des Rechts auf informationelle Selbstbestimmung dar und soll überall dort vorrangig zur Anwendung kommen, wo sich die Erhebung der personenbezogenen Daten zwar über ein informationstechnisches System erfolgt. Die Erhebung jedoch unabhängig von einer konkreten Kommunikation (,außerhalb der laufenden Telekommunikation“, BVerfGE 120, 274 (308)) erfolgt, sondern losgelöst vom Einzelfall eine Datengesamtheit erfasst werden soll. Etwa die Auswertung der Festplatte eines Computers. Kritisch zur Neuschaffung dieses Grundrechts Gusy, DuD 2009, 33; Böckenförde, JZ 2008, 925 ff.; Hirsch, NJOZ 2008, 1907; Hoffmann-Riem, JZ 2008, 1009; Hornung/Schnabel, DVBl. 2010, 824. BVerfGE 100, 313 (358 f.); BVerfG, CR 2010, 232 (233); Pagenkopf in: Sachs, Art. 10 GG, Rn. 53; danach besteht die enge Verbindung durch die sich ähnelnden Schutzgüter, wobei Art. 10 GG lex specialis zu Art. 2 Abs. 1 iVm. Art. 1 Abs. 1 GG ist. In die Richtung ebenfalls BVerfGE 125, 260 (310); Löwer in: v. Münch/Kunig, Art. 10 GG, Rn. 24 Heuner in: Taeger/Wiebe, Inside the cloud, 2009, S. 107 (114).

26 Durer in: Maunz/Dürig, Art. 10 GG, Rn. 92 ff.; ders., ZUM 2010, 833 (844).

Dies begibt sich aus einer Heranziehung der Wertung aus $\int 3$ Abs. 1 BDSG, welcher eine einfach-gesetzliche Ausprägung des Rechts auf informationelle Selbstbestimmung darstellt. 
Übertragen auf die hier in Frage stehende IP-Adresse ist Voraussetzung für ihre Einordnung als personenbezogenes Verkehrsdatum, dass bereits über die Erhebung und Verarbeitung der IP-Adressierung während des Datenübertragungssowie Sperrvorgangs tatsächlich Rückschlüsse auf die an der Kommunikation Beteiligten zugelassen werden können. Eben vor diesem Hintergrund wird der Schutzbereichscharakter der IP-Adresse teilweise verneint. ${ }^{828}$ Schließlich handelt es sich bei IP-Adressen lediglich um nummerische Zeichenfolgen, die während ihrer Erhebung zur Bewerkstelligung des Datenverarbeitungsprozesses beziehungsweise zur Verwerfung desselben gebraucht werden. Folglich geben sie lediglich Auskunft über die miteinander in Verbindung tretenden Computersysteme (anfragender und die Information tragender Webserver), stellen aber nicht automatisch auch einen individuellen Bezug zu den hinter den jeweiligen Computersystemen stehenden Personen her. Für die Bestimmbarkeit der hinter dem jeweiligen Computersystem stehenden Personen ist vielmehr der Einbezug weiteren „Zusatzwissens" 829 notwendig, um die nummerische Zahlenfolge einem bestimmten Anschlussinhaber zuzuordnen.

Auch unter Zugrundelegung der Notwendigkeit eines Zusatzwissens wird die IP-Adresse, die während der IP-Sperrmethode zur Blockade kinderpornographischer Seiten gebraucht wird, als personenbezogenes Verkehrsdatum zu verstehen sein und folglich dem Schutzumfang des Fernmeldegeheimnisses unterfallen:830

Nach einer Ansicht ist der Personenbezug absolut zu bestimmen. ${ }^{831}$ Danach reicht bereits die „objektive“ Möglichkeit aus, dass eine Verknüpfung der IPAdresse zu einem bestimmten Anschlussinhaber denkbar ist. Soweit ein beliebiger Dritter eine Zuordnung der vergebenen IP-Adresse zu einem bestimmten Anschlussinhaber „grundsätzlich“ leisten kann, reiche dies aus, um grundlegend den Personenbezug anzunehmen. Nach dieser Ansicht wird die Bestimmbarkeit ohne Bezug zu einer konkreten Person oder Stelle losgelöst vom konkreten Einzelfall beurteilt.

Nach anderer Auffassung ist der Personenbezug relativer Natur. ${ }^{832}$ Ein und dasselbe Datum, kann nach dieser Auffassung in einer bestimmten Konstellation ein personenbezogenes Datum sein, innerhalb einer anderen Konstellation den Personenbezug nicht leisten. Ein Personenbezug ist danach dann zu bejahen,

828 Zum Streitstand Schmitz in: Hoeren/Sieber, Hdb. Multimedia-Recht, Teil 16.2, Rn. 257 mwN.

829 Dammann in: Simitis, \3 BDSG, Rn. 29; Härting, CR 2008, 743 (744); Meyerdieks, MMR 2009, 8; Kircbberg-Lennart2/Weber, DuD 2009, 479; Sacbs, CR 2010, 547.

830 So jetzt ausdrücklich auch EuGH, ZD 2012, 33, hierzu auch Hawellek, ZD-Aktuell 2011, 129.

831 Weichert, DuD 2007, 113 (119); Pablen-Brandt, K\&R 2008, 288; Weichert in: Däubler/Klebe/Wedde/Weichert, \ 3 BDSG, Rn. 13; differenziert aber IE wohl auch von einer absoluten Bestimmbarkeit ausgehend, AG Berlin, K\&R 2007, 600.

832 Dammann in: Simitis, \3 BDSG, Rn. 62; Gabriel/Cornels, MMR 11/2008, XIV (XV); Härting, CR 2008, 743 (744 ff.); Sacbs, CR 2010, 547 (548). 
wenn es nach der Lebenserfahrung oder wissenschaftlichen Prognose wahrscheinlich ist, den Betroffenen anhand des vorliegenden Datums bestimmen zu können. Entscheidend ist, ob die das Datum verarbeitende Stelle unter Einbezug der ihr zur Verfügung stehenden Mittel und ohne unverhältnismäßigen Aufwand den betroffenen Anschlussinhaber herausfinden kann oder zumindest nicht mit Wahrscheinlichkeit ausgeschlossen werden kann, dass die Herstellbarkeit eines etwaigen Personenbezugs möglich ist. ${ }^{833} \mathrm{Im}$ Mittelpunkt der Annahme einer Bestimmbarkeit steht hier, anders als bei der absoluten Bestimmbarkeit, ausschließlich die Daten verarbeitende Stelle.

Obgleich die differenzierte Betrachtung damit zwangsläufig je nach Situation in unterschiedlichen Ergebnissen hinsichtlich der Herstellbarkeit des Personenbezugs mündet, wird in der vorliegenden Konstellation der Personenbezug regelmäBig gegeben sein und dies unabhängig davon, ob es sich um eine statisch oder dynamisch vergebene IP-Adresse handelt. Soweit man von einem absoluten Begriff der Bestimmbarkeit ausgeht, kommt man nicht umhin, eine statische IPAdresse stets als personenbezogenes Datum zu verstehen. ${ }^{834}$ Eine statische IPAdresse wird in jedem Fall die Information tragen, welche Anschlüsse miteinander in Kommunikationsversuch getreten sind. ${ }^{835}$ Das geforderte „Zusatzwissen“ wird irgendeine Stelle aufweisen, um die jeweilige IP-Adresse dem betreffenden Anschlussinhaber zuzurechnen. Soweit die IP-Adresse statisch vergeben wird, wird zumindest der Access-Provider über einen Abgleich der Bestandsdatenbanken, die Anschrift und den Namen, letztlich über die Zusammenfügung weiterer Verkehrsdaten ermittelt werden können, welchem Nutzer der durch die IPAdressierung benannte Anschluss gehört. ${ }^{836}$

Deutlich schwieriger ist es anhand der dynamischen IP-Adressierung einen Personenbezug herzustellen. Eine dynamische IP-Adresse hat für sich genommen keinen eigenständigen Aussagegehalt. Es handelt sich im Augenblick ihrer Erhebung während der Datenverarbeitung lediglich um eine nummerische Zahlenfolge, die vielen Anschlüssen zugeordnet werden kann. Erst durch die Verbindung der zugewiesenen IP-Adressierung mit dem konkreten Zeitpunkt der Kommunikation reduziert sich die Zahl auf einen einzigen Anschluss und macht den PersonenbeZUM 2009, 75 (76), der die statische IP-Adresse unter \3 Nr. 3 TKG subsumiert und rein als „für die inhaltliche Ausgestaltung eines Vertragsverhältnisses über Telekommunikation“ als erhoben anerkennt.

836 Sankol, K\&R 2008, 469 (470); Eckhardt, K\&R 2007, 602 (603) darauf bezugnehmend Härting, CR 2008, 743 (746); Sachs, CR 2010, 547 (548); im Bereich der personenbezogenen Daten i.S.d. \ 3 BDSG, Dammann in: Simitis, $\int 3$ BDSG, Rn. 63. 
zug herstellbar. ${ }^{837}$ Wenngleich bei einem unabhängigen Dritten das notwendige Zusatzwissen um die Zugehörigkeit des jeweiligen Anschlussinhabers zum Zeitpunkt der Vergabe einer bestimmten IP-Adresse nicht immer zur Verfügung stehen wird oder nur über die Einbeziehung zusätzlicher Mittel wie etwa Auskunftsansprüche zu ermitteln sein wird, ${ }^{838}$ werden Access-Provider, als die Daten verarbeitende Stelle, ${ }^{839}$ zumindest soweit wie sie intern die Verbindungsdaten speichern und aufbewahren, den notwendigen Personenbezug herstellen können. ${ }^{840}$ Die Erhebung, Nutzung und Verarbeitung der Daten erfolgt zwar automatisiert über die entsprechenden Anwendungsprotokolle im TCP/IP-Schichtenmodell, dies allein schließt aber doch nicht ihre Auswertung im Nachhinein aus. Folglich wird auch die Personenbezogenheit bei statischen wie auch dynamischen IP-Adressen zumindest für Access-Provider herstellbar sein.

\section{(b) Personenberng auch Nutzerbezug?}

Problemtisch gestaltet sich, dass auch die Access-Provider letztlich nur den jeweiligen Anschlussinhaber ermitteln, nicht jedoch auch tatsächlich den jeweiligen Nutzer. Bedenke man beispielsweise die IP-Adresse wurde dem Betreiber eines Internetcafés oder zugeordnet. Wenngleich nach der obigen Ansicht auch im Falle der dynamischen Adressierung ein Personenbezug grundsätzlich herstellbar ist, also der Betreiber des Internetcafés für den Access-Provider rekonstruierbar ist, so wird der in dem Moment der Sperrmaßnahme am Rechner sitzende Nutzer kaum zu identifizieren sein. ${ }^{841}$

837 Kindt, MMR 2009, 147 (151); Erläuterung auch bei Graf in: Graf, StPO-Komm., \100a StPO, Rn. 15.

838 LG Frankenthal, MMR 2008, 687 (689).

839 Dass es vorliegend rein auf die Kenntnis der Access-Provider ankommen muss, wird zugleich unter 3. Teil C. II. 1. a) erläutert.

840 IE. Sachs, CR 2010, 547 (548); Kircbberg-Lennarty/Weber, DuD 2010, 479; Kindt, MMR 2009, 147 (151); Nietsch, K\&R 2011, 101 (102); Köcher, PIK 2010, 205 (207). IE. wohl auch Durer, ZUM 2010, 833 (845), der aber grundsätzlich bereits die Internetkommunikation aus dem Schutzbereich des Fernmeldegeheimnis herausnimmt. Gegen einen Personenbezug dagegen deutlich BGH, BVerfG, MMR 2010, 261 (262): „Der IP-Adresse kommt keine mit einem ebay-Konto vergleichbare Identifikationsfunktion zu. Anders als letzteres ist sie keinem konkreten Nutzer zugeordnet, sondern nur einem Anschlussinhaber, der grundsätzlich dazu berechtigt ist, beliebigen Dritten Zugriff auf seinen Internetanschluss zu gestatten." In Abkehr davon BGH, ZUMRD 2011, 151, der jetzt wohl auch vom Personenbezug ausgeht. Ebenfalls nunmehr EuGH, ZD 2012, 33; zusammenfassend zur Diskussion, Karg, MMR-Aktuell 2011, 315811; Venףke, ZD 2011, 114.

841 Breyer, NJOZ 2010, 1085 (1086), jedoch im Zusammenhang mit Telekommunikationsanschlüssen. 
Aufgrund dessen ist es gerechtfertigt, die Herstellbarkeit eines nutzerspezifischen Personenbezugs letztlich auch bei Access-Providern zu bezweifeln. Somit eröffnet sich bei der Beurteilung des Schutzbereichs einer IP-Adresse ein weiteres verfassungsrechtliches Problem, das heißt, die Frage, ob die IP-Adresse über das Fernmeldegeheimnis des Art. 10 Abs. 1, Var. 3 GG verfassungsrechtlichen Schutz als „näherer Umstand einer Kommunikation“ genießt, obgleich ein konkret verstellbarer Nutzerbezug regelmäßig nicht möglich sein wird. Art. 10 Abs. 1 GG ist jedoch gerade ein spezifisches Nutzergrundrecht und knüpft personell an den Grundrechtsträger und dessen Schutzbedürftigkeit auf Grund der Einschaltung Dritter in den Kommunikationsvorgang an. ${ }^{842}$

Die Möglichkeit der Herstellung eines Bezuges zum Anschlussinhaber, welcher bei einer Sperrmaßnahme durch Access-Provider grundsätzlich gegeben sein wird, muss auch unabhängig eines konkreten Nutzerbezugs als ein „Umstand der Kommunikation" verstanden werden.

Diese Wertung ergibt sich bereits aus einer Analyse der Rechtsprechungsvorgabe. Das Bundesverfassungsgericht zieht den Schutzbereich des Art. 10 Abs. 1 GG verhältnismäßig weit, indem es neben dem eigentlichen Inhalt der Fernkommunikation auch die Frage „wer, mit wem, zu welcher Zeit“ als Umstände der Kommunikation wertet. Dabei ist die Auslegung keineswegs abschließend. Vielmehr werden die Beispiele immer mit „insbesondere“ verbunden, was auf eine weite Auslegung des verfassungsrechtlichen Schutzes hindeuten lässt.

Zudem ist es sämtlichen von Art. 10 Abs. 1 GG umfassten technischen Mitteln immanent, dass nur näher bestimmt werden kann, wer an der Kommunikation beteiligt ist, keineswegs jedoch individualisiert auf den einzelnen Nutzer abgestellt werden kann. Typischerweise wird auch bei Telefonanschlüssen, Internetcafés, Mobiltelefonen sowie sämtlichen Einrichtungen die Hotspots, ${ }^{843}$ also frei zugängliche Internet-WLAN Verbindungen, ermöglichen, nachträglich nicht ohne weiteres feststellbar sein, wer konkreter Benutzer des Internets zu einem bestimmten Zeitpunkt war. ${ }^{844}$

Würde man folglich die IP-Adresse allein aufgrund des mangelnden Individualisierungsmöglichkeit des konkreten Nutzers schon aus dem Schutzbereich des Fernmeldegeheimnisses herausnehmen, so würde man den Grundrechtsschutz letztlich davon abhängig machen, ob der Grundrechtsträger den eigenen Internetanschluss auch Dritten zur Verfügung stellt ob er alleiniger Benutzer des Fernkommunikationsmittels bleibt und andere aus der Verfügungsgewalt ausschließt. Dies allein kann in Anbetracht der verfassungsrechtlichen Intention eines umfassend entwicklungsoffenen Schutzes nicht ausschlaggebend dafür sein, den verfassungsrechtlichen Schutz abzusprechen. Vielmehr betont das Bundesverfassungs- 
gericht, dass es dem Schutz des Fernmeldegeheimnisses nicht entgegensteht, wenn die erfassten Daten nicht sofort einer bestimmten Person zugeordnet werden können. 845

Auch unter Heranziehung der Anforderungen des Personenbezugs im Sinne des Rechts auf informationelle Selbstbestimmung wird hier keine andere Wertung angebracht sein. Schließlich geht der grundrechtliche Schutz dort auch nur von einer Bestimmbarkeit aus, keineswegs von einer konkreten Bestimmung des tatsächlichen Nutzers. Um Schutzlücken im Rahmen der grundrechtlichen Gewährleistung zu vermeiden, sollte die aus technischen und organisatorischen Gründen mangelhafte Identifizierung nicht zur Verneinung des Schutzbereiches führen. Access-Provider werden bei der automatischen Erhebung der IP-Adresse regelmäßig nicht wissen, ob eine bestimmte IP-Adresse die Identifizierung eines konkreten Nutzers ermöglicht oder nicht und daher die mit dieser IP-Adresse verknüpften Daten genauso verarbeiten wie Informationen, die mit IP-Adressen von ordnungsgemäß registrierten und bestimmbaren Benutzern verknüpft sind. ${ }^{846}$ Soweit der Zugangsdiensteanbieter nicht mit absoluter Sicherheit erkennen kann, dass die Daten zu nicht bestimmbaren Benutzern gehören, müssen daher alle IPInformationen wie personenbezogene Daten mit grundrechtlichem Schutz behandelt werden. Letztlich deckt sich hier der Schutzbereich wieder mit den Anforderungen, die für das Recht auf informationelle Selbstbestimmung aus Art. 2 Abs. 1 i.V.m. Art. 1 Abs. 1 GG herausgebildet wurden. Indes reicht hier eben auch nur die „Bestimmbarkeit“ und nicht auch eine konkreter Nutzerbezug.

Dies bekräftigt nunmehr auch die jüngere Rechtsprechung des Bundesverfassungsgerichts, die ohne die Problematik des Personenbezugs zu eröffnen, von einer Einbeziehung der IP-Adresse unter die schutzbereichsrelevanten Umstände der Kommunikation ausgeht. In der Entscheidung zur Verfassungsmäßigkeit der Vorratsdatenspeicherung ${ }^{847}$ hatte das Bundesverfassungsgericht die IP-Adresse ausdrücklich als schutzbereichseröffnenden Umstand der Kommunikation eingeordnet. Das Bundesverfassungsgericht stellt bei der Schutzbedürftigkeit der IPAdresse auf die inhaltsbezogene Rekonstruktionsmöglichkeit ab. Danach könne aus einer IP-Adresse der dahinter stehende Kommunikationsvorgang mit „erheblicher Wahrscheinlichkeit“ individualisiert werden. ${ }^{848}$ IP-Adressen seien weitaus

So BVerfG, NJW 2000, 55 (59), Spätestens bei etwaigen Ermittlungen lässt sich bereits aus der Tatsache, dass der Anschlussinhaber zu ermitteln ist, letztlich auch ein konkreter Nutzerbezug regelmäßig herstellen.

846 In die Richtung Gruppe Artikel 29, Stellungnahme zum Begriff „personenbezogene Daten“ 01 248/07/DE WP 136, im Rahmen der Richtlinie 95/46/EG, S. 20, abrufbar unter:

http://ec.europa.eu/justice/policies/privacy/docs/wpdocs/2007/wp136_de.pdf (zuletzt abgerufen 20.5.2012).

847 BVerfG, CR 2010, 232.

848 BVerfG, CR 2010, 232 (242). 
mehr inhaltlich an die Kommunikation angenähert als beispielsweise eine bloße Telefonnummer. ${ }^{849}$ Während die Telefonnummer nur unter gleichzeitiger Fixierung des gesprochenen Wortes Auskunft über den Inhalt der Kontaktaufnahme biete, kann über eine kontextbezogene Filterung der aufgerufenen Seiten ein aussagekräftigeres Inhaltsprofil der internetspezifischen Informationsrecherche des Nutzers anhand der IP-Adressierung auch noch im Nachhinein erzielt werden. Maßgeblich dafür sei die Langlebigkeit der Webseiten. Anhand der angeforderten IP des entsprechenden Webservers könne der Inhalt der Webseiten auch noch weit nach der Beendigung des Datenbearbeitungsprozesses rekonstruiert werden. Die IP-Adressen bewirken im Ergebnis, dass die Unterscheidung zwischen reinen Inhalten und näheren Umständen praktisch aufgehoben werde. Kann der Anschlussinhaber über eine IP-Adresse individualisiert werden, wisse man nicht nur wer, mit wem, wann kommuniziert hat, sondern kann daraus auch die Inhalte der Kommunikation ableiten. Letztlich bestätigen auch die Ausführungen des Bundesverfassungsgerichts die obige Annahme, dass die IP-Adressen den Schutzbereich des Fernmeldegeheimnisses eröffnen.

Im Ergebnis muss demnach gelten: Wenngleich Access-Provider den „hypothetischen" Personenbezug zwischen IP-Adresse und dahinterstehenden Nutzer herstellen können hingegen nicht unmittelbar der tatsächliche Nutzer anhand der IP-Adresse ermittelbar ist, so stellt die IP-Adresse verfassungsrechtlich dennoch einen schutzbereichsrelevanten Umstand der Kommunikation dar und eröffnet den Schutzbereich des Art. 10 Abs. 1 GG. ${ }^{850}$

(bb) Proxy-Sperrmethode als schutzbereichsrelevanter Umstand der Kommunikation

Im Falle der Filterung des Datenbestandes auf IP-Übereinstimmung belaufen sich die anfallenden Daten konkret auf den Umstand, dass zu einer bestimmten Zeit, ein bestimmter Server, mit einer bestimmten IP-Adresse angesprochen und ein entsprechender Verbindungsversuch gestartet werden sollte. Damit lassen die zur IP-basierten Filterung benötigten Daten einen herstellbaren Personenbezug zu und stellen gleichsam der eigentlichen IP-Sperrmethode typische Verbindungsda-

In die Richtung BVerfG, CR 2010, 232 (242).

850 LG Hamburg, ZUM 2010, 902 (905); BVerfG, WM 2011, 211 (212); so schon Greiner, Die Verhinderung verbotener Internetinhalte, 2001, S. 116, dies aufgreifend Sieber/Nolde, Sperrverfügungen im Internet, 2008, S. 83; Schnabel, K\&R 2008, 26 (30); Bitzer, DuD 2007, 602; Frey/Rudolph, Rechtsgutachten BVDW, 2008, Rn. 19; Sievers, Der Schutz der Kommunikation im Internet, 2003, S. 131, der die IP-Adresse allerdings noch zu den Inhalten rechnet; Schmidt, Die RechtmäBigkeit staatlicher Gefahrenabwehr im Internet, 2006, S. 186; Rehart, MMR-Aktuell 2010, 303415; iE. auch Sievers, Der Schutz der Kommunikation im Internet, 2003, S. 131. 
ten dar, die den Schutzbereich des Art. 10 Abs. 1 GG eröffnen. ${ }^{851}$ Bei einer ProxySperrmethode, die auf einen Bild- beziehungsweise Keywordabgleich ausgerichtet ist, sind die zur Sperrung anfallenden Daten nicht nur rein verbindungstechnischer Natur, sondern ermöglichen darüber hinaus auch einen direkten Rückschluss auf den Inhalt der Anfrage. Der hierfür verwendete Filtermechanismus greift zur Sperrung unmittelbar auf die Inhalte zurück, gleicht diese mit kinderpornographischen Identifikationsmerkmalen wie Bilden oder bestimmten Schlüsselbegriffen ab und entlässt nur nicht indexierte Anfragen zur eigentlichen Applikation weiter. Damit unterfallen die bei der inhaltsbezogenen Proxy-Sperrmethode anfallenden Daten ebenfalls dem Schutzumfang des Art. 10 Abs. 1 GG. ${ }^{852}$

(cc) DNS-Sperrmethode als schutzbereichsrelevanter Umstand der Kommunikation

Problematisch ist, ob auch bei der DNS-Sperrmethode nähere Umstände der Kommunikation betroffen sind. Zur Herbeiführung einer DNS-Sperrung müssen die DNS-Server betreibenden Provider Softwareeinstellungen vornehmen, welche in ihrer Wirkung die entsprechenden Einträge im DNS-Server dergestalt verändern, dass die vom Nutzer eingegebene URL der aufzurufenden Webseite nicht in die entsprechende numerische IP-Adresse umgewandelt und damit die aufgerufene Seite nicht auf der Benutzeroberfläche des Anwenders angezeigt werden kann.

Ausgehend von dem technischen Verständnis der Sperrmethode wird ein fernmeldetechnisch schutzbedürftiges Datum bei Vornahme der Sperrmethode abgelehnt. ${ }^{853}$ Bei der DNS-Server-Sperrmethode verwirkliche sich danach nicht das „typische Risiko räumlich distanzierter Kommunikation“, die während der Übertragung dem Zugriff Dritter ausgesetzt wäre. Denn gegenüber anderen Sperrmethoden, spiele sich die Wirkweise dieser Sperrtechnik nämlich rein in der Sphäre des Nutzers ab. Die involvierten DNS-Server seien nur ein zwischengeschaltetes Computersystem, das die Anfrage nutzerseitig verwirft, ehe es überhaupt zu einem Verbindungsversuch gekommen ist. ${ }^{854}$ Der Nutzer ist im direkten

851 Koreng, Zensur im Internet, 2010, S. 142; Greiner, Die Verhinderung verbotener Internetinhalte, 2001, S. 116.

852 Greiner, Die Verhinderung verbotener Internetinhalte, 2001, S. 116.

853 So Sieber/Nolde, Sperrverfügungen im Internet, 2008, S. 85; Koreng, Zensur im Internet, 2010, S. 142 f.; strikt ablehnend LG Hamburg, ZUM 2010, 902 (905); Marberth-Kubicki, NJW 2009, 1792 (1793); Frey/Rudolph, Rechtsgutachten BVDW, 2008, Rn. 19.

854 BMI u.a, Sitzung der Arbeitsgruppe „Access-Blocking“ am 12.2.2009, „Grundrechtliche, telekommunikations- und telemedienrechtliche Fragen im Zusammenhang mit der Sperrung kinderpornographischer Inhalte im Internet“ v. 19.2.2009, S. 2, abrufbar unter: http://blog.odem.org/2009/02/19/finale-stellungnahme.pdf (zuletzt abgerufen 20.5.2012); in die gleiche Richtung auch Sieber/Nolde, Sperrverfügungen im Internet, 2008, S. 85; Koreng, Zensur im Internet, 2010, S. 143. 
mit dem DNS-Server, indem er die Anfrage mittels Eingabe der URL in dem Browserfenster seines Rechners startet und der DNS-Server daraufhin selbstständig die zugehörige IP-Adresse ermittelt. Sollte die IP-Adresse als kinderpornographisch eingestuft worden sein, so verwirft der DNS-Server die Anfrage und leitet die Nutzeranfrage erst gar nicht in das weitere Kommunikationsnetz. Der DNSServer fungiert nach dieser Ansicht damit als „intermediärer Kommunikationspartner“ nicht aber als „reiner Übermittler zwischen Nutzer und Telemedienanbieter". 855

Dieser Auffassung ist jedoch nicht zuzustimmen. ${ }^{856}$ Die Umwandlung der eingegebenen URL in die zugehörige IP-Adresse ist ein stark technisierter Vorgang, der nicht losgelöst von der gesamten Datenübertragung in einzelne „Sphären der Kommunikationspartner" eingeordnet werden kann. Zwar mag die vorgeschlagene Differenzierung unter Betrachtung rein technischer Aspekte angebracht sein, ${ }^{857}$ jedoch verkennt diese Ansicht, dass es sich beim DNS-Server lediglich um eine nutzerseitige Vereinfachung der Internetkommunikation handelt. Anstelle der Domain könnte der Nutzer gleich die zugehörige IP-Adresse der gewünschten Seite eingeben. Bei dieser Vorgehensweise würde der Schutzbereich des Fernmeldegeheimnisses gerade eröffnet werden, weil der Kommunikationsvorgang hier nicht schon am zwischengeschalteten Computersystem unterbrochen, sondern die Anfrage erst nach Eingang in den eigentlichen Kommunikationsaufbau verworfen wird. 858 Wenngleich man diese Ansicht anerkennt, würde es bedeuten, dass der Grundrechtsschutz davon abhängig sei, ob der Nutzer die technikspezifische Vereinfachung des Umwandlungsmechanismus benutzte oder auf anderem Wege an die gewünschte Seite gelange. ${ }^{859}$ Eine solche Betrachtung erscheint aber verfassungsrechtlich nicht haltbar, denn schließlich haben die Kommunikationsteilnehmer regelmäßig keine Kenntnis von den technischen Abwicklungselementen des Providers und wären im Falle der eingegebenen Domain schutzlos gestellt.

Außerdem lässt die eingegebene URL in ihrer spezifischen textlichen Ausgestaltung gerade auch einen Rückschluss auf den Inhalt der Kommunikation zu. Der DNS-Server bedient sich zur Auflösung der Eingabe des Nutzers in die dazugehörige IP-Adresse der „Domain“ als Bestandteil der gesamten URL-Adresse, diese zeigt häufig einen inhaltlichen Bezug zur angeforderten Seite. ${ }^{860}$ Die Regist-

So Sieber/Nolde, Sperrverfügungen im Internet, 2008, S. 85.

IE. ebenso LG Hamburg, ZUM 2010, 902 (905); Marberth-Kubicki, NJW 2009, 1792 (1793);

Frey/Rudolph, Rechtsgutachten BVDW, 2008, Rn. 19.

857 Dies anmerkend Durer, ZUM 2010, 833 (842), iE. aber ablehnend.

8 Durer, ZUM 2010, 833 (842); Heuner in: Taeger/Wiebe, Inside the cloud, 2009, S. 107 (113).

IE. wohl Heuner in: Taeger/Wiebe, Inside the cloud, 2009, S. 107 (113).

Dies erkennen auch Sieber/Nolde, Sperrverfügungen im Internet, 2008, S. 86 f. jedoch nur in Bezug auf die eingegebene URL Adresse. „Die Abfrage einer URL greift daher - noch stärker als die Abfrage einer IP-Nummer - in das Fernmeldegeheimnis ein.“ Dabei verkennen sie je- 
rierung einer Domain muss zwar nicht zwangsläufig mit der inhaltlichen Dimension dergleichen übereinstimmen, in der Regel werden die textliche Wiedergabe und das inhaltliche Angebote schon aus „Werbe und Auffindbarkeitszwecken“ deckungsgleich sein. Durch die Überschneidung von inhaltlicher und kommunikationsspezifischer Natur beim Umwandlungsvorgang der URL in die dazugehörige IP-Adresse sowie aufgrund unvermeidbarer Abgrenzungsschwierigkeiten muss auch die DNS-Sperrmethode der Schutzbereich eröffnet sein. ${ }^{861}$

Zusammenfassend muss demnach gelten, dass alle technikbasierten Daten, die während des Datenübertragungs- und Sperrvorgangs anfallen, zu den relevanten „,näheren Umständen der Kommunikation“ zählen. ${ }^{862}$ Folglich ist der Schutzbereich des Fernmeldegeheimnisses bei allen Sperrmethoden eröffnet.

\section{Eingriff in den Schutzbereich}

Ein Eingriff in den Schutzbereich des Fernmeldegeheimnisses ist jede Kenntnisnahme, Aufzeichnung und Verwertung des Kommunikationsinhaltes oder den näheren Umständen der Kommunikation, sowie jede Auswertung ihres Inhalts oder sonstige Verwendung durch staatliche Stellen. ${ }^{863}$

a) Kenntnis der Provider ausreichend?

Vorgelagert stellt sich die Frage, ob bereits aufgrund der Tatsache, dass bei Sperrmaßnahmen nicht der Staat selbst eine etwaige Kenntnis von den schutzbereichsrelevanten Umständen der Kommunikation erlangt, sondern die Kenntnis während des Datenverarbeitungsvorgangs zunächst allein bei Access-Providern entsteht, ein Eingriff in das Fernmeldegeheimnis von vorneherein ausscheiden muss.

doch, dass die URL und die Domainadresse erst zusammen betrachtet einen Rückschluss auf den Inhalt der Seite ermöglichen und der textlich inhaltliche Rückschluss gerade über den Domainteil geschaffen werden kann, da allein die Protokollangabe „http.//“ und die Bezeichnung des Dienstes z.B. „www“ wenig Ausschluss über den angeforderten Inhalt vermitteln.

861 Im Ergebnis auch Frey/Rudolph, Rechtsgutachten BVDW, 2008, Rn. 19 sowie Fn. 46; LG Hamburg, ZUM 2010, 902 (905); Marberth-Kubicki, NJW 2009, 1792 (1793).

862 IE. wohl auch Eckhardt in: Spindler/Schuster, Recht der elektronischen Medien, 2008, \88 TKG, Rn. 10; Gusy in: v. Mangoldt/Klein/Starck, Art. 10 GG, Rn. 45; Hofmann in: SchmidtBleibtreu/Hofmann/Hopfauf, Art. 10 GG, Rn. 10, die auf eine spezifische Differenzierung verzichten. In die Richtung auch Frey/Rudolph, Rechtsgutachten BVDW, 2008, Rn. 19.

863 BVerfGE 67, 157 (171 f.); BVerfGE 100, 313 (358); BVerfGE 106, 28 (37); BVerfGE 110, 33 (52 f.); BVerfG, CR 2010, 232 (233); Badura in: Bonner Kommentar, Art. 10 GG, Rn. 22 f.; Jarass in: Jarass/Pieroth, Art. 10 GG, Rn. 11; Gusy in: v. Mangoldt/Klein/Starck, Art. 10 GG, Rn. 58; Hermes in: Dreier, Art. 10 GG, Rn. 53. 
Grundsätzlich verpflichtet Art. 10 GG entsprechend Art. 1 Abs. 3 GG alle Staatsgewalt zur Wahrung des Fernmeldegeheimnisses. ${ }^{864}$ Access-Provider als diejenige verarbeitende Stelle, die während der Datenübertragung eine mögliche Kenntnis über die schutzbereichsrelevanten Daten erhalten, sind hingegen Privatrechtssubjekte die grundsätzlich nicht der unmittelbare Bindungswirkung der Grundrechte unterfallen. Im vorliegenden Fall erschließt sich die notwendige Unterwerfung der Access-Provider unter das Fernmeldegeheimnis jedoch aus mehreren Aspekten:

Zunächst liegt im Falle der Sperrung kinderpornographischer Inhalte mittels einer gesetzlichen Sperrverpflichtung eine spezielle Konstellation vor, in der sich der Staat der Access-Provider im Wege der funktionalen Privatisierung ${ }^{865}$ bedient. Bereits daraus ist abzuleiten, dass hinsichtlich der Bindungswirkung an das Grundrecht des Art. 10 GG nichts anderes gelten kann, als bei der Frage nach einer grundsätzlichen Bindungswirkung von gesetzlich veranlassten Sperrmaßnahmen an den Verhältnismäßigkeitsgrundsatz: Access-Provider fungieren bei der Implementierung von technischen Sperrmechanismen gerade nicht als selbstständige Privatrechtssubjekte, vielmehr führen sie unmittelbar Aufgaben der staatlichen Gefahrenabwehr aus. ${ }^{866}$ Sie sind demnach als Erfüllungsgehilfen des Staates einzuordnen, so dass aufgrund der dadurch hervorgerufenen Nähe zum Staat, Handlungen sowie auch etwaige Kenntnisse dem Staat zuzurechnen sind. ${ }^{867}$ Es wäre nicht zu billigen, wenn der Staat sich einerseits Privater zur Durchsetzung von Staatsaufgaben, die er selbst mit eigenen Mitteln nicht leisten kann, bedienen dürfte, andererseits sich der Staat aber gerade durch diesen Umstand von jeglicher Kenntnisnahme freisprechen könnte. Vielmehr muss auch hier gelten, dass derjenige der sich eines Dritten bedient, auch das daraus resultierende Risiko zu tragen hat. ${ }^{868}$ Anders wäre der Fall etwa dann zu betrachten, wenn die Vornahme einer

BVerwGE 6, 299 (300); Dürig in: Maunz/Dürig, Art. 10 GG, Rn. 26; Gusy in: v. Mangoldt/Klein/Starck, Art. 10 GG, Rn. 51; Hermes in: Dreier, Art. 10 GG, Rn. 49 ff.; Jarass in: Jarass/Pieroth, Art. 10 GG, Rn. 1a.

Di Fabio, JZ 1999, 585 (588); Gersdorf, JZ 2008, 831 (832); Schoch, NVwZ 2008, 241 (246); Koreng, Zensur im Internet, 2010, S. 143.

866 Allgemein zum gesamten Komplex Gerstorf, JZ 2008, 831 (832); Schoch, NVwZ 2008, 241 (246); Koreng, Zensur im Internet, 2010, S. 143, mit direktem Bezug zu staatlichen Sperrverfügungen. So in Bezug auf die Vornahme der Vorratsdatenspeicherung durch Access-Provider, BVerfG, NJW 2010, 833 (836); ähnlich schon Germann, Gefahrenabwehr im Internet, 2000, S. 445 darauf bezugnehmend Sieber/Nolde, Sperrverfügungen im Internet, 2008, S. 86; Koreng, Zensur im Internet, 2010, S. 143. So beispielsweise die Kenntniszurechnung im Stellvertretungsrecht gem. \166 Abs. 2 BGB, bei dem sich der Vertretene bei Kenntnis seines Weisungsgebundenen Vertreters nicht auf Unkenntnis berufen kann. In die gleiche Richtung auch sämtliche Haftungsnormen bei zur Hilfenahme eines Dritten, wie z.B. \278 BGB greifen. 
Sperrung durch die Access-Provider nicht aufgrund einer gesetzlichen Handlungsverpflichtung durchzuführen wäre, sondern die Access-Provider über einen zivilrechtlichen Anspruch zur Sperrmaßnahme beispielsweise von urheberrechtsverletzenden Inhalten verpflichtet wären. Nach der herrschenden „Theorie der mittelbaren Drittwirkung der Grundrechte" gelten die Grundrechte und damit auch Art. 10 Abs.1 GG im Verhältnis Privater untereinander nicht unmittelbar. ${ }^{869}$ In dieser Hinsicht unterscheiden sich zivilrechtliche Konstellationen gerade von gesetzlich angeordneten Sperrverpflichtungen. ${ }^{870}$ In die gleiche Richtung geht auch die jüngere Rechtsprechung des Bundesverfassungsgerichts. ${ }^{871}$ Dieses betont im Zusammenhang mit einem Eingriff in Art. 10 GG durch die Vorratsdatenspeicherung von Access-Providern, das die Eingriffsqualität ,nicht dadurch in Frage gestellt [werde], dass die in dieser Vorschrift [ $\$ 113$ a TKG] vorgeschriebenen Speicherung nicht durch den Staat selbst, sondern durch private Diensteanbieter erfolgt. Denn diese werden allein als Hilfspersonen für die Aufgabenerfüllung durch staatliche Behörden in Anspruch genommen. (...) Unter diesen Voraussetzungen ist die Speicherung der Daten rechtlich dem Gesetzgeber als unmittelbarer Eingriff in Art. 10 GG zuzurechnen." 872 Die Vorgaben an die Eingriffsqualität der Vorratsdatenspeicherung lassen sich vergleichsweise auch auf die Konstellation der Datenerhebung zu Zwecken der Sperrung kinderpornographischer Inhalte übertragen. Da hierbei die Access-Provider auch zu Zwecken der Gefahrenabwehr im Internet unmittelbar aufgrund einer gesetzlichen Handlungsverpflichtung in Anspruch genommen werden, stellt sich eine eventuell ihrerseits entstehende Kenntnis als ein Eingriff in Schutzbereich des Fernmeldegeheimnisses dar. ${ }^{873}$

Die gleiche Folgerung lässt sich auch aus einer Zusammenschau der Sperrmaßnahme im Kontext zur einfachgesetzlichen Ausprägung des Fernmeldegeheimnisses ableiten. In Ausprägung der grundrechtlichen Schutzpflicht des Fernmeldegeheimnisses ${ }^{874}$ wird über $\int 88$ Abs. 2 TKG der Kreis der vom Fernmelde-

869 Ständ. Rspr. vgl. z.B. BVerfGE 7, 198; BVerfGE 81, 242; BVerfGE 89, 214; Papier in: Merten/Papier, Hdb. Grundrechte, 2006, Bd. II, \55, Rn. 1 ff.; Poscher, Grundrechte als Abwehrrechte, 2003, S. $243 \mathrm{ff}$. sowie $266 \mathrm{ff}$.

870 IE. wohl auch Durner, ZUM 2010, 833 (838).

871 BVerfG, NJW 833 (836).

872 BVerfG, NJW 2010, 833 (838). IE. ebenso schon BVerfGE 107, 299.

873 Anders BMI u.a, Sitzung der Arbeitsgruppe „Access-Blocking“ am 12.2.2009, „Grundrechtliche, telekommunikations- und telemedienrechtliche Fragen im Zusammenhang mit der Sperrung kinderpornographischer Inhalte im Internet" v. 19.2.2009, S. 3 ff., die hier mangels Kenntnisnahme des Staates einen Eingriff ablehnen und über einen mittelbaren Eingriff nur bei öffentlich-rechtlichen Verträgen mit den Access-Providern nachdenken, jedoch iE. auch diesen verneinen, abrufbar unter: http://blog.odem.org/2009/02/19/finale-stellungnahme.pdf (zuletzt abgerufen 20.5.2012).

874 Hierzu Gusy in: v. Mangoldt/Klein/Starck, Art. 10 GG, Rn. 54 ff. 
geheimnis verpflichteten ausdrücklich auch auf die jeweiligen Diensteanbieter nach $\int 3$ Nr. 6 TKG ausgeweitet. Der Staat muss die Freihaltung der Kommunikation nicht nur vor staatlichen Eingriffen, sondern auch vor Eingriffen durch Private Dritte sicherstellen, da über diese, die schützenswerte Geheimhaltung ebenso beeinträchtigt werden kann, wie durch den Staat selbst. Diensteanbieter im Sinne der Norm ist jeder der ganz oder teilweise geschäftsmäßig Telekommunikationsdienste erbringt oder an der Erbringung solcher Dienste mitwirkt. Entsprechend $\int 3$ Nr. 24 sind Telekommunikationsdienste als ,in der Regel gegen Entgelt erbrachte Dienste, die ganz oder überwiegend in der Übertragung von Signalen über Telekommunikationsnetze bestehen, einschließlich Übertragungsdienste in Rundfunknetzen“ definiert. Die Tätigkeit der Access-Provider, die über ihr Leistungsnetz den Zugang zum Internet vermitteln sowie die technische Übertragung von Signalen über die Bereitstellung von infrastrukturellen Kernelementen der Datenverarbeitung (Router, Anwendungsprotokolle) ermöglichen, wird nach einhelliger Auffassung zugleich als Erbringung eines Telekommunikationsdienstes verstanden, so dass diese dem Diensteanbieterbegriff des TKG entsprechen. ${ }^{875}$ Folglich untermauert auch die einfach-gesetzliche Ausprägung des Fernmeldegeheimnisses die verfassungsrechtliche Herleitung der Bindungswirkung.

875 Bock in: Beck'scher TKG-Komm., \88 TKG, Rn. 22; Sieber/Höfinger, MMR 2004, 575 (582). Zu unterscheiden ist hiervon die Frage, ob sich die Tätigkeit der Access-Provider in der Erbringung des Telekommunikationsdienstes erschöpft. Die Beurteilung dessen ist etwa für die Einordnung der Access-Provider als Diensteanbieter i.S.d. \8 TMG notwendig, da hierfür zunächst die Voraussetzung des Anwendungsbereichs entsprechend $\int 1$ Abs. 1 S.1 TMG gegeben sein müsste. Hierfür ist aber auschlaggebend, dass kein reiner Telekommunikationsdienst, also ein Dienst der ganz auf der Übertragung von Signalen basiert, erbracht wird. IE. werden die Access-Provider als die „typischen“ Diensteanbieter i.S.d. \8 TMG verstanden, da sie neben der rein Telekommunikations-Leistungserbringung auch zusätzliche Aufgaben übernehmen, die die Bereitstellung von entsprechenden Protokollfunktionen oftmals auch selbstständige E-Mail-Zugänge, Suchmaschinenbetrieb oder die Vermittlung von Sprachdienstleistungen anbieten und in den gesamten Ablauf der Kommunikation eingegliedert sind. Folglich erbringen sie keine reinen Telekommunikationsdienste, so dass auch der Anwendungsbereich des TMG eröffnet ist. Hierzu Spindler in: Spindler/Schmitz/Geis, $\ 9$ TDG, Rn. 14 mwN.; in die gleiche Richtung auch Sieber, Verantwortlichkeit im Internet, 1999, Rn. 23; Sieber/Nolde, Sperrverfügungen im Internet, 2008, S. 125; differenzierter mit der Tendenz zur a.A. Mantz, Rechtsfragen offener Netze, 2008, S. 50; Wittern/Schuster in: Beck'scher TKG- Komm., \ 3 TKG, Rn. 49; Heckmann in: jurisPK-Internetrecht, Kap. 1 Rn. 44; Lünenbürger in: Scheurle/Mayen, \ 3 TKG Rn. 58 ff.; Hoeren, NJW 2007, 801 (802): „bezogen auf Access-Provider muss also bei jeder einzelnen Dienstleistung eines solchen Anbieters genau geschaut werden, ob mehr die Transportleistung im Vordergrund steht oder der transportierte Inhalt"“. 
b) Tatsächliche Kenntnisnahme?

Problematisch ist allerdings, ob die Access-Provider während der Sperrmaßnahme auch tatsächlich Kenntnis von den schutzbereichsrelevanten Daten erlangen und dieses Verhalten damit als Eingriff zu werten ist.

(aa) Kein Eingriff bei bloßer Verhinderung des Datenübertragungsvorgangs

Teilweise wird ein Eingriff in das Fernmeldegeheimnis bereits mit der Argumentation abgelehnt, dass bei Sperrmethoden nicht die Kenntnisnahme der Kommunikation im Vordergrund stehe, sondern die Verhinderung der Entstehung derselben. ${ }^{876}$ Tatsächlich widerspricht eine solche Betrachtungsweise dem ersten Anschein nach dem eigentlichen Abwehrcharakter der Grundrechtsnorm des Art. 10 Abs. 1 GG, welcher gerade die Vertraulichkeit der Kommunikation garantiert und demnach das Stattfinden vom Kommunikation voraussetzt. ${ }^{877}$ Jedoch übersieht diese Ansicht, dass bei gesetzlich angeordneten Sperrmaßnahmen nicht sämtlicher Zugriff auf den Kommunikationsinhalt verhindert beziehungsweise der Verbindungaufbau per se negiert wird, sondern nur der Zugriff auf Inhalte, die entsprechend vorgegebenen Kriterien als kinderpornographisch zu qualifizieren sind. Sperrmaßnahmen gehen also in ihrer spezifischen Funktion über die reine Unterbindung der Kommunikation hinaus. Folglich kann ihnen nicht bereits wegen der Zugriffsverweigerung grundsätzlich jeglicher Eingriffscharakter abgesprochen werden. ${ }^{878}$ Diese Sichtweise findet zudem auch in der Rechtsprechung des Bundesverfassungsgerichts Zuspruch. Schließlich hebt dieses ausdrücklich hervor, dass es zu den vom Schutzbereich des Art. 10 Abs. 1 GG geschützten Umständen der Kommunikation gehört, inwiefern ein Telekommunikationsverkehr stattgefunden oder zumindest ,versucht worden ist““.879 Folglich verlagert sich die Eingriffsqualität der staatlichen Maßnahme auch auf den Moment des Zustandekommens von Kommunikation. Dies ist auch vor dem teleologischen Hintergrund des Fernmeldegeheimnisses zwingend anzunehmen. Soweit das Fernmeldegeheimnis als verfassungsrechtliche Kompensationsnorm für die Gleichstellung einer vom staatlichen Zugriff freizuhaltenden Kommunikation zwischen An- und Abwesenden verstanden wird, müssen auch die über bloße Zugriffsversuche herauszufilternden Rückschlussmöglichkeiten auf die Kommunikationsteilnehmer geschützt sein. Schon der Vorgang eines Kommunikationsaufbaus beinhaltet die Gefahr des Verlustes der grundrechtlich gewährleisteten Vertraulichkeit, da bereits

876 In die Richtung Degen, Freiwillige Selbstkontrolle, 2007, S. 288; wohl auch Durer, ZUM 2010, 833 (838), jedoch auf urheberrechtliche Sperrverfügungen bezogen.

877 Gusy in: v. Mangoldt/Klein/Starck, Art. 10 GG, Rn. 57.

878 Heuner in: Taeger/Wiebe, Inside the cloud, 2009, S. 107 (113); Germann, Gefahrenabwehr im Internet, 2000, S. 87.

879 BVerfGE 100, 313 (358); BVerfGE 107, 299 (312 f.); BVerfGE 1143, 348 (365); BVerfGE 115, 166 (183). 
über für Versuch der Verbindung im Internet, die Erhebung und Nutzung von schutzbereichsrelevanten Daten notwendig ist. Dem folgend, kann der Versuch einer Verbindung, die etwaig negiert wird, nicht schon als mangelnder Eingriff in das Fernmeldegeheimnis gewertet werden.

(bb) Intensität des Eingriffs entscheidend

Bei der Beurteilung der Eingriffsqualität von Sperrmaßnahmen muss jedoch der Umstand, dass sämtliche schutzbereichsrelevanten Daten, die als nähere Umstände der Kommunikation begriffen werden können aufgrund der technischen Gegebenheiten der Datenübertragung im Internet, ohnehin überprüft werden müssen. Die in den Kommunikationsprozess involvierten Computersysteme wie Router, DNS-Server und Proxy-Server können ihre Funktion innerhalb der einzelnen Schichten des TCP/IP-Modells erst wahrnehmen, wenn entsprechend die von den Protokollen vorgenommene Adressierung auswertet wird und ihr entnommen werden kann, wer mit wem kommunizieren will. ${ }^{880}$ Es findet also schon während des reinen Datenübertragungsvorgangs zwangsläufig ein Abgleich der Adressierung der Datenpakete statt, um die aufgerufene Webseite tatsächlich zu erhalten. ${ }^{881}$ Fraglich ist demnach, ob allein diese auch sonst übliche Erfassung der Daten durch die Access-Provider von ihrer Intensität her betrachtet als ein verfassungsrechtlicher Eingriff in Art. 10 Abs. 1 GG zu werten ist.

Zur Beantwortung kann wiederholt auf die enge Verbindung zwischen dem Fernmeldegeheimnis und dem Recht auf informationelle Selbstbestimmung zurückgegriffen werden. Soweit die Anforderungen an das Selbstbestimmungsrecht gleichfalls auch auf die grundrechtliche Gewährleistung des Fernmeldegeheimnisses zu übertragen sind, müssen auch die Anforderungen an die Eingriffsqualität ergänzend herangezogen werden. ${ }^{882}$ Danach ist die Tatsache, dass die Daten ohnehin erhoben werden, zunächst unschädlich für die Bejahung eines grundrechtsrelevanten Eingriffs: Denn die bei den Sperrmethoden vorgenommene Erfassung der Daten erfolgt zu einem neuen Verwendungszweck. Im Vordergrund der Er-

880 So Schnabel, Sperrungsverfügungen gegen Access-Provider, 2002, S. 62, abrufbar unter: http://www.eulisp.de/tl_files/eulisp\%20abschlussarbeiten/schnabel_christoph.pdf, (zuletzt abgerufen 20.5.2012).

881 Schnabel, Sperrungsverfügungen gegen Access-Provider, 2002, S. 62, 38, abrufbar unter: http://www.eulisp.de/tl_files/eulisp\%20abschlussarbeiten/schnabel_christoph.pdf, (zuletzt abgerufen 20.5.2012); in die Richtung auch Sieber/Nolde, Sperrverfügungen im Internet, 2008, S. 88.

882 Zur ergänzenden Anwendung der beiden Grundrechte zueinander BVerfGE 100, 313 (358 f.); BVerfG, CR 2010, 232 (233); Pagenkopf in: Sachs, Art. 10 GG, Rn. 53; danach besteht die enge Verbindung durch die sich ähnelnden Schutzgüter, wobei Art. 10 GG lex specialis zu Art. 2 Abs. 1 i.V.m. Art. 1 Abs. 1 GG ist. In die Richtung ebenfalls Heuner in: Taeger/Wiebe, Inside the cloud, 2009, S. 107 (114). In dem Sinne der Übertragbarkeit der Eingriffsqualität, Sieber/Nolde, Sperrverfügungen im Internet, 2008, S. 89. 
fassung steht nicht, wie gewöhnlich, die reine Nutzung der Daten zum Zwecke der Datenübertragung, sondern darüber hinausgehend eine spezifische Zugriffsunterdrückung kinderpornographischer Inhalte. ${ }^{883}$ Durch die Zweckänderung von rein privat-geschäftlicher Dienstleistung zur Realisierung unmittelbar staatlichen Handelns kann ein Eingriff in das Fernmeldegeheimnis angenommen werden, da eine vergleichbare Zweckänderung der Datenerhebung bei einem Eingriff in das Recht auf informationelle Selbstbestimmung ebenfalls als ausreichend betrachtet wird. ${ }^{84}$ Grundsätzlich würde danach jede im normalen Geschäftsverkehr übliche Datenerfassung zu einem neuen Zweck einen Eingriff in das Fernmeldegeheimnis begründen.

Diese Ansicht erscheint aufgrund der engen Verbindung zwischen dem Recht auf informationelle Selbstbestimmung und dem Fernmeldegeheimnis durchaus gerechtfertigt, muss aber gerade wegen einer klaren Rechtsprechungslinie selbst wiederrum eingeschränkt werden: Das Bundesverfassungsgericht selbst lässt den Eingriff in Art. 10 Abs. 1 GG wieder entfallen, wenn die Eingriffsintensität nicht dergestalt zu veranschlagen ist, als sie dem Charakter eines grundrechtlichen Eingriffs würdig ist. Dies ist etwa dann der Fall, wenn die technisch erfassten und in Kenntnis genommenen Daten nach ihrer Erhebung wieder ausgesondert und unverzüglich gelöscht werden, bevor der Staat die Daten zu anderen Zwecken gebrauchen kann. 885 So äußerte das Bundesverfassungsgericht im Abhörurteil explizit, dass es an einem Eingriff fehlt, „soweit Fernmeldevorgänge zwischen deutschen Anschlüssen ungezielt und allein technikbedingt zunächst miterfasst, aber unmittelbar nach der Signalaufbereitung technisch wieder spurenlos ausgesondert werden." ${ }^{\text {"886 }}$

Dieses bestätigen auch teleologische Erwägungen: Denn nach unverzüglicher Löschung der Daten kann sich das vom Sinn und Zweck des Fernmeldegeheimnisses getragene typische Risiko des Bruchs der „Vertraulichkeit der Daten“ nicht verwirklichen. ${ }^{887}$ Soweit eröffnet die Erhebung der zur Datenübertragung benötigten Daten zwar den Schutzbereich, in dem sie potentiell Rückschlussmöglichkeiten auf die äußeren Umstände der Kommunikation ermöglicht, jedoch erschöpft sich die Verarbeitung in diesem eröffnenden Akt. Nachträgliche Rückschlüsse können über die potentielle Möglichkeit hinaus nur dann tatsächlich gezogen werden, wenn die Daten über die eigentliche Nutzung zur Datenverarbeitung noch zur Verfügung stehen und nicht automatisch wieder verworfen werden. Dies unterscheidet die vorliegende Sperrkonstellation eben auch von der Fallvariante, welche das Bundesverfassungsgericht zur Annahme eines Eingriffs in Art. 10 GG 
im Falle der Vorratsdatenspeicherung veranlasst hatte. Zwar können dessen Erwägungen im Rahmen der Kenntniserlangung vergleichbar übertragen werden; in Bezug auf die Eingriffsqualität kann eine Sperrmaßnahme, die über die Sperrung des Inhalts keinen hinausgehenden Datenverarbeitungscharakter ausweist, nicht gleichgestellt werden mit einer ,anlasslosen“ Speicherung der Daten mit Weiterleitungsverpflichtungen an die Behörden. ${ }^{888}$ Dort ging es ausdrücklich um eine Datenspeicherung und die anschließende Auskunftserteilung der ,auf Vorrat" gespeicherten Daten an Strafverfolgungsbehörden für weitere Zwecke. Gerade die spezifische Gefahr, die der Hinterlassung von kommunikativen Spuren im Internet innewohnt, realisiert sich in einem solchen Fall in zweifacher Weise. Zunächst über die Speicherung der Daten sowie anschließend in der Folgeverwendung in Form der Weitergabe, die ebenfalls am Grundrecht des Art. 10 GG zu messen sei. ${ }^{889}$ Beides liegt innerhalb der bloßen automatischen Erfassung der Daten mit anschließender Vernichtung allerdings nicht vor. Zwar werden über die Datennutzung kommunikative Spuren hinterlassen, diese verschwinden jedoch nach ihrer Beschaffung und können somit nicht im Nachhinein ausgelesen werden. Folglich mangelt es an der Intensität die einem Eingriffscharakter im Sinne des Fernmeldegeheimnisses entsprechen würde. ${ }^{890}$

Der vom Bundesverfassungsgericht angeführte Gedankengang lässt sich aber dann auch auf die Beurteilung einer gesetzlichen Sperrverpflichtung übertragen, wenn die zur Sperrung ohnehin erfassten Daten nicht unverzüglich gelöscht, sondern gleichzeitig mit der Vornahme einer Sperrung auch eine Weiterleitung der

BVerfG, NJW 2010, 833, explizit zum Eingriffscharakter einer solchen Maßnahme S. 836.

889 So ausdrücklich klarstellend BVerfG, NJW 2010, 833 (836) mit Verweis auf BVerfGE 100, 313 8359; BVerfGE 110, 33 (68 f.); BVerfGE 113, 348 (365). IE. Heuner in: Taeger/Wiebe, Inside the cloud, 2009, S. 107 (114 f.); Aufgrund der Tatsachen wurde wohl auch die ursprüngliche Gesetzesfassung des Zugangserschwerungsgesetzes (dort noch über eine Änderung des TMG), wonach eine Weiterleitung der bei der Sperrung auftretenden Verkehrsdaten an die Strafverfolgungsbehörden aufgehoben, hierzu Bäcker, Ausschussdrucksache 16 (9) 1554, S. 10; ebenso Frey/Rudolph, Ausschussdrucksache 16 (9) 1546, S. 18; Sieber, JZ 2009, 653 (655); zu Bedenken auch an der Neuformulierung mit expliziten Ausschluss der Nutzung zu Strafverfolgungszwecken, Frey/Rudolph, Stellungnahme der Sachverständigen im Rechtsausschuss v. 7.11.2010, S. 11, abrufbar unter:

http://www.bundestag.de/bundestag/ausschuesse17/a06/anhoerungen/archiv/03_Zugangsers chwerung/04_Stellungnahmen/Stellungnahme_Frey.pdf (zuletzt abgerufen, 20.5.2012). Die Herleitung anführend auch Durer, ZUM 2010, 833 (842). A.A. Rehart, MMR-Aktuell 2010, 303415, der aufgrund der Zitierung des Art. 10 GG in \11 ZugErschwG von einem Eingriff in Art. 10 GG ausgeht, ohne diesen zu hinterfragen. 
erfassten Daten, etwa an Strafverfolgungsbehörden ${ }^{891}$ angeordnet wird. In einem solchen Fall wird letztlich von einer erheblichen Eingriffsintensität auszugehen und ein Eingriff in das Fernmeldegeheimnis nach Art. 10 Abs. 1 GG durchaus zu bejahen sein. Für die Verfassungsmäßigkeit des Eingriffs wären dann die zusätzlichen Voraussetzungen des Art. 10 Abs. 2 GG notwendig. Danach dürfen Beschränkungen nur „durch oder aufgrund eines Gesetzes“, angeordnet werden, also einem einfachen Gesetzesvorbehalt unterliegen, der hinreichend bestimmt ist, so dass der betroffene Nutzer im Einzelfall die Rechtslage erkennen und sein Verhalten darauf ausrichten kann. ${ }^{892}$ Zudem ist über Art. 19 Abs. 1 Satz 2 GG das Zitiergebot einzuhalten, dass innerhalb des beschränkenden Gesetzes eine explizite Nennung der eingeschränkten Grundrechtnorm voraussetzt. 893

Die Eingriffsvoraussetzungen sind allerdings nicht schon deshalb gegeben und die Voraussetzungen des Art. 10 Abs. 2 Satz 2, 19 Abs. 1 Satz 2 GG zusätzlich einzuhalten, wenn die Sperrmaßnahme in eine Umleitung auf eine vordefinierte Sperrseite mündet, die dem Nutzer Auskunft über die Notwendigkeit der Sperrung gibt. Das Fernmeldegeheimnis soll vor einer Kenntnisnahme des Kommunikationsvorgangs, also der Verbindung an sich schützen, nicht aber einen Schutz einer Verbindung zu einem bestimmten Ziel gewährleisten. ${ }^{894}$ Zudem stellt die Weiterleitung zu einer vordefinierten Sperrseite anders als die Weiterleitung der Daten an staatliche Stellen zum Zwecke der Strafverfolgung kein eingriffsrelevantes „Gebrauchmachen“ der Daten dar. Die zur Weiterleitung an einen StoppServer benötigten und durch die Access-Provider zur Kenntnis genommenen Daten fallen wie bei der Negierung der Verbindung ohnehin nur zu einem bestimmten Zweck - der Vornahme einer Sperrmaßnahme - an. Die Weiterleitung an einen speziellen „Stopp“-Server stellt keinen eigenen über die reine Sperrmaßnahme hinausgehenden Zweck dar, sondern dient gerade nur der Vervollständigung der Sperrmaßnahme durch Aufklärung des Nutzers. Da die Access-Provider in der Regel selbst die entsprechenden Stopp-Server betreiben werden, erhält auch

891 So noch die Vorgängerregelung des ZugErschwG, \ 8a Abs. 5 TMG-Entwurf, die letztlich aber keinen Eingang ins Zugangserschwerungsgesetz gefunden hat, sondern ausdrücklich aufgehoben wurde. Hierzu BT-Drs. $16 / 13411$.

892 BVerfGE 110, 33 (53); BVerfGE 113, 348 (375 f.).

893 Zum Zitiergebot ausführlich Jarass in: Jarass/Pieroth, Art. 10 GG, Rn. 3; Enders in: Epping/Hillgruber, Art. 19 GG, Rn. 15; Remmert in: Maunz/Dürig, Art. 19 GG, Rn. 40, zu den inhaltlichen Anforderungen an das Grundrechtszitat, Rn. 43 ff.

894 BMI u.a, Sitzung der Arbeitsgruppe „Access-Blocking“ am 12.2.2009, „Grundrechtliche, telekommunikations- und telemedienrechtliche Fragen im Zusammenhang mit der Sperrung kinderpornographischer Inhalte im Internet“ v. 19.2.2009, S. 6, abrufbar unter: http://blog.odem.org/2009/02/19/ finale-stellungnahme.pdf (zuletzt abgerufen 20.5.2012). 
niemand der sonst keine Kenntnis von den Daten des Nutzers hätte, durch die Weiteleitung entsprechende Kenntnis. ${ }^{895}$

Zusammenfassend wird im Regelfall ein Eingriff in das Fernmeldegeheimnis durch Vornahme von Sperrmaßnahmen durch Access-Provider zur Unterbindung kinderpornographischer Angebote im Internet damit ausscheiden. ${ }^{896}$

\section{Ergebnis: Fernmeldegeheimnis}

Zusammenfassend ist festzustellen, dass der Schutzbereich des verfassungsrechtlichen Fernmeldegeheimnisses bei allen denkbaren Sperrmethoden eröffnet ist. Jedoch ist ein darüber hinausgehender Eingriff in den Schutzbereich durch Vornahme der Sperrmethode nicht vorliegt. Damit ist eine Beeinträchtigung des Nutzers unter Zugrundelegung der verfassungsrechtlichen Gewährleistung des Fernmeldegeheimnisses gemäß Art. 10 Abs. 1 GG abzulehnen.

\section{III. „Computergrundrecht“ Art. 2 Abs. 1 i.V.m. Art. 1 Abs. 1 GG}

Die gesetzliche Sperrverpflichtung ist nicht am Allgemeinen Persönlichkeitsrecht des Nutzers in seiner besonderen Ausprägung als Grundrecht der Gewährleistung der Vertraulichkeit und Integrität informationstechnischer Systeme gemäß Art. 2 Abs. 1 GG i.V.m. Art. 1 Abs. 1 GG zu messen. Zwar schützt das vom Bundesverfassungsgericht im Grundsatzurteil zur Online-Durchsuchung aus Art. 2 Abs. 1 GG i.V.m. Art. 1 Abs. 1 GG abgeleitete Grundrecht vor einem Eingriff in ein informationstechnisches System, ${ }^{897} \mathrm{zu}$ welchen grundsätzlich auch der Personalcomputer zu zählen ist. ${ }^{898}$ Jedoch muss der Schutz hier im Wege der Grundrechtskonkurrenz zurücktreten. Das Bundesverfassungsgericht stellt in dieser

895 IE. auch BMI u.a, Sitzung der Arbeitsgruppe „Access-Blocking“ am 12.2.2009, „Grundrechtliche, telekommunikations- und telemedienrechtliche Fragen im Zusammenhang mit der Sperrung kinderpornographischer Inhalte im Internet" v. 19.2.2009, S. 6 aE., abrufbar unter: http://blog.odem.org/2009/02/19/finale-stellungnahme.pdf (zuletzt abgerufen 20.5.2012).

896 Anders wohl der Gesetzgeber, der beim ZugErschwG explizit in $\int 11$ den Gesetzesvorbehalt nach Art. 10 Abs. 2 GG, 19 GG eingefügt hat. Was aber durch die nunmehr mangelnde Heranziehung der anfallenden Daten zu Strafverfolgungszwecken, vgl. \5 ZugErschwG nach der hier vertretenen Meinung obsolet geworden ist. Anders noch die Vorgängerregelung in $\int 8 \mathrm{a}$ Abs. 5 TMG-E, hierzu BT-Drs. 16/12850, S. 7, die ausdrücklich die Weiterleitung der Daten zu Strafverfolgungszwecken vorsah.

897 BVerfGE 120, 247.

898 Als informationstechnisches System definiert das BVerfG alle Systeme, die ,allein oder in ihren technischen Vernetzungen personenbezogene Daten des Betroffenen in einem Umfang und in einer Vielfalt enthalten können, dass ein Zugriff auf das System es ermöglicht, einen Einblick in wesentliche Teile der Lebensgestaltung einer Person zu gewinnen oder gar ein aussagekräftiges Bild der Persönlichkeit zu erhalten“, BVerfGE 120, 247 (305). 
Entscheidung eindeutig heraus, dass „Diese Ausprägung des allgemeinen Persönlichkeitsrechts [erläuternd: das Computergrundrecht] vor Eingriffen in informationstechnische Systeme [schütze], soweit der Schutz nicht durch andere Grundrechte, wie insbesondere Art. 10 oder Art. 13 GG, sowie durch das Recht auf informationelle Selbstbestimmung gewährleistet ist" ${ }^{\text {" } 899}$ Zuweilen mag aufgrund der Aussage zwar Uneinigkeit bezüglich einer zutreffenden Einordnung des „Computergrundrechts“ im Konkurrenzverhältnis zu anderen Grundrechten herrschen, 900 jedoch kommt es im Falle der gesetzlichen Sperrverpflichtungen einer Verdrängung des Computergrundrechts durch das Fernmeldegeheimnis kommen. Denn das Bundesverfassungsgericht führt weiter aus, dass soweit sich „eine Ermächtigung auf eine staatliche Maßnahme beschränkt, durch welche die Inhalte und Umstände der laufenden Telekommunikation im Rechnernetz erhoben oder darauf bezogene Daten ausgewertet werden“, sei der Eingriff ,allein an Art. 10 Abs. 1 GG“ zu messen. ${ }^{901}$ Die technische Realisierung der Sperrmethoden setzt spezifisch an den laufenden Kommunikationsvorgang an, indem dieser zielorientiert negiert werden soll, nicht jedoch auf bereits abgelegte Daten auf dem Computersystem. Bereits die Einordnung einer solchen Maßnahme unter den Schutzbereich des Fernmeldegeheimnisses des Art. 10 Abs. 1 GG verdrängt im Wege der Grundrechtskonkurrenz die Einschlägigkeit des „Computergrundrechts“, auch wenn letzten Endes kein Eingriff in das primär eröffnete Grundrecht gegeben ist. ${ }^{902}$

Auch unabhängig der vermuteten Subsidiarität würde die Gewährleistung der Integrität und Vertraulichkeit informationstechnischer Systeme hier letztlich ebenfalls an den bereits im Rahmen des Eingriffs in Art. 10 GG vorgebrachten Argu-

in der Form, dass als „besonders gefasster Ausschnitt des Allgemeine Persönlichkeitsrechts ohnehin eine subsidiäre Anwendung gegenüber anderen Freiheitsrechten gegeben ist und zusätzlich auch gegenüber den spezielleren Gewährleistungen die aus dem Allgemeinen Persönlichkeitsrecht selbst (vor allem Recht auf informationelle Selbstbestimmung). Nach Hoffmann-Riem, JZ 2008, 1009 (1019 ff.) liegt sogar Spezialität des Grundrechts auf Gewährleistung der Integrität und Vertraulichkeit informationstechnischer Systeme vor, soweit eine Infiltration eines informationstechnischen Systems - also eine technische Manipulation des Gerätes - vorliegt Knüpfe die Maßnahme auch noch auf andere Datenerhebungsmittel etwa Befragungen etc. an, so ist ausschließlich das Recht auf informationelle Selbstbestimmung berührt. Im Konkurrenzverhältnis zu Art. 10 GG gehe das Computergrundrecht auch in dem Fall vor, indem die TKÜberwachungsmaßnahme auch auf eine Infiltration angewiesen sei. Hoffmann, CR 2010, 514 (517) spricht sich indes für ein Nebeneinander von Computergrundrecht und weiteren grundrechtlichen Gewährleistungen aus.

901 BVerfGE 120, 247 (307).

902 Zur Grundrechtskonkurrenz Jarass in: Jarass/Pieroth, Vorb. vor Art. 1 GG, Rn.17. 
menten scheitern. Soweit die Daten nur im Wege des üblichen Geschäftsverkehrs erfasst und ohne die Möglichkeit der Weitergabe gleich wieder gelöscht werden, kann die Eingriffsintensität vor dem teleologischen Hintergrund der grundrechtlichen Gewährleistung nicht als grundrechtlich relevanter Eingriff ausgelegt werden. Folglich scheidet eine Berufung des Nutzers auf das „Computergrundrecht“ aus Art. 2 Abs. 1 GG i.V.m. Art. 1 Abs. 1 GG aus.

\section{Entgegenstehende Grundrechte der Anbieter}

Der Vollständigkeit halber ist darauf hinzuweisen, dass eine gesetzliche Sperrverpflichtung neben den Belangen der Normadressaten sowie der Internetnutzer zwangsläufig auch individuelle Belange der Inhaltsanbieter, das heißt der Contentsowie Hostprovider, berührt.

Dabei ist zu beachten, dass die Sperrung einer Webseite stets nur als ultima ratio-Lösung in Betracht kommt. Bedingt durch die Tatsache, dass eine Löschung des fraglichen Webinhalts geringere grundrechtliche Belastungen und eine höhere Effektivität mit sich bringt, ist diese Maßnahme schon aufgrund der verfassungsrechtlichen Erforderlichkeit vorrangig gesetzlich zu normieren. Bei inländischen wie innereuropäischen Webinhalten wird eine Ermittlung der verantwortlichen Provider und damit die Grundlage zur Vornahme einer Löschung im Regelfall ohne weiteres möglich und eine punktuelle Herausnahme des illegalen Inhalts auf diese Weise zu realisieren sein. Das Hauptanwendungsgebiet der Sperrmaßnahmen werden daher ausländische Angebote ausmachen, bei denen eine Rechtsdurchsetzung scheitert. Zwar ist einer Sperrverpflichtung auch hierbei immanent, dass diese zum befürchteten Over-Blocking-Effekt führt, sie bleibt oftmals jedoch die einzige Möglichkeit den erkannten und als kinderpornographisch eingestuften Inhalt im Zugriff zu erschweren.

Entsprechend Art. 1 Abs. 3 GG ist die Grundrechtsbindung des Gesetzgebers nicht nur auf ein Tätigwerden im Inland beschränkt, sondern ist auch dann zu beachten, wenn die gesetzlichen Maßnahmen auch außerhalb des deutschen Hoheitsgebiets wirken. ${ }^{903}$ Daher kommen die ausländischen Anbieter grundsätzlich als Grundrechtsberechtigte in Betracht. Der Gesetzgeber ist jedoch nur insoweit verpflichtet die Grundrechte der ausländischen Anbieter zu wahren, als es sich um so genannte „Menschenrechte“ handelt, die jedermann zukommen. ${ }^{904}$ Menschenrechte differenzieren nicht nach der Staatsangehörigkeit des Grundrechtsträgers, sondern kommen allen Grundrechtsberechtigten gleichermaßen zu. Handelt es

903 BVerfGE 6, 290 (295); BVerfGE 57, 9 (23); Stern in: Stern, Staatsrecht, 1994, Bd. 3/2, S. 1230.

904

Dreier in: Dreier, Vorb., Rn. 72; Stern in: Stern, Staatsrecht, 1988, Bd. 3/1, S. 1009 f.; explizit in Bezug auf Sperrverfügungen gegen Access-Provider, Sieber/Nolde, Sperrverfügungen im Internet, 2008, S. 66; zur Berufung der Provider auf Grundrecht auch Greiner, Die Verhinderung verbotener Internetinhalte, 2001, S. 158 f. 
sich bei den tangierten Belangen jedoch um sogenannte Bürgerrechte („Deutschen-Grundrechte"), bei welchen das Grundgesetz den persönlichen Schutzbereich bereits auf deutsche Staatsangehörige nach Art. 116 GG beschränkt, ist eine direkte Berufung auf das Grundrechte verwehrt. ${ }^{905}$ Den Beteiligten bleibt in einem solchen Fall nur die Berufung auf den (geringeren) Schutz über Art. 2 Abs. 1 GG.906

Entsprechend kommt bei einer gesetzlichen Sperrverpflichtung als entgegenstehender Belang der Inhaltsanbieter vor allem die Meinungsfreiheit gemäß Art. 5 Abs. 1 Satz 1, Alt. 1 GG in Betracht. Sind beruflichen Interesse der ausländischen Anbieter berührt, so hat der Gesetzgeber bei der Formulierung einer gesetzlichen Sperrpflicht nur die Anforderungen des Art. 2 Abs. 1 GG zu wahren, da die Berufsfreiheit ausdrücklich auf „Deutsche“ beschränkt ist.

I. Meinungsfreiheit Art. 5 Abs. 1, Satz 1, Alt. 1 GG

\section{Eingriff in den Schutzbereich}

Die Meinungsfreiheit der Anbieter ist grundsätzlich bei einer gesetzlichen Sperrverpflichtung berührt. Denn anders als bei Access-Providern, deren Tätigkeit auf einer inhaltsunabhängigen Weiterleitung der Daten beruht, ist die Tätigkeit der Anbieter gerade darauf ausgerichtet bestimmte Inhalte im Internet anzubieten und deren Inhalt anderen zugänglich zu machen. ${ }^{907}$ Es ist nicht auszuschließen, dass die im Zugriff erschwerten Inhalte grundrechtlich geschützte „Meinungen“ i.S.d. Art. 5 Abs. 1, Satz 1, Alt. 1 GG beinhalten und damit Werturteile, Stellungnahmen, wahre Tatsachenbehauptungen und andere Äußerungen darstellen, die dem Kommunikationsprozess zuträglich sind. ${ }^{908}$

Dabei darf im Schutzbereich der Meinungsfreiheit kein Unterschied gemacht werden zwischen der von den Anbietern verbreiteten kinderpornographischen Meinung und sonstiger über das Internet verbreiteter rechtlich unbedenklicher Inhalte. Letztlich muss auch hier das gelten, was im Rahmen der Informationsfreiheit bereits herausgestellt wurde: Die rechtliche Einordnung des beschränkten Inhaltes ist für die Eröffnung des Schutzbereich des Kommunikationsgrundrechts irrelevant, da es für einen verfassungsrechtlichen Schutz nicht auf die Frage ankommen kann, ob die Inhalte nach einfachem Recht als rechtswidrig oder recht-

905 Sperrverfügungen im Internet, 2008, S. 71; Dreier in: Dreier, Vorb., Rn. 73.

906 BVerfGE 78, 179 (196).

907 Zur mangelnden Schutzbereichseröffnung bei Access-Providern oben 3. Teil B. III.

908 Allgemein zur grundgesetzlichen geschützten Meinung, BVerfGE 94, 1 (7); BVerfGE 61, 1 (8 f.), Stern in: Stern, Staatsrecht, 2006, Bd. 4/1, Rn. 1393 f.; Zur Eingrenzung des Schutzbereichs auf bewusst unwahre Tatschen, Jarass in: Jarass/Pieroth, Art. 5 GG, Rn. 4. 
mäßig einzustufen sind. ${ }^{909}$ Anderenfalls hätte es der Staat im Widerspruch zur Zielsetzung und Systematik der Grundrechte aus Art. 5 Abs. 1 GG in der Hand, den verfassungsrechtlichen Schutzgehalt der Meinung nach Belieben zu begrenzen, ohne an die Voraussetzungen des Art. 5 Abs. 2 GG gebunden zu sein. ${ }^{910}$ Die zusätzlichen „erhöhten“ Anforderungen an die Einschränkung der Kommunikationsgrundrechte wären in diesem Fall obsolet, was eindeutig nicht von der verfassungsrechtlichen Intention getragen ist. Demnach bleibt die rechtliche Einordnung der verbreiteten Meinung für die Eröffnung des Schutzbereichs grundsätzlich außer Betracht. Etwas anderes kann nur gelten, soweit es sich bei dem verbreiteten Inhalt schon nicht um eine grundrechtlich geschützte Meinung handelt. Aus dem Schutzbereich fallen regelmäßig Ansichten heraus, die auf bewusst unwahren Tatsachen beruhen oder erwiesen unrichtige Tatsachen sind, da diese nicht als Voraussetzung zur Bildung einer Meinung beitragen können. ${ }^{911}$ Eine Differenzierung zwischen der strafrechtlichen Verwerflichkeit der verbreiteten Meinung und der bloßen Mitsperrung völlig legaler Inhalte ist erst auf der Ebene der verfassungsmäßigen Rechtfertigung des Eingriffs vorzunehmen. ${ }^{912}$

Im Bereich der Meinungsfreiheit stellt jede staatliche Maßnahme, die die Meinungsäußerung sowie Verbreitung verbietet, behindert oder aufzwängt, einen relevanten Eingriffsakt dar. ${ }^{913}$ Durch eine gesetzliche Sperrverpflichtung wird der Zugriff auf bestimmte Webinhalte zumindest erschwert und damit die Verbreitung der Meinung behindert. Folglich ist durch eine gesetzliche Sperrverpflichtung in die Meinungsfreiheit der Anbieter eingegriffen.

\section{Verfassungsmäßige Rechtfertigung}

Hinsichtlich der Anforderungen an die Rechtfertigung des Eingriffs in die Meinungsfreiheit müssen die gleichen Anforderungen gelten, die bereits bei der Verletzung der Informationsfreiheit der Nutzer angeführt worden sind. Da Meinungsfreiheit und Informationsfreiheit, neben Presse-, Rundfunk- und Filmfreiheit in ihrer systematischen Stellung zu den verfassungsrechtlichen Kommunikationsfreiheiten zusammengefasst werden, unterfallen alle Garantien den Schranken des BVerfGE 27, 71 (83 f.); Neumann, Ordnungsrechtliche Sperrungsverfügungen und die Informationsfreiheit nach Art. 5 Abs. 1 S. 1 2. Alt. GG, abrufbar unter: http://www.artikel5.de/artikel/sperrunginffreiheit.html (zuletzt abgerufen 20.5.2012).

911 BVerfGE 61, 1, 8; BVerfGE 90, 241 (247); BVerfGE 99, 185 (197); darauf bezugnehmend auch Sieber/Nolde, Sperrverfügungen im Internet, 2008, S. 77. Grundlegend Schemmer in: Epping/Hillgruber, Art. 5 GG, Rn. 6; Schulze-Fielitz in: Dreier, Art. 5 GG, Rn. 64.

912 So Sieber/Nolde, Sperrverfügungen im Internet, 2008, S. 77 ff.; Degen, Freiwillige Selbstkontrolle, 2007, S. 265; in die Richtung eines Abwägungsbedürfnisses auch Landmann, NJW 1996, 3309 (3310).

913 Schulze-Fielitz in: Dreier, Art. 5 GG, Rn. 124; Schemmer in: Epping/Hillgruber, Art. 5 GG, Rn. 6. 
Art. 5 Abs. 2 GG. ${ }^{914}$ Demnach sind aufgrund der für die freie und demokratische Meinungsbildungsbildung unerlässlichen Kommunikationsfreiheiten, die Anforderungen an die Verfassungsmäßigkeit des Eingriffs an das Vorliegen eines allgemeinen Gesetzes gekoppelt und müssen auch die hohe Wertigkeit des Grundrechts entsprechend würdigen. ${ }^{915}$ In Übereinstimmung zur Informationsfreiheit sind Eingriffe durch allgemeine Gesetzes verfassungsrechtlich nur gerechtfertigt, soweit sie dem Gewicht der Kommunikationsrechte bei der Einschränkung entsprechende Berücksichtigung verleihen, und dem Schutz eines enorm wichtigen Rechtsgutes dienen. ${ }^{916}$ Letztlich wird es sich auch hier um eine einzelfallbezogene Abwägung handeln müssen, die nicht schon dadurch entfällt, weil der Gesetzgeber mit der Reglung die Unterbindung strafrechtlich geahndeter Inhalte nach \184b StGB beabsichtigt. Wie festgestellt, ist die einfach-gesetzliche Einordnung eines Inhaltes nicht ausschlaggebend für die verfassungsrechtliche Beurteilung. ${ }^{917}$ Innerhalb der erforderlichen Abwägung wird die Meinungsfreiheit der Anbieter von kinderpornographischen Inhalten aber regelmäßig gegenüber dem staatlichen Interesse an einer Verhinderung des Zugriffs zum kinderpornographischen Angebot zurücktreten müssen. Da die Verfolgung des Jugendschutzes sowie das Interesse der Allgemeinheit an der Aufrechterhaltung der Sicherheit und Ordnung wichtige Belange sind, die auch von Verfassungswegen einen hohen Stellenwert genießen, sind sie potentiell in der Lage, auch in Anbetracht der fundamentalen Bedeutung der Kommunikationsgrundrechte für die Demokratie, in der Gesamtabwägung die Meinungsfreiheit zu überwiegen.

Differenzierter gestaltet sich die Abwägung in Bezug auf die Inhalte die aufgrund der mangelnden technischen Präzision der Sperre nur zufällig mitgesperrt werden. Gerade bei Sperrmethoden mit hohen „Nebenwirkungen“ kann der Meinungsfreiheit der Anbieter legaler Inhalte im Einzelfall bei der Abwägung mehr Gewicht zukommen als dem legitimen Zweck des Gesetzgebers an der Verhinderung des Zugriffs. ${ }^{918}$ Das zentrale Problem der Angemessenheit der Sperrung ist auch hier folglich der „Overblocking“-Effect, der je nach Art der vorgenomme-

914 Ausführlich Hoffmann-Riem in: Alternativkommentar GG, Art. 5 GG, Rn. 141 ff. Allgemein auch Schulze-Fielitz in: Dreier, Art. 5 GG, Rn. 86; Jarass in: Jarass/Pieroth, Art. 5 GG, Rn. 55 ff. Ausführliche Würdigung bei Sieber/Nolde, Sperrverfügungen im Internet, 2008, S. 222.

915 Im Einzelnen kann hier auf die obigen Ausführungen zum legitimen Zweck, Geeignetheit und Erforderlichkeit verwiesen werden. Wenn überhaupt, dann können sich unterschiede nur im Rahmen der Angemessenheit der Norm ergeben.

916 Zur sog Wechselwirkungslehre, BVerfGE 7, 198, 210); BVerfGE 35, 202 (223); BVerfGE 59, 232 (265); BVerfGE 71, 162 (181); BVerfGE 77, 65 (75).

917 Oben unter 3. Teil C. I. 2.

918 Sieber/Nolde, Sperrverfügungen im Internet, 2008, S. 223; Koreng, JURA 2010, 931 (937); der im Rahmen eines klausurartigen Aufbaus, die Verhältnismäßigkeit der Sperrungen verneint; wohl auch Schöttle, K\&R 2007, 366 (369). 
nen Sperrung zu einer unterschiedlichen Intensität der Beeinträchtigung des Grundrechtsträgers führen kann.

Auf Seiten des staatlichen Verfolgungsinteresses ist erneut der hohe Rang des hinter der gesetzlichen Sperrverpflichtung stehenden Rechtsgutes zu beachten und die großen Gefährdungen die von der ungehinderten Verbreitung der kinderpornographischen Inhalte ausgehen können. Zudem sind die eigenständigen Handlungsmöglichkeiten des Staates im Bereich der internetbasierten Gefahrenabwehr stark zurückgedrängt und hinsichtlich ihrer Effektivität auf Eingriffsbefugnisse gegenüber Dritten angewiesen. ${ }^{919}$ Die technische Ausgestaltung der Eingriffe bedingt dabei erst die schwerwiegenden Auswirkungen auf die verbreiteten Meinungsinhalte, welche im Falle der Sperrung nicht zu vermeiden sind.

Allein aufgrund des hohen Rangs des Rechtsgutes, der mangelnden Ausweichmöglichkeiten auf andere Handlungsalternativen und der technischen Eigenart der Sperrung wird man dem staatlichen Ansatz gegenüber der Beeinträchtigung der Meinungsfreiheit durch die Mitsperrung der legalen Inhalte in der Abwägung noch nicht Vorrang gewähren können.

Vielmehr müssen demgegenüber die entgegenstehenden Interessen der Betreiber betrachtet werden. Die Betreiber haben im Regelfall keine Möglichkeit auf die Anzahl, sowie auf die Art der zufällig mitgesperrten Inhalte Einfluss zu nehmen. Die Nutzer des Internets wie auch die Anbieter sind der staatlichen Maßnahme vergleichsweise praktisch „kampflos“ ausgeliefert. Weder stehen ihnen wirksamen Vorabrechtsschutzmöglichkeiten zu, die eine Überprüfung der Einordnung bestimmter Inhalte als kinderpornographisch und damit die Notwendigkeit der Sperrung auch legaler Inhalte nachweisen würden. ${ }^{920}$ Noch handelt es sich bei der Sperrung um ein besonders effektives Instrument, dass zum Erreichen des gesetzgeberischen Ziels eingesetzt wird. ${ }^{921}$ Zudem ist die Einschränkung der Meinungsfreiheit besonders schwerwiegend. Durch die Sperrung werden die meinungstragenden Webangebote nur über Umwege zugänglich und können potentielle Adressaten gar nicht erreichen. Im Gegenzug können sich die potentiellen Adressaten keine neuen, eigenen Meinungen aufgrund der Unerreichbarkeit der Angebote bilden und diese erneut weitertragen. Somit zieht sich der von der Maßnahme einschränkende Prozess weiter fort und ist nicht auf den Moment der Sperrmethode beschränkt.

$919 \mathrm{Zu}$ den weiteren Mitteln die zur Verhinderung der Kinderpornographie in Betracht kommen, oben 3. Teil C. I. 2.

920 Koreng, JURA 2010, 931 (937).

921 Deshalb wird oftmals die Zumutbarkeit der Sperre ganz in Frage gestellt, so in Bezug auf zivilrechtliche Sperrverfügungen, LG Hamburg, NJOZ 2010, 443 (445); LG Kiel, MMR 2008, 123 (124); Gercke, MMR 2008, 291. 
Als wesentlichstes Kriterium innerhalb der Abwägung ist aber die fundamentale Wichtigkeit der Meinungsfreiheit anzuführen. ${ }^{922}$ Es kann nahezu nicht abgesehen werden, welchen Gehalt die zufällig unterdrückten Meinungen im laufenden Meinungsbildungsprozess hätten. Sie können zur politischen wie gesellschaftlichen Meinungsbildung beitragen, gleichfalls können sie in ihrem Aussagegehalt völlig losgelöst von jeglichem Meinungsprozess sein. Dem Internet ist es immanent, dass durch die Verbreitung einer bestimmten Meinung eine viel größere Anzahl von Personen erreicht werden kann und sich die Meinung daher ganz anders ausbreiten und verfestigen kann, als wenn die Meinung außerhalb des Internets im zwischenmenschlichen Bereich individuell verbreitet worden wäre. Damit ist dem Meinungsportal Internet eine besondere Stellung innerhalb der fundamentalen demokratischen Legitimation der uneingeschränkten Meinungsfreiheit des Art. 5 Abs. 1, Satz 1, Alt. 1 GG einzuräumen. Der enormen Einschränkung der Meinungsfreiheit steht der relativ kleine Beitrag der technischen Sperrungen zur gesetzgeberischen Zielerreichung gegenüber. Aufgrund des weiten Umgehungspotentials können sämtliche Sperren mit einfachsten Mitteln umgangen werden und den verdeckten Inhalt wieder zum Vorschein bringen.

Letztlich wird man auch in Bezug auf die Unterdrückung der Meinungsfreiheit der Anbieter durch die gesetzlichen Sperrverpflichtungen die gleichen verfahrensrechtlichen Kompensationsmittel fordern müssen, wie bei der Beschränkung der Informationsfreiheit. Da Meinungsfreiheit und Informationsfreiheit in ihrer systematischen Stellung zu den verfassungsrechtlichen Kommunikationsfreiheiten zusammengefasst sind, können auch die Sicherungsmittel zur Verfassungsmäßigkeit der gesetzlichen Regelung entsprechend übertragen werden: Um die Heimlichkeit und Schwere des Eingriffs in dieses für die Demokratie fundamentale Grundrecht abzumildern, muss gewährleistet sein, dass die Notwendigkeit der Sperrung auf den Einzelfall beschränkt ist. Neben der ultima-ratio Formulierung der Sperre muss ein unabhängiger Richter hierfür die ausnahmsweise Notwendigkeit der Sperrung des Inhaltes bestätigen. Wenn die Sperrung unumgänglich erscheint, dann haben die Anbieter auch die unbeabsichtigten Nebenfolgen der Sperrung legaler Meinungen hinzunehmen. In diesem Fall müssen die Belange an der Unterbindung des gefahrtragenden Webcontent die Belange der Anbieter überwiegen. Da je nach Art der Sperrmethode unterschiedlich viele legale Inhalte mitgesperrt werden, hat der Richter zudem auch die Art der Sperrmethode zu überprüfen und das mögliche Ausmaß einer Sperrung ins Verhältnis zur Gefährlichkeit des kinderpornographischen Inhaltes zu setzen. Die Wahl der Sperrmethode darf folglich nicht den Access-Providern überlassen sein.

922 So auch Billmeier, Die Düsseldorfer Sperrungsverfügung, 2007, S. 264, 273. 


\section{Ergebnis: Meinungsfreiheit}

Auch die Meinungsfreiheit der Anbieter steht einem gesetzlichen Sperransatz zur Zugriffserschwerung auf kinderpornographische Inhalte entgegen. In Übereinstimmung zur Informationsfreiheit der Nutzer muss der Gesetzgeber hier bemüht sein die Anwendbarkeit der Sperre auf Einzelfälle zu begrenzen. Nur soweit auch verfahrensrechtliche Sicherungsmittel normiert werden kann überhaupt gewährleistet sein, dass die Sperrung in Anbetracht der fundamentalen Bedeutung der Kommunikationsgrundrechte für die Demokratie verfassungsrechtlich zu rechtfertigen ist.

\section{E. Gesamtwürdigung: Entgegenstehende Grundrechte}

Die Verfassungsmäßigkeit von gesetzlichen Zugriffssperren kann nach alledem nicht per se ausgeschlossen werden. Sie ist allerdings durch verfassungsrechtliche Feinheiten wesentlich begrenzt. Im Hinblick auf entgegenstehende Grundrechte steht der Gesetzgeber deshalb vor dem Erfordernis die Norm so zu formulieren, dass ihre Verfassungsverträglichkeit im Einzelfall sichergestellt ist.

Im Hinblick auf die Berufs- sowie Wissenschaftsfreiheit der Access-Provider kann eine Verfassungsverträglichkeit noch mit relativ einfachen Mittel garantiert werden. Im Abwägungsverhältnis stellt sich die Einschränkung der tangierten Grundrechte in Verhältnis zum staatlicherseits verfolgten Schutzweck als nicht so gravierend dar, als könnte sie zu einer verfassungsrechtlichen Verwerfung führen. Indem der Gesetzgeber von Vorneherein einen Entschädigungstatbestand an die gesetzliche Pflicht zur Sperrung koppelt und die forschenden Institutionen aus dem personellen Anwendungsbereich der Norm herausnimmt, können unzumutbare Eingriffe relativiert und ein schonender Ausgleich zwischen der jugendschutz- wie gefahrenabwehrrechtlich notwendigen Sperrung und der ihr zugrundeliegenden Problematik geschaffen werden.

Weitaus schwieriger gestaltet sich die Rechtfertigung der Einschränkung von Kommunikationsgrundrechten wie der Meinungs- und Informationsfreiheit. Hier ist vor allem das Gefährdungspotential des Inhaltes im Einzelfall sowie die Zielgenauigkeit der jeweiligen Sperrung maßgeblich, um überhaupt eine Einschränkung rechtfertigen zu können. ${ }^{923}$ Kinderpornographischen Angeboten wohnt zwar

923 In die Richtung Sieber/Nolde, Sperrverfügungen im Internet, 2008, S. 226; „Sperrverfügung gegen Internet-Provider", Ausarbeitung des Wissenschaftlichen Dienstes des Bundestages, WD3-3000010/2009, S. 22; Stadler, MMR 2009, 581 (582); Höbne/Dienst, jurisPR ITR 13/2009, Anm. 6; Spoenle, jurisAnwZert ITR 17/2009, Anm. 2; Sieber, JZ 2009, 653 (654); Heckmann, Stellungnahme der Sachverständigen im Rechtsausschuss, S. 15, abrufbar unter:

http://www.bundestag.de/bundestag/ausschuesse17/a06/anhoerungen/archiv/03_Zugangsers chwerung/04_Stellungnahmen/Stellungnahme_Heckmann.pdf (zuletzt abgerufen 20.5.2012). 
ein großes Gefährdungspotential inne, so dass zumindest vorstellbar ist, dass selbst größere, nicht vermeidbare Kollateralschäden hinzunehmen sind. ${ }^{224}$ Ebenso kann auch die Hinnahme von unüberschaubaren Sperren trotz eines Verstoßes gegen $\$ 184 \mathrm{~b}$ StGB hinzunehmen sein. Dies erklärt sich letztlich damit, dass die gesetzliche Normierung einer Sperrpflicht für kinderpornographische Inhalte zwar abstrakt einem hohen Schutzgut dient, allerdings kann das Sperrkonzept dieses Schutzziel aufgrund teilweise einfachster Umgehungsmöglichkeiten nur in eingeschränktem Maß realisieren. ${ }^{925}$ Die begrenzte Zweckerreichung im Kampf gegen Kinderpornographie und die unterschiedlich schwerwiegende Beeinträchtigung der am Kommunikationsprozess beteiligten Akteure sind folglich bestimmend für die verfassungsrechtliche Zulässigkeit der Normierung. Die weitreichenden Einschränkungen der Grundrechte können nur hingenommen werden, wenn die Möglichkeit der Sperrung gesetzlich bereits auf ein Minimum beschränkt wird. Neben der unerlässlichen Ausgestaltung der Sperrung als ultima-ratio-Lösung müssen auch verfahrensrechtliche Sicherungsmittel eingesetzt werden, um die Anwendbarkeit der Zugriffssperre so weit wie möglich zu begrenzen und die Verfassungsmäßigkeit der Maßnahme im Einzelfall sicherzustellen.

\section{F. Einzuhaltende Verfassungsprinzipien}

Nicht nur Grundrechte können einer gesetzlichen Sperrverpflichtung entgegenstehen. Neben der Wahrung der Grundrechte ist der Staat gleichermaßen auch an die Vereinbarkeit einer gesetzlichen Vorschrift an wesentliche Verfassungsprinzipien gebunden. Die Nichteinhaltung dieser tragenden Grundsätze führt zu einer Nichtigkeit des Gesetzes. ${ }^{926}$

\section{Einhaltung des Bestimmtheitsgebots Art. 20 Abs. 3 GG}

Der Gesetzgeber muss innerhalb der Formulierung einer gesetzlichen Sperrverpflichtung das Bestimmtheitserfordernis wahren. Danach liegt eine Unvereinbarkeit mit dem rechtsstaatlichen Gebot aus Art. 20 Abs. 3 GG vor, wenn der Normadressat aus der gesetzlichen Regelung heraus die rechtliche Konsequenz seines Handelns nicht vorhersehen kann und sein Handeln demnach nicht nach dem

924 So in Bezug auf Sperrungen wegen Verstoß gegen JMStV-Regelungen, Sieber/Nolde, Sperrverfügungen im Internet, 2008, S. 226.

925 Ausdrücklich zu Sieber/Nolde, Sperrverfügungen im Internet, 2008, S. 226.

926 Zum Verstoß gegen den Wesentlichkeitsgrundsatz: BVerfGE 84, 212 (226); BVerfGE 49, 89 (126); BVerfGE 116, 24 (58); Zum Verstoß gegen das Bestimmtheitsgebot: BVerfGE 49, 168 (181); BVerfGE 59, 104 (114); BVerfGE 62, 169 (183); BVerfGE 103, 107; Zum Verstoß gegen das Zitiergebot: BVerfGE 5, 13 (15); BVerfGE 64, 72 (79); BVerfGE 85, 386 (402); BVerfGE 113, 348 (366). 
Gesetz ausrichten kann.927 An den Gesetzgeber sind bei der Formulierung des Gesetzes also ganz spezielle Anforderungen zu stellen. Das Gesetz muss abstrakt dazu dienen zahllose Einzelfälle, wie sie sich im täglichen Leben stellen, zu Fallgruppen zu bündeln und möglichst die gleiche Behandlung für alle zu garantieren.928 Geprägt von diesem „Idealbild“ müsste der Gesetzgeber folglich eine Regelung so umfassend und differenziert ausgestalten, dass sämtliche Normadressaten ihr Verhalten danach ausrichten können. ${ }^{929}$ Um mangelnder Übersichtlichkeit vorzubeugen, ist es für den Gesetzgeber zulässig beispielsweise unter zu Hilfenahme von Generalklauseln und unbestimmten Rechtsbegriffen, einen entsprechenden Spielraum bei der Auslegung des Gesetzes einzuräumen. ${ }^{930}$ Allein die Heranziehung solcher Apparate führt nicht zur verfassungsrechtlich nicht hinnehmbaren Unbestimmtheit des Gesetzes, es muss aber auch in diesem Fall sichergestellt sein, dass das Handeln der Verwaltung messbar und für den Einzelnen berechenbar, insbesondere im Hinblick auf eine spätere Gerichtskontrolle. ${ }^{931}$ Dies gilt umso mehr für grundrechtseinschränkende Gesetze, die einen rechtlich höchst sensiblen Freiheitsbereich des Bürgers tangieren. ${ }^{932}$

Die Sperrverpflichtung unterscheidet sich in ihrer Eingriffsintensität bezüglich der Rechte der Normadressaten (Access-Provider) wie auch mittelbar beteiligter Dritter (Nutzer; Anbieter), je nach gewählter Sperrmethode. 933 Während etwa die DNS-Sperrmethode wirtschaftlich die geringsten Belastungen der Provider mit sich bringt, kann sie in Bezug auf die Kommunikationsfreiheiten von Nutzern und Anbietern zu einem besonders großen Overblocking-Effect und zu unzumutbaren Belastungen führen. Demnach ist im Hinblick auf die Bestimmtheit der Norm eine enge gesetzliche Formulierung wünschenswert, welche für die jeweiligen Access-Provider nur wenig Entscheidungsspielraum hinsichtlich der Art nach der

BVerfGE 31, 255 (264); BVerfGE 83, 130 (145); BVerfGE 110, 33 (53); im Kontext zum Zugangserschwerungsgesetz Schnabel, JZ 2009, 994 (998); Spoenle, jurisAnwZert ITR 17/2009, Anm. 2; Kabl, SächsVBl. 2010, 180 (184); Sieber/Nolde, Sperrverfügungen im Internet, 2008, S. 173; Billmeier, Die Düsseldorfer Sperrungsverfügung, 2007, S. 138. So Herzog, NJW 1999, 25 (26). Zur Bestimmtheit ebenfalls Heckmann, Stellungnahme der Sachverständigen im Rechtsausschuss, S. 6, abrufbar unter: http://www.bundestag.de/bundestag/ausschuesse17/a06/anhoerungen/archiv/03_Zugangsers chwerung/04_Stellungnahmen/Stellungnahme_Heckmann.pdf (zuletzt abgerufen 20.5.2012).

929 Herzog, NJW 1999, 25 (26).

930 BVerfGE 78, 214 (226); Huster/Rux in: Epping/Hillgruber, Art. 20 GG, Rn. 169; Sommermann: in: v. Mangoldt/Klein/Starck, Art. 20 GG, Rn. 279.

931 BVerfGE 110, 33 (53).

932 BVerfGE 57, 295 (326 f.); BVerfGE 62, 169 (182); BVerfGE 109, 133 (188).

933 Ausführlich Sieber/Nolde, Sperrverfügungen im Internet, 2008, S. 85; angedeutet bei Schnabel, JZ 2009, 994 (999); Spoenle, jurisAnwZert ITR 17/2009, Anm. 2. 
vorzunehmenden technischen Umsetzung der Sperrverpflichtung zulässt. ${ }^{934}$ Nur so kann der Normadressat präzise erkennen, welche Folgen sein Handeln für alle Grundrechtsbeteiligten hat und seine Handlungen danach ausrichten. ${ }^{935}$ Zwar ist eine technologieneutrale Formulierung bezüglich der jeweiligen Sperrmethode in der Lage einen zeitnahen Aktualitätsverlust durch die „rasante Fortentwicklung der Technik“"936 zu kompensieren, dieses würde jedoch eindeutig der Bestimmtheit der Norm zuwiderlaufen. ${ }^{937}$ In Anbetracht dessen, ist der Gesetzgeber verpflichtet konkrete Vorgaben für die Art der Sperrmethode zu normieren um dem Bestimmtheitserfordernis zu entsprechen.

\section{Einhaltung des Wesentlichkeitsgrundsatzes Art. 20 Abs. 3 GG}

In Korrespondenz zum Bestimmtheitserfordernis ist auch aufgrund des rechtsstaatlichen Wesentlichkeitsgrundsatzes des Art. 20 Abs. 3 GG zu fordern, dass der Gesetzgeber die Wahl der jeweiligen Sperrmethode nicht der Entscheidungskompetenz der Access-Provider überlässt. ${ }^{938}$ Ausgangspunkt des rechtsstaatlichen Verfassungsprinzips ist, dass der Gesetzgeber in ,grundlegenden normativen Bereichen“ alle „wesentlichen Entscheidungen“" "939 selbst zu treffen habe und diese nicht anderen Normgebern überlassen könne. ${ }^{940}$ Je mehr Wesentlichkeit einer

934 IE. auch Schnabel, JZ 2009, S. 994 (999); so schon Billmeier, Die Düsseldorfer Sperrungsverfügung, 2007, S. 138 ff. mwN; Frey/Rudolph, Ausschussdrucksache 16 (9) 1546, S. 5.

$935 \mathrm{Zu}$ alledem auch Billmeier, Die Düsseldorfer Sperrungsverfügung, 2007, S. 138 f.

936 Ausdrücklich die Erläuterung im Rahmen der Begründung zum Vorgänger des ZugErschwG BT-Drs. 16/12850, S. 6. Darauf bezugnehmend ebenfalls Schnabel, JZ 2009, 994 (999).

937 IE. teilweise jedoch ohne hinreichende Begründung, Spoenle, jurisAnwZert ITR 17/2009, Anm. 2; Schnabel, JZ 2009, 994 (999); ders., Stellungnahme der Sachverständigen im Rechtsausschuss v. 8.11.2010, S. 5, abrufbar unter:

http://www.bundestag.de/bundestag/ausschuesse17/a06/anhoerungen/archiv/03_Zugangsers chwerung/04_Stellungnahmen/Stellungnahme_Schnabel.pdf (zuletzt abgerufen 20.5.2012); Kabl, SächsVBl. 2010, 180 (184).

938 In die Richtung ebenso Boecker, Stellungnahme der Sachverständigen im Rechtsausschuss v. 8.11.2010, S. 5, abrufbar unter: http://www.bundestag.de/bundestag/ausschuesse17/a06/anhoerungen/archiv/03_Zugangsers chwerung/04_Stellungnahmen/Stellungnahme_Boecker.pdf (zuletzt abgerufen 20.5.2012).

939 BVerfGE 48, 89 (126); BVerfGE 61, 260 (275); BVerfGE 88, 103 (116).

940 BVerfGE 40, 237 (249); BVerfGE 49, 89 (126 f.); BVerfGE 83, 130 (152); BVerfGE 95, 267 (309); BVerfGE 101, 1 (34); Herzog/Gržeszick in: Maunz/Dürig, Art. 20 GG, Rn. 107; Sommermann in: v. Mangoldt/Klein/Starck, Art. 20 GG, Rn. 263 ff.; Kloepfer, JZ 1984, 685 (690); explizit in Bezug auf gesetzliche Sperrmaßnahmen, Heckmann, Stellungnahme der Sachverständigen im Rechtsausschuss v. 8.11.2010, S. 17, abrufbar unter:

http://www.bundestag.de/bundestag/ausschuesse17/a06/anhoerungen/archiv/03_Zugangsers chwerung/04_Stellungnahmen/Stellungnahme_Heckmann.pdf (zuletzt abgerufen 20.5.2012). 
Entscheidung beizumessen ist, desto mehr selbstständige Regelungsdichte trifft den Gesetzgeber. ${ }^{941}$ Die Frage, welche Angelegenheiten wesentlich und daher durch parlamentarisches Gesetz zu regeln sind, ist dabei mittels „,verschiedener Kriterien und unter Reflexion expliziter Vorbehaltsregelungen“ jeweils gesondert zu ermitteln. ${ }^{942}$ Unstreitig ist, dass eine bloße politische Brisanz einer Angelegenheit noch keine Wesentlichkeit begründet. ${ }^{943}$ Maßgeblich ist vielmehr das Grundgesetz selbst: Liegt eine hohe Grundrechtsrelevanz der Angelegenheit vor, spricht dieses ausdrücklich für das Bedürfnis nach einer parlamentarischen Entscheidung. ${ }^{944}$ Dabei richtete sich die Wesentlichkeit einer Regelung nicht allein nach der Bedeutung der betroffenen Rechtsgüter, maßgeblich sei auch der „Grad der Betroffenheit" derselben. ${ }^{945}$

In Bezug auf die Formulierung einer gesetzlichen Sperrverpflichtung bedeutet dieses, dass aufgrund der enormen Grundrechtsrelevanz, die von der Implementierung einer technischen Zugriffssperre ausgeht und des hohen Rangs der betroffenen Grundrechte, der Gesetzgeber verpflichtet ist die Einzelheiten der Sperrung weitestgehend eigenständig zu regeln und darf die Entscheidung nach der Art der vorzunehmenden Sperrmaßnahme nicht in die Entscheidungskompetenz der Provider stellen darf. ${ }^{946}$

Im Ergebnis muss der Gesetzgeber auch die Auswahl der anzuwendenden Sperrtechnologie, auch aufgrund des Wesentlichkeitsgrundsatzes, selbst innerhalb der Formulierung der gesetzlichen Sperrverpflichtung festlegen. ${ }^{947}$

941 Explizit Heckmann, Stellungnahme der Sachverständigen im Rechtsausschuss v. 8.11.2010, S. 17, abrufbar unter:

http://www.bundestag.de/bundestag/ausschuesse17/a06/anhoerungen/archiv/03_Zugangsers chwerung/04_Stellungnahmen/Stellungnahme_Heckmann.pdf (zuletzt abgerufen 20.5.2012).

Reimer in: Hoffmann-Riem/Schmidt-Aßmann/Voßkuhle, Grundlagen des Verwaltungsrechts, 2006, Bd. I, \ 9 Rn. 48; Herzog/Grzeszik in: Maunz/Dürig, Art. 20 GG, Rn. 107 jeweils mwN.

943 Sommermann in: v. Mangoldt/Klein/Starck, Art. 20 GG, Rn. 265.

944 BVerfGE 46, 47 (79); Heræog/Grzeszite in: Maunz/Dürig, Art. 20 GG, Rn. 107; ausführlich Sommermann in: v. Mangoldt/Klein/Starck, Art. 20 GG, Rn. 267 ff. mwN.

945 Sommermann in: v. Mangoldt/Klein/Starck, Art. 20 GG, Rn. 269.

946 Ebenso Heckmann, Stellungnahme der Sachverständigen im Rechtsausschuss v. 8.11.2010, S. 17, abrufbar unter:

http://www.bundestag.de/bundestag/ausschuesse17/a06/anhoerungen/archiv/03_Zugangsers chwerung/04_Stellungnahmen/Stellungnahme_Heckmann.pdf (zuletzt abgerufen 20.5.2012).

947 In die Richtung ebenso Heckmann, Stellungnahme der Sachverständigen im Rechtsausschuss v. 8.11.2010, S. 18, abrufbar unter:

http://www.bundestag.de/bundestag/ausschuesse17/a06/anhoerungen/archiv/03_Zugangsers chwerung/04_Stellungnahmen/Stellungnahme_Heckmann.pdf (zuletzt abgerufen 20.5.2012); ebenfalls Schnabel, JZ 2009, 996 (998); Spoenle, AnwZert ITR 17/2009, Anm. 2; Frey/Rudolph, CR 


\section{Einhaltung des Zitiergebots Art. 19 Abs. 1 Satz 2 GG}

Soweit ein Grundrecht „durch oder aufgrund eines Gesetzes“ eingeschränkt werden kann, mithin einem einfachen Gesetzesvorbehalt im Sinne eine Einschränkungsvorbehalts unterfällt, muss für die Vereinbarkeit der Maßnahme mit der Verfassung das eingeschränkte Grundrecht innerhalb des einschränkenden Gesetzes selbst zitiert werden.948 Die hinter der Notwendigkeit der Einhaltung einer Zitierung stehende Intention des Art. 19 Abs. 1 Satz 2 GG ist in zweifacher Hinsicht ausgestaltet: Einerseits stellt es für den Gesetzgeber selbst eine zu beachtende Schranken-Schranke dar, die eine Art „Warn- und Besinnungsfunktion“ fördern soll, wonach nur „gewollte“ und „überdachte“ Grundrechtseinschränkungen erfolgen und sich der Gesetzgeber über die Einschränkung der betroffenem Grundrechte praktisch selbst eine Rechenschaft ablegt. ${ }^{949}$ Darüber hinaus soll das Zitiergebot andererseits auch dem Rechtsicherheitsgefühl des Grundrechtsberechtigten zu Gute kommen. Indem die Nennung des eingeschränkten Grundrechts eine „Informations-, Hinweis- und Klarstellungsfunktion“950“، für den einzelnen Grundrechtsträger erfüllt.

Das verfassungsrechtliche Zitiergebot ist nicht auf jegliche Grundrechtseinschränkungen ausgeweitet, sondern nur auf solche, die einem einfachen Einschränkungsvorbehalt unterfallen. Dies ergibt sich aus der systematischen Gesamtschau zum verbotenen Einzelfallgesetz des Art. 19 Abs. 1 GG. Nur für die

2009, 644 (647), wobei letztere 3 Autoren die Wesentlichkeitsaspekte mit Aspekten der Bestimmtheit gleichsetzen.

948 Zum Zitiergebot ausführlich, Huber in: v. Mangoldt/Klein/Starck, Art. 19 GG, Rn. 62 ff.; Enders in: Epping/Hillgruber, Art. 19 GG, Rn. 15; Schwarz, Zitiergebote, 2002 jeweils mwN; in Bezug auf Sperrmaßnahmen im Internet.

949 Ganz herrschende Meinung: u.a. BVerfGE 64, 72 (79); BVerfGE 85, 386 (403 f.); BVerfGE 100, 313 (360); BVerfGE 113, 348 (366); BVerfGE 120, 274 (343); Jarass in: Jarass/Pieroth, Art. 19 GG, Rn. 4; Dreier in: Dreier, Art. 19 GG, Rn. 18; Hesse, Grundzüge des Verfassungsrechts der Bundesrepublik Deutschland, 1999, Rn. 331; Stern in: Stern, Staatsrecht, 1994, Bd. 3/2, S. 747; Lerche in: Isensee/Kirchhof, Hdb. StaatsR, 2002, Bd. V, \ 122, Rn. 41; Scbwarz, Zitiergebote, 2002, S. 22; Sieber/Nolde, Sperrverfügungen im Internet, 2008, S. 89.

950 Auf die Funktion abstellend Remmert in: Maunz/Dürig, Art. 19 GG, Rn. 41, der darauf hinweise dass die Terminologie der gesetzgeberischen Intention uneinheitlich verstanden wird, z.B. Menger in: Bonner Kommentar, Art. 19 GG, Rn. 195 ff.; Dreier in: Dreier, Art. 19 GG, Rn. 18 (Hinweisfunktion); Huber in: v. Mangoldt/Klein/Starck, Art. 19 GG, Rn. 69 (Klarstellungs- oder Verdeutlichungsfunktion); Denninger in: Alternativkommentar GG, Art. 19 GG, Rn. 16; Stern in: Stern, Staatsrecht, 1994, Bd. 3/2, S. 747, Schwarz, Zitiergebote, 2002, S. 23 f. (Hinweisfunktion). Im Ergebnis gehen alle terminologischen Bezeichnungen in ihrer Sinnhaftigkeit allerding konform. 
dort erfassten Fälle, bestimmt die Verfassung die Beachtung des Zitiergebots. ${ }^{951}$ Bei Grundrechten mit qualifizierten Vorbehalt oder vorbehaltslos gewährten Grundrechten untersteht der Gesetzgeber folglich keiner Zitatpflicht. Dabei handelt es sich nicht um höhere Anforderungen an das einschränkende Gesetz, die praktisch systemwidrig zur vermeintlich geringeren Einschränkungsmöglichkeit mittels einfachen Gesetzesvorbehalt stehen würden; vielmehr sei sich der Gesetzgeber bei Grundrechten mit höheren Schrankenvoraussetzungen ohnehin bewusst, sich im grundrechtlich sensiblen Bereich zu befinden, weshalb er nicht der Warnung und Besinnung auf den grundsätzlichen Respekt der grundrechtlichen Freiheitsgewährung erinnert werden soll. ${ }^{952}$ Würde man den Gesetzgeber über die qualifizierenden Voraussetzungen an die Zulässigkeit des Eingriffs in einen grundrechtlich abgesicherten Bereich auch zum ausdrücklichen Hinweis auf das Grundrecht zwingen, so würde das verfassungsrechtliche Statut zu einer „bloßen Förmelei“ verkommen. ${ }^{953}$ Daher gebietet sich im Rahmen des Zitatrechts stets eine restriktive Auslegung. ${ }^{954}$

So interpretiert muss der Gesetzgeber bei der gesetzlichen Sperrverpflichtung die Einschränkung eines Grundrechtes nicht zwangsläufig nennen. Nach der obigen Ausarbeitung greift eine gesetzliche Sperrverpflichtung zwar in Grundrechte aus Art. 12 GG, Art. 14 GG sowie die Kommunikationsgrundrechte des Art. 5 Abs. 1 GG von Nutzern (Informationsfreiheit) und Anbietern (Meinungsfreiheit) ein. All diese Grundrechte unterliegen jedoch spezifischen Anforderungen an die Zulässigkeit ihrer Einschränkung, wie Regelungsvorbehalten, Inhaltsbestimmungen oder qualifizierten Schranken. Lediglich Art. 10 GG untersteht einem einfachen Gesetzesvorbehalt ${ }^{955}$ und würde abstrakt betrachtet bei gesetzlichen Sperrverpflichtungen zu einer Angabe des eingeschränkten Grundrechts zwingen. Nach vorliegender Analyse, wird in das Fernmeldegeheimnis aus Art. 10 Abs. 1, Var. 3 GG über die Eröffnung des Schutzbereichs hinaus jedoch nicht eingegriffen, soweit die schutzbereichsrelevanten Daten nur im Rahmen der üblichen Geschäftserbringung erhoben und ohne „Mehrwert“ nach der Erhebung gleichzeitig

BVerfGE 64, 72 (79), darauf bezugnehmend auch Huber in: v. Mangoldt/Klein/Starck, Art. 19 GG, Rn. 72 .

952 In die Richtung BVerfGE 64, 72 (79); Sieber/Nolde, Sperrverfügungen im Internet, 2008, S. 90. IE. auch Huber in: v. Mangoldt/Klein/Starck, Art. 19 GG, Rn. 72.

953 So explizit zum mangelnden Zitaterfordernis bei einer Einschränkung des Berufsgrundrechts, BVerfGE 64, 72 (81). Zwar ist dieses ebenfalls über einen einfachen Gesetzesvorbehalt einschränkbar, jedoch untersteht Art. 12 einen Regelungsvorgehalt, nicht einen Einschränkungsvorbehalt, der ausschlaggebend für die Anwendung des Art. 19 Abs. 1 GG ist.

954 BVerfGE 28, 36 (46); BVerfGE 35, 185 (188); BVerfGE 64, 72 (78 f.); Gercke, MMR 2003, 453 (456).

955 Zur Notwendigkeit der Zitierung beim Eingriff in Art. 10 GG, BVerfGE 113, 348 (366). 
wieder gelöscht werden. 956 Soweit das Zitiergebot nicht zur „bloßen Förmelei“ verkommen soll, reicht die bloße Eröffnung des Schutzbereiches durch eine gesetzliche Maßnahme noch nicht aus, um die Zitatpflicht auszulösen. Vielmehr setzt das Bundesverfassungsgericht stets einen Eingriff in das jeweilige Grundrecht voraus. ${ }^{957}$ Dem ist auch teleologisch zuzustimmen. Wenn das Zitiergebot nicht nur zur „bloßen Förmelei“ verkommen soll, ist der Gesetzgeber nur verpflichtend daran gebunden, soweit zwingend eine Betroffenheit im Sinne eines Eingriffs in das entsprechende Grundrecht gegeben ist. Schließlich ist es nicht abzusprechen, dass viele legislatorische Mittel mehr oder weniger in der Lage sind zumindest im Ansatz schutzbereichsrelevante Lebenslagen des einzelnen Bürgers zu tangieren. Würde der Gesetzgeber hierbei jedes Mal gehalten sein die Einschränkung als solche zu nennen, so würde sich die „Warn- und Besinnungsfunktion" des Zitiergebot nur noch in aussageloser Notwendigkeit verlieren.958

Im Ergebnis ist somit die Berührung des Schutzbereichs des Fernmeldegeheimnisses Art. 10 GG durch die gesetzliche Sperrverpflichtung nicht ausschlaggebend dafür, dass der Gesetzgeber das Grundrecht als solches auch in der gesetzlichen Formulierung erwähnen soll. 959

\section{Widerspruch zum Zensurverbot Art. 5 Abs. 1 Satz 3 GG}

Staatliche Eingriffe in den Kommunikationsprozess im Internet sehen sich zwangsläufig mit dem Vorwurf zensurähnlicher Beschränkung von Internetinhalten konfrontiert. 960

956 Herleitung oben unter 3. Teil C. II. 2.

957 BVerfGE 64, 72 (79); BVerfGE 113, 348 (366).

958 BVerfGE 28, 36 (46); BVerfGE 35, 185 (188); BVerfGE 64, 72 (79); kritisch zu dieser Entwicklung Herzog in: Maunz/Dürig, Art. 19 GG, Rn. 12, 58; zum Verstoß gegen das Zitiergebot durch die unbenannte Einschränkungen des Art. 10 GG durch \100 i StPO, Gercke, MMR 2003, 453.

959 Anders der Gesetzgeber, der beim ZugErschwG explizit in $\int 11$ den Gesetzesvorbehalt nach Art. 10 Abs. 2 GG, 19 GG eingefügt hat. Anders noch die Vorgängerregelung in \8a Abs. 5 TMG-E, hierzu BT-Drs. 16/12850, S. 7, die ausdrücklich die Weiterleitung der Daten zu Strafverfolgungszwecken vorsah. IE. geht der Gesetzgeber damit wohl von einem Eingriff in den Schutzbereich des Art. 10 Abs. 1 GG aus.

960 Unter anderem:

https:/ /www.readers-edition.de/2011/03/01/zensur-heisst-heute-zugangserschwerungsgesetz (zuletzt abgerufen 10.3.2011); http://odem.org/informationsfreiheit/; Lischka, spiegel-online, „fehlerhafte Zensur-Methode, Arcor stoppt den Porno-Filter, Beitrag v. 17.9.2007, abrufbar unter: http://www.spiegel.de/netzwelt/web/0,1518,506143,00.html (zuletzt abgerufen 20.5.2012). Zum Thema Internetzensur durch technische Eingriffsbefugnisse des Gesetzgeres, Onlineauftritt des Arbeitskreis gegen Internetsperren und Zensur http://ak-zensur.de/ (zuletzt abgerufen 20.5.2012) mit zahlreichen Forderungen, u.a. das Verbot der Internetsperren im Grundgesetz, hierzu Stellungnahme des AK-Zensur zum Referentenentwurf der Bundesregierung zur Aufhe- 
Die Diskussion um die Zulässigkeit von gesetzlichen Sperrungen gründet in der Verfassungsnorm des Art. 5 Abs. 1 Satz 3 GG. Danach findet eine Zensur nicht statt. Die rechtliche Dimension der Formulierung ist allerdings nicht so eindeutig: Der Zensurbegriff ist nicht, wie der Wortlaut nahelegt, auf eine Unzulässigkeit sämtlicher Beeinträchtigung im Vor- oder Nachhinein, von staatlicher wie privater Seite, zu verstehen, ${ }^{961}$ sondern umfasst nach der überwiegenden Ansicht lediglich die formelle „Vorzensur“, also die Unzulässigkeit eines Präventivkontrollverfahren, welches die Veröffentlichung der Inhalte insbesondere von der Vorschaltung „einer behördlichen Vorprüfung und Genehmigung“ abhängig macht. ${ }^{962}$ So verstanden, wirkt das Zensurverbot nicht absolut, sondern verbietet nur jedes präventive Tätigwerden gegen Kommunikationsinhalte und verweist den Staat zum umfassenden Rechtsgüterschutz auf repressive Hilfsmittel. ${ }^{963}$

Die Rechtsprechung hat dieses Verständnis erarbeitet ${ }^{964}$ und auch heute gibt es für viele Autoren ${ }^{965}$ die Dimension des Zensurbegriffs vor. Die Beschränkung der „verbotenen“ Zensur auf die „Vorzensur“ gründet in dem Umstand, dass ein weites Verständnis des verfassungsrechtlichen Zensurverbots die Gefahr begründe, dass die Handlungsapparate des Staates im Bereich der Kommunikationsfreiheiten des Art. 5 Abs. 1 GG zu sehr beeinträchtigt wären und auch eine effektive Strafverfolgung nicht mehr gewährleistet sei. ${ }^{966}$ Gleichzeitig fußt die Einschränkung auf einer systematischen Überlegung: Art. 5 Abs. 1 S. 3 GG stelle kein eigenständiges Grundrecht dar, sondern eine Schranken-Schranke. ${ }^{967}$ Das Bundesver-

bung des Zugangserschwerungsgesetzes, Referentenentwurf, abrufbar unter: http://akzensur.de/download/Referententwurf-Aufhebung-ZugErschwG.pdf (zuletzt abgerufen 20.5.2012); Stellungnahme abrufbar unter: http://ak-zensur.de/download/StellungnahmeZugErschwG-Aufhebung.pdf (zuletzt abgerufen 20.5.2012); Gesetzesentwurf der Bundesregierung BT-Drs. 319/11; insgesamt auch Frey/Rudoplph/Oster, MMR-Beil. 3/2012, S. 10.

961 Fiedler, Die formale Seite der Äußerungsfreiheit, 1999, S. 30, darauf bezugnehmend, Koreng, Zensur im Internet, 2010, S. 212; Härting, K\&R 2012, 264 (265). BVerfGE 33, 52 (72); BVerfGE 73, 118 (166); BVerfG 83, 130 (155); BVerfGE 87, 209 (230). Hopf, ZUM 2000, 739 (740); Koreng, Zensur im Internet, 2010, S. 251.

BVerfGE 33, 52 (72); BVerfGE 73, 118 (166); BVerfG 83, 130 (155); BVerfGE 87, 209 (230). Dem im Wesentlichen auch bei Übertragung auf die Sperrungen von Internetseiten folgend, jedoch ohne spezifische Begründung, VG Köln, MMR 2005, 399; OVG Münster, NJW 2003, 2183; VG Düsseldorf, CR 2005, 891; AG Arnsberg, ZUM-RD 2005, 293.

965 Degenhart, UFITA 2009, 331 (365); Dietlein/Heinemann, K\&R 2004, 418 (422); Spindler/Volkmann, K\&R 2002, 398 (402); Billmeier, Die Düsseldorfer Sperrungsverfügung, 2007, S. 163; Storr in: Heermann/Ohly, Verantwortlichkeit im Netz, 2003, S. 103 (119).

966 Bullinger in: Löffler, Handbuch des Presserechts, 2005, \1, Rn. 122; zu alledem Koreng, Zensur im Internet, 2010, S. $212 \mathrm{ff}$.

967 Schlemmer in: Epping/Hillgruber, Art. 5 GG, Rn. 114; Herzog in: Maunz/Dürig, Art. 5 GG, Rn. 78; Jarass in: Jarass/Pieroth, Art. 5 GG, Rn. 63; Bethge in: Sachs, Art. 5 GG, Rn. 89; Frey/Rudolph, 
fassungsgericht formuliert indem Zusammenhang folgendermaßen: „Ist das Geisteswerk erst einmal an die Öffentlichkeit gelangt und vermag es seine Wirkung auszuüben, so gelten die allgemeinen Regeln über Meinungs- und Pressefreiheit und ihre Schranken. Diese würden gegenstandslos, wenn das Zensurverbot auch die Nachzensur umfasste, d.h. Kontroll- und Repressivmaßnahmen, die erst nach der Veröffentlichung eines Geisteswerkes einsetzen.968 Die Wirkung des Zensurverbots kann infolgedessen nicht dazu führen, dass die Schranken des Absatz. 2 an eigenständiger Bedeutung verlieren. Das Verständnis als Schranken-Schranke impliziert nämlich, dass eine Einschränkung nicht nur über kollidierendes Verfassungsrecht vorzunehmen ist, sondern eben eine Einschränkung schon über jugendschützende Bestimmungen oder allgemeine Gesetze möglich sei. ${ }^{969}$

Neben systematischen Erwägungen finden sich auch teleologische wie historische Gründe für eine Einschränkung des Anwendungsbereich des Zensurverbots auf die Vorzensur: Ausschlaggebend für die Formulierung eines Zensurverbots in die Verfassung war danach eine drohende „Lähmung des Geisteslebens“, die insbesondere im Falle einer (präventiven) Einschränkung der Meinungsfreiheit zu befürchten war. ${ }^{970}$ Der Einzelne sollte seinem Kommunikationsprozess freien Lauf lassen dürfen, ohne befürchten zu müssen aufgrund möglicher staatlicher Maßnahmen seinen Kommunikationspartner nicht zu erreichen. Die größere Gefahr einer Vorzensur (gegenüber der Nachzensur) begründe sich nach der Auffassung damit, dass bereits die Kenntnis der Existenz eines präventiven Kontrollapparates dazu bewegen könnte, eine beabsichtige Meinungskundgabe vor ihrer „Entlassung in den Kommunikationsprozess“ aufzugeben, wenn sie vorher einer staatlichen Stelle vorzulegen wäre. ${ }^{971}$ Sei das jeweilige geistige Meinungswerk bereits in den Kommunikationsprozess gelangt, kann es vom Zeitpunkt seiner Kundgabe bereits seine Wirkung entfalten und zur Meinungsbildung beitragen. Eine nachträgliche Beschränkung, etwa in Form einer Verbreitungsbeschränkung mit nachzensurartigem Charakter, hätte zwar für die einzelne kundgegebene Mei-

Rechtsgutachten BVDW, 2008, Rn. 27; Jarass, Massenmedien, 1978, S. 209 f.; Starck in: v. Mangoldt/Klein/Starck, Art. 5 GG, Rn. 173; Degenhart in: Bonner Kommentar, Art. 5 GG, Rn. 919; Wendt in: v. Münch/Kunig, Art. 5 GG, Rn. 66; anders Z.B. Ott, JuS 1968, 459 (461).

968 BVerfGE 33, 52 (72).

969 Stern in: Stern, Staatsrecht, 2006, Bd. 4/1, S. 1459.; Wienstroth, Bucerius Law Journal 2009, 98 (99).

970 BVerfGE 33, 52 (72); Hoffmann-Riem in: Alternativkommentar GG, Art. 5 Abs. 1, Rn. 77; Sieber/Nolde, Sperrverfügungen im Internet, 2008, S. 101; ausführlich Koreng, Zensur im Internet, 2010, S. 212 ff.; ders., JURA 2010, 931 (938).

971 Im Ausgangspunkt BVerfGE 33, 52 (72); Sieber/Nolde, Sperrverfügungen im Internet, 2008, S. 101, Wienstroth, Bucerius Law Journal 2009, 98 (101). 
nung eine stark beschränkende Wirkung, der Meinungsprozess an sich, der bereits in Gang gesetzt wurde, würde demgegenüber nur leicht beeinträchtigt werden. ${ }^{972}$

Übertragen auf die Sperrdebatte wäre diesem klassischen Verständnis folgend keine Zensur gegeben. Für die Einordung eines Inhalts als sperrungswürdig (in gegebenem Fall als kinderpornographisch) und die anschließende Vornahme der Sperrung muss der Inhalt bereits vorhanden und im Internet zugänglich sein. Die staatliche Einschränkung über die Formulierung einer Sperrverpflichtung wäre damit nur in dem Bereich der Nachzensur zuzuordnen, welche nach dieser Ansicht keine verfassungsrechtlich relevante Grenze für den Gesetzgeber darstellt. ${ }^{973}$

Demgegenüber wird dieses gefestigte Verständnis insbesondere vor dem Hintergrund der „,neuen Medien“ zunehmend in Frage gestellt. Die Erwägungen, die für eine Beschränkung auf die Vorzensur sprachen seien auf das Zeitalter des Internets nicht mehr pauschal zu übertragen. ${ }^{974} \mathrm{Im}$ Wesentlichen wird die Ansicht davon bestimmt, dass im Internet der ,,rein formale Vorgang der Veröffentlichung“ (anders als etwa im früheren Bereich der Printmedien) nicht gleichsam auch eine Rezeption des Gedankenguts bedeutet. ${ }^{975}$ Vielmehr verschwimmen bei einer Beschränkung des Inhalts im Internet die Grenzen zwischen unzulässiger Vor- und zulässiger Nachzensur. ${ }^{976}$ Eine im Internet eingestellte und der Öffentlichkeit zugängliche Seite könne schon lange Zeit potentiell zugänglich sein, ohne tatsächlich abgerufen zu werden. Die Anbieter von Inhalten könnten wegen der geringen Wirkungschance des Inhaltes und der gleichzeitigen Gefahr vor staatlichen Beschränkungen ganz von einer Veröffentlichung der Meinung absehen.977

Zusammenfassend hierzu Hoffmann-Riem in: Alternativkommentar GG, Art. 5 GG, Rn. 78, im Ergebnis jedoch ablehnend, ebenso Wienstroth, Bucerius Law Journal 2009, 98 (101).

973 Ebenso die Tendenz der verwaltungsgerichtlichen Rechtsprechung im Falle der Düsseldorfer Sperrverfügungen, die einheitlich von einer Nichtanwendung des Zensurverbots ausgingen bzw. die Diskrepanz der „Sperrverfügung“ zum Zensurverbot erst gar nicht diskutierten, z.B. VG Köln, MMR 2005, 399; OVG Münster, MMR 2003, 348 (350); VG Düsseldorf, CR 2005, 891; AG Arnsberg, ZUM-RD 2005, 293.

974 Insbesondere Hoffmann-Riem in: Alternativkommentar GG, Art. 5 GG, Rn. 78 ff.; Degen, Freiwillige Selbstkontrolle, 2007, S. 279; Sieber/Nolde, Sperrverfügungen im Internet, 2008, S. 101 ff.; Koreng, Zensur im Internet, 2010, S. 211 ff.; Engel, MMR-Beilage 4/2003, 1 (12); Degenhart in: Bonner Kommentar, Art. 5 GG, Rn. 933.

975 So zusammengefasst Koreng, Zensur im Internet, 2010, S. 217; zur „Neujustierung des Zensurbegriffs, Erdemir in: Eifert/Hoffmann-Riem, Innovation, Recht und öffentliche Kommunikation, 2011, S. 27 (39).

976 Ausdrücklich Degen, Freiwillige Selbstkontrolle, 2007, S. 281.

977 im Wesentlichen Koreng, Zensur im Internet, 2010, S. 216 ff. mwN. Zuvor auch schon herausgebildet bei Degen, Freiwillige Selbstkontrolle, 2007, S. 281. 
Damit würden gerade die „Lähmungseffekte“ eintreten, denen Art. 5 Abs. 1 Satz 3 GG entgegenwirken will. ${ }^{978}$

Darüber hinausgehend wird auch angeführt, dass einer Sperrung im Internet auch objektiv eine vorzensuräquivalente Wirkung zukommt. ${ }^{979}$ Eine Sperrung mittels IP-oder DNS-Methode kann nicht nur den gegenwärtig veröffentlichten Inhalt unzugänglich machen, sondern wirkt sich teilweise auch unmittelbar auf diejenigen zukünftigen Inhalte aus, die unter der gleichen Domain beziehungsweise IP-Adresse gespeichert werden, auch wenn sie vom gesperrten Inhalt „abweichen. ${ }^{980}$ Gleichzeitig eröffnen die technischen Gegebenheiten des Internets die Möglichkeit einer automatisierten systematisch verlaufenden massenhaften Überprüfung von Informationen, wie sie durch die manuelle Kontrolle bei traditionellen Medien nicht in vergleichbarer Weise vorzunehmen wäre. ${ }^{981}$ Hierdurch kann verstärkt eine grundrechtlich bedenkliche Einengung des gesamten Kommunikationsprozesses gefolgert werden, die die Ausweitung von Vor- auf Nachzensur rechtfertige. 982

Weiterhin wird angeführt, dass auch die Rechtsprechung nicht auf eine zu enge Auslegung des Zensurbegriffs dränge. ${ }^{983}$ So sprach sich das Bundesverwaltungsgericht dafür aus, dass auch im Nachhinein nicht erteilte Steuervergünstigungen eine „Umgehung des Zensurverbotes“ begründen könnten. ${ }^{984}$ Auch das Bundesverfassungsgericht ${ }^{985}$ formuliere, dass Zensur dann vorliege, wenn „insbesondere“ die Veröffentlichung von einer „Vorprüfung des Inhalts und seiner Genehmigung" abhängig gemacht werde. Auch diese Formulierung sei ein Indiz dafür, dass wohl auch das Bundesverfassungsgericht selbst ein weites Verständnis

978 Degen, Freiwillige Selbstkontrolle, 2007, S. 281.

979 Hoffmann-Riem in: Alternativkommentar GG, Art. 5 GG, Rn. 78; Engel, MMR-Beil. 4/2003, 1 (11 f.); Ladeur, ZUM 1997, 372 (379); angedeutet auch bei Spindler/Volkmann, MMR 2003, 353 (354); Degen, Freiwillige Selbstkontrolle, 2007, S. 280 f.; Sieber/Nolde, Sperrverfügungen im Internet, 2008, S. 104 f.; Koreng, Zensur im Internet, 2010, S. 211 ff.

980 Sieber/Nolde, Sperrverfügungen im Internet, 2008, S. 106; Schumann, ZUM 2004, 697 (698); auf beide bezugnehmend ebenso Koreng, Zensur im Internet, 2010, S. 160.

981 Frey/Rudolph, Rechtsgutachten BVDW, 2008, Rn. 29 mit Verweis auf Sieber/Nolde, Sperrverfügungen im Internet, 2008, S. 105. Diese wiederrum unter Bezugnahme auf Hüper, Zensur und neue Kommunikationstechnologien, 2004, S. 106.

982 Hierzu auch Kahl, SächsVBl. 2010, 180 (184).

$983 \mathrm{Zu}$ alledem Hoffmann-Riem in: Alternativkommentar GG, Art., 5 GG, Rn. 77; Bullinger in: Löffler, Handbuch des Presserechts, 2005, \1, Rn. 132.

984 BVerwGE 23, 194 (199).

985 BVerfGE 33, 78. 
von Zensur und damit den Weg zur Anerkennung der Nachzensur nicht von vorneherein ausschließt. ${ }^{986}$

Auch unter Zugrundelegung der Richtigkeit einer Ausweitung der Zensur im Zeitalter der Onlinepublikation würde die gesetzliche Sperrverpflichtung im Ergebnis verfassungsrechtlich nicht an dem Zensurbegriff scheitern. Denn die Zensur ist in ihrer klassischen wie auch innerhalb des modifizierten Verständnisses, weiterhin auf eine planmäßig vorgehende, systematisch ablaufende und vor allem „anlasslose“ Beschränkung der Kommunikation von staatlicher Seite ausgerichtet. ${ }^{987}$ Denn nur so ausgelegt kann der verfassungsrechtliche Zensurbegriff nicht zu einer der befürchteten Einschränkung repressiver Staatsgewalt führen und lässt meinungsunterdrückende Maßnahmen wie Strafprozesse und Ermittlungsmaßnahmen gegen bestimmte Meinungen unberührt. Deshalb liegt Zensur, unabhängig vom Verständnis einer Vor- oder Nachzensur, nur dann vor, wenn die inhaltsbeschränkende Maßnahme nicht einen konkreten Rechtsgüterschutz beabsichtigt, sondern gänzlich losgelöst ist von einer konkreten Rechtsgütergefährdung, also anlasslos, planmäßig, systematisch veranlasst wurde.

Eine gesetzliche Sperrverpflichtung, die eine umfassende systematische Filterung des Webcontent auf kinderpornographische Inhalte bezweckt, ist zwar nicht als Vorzensur im klassischen Sinne einzuordnen, da die Verbreitung des Inhalts bereits vorliegt, in ihrer Wirkweise kann sie durchaus faktisch einer Zensur nahekommen. Eine nachträgliche Beschränkung der Seiten ist jedoch gerade an einen bestimmten Rechtsgüterschutz gebunden (Schutz der abgebildeten Kinder sowie Rezipienten und Schutz der Allgemeinheit) und gerade wegen dieses Schutzes schließlich verfassungsrechtlich gedeckt. Zwar handelt es sich bei einer gesetzlichen Sperrverpflichtung um ein planmäßiges und systematisches Vorgehen gegen kinderpornographische Webinhalte, allein eine gewisse Planmäßigkeit ist jedoch noch kein aussagekräftiges Indiz für eine am grundrechtlichen Verfassungsbegriff zu messende Maßnahme. Bedenkt man die hinter dem Zensurbegriff stehende Intention der Verhinderung von Lähmungseffekten der Kommunikation, so können diese eben aufgrund einer Planmäßigkeit der Maßnahme gerade gemildert werden, weil die Bürger sich durch die Systematik des Vorgehens in innerhalb ihrer Kommunikation auf die Beschränkung einstellen und nicht gerade deswegen von ihr absehen müssen. ${ }^{988}$ Anders wäre dies aber dann zu beurteilen, wenn sich

So die Interpretation der Passage durch Hoffmann-Riem in: Alternativkommentar GG, Art., 5 GG, Rn. 77. Zur „Neujustierung“ des Zensurbegriffs auch Erdemir in: Eifert/Hoffmann-Riem, Innovation, Recht und öffentliche Kommunikation, 2011, S. 27 (39).

987 Ausdrücklich Hoffmann-Riem in: Alternativkommentar GG, Art. 5 GG, Rn. 77; in die Richtung auch die Stellungnahme zum Zensurbegriff, Sieber/Nolde, Sperrverfügungen im Internet, 2008, S. 104; ebenso Kabl, SächsVBl. 2010, 180 (184); Schnabel, JZ 2009, 996 (999).

988 So Koreng, Zensur im Internet, 2010, S. 222, mit Verweis auf die sog. „Zensurspiele“ zwischen Autor und Behörde, durch welche die Autoren versuchten mit zweideutigen Unterschwelligen 
an die Planmäßigkeit eine anlasslose systematische Zugriffsunterdrückung unabhängig konkreter rechtsgefährdender Anzeichen anschließen würde. Durch die Gewissheit einer ständigen Meinungsüberwachung ist es nicht auszuschließen, dass der Einzelne von einer Kommunikation im Internet absieht und sich ausschließlich im ,geschützten“ Bereich der persönlichen Individualkommunikation bewegt.

Nicht zu übersehen ist, dass die Einrichtung einer Sperrinfrastruktur, wie sie zur Vornahme der unterschiedlichen Sperrmethoden notwendig ist, die Gefahr birgt auf andere völlig vom Kontext der Kinderpornographie losgelöste Inhalte übertragen zu werden. ${ }^{989}$ So könnten Access-Provider zukünftig leichter auch zur Sperrung von urheberrechtsverletzenden Portalen, Glückspielangeboten ${ }^{990}$ oder persönlichkeitsrelevanten Rechtsverletzungen veranlasst werden. Jedoch kann die Befürchtung einer Ausweitung kein verfassungsrechtlich haltbarer Grund dafür sein, die gesetzliche Sperrverpflichtung vor dem Hintergrund des Zensurverbots scheitern zu lassen. Wenn die gesetzliche Sperrverpflichtung auf die ausschließliche und abschließende Anwendbarkeit zur Unterdrückung kinderpornographischer Inhalte beschränkt ist ${ }^{991}$ und sich die Umsetzung der gesetzlichen Pflicht auch auf den Bereich fixiert, ist die gesetzliche Sperrverpflichtung zumindest verfassungsrechtlich gegen einen Verstoß gegen das Zensurverbot abgesichert. ${ }^{992}$ Erst wenn sich dahingehende Befürchtungen tatsächlich verdichten, die Sperrung praktisch als ,regulatorisches Allheilmittel“"993 eingesetzt wird, müsste die Vereinbarkeit eines derartigen Vorgehens mit dem Zensurgebot neu überdacht werden.

Unter Ausklammerung dieses Aspekts bleibt die innerhalb der Sperrdebatte vorgebrachte Kritik bezüglich einer angeblichen Unvereinbarkeit der Sperransätze mit dem Zensurverbot des Art. 5 Abs. 1 Satz 3 GG lediglich eine rechtlich nicht

Auslassungen eine Zensur zu umgehen. Ebenso Hilker, Grundrechte im deutschen Frühkonstitutionalismus, 2005, S. 279.

$989 \mathrm{Zu}$ der einzeln vorangegangenen Kritik aus der Gesellschaft exemplarisch, eco, Ausschussdrucksache 16 (9) 1542, S. 2; Bitkom, Ausschussdrucksache 16 (9) 1538, S. 4 f.; Boecker, Stellungnahme der Sachverständigen im Rechtsausschuss v. 8.11.2010, S. 8, abrufbar unter: http://www.bundestag.de/bundestag/ausschuesse17/a06/anhoerungen/archiv/03_Zugangsers chwerung/04_Stellungnahmen/Stellungnahme_Boecker.pdf (zuletzt abgerufen 20.5.2012).

990 Hierzu Frey/Rudolph/Oster, MMR-Beil. 3/2012, S. 1, 5.

991 So, jedoch im Zusammenhang mit dem Bedürfnis nach einem eigenständigen Rechtsrahmen, eco, Ausschussdrucksache 16 (9) 1542, S. 2.

992 Dies wird im Ergebnis auch ein Grund dafür gewesen sein, die gesetzliche Fixierung einer gesetzlichen Sperrverpflichtung nicht als Sondervorschrift in das TMG zu integrieren, sondern in ein eigenständiges Gesetz zu überführen. Vgl. hierzu den anfänglichen Gesetzesentwurf, BTDrs. 16/12850 aufgehoben durch 16/13411. Wesentliche Kritik abgedruckt, BT-Drs. 16/13411, S. 9 .

993 Bitkom, Ausschussdrucksache 16 (9) 1538, S. 5. 
fundierte Vermutung und ist folglich nicht in der Lage der gesetzlichen Sperrverpflichtung ihre Verfassungsmäßigkeit abzusprechen.

\section{G. Ergebnis: Verfassungsmäßige Analyse}

Zusammenfassend ist herauszustellen, dass gesetzliche Sperrverpflichtungen der Access-Provider unter bestimmten Voraussetzungen einer verfassungsmäßigen Überprüfung standhalten. Aufgrund ihrer eingeschränkten Wirkweise und der Vielzahl der grundrechtlich tangierten Belange müssen sie einem strengen Subsidiaritätsgrundsatz gegenüber der Löschung unterworfen sein. Soweit Sperrverpflichtungen als Absicherung des Schutzziels nachrangig Anwendung finden, muss die gesetzliche Formulierung weitere Sicherungsmittel enthalten, um die verfassungsrechtlichen Einschränkungen zu kompensieren. Neben einem strengen Richtervorbehalt muss auch eine Entschädigung vorgesehen sowie Forschungseinrichtungen aus dem Anwendungsbereich herausgenommen sein. Zudem muss der Gesetzgeber die Regelung am Grundsatz der Bestimmtheit und Wesentlichkeit ausrichten. 



\section{Teil Fallbeispiel - Zugangserschwerungsgesetz}

In den Jahren 2009 bis 2011 erlebte die Debatte um die Vereinbarkeit eines Sperransatzes mit der Verfassung eine Renaissance, ${ }^{994}$ zunächst durch den ersten gesetzlichen Ansatz zur Regulierung des Internets, dem Zugangserschwerungsgesetz, sowie durch stetige europäische Bemühungen bezüglich einer Harmonisierung des Rechtsrahmens zur Bekämpfung von internetverbreiteter Kinderpornographie. Die gesetzliche Struktur des Zugangserschwerungsgesetzes soll zum Anlass genommen werden, um aufzuzeigen, inwiefern der Gesetzgeber die Vorgaben an die Verfassungskonformität eines solchen gesetzlichen Ansatzes tatsächlich umgesetzt hatte. Eine Darstellung des Zugangserschwerungsgesetzes kommt nicht umhin gleichzeitig auch eine kurze Bewertung des „holprigen gesetzlichen Werdegangs" vorzunehmen. Ein verfassungsrechtlich fragwürdiges Novum war die damalige „Aussetzung der Anwendung des Gesetzes“ per „Erlass“ des Bundesministeriums des Innern. ${ }^{995}$ Denn bereits vor Inkrafttreten und Verkündung des Gesetzes, erlies das BMI gegenüber dem BKA einen umstrittenen „Erlass“, der faktisch zur Nichtanwendung der gesamten gesetzlichen Struktur führte, weil sich

994 Ebenso Koreng, Zensur im Internet, 2010, S. 120. Überblicksartig zu den Problemen u.a. Schnabel, JZ 2009, 996; Frey/Rudolph, CR 2009, 644; Höhne/Dienst, jurisPR ITR 13/2009, Anm. 6; Spürck/Erdemir in: Nikles/Roll/Spürck/Erdemir/Gutknecht, Jugendschutzrecht, \184b StGB, Rn. 4 f; Frey/Rudoplph/Oster, MMR-Beil. 3/2012, S. 3 f; Gercke, ZUM 2011, 609.

995 Nichtanwendungserlass im Wortlaut abrufbar unter: http://blog.odem.org/2010/02/19/ErlassZugErschwG.pdf (zuletzt abgerufen 20.5.2012). 
der Rechtsrahmen einzig auf Löschungen reduzierte. Erst Ende Mai 2011 beschloss das Bundeskabinett dann auch die formelle Aufhebung des Zugangserschwerungsgesetzes und reichte einen entsprechenden Aufhebungsentwurf ein.996 Nachdem der Bundestat am 01.12.2011 und der Bundesrat am 16.12.2011 auf Empfehlung des Rechtsausschusses diesen Gesetzesentwurf unverändert verabschiedet hatten, wurde das Gesetz mit Verkündung im Amtsblatt letztlich mit Wirkung zum 29.12.2011 aufgehoben.997

Neben der folgenden Darstellung der formellen und materiellen Probleme des Gesetzes soll auch ein Ausblick auf die Konstellation eines Löschgesetzes gewagt werden, welches während des Aufhebungsprozesses des Zugangserschwerungsgesetzes immer wieder im Fokus stand. Anschließend soll der europäische Rechtsrahmen mit den entsprechenden Harmonisierungsbemühungen sowie dessen Auswirkungen auf die Aufhebung des Zugangserschwerungsgesetzes sowie ein etwaiges Löschgesetz dargestellt werden.

\section{A. Historische Entwicklung des ZugErschwG}

In Anbetracht des weitreichenden Gefährdungsbereichs, der mit einer ungehinderten Verbreitung von Kinderpornographie einhergeht und der erklärten gesetzgeberischen Intention ,gegen die sexuelle Ausbeutung von Kindern im Internet muss mit allen Mitteln vorgegangen werden ",998 sind immer wieder Forderungen aufgekommen, die gesetzlichen Handlungsbefugnisse, die einen direkten Eingriff in den Kommunikationsprozess im Internet erlauben, zielorientiert auf den Bereich der Kinderpornographie auszuweiten und nicht lediglich als Nebenmaterie innerhalb eines jugendschützenden Gesamtkonzepts zu verwirklichen. ${ }^{999}$ Nach-

996 BT-Drs. 17/6644. Hierzu Pressemitteilung des BMJ v. 25.5.2011, Digitale Welt - Absage an die Netzsperren wichtiger Schrittin der Netzpolitik“, abrufbar unter:

http://www.bmj.de/SharedDocs/Pressemitteilungen/DE/2011/20110525_Loeschen_statt_spe rren.html?nn=1468940 (zuletzt abgerufen 20.5.2012); ebenfalls Pressemitteilung der Bundesregierung v. 25.5.2011, „Löschen statt Sperren“, abrufbar unter:

http://www.bundesregierung.de/nn_1272/Content/DE/Artikel/2011/05/2011-05-25-

aufhebung-zugangserschwerungsgesetz.html (zuletzt abgerufen 20.5.2012).

997 BGBl I 2011, Nr. 70. S. 2958.

998 So die Begr. FrakE BT-Drs. 16/12850, S. 5.

999 Die Debatte wurde insbesondere durch die damals amtierende Bundesfamilienministerien Ursula von der Leyen initiiert, zu den vorherigen Diskussionen vgl. Zusammenfassung bei BT-Drs. 16/12850, S. 5; Marbeth-Kubicki, NJW 2009, 1792. Vor dem ZugErschwG sah lediglich die jugendschutzrechtliche Generalklausel des $\ 20$ JMStV i.V.m. \59 Abs. 3,4 RStV eine direkte Herausnahmemöglichkeit des Webcontents über entsprechende einzelfallabhängige Lösch-sowie Sperrverfügungen gegen Access-Provider vor. Hierbei handelt es sich jedoch um eine Möglichkeit, die allgemein auf alle jugendschutzrelevanten Belange ausgerichtet ist, etwa bei sämtliche 
dem zunächst Selbstverpflichtungsvereinbarungen, der fünf größten Zugangsdiensteanbieter mit dem BKA Anfang des Jahres 2008, zur Vornahme von gezielten technischen Sperrungen kinderpornographischer Inhalte favorisiert wurden; ${ }^{1000}$ sollte schon bald darauf ein gesetzlicher Handlungsrahmen kreiert werden, der auf eine generelle Verpflichtung aller inländischen Zugangsdiensteanbieter zur Sperrung von kinderpornographischen Inhalten ausgerichtet war. Bereits Anfang Mai 2009 reichten die Fraktionen CDU/CSU und SPD den Entwurf eines Gesetzes zur Bekämpfung der Kinderpornographie in Kommunikationsnetzen ein. ${ }^{1001}$ Der Lösungsansatz des Gesetzesentwurfs basierte zunächst nicht auf einem spezialgesetzlichen Rechtsrahmen, sondern war als Änderung des Telemediengesetzes (TMG) konzipiert, indem die vorhandene Gesetzesstruktur um Legitimationsbefugnisse für Sperrverpflichtungen der Zugangsdiensteanbieter ( $\$ 8 \mathrm{a}$ TMGEntwurf) erweitert werden sollte. ${ }^{1002}$ Danach oblag es dem BKA eine Sperrliste zu führen, die „vollqualifizierte Domainnamen, Internetprotokoll-Adressen und Zieladressen von Telemedien, die Kinderpornographie nach $\$ 184 \mathrm{~b}$ StGB enthalten oder deren Zweck darin besteht, auf derartige Telemedienangebote zu verweisen" enthielt, welche arbeitstäglich an die entsprechenden Zugangsanbieter weiterzuleiten war. $\int 8 \mathrm{a}$ Abs. 2 TMG-E verpflichtete die Zugangsdiensteanbieter daraufhin, „geeignete und zumutbare technische Maßnahmen zu ergreifen, um den Zugang zu Telemedienangeboten, die in der Sperrliste aufgeführt sind, zu erschweren." Etwaige Nutzeranfragen auf kinderpornographische Webseiten sollten die Diensteanbieter gemäß $\ 8$ Abs. 4 TMG-E auf ein von ihnen betriebenes und vom BKA vorgegebenes Telemedienangebot mit einer „Stoppmeldung“" weiterleiten, das Angaben zu Sperrungsgründen und Kontaktmöglichkeiten enthielt. $\S 8$ a Abs. 5 TMG-E normierte in diesem Kontext eine Legitimation zur Erhebung personenbezogener Daten durch die Diensteanbieter, soweit diese zur Vornahme der inhaltsbeschränkenden Maßnahme notwendig waren und sah eine Weiterleitungsbefugnis der Daten an die betreffenden Strafverfolgungsbehörden zum Zwecke der Strafverfolgung vor.

Diese Erweiterung des TMG sah sich bald scharfer Kritik aus politischen wie gesellschaftlichen Lagern gegenüber. ${ }^{1003}$ Die Bedenken innerhalb der einschlägigen Internetinteressenverbände, politischen Parteien sowie interessierten Bürgern

entwicklungsbeeinträchtigenden, rechtsextremistischen oder sonst jugendgefährdenden Angeboten in Betracht kommt.

1000 BT-Drs. 16/12850, S. 12; zusammenfassend Marbeth-Kubicki, NJW 2009, 1792; Süme, MMR $2009,1$.

1001 BT-Drs. 16/12850, hierzu u.a. Sieber, JZ 2009, 653.

1002 Nachfolgend TMG-E genannt.

1003 Zur poltischen und gesellschaftlichen Kritik siehe einzelne Stellungsnahmen innerhalb der Expertenanhörung, Stellungnahmen abgedruckt bei BT-Drucks. 16/13411 S. 9 f., sowie die jeweilige Ausschussdrucksache (jeweils selbstständig zitiert). 
mündeten letztlich in der mit 134015 Unterzeichnern bislang größten Onlinepetition der Geschichte der Bundesrepublik Deutschland. ${ }^{1004}$

Als Konsequenz der gesellschaftlichen Aufrufe nach einer Überarbeitung des Gesetzes sowie Forderungen nach einer autonomen Formulierung der geplanten Sperrmaßnahmen, ${ }^{1005}$ beschloss der Bundestag am 18.06.2009 ein Spezialgesetz, das zahlreiche Änderungen des bestehenden Gesetzesentwurfs innerhalb eines eigenständen Gesetzesentwurfs zusammenfasste. Den Mittelpunkt bildete die gesetzliche Statuierung des Grundsatzes „Löschen vor Sperren“ in $\int 1$ Abs. 1 ZugErschwG, der damit die durch den ersten Gesetzesentwurf vorgesehenen Sperrverfügungen nur noch als ultima ratio für zulässig erachtete. ${ }^{1006}$ Mit Beschluss des Spezialgesetzes wurde der frühere Gesetzesentwurf und damit die Änderungen des Telemediengesetzes für erledigt erklärt. ${ }^{1007}$

Mit dem im Oktober 2009 vollzogenen Regierungswechsel verzögerte sich die weitere Durchsetzung des Zugangserschwerungsgesetzes allerdings. Zunächst veranlassten die gesellschaftliche und politische Kritik sowie die Ergebnisse der Onlinepetition die neue Regierung dazu, sich in ihren Koalitionsvertrag darauf zu verständigen, das Zugangserschwerungsgesetz „,vorerst auszusetzen“. Per „Nichtanwendungserlass“ des Bundesministeriums des Innern gegenüber dem BKA 1008 wurde diese Vorgabe dann auch dahingehend umgesetzt, als das BKA auf Grundlage des Zugangserschwerungsgesetzes ausschließlich auf die Löschung kinderpornographischer Angebote hinwirken sollte.

Trotz dieser Ereignisse fertigte der damals amtierende Bundespräsident Horst Köhler das Gesetz aus. ${ }^{1009}$ Damit trat das Gesetz am 23.02.2010 in Kraft, wobei

1004 Petition: Internet - Keine Indizierung und Sperrung von Internetseiten 22.04.2009, Text der Petition abrufbar unter: https://epetitionen.bundestag.de/index.php?action=petition;sa=details;petition=3860 (zuletzt abgerufen 20.5.2012). Zum gesamten Kontext der Gesetzeshistorie, Volkmann in: Spindler/Schuster, Recht der elektronischen Medien, 2011, Vorb. ZugErschwG, Rn. 1 ff.; Tinnefeld, DuD 2010, 15.

1005 Z.B. Stellungnahme der Bitkom, innerhalb des Gesetzgebungsverfahrens, Ausschussdrucksache 16 (9) 1538, S. 5; ebenfalls Stellungnahme Frey/Rudolph, Ausschussdrucksache 16 (9) 1546, S. 23.

1006 Hierzu Frey/Rudolph, CR 2009, 644 (648); Schnabel, JZ 2009, 996 (1001); Volkmann in: Spindler/Schuster, Recht der elektronischen Medien, 2011, \1 ZugErschwG, Rn. 4 f.

1007 BT-Drs. 16/13411; zum gesamten Komplex zusammenfassend Frey/Rudolph, CR 2009, 644.

1008 Nichtanwendungserlass im Wortlaut abrufbar unter: http://blog.odem.org/2010/02/19/ErlassZugErschwG.pdf (zuletzt abgerufen 20.5.2012).

1009 Zuvor verweigerte er zwischenzeitig die Ausfertigung mit der Begründung, er wolle die verfassungsrechtlichen Bedenken prüfen, ehe es doch zur Ausfertigung kam. So die Pressemitteilung des Bundespräsidenten „Ausfertigung des „Gesetzes zur Bekämpfung von Kinderpornographie in Kommunikationsnetzen“ vom 17.2.2010 
die Geltungsdauer des Gesetzes entsprechend Artikel 4 Abs. 3 bis zum Ablauf des 31.12.2012 befristet war. ${ }^{1010}$

Nachdem das Zugangserschwerungsgesetz damit „scheinbar“ im Zuge eines ordnungsgemäßen Gesetzgebungsverfahrens zu Stande kam und in Kraft trat, beschränkte sich die Anwendung des Gesetzes - dem Ministerialerlass entsprechend - ausschließlich auf dem gegenüber dem Vorgängergesetz neu eingeführten Grundsatz „Löschen vor Sperren“. 1011

Bereits zuvor kam eine Sachverständigenanhörung im Rechtsausschuss überwiegend zu dem Ergebnis, dass die gesetzliche Umsetzung der Sperrvariante verfassungsrechtlich problematisch war und sich nur bedingt als Mittel zur Unterbindung kinderpornographischer Gefahren eignete. ${ }^{1012} \mathrm{Im}$ gleichen Zuge ergab die Expertise, dass auch die über den Erlass hervorgerufene Aussetzung des Gesetzes zu einem verfassungsrechtlichen „Schwebezustand“ führte, welcher nicht tragbar war und klar in die Richtung einer Aufhebung des Zugangserschwerungsgesetzes deutete. Im Einzelnen beinhaltete der Nichtanwendungserlass des BMI, der im Zuge der Umsetzung der Vorgaben des Koalitionsvertrages vom BMI gegenüber

abrufbar unter: http://www.bundespraesident.de/Journalistenservice/Pressemitteilungen,11107.662222/Ausfertigung-des-Gesetzes-zur-.htm?global.back=/Journalistenservice/\%2c11107\%2c5/Pressemitteilungen.htm\%3flink\%3dbpr_liste (zuletzt abgerufen 20.5.2012).

1010 BT-Drucks. 16/13411 S. 12.

1011 So wird stets auf eine Stellungnahme der Bundesregierung Bezug genommen, aus der zitiert wird: „auf der Grundlage des Zugangserschwerungsgesetzes ausschließlich und intensiv für die Löschung derartiger Seiten einsetzen, Zugangssperren aber nicht vornehmen“, so Berg/Rosenbach, spiegel-online vom 8.2.2010 „Schwarz-Geld rückt von Internetsperren ab“, abrufbar unter: http://www.spiegel.de/politik/deutschland/0,1518,676669,00.html; Krempl in: heise-online vom 9.2.2010 „Schwarz-Geld plant statt Websperren Gesetz zur Löschung von Kinderpornographie“, abrufbar unter: http://www.heise.de/newsticker/meldung/Schwarz-Gelb-plant-stattWebsperren-Gesetz-zur-Loeschung-von-Kinderpornographie-924950.html; die nicht bestätigte Stellungnahme wurde von Aktivisten in einer geschwärzten Fassung ins Netz eingebracht: abrufbar unter: http://blog.odem.org/2010/02/19/Erlass-ZugErschwG.pdf; zu den Plänen bezüglich eines Löschgesetzes Krempl in: heise-online vom 24.4.2010 „Entwurf für Kinderpornographie-Löschgesetz ist durchgesickert“", abrufbar unter:

http://www.heise.de/newsticker/meldung/Entwurf-fuer-Kinderpornografie-Loeschgesetz-istdurchgesickert-985710.html; Krempl in: Heise-online vom 22.3.2010 „Löschgesetz soll Missbrauchsbilder rascher aus dem Netz befördern“, abrufbar unter:

http://www.heise.de/newsticker/meldung/Loeschgesetz-soll-Missbrauchsbilder-rascher-ausdem-Netz-befoerdern-959998.html (jeweils zuletzt abgerufen 20.5.2012). Ausführlich zum Nichtvollzug des ZugErschwG, Höhne, jurisPR ITR 24/2010, Anm. 2.

1012 Stellungnahmen der Sachverständigen im Rechtsausschuss abrufbar unter: http://www.bundestag.de/bundestag/ausschuesse17/a06/anhoerungen/archiv/03_Zugangsers chwerung/04_Stellungnahmen/index.html (zuletzt abgerufen 20.5.2012). 
dem BKA ergangen war, die Anweisung an das BKA, den in ,\$ 1 Abs. 2 ZugErschwG eingeräumten Beurteilungsspielraum dahin gehend zu nutzen, dass keine Aufnahme in die Sperrlisten erfolgt und Zugangssperren unterbleiben." Faktisch implizierte die Reduzierung der inhaltsbeschränkenden Maßnahmen auf die Löschung, dass der gesamte gesetzliche Rahmen, der mit der Sperrung nach dem Zugangserschwerungsgesetz einherging, nicht angewendet und damit ohne rechtliche Bindungswirkung blieb. Dieses Vorgehen sollte zunächst für einen Evaluationszeitraum von einem Jahr ab Kenntnisnahme des Erlasses erfolgen. Innerhalb dieses Zeitraums sollte die tatsächliche Effektivität der Löschbemühungen bewertet werden. 1013

Am 13.04.2011 einigte sich die Bundesregierung dann auf ein EckpunkteProgramm, dass die gesetzgeberischen Maßnahmen zum Grundsatz Löschen vor Sperren regeln sollte. Die Eckpunkte sahen unter anderen die formell ordnungsgemäße Aufhebung des Zugangserschwerungsgesetzes vor. Kinderpornographische Inhalte sollten weiterhin auf der Grundlage des geltenden Rechts gelöscht werden und Sperrungen ganz unterblieben. Am 25.5.2011 beschloss die Bundesregierung daraufhin einen Gesetzentwurf zur Aufhebung des Zugangserschwerungsgesetzes, der die zuvor aufgestellten Eckpunkte umsetzen sollte.1014 Als Begründung führte die Bundesregierung aus, dass die in den vorangegangenen Monaten intensivierte Zusammenarbeit zwischen dem Bundeskriminalamt und den Beschwerdestellen der Internetwirtschaft zu erfreulichen Evaluationsergebnissen beim Löschen kinderpornographischer Inhalte geführt hatte und es daher möglich war, auf Sperrungen ganz zu verzichten. ${ }^{1015}$ Der Bundesrat befürwortete die Aufhebung des Zugangserschwerungsgesetzes in seiner Sitzung im Juli 2011, er emp-

1013 Koalitionsvertrag CDU/CSU u. FDP v. 26.10.2009, S. 106, abrufbar unter:

http://www.cdu.de/doc/pdfc/091026-koalitionsvertrag-cducsu-fdp.pdf (zuletzt abgerufen 20.5.2012); sowie der spätere Nichtanwendungserlass abrufbar unter: http://blog.odem.org/2010/02/19/Erlass-ZugErschwG.pdf.

1014 Entwurf eines Gesetzes zur Aufhebung von Sperrregelungen bei der Bekämpfung von Kinderpornographie in Kommunikationsnetzen, BT-Drs. 17/6644. S. 7.

1015 Begründung BT-Drs. 17/6644, S. 7; zu der Argumentation ebenfalls „Antwort zur kleinen Anfrage“, BT-Drs. 17/3164, der Abgeordneten Sitte sowie der Fraktion DIE LINKE an die Bundesregierung, S. 2 abrufbar unter:

http://blog.die-linke.de/digitalelinke/wp-content/uploads/Antwort-Loeschen-statt-

Sperren.pdf. Zu den Löscherfolgen Bleich, heise-online, Meldung v. 18.3.2011, „Kampf gegen Kinderpornos: BKA Zahlen belegen den Erfolg von Löschen statt sperren“, abrufbar unter: http://www.heise.de/newsticker/meldung/Kampf-gegen-Kinderpornos-BKA-Zahlen-belegenden-Erfolg-von-loeschen-statt-sperren-1210432.html; Koch in: digitale linke, Beitrag v. 17.3.2011, „BKA Zahlen bestätigen Erfolg von „Löschen statt sperren“, abrufbar unter: http://blog.dielinke.de/digitalelinke/bka-zahlen-bestatigen-erfolg-von-loschen-statt-sperren/ (jeweils zuletzt abgerufen 20.5.2012). 
fahl der Bundesregierung jedoch die Löschungserfolge ab Aufhebung des Zugangserschwerungsgesetzes bis 31.12.2012 weiterhin zu evaluieren und entsprechend Bericht zu erstatten. Der Bundesrat begründete die Empfehlung ausdrücklich damit, dass nicht abzusehen wäre, ob die positive Entwicklung hinsichtlich der zeitnahen Löschung auch weiterhin beibehalten werden konnte, so dass eine Evaluation eventuellen Schutzlücken entgegentreten könne.1016 Nachdem am 30.11.2011 der Rechtsausschuss des Bundestags dem Bundestag die Zustimmung zum eingebrachten Gesetzesentwurf empfohlen hatte, beschloss der Bundestag am 01.12.2011 den Gesetzentwurf unverändert zu verabschieden. Um den Bedenken des Bundesrates hinreichend Rechnung zu tragen, wurde gleichzeitig eine Entschließung angenommen, mit der die Bundesregierung auffordert wird, dem Bundestag ab dem Jahr 2013 jährlich über den Erfolg der Löschmaßnahmen, zu berichten. ${ }^{1017}$

Eine neue Dynamik, die letztlich in der ordnungsgemäßen Aufhebung mündete, erhielt die Debatte, als auf europäischer Ebene erste Initiativen bekannt wurden, die auf einen europaweit verbindlichen Aktionsplan zur Bekämpfung von Kinderpornographie im Internet abzielten. Auch Europa sah seinerzeit den Sperransatz als ein Mittel zur Bekämpfung vor. ${ }^{1018}$ So enthielt ein Richtlinienvorschlag der Europäischen Kommission eine einheitliche politische Vorgabe an die Mitgliedstaaten, wonach diese zu Regulierungsmechanismen in Form von internetspezifischen Zugangserschwerungen verpflichtet wurden. ${ }^{1019}$

1016 Stellungnahme des Bundesrates, BR-Drs. 319/11 (Beschluss).

1017 BGBl I 2011, Nr. 70, S. 2958.

1018 Europäischer Aktionsplan zur Unterbindung der Cyberkriminalität vom 8.3.2010, 5957/1/10 RV 1, abrufbar unter: http://ak-zensur.de/download/europarat--access-blocking-re01.en10.pdf; hierzu heise-online Meldung vom 24.3.2010 „EU forciert Pläne zu europaweiten Web-Sperren“, abrufbar unter:

http://www.heise.de/newsticker/meldung/EU-forciert-Plaene-zu-europaweiten-Web-Sperren962820.html, mit Bezugnahme auf die Angaben des Arbeitskreises gegen Internet-Sperren und Zensur (AK Zensur), einem privaten Internetinteressenverbund, der sich für ein „freies Internet „ohne gesetzliche Regulierungsmaßnahmen ausspricht, abrufbar unter: http://akzensur.de/2010/03/ministerrat-stoppschild.html (jeweils zuletzt abgerufen 20.5.2012).

1019 Richtlinienvorschlag vom Art. 1 Abs. 1. lautet: „Jeder Mitgliedstaat trifft die erforderlichen Maßnahmen, damit der Zugang von Internet-Nutzern zu Webseiten, die Kinderpornografie enthalten oder verbreiten, gesperrt wird. Die Zugangssperrung erfolgt vorbehaltlich angemessener Schutzvorschriften; insbesondere soll sichergestellt werden, dass die Sperrung auf das Nötige beschränkt wird, dass die Nutzer über die Gründe für die Sperrung informiert werden und dass Inhaltsanbieter im Rahmen des Möglichen darüber unterrichtet werden, dass sie die Entscheidung anfechten können.

Abs. 2.: „Unbeschadet des Vorstehenden trifft jeder Mitgliedstaat die erforderlichen Maßnahmen, damit Webseiten, die Kinderpornografie enthalten oder verbreiten, aus dem Internet ent- 
Vergleichbar der Debatte in Deutschland wurde daraufhin auch auf europäischer Ebene stark über die Effektivität solcher Maßnahmen diskutiert. Der erzielte Konsens, der letztlich in die Richtlinie Einzug hielt, sah entgegen ersten Richtlinienvorschlägen, die Möglichkeit der Löschung des kinderpornographischen Inhalts in allen Mitgliedstaaten verbindlich vor. Darüber hinausgehende Sperrmaßnahmen bleiben den Mitgliedstaaten zur selbstständigen Regelung vorbehalten. ${ }^{1020}$

\section{B. Regelungsmechanismen des ZugErschwG}

Nachfolgend sollen die wesentlichen Regelungen des Zugangserschwerungsgesetzes, wie sie grundsätzlich zur Anwendung kommen sollten, umrissen werden.

\section{Sperrliste}

Wie bereits in der Erstfassung angelegt, verpflichtete die spezialgesetzliche Fixierung des $\int 1$ Abs. 1 ZugErschwG das BKA dazu, eine Sperrliste zu führen, die Domainnamen, Internetprotokoll-Adressen und Zieladressen von Telemedienangeboten - mithin Identifikationskategorien - enthielt, die kinderpornographische Verbotsinhalte entsprechend $\int 184 b$ StGB benannte. Gleichfalls waren auch solche Telemedienangebote in der Liste aufzunehmen, die auf kinderpornographische Webseiten verwiesen. ${ }^{1021}$ Die Beurteilung dessen, ob ein Internetangebot tatsächlich den Anforderungen des Straftatbestandes des \184b StGB zuzuordnen ist, oblag dem BKA. Gemäß \9 ZugErschwG sollte aus Transparenzgründen jedoch ein Expertengremium jederzeit zur stichprobenartigen Überprüfung der vom BKA erstellten Sperrliste eingesetzt werden. Dieses hatte die Aufgabe die Voraussetzungen des $\int 184 \mathrm{~b}$ StGB und damit die Sperrnotwendigkeit ergänzend zu überprüfen. ${ }^{1022}$ Entsprechend $\int 1$ Satz 2 ZugErschwG hatte das BKA die er-

\footnotetext{
fernt werden.“, so der Wortlaut des Art. 21 des Vorschlages „für eine Richtlinie des Europäischen Parlaments und des Rates zur Bekämpfung des sexuellen Missbrauchs und der sexuellen Ausbeutung von Kindern sowie der Kinderpornografie und zur Aufhebung des Rahmenbeschlusses 2004/68/JI des Rates /KOM/2010/0094 endg. - COD 2010/0064“ v. 29.3.2009.

1020 Der Änderungsvorschlag des Kulturausschusses ist abrufbar unter: http://www.europarl.europa.eu/sides/getDoc.do?pubRef=//EP//NONSGML+COMPARL+PE-442.976+01+DOC+PDF+V0//EN\&language $=\mathrm{EN}$ (zuletzt abgerufen 20.5.2012).

1021 Volkmann in Spindler/Schuster, Recht der elektronischen Medien, 2011, \1 ZugErschwG, Rn. 1.

1022 Als personelle Vorgaben an das Expertengremium nennt \9 S. 3 ZugErschwG lediglich, dass mindestens die Hälfte der vorgesehenen 5 Gremiumsmitglieder die Befähigung zum Richteramt
} 
stellte Liste den Zugangsanbietern täglich zur Verfügung zu stellen und gemäß Satz 2 laufend zu aktualisieren. ${ }^{1023}$ Die Aktualisierungsverpflichtung beinhaltete die stichprobenartige Überprüfung der Einträge auf die Erfüllung der Voraussetzungen des $\ 184 \mathrm{~b}$ StGB; hierfür sollten die gelisteten Einträge auf wesentliche Veränderungen im Vergleich zum vorherigen Aufnahmezeitpunkt gesichtet und bei Vorliegen von Veränderungen auf erneute Tatbestandsvoraussetzungen des \184b StGB überprüft werden. .024 $^{2}$

Aufgrund der geäußerten Kritik wurde in $\ 1$ Abs. 2 ZugErschwG letztlich der ausschließlich angewendete Subsidiaritätsgrundsatz „Löschen vor Sperren“ normiert. ${ }^{1025}$ Die Regelung sollte ausweislich der Gesetzesbegründung der Wahrung des verfassungsrechtlichen Grundsatzes der Verhältnismäßigkeit dienen. ${ }^{1026} \mathrm{Da}$ nach sollte die Aufnahme in die Sperrliste und die daraus folgende Sperrverpflichtung untersagt werden, ,soweit zulässige Maßnahmen, die auf die Löschung des Telemedienangebots abzielen nicht oder nicht in angemessener Zeit erfolgsversprechend sind“. Stellte sich ein Vorgehen gegen diejenigen, die selbst Anbieter oder direkte Zugriffsberechtigte der kinderpornographischen Inhalte waren, als möglich dar, so war dieses Vorgehen primär durchzuführen, mit der Folge, dass die Zugangsdienstanbieter überdies nicht zur Vornahme einer Sperrungsmaßnahme verpflichtet werden sollten. ${ }^{1027}$ Begleitend zur Subsidiaritätsklausel führte das Zugangserschwerungsgesetz auch Vorschriften ein, um die im Gesetzgebungsverfahren geforderte Europarechtskonformität des Gesetzes herbeizuführen:1028 Diesbezüglich beinhaltete $\int 1$ Abs. 2 Satz 2 ZugErschwG Regelungen zu Angeboten aus Mitgliedstaaten der Europäischen Union. Danach konnten Angebote eines Diensteanbieters, der sich in einem anderen Staat des Geltungsbereichs der Richtlinie 2000/31/EG (Richtlinie über den elektronischen Geschäftsverkehr) ${ }^{1029}$ niedergelassen hatte, nur dann in die Sperrliste aufgenommen werden, wenn zuvor

haben soll, um die juristischen Feinheiten des gesetzlichen Tatbestandes unter die Angebote zu subsumieren, Begr. ZugErschwG BT-Drs. 16/13411, S. 14.

1023 Begr. ZugErschwG, BT-Drucks. 16/13411, S. 17.

1024 Begr. ZugErschwG, BT-Drucks. 16/13411, S. 17.

1025 Hierzu BT-Drucks. 16/13411, S. 12.

1026 Begr. ZugErschwG BT-Drs. 16/13411, S. 12/13. U.a. Stellungnahme des Eco innerhalb des Gesetzgebungsverfahrens, Ausschlussdrucksache 16 (9) 1542, S. 3; ebenfalls Stellungnahme Bäcker, Ausschussdrucksache 16 (9) 1554, S. 6.

1027 BT-Drucks. 16/13411 S. 13.

1028 Stellungnahme Frey/Rudolph, Ausschussdrucksache 16 (9) 1546, S. 14; hierzu auch Stellungnahme Kubnen, Ausschussdrucksache 16 (9) 1545, Punkt 3.3.

1029 Richtlinie 2000/31/EG des Europäischen Parlaments und des Rates vom 8. Juni 2000 über bestimmte rechtliche Aspekte der Dienste der Informationsgesellschaft, insbesondere des elektronischen Geschäftsverkehrs, im Binnenmarkt über den elektronischen Geschäftsverkehr, ABl. 2000 Nr. L 178, S. 1. 
das Konsultationsverfahren gem. \3 Abs. 5 Satz 2 TMG durchgeführt wurde. ${ }^{1030}$ Hierfür bedurfte es einer erfolglosen Aufforderung des Mitgliedstaates, in welchem der fragliche Diensteanbieter seinen Sitz hatte, bezüglich einer Vornahme eigener Maßnahmen gegen die Rechtsverletzung. Gleichzeitig sollte die EUKommission über die Absicht Maßnahmen zu treffen in Kenntnis gesetzt werden. $\int 1$ Abs. 2 Satz 3 ZugErschwG regelte in dem Zusammenhang die Aufnahme in die Sperrliste bei Angeboten, die außerhalb der Europäischen Union gespeichert waren. Hiernach durften die Angebote ohne weitere Konsultation mit den Behörden des Niederlassungsstaates des jeweiligen Diensteanbieters in die Sperrliste aufgenommen werden, wenn das BKA nach eigener Einschätzung davon ausging, dass ,in dem betroffenen Staat andere Maßnahmen, insbesondere Mitteilungen an die für den polizeilichen Informationsaustausch zuständigen Stellen, nicht oder nicht in angemessener Zeit zu einer Löschung des kinderpornografischen Telemedienangebots führen“. Absatz 3 statuierte eine Unterrichtungspflicht der Content- und Hostprovider ${ }^{1031}$ nach Aufnahme in die Sperrliste. Dabei korrespondierte die Unterrichtungspflicht eng mit dem Subsidiaritätsgrundsatz des Absatzes 2: Soweit Kenntnis bezüglich des Anbieters bestand und dieser überdies seinen Sitz in Deutschland hatte, konnte es nach dem Wortlaut des Absatzes 2 bereits nicht zu einer Aufnahme des Inhalts in die Sperrliste kommen, da in diesem Fall direkte Maßnahmen gegen die Anbieter möglich und aufgrund von Absatz 2 auch vorrangig geboten waren. ${ }^{1032}$ Eine Unterrichtungspflicht bestand überdies, wenn der Diensteanbieter seinen Sitz im Ausland hatte. In diesen Fällen sollte das BKA, die in diesem Staat für den polizeilichen Informationsaustausch zuständigen Stellen über die Aufnahme des Inhalts in die Sperrliste unterrichten. ${ }^{1033}$

\section{Zugangserschwerung gem. \2 Abs. 1 ZugErschwG}

J 2 Abs. 1 ZugErschwG normierte die maßgebliche Pflicht der Zugangsanbieter zur Vornahme der Sperrmaßnahmen. Der Erhalt der Liste korrespondierte mit einer unmittelbaren staatlichen Handlungsverpflichtung, welche die Zugangsanbieter, die „Zugang zur Nutzung von Informationen über ein Kommunikationsnetz für mindestens 10000 Teilnehmer oder sonstige Nutzungsberechtige ermöglichen“, dazu verpflichtete ,geeignete Maßnahmen zu ergreifen, um den Zugang

1030 Zum Konsultationsverfahren Volkmann in: Spindler/Schuster, Recht der elektronischen Medien, 2011, \59 RStV Rn. 13; Frey/Rudolph, ZUM 2008, 564 (568).

1031 Mithin ordnet $₫ 1$ Abs. 1 ZugErschwG eine Unterrichtungspflicht gegen den Dienstanbieter nach $₫ 7$ Abs. 1 TMG sowie nach $₫ 10$ TMG an, es genügt hier lediglich das herausstellen, dass der Content- ( $\mathbb{7}$ TMG) und der Hostprovider ( $\mathbb{1 0}$ TMG) den Diensteanbietern im Sinne der vorgenannten TMG Regelungen entspricht.

1032 So Volkmann in: Spindler/Schuster, Recht der elektronischen Medien, 2011, \1 ZugErschwG, Rn. 8.

1033 BT-Drucks. 16/13411, S. 13. 
zu Telemedienangeboten, die in der Sperrliste aufgeführt sind, zu erschweren“. Diese als Handlungspflicht ausgestaltete Regelung war explizit entwicklungsoffen formuliert. Geringfügige Informationen zur technischen Ausgestaltung der Sperrmaßnahmen enthielt jedoch $\ 2$ Abs. 2 ZugErschwG. Danach durften für die Sperrung „vollqualifizierte Domainnamen, Internetprotokoll-Adressen und Zieladressen Telemedienangeboten verwendet werden", wobei die Sperrung „mindestens auf der Ebene der vollqualifizierten Domainnamen“ stattzufinden hatte. Diese ausdrückliche Nennung der Mindestvoraussetzung der Sperrung vollqualifizierter Domainnamen sollte den Bedenken hinsichtlich eines möglichen „Overblocking", welches bei anderen Sperrmethoden im großen Maße zu befürchten war, entgegentreten. ${ }^{1034}$ Obgleich der Erstentwurf noch eine Beschränkung der Sperrverpflichtung auf privatrechtliche Anbieter vorsah, ${ }^{1035}$ wurde diese Einschränkung im Zugangserschwerungsgesetz aufgehoben und der Anwendungsbereich auf alle großen Internetzugangsanbieter ausgedehnt. Lediglich solche Diensteanbieter, die nicht-öffentliche Internetzugänge anboten - etwa Universitäten und andere staatliche Einrichtungen - sollten von der Sperrverpflichtung befreit sein, soweit sie bereits vergleichbar wirksame Sperrmaßnahmen einsetzten. ${ }^{1036}$ Darüber hinaus schrieb $\ 2$ Abs. 3 ZugErschwG vor, dass die Sperrmaßnahmen unverzüglich, das heißt „ohne schuldhaftes Zögern“, spätestens jedoch innerhalb von sechs Stunden nachdem das BKA die aktuelle Sperrliste zur Verfügung gestellt hatte, durch die Zugangsanbieter vollzogen werden mussten. ${ }^{1037}$ Alle Nutzeranfragen zu Telemedienangeboten, die auf der Sperrliste geführt wurden, waren von den Zugangsanbietern gemäß $\ 4$ ZugErschwG auf einen Stopp-Server mit einer offenkundigen „Stoppmeldung“ umzuleiten. \4 ZugErschwG sollte den Nutzer über Notwendigkeit und Vorliegen der Sperrmaßnahme informieren. Alle aufgrund der Umleitung anfallenden Verkehrs- und Nutzungsdaten durften gemäß $\ 5$ ZugErschwG - entgegen den Regelungen des Erstentwurfs - nicht für Zwecke der Strafverfolgung verwendet werden.

\section{Ergänzende Regelungen}

Die übermittelte Sperrliste war entsprechend $₫ 3$ ZugErschwG geheim zu halten. Hierdurch sollte verhindert werden, dass sie praktisch als eine Art „schwarz auf weiß“-Katalog kinderpornographischer Webseiten für Pädophile missbraucht werden konnte. ${ }^{1038}$ Folglich ordnete die Vorschrift an, dass die Sperrliste von den

1034 Ausführlich hierzu Stellungnahme von Sieber, Ausschussdrucksache 16 (9) 1559; Volkmann in: Spindler/Schuster, Recht der elektronischen Medien, 2011, Vorb. ZugErschwG, Rn. 6.

1035 BT-Drucks. 16/12850, S. 5.

1036 BT-Drucks. 16/13411, S. 13.

1037 Volkmann in: Spindler/Schuster, Recht der elektronischen Medien, 2011, \ 2 ZugErschwG, Rn. 10.

1038 Schnabel, JZ 2009, 996 (998): „Virtueller Routenplaner für Pädophile“. 
Diensteanbietern durch geeignete Maßnahmen gegen eine Kenntnisnahme durch Dritte abzusichern war. Wöchentlich sollte eine anonymisierte Aufstellung über die Anzahl der stündlichen Zugriffsversuche auf in der Liste befindliche Telemedienangebote gemäß $\int 6$ ZugErschwG an das BKA übermittelt werden. In Korrespondenz zur Inanspruchnahme der Diensteanbieter für staatliche Zwecke sowie die dadurch entstehende Bindungswirkung der Diensteanbieter an die Grundrechte, wurde im Gegensatz zum Vorgängergesetz im Rahmen der Neufassung explizit herausgestellt, dass zivilrechtliche Ansprüche gegen die sperrenden Access-Provider entsprechend \ 7 Abs. 2 ZugErschwG ausgeschlossen waren. Mit dieser Klarstellung entgegnete man ausweislich der Begründung der Befürchtung, dass „Gerichte zukünftig aufgrund der durch das Sperrlistenverfahren nach diesem Gesetz vorhandenen technischen Infrastrukturen zu der Schlussfolgerung gelangen könnten, Zugangsvermittler seien nunmehr auch im Hinblick auf andere Rechtsverletzungen (z.B. Rechte am geistigen Eigentum) zivilrechtlich zumutbar zur Sperrung heranzuziehen“. ${ }^{1039}$ Gleichzeitig wurde in $\ 12$ ZugErschwG der Verwaltungsrechtsweg für Streitigkeiten um die Aufnahme eines Angebotes in die Sperrliste eröffnet. \8 ZugErschwG normierte Dokumentations- und Auskunftspflichten des BKA. Danach musste das BKA Unterlagen vorhalten, aus denen ersichtlich wird, dass zum Zeitpunkt der Sperrung ein bestimmtes Angebot den tatbestandlichen Anforderungen des $\int 184 \mathrm{~b}$ StGB tatsächlich entsprochen und somit „sperrungswürdig“ war. Neben Bußgeldvorschriften, die im Falle einer Nichtvornahme der Sperrungsverpflichtung gegenüber den Access-Providern oder bei mangelhafter Sicherung der Sperrliste vor einem unbefugten Zugriff durch Dritte griffen ( $\$ 13$ ZugErschwG), wurde die zeitliche Begrenzung der Geltungsdauer des Gesetzes bis zum 31.12.2012 festgeschrieben.

\section{Gründe des Scheiterns des ZugErschwG}

In der Theorie sollte die gesetzliche Umsetzung des Zugangserschwerungsgesetzes einen einheitlichen Rechtsrahmen für Eingriffe in den Kommunikationsprozess erlauben. Der historische Werdegang, die fragliche Aussetzung und die schlussendliche Aufhebung des Regelungskonstrukts zeigen jedoch, dass das Zugangserschwerungsgesetz hinter seinen Erwartungen zurückblieb und folgerichtig zur formellen Aufhebung veranlasste. Nachfolgend sollen überblickartig die formellen und materiellen Kritikpunkte, die letztlich ausschlaggebend für das Scheitern des Gesetzes waren, dargelegt und bewertet werden.

Gleichzeitig dient die Ausführung einem Ausblick auf die Schaffung eines Löschgesetzes, wie es von der europäischen Richtlinie favorisiert wird. ${ }^{1040} \mathrm{Da}$ der Gesetzgeber hierdurch zur Schaffung eines Löschgesetzes verpflichtet wird, kann

1039 BT-Drs. 16/13411, S. 14.

$1040 \mathrm{Zu}$ den europäischen Harmonisierungsvorgaben ausführlich 5. Teil . 
er entsprechende „Lehren aus dem Zugangserschwerungsgesetz“ ziehen, um von Anfang an verfassungsrechtlichen Bedenken entgegenzuwirken.

\section{Formelle Probleme}

Bereits seit Beginn der Gesetzesinitiative wurden dem Zugangserschwerungsgesetz formelle „handwerkliche Mängel“1041 attestiert, die insbesondere in der bundesrechtlichen Ausrichtung des Sperransatzes gründeten. Anders als bei der einzelfallabhängigen gesetzlichen Ermächtigung zum Erlass von Sperrverfügungen aus $\int 20 \mathrm{JMStV}$ i.V.m. \59 RStV, beanspruchte hier der Bundesgesetzgeber den Kompetenztitel für den Erlass des Gesetzes, obgleich es sich um eine gefahrenabwehrrechtliche Regelungsmaterie handelte. Auch hinsichtlich einer Verwaltungskompetenz zur Erstellung einer Sperrliste durch das BKA sowie des gesamten Gesetzgebungsverfahrens bestanden von Anfang an Zweifel an der Verfassungsmäßigkeit. Die vorgebrachten Argumente sollen hier zum Anlass genommen werden, die formelle Verfassungskonformität zu untersuchen und damit gleichzeitig aufzeigen, ob der Bundesgesetzgeber auch vor dem Hintergrund eines zu kreierenden Löschgesetzes verfassungsrechtlich abgesichert wäre.

\section{Feblende Gesetzgebungskompetenz.}

Voranzustellen ist, dass staatliches Handeln im Bereich der Zugangserschwerung in Form der Löschung und Sperrung im Schwerpunkt nicht auf die Verfolgung der Täter und Ermöglichung eines Strafverfahrens im Hinblick auf die Verbreitung kinderpornographischen Materials gerichtet ist, sondern im Wesentlichen dem präventiven Bereich der Gefahrenabwehr dient. Mit dem Sperr- beziehungswiese Löschansatz sollen präventiv erneute Stigmatisierungen der dargestellten Kinder verhindert, wie auch negative Auswirkungen auf den Rezipienten unterbunden werden, die durch den Konsum kinderpornographischen Materials entstehen können. Neben einer Eindämmung eines visuellen Nachahmungseffektes dient die Herausnahme eines kinderpornographischen Inhalts aus dem Internetbestand auch dem präventiven Schutz der Allgemeinheit vor einer Verletzung der Rechtsordnung durch Verstöße gegen geltende Normen des StGB.

Der Bundesgesetzgeber ist nach der verfassungsmäßigen Grundstruktur der Art. 70 ff. GG nur zum Erlass von Gesetzen befugt, soweit ihm das Grundgesetz die entsprechende Kompetenz hierzu erteilt. Findet sich keine entsprechende Zuweisung beanspruchen die Länder nach dem „Regel-Ausnahme-Prinzip“ des Art. 70 GG, ${ }^{1042}$ den jeweiligen Kompetenztitel für sich. Soweit eine Materie per Grundgesetz ausnahmsweise dem Bundesgesetzgeber zugewiesen wird, unter-

1041 Frey/Rudolph, CR 2009, 644.

1042 BVerfGE 10, 89 (101); Pieroth in: Jarass/Pieroth, Art. 70 GG, Rn. 1, 11; Liesching, ZUM 2002, 868 (869). 
scheidet man zwischen der ausschließlichen (Art. 71, 73 GG) sowie der konkurrierenden Gesetzgebung (Art. 72, 74 GG). Auf dem Gebiet der ausschließlichen Gesetzgebung, bei welcher allein der Bund zur Gesetzgebung ermächtigt ist, werden die entsprechenden Regelungsmaterien in Art. 73 GG normiert. Im Gegensatz dazu begründet die konkurrierende Gesetzgebung wechselnde Kompetenzen. Auf den in Art. 74 GG abschließend benannten Gebieten dürfen die Länder ohne ausdrückliche Ermächtigung legislatorisch tätig werden. Dies gilt jedoch nur, „,solange und soweit" der Bund von seiner Gesetzgebungszuständigkeit nicht selbst Gebrauch gemacht hat.

Im grundgesetzlichen Kompetenzgefüge der Art. 72, 73, 74 GG, welches dem Bundesgesetzgeber die Kompetenz zum Erlass der Gesetze zuspricht, findet sich keine eindeutige Formulierung, die den Sachbereich der Gefahrenabwehr eindeutig als solchen benennt. Grundsätzlich wären nach dem Regel-Ausnahme-Prinzip des Art. 70 GG damit die Länder für den Bereich der präventiven Gefahrenabwehr zuständig. Es obliegt folglich den Ländern allgemeine Gesetze im Bereich des Polizei- und Ordnungsrechts, wie auch spezialgesetzliche Ausformungen des Gefahrenabwehrrechts zu erlassen. ${ }^{1043}$ Von dem Aspekt her betrachtet, scheint die gegen das Zugangserschwerungsgesetz vorgebrachte Kritik bezüglich einer mangelnden Bundeszuständigkeit durchaus grundrechtlich fundiert zu sein und auch einem bundesgesetzlich realisierten Löschgesetz entgegenzustehen. Soweit sich allerdings eine anderweitige Gesetzgebungskompetenz des Bundes ergibt, so ist er befugt in diesem Zusammenhang auch gefahrenabwehrrechtliche Regelungen zu erlassen. ${ }^{1044}$

\section{a) Kompetenz aus dem Recht der Wirtschaft Art. 74 Abs. 1 Nr. 11 GG}

Ausweislich der Begründung stützte der Gesetzgeber seine Kompetenz zum Erlass des Zugangserschwerungsgesetzes auf das Recht der Wirtschaft aus Art. 74 Abs. 1 Nr. 11 GG. ${ }^{1045}$ Der vom Bundesgesetzgeber beanspruchte Kompetenztitel zählt zum Bereich der konkurrierenden Gesetzgebung, in welchem grundsätzlich die Länder die Gesetzgebungsbefugnis haben, ,solange und soweit der Bund von seiner Gesetzgebungszuständigkeit nicht durch Gesetz Gebrauch gemacht hat“. Betrachtet man die Richtigkeit dieser Kompetenzzuweisung zunächst am Wortlaut

1043 Depenheuer in: Maunz/Dürig, Art. 87a GG, Rn. 12 ff. Lediglich im Bereich der „äußeren Gefahren“, hat der Bund die entsprechende Gesetzgebungsbefugnis, dabei handelt es sich um Gefahren, die im Zusammenhang mit Terrorimusbekämpfung oder mit Gefahren für den Bestand des Staates stehen, Art. 73 Abs. 1 Nr. 10 GG, hierzu Uble in: Maunz/Dürig, Art. 73 GG, Rn. 206 ff.

1044 BVerfGE 3, 407 (433); BVerfGE 8, 143 (149 f.); ebenso Heckmann, Stellungnahme der Sachverständigen im Rechtsausschuss v. 8.11.2010, S. 6, abrufbar unter: http://www.bundestag.de/bundestag/ausschuesse17/a06/anhoerungen/archiv/03_Zugangsers chwerung/04_Stellungnahmen/Stellungnahme_Heckmann.pdf (zuletzt abgerufen 20.5.2012).

1045 Begr. BT-Drs. 16/2850, S. 5. 
des Kompetenztitels, so erscheint die Beanspruchung des Rechts der Wirtschaft für den Erlass des Zugangserschwerungsgesetzes nicht unproblematisch: Entsprechend Art. 74 Abs. 1 Nr. 11 GG fasst das Grundgesetz den Kompetenzbereich in eine generalklauselartige Formulierung, indem allgemein das gesamte Recht der Wirtschaft dem Kompetenztitel zugesprochen wird. Gleichzeitig fügt das Grundgesetz jedoch einen Klammerzusatz hinzu, der eine Aufzählung von Einzelbereichen des Wirtschaftslebens enthält. Diese kategorisch dem Recht der Wirtschaft zugeordneten Materien sind danach „Bergbau, Industrie, Energiewirtschaft, Handwerk, Gewerbe, Handel, Bank- und Börsenwesen, privatrechtliches Versicherungswesen“.

Der Bereich der präventiven jugendschutzrechtlich motivierten Zugangserschwerung scheint bereits auf den ersten Blick keinem der aufgelisteten Einzelbereiche des Rechts der Wirtschaft zugeordnet zu sein. Weder handelt es sich hierbei um einen Bereich der Industriefragen abdeckt, die nach allgemeiner Auffassung die „fabrikmäßige, arbeitsteilige Herstellung von Produktions- und Verbrauchsgütern"1046 betreffen, noch um einen Handelsbereich, der auf die „gewerbsmäßige, gegen Entgelt erfolgende Veräußerung von Waren“1047 gerichtet ist. Zwar ist die Verpflichtung der Zugangsanbieter mittelbar auch auf Teilaspekte des Handels zurückführbar, da hinter der Herstellung und Verbreitung von Kinderpornographie, stets auch der Vertrieb von derartigen Produktionen gegen Entgelt stehen mag, jedoch greift der Gesetzgeber hier durch die Verpflichtung zu regulatorischen Maßnahmen gerade nicht vorrangig in den Handel mit entsprechenden Angeboten ein, sondern in den technischen Bereich der Datenübertragung im Internet. Zwar umfasst der Kompetenztitel zum Handel im Sinne des Art. 74 Abs. 1 Nr. 11 GG auch Vorbereitungshandlungen, die dem Vertrieb und Güteraustausch dienen, ${ }^{1048}$ jedoch handelt es sich hierbei stets um typische Konstellationen des Handelsrechts, wie die Organisation der Handelstreibenden in Handelskammern sowie das Recht der Handelsgeschäfte im kaufmännischen Sinne. ${ }^{1049}$ Die mittelbare Unterbindung der internetspezifischen Vertriebskette im Bereich der Kinderpornographie kann aber gerade nicht einer solchen typischen Konstellation des Handelsgeschäfts zugeordnet werden. Vielmehr handelt es sich beim technisierten Eingriff in den Kommunikationsbereich um einen außerhalb des kaufmännischen Betriebes stehenden Nebenbereich, der nur schwerlich vom Sinn und Zweck der Norm betrachtet, dem Handel als solchen zugeordnet werden kann. Folglich kann die gesetzliche Legitimation zum Erlass eines Gesetzes nicht an-

\footnotetext{
1046 Maunz in: Maunz/Dürig, Art. 74 GG, Rn. 58; Stettner in: Dreier, Art. 74 GG, Rn. 58.

1047 Maunz in: Maunz/Dürig, Art. 70 GG, Rn.143; Oeter in: v. Mangoldt/Klein/Starck, Art. 74 GG, Rn. 109; Kunig in: v. Münch/Kunig, Art. 74 GG, Rn. 45.

1048 Pestolozzo in: v. Mangoldt/Klein/Starck, Art. 74 GG, Rn. 598 ff., mit einer Liste der unter dem Kompetenztitel ergangenen Gesetze.

1049 Oeter in: v. Mangoldt/Klein/Starck, Art. 74 GG Rn. 83.
} 
hand eines grundgesetzlich aufgezählten Beispiels innerhalb der Klammerformulierung beim Rechts der Wirtschaft hergeleitet werden.

Fraglich ist indes, ob die innerhalb des Klammerzusatzes getätigte Aufzählung einer dem Recht der Wirtschaft zugehörigen Materie überhaupt abschließende Funktion hat, oder der Klammerzusatz lediglich zur Klarheit innerhalb der thematischen Eingrenzung des Oberbegriffs des Rechts der Wirtschaft dient. Sollte letzteres anzunehmen sein, so können auch andere über die aufgezählten Teilsachbereiche hinausgehenden Regelungsmaterien, die mit Wirtschaft im weitesten Sinne zusammenhängenden, vom Kompetenztitel als abgedeckt gelten und gerade die Kompetenz für den Erlass eines Zugangserschwerungsgesetzes herbeiführen. Rein sprachlich vermag der Wortlauts diese Frage nicht zu beantworten, eigentlich ergibt sich daraus nur das „Wirtschaft" als „der zusammenfassende Oberbegriff der eingeklammerten Einzelsachgebiete“ zu verstehen ist. ${ }^{1050}$ Die Rechtsprechung ${ }^{1051}$ und Literatur ${ }^{1052}$ gehen indes von einem weiten Verständnis der Formulierung aus und weisen der Kompetenznorm des Rechts der Wirtschaft eine Generalermächtigung zu. ${ }^{1053}$ Damit werden jegliche Arten von Regelungen abgedeckt, die sich in irgendeiner Form auf das wirtschaftliche Leben beziehen und die wirtschaftliche Betätigung als solche regeln und damit zumindest auch wirtschaftslenkende Funktion aufweisen. ${ }^{1054}$ Darauf wies auch der Gesetzgeber im Rahmen der Begründung des Zugangserschwerungsgesetzes explizit hin ${ }^{1055}$ und übertrug diese weite Auslegung auf die Kompetenz zum Erlass des Zugangserschwerungsgesetzes: ${ }^{1056}$ „Die den Zugangsvermittlern auferlegte Pflicht, den Zugang zu kinderpornographischen Angeboten durch entsprechende technische Vorkehrungen zu erschweren, ist als solche wirtschaftslenkende Maßnahme zu qualifizieren, da sie die Diensteanbieter in der Ausübung ihrer wirtschaftlichen Tätigkeit reglementiert."

Die Einordnung ist in Bezug auf die vorherige Feststellung, dass die Verpflichtung zu technischen Zugangserschwerungen vordergründig dem präventiven Bereich der Gefahrenabwehr zuzuordnen sei nicht unproblematisch. Zieht man die Rechtsprechung des Bundesverfassungsgerichts heran, so können ausdrücklich auch sicherheitsrelevante Fragen vom Bundesgesetzgeber im Rahmen der Kom-

1050 Oeter in: v. Mangoldt/Klein/Starck, Art. 74 GG Rn. 83.

1051 BVerfGE 8, 143 (148 f.); BVerfGE 28, 119 (146); BVerfGE 68, 319 (330).

1052 Degenhart in: Sachs, Art. 74 GG, Rn. 37; Kunig in: v. Münch/Kunig, Art. 74 GG, Rn. 36 ff.; Rengeling in: Isensee/Kirchhof, Hdb. StaatsR, 1999, Bd. IV, \ 100, Rn. 39; Emmerich, BB 1972, 457.

1053 BVerfGE 8, 143 (148 f.); BVerfGE 28, 119 (146); BVerfGE 68, 319 (330).

1054 BVerfGE 8, 143 (148 f.); BVerfGE 26, 246 (254); BVerfGE 68, 319 (330).

1055 Explizit zitiert der Gesetzgeber hier die Entscheidung BVerfGE 68, 319 (330).

1056 Amt. Begr. Gesetz zur Bekämpfung der Kinderpornographie in Kommunikationsnetzen (Vorgänger ZugErschwG), S. 6. 
petenz zum Recht der Wirtschaft geregelt werden; soweit der Bund ein Recht zur Gesetzgebung in einem bestimmten Lebensbereich hat, so muss er in demselben Sachbereich auch das Recht haben, spezielle gefahrenabwehrrechtliche Vorschriften zu erlassen. ${ }^{1057}$ Wird die legislatorische Tätigkeit des Bundes dem Lebensbereich der Wirtschaft zugeordnet, so kann er demnach auch ordnungsrechtlich tätig werden, allerdings müssen sich die erlassenen Vorschriften dann als „Annex“ des Rechts der Wirtschaft darstellen und so in dem notwendigen Zusammenhang zu dem wirtschaftslenkenden Maßnahmen stehen. ${ }^{1058}$ Damit schließt nicht schon die Zugehörigkeit der Materie zum Gefahrenabwehrrecht die Bundeskompetenz aus, als weitere Einschränkung muss dazukommen, dass sich die gefahrenabwehrrechtlichen Vorschriften auf eine spezifische „von der Wirtschaftstätigkeit ausgehende Gefahr" beziehen, allgemeine gefahrenabwehrrechtliche Belange verbleiben in der Zuständigkeit der Länder. ${ }^{1059}$ Entscheidend ist demnach, ob die von der Rechtsmaterie des Zugangserschwerungsgesetzes umfassten Gefahren als spezifische Gefahren der Wirtschaftstätigkeit verstanden werden konnten.

In diesem Zusammenhang ist zu beachten, dass die vorgesehene Zugangserschwerung das wirtschaftliche Betätigungsfeld der Zugangsanbieter durch die gesetzliche Verpflichtung zur Sperrung durchaus berühren sollte und zumindest mittelbar wirtschaftslenkende Funktion hatte. Denn die Zugangsanbieter, als primäre Adressaten, sollten durch die gesetzlichen Bestimmungen zur vollständigen Tragung der Investitionskosten für die technischen Vorkehrungen zur Realisierung der Zugangserschwerung verpflichtet werden. ${ }^{1060}$ Langfristig hätte eine wirtschaftslenkende Funktion durch das Gesetz für den Markt der Zugangsdienstleistungen zum Internet nicht per se ausgeschlossen werden können. ${ }^{1061}$ Jedoch ist die wirtschaftslenkende Funktion nicht allein ausschlaggebend für die Zugehörigkeit zum Kompetenztitel im ordnungsrechtlichen Bereich ist. Hinzukommen muss, dass sich im Falle gefahrenabwehrrechtlicher Regelungen, die Vorschriften als Annex des Rechts der Wirtschaft darstellen und auf die Unterbindung einer von der Wirtschaftstätigkeit der Zugangsanbieter ausgehenden Gefahr ausgerichtet sind. Diese Voraussetzung lag beim Zugangserschwerungsgesetz nicht vor. Vorrangiges Ziel des Gesetzes war die Unterbindung der Gefahren, die im Zusammenhang mit der internetermöglichten Verbreitung von Kinderpornographie stehen. Dass die Zugangsanbieter durch die Verpflichtung zur Sperrung auch in ihrer wirtschaftlichen Freiheit Einbußen erfahren, stellte sich nicht als Annex der

1057 BVerfGE 3, 407 (433); BVerfGE 8, 143 (149 f.).

1058 BVerfGE 8, 143 (149).

1059 BVerfGE 100, 313 (371).

1060 BT-Drs. 16/12850, S. 1 Vorgänger ZugErschwG; dergl. BT-Drs. 16/13411, S. 2, ZugErschwG. Nach der hier vertretenen Auffassung ist den Access-Providern schon aus verfassungsrechtlichen Aspekten eine Entschädigung zu gewähren.

1061 Dies zunächst herausstellend Frey/Rudolph, Ausschussdrucksache 16 (9)1546, S. 21. 
bezweckten Gefahrenabwehr dar, vielmehr nur als „logischer Reflex“ der durch die Regelung bezweckten Gefahrenabwehr. ${ }^{1062}$ Zudem muss auch die weitere Voraussetzung der Bundeszuständigkeit ist, beim Zugangserschwerungsgesetz in Abrede gestellt werden. Die Vorschriften müssen auf eine von der Wirtschaftstätigkeit der Zugangsanbieter ausgehende Gefahr, die im Rahmen des Zugangserschwerungsgesetzes unterbunden werden soll, gerichtet sein. ${ }^{1063}$ Adressat der Sperrverfügung waren hier eindeutig die Provider, die den Zugang zum Internet gewähren. ${ }^{1064}$ Diese Wirtschaftstätigkeit müsste für die Herleitung einer Bundeskompetenz als Ausgangspunkt der mit dem Gesetz zu unterbindenden Gefahren zu werten sein. Die vorrangig vom Gesetz zu unterbindenden Gefahren waren aber nach dem hier bereits im Rahmen der allgemeinen verfassungsrechtlichen Ausführungen vertretenen Ergebnis in keinster Weise rechtlich dem Verantwortungsbereich der Access-Provider zuzuordnen. 1065 Auch der Gesetzgeber selbst schien dieses anzunehmen, indem er den Zugangsanbietern im Zugangserschwerungsgesetz ebenfalls explizit als „nicht-verantwortlich“, mithin als Nichtstörer im Sinne des allgemeinen Gefahrenabwehrrechts, einstufte. ${ }^{1066}$ Schon diese Einstufung lief der oberen Forderung einer von der Wirtschaftstätigkeit ausgehenden Gefahr zuwider, da jemand der in Bezug auf den mit dem Gesetzestext verfolgten Schutzzweck eindeutig als Nicht-Verantwortlicher eingestuft wurde, an anderer Stelle nicht zum Verantwortlichen der Gefahr gemacht werden kann, um eine Gesetzgebungszuständigkeit herbeizuführen.

Darüber hinaus führte der Gesetzgeber ein weiteres Argument an, mit dem er einen Beleg für die Bundeskompetenz im Bereich der Zugangserschwerung für sich beanspruchte: „Im Übrigen stützt sich das Telemediengesetz auch schon bislang auf Art. 74 Absatz 1 Nummer 11“..1067

1062 In diese Richtung dann auch Frey/Rudolph, Ausschussdrucksache 16 (9), 1546, S. 21.

1063 BVerfGE 100, 313 (371).

1064 Hierzu bereits oben 3. Teil A. II.

1065 Ausdrücklich ebenso Frey/Rudolph, Stellungnahme der Sachverständigen im Rechtsausschuss, S. 15, abrufbar unter: http://www.bundestag.de/bundestag/ausschuesse17/a06/anhoerungen/archiv/03_Zugangsers chwerung/04_Stellungnahmen/Stellungnahme_Frey.pdf (zuletzt abgerufen 20.5.2012). Zur mangelnden Gefahrbegründung durch die Access-Provider, bereits Spindler/Volkmann, K\&R 2002, 398 (404 ff f.); ausführlich Volkmann, Der Störer im Internet, 2005, S. 208 ff. mwN. und einer detaillierten Auseinandersetzung mit Sonderformen der Verhaltensstörereigenschaft wie Zweckveranlasser oder latente Gefabr, jeweils zu Recht ablehnend. Dem anschließend Sieber/Nolde, Sperrverfügungen im Internet, 2008, S. $154 \mathrm{f}$.

1066 Begr. ZugErschwG, BT-Drs. 16/13411, S. 12, so auch Volkmann in: Spindler/Schuster, Recht der elektronischen Medien, 2011, Vorb. ZugErschwG, Rn. 4;

1067 BT-Drs. 16/12850, S. 6. 
Das Argument, dass wohl darauf abzielt, dass die Änderung eines Gesetzes, das vom Bund erlassen wurde, erneut in die gleiche Bundeskompetenz fällt, ${ }^{1068}$ vermag hier nicht mehr zu greifen. Nicht nur, dass der Wirtschaftsbezug bei den gesetzlichen Verpflichtungen zur Sperrung nicht besteht, auch war das Zugangserschwerungsgesetz anders als das der oben zitierten Begründung zugrundeliegenden Vorgängergesetz, gerade nicht mehr auf eine Änderung des TMG ausgerichtet, sondern als eigenständiges Spezialgesetz erlassen worden. Damit erkannte der Gesetzgeber, dass sich die Regelungsmaterie der Zugriffserschwerung deutlich von der Regelungsmaterie des TMG abhob und aus gesetzessystematischer Sicht gerade nicht unter den 3. Abschnitt „Verantwortlichkeit“ des TMG hineinpasste. ${ }^{1069}$

Zusammenfassend war entgegen dem vom Gesetzgeber beanspruchten Kompetenztitel, das Zugangserschwerungsgesetz nicht auf die Bundeskompetenznorm des Rechts der Wirtschaft aus Art. 74 Abs. 1 Nr. 11 GG zu stützen. ${ }^{1070}$ Auch ein etwaiges Löschgesetz wird aus den vorgenannten Gründen nur schwerlich unter diesem Kompetenztitel erlassen werden dürfen. Auch wenn sich hier die Verantwortlichkeit der in Anspruch genommenen Diensteanbieter (Host- und Contentprovider) anders als bei Access-Providern mit entsprechender Argumentation durchaus herleiten ließe, so wird die Kompetenz spätestens an der Ausrichtung der Rechtsmaterie scheitern. Vordergründig bleibt es ein technischer Eingriff in den Kommunikationsbereich, der sich nicht als Annex einer Wirtschaftstätigkeit der Provider darstellt, sondern notwendige Konsequenz zur Erfüllung der gesetzlichen Pflicht ist. Dem Gesetzgeber bleibt dieser Kompetenztitel somit verwehrt.

b) Kompetenz aus dem Strafrecht Art. 74 Abs. 1 Nr. 1 GG

Unter die Regelungsmaterie des Strafrechts gemäß Art. 74 Abs. 1 Nr. 1 fallen alle Rechtsnormen, die spezifische Sanktionen an die Übertretung bestimmter rechtlicher Gebote knüpfen. ${ }^{1071}$ Darüber hinaus kann der Bundesgesetzgeber darauf gestützt auch Maßnahmen erlassen, die sich auf Vorbereitungshandlungen zur

1068 Das Verständnis zugrundelegend wohl auch Höbne, jurisPR ITR 13/2009, Anm. 6.

1069 So Bitkom, Ausschussdrucksache 16 (9) 1538, S. 5 f.; ebenfalls Eco, Ausschussdrucksache 16 (9) 1542, S. 1 f.

1070 AA. Heckmann, Stellungnahme der Sachverständigen im Rechtsausschuss v. 8.11.2010, S. 7, abrufbar unter:

http://www.bundestag.de/bundestag/ausschuesse17/a06/anhoerungen/archiv/03_Zugangsers chwerung/04_Stellungnahmen/Stellungnahme_Heckmann.pdf (zuletzt abgerufen 20.5.2012), der über äußerst weite Auslegung des Anwendungsbereichs des Rechts der Wirtschaft die vorliegende Konstellation noch unter den Kompetenztitel subsumiert.

1071 BVerfGE 85, 134 (142); Maunz in: Maunz/Dürig, Art. 74 GG, Rn. 63 ff.; Oeter in: v. Mangoldt/Klein/Starck, Art. 74 Abs. 1 Nr. 1 GG, Rn. 14. 
Strafverfolgung beziehen. ${ }^{1072}$ Auch diese Kompetenznorm war für das Zugangserschwerungsgesetz jedoch nicht einschlägig. Zwar hob das Zugangserschwerungsgesetz in seiner gesetzlichen Verpflichtung zur Vornahme von Sperrungen die strafrechtliche Sanktionsnorm des $\$ 184 \mathrm{~b}$ StGB explizit in den Kontext, so dass grundsätzlich zu überlegen wäre, ob der Gesetzgeber den Kompetenztitel des Strafrechts für sich beanspruchen konnte; jedoch waren die Maßnahmen des $\mathrm{Zu}$ gangserschwerungsgesetzes in erster Linie nicht darauf gerichtet Straftaten nach \184b StGB aufzuklären, sondern sollten verhindern, dass kinderpornographische Inhalte nach $₫ 184 \mathrm{~b}$ StGB aufgerufen wurden. ${ }^{1073}$ Die Bezugnahme zu $\ 184 \mathrm{~b}$ StGB diente damit ausschließlich als Definitionsvorgabe für die inhaltliche Einordnung eines Angebotes als „sperrungswürdig“. Zwar begründet die Sperrung beziehungswiese Löschung eines kinderpornographischen Inhalts gleichzeitig auch eine Vorfeldmaßnahme im Hinblick auf die Verhinderung zukünftiger Rechtsverstöße gegen diese Strafrechtsnorm, hierbei handelt es sich aber um Vorfeldmaßnahmen im Anliegen der Gefahrenabwehr und nicht im Hinblick auf eine spätere Strafverfolgung. ${ }^{1074}$ Dafür spricht auch die eigenständige Herausnahme der Übermittlungsmöglichkeit, der während einer Sperrmaßnahme anfallenden Verkehrsund Nutzerdaten, an die Ermittlungsbehörden, welche im Vorgängergesetz über \8a Abs. 5 Satz 2 TMG-E vorgesehenen war. Hierdurch positionierte sich der Gesetzgeber eindeutig zulasten eines repressiv verfolgten Gesetzesansatzes. ${ }^{1075}$ Mithin fehlte es an einem zulässigen Anknüpfungspunkt der Strafverfolgung; eine Kompetenz aufgrund des Strafrechts aus Art. 74 Abs. 1 Nr. 1 GG schied für den Erlass des Zugangserschwerungsgesetzes aus und kann auch nicht für ein etwaiges Löschgesetz herangezogen werden.

c) Kompetenz aus dem Recht der Telekommunikation Art. 73 Abs. 1 Nr. 7 Var. 2 GG

Das Gesetz basierte auch nicht auf den Kompetenztitel zur Regulierung des Telekommunikationsrechts aus Art. 73 Abs. 1 Nr. 7 Var. 2 GG. Zwar handelte es sich bei den Sperr- und Löschverpflichtungen, um technische Eingriffe in ein Kommunikationsnetz. Im Rahmen der ausschließlichen Gesetzgebung nach Art. 73 Abs. 1 Nr. 7 GG ist anerkannt, dass auch präventive Regelungen im Sinne einer Gefahrenabwehr als vom Kompetenztitel umfasst gelten.1076 Jedoch bezieht sich die ausschließliche Kompetenz zur Regelung der Telekommunikation nach ständiger Rechtsprechung allein auf die rein technische Infrastruktur der Telekommu-

\footnotetext{
1072 BVerfGE 30, 1 (29); Stettner in: Dreier, Art. 74 GG, Rn. 27; Degenhart in: Sachs, Art. 74 GG, Rn. 27.

1073 In die Richtung auch Bäcker, Ausschussdrucksache 16 (9) 1554, S. 3.

1074 Ebenso Bäcker, Ausschussdrucksache 16 (9) 1554, S. 3.

1075 Hierzu bereits oben 4. Teil C. I. 1. a) .

1076 Heintzen in: v. Mangoldt/Klein/Starck, Art. 73 GG, Rn. 77.
} 
nikation. ${ }^{1077}$ Daher obliegt den Ländern die gesetzliche Ausgestaltung aller inhaltsbezogenen und aufsichtsrechtlichen Regelungen der Telekommunikation vorzunehmen, ${ }^{1078}$ dem Bund steht nur die Bestimmung für den technischorganisatorischen Bereich zu. ${ }^{1079}$ Damit ist bei der Kompetenzfrage zur Regelung von Rechtsfragen im Zusammenhang mit Telekommunikation, die auch präventiver Natur sein können, stets danach zu trennen, ob es sich um Angelegenheiten handelt, die im engen Zusammenhang zum rein technischen Übermittlungsvorgang stehen oder ob der Kern der zu regelnden Rechtsmaterie die über die Telekommunikationsleitungen verbreiteten Inhalte sind. Im Bereich der präventiven Abwehr von internetbasierter Kinderpornographie geht es eindeutig um die „transportierten“ Inhalte als solche. ${ }^{1080}$ Daher konnte auch der Kompetenztitel des Art. 73 Abs. 1 Nr. 7 Var. 2 GG nicht zur Kompetenz des Bundes für Maßnahmen zur Zugangserschwerung, wie Sperrung und Löschung, in Anspruch genommen werden.

d) Kompetenz aus der Zusammenarbeit im Bereich der Kriminalpolizei Art. 73 Abs.1 Nr. 10 GG

Eine Gesetzgebungskompetenz des Bundes ließ sich auch nicht aus Art. 73 Abs. 1 Nr. 10 GG ableiten. Danach kann der Bund grundsätzlich die Zusammenarbeit des Bundes und der Länder in der Kriminalpolizei und die internationale Verbrechensbekämpfung regeln. Es handelt sich hierbei um ein auf Dauer angelegtes gemeinsames Zusammenwirken mit gegenseitiger Unterstützung und Abhängigkeit. ${ }^{1081}$ Die „Zusammenarbeit in der Kriminalpolizei“" umfasst die Verhütung, Aufklärung und Verfolgung bedeutsamer Straftaten, nicht aber die allgemeine Gefahrenabwehr. ${ }^{1082}$ Das Regelungskonzept des Zugangserschwerungsgesetzes passte damit in zweifacher Hinsicht nicht unter den Kompetenztitel: Zum einen sah das Gesetz eben keine Zusammenarbeit von Bund und Ländern vor, sondern wies eine Aufgabe der Sperrlistenführung und Übermittlung ausschließlich einer Bundesbehörde zu. Zum anderen handelte es sich bei der Erschwerungsmaßnah-

1077 Nicht abschließend BVerfGE 12, 205 (225 ff.); BVerfGE 113, 348 (368); BVerfGE 114, 371, 385); BVerfGE 121, 30 846); BVerwGE 112, 194 (198).

1078 Grundlegend BVerfGE 12, 205 (226).

1079 BayVerfGHE 43, 95 (98 f.).

1080 In die Richtung auch Bäcker, Ausschussdrucksache 16 (9) 1554, S. 3.

1081 Pieroth in: Jarass/Pieroth, Art. 73 GG, Rn. 31; Seiler in: Epping/Hillgruber, Art. 73 GG, Rn. 46; Stettner in: Dreier, Art. 73 GG, Rn. 43.

1082 Pieroth in: Jarass/Pieroth, Art. 73 GG, Rn. 32; Seiler in: Epping/Hillgruber, Art. 73 GG, Rn. 47; Degenhart in: Sachs, Art. 73 GG, Rn. 48. Mit Bezug zum ZugErschwG Tinnefeld, DuD 2010, 15 (17); strikt gegen eine Kompetenzzuweisung Hoffmann-Riem, Interview im ZDF-Magazin, ,aspekte“, v. 31.9.2009, abrufbar unter: http://www.wikio.de/video/zdf-aspekte-interviewwolfgang-hoffmann-riem-1479171 (zuletzt abgerufen 20.5.2012). 
men, wie erläutert, gerade um Maßnahmen der allgemeinen Gefahrenabwehr, die der Kompetenztitel des Art. 73 Abs.1 Nr. 10 GG nicht zu regeln vermag. ${ }^{1083}$

Auch konnte man die Zugriffserschwerung nicht als Maßnahmen der internationalen Verbrechensbekämpfung begreifen. Der ausschließliche Kompetenztitel des Bundes ermächtigt gemäß Art. 73 Abs. 1 Nr. 10 Alt. 3 GG zur Verbrechungsbekämpfung mit internationalem Charakter. Ausschlaggebend für den internationalen Charakter ist hier nicht die Internationalität des Verbrechens oder die Internationalität der Täter oder ihrer Organisationen, ${ }^{1084}$ vielmehr wird überwiegend auf die Grenzüberschreitung der Bekämpfungsmaßnahmen abgestellt, die sich insbesondere in der Vernetzung von in- und ausländischer Behörden widerspiegeln können. ${ }^{1085}$ Allein der Materie des Internets ist es geschuldet, dass sich im Zugangserschwerungsgesetz durchaus Vorschriften fanden, die auf grenzüberschreitende Befugnisse ausgerichtet waren: So war unter anderem in $\ 2$ Abs. 2 und 3 ZugErschwG geregelt, dass ein kinderpornographisches Angebot, dass von einem Diensteanbieter außerhalb des Geltungsbereichs der EU, sofort in die Sperrliste nach $\int 1$ Abs. 1 ZugErschwG aufgenommen werden durfte, was eine nationale Sperrverpflichtung durch die Zugangsanbieter nach sich zog. Zudem oblag dem BKA schon gemäß \ 3 Abs. 2 BKAG grundsätzlich der zur Verhütung von Straftaten erforderliche Dienstverkehr mit den zuständigen öffentlichen Stellen anderer Staaten. Folglich ließen all diese Normen zumindest im Ansatz auf den Kompetenztitel des Bundesgesetzgebers aus Art. 73 Abs. 1 Nr. 10 Alt. 3 GG schließen. Jedoch muss bei der Beurteilung der Kompetenz stets der Gesamtcharakter des Gesetzes im Vordergrund stehen: Das Zugangserschwerungsgesetz war im Kern auf die Verpflichtung der nationalen Zugangsdiensteanbieter zur Sperrung kinderpornographischer Seiten ausgerichtet und sollte damit zur Eindämmung der Verbreitung kinderpornographischer Angebote beitragen. Der internationale Einschlag des Gesetzes war lediglich damit begründet, dass das Gesetz Eingriffsbefugnisse auf ein internationales Datennetzwerk erlaubte. ${ }^{1086}$

In Bezug auf ein Löschgesetz wären zwar primär die ausländischen Diensteanbieter Adressaten der Maßnahme, auch hier geht es vordergründig aber um die

1083 In die Richtung auch Frey/Rudolph, Stellungnahme der Sachverständigen im Rechtsauschuss, S. 15 f., abrufbar unter:

http://www.bundestag.de/bundestag/ausschuesse17/a06/anhoerungen/archiv/03_Zugangsers chwerung/04_Stellungnahmen/Stellungnahme_Frey.pdf (zuletzt abgerufen 20.5.2012).

1084 Heintzen in: v. Mangoldt/Klein/Starck, Art. 73 GG, Rn. 136; Pieroth in: Jarass/Pieroth, Art. 73 GG, Rn. 35.

1085 BVerfGE 100, 313 (369); Gärditz, Strafprozeß und Prävention, 2003, S. 275 f.

1086 Ebenso Bäcker, Ausschussdrucksache 16 (9) 1554, S. 3; Frey/Rudolph, Stellungnahme der Experten im Rechtsausschuss v. 7.11.2010, S. 15 f., abrufbar unter:

http://www.bundestag.de/bundestag/ausschuesse17/a06/anhoerungen/archiv/03_Zugangsers chwerung/04_Stellungnahmen/Stellungnahme_Frey.pdf (zuletzt abgerufen 20.5.2012). 
Unerreichbarkeit des Inhalts auf deutschen Gebiet aufgrund des Vorliegens von Strafbarkeitskriterien des \$184b StGB. Hierbei kann nichts anderes gelten, als es sich vorrangig um präventive Eingriffsbefugnisse auf nationalem Gebiet handelt, um inländische Rechtsverstöße zu bewahren. Folglich könnte sich der Gesetzgeber nicht auf eine Kompetenz aus Art. 73 Abs.1 Nr. 10 GG für den Erlass eines Löschgesetzes berufen.

e) Kompetenz aus dem Jugendschutz im Rahmen der öffentlichen Fürsorge Art. 74 Abs. 1 Nr. 7 GG

Bisweilen scheint die Auseinandersetzung tatsächlich von einer fehlenden Kompetenz für den Erlass des Zugangserschwerungsgesetzes und damit in die Richtung der Länderzuständigkeit für ein etwaiges Löschgesetz zu deuten. Allerdings wurde bei der Diskussion - auch vom Bundesgesetzgeber selbst - übersehen, dass sich die Regelungsmaterie der Zugangserschwerung zu kinderpornographischen Inhalten unter die Kompetenznorm der öffentlichen Fürsorge aus Art. 74 Abs. 1 Nr. 7 GG einfügen ließe. Denn die Kompetenznorm der „öffentlichen Fürsorge“ umfasst auch die Kompetenz für den Jugendschutz, welcher als Ausgangspunkt zur Realisierung bundesrechtlicher Normen, die auf inhaltsbeschränkende Maßnahmen im Internet mit dem Ziel des Jugendschutzes gerichtet sind, Anwendung finden kann.

Unstreitig steht die dauerhafte Unterbindung kinderpornographischer Inhalte im Internet in einem engen Kontext zur Verpflichtung des Staates zur Realisierung eines effektiven Jugendschutzes. Vorrangiges Ziel des Gesetzes ist die Unterbindung der Kinderpornographie und die Vorbeugung der mit der Kinderpornographie einhergehenden Gefahren. Problematisch erscheint jedoch, dass neben den vorrangig jugendschützenden Interessen mit dem Konzept der Zugangserschwerung auch über den Jugendschutz hinausgehende Rechtsgüter der Allgemeinheit verfolgt werden sollen. ${ }^{1087}$ Fraglich ist, ob bereits der Doppelcharakter eines Gesetzes, die Berufung auf einen etwaigen Jugendschutzkompetenztitel verwehrt. Die meisten Gesetze dienen von ihrer Zielmaterie betrachtet jedoch dem Schutz mehrerer Rechtsgüter. So sind beispielsweise mit wirtschaftslenkenden Gesetzen oftmals auch Interessen, der hinter dem wirtschaftlichen Bezug stehenden Arbeitgeber und Arbeitsnehmer verbunden, gleichfalls können mit Gesetzen, die sich im Bereich des Waffenrechts bewegen, zwangsläufig auch übergeordnete Interessen am Schutz des Einzelnen in seiner körperlichen Integrität verbunden sein. ${ }^{1088}$ Nicht entscheidend ist folglich, dass ein gesetzliches Kon-

1087 Zur Auseinandersetzung mit den ebenfalls berührten Rechtsgütern, 2. Teil A. II. 1. c) .

1088 So auch Altenhain in: Roßnagel, Recht der Multimedia-Dienste, 2005, Teil 9 GjS Einl., Rn. 17 mwN; für die Anwendung des Kompetenztitels besonders auf Medieninhalte, Degenhart in: Sachs, Art. 74 GG, Rn. 38; in die Richtung auch BVerfGE 21,113 (117); BVerfGE 19, 94 (96). 
strukt auch anderen Schutzzwecken dient, vielmehr kommt es darauf an, welcher spezifische Rechtsgüterschutz sich hinter der Regelungsmaterie im Schwerpunkt verbirgt:1089 Der gesetzlichen Verpflichtung zur Zugangserschwerung kinderpornographischer Inhalte kann indes schwerlich der Schwerpunkt eines jugendschützenden Gesetzes abgesprochen werden. Auch der Gesetzgeber erwähnte innerhalb der Gesetzesbegründung zum Zugangserschwerungsgesetz schließlich immer wieder die Wichtigkeit des Themas und stellte diese in den Mittelpunkt der gesetzlichen Ausrichtung: „Gegen die sexuelle Ausbeutung von Kindern muss mit allen Mitteln vorgegangen werden“ (...) Dies zeigt, dass die technische Sperrung solcher Seiten durch Zugangsvermittler einen wichtigen Beitrag leisten kann, um die Verbreitung und Besitzverschaffung von Kinderpornographie zu erschweren"1090 Damit positioniert sich der Gesetzgeber selbst hinsichtlich der jugendrechttangierten Schutzmaterie so stark, dass die Möglichkeit einer Kompetenz aus dem Jugendschutz, für den Erlass des Zugangserschwerungsgesetzes wie auch für ein etwaig folgendes Löschgesetz nicht unberücksichtigt bleiben darf.

(aa) Jugendschutz als Teilbereich der öffentliche Fürsorge

Damit sich der Bundesgesetzgeber bei der Regelung des Zugangserschwerungsgesetzes und eines folgenden Löschgesetzes tatsächlich auf den Kompetenztitel aus Art. 74 Abs. 1 Nr. 7 GG berufen konnte und zukünftig kann, ist zunächst erforderlich, dass der Begriff der öffentlichen Fürsorge als Kompetenznorm für den Jugendschutz ausgelegt wird. Anerkannterweise ist der Begriff der öffentlichen Fürsorge weit zu verstehen und damit grundsätzlich auch dem Bereich des Jugendschutzes zugänglich. ${ }^{1091}$ Das traditionelle Begriffsverständnis der öffentlichen Fürsorge umfasste jedwede Unterstützung von Hilfsbedürftigen durch öffentlichrechtliche Rechtsträger. ${ }^{1092}$ Die Rechtsprechung ist mit der Zeit jedoch weit über dieses klassische Verständnis hinausgegangen: In seiner thematischen Weite umfasst der Kompetenztitel heute als „verfassungsrechtlicher Gattungsbegriff“"1093 alle Lebenssachverhalte, wenn sie in ihrem Kernelementen dem Bild der klassischen

Gegen die Einordnung unter den Kompetenztitel zum Jugendschutz, Koreng, JURA 2010, 931 (935).

1089 Zur „Schwerpunkttheorie“, BVerfGE 97, 228 (252); in die Richtung auch Tinnefeld, DuD 2010, 15 (17).

1090 Begr. BT-Drs. 16/12850, S. 5.

1091 BVerfGE 88, 203 (329); BVerfGE 97, 332 (341), zumindest im Bezug auch die Sozialstaatlichkeit.

1092 Maunz in: Maunz/Dürig, Art. 74 GG, Rn. 107; Degenhardt in: Sachs, Art. 74 GG, Rn. 32, wobei früher noch auf die wirtschaftliche Lage als Grund für die Hilfsbedürftigkeit gefordert wurde, hierzu Maunz in: Maunz/Dürig, Art. 74 Abs. 1 Nr. 7 GG, Rn. 112; Oeter in: v. Mangoldt/Klein/Starck, Art. 74 Abs. 1 Nr. 7 GG, Rn. 68.

1093 So BVerfGE 81, 156 (186). 
Fürsorge entsprechen. Ist dies der Fall, so können über den Kompetenztitel nicht nur abhelfende repressive Maßnahmen, ${ }^{1094}$ sondern gerade auch präventiv staatliches Handeln, normspezifisch gestaltet werden, solange die erlassenen Vorschriften nur in einer engen Relation zum Bedürftigkeitsbereich stehen. ${ }^{1095}$ Der notwendige Bedürftigkeitseinschlag wurde von der Rechtsprechung etwa im Bereich der Jugendpflege ${ }^{1096}$, aber auch explizit im Bereich des allgemeinen Jugendschutzes ${ }^{1097}$ angenommen. Beide Bereiche beziehen sich klassischerweise auf Konstellationen, bei denen eine potentielle Notlage besteht, aus der sich der Betroffene aufgrund seiner Hilfslosigkeit nicht selbst befreien kann. Daneben kann der unter die öffentliche Fürsorge fallende Jugendschutz auch dahingehend ausgelegt werden, dass Maßnahmen geschaffen werden, die verhindern, dass der Hilfsbedürftige erst gar nicht in eine Notlage gerät, die später in klassischen Fürsorgemaßnahmen münde würde. ${ }^{1098}$ Folglich ist der Bundesgesetzgeber unter dem Kompetenztitel der öffentlichen Fürsorge ermächtigt entsprechende Gesetze für den Jugendschutz zu erlassen, die auf die Unterbindung beziehungsweise Vorbeugung von jugendspezifischen Gefahren gerichtet sind. In ihrer tatsächlichen Ausgestaltung ist der Gesetzgeber aufgrund der Weite des Kompetenztitels verhältnismäßig frei: Gerade in dem vorgelagerten Bereich, indem es um die „Abwendung unmittelbar drohender Gefahren geht, die erfahrungsgemäß schädigend auf die geistige und

1094 Z.B wurde unter dem Kompetenztitel auch das Gesetz über die Entschädigung von Opfern von Gewalttaten, Opferentschädigung, BGBl. I, 1976, S. 1181 erlassen; der Familienlastenausgleich, BVerfGE 87, 1 (34 f.), hierzu Kunig in: v. Münch/Kunig, Art. 74 GG, Rn. 28.

1095 Oeter in: v. Mangoldt/Klein/Starck, Art. 74 Abs. 1 Nr. 1 GG, Rn. 67; Maun₹ in: Maunz/Dürig, Art. 74 GG, Rn. 106.

1096 BVerfGE 22, 180 (212); BVerwGE 19, 94 (96).

1097 BVerfGE 31, 113 (117); BVerwGE 19, 94 (96f.), „Nach erneuter Überprüfung trägt der erkennende Senat keine Bedenken mehr anzunehmen, dass in erster Linie Art. 74 Abs. 1 Nr. 7 GG dem Bund die Kompetenz zum Erlass des Jugendschutzgesetzes (...) gibt“; BVerwGE 23, 112 (113); BVerwGE 85, 202 (230), die Gesetzgebungskompetenz ergebe sich „,wie sonst allgemein beim Jugendschutz aus Art. 74 Abs. 1 Nr. 7 GG“, allgemein hierzu Hering, DöV 1975, 8 (10).

1098 So Reinwald, ZUM 2002, 119 (123) zur Anerkennung des Jugendschutzes als Teilbereich der öffentlichen Fürsorge weitgehend neben der Rspr. auch die Literatur, Liesching, ZUM 2002, 868; Ory, ZUM 1986, 123 (126); Weides, NJW 1987, 224 (230); Beisel/Heinrich, NJW 1996, 491 (492); ausführlich zur Bundeskompetenz für den Jugendschutz, Taubert, Bundeskompetenz für Jugendschutz, 2003, S. 20 ff.; a.A. Vlachopoulos, Kunstfreiheit und Jugendschutz, 1996, S. 37 bei Fn. 58, im Anschluss an Bettermann, AöR 83 (1958), 91 (108f.), die iE. wohl für eine grundsätzliche Länderkompetenz bei gefahrenabwehrrechtlichen Regelungen plädieren, in die gleiche Richtung auch Reinwald, ZUM 2002, 119. 
seelische Entwicklung der Jugendlichen und Kinder auswirken“,1099 können zur Abwehr dieser potentiellen Notlage auch Verbote zum Zwecke der Gefahrenabwehr vom Bundesgesetzgeber erlassen werden, die an sich in die Länderzuständigkeit fallen, insbesondere wenn es um vorbeugende Maßnahmen geht. ${ }^{1100}$

Die Gegenwärtigkeit jugendschutzrechtlicher Gesetze mit gefahrenabwehrrechtlichen Charakter auf Bundesebene und die weitgehende Zustimmung der Literatur ${ }^{1101}$ zur kompetenzrechtlichen Einordnung des Jugendschutzes unter das Recht der öffentlichen Fürsorge sprechen indes dafür, dass der Bundesgesetzgeber diesen Kompetenztitel grundsätzlich beanspruchen kann.

Fraglich ist, ob auch in der gegenwärtigen Situation, also bei einem Gesetz, dass auf inhaltsbeschränkende Maßnahmen im Internet ausgerichtet ist, dem Staat eine Berufungsmöglichkeit auf diesem Kompetenztitel zusteht. Hierfür spricht zunächst, dass die Bewahrung des Einzelnen vor sexueller Ausbeutung während der Produktion kinderpornographischer Angebote gerade das spezifische Bedürftigkeitsverhältnis eröffnet, dass über Maßnahmen die von der Kompetenznorm gedeckt sind, bekämpft werden soll. Zwar diente das Zugangserschwerungsgesetz beziehungsweise ein zukünftiges Löschgesetz nicht unmittelbar der Bekämpfung von sexueller Ausbeutung, jedoch kann nicht ausgeschlossen werden, dass die Maßnahmen langfristig zu einer Verringerung der Absatzzahlen und damit auch der Produktionszahlen führen und somit staatlichen Hilfsmaßnahmen vorbeugen. Auch unabhängig hiervon eröffnet der unmittelbare Zugriff auf das Internet mit dem Ziel der Herausnahme eines kinderpornographischen Inhaltes den „Bedürftigkeitscharakter“, welcher dem Anwendungsbereich der Regelungsmaterie der öffentlichen Fürsorge unterfällt: Denn die Herausnahme beziehungsweise die Unzugänglichkeit eines kinderpornographischen Webcontent ist gleichbedeutend mit der Verhinderung einer erneuten Stigmatisierung der dargestellten Kinder und der Einschränkung persönlichkeitsbeeinträchtigender Folgen, die von einer Rezeption des Inhalts ausgehen können. Folglich sollen diejenigen Folgen verhindert werden, die sich „erfahrungsgemäß schädigend auf die geistige und seelische Entwicklung der Jugendlichen und Kinder“ auswirken. ${ }^{1102}$ Mithin ist die der Zugangserschwerung zugrundeliegende Regelungsmaterie mit Lebenssachverhalten vergleichbar, die in ihren Kernelementen dem Bild der klassischen Fürsorge ent-

1099 BVerwGE 19, 94 (15); Zum Problem der Anwendung des Kompetenztitels Jugendschutz für gefahrenabwehrrechtliche Maßnahmen, Altenhain in: Roßnagel, Recht der Multimedia-Dienste, 2005, Teil 9 GjS Einl., Rn. 17 mwN.

1100 BVerwGE 19, 94 (96).

1101 Liesching, ZUM 2002, 868; Ory, ZUM 1986, 123 (126); Weides, NJW 1987, 224 (230); Beisel/Heinrich, NJW 1996, 491 (492); ausführlich zur Bundeskompetenz für den Jugendschutz, Taubert, Bundeskompetenz für Jugendschutz, 2003, S. 20 ff.; a.A. Bettermann, AöR 83 (1958), 91 (108 f.) iE. Wohl für Länderkompetenz, Reinwald, ZUM 2002, 119.

1102 BVerwGE 19, 94 (96). 
sprechen und somit nach ständiger Rechtsprechung des Bundesverfassungsgerichts den spezifischen Anwendungsbereich der Kompetenzzuweisung des Bundes aus Art. 74 Abs.1 Nr. 7 unterstehen. ${ }^{1103}$ Der Bundesgesetzgeber konnte damit zu Recht beim Erlass des Zugangserschwerungsgesetzes einen Kompetenztitel für die Schaffung des Zugangserschwerungsgesetzes beanspruchen und wird diesen auch bei der Einführung eines bundesgesetzlichen Löschgesetzes in Betracht ziehen können.

Hiergegen kann auch nicht vorgebracht werden, dass das Zugangserschwerungsgesetz zwar jugendschutzmotiviert erlassen wurde, es überdies aber auch Rechtsgüter der Allgemeinheit präventiv bewahren will und damit nicht ausschließlich dem Jugendschutz dient. Letzteres ist kein sachlicher Grund dafür, dem Gesetz die Berufung auf dem Kompetenztitel der öffentlichen Fürsorge zu versagen. Dem widerspricht bereits, dass es selten ein Gesetz geben wird, dass ausschließlich nur einen speziellen Rechtsgüterschutz verfolgt. Vielmehr werden die verfolgten Belange wohl überwiegend mehreren Individual- wie objektivrechtlichen Zielen zugeordnet werden können. In einem solchen Fall muss für die Kompetenzzuordnung explizit nach dem Schwerpunkt des gesetzlichen Charakters geurteilt werden. ${ }^{1104}$ Hier ist der Schwerpunkt, wie auch wiederholt vom Gesetzgeber selbst herausgestellt, vorrangig im Kampf „gegen die sexuelle Ausbeutung von Kindern“ über die „technische Sperrung“, die „einen wichtigen Beitrag" ${ }^{\prime 1105}$ dazu leistet, zu sehen und damit schwerpunktmäßig explizit in Belangen des Jugendschutzes zuzuordnen. Dementsprechend kam dem Bundesgesetzgeber für den Erlass des Zugangserschwerungsgesetzes grundsätzlich der Kompetenztitel des Jugendschutzes in spezieller Ausprägung der öffentlichen Fürsorge aus Art. 74 Abs. 1 Nr. 7 GG zu.

(bb) Einschränkung des Kompetenztitels wegen „Erforderlichkeit“

Der hier hergeleitete Kompetenztitel aus Art. 74 Abs. 1 Nr. 7 GG stellt einen in Art. 72 Abs. 2 GG genannten Gegenstand dar und untersteht demnach der Erforderlichkeitsklausel. ${ }^{1106}$ Danach darf der Bund die in Art. 72 Abs. 2 GG genann-

1103 IE. wohl auch Tinnefeld, DuD 2010, 15 (17), die allerdings auf eine bereits Herleitung und Begründung verzichtet. Andeutungsweise, dass die Kompetenz aus dem Recht der öffentlichen Fürsorge abgeleitet werden kann, iE aber ablehnend, Heckmann, Stellungnahme der Sachverständigen im Rechtsausschuss v. 8.11.2010, S. 15, abrufbar unter: http://www.bundestag.de/bundestag/ausschuesse17/a06/anhoerungen/archiv/03_Zugangsers chwerung/04_Stellungnahmen/Stellungnahme_Heckmann.pdf (zuletzt abgerufen 20.5.2012).

1104 BVerfGE 97, 228 (252); zur Auflösung von Kompetenzkonflikten Maunz in: Maunz/Dürig, Art. 74 GG, Rn. 7 ff.

1105 Begr. BT-Drs. 16/12850, S. 5.

1106 Teilweise auch als „Subsidiaritätsklausel“ verstanden, z.B. Seiler in: Epping/Hillgruber, Art. 72 GG, Rn. 9. 
ten Gegenstände der konkurrierenden Gesetzgebung nur regeln, „wenn und soweit die Herstellung gleichwertiger Lebensverhältnisse im Bundesgebiet oder die Wahrung der Rechts- oder Wirtschaftseinheit im gesamtstaatlichen Interesse eine bundesgesetzliche Regelung erforderlich macht.“ Art. 72 Abs. 2 GG regelt folglich unter welchen Voraussetzungen das Gesetzgebungsrecht des Bundes den Ländern vorgeht. Der Bund darf nur legislatorisch tätig werden, wenn mangels oder gerade wegen einer bestehenden Vielzahl landesrechtlicher Regelungen „eine Rechtszersplitterung mit problematischen Folgen (...), die im Interesse sowohl des Bundes als auch der Länder nicht hingenommen werden können“1107 drohe. Dies hatte der Gesetzgeber beim Erlass des Zugangserschwerungsgesetzes - auch wenn er sich auf den Kompetenztitel des Rechts der Wirtschaft berief, der aber gleichsam der Erforderlichkeitsklausel des Art. 72 Abs. 2 GG unterfällt - erkannt und innerhalb der Begründung herausgestellt, dass ihm das Gesetzgebungsrecht im Bereich der konkurrierenden Gesetzgebung deshalb zustehe: „weil die Wahrung der Rechts- und Wirtschaftseinheit im gesamtstaatlichen Interesse eine bundeseinheitliche Regelung erforderlich macht (Art. 72 Absatz 2 GG). “1108

Unter Rechtseinheit wird die „Gleichheit der rechtlichen Rahmenbedingungen für alle Rechtsunterworfenen“, die letztlich Rechtssicherheit für die Bürger bedeutet, verstanden. ${ }^{1109}$ Unter Wirtschaftseinheit hingegen, das Gelten „einheitlicher rechtlicher Rahmenbedingungen für die wirtschaftliche Betätigung im ganzen Bundesgebiet, die der Herstellung oder den Fortbestand der Funktionsfähigkeit des Wirtschaftsraums dienen“. 1110 Wahrung ist nicht nur auf einem Fortbestand, also geltungserhaltende Maßnahmen beschränkt, vielmehr ist der Begriff „dynamisch" zu verstehen und umfasst auch das erstmalige Aufbauen und Herstellen der notwendigen Rechts- und Wirtschaftseinheit. ${ }^{111}$

Nach der hier vertretenen Auffassung war der vom Gesetzgeber beanspruchte Wirtschaftsbezug bei der Materie des Zugangserschwerungsgesetzes jedoch explizit abzulehnen. ${ }^{1112}$ Daher wäre hier lediglich die Wahrung der Rechtseinheit denkbar, die eine bundesgesetzliche Regelung des Zugangserschwerungsgesetzes erforderlich i.S.d. Art. 72 Abs. 2 GG machte und auch in Bezug auf die Erforderlichkeit eines zukünftigen Löschgesetzes notwendig wird.

1107 BVerfGE 106, 62 (145); hierzu Seiler in: Epping/Hillgruber, GG, Art. 74 GG, Rn. 10, Pieroth in: Jarass/Pieroth, Art. 72 GG, Rn. 13. Im Bezug auf den Jugendschutz im Internet speziell Faber, Jugendschutz im Internet, 2005, S.108 f.

1108 BT-Drs. 16/12850, S. 6.

1109 Rybak/Hoffmann, NVwZ 1995, 230 (232); das aufgreifend Liescbing, ZUM 2002, 868 (874); Maunz in: Maunz/Dürig, Art. 74 GG, Rn. 23.

1110 BVerfGE 106, 62 (146); Schmebl, DöV 1996, 724 (727).

1111 Rybak/Hoffmann, NVwZ 1995, 230 (232); das aufgreifend Liesching, ZUM 2002, 868 (874).

1112 Zur Ablehnung des Wirtschaftsbezugs oben unter 4. Teil C. I. 1. a) . 
(cc) Mangelnde Erforderlichkeit wegen Bestehen eines Staatsvertrages?

Die Erforderlichkeit zur Wahrung der Rechtseinheit ist dann anzunehmen, wenn ohne eine bundesgesetzliche Regelung eine „Rechtszersplitterung mit problematischen Folgen" droht.1113 Dem kann vorliegend bereits entgegenhalten werden, dass über den JMStV ein Staatsvertrag in Kraft ist, der gerade die Materie der Sperrung und Löschung (hier Untersagung genannt) kinderpornographischer Angebote durch Diensteanbieter hinreichend regelt. Insofern wäre die hinter der Erforderlichkeitsklausel stehende verfassungsmäßige Intention einer Verhinderung der Rechtszersplitterung aufgrund der bereits bestehenden gleichwertigen Rechtsverhältnisse überhaupt nicht gegeben. ${ }^{1114}$ Dem widerspricht jedoch, dass eine landesrechtlich einheitliche Regelung im Sinne eines Staatsvertrages dann in der Lage wäre, die Gesetzgebungsbefugnisse des Bundesgesetzgebers systemwidrig zu beschränken: Der Bundesgesetzgeber wäre im Fall der konkurrierenden Gesetzgebung mit Erforderlichkeitsvorbehalt beim Vorliegen eines Staatsvertrages auf die Zustimmung zur Aufhebung desgleichen durch die Bundesländer angewiesen. ${ }^{1115}$ Forderungen nach einer Kopplung der Zustimmungspflicht der Bundesländer an die Erforderlichkeitsprüfung wurden aber bewusst bei der Neugestaltung des Art. 72 Abs. 2 GG im Rahmen der Föderalismusreform zurückgewiesen und sollten gerade keinen Einklang ins Grundgesetz finden. ${ }^{1116}$

Des Weiteren verhindert die länderübergreifende Ausgestaltung des Staatsvertrages nicht mit hinreichender Sicherheit, dass künftig die Bundesländer legislative Regelungen erlassen, die dann weit ab einer gesicherten bundeseinheitlichen Rechtsmaterie angesiedelt wären. ${ }^{1117}$ Schließlich sieht der JMStV in \26 Abs. 1 Satz 1 ein Kündigungsrecht der vertragschließenden Länder mit einer einjährigen Frist vor. Gemäß Satz 7 lässt die Kündigung eines Landes zwar das Vertragsverhältnis im Übrigen unberührt, jedoch verkürzt sich dadurch die Frist zur Kündigung für die anderen Bundesländer auf drei Monate. Damit kann bereits ein einzelnes Bundesland die bundeseinheitliche Rechtswirkung entfallen lassen und die Fortgeltung des Staatsvertrages für die übrigen Bundesländer zumindest mittelbar beeinflussen. ${ }^{1118}$ Auch gingen die im Zugangserschwerungsgesetz niedergelegten

1113 BVerfGE 106, 62 (145).

1114 So wohl Pieroth in: Jarass/Pieroth, Art. 72 GG, Rn. 18; D. Müller, RdJB 1994, 467 (468); Rohn/Sannwald, ZRP 1994, 65 (68). Zu Staatsverträgen allgemein, Knothe, ZRP 2010, 181. Im Zusammenhang mit der Hinterfragung der Kompetenz zum Jugendschutz hinterfragend iE aber ablehnend Liesching, ZUM 2002, 868 (874).

1115 Ebenso Liescbing, ZUM 2002, 868 (874) unter Bekräftigung der Aussage von Rybak/Hoffmann, NVwZ 1995, 230 (232). In die Richtung auch BVerfGE 106, 62 (151).

1116 Abschlussbericht der gemeinsamen Verfassungskommission zur Änderung des Grundgesetzes, BT-Drs. 12/6000, S. 33.

1117 In die Richtung auch Liesching, ZUM 2002, 868 (874).

1118 In die Richtung auch Liesching, ZUM 2002, 868 (874). 
Rechtswirkungen über die Vorgaben des Staatsvertrages hinaus, da es auf ein Gesamtkonzept ausgerichtet war und nicht nur eine einzige legislatorische aufsichtsrechtliche Maßnahme. Damit kann allein das Bestehen eines Staatsvertrages nicht als Argument gegen eine bundeseinheitlich erforderliche Regelung angeführt werden.

(dd) Mangelnde Erforderlichkeit wegen Zersplitterung der Kompetenzen?

Möglicherweise kann die Erforderlichkeit einer bundeseinheitlichen Regelung aus anderen Gründen abgesprochen werden. Ziel der Erforderlichkeitsklausel ist es Rechtssicherheit durch Rechtseinheit zu schaffen. ${ }^{1119}$ Damit verbirgt sich hinter dem Erforderlichkeitbedürfnis eine angedeutete Verhältnismäßigkeitsbetrachtung. ${ }^{1120}$ Die bundesgesetzliche Regelung ist nicht erforderlich, wenn sie nicht geeignet ist, die zur Voraussetzung gemachten Ziele - mithin die hinter der Rechtseinheit stehende Rechtssicherheit - zu erreichen. ${ }^{1121}$ Die Beantwortung der Frage nach einer entsprechenden Zielerreichung durch ein bundesrechtliches Zugangserschwerungs- beziehungsweise Löschgesetz kann nicht ohne eine kurze Betrachtung der Rechtshistorie erfolgen. Gegenwärtig finden sich sowohl landeswie auch bundesrechtliche Jugendschutznormen. So enthält beispielsweise der landesrechtliche JMStV gegenüber der gesetzlichen Sperrverpflichtung des Zugangserschwerungsgesetzes - zumindest in Bezug auf die Kinderpornographie ähnliche Eingriffsbefugnisse. ${ }^{1122}$ Darüber hinaus sind die landesrechtlichen Verbotstatbestände des $\int 4 \mathrm{JMStV}$ beinahe identisch mit den bundesrechtlichen Straftatbeständen des StGB. Diese Verteilung basiert auf einer Kompromisslösung zwischen Bund und Ländern. ${ }^{1123}$ Sie war gerade darauf ausgelegt, die bestehenden Missverständnisse im Kompetenzbereich des Jugendschutzes zu relativieren, die insbesondere aus dem technischen Fortschritt resultierten. ${ }^{1124}$ Infolge dessen wur-

1119 iE. wohl BVerfGE 106, 62 (145).

1120 Degenhart in: Sachs, Art. 72 GG, Rn. 10; Liesching, ZUM 2002, 868 (874); Pieroth in: Jarass/Pieroth, Art. 72 GG, Rn. 18.

1121 Pieroth in: Jarass/Pieroth, Art. 72 GG, Rn. 18; Oeter in: v. Mangoldt/Klein/Starck, Art. 72 GG, Rn. 86 ff.

1122 Die Eingriffsbefugnis nach \ 20 Abs. 4 JMStV iVm. \59 Abs. 4 RStV erlaubt es Sperrverpflichtungen gegen Zugangsanbieter zu erlassen, soweit ein Verstoß gegen die Verbotsvorschriften des JMStV vorliegt. Gegen den JMStV verstoßen gem. \ 4 Abs. 1 Nr. 10 JMStV gerade auf die strafrechtlichen absoluten Verbreitungsverbote Bezug nimmt, zum JMStV und seinen Regelungen vgl. oben 2. Teil A. III. 1. b) .

1123 Ausführlich Ukrow, Jugendschutzrecht, 2004, Rn. 30, 73.

1124 Hierzu ausführlich Ukrow, Jugendschutzrecht, 2004, Rn. 30, 73. Faber, Jugendschutz im Internet, 2005, S. 114; Stumpf, Jugendschutz oder Geschmackszensur, 2009, S. 84 ff.; insbesondere die vor Erlass des TMG notwendige Abgrenzung zwischen Tele- und Mediendiensten (Teledienste waren dem Bundesgesetzgeber; Mediendienste dem Landesgesetzgeber unterstellt) geriet immer 
de die Kompetenzverteilung in Bezug auf den Jugendschutz wie folgt geordnet: „Die Länder schaffen eine einheitliche Rechtsgrundlage für den materiellen Jugendschutz in den Online-Medien und vereinheitlichen die Aufsichtsstruktur", „Ziel ist es die Unüberschaubarkeit des geltenden materiellen Jugendschutzrechts und die Zersplitterung der Aufsichtsstruktur zu überwinden." "1125 Als Begründung wurde der unmittelbare Zusammenhang zwischen den Medieninhalten und deren rechtlichen Rahmenbedingungen angeführt: „Da die Regulierung der Medieninhalte bei den elektronischen Medien überwiegend in die Kompetenz der Länder fällt, liegt es nahe, auch den Jugendschutz in diesem Bereich durch die Länder regeln zu lassen“"1126 „Vor diesem Hintergrund haben sich die Regierungschefs der Länder und der Bundeskanzler darauf geeinigt, dass der Bund den Jugendschutz bei den Offline-Medien und den Jugendschutz außerhalb des Medienbereichs neu regelt“. „Neben dem Jugendschutz für Rundfunk (...) den auch bisher schon die Länder geregelt hatten, wird nunmehr der Jugendschutz für alle elektronischen Angebote [von den Ländern] erfasst, d.h. im Rundfunk sowie (...) Telemedien." "1127

Indes könnte eben diese Kompromisslösung der Erforderlichkeit einer bundeseinheitlichen Regelung widersprechen. Ein „Ansichreißen“ der Kompetenz für den Erlass des Zugangserschwerungsgesetzes wäre nämlich gleichbedeutend mit einer Abkehr von dem geltenden Kompromiss, da sich die Regelungen der Zugriffserschwerung auf den Jugendschutz im Offlinebereich beziehen sollten, was der Kompromisslösung zufolge in die Zuständigkeit der Länder fiele. Die hierdurch hervorgerufene Situation würde folglich zu einer von der Erforderlichkeitsklausel entgegenzuwirkenden Zersplitterung der Kompetenzen führen und damit gerade nicht wie gefordert der Rechtssicherheit dienen.

Jedoch wird man dem Bundesgesetzgeber bei der Erforderlichkeit einer bundeseinheitlichen Regelung zur Wahrung der Rechtseinheit eine weite Einschätzungsprärogative zugestehen müssen, die verfassungsgerichtlicher Kontrolle untersteht. ${ }^{1128}$ Allein ein interner Kompromiss zwischen Bund und Ländern, der keinerlei rechtsverbindliche Wirkungen nach außen entfaltet, wird kaum als Fall „evident fehlender Erforderlichkeit“ einzuordnen sein, der eine Überschreitung der Einschätzungsprärogative bedeuten würde. Vorliegend führt der Gesetzgeber

wieder in Kritik. Später wurde über eine Angleichung an den Begriff der Telemedien aufgehoben. Hierzu BT-Drs. 16/3078, S. 11.

1125 Begr. JuSchG, BT-Drs. 14/9013, S. 13.

1126 Begr. BT-Drs. 14/9013, S. 13.

1127 Begr. BT-Drs. 14/9013, S. 14.

1128 Hierfür plädieren auch Degenhart in: Sachs, Art. 72 GG, Rn. 15; Schmebl, DöV 1996, 724 (726); anerkennend auch Oeter in: v. Mangoldt/Klein/Starck, Art. 72 GG, Rn. 111. Grundlegend, BVerfGE 106, 62; im Bezug auf den Jugendschutz im Internet, Faber, Jugendschutz im Internet, 2005, S. 111 ff. 
an, dass eine Sperrung unter einer bundesgesetzlichen Regelung erforderlich erscheint, da hierdurch nicht nur „Ungleichbehandlungen der betroffenen Diensteanbieter" vermieden werden würden, sondern explizit die Globalität des Sperransatzes eine bundeseinheitliche Regelung fordert: „Besonders die Sperrung ausländischer Webseiten ist nicht an Grenzen der einzelnen Bundesländer gebunden und kann aus technischen Gründen auch nicht daran gebunden werden."1129 Soweit man hier mit dem Gesetzgeber auf die technische Seite und die internationale Wirkung der Sperrung beziehungsweise Löschung abstellt, wird man eine gewisse Notwendigkeit einer einheitlichen Regelung nicht absprechen können. Auch die durch den Sperr- und insbesondere Löschansatz notwendige länderübergreifende Interaktion, wie vorherige Konsultations- und Informationspflichten mit anderen Staaten, können über eine Bundesregelung mit der gleichzeitigen Zuständigkeit einer Bundesbehörde wohl besser umzusetzen sein, als die Vornahme über eine Landesbehörde.

Folglich wird man grundsätzlich dem Bundesgesetzgeber eine Kompetenz zum Erlass des Zugangserschwerungsgesetzes beziehungsweise zum Erlass eines zukünftigen Löschgesetzes auch unter dem Aspekt der Erforderlichkeit nach Art. 72. Abs. 2 iVm. Art. 74 Abs. 1 Nr. 7 GG zugestehen müssen.

\section{f) Ergebnis: Bundeskompetenz}

Der Bund kann sich auf den Kompetenztitel aus Art. 74 Abs. 1 Nr. 7 GG für dem Erlass des Zugangserschwerungsgesetzes berufen und wird diesen Kompetenztitel auch für ein etwaiges Löschgesetz beanspruchen können. Der Regelungsgegenstand untersteht dem Erforderlichkeitsvorbehalt des Art. 72 Abs. 2 GG. Eine Sonderregelung, wie sie der Gesetzgeber hier vorsah ist aber unter Berücksichtigung der weiten Einschätzungsprärogative als erforderlich zur Wahrung der Rechtseinheit anzusehen. Zwar widerspricht sich der Gesetzgeber hierbei seiner eigenen Kompromisslösung, wonach die Kompetenzverteilung für den Jugendschutz im Onlinebereich den Ländern unterstellt wird; allein aufgrund dieser rechtlich unverbindlichen Einigung kann dem Gesetzgeber eine „Wiederaufnahme“ seiner Kompetenz jedoch nicht verwehrt werden.

\section{Weitere formelle Probleme im Überblick: ZugErschwG und sein mangelhaftes Gesetzge- bungsverfahren}

Losgelöst von der Absicht ein Löschgesetz zu erlassen, wird nachfolgend das Gesetzgebungsverfahren des Zugangserschwerungsgesetzes kritisch begutachtet. Die Ausführung wird zeigen, dass nicht nur allgemeine Bedenken an der Verfassungsmäßigkeit eines inhaltsbeschränkenden Regulierungsansatzes im Internet ausschlaggebend für die Abkehr der Regierung vom Sperrkonzept waren, sondern

1129 BT-Drs. 16/12850, S. 6. 
dass gerade auch spezifische Fehler im Rahmen der gesamten gesetzlichen Entstehung letztlich zur Aufhebung führen mussten. Insbesondere wurden dem $\mathrm{Zu}$ gangserschwerungsgesetz Mängel im Rahmen seiner formalen Entstehungsgeschichte aufgrund wesentlicher Verstöße gegen Vorgaben der Geschäftsordnung des Bundestages (GOBT) vorgeworfen. Gerügt wurde zum einen die Nichtdurchführung einer erneuten Experten- und Sachverständigenanhörung zum überarbeiteten und in ein Spezialgesetz überführten Gesetzesentwurf, obgleich ein entsprechender Geschäftsordnungsantrag nach $\ 70$ Abs. 1 Satz 2 GOBT im federführenden Ausschuss für Wirtschaft und Technologie gestellt wurde. ${ }^{1130}$ Gleichzeitig zielte eine weitere Rüge darauf ab, dass das Zugangserschwerungsgesetz unter Verstoß gegen $\ 78$ GOBT zu Stande kam, da die Kreation des eigenständigen Gesetzes aus dem Gesetz zur Bekämpfung von Kinderpornographie in Kommunikationsnetzen nicht noch einmal einer ersten Lesung zugeführt, sondern das Spezialgesetz gleich in zweiter und dritter Lesung beraten und letztlich verkündet wurde. ${ }^{1131}$

a) Verstoß gegen Geschäftsordnung und Verfassungswidrigkeit

Allein aus dem Befund, dass das Zugangserschwerungsgesetz unter Verstoß gegen die Bestimmungen der $\int \$ 70$ sowie 81,82 GOBT zustande kam, kann noch kein Schluss auf dessen Verfassungswidrigkeit gezogen werden. Es ist anerkannt, dass es sich bei der Geschäftsordnung um rein innerorganisatorisches Recht handelt. ${ }^{1132}$ Folglich können parlamentarische Rechtsakte, die Rechtswirkungen gegenüber Dritten entfalten, nicht am „Maßstab des parlamentarischen Binnenrechts" gemessen und allein deshalb verworfen werden. ${ }^{1133}$ Vielmehr kann eine nachfolgende Beratung im Plenum einen vorangegangenen Geschäftsordnungsverstoß sogar heilen. ${ }^{1134}$ Freilich muss von diesem Verständnis dann eine Aus-

${ }^{1130}$ Hierzu BT-Drs. 16/13411, S. 11 f.; zu den entsprechenden Anträgen der Oppositionsparteien auf Durchführung einer erneuten Anhörung, Ausschussdrucksache 16 (9) 1616 sowie zuvor zwei Anträge auf Absetzung der Tagesordnung, Ausschussdrucksache 16 (9) 1614; 16 (9) 1615.

1131 Hierdrauf weist auch Spoenle, jurisAnwZert ITR 17/2009, Anm. 2 hin. So auch schon die vermeintliche Verfassungsbeschwerde von Jörg Tauss (Piratenparteien vormals SPD), die letztlich aber wegen der Verurteilung Tauss untergegangen ist. Hierzu zeit-online v. 2.7.2009 „Tauss klagt in Karlsruhe gegen netzsperren“ abrufbar unter: http://www.zeit.de/online/2009/28/taussinternet-sperre-verfassung (zuletzt abgerufen 20.5.2012).

1132 Klein in: Maunz/Dürig, Art. 40 GG, Rn. 34 ff.; Achterberg/Schulte in: v. Mangoldt/Klein/Starck, Art. 40 GG, Rn. 39; Brocker in: Epping/Hillgruber, Art. 40 GG, Rn. 29.

1133 Klein in: Maunz/Dürig, Art. 40 GG, Rn. 57; Molok in: Dreier, Art. 40 GG, Rn. 22; Pietzcker in: Schneider/Zeh, Parlamentsrecht und Parlamentspraxis, 1989, 』 10, Rn. 42; Brandner, NVwZ 2009, 211 (212); Frenzel, JuS 2010, 119 (120). Überblicksartig mit anschließender Kommentierung der $\iint 78$ ff. GOBT Masing in: v. Mangoldt/Klein/Starck, Art. 77 GG, Rn. 24 mwN.

1134 Heynckes, ZParl 2008, 459 (460). 
nahme gemacht werden, soweit mit dem Verstoß gegen die Geschäftsordnung gleichzeitig auch ein Verstoß gegen die Verfassung einhergeht. Wenn die Geschäftsordnungsvorschrift eine wesentliche Konkretisierung eines verfassungsrechtlichen Grundsatzes darstellt und dieser im Gesetzgebungsverfahren gänzlich verkannt wurde, kann eine Verfassungswidrigkeit des gesamten Gesetzes, ausgehend von einem Geschäftsordnungsverstoß, gefolgert werden. ${ }^{1135}$

\section{(aa) Mangelnde erste Lesung: Kein evidenter Verfassungsverstoß}

Unter Zugrundlegung dieses vom Bundesverfassungsgericht vorgegebenen Maßstabs war die Nichtdurchführung einer erneuten ersten Lesung vor Erlass des Zugangserschwerungsgesetzes lediglich als Verstoß gegen die Vorgaben der $\int S 78$ ff. GOBT, hingegen nicht als evidenter Verstoß gegen die Verfassung zu werten. Denn die Verabschiedung eines Gesetzes in drei Lesungen gehört nicht zu den „unabdingbaren Grundsätzen der demokratischen Ordnung "'1136 und auch gewohnheitsrechtlich eröffnet sich keine Notwendigkeit für die zwingende Einhaltung von drei Lesungen. ${ }^{1137}$ Vielmehr kommt es in der Praxis des Gesetzgebungsverfahrens immer wieder vor, dass Gesetzesentwürfe während der Phase der parlamentarischen Beratungen durch Änderungen des ursprünglichen Entwurfs ergänzt oder in sonstiger Weise modifiziert werden, ohne dass entsprechend die nochmalige Durchführung der ersten Lesung erfolge. ${ }^{1138}$ Nur wenn gerade aufgrund der Auslassung, die hinter den Lesungen stehenden Mitwirkungsrechte der Abgeordneten als Ausdruck der „repräsentativen Demokratie“ gänzlich missachtet würden, sei ein Verfassungsverstoß zu folgern. ${ }^{1139}$

1135 BVerfGE 1, 144 (151); BVerfGE 29, 221 (234), BVerfGE 31, 47 (53); BVerfGE 34, 9 (21 ff.); BVerfGE 44, 308 (313); erläuternd mit Bezügen zum Finanzmarktstabilisierungsgesetz Brandner, NVwZ 2009, 211 (212); ausführlich zum gesamten Bereich der Geschäftsordnung und ihrer Auswirkungen auf die Verfassung Heynckes, ZParl 2008, 459; überblicksartig mit anschließender Kommentierung der $\iint 78$ ff. GOBT Masing in: v. Mangoldt/Klein/Starck, Art. 77 GG, Rn. 24 mwN.

1136 BVerfGE 1, 144 (151); BVerfGE 29, 221 (234), darauf bezugnehmend auch SaarlVerfGH, NVwZ-RR 2006, 665 (666).

1137 Ausdrücklich BVerfGE 1, 144 (150); BVerfGE 29, 221 (234).

1138 Z.B während der Gesetzgebungsverfahrens zum Haushaltsbegleitgesetz 2004, BGBl. I 2004, S. 3076, hierzu Stellungnahme des wissenschaftlichen Beirats des Fachbereichs Steuern der Ernst \& Young AG zum Zustandekommen des Haushaltsbegleitgesetzes, BB 2004, 695; Gröpl, LKV 2004, 438. Verkürzt wurde etwa jüngst auch das Gesetzgebungsverfahren im Rahmen der Entstehung des Finanzmarktstabilisierungsgesetzes 2008, BGBl. I, 2008, S. 1982, dazu Brandner, NVwZ 2009, 211 (212).

1139 BVerfGE 29, 221 (235); BVerfGE 31, 47 (53); BVerfGE 34, 9 (21 ff.); BVerfGE 44, 308 (313); ausführlich zum gesamten Bereich der Geschäftsordnung und ihrer Auswirkungen auf die Verfassung Heynckes, ZParl 2008, 459; überblicksartig mit anschließender Kommentierung der \S 78 
Eine solche evidente Missachtung der Mitwirkungsrechte war im Rahmen des Zustandekommens des Zugangserschwerungsgesetzes nicht feststellen: So wurde der entsprechende Gesetzesvorschlag ordnungsgemäß von der Bundesregierung eingebracht und einer ersten Beratung zugeführt. Ferner wurde der Gesetzesentwurf anschließend an den federführenden Ausschuss für Wirtschaft und Technologie zugeleitet, in welchem, sowohl den Regierungs- wie auch den Oppositionsparteien die Möglichkeit zu Teil wurde in kommunikativen Austausch zu treten und die widerstreitenden Interessen im Dialog gegeneinander abzuwägen. ${ }^{1140}$ Ergänzt durch die Heranziehung und Veröffentlichung einer gutachterlichen Expertise wurde der Verhandlungsgegenstand auch in der Ausschussarbeit wissenschaftlich aufgearbeitet und dem Meinungsbildungsprozess unterstellt. Zwar unterlag das Zugangserschwerungsgesetz im Rahmen seines weiteren Werdegangs wesentlichen Veränderungen gegenüber der in den Ausschuss eingebrachten Fassung und wurde sogar in einen eigenständigen Rechtsrahmen überführt, die Veränderungen und Ergänzungen waren aber nicht etwa als einseitige Leistung der Regierungsparteien zu werten, sondern basierten auf einer Synopse, die gerade auf den Argumenten der vorangegangenen Ausschussarbeit fußte. Folglich waren auch die vorgenommenen Veränderungen als demokratisch legitimiert anzusehen, zumal in den anschließenden Beratungen (2. und 3. Lesung) gemäß $\iint 81,82$ GOBT über jede einzelne Bestimmung des Gesetzesentwurfs erneut abgestimmt und Änderungsanträge eingebracht werden konnten. Auch wenn damit die erste Lesung ausblieb, konnten in gleicher Weise auch in den nachfolgenden Lesungen die Mitwirkungsrechte der einzelnen Abgeordneten geltend gemacht werden und damit eine „Heilung“ des vorangegangenen GOBT-Verstoßes bewirken.

(bb) Versagung der Anhörung als Verfassungsverstoß

Ein Verfassungsverstoß liegt hingegen dadurch vor, dass keine erneute Anhörung im federführenden Ausschuss für Wirtschaft und Technologie nach $\int 70$ Abs. 1 GG GOBT durchgeführt wurde, obgleich ein Minderheitenquorum der Oppositionsparteien den entsprechenden Antrag gestellt hatte. ${ }^{1141}$

Das in \70 Abs. 1 GOBT verankerte Recht auf Durchführung einer Anhörung dient einer Stärkung der Minderheitenrechte im Parlament. Das Bundesver-

ff. GOBT Masing in: v. Mangoldt/Klein/Starck, Art. 77 GG, Rn. 24 mwN.IE. wohl Frenzel, JuS 2010, 119 (120). Zum Recht des Abgeordneten auf ,verhandeln” BVerfGE 40, 237 (249).

1140 BVerfGE 40, 237 (249).

1141 Antrag auf Durchführung einer erneuten Anhörung, Ausschussdrucksache 16 (9) 1616. Das Minderheitenquorum wurde mit einem Verweis auf die Einarbeitung der bereits innerhalb der ersten Anhörung geäußerten Bedenken in die neue Gesetzesfassung abgelehnt, BT-Drs. 16/13411, S. 11 f; im Ergebnis wohl auch die Argumentation von AK Zensur, Pressemitteilung vom 23.2.2011 abrufbar unter:

http://ak-zensur.de/2011/02/verfassungsbeschwerde.html (zuletzt abgerufen 20.5.2012). 
fassungsgericht selbst misst dem Minderheitenschutz eine tragende Rolle im Rahmen der demokratischen Ordnung zu: „Das Gebot, parlamentarische Minderheiten zu schützen, sowie das Recht auf verfassungsmäßige Bildung und Ausübung der Opposition wurzeln im demokratischen Prinzip (Art. 20 Abs. 1 und 2; vgl. BVerfGE 2, 1 [13]; 44, 308 [321])."1142 Der Minderheit wird daher explizit auch ein Initiativrecht zugebilligt, welches ihr eine umfassende Beteiligung am politischen Willensbildungsprozess garantiert. ${ }^{1143}$ Anhörungen als Ausdruck dieses Initiativrechts sind dabei jedoch nicht als „Selbstzweck“" anzusehen, bei denen es darum geht formal Minderheitenrechte $\mathrm{zu}$ wahren, ${ }^{1144}$ vielmehr dienen sie dazu auch der Regierungspartei die Möglichkeit zu geben, sich über den Gesetzesentwurf zusätzliche Informationen einzuholen und die einzelnen Vorschriften mittels „,externen Sachverstand“ überprüfen zu lassen. ${ }^{1145}$

Die über das Recht der Anhörung verfolgten Abgeordnetenrechte finden ihre direkte Legitimation in Art. 38 GG i.V.m. Art. 20 GG. Wesentlicher Pfeiler der Demokratie ist es danach, dem einzelnen Abgeordneten ein Recht auf umfassende Information zu gewähren. ${ }^{1146}$ Dem Abgeordneten wird daher nicht nur ein Recht auf „Beschließen“ sondern eben auch ein Recht auf „Verhandeln“ bei der Mandatsausübung zugebilligt. ${ }^{1147}$ Unter Zugrundlegung dieser Intention wird man aus den Anhörungsrechten regelmäßig auch eine Anhörungspflicht herauslesen müssen, da anderenfalls die darin konkretisierten verfassungsrechtlichen Garantien in Folge einer Ablehnung der begehrten Anhörung völlig unterlaufen werden könnten. ${ }^{1148}$

Im Rahmen des Zugangserschwerungsgesetzes wurde eine Anhörung von der Bundesregierung zwar abgelehnt, es lag aber die Besonderheit vor, dass bereits zuvor eine Anhörung mit ausführlicher Expertenexpertise im Ausschuss stattgefunden und der Gesetzesentwurf dort der politischen Diskussion zugänglich gemacht wurde.

Bei Anhörungsrechten ist es aber anerkannt, dass bei wesentlichen Veränderungen des Verhandlungsgegenstandes auch eine erneute Anhörung verlangt werden kann, ${ }^{1149}$ soweit anderenfalls die Minderheiten- und Abgeordnetenrechte völlig unterlaufen würden. ${ }^{1150}$

1142 BVerfGE 70, 324 (363).

1143 BVerfGE 80, 188 (218); BVerfGE 84, 304 (328).

1144 Heynckes, ZParl 2008, 458 (468).

$1145 \mathrm{Zu}$ alledem Heynckes, ZParl 2008, 458 (468) bezugnehmend auf Schwerin, Der Deutsche Bundestag als Geschäftsordnungsgeber, 1998, S. 226.

1146 In die Richtung BVerfGE 70, 234 (355) sowie iE. auch BVerfGE 84, 304 (324).

1147 BVerfGE 70, 324 (355).

1148 In die Richtung der Pflicht zur Anhörung Heynckes, ZParl 2008, 458 (471).

1149 Roll in: GOBT-Kommentar, $\ 70$ GOBT, Rn. 4.

1150 Heynckes, ZParl 2008, 459 (468, 471). 
Eine totale Ablehnung einer ordnungsgemäß durch die Minderheit beschlossenen Anhörung seitens der Bundesregierung - wie im Rahmen des Zugangserschwerungsgesetzes geschehen - stellt ein solches Unterlaufen der Minderheitenrechte dar. Den Parteien wird in diesem Fall keine mit der Sachverständigenanhörung im Ausschuss vergleichbare Möglichkeit eingeräumt über den veränderten Gesetzesentwurf zu debattierten und die wesentlichen Veränderungen erneut gutachterlich prüfen zu lassen. Anders als im Falle der mangelnden erneuten ersten Lesung kann an dieser Stelle nicht aus den über $\ 82$ GOBT eingeräumten Rechten, eine Art Heilung des vorherigen Verstoßes angenommen werden. Die Teilhaberechte im Plenum sind nämlich in ihrer Wirkung nicht so weitgehend, wie der individuelle und mit dem notwendigen fachspezifischen Zusatzwissen der Experten zu belegene Diskussion in der Ausschussarbeit. Zum einen liegt es daran, dass die Beratung in den Ausschüssen wesentlich offener und ausführlicher als im Plenum des Bundestages stattfinden kann. ${ }^{1151}$ Zum anderen fördert der direkte Austausch mit den Sachverständigen eine fachkundige und offene Debatte und verlangt auch eine gewisse Einbringung des einzelnen Abgeordneten zu qualifizierten Fragestellungen, was im Rahmen der Plenumssitzung oftmals nicht vergleichbar angenommen werden kann. ${ }^{1152}$

Zwar widerlegte die Bundesregierung die Notwendigkeit einer erneuten Anhörung im Rahmen des Zugangserschwerungsgesetzes ausdrücklich mit dem Argument, die wesentlichen Bedenken, die in der Ausschussarbeit und Expertenanhörung geäußert wurden, seien in die neue Fassung eingearbeitet worden, ${ }^{1153}$ dieses

1151 So Klein in: Maunz/Dürig, Art. 40 GG, Rn. 127, der hier ergänzend noch die Anonymität der Ausschussarbeit als Argument anführt, entgegen der öffentlichen Sitzung im Plenum, könnten die Abgeordneten im Ausschuss auch mit „spontanen“ Äußerungen zu Wort melden, ohne vor der Öffentlichkeit „ihr Gesicht zu verlieren“. Dies kann vorliegend aber nicht angeführt werden, da die begehrte Anhörung gerade auf eine öffentliche Sitzung hinauslief.

1152 Heynckes, ZParl 2008, 458 (471).

1153 „Alle seien sich einig, dass man gegen Kinderpornographie vorgehen müsse. Durch das AccessBlocking soll der Zugang zu kinderpornographischen Internetseiten erschwert werden. In der Anhörung haben die Sachverständigen das Access-Blocking nicht in Frage gestellt, sie haben aber die Transparenz der Liste des BKA kritisiert. Diesen Bedenken, die auch die Internetcommunity teile, werde im Änderungsantrag Rechnung getragen. Dort werde geregelt, dass ein Expertengremium aus fünf Personen, mehrheitlich Richter, beim Bundesdatenschutzbeauftragten angesiedelt werden soll und die Liste des BKA einsehen soll. Dies führe zu einer Ex-postKontrolle der BKA-Liste. Die Stelle des Bundesbeauftragten für den Datenschutz und die Informationsfreiheit sei für diese Aufgabe in besonderem Maße qualifiziert. Der ebenfalls kritisierte abstrakte Verdacht sei im Änderungsantrag abgeschafft worden. Es werde auch keine strafrechtliche Verwendung der Daten aus der Umleitung auf den Stoppbereich geben. Der Grundsatz des Löschens vor der Sperrung werde betont. Im Bereich der EU müsse die Dienstleistungsrichtlinie beachtet werden. Die deutschen Behörden werden sich mit den entsprechenden 
kann aber nicht zu einer „Rechtfertigung“ der Ablehnung führen und dadurch die grundlegende Übergehung der Abgeordneten- und Minderheitenrechte und den damit einhergehenden Verfassungsverstoß heilen. Letztlich steht weder die Richtigkeit der Argumentation der Bundesregierung fest, ${ }^{1154}$ noch vermag sie etwas an der Annahme ändern, dass das verfassungsrechtlich abgesicherte Informationsbedürfnis der Abgeordneten nicht hinreichend gewahrt und der Minderheit durch die Ablehnung der erneuten Anhörung hier gänzlich verwehrt wurde in eine erneuten politischen Analyse einzutreten.

(cc) Ergebnis: Geschäftsordnungsverstoß

Das Zugangserschwerungsgesetz kam unter Verstoß gegen die Geschäftsordnung zu Stande. Dabei ist der Verstoß gegen das dreimalige Lesungserfordernis ( $\mathbb{S} 78$ ff. GOBT) und der Missachtung des Anhörungsgesuchs des Minderheitenquorums ( $(\mathbb{S} 70$ Abs. 1 Satz 2$)$ zu unterscheiden. Während ersteres nur innerorganisatorisches Recht betraf, dass keine Rechtswirkungen auf ein gegenüber Dritten wirkendes Gesetz entfaltete, führt die grundlose Ablehnung des Anhörungsbeschlusses der Minderheit durchaus dazu, die Verfassungskonformität des Zugangserschwerungsgesetzes zu hinterfragen. Denn hierdurch umging die Regierung wesentliche Verfassungsprinzipien, die ihre unmittelbare Konkretisierung in den Anhörungsrechten der GOBT erhalten. Dabei darf der Regierung nicht einfach zugebilligt werden eigenmächtig zu entscheiden, ob die vorgebrachten Argumente tatsächlich in den veränderten Gesetzesentwurf eingeflossen sind. Vielmehr würde eine solche Ansicht die Minderheitenrechte völlig unterwandern können und kann auch rechtsstaatlichen Aspekten nicht hingenommen werden. Zusammenfassend ist festzustellen, dass die formelle Verfassungsmäßigkeit aufgrund der mangelnden Anhörung in der Tat bedenklich war.

\section{b) Fehlende Verwaltungskompetenz}

Unterstellt die Bundesregierung wolle einen an das Zugangserschwerungsgesetz angelehnten Löschansatz bei kinderpornographischen Inhalten verfolgen, stellt sich vergleichbar der Konstellation im Zugangserschwerungsgesetz die Frage, in

anderen Behörden in der EU zusammensetzen, um diesen Grundsatz durchzusetzen. Für die Nicht-EU-Länder sei das Access-Blocking erste Wahl. Es werde klargestellt, dass nur kinderpornographische Seiten gesperrt werden. Zusätzlich werde das Gesetz auf drei Jahre begrenzt.“, BT-Drs. 16/13411, S. 11.

1154 Dies zeigt sich daraus, dass die nach dem Nichtanwendungsbeschluss eingeholten Sachverständigengutachten im Rechtsausschuss belegen, dass auch das Zugangserschwerungsgesetz wesentliche formelle und materielle Bedenken aufweist, Stellungnahmen im Rechtsausschuss abrufbar unter:

http://www.bundestag.de/bundestag/ausschuesse17/a06/anhoerungen/archiv/03_Zugangsers chwerung/04_Stellungnahmen/index.html (zuletzt abgerufen 20.5.2012). 
wie fern die Bundesregierung das BKA mit der Wahrnehmung inhaltsbeschränkender Maßnahmen betrauen kann. Voraussetzung für die Rechtmäßigkeit einer solchen Aufgabenzuweisung an das BKA wäre eine eigenständige im Grundgesetz angelegte Verwaltungskompetenz des Bundes. Soweit keine Spezialzuweisung vorliegt, unterfällt die Ausführung der Gesetze gemäß Art. 83 GG grundsätzlich dem Kompetenzbereich der Länder. Das Vorliegen einer etwaigen Kompetenzzuweisungsnorm wurde jedoch im Rahmen des Zugangserschwerungsgesetzes zunehmend bemängelt und auch deshalb eine formelle Verfassungswidrigkeit des Gesetzes gefolgert. ${ }^{1155}$ Derzeit scheint auch der präferierte Löschansatz im Koordinationsbereich des BKA angesiedelt zu sein. ${ }^{1156}$ Insofern dient die nachfolgende Analyse des Zugangserschwerungsgesetzes auch als Ausgangspunkt zukünftiger Gesetzesvorhaben und kann vergleichbar für ein etwaiges Löschgesetz herangezogen werden.

(aa) Zentralstelle nach Art. 87 Abs. 1 Satz 2 GG

Als speziellen Kompetenztitel benennt das Grundgesetz Art. 87 Abs.1 Satz 2 GG. Danach ist es dem Bund in bundeseigener Verwaltung gestattet, eine Zentralstelle für bestimmte sicherheitsrelevanten Aufgaben zu schaffen, wie das polizeiliche Auskunfts- und Nachrichtenwesen und für die Kriminalpolizei. ${ }^{1157}$

1155 U.a. Schnabel, JZ 2009, 996 (997); Stadler, MMR 2009, 581 (582); Spoenle, jurisAnwZert ITR 17/2009, Anm. 2; Heckmann, Stellungnahme der Sachverständigen im Rechtsausschuss v. 8.11.2010, S. 19, abrufbar unter: http://www.bundestag.de/bundestag/ausschuesse17/a06/anhoerungen/archiv/03_Zugangsers chwerung/04_Stellungnahmen/Stellungnahme_Heckmann.pdf; Bäcker, Ausschussdrucksache 16 (9) 1554, S. 4. Boecker, Stellungnahme der Sachverständigen im Rechtsausschuss v. 8.11.2011, abrufbar unter:

http://www.bundestag.de/bundestag/ausschuesse17/a06/anhoerungen/archiv/03_Zugangsers chwerung/04_Stellungnahmen/Stellungnahme_Boecker.pdf (jeweils zuletzt abgerufen 20.5.2012).

1156 So wurde das BKA schon im Nichtanwendungserlass verpflichtet auf die Löschung eines Angebotes hinzuwirken, zum Erlass 4. Teil C. III., auch weist der Aufhebungsentwurf zum auf die koordinative Tätigkeit des BKA bei der Löschung hin, BR-Drs. 319/11.

${ }^{1157}$ Der Bundesgesetzgeber schien diesen Kompetenztitel bei der Gesetzesinitiative des Zugangserschwerungsgesetzes im Sinn gehabt zu haben und verwies schon im Wortlaut des Vorgängergesetzes auf den Zentralstellencharakter des BKA bei der Errichtung einer Sperrliste. So hieß es in $\int 8$ a Abs. 1 Satz 1 TMG-E: „Im Rahmen seiner Aufgaben als Zentralstelle nach $\ 2$ des Bundeskriminalamtgesetzes führt das Bundeskriminalamt eine Liste über vollqualifizierte Domainnamen, Internetprotokoll-Adressen und Zieladressen von Telemedienangeboten, die Kinderpornographie nach $\int 184 \mathrm{~b}$ des Strafgesetzbuchs enthalten oder deren Zweck darin besteht, auf derartige Telemedienangebote zu verweisen (Sperrliste).“, BT-Drs. 16/12850, S. 3. 
Die Tätigkeitsbereiche der Zentralstellen für das polizeiliche Auskunfts- und Nachrichtenwesen und für die Kriminalpolizei sind gemäß \2 Abs. 1 BKAG im Bundeskriminalamt zusammengefasst. ${ }^{1158}$ Welche Aufgaben und Befugnisse einer Zentralstelle zur Wahrnehmung dieser Aufgaben im Einzelnen zugesprochen werden, ist umstritten. ${ }^{1159}$ Aus einer Zusammenschau des Art. 87 Abs. 1 Satz 2 GG mit der Norm des Art. 73 Abs. 1 Nr. 10 GG, auf der die materiell-rechtlichen Grundlagen der Zentralstellen beruhen, ${ }^{1160}$ ergibt sich, dass der Zentralstelle aufgrund der in Art. 73 Abs. 1 Nr. 10 GG zugesprochenen „Zusammenarbeit des Bundes und der Länder“ in erster Linie eine Art „Servicefunktion“ der in Art. 87 Abs. 1 Satz 2 GG benannten Behörden im Verhältnis zu Länderverwaltungen zukommt. ${ }^{1161}$ Die Tätigkeit der Zentralstelle erschöpft sich somit in rein koordinativen Tätigkeiten, ohne der Bundesbehörde inhaltlich erweiterte Befugnisse zu verleihen. ${ }^{1162}$ Insbesondere bei Maßnahmen mit Auslandsbezug, sollen über die Funktion der Zentralstelle eine Koordination zusammenlaufender Informationen und eine Unterstützung bei der Durchführung von Verwaltungsaufgaben erfolgen. ${ }^{1163}$

Allein von diesem Aspekt her betrachtet, erscheint die Annahme einer Bundesverwaltungskompetenz zur Betrauung des BKA mit der Unterbindung kinderpornographischer Inhalte im Internet gerechtfertigt, da es sich beim Internet schließlich um ein globales Kommunikationsnetz handelt, dass zwangsläufig von internationaler Bedeutung ist. Jedoch würde hier eine Anerkennung der Verwal-

1158 Gesetz über das Bundeskriminalamt und die Zusammenarbeit des Bundes und der Länder in kriminalpolizeilichen Angelegenheiten (Bundeskriminalamtgesetz - BKAG) v. 7.7.1997, BGBl. I 1997, S. 1650.

1159 Bäcker, Ausschussdrucksache 16 (9) 1554, S. 4. Zum Streitstand Burgi in: v. Mangoldt/Klein/Starck, Art. 87 GG, Rn. 46; Hermes in: Dreier, Art. 87 GG, Rn. 48; umstritten ist im Einzelnen, ob die Tätigkeit der Zentralstellen auch nach außen hin Wirkung entfaltet und ob daran anschließend auch ein Weisungsrecht gegenüber Landesbehörden zubilligt wird.

1160 Suerbaum in: Epping/Hillgruber, Art. 87 GG, Rn. 24; Hermes in: Dreier, Art. 87 GG, Rn. 47, hier „Koordinationsfunktion“ genannt, iE. aber keine Differenzierung zur Servicefunktion gewollt. Ebenfalls BVerfGE 110, 33 (51), Gusy, DVBl. 1993, 1117 (1120).

1161 So Suerbaum in: Epping/Hillgruber, Art. 87 GG, Rn. 24. Ausführliche Herleitung aus dem Verhältnis der beiden Verfassungsnomen zueinander Burgi in: v. Mangoldt/Klein/Starck, Art. 87 GG, Rn. 46; Hermes in: Dreier, Art. 87 GG, Rn. 47.

1162 Ausdrücklich Bäcker, Stellungnahme der Experten, Ausschussdrucksache, 16 (9) 1554, S. 4; darauf bezugnehmend darauf auch Schnabel, Stellungnahme der Sachverständigen im Rechtsausschuss v. 8.11.2010, abrufbar unter:

http://www.bundestag.de/bundestag/ausschuesse17/a06/anhoerungen/archiv/03_Zugangsers chwerung/04_Stellungnahmen/Stellungnahme_Schnabel.pdf (zuletzt abgerufen 20.5.2012).

1163 Lisken/Denninger in: Lisken/Denninger, Hdb. PolR, 2007, Teil C, Rn. 157; Hermes in: Dreier, Art. 87 GG, Rn. 47. 
tungskompetenz aus dem Zentralstellencharakter, den beschränkten inhaltlichen Befugnissen dergleichen zuwiderlaufen. Es ist anerkannt, dass aus Art. 87 Abs. 1 Satz 2 GG kein sachlicher Zuständigkeitsbereich folge, ${ }^{1164}$ das heißt dem Bund ist es nicht möglich, das BKA mit polizeilichen Befugnissen auszustatten, die unmittelbar außenwirksame Maßnahmen nach sich ziehen. ${ }^{1165}$ Zwar mag dem ausdrücklich die Regelung des $\int 4$ Abs. 1 BKAG entgegenstehen, die dem BKA durchaus auch die Wahrnehmung polizeilicher Aufgaben auf dem Gebiet der Strafverfolgung zuweist. Die Regelung muss aber, wie im Wortlaut angelegt, restriktiv ausgelegt und nur auf den repressiv-polizeilichen Bereich und dann auch nur unter Zugrundlegung klarer Befugnisabgrenzungen begrenzt werden. ${ }^{1166}$ Sie kann also nicht präventiv-polizeiliche Befugnisse, wie sie bei der Unterbindung kinderpornographischer Internetinhalte im Vordergrund stehen, betreffen. Gerade im gefahrenabwehrrechtlichen Bereich sind die Aufgaben des BKA nur auf reine Unterstützungshandlungen der kriminalpolizeilichen Arbeit anderer Behörden beschränkt.1167 Soweit man das BKA eigenständig mit einer gewissen Entscheidungsbefugnis hinsichtlich der Eingriffsmittel und der Eingriffsart bei der Unterbindung kinderpornographischer Webinhalte ausstattet, setzt man sich über diese verfassungsrechtlich vorgegebenen Grenzen hinweg und erweitert die Befugnisse unzulässig auf die inhaltlicher Ebene, was aber nicht mehr vom verfassungsrechtlichen Kompetenztitel des Art. 87 Abs. 1 Satz 2 GG gedeckt ist. ${ }^{1168}$

1164 Lisken/Denninger in: Lisken/Denninger, Hdb. PolR, 2007, Teil C, Rn. 157.

1165 Bäcker, Ausschussdrucksache, 16 (9) 1554, S. 4; der ergänzend darauf hinweise, dass die Präventivpolizeilichen Bereich nur bei der Terrorismusbekämpfung auch dem BKA als Zentralstelle zugewiesen werden kann, bei der Sachmeterie des Zugangserschwerungsgesetzes liegt eine solche Konstellation aber gerade nicht vor; Sachs in: Sachs, Art. 87 GG, Rn. 45; Hermes in: Dreier, Art. 87 GG, Rn. 48.

1166 Bäcker, Ausschussdrucksache 16 (9), 1554 S. 4.

1167 Bäcker, Ausschussdrucksache 16 (9), 1554 S. 4, darauf Bezugnehmend Schnabel, JZ 2009, 994 (997); klar die Zentralstellenfunktion des BKA im Rahmen des ZugErschwG ablehnend, Volkmann in: Spindler/Schuster, Recht der elektronischen Medien, 2011, Vorb., Rn. 1, ebenso Schnabel, MMR 2009, 581 (582); Spoenle, jurisAnwZert ITR 17/2009, Anm. 2; Heckmann, Stellungnahme der Sachverständigen im Rechtsausschuss, S. 20, abrufbar unter: abrufbar unter: http://www.bundestag.de/bundestag/ausschuesse17/a06/anhoerungen/archiv/03_Zugangsers chwerung/04_Stellungnahmen/Stellungnahme_Heckmann.pdf (zuletzt abgerufen 20.5.2012).

1168 Anscheinend erkannte dies auch der Bundesgesetzgeber. Im Rahmen des neuen $\ 1$ Abs. $1 \mathrm{Zu}$ gErschwG, der die äquivalente Norm zum vormaligen $\ 8 \mathrm{a}$ Abs. 1 TMG-E darstellte, war der Zentralstellencharakter des BKA bei der Befugnis zur Erstellung der Sperrliste explizit herausgenommen worden, weil „das Bundeskriminalamt weitere über die Zentralstellenfunktion hinausgehende gesetzliche Aufgaben wahrnimmt. Das Bundeskriminalamt kann Informationen über kinderpornographische Angebote erhalten, diese für die Sperrliste verwerten und diese Dritten mitteilen.“ 
(bb) Generalklausel für die Bundesverwaltungskompetenz Art. 87 Abs. 3 GG Da eine Verwaltungskompetenz für die Zuständigkeit des BKA aufgrund des Art. 87 Abs. 1 Satz 2 GG ausscheidet, liegt die Herleitung einer Verwaltungskompetenz über die Generalklausel ${ }^{1169}$ des Art. 87 Abs. 3 GG nahe. Art. 87 Abs. 3 Satz 1 begründet eine fakultative Bundesverwaltungskompetenz für alle Sachbereiche, die der Gesetzgebungskompetenz des Bundes unterfallen. ${ }^{1170}$ Die Bundesverwaltungskompetenz unterliegt damit dem Vorbehalt des Bundesgesetzes. ${ }^{1171}$ Art. 87 Abs. 3 GG bildet folglich eine Ausnahme zu der in Art. 83 GG normierten grundsätzlichen Trennung von Gesetzgebungs- und Verwaltungskompetenzen. ${ }^{1172}$ Nach der hier vertretenen Ansicht kann eine Bundeskompetenz für den Erlass eines Gesetzes mit der Zielrichtung der Unterbindung kinderpornographischer Internetinhalte aus Art. 74 Abs. 1 Nr. 7 GG - dem Jugendschutz als Ausdruck des Rechts der öffentlichen Fürsorge - hergeleitet werden. ${ }^{1173}$ Grundsätzlich steht es dem Bundesgesetzgeber damit frei, anhand dieser Kompetenzzuweisung auch eine selbstständige Bundesbehörde zu errichten, die sich mit der Ausführung der unter die Bundeskompetenz fallenden Angelegenheiten befasst. Angesichts mangelnder wortlautspezifischer Begrenzung eröffnet die Ermächtigung des Art. 87 Abs. 3 GG eine weite Möglichkeit der Durchsetzung von Bundesverwaltung, ist damit auch denkbarer Ausgangspunkt für die Betrauung des BKA mit Aufgaben rund um die Sperrung und Löschung von kinderpornographischer Inhalte. Als inhaltliche Begrenzung erlaubt sie alle Tätigkeiten, soweit diese „materienbezogen“ im Zusammenhang mit der Bundeskompetenz stehen. ${ }^{1174}$ Es muss sich also um eine Materie handeln, die zumindest geeignet ist, für das ganze Bundesgebiet zentral und ohne Inanspruchnahme von Verwaltungsbehörden der Länder wahrgenom-

1169 Begriff begründet von Köttgen, AöR 90 (1965), 205 (224); übernommen von Burgi in: v. Mangoldt/Klein/Starck, Art. 87 GG, Rn. 105; Becker, Öffentliche Verwaltung, 1989, S. 179; Hermes in: Dreier, Art. 87 GG, Rn. 65.

1170 Hermes in: Dreier, Art. 87 GG, Rn. 65; zum Begriff der fakultativen Verwaltungskompetenz Burgi in: v. Mangoldt/Klein/Starck, Art. 86 GG, Rn. 14, 16 sowie Art. 87 GG, Rn. 104; Lerche in: Maunz/Dürig, Art. 87 GG, Rn. 165. Fakultative Verwaltungskompetenzen sind danach dadurch gekennzeichnet, dass nach Maßgabe anderer Normen ,zugelassen“ ist, dass sich der Bund der betreffenden verwaltungsmäßigen Materie annimmt. Zu Unterscheiden sind hiervon sog. obligatorische Verwaltungskompetenzen, bei denen wird nicht per Gesetz die die Bundesverwaltung zugelassen, sondern im Sinne des Art. 83 Hs. 2 GG ,bestimmt“ dass der Bund zuständig ist.

1171 Burgi in: v. Mangoldt/Klein/Starck, GG, Art. 87 GG, Rn. 105.

1172 Hermes in: Dreier, Art. 87 GG, Rn. 66 sowie Art. 83 GG, Rn. 66; Lerche in: Maunz/Dürig, Art. 87 GG, Rn. 166; Böckenförde, Organisationsgewalt, 1998, S. 218 f.

1173 Hierzu ausführlich 4. Teil C. I. 1. e) .

${ }^{1174}$ Lerche in: Maunz/Dürig, Art. 87 GG, Rn. 178; ähnlich Hermes in: Dreier, Art. 87 GG, Rn. 68; Welz, Ressortverantwortung, 1988, S. 100. 
men zu werden. ${ }^{1175}$ Im Unterschied zur bloß koordinativen Tätigkeit der Zentralstelle, darf die selbstständige Bundesbehörde die gesamte Organisationsstruktur, folglich eigenständig alle sachlichen, personellen und aufgabenmäßigen Aufteilungen der Behörde regeln, soweit dies die Durchsetzung der ihr zugrundliegenden Rechtsmaterie verlangt. ${ }^{1176}$

Die Durchsuchung des Internets nach kinderpornographischen Inhalten, genauso wie das Zusammenführen von Informationen die zur Anbieterermittlung kinderpornographischer Angebote führen können sowie die Kooperation mit anderen Staaten um eine Löschung der Angebote zu bewirken, stellt im Wesentlichen eine solche Materie, die zentral wahrgenommen werden kann, dar. Hierfür spricht zunächst der globale Charakter des Internets. Das BKA ist im Rahmen seiner Zentralstellenfunktion im Kampf gegen Kinderpornographie bisweilen ohnehin international tätig und damit betraut Informationen zusammenzufügen. ${ }^{1177}$ Die Erstellung einer Informationszusammenschau allein für den Bereich der kinderpornographischen Angebote erscheint zumindest nicht völlig am sonstigen Tätigkeitsfeld des BKA vorbeizugehen. Die bisweilen präferierte internationale Ausrichtung des BKA ${ }^{1178}$ kann auch im Zusammenhang mit dieser zusätzlichen Aufgabenerfüllung förderlich sein. So fungiert das BKA auch ohne, dass eine gesetzliche Normierung vorliegt, bereits grenzübergreifend als Koordinationsstelle für die Zusammenführung von Informationen über mögliche Täter und Opfer kinderpornographischer Produktionen und hat auch bezüglich der internetbasierten Verbreitung bereits ein weites Spektrum an Handlungs- und Auskunftsmechanismen errichtet, die auf eine internationale Herausnahme der Inhalte aus dem Gesamtbestand des Internets ausgerichtet sind. ${ }^{1179}$ Zudem ist dieser Aufgabenbereich der Realisierung des Jugendschutzes zugeordnet und daher im unmittelbaren Zusammenhang zur bundesgesetzlichen normierten Regelungsmaterie zu sehen. Effektive Löschbemühungen sind daneben auch eine Tätigkeit, die nicht notwendigerweise auf die Zuhilfenahme anderer Länderbehörden angewiesen ist. Das

1175 BVerfGE 14, 197 (211); BVerfGE 110, 33 (49); BVerwG, DöV 2006, 116 (120); Hermes in: Dreier, Art.87 GG, Rn. 87; Henneke in: Schmidt-Bleibtreu/Hofmann/Hopfauf, Art. 87 GG, Rn. 8; Sachs in: Sachs, Art. 87 GG, Rn. 65. Abzulehnen ist die Zentrale Struktur etwa, wenn die Aufgabenwahrnehmung nicht ohne Amtshilfe von Landesbehörden erfolgen kann. Unschädlich ist hingegen, wenn die Aufgabenwahrnehmung notwendigerweise die Zusammenarbeit mit anderen Bundesbehörden voraussetzt, dazu BVerfGE 110, 33 (49); BVerwGE 124, 47 (68); BVerwG, NVwZ 2007, 88; Schewerda, Verteilung der Verwaltungskompetenzen, 2008, S. 122.

1176 Burgi in: v. Mangoldt/Klein/Starck, Art. 87 GG, Rn. 115; Lerche in: Maunz/Dürig, Art. 87 GG, Rn. 175 ff.

1177 Zum Aktionismus des BKA im Bezug auf die Verfolgung von Kinderpornographie im Internet oben 2. Teil A. III. 2. .

$1178 \mathrm{Zu}$ den Befugnissen des BKA im internationalen Bereich, \14 BKAG.

1179 BKA, Ausschussdrucksache 16 (9) 1548, S. 6 ff. 
BKA kann aber zur besseren Durchsetzung des verfolgten Zwecks aufgrund der Fülle der im Internet verbreiteten Seiten auch auf die Informationen zum Bestand kinderpornographischer Inhalte über Dritte, wie beispielsweise andere Landesbehörden, Private sowie Jugendschutzeinrichtungen zurückgreifen. Die bloße Möglichkeit der Einbindung Dritter führt indes nicht dazu, dem BKA die zentrale Eignung zur bundesgesetzlichen Aufgabenerfüllung abzusprechen. Unter Zugrundelegung dieser Aspekte ist Art. 87 Abs. 3 Satz 1 GG damit als Ausgangspunkt der Verwaltungskompetenz denkbar.

Art. 87 Abs. 3 Satz 1 GG setzt aber einschränkend die Errichtung der Bundesbehörde „durch Bundesgesetz“ voraus. Folglich bedarf es zur Betrauung mit inhaltlichen Aufgaben eines formellen Errichtungsaktes. Für die nähere Ausgestaltung des Errichtungsaktes ist es notwendig, dass „das Bundesgesetz mindestens die nach Art. 30 und 83 GG eigentlich von den Ländern wahrzunehmende Verwaltungsaufgabe, die nunmehr durch den Bund wahrgenommen werden soll, klar benennt und inhaltlich umschreibt." 1180 Unter Beachtung dieser Anforderungen dürfte es möglich sein, durch die bloße Aufnahme der neuen Aufgabe in den Gesetzestext, d.h. der Unterbindung kinderpornographischer Inhalte im Internet durch das BKA, gleichzeitig auch die Zuweisung der Verwaltungskompetenz zu erkennen, mithin den notwendigen Errichtungsakt. Die Bestimmung des Aufgabenbereichs muss dann aber klar und inhaltlich eng umrissen sein und die thematische Richtung der „neuen“ Aufgaben des BKA klar und verständlich vorgeben.

Gegen eine Verwaltungskompetenz im Sinne des Art. 87 Abs. 3 GG kann indes auch nicht der Umstand angeführt werden, dass das BKA bereits als Zentralstelle nach Art. 87 Abs. 1 Satz 2 GG fungiert. ${ }^{1181}$ Allein die Tatsache, dass eine Verwaltungskompetenz schon anderweitig zugewiesen ist, widerspricht nicht der Möglichkeit einer Errichtung nach Art. 87 Abs. 3 GG. ${ }^{1182}$ Vielmehr ist es zulässig auch neue Aufgaben an bereits bestehende Bundesbehörden zu übertragen. ${ }^{1183}$ Freilich mag man dieser Annahme entgegenhalten, dass es dem Bund damit zugestanden wird, eigenständig die Regelung der ausnahmsweisen Bundesverwaltung des Art. 83 GG zu unterlaufen, indem man beispielsweise eine Bundesbehörde, im Rahmen einer Zentralstelle nach Art. 87 Abs. 1 Satz 2 GG nicht mit über den koordinativen Bereich hinausgehenden Rechten betrauen kann, dies über die Errichtung einer selbstständigen Bundesbehörde nach Absatz 3 letztlich aber problemlos möglich wäre. Dies ist jedoch nur ein Argument nicht zwingend, denn die

1180 Hermes in Dreier, Art. 87 GG, Rn. 83.

1181 So aber Hermes in: Dreier, Art. 87 GG, Rn. 72. Wie hier BVerfGE 110, 33 (50 f.), dass ausdrücklich im Verhältnis zwischen Art. 87 Abs. 3 GG und Art. 87 Abs. 1 GG eine Subsidiarität ablehnt.

1182 Pieroth in: Jarass/Pieroth, Art. 87 GG, Rn. 13; Lerche in: Maunz/Dürig, Art. 87 GG, Rn. 175. Kritisch und iE. wohl ablehnend Hermes in: Dreier, Art. 87 GG, Rn. 72 ff.

1183 Pieroth in: Jarass/Pieroth, Art. 87 GG, Rn. 13; Lerche in: Maunz/Dürig, Art. 87 GG, Rn. 175. 
vermeintlich milderen Voraussetzungen des Absatzes 3, mithin die Errichtung einer selbstständigen Bundesbehörde, sind selbst wiederrum durch das Grundgesetz begrenzt, weil ausdrücklich das Bestehen einer Bundeskompetenz und die inhaltliche Ausrichtung an dieser gefordert wird. Dadurch wird gewährleistet, dass der Bundesgesetzgeber nicht „willkürlich“ etwaige Kompetenzen an sich reißen kann und den Grundsatz der grundsätzlichen Länderverwaltung des Art. 83 GG unterläuft. ${ }^{1184}$ Zudem kann nur dann hinreichend gewährleistet sein, dass die mit dem Gesetz bezweckte Aufgabenerfüllung bestmöglich wahrgenommen werden kann, wenn man dem Bundesgesetzgeber zubilligt, eine im Rahmen seiner Kompetenz erlassene Rechtsmaterie auch durch seine eigene Behörden durchsetzen zu können. Dies bestätigt auch das Bundesverfassungsgericht, obgleich es sich einer hinreichenden Erläuterung enthält. Jedoch merkt es in Bezug auf das Verhältnis der beiden Verfassungsnormen zueinander ausdrücklich an:1185 „Das Recht und die Pflicht zur Wahl einer sachgerechten Organisationsstruktur würden ohne hinreichenden Grund eingeengt, wenn die von der Antragstellerin im Einklang mit einem Teil der Literatur (vgl. Dittmann, Die Bundesverwaltung, 1983, S. 252 f.; Hermes, in: Dreier, Grundgesetz, Band III, 2000, Art. 87 Rn. 72; Lerche, in: Maunz/Dürig, Grundgesetz, Art. 87 Rn. 170, 175, Stand: Dezember 1992; Sachs, in: ders., Grundgesetz, 3. Aufl., 2003, Art. 87 Rn. 78)) behaupte Subsidiarität von Art. 87 Abs. 3 Satz 1 GG im Verhältnis zu Art. 87 Abs. 1 GG anzuerkennen wäre. Eine solche Einengung folgt auch nicht aus der Einleitung des Absatzes 3 durch das Wort „Außerdem“ (so aber etwa Lerche, a.a.O., Rn. 170). Dieses Wort knüpft an die in den beiden ersten Absätzen des Art. 87 GG aufgeführten Fälle bundeseigener Verwaltung an (vgl. BVerfGE 14, 197 [210].) Damit wird nicht zum Ausdruck gebracht, dass der Bund von der Ermächtigung des Absatzes 3 nur Gebrauch machen darf, wenn er keine anderen Möglichkeiten zur Einrichtung bundeseigener Behörden nicht hat. Zieht er im Interesse effektiver Aufgabenbewältigung die in Art. 87 Abs. 3 Satz 1 GG ermöglichte Organisationsform der nach Art. 87 Abs. 1 GG eröffneten vor, so ist dies verfassungsrechtlich nicht zu beanstanden. Der Bund musste sich daher nicht darauf beschränken, das Zollkriminalamt auf der Grundlage des Art. 87 Abs. 1 Satz 2 GG als Zentralstelle einzurichten. Dort, wo eine Zentralstelle im Hinblick darauf, dass diese im Wesentlichen auf die Wahrnehmung von Koordinationsaufgaben beschränkt ist, für die Erfüllung einer Aufgabe nicht ausreicht, darf der Bund unter den Voraussetzungen des Art. 87 Abs. 3 Satz 1 GG eine selbständige Bundesoberbehörde einrichten. " ${ }^{1186}$ Nach der hier in Anlehnung an das Bundesverfassungsgericht vertretenen Auffassung be-

1184 Zur Kompetenzrechtlichen Verdrängung des Art. 87 Abs. 1 GG durch Art. 87 Abs. 3 GG, Lerche in: Maunz/Dürig, Art. 87 GG, Rn. 170; Pieroth in: Jarass/Pieroth, Art. 87 GG, Rn. 13; Burgi in: v. Mangoldt/Klein/Starck, Art. 87 GG, Rn. 91.

1185 BVerfGE110, 33 (51).

1186 BVerfGE110, 33 (51). 
gründet der Umstand, dass das BKA bereits als Zentralstelle im Sinne des Art. 87 Abs. 1 Satz 2 GG fungiert, keinen Ausschluss der Zuweisung weiterer Aufgaben an das BKA. Folglich war schon die im Zugangserschwerungsgesetz angelegte Betrauung des BKA mit der zusätzlichen Aufgabe der Erstellung, Aktualisierung und Weiterleitung einer Sperrliste mit Identifikationskriterien von kinderpornographischen Webinhalten verfassungsrechtlich über Art. 87 Abs. 3 Satz 1 GG abgesichert und kann auch bei der Zuweisung von Aufgaben, die mit der Löschung solcher Angebote einhergehen, vergleichbar herangezogen werden. Unter dem Aspekt betrachtet war die formelle Verfassungsmäßigkeit des Gesetzes somit nicht anzugreifen.

\section{Ergebnis: Formelle Probleme}

Im Rahmen des Gesetzgebungsverfahrens zum Zugangserschwerungsgesetz bestanden tatsächlich „handwerkliche Mängel“. Entgegen einer weit vertretenen Ansicht, konnte das Zugangserschwerung aber auf den Kompetenztitel aus Art. 74 Abs. 1 Nr. 7 GG gestützt werden. Gleichzeitig stand dem Bundesgesetzgeber damit auch die Verwaltungskompetenz zu. Bei der Kreation eines eigenständigen Löschgesetzes hat der Bundesgesetzgeber hier lediglich zu beachten, dass die $\mathrm{Zu}$ weisung externer Aufgaben an das BKA zur Ausführung bundeseigener Verwaltung einen formellen Errichtungsakt voraussetzt, der aber vergleichbar dem $\mathrm{Zu}$ gangserschwerungsgesetz durch die bloße Aufnahme der Aufgabe in den Gesetzestext rechtsstaatlich leicht umzusetzen ist.

Schwerwiegender war hingegen die Ablehnung einer erneuten Anhörung, die von Minderheitenquorum im Gang des Gesetzgebungsverfahrens beschlossen wurde. Hierin liegt ein über die bloße binnenorganisatorische Geschäftsordnung hinausgehender Verfassungsverstoß, der die Abgeordneten- und Minderheitenrechte unzulässig beeinträchtigt.

\section{Materielle Probleme}

Nicht nur formelle Probleme waren in Bezug auf das Zugangserschwerungsgesetz immer wieder in den Fokus der politischen und gesellschaftlichen Debatte eingeflossen. Vielmehr wurden auch Bedenken an einer materiellen Vereinbarkeit der gesetzlichen Initiative mit der Verfassung geäußert. Verfassungsrechtlich ist ein Sperransatz jedoch zulässig, soweit er bestimmten Anforderungen genügt. Ob das Zugangserschwerungsgesetz diesen hinreichend Rechnung trug, soll nachfolgend erläutert werden. 
1. Entscheidungskompetenz der Access-Provider über die vorzunehmende Sperrmethode - verfassungsrechtlich tragbar?

a) Overblocking

Für die Verfassungsmäßigkeit des Sperransatzes wurde im Rahmen des dritten Teils der Bearbeitung eine verpflichtende Nennung der durch die Access-Provider vorzunehmenden technischen Sperrmethode gefordert, da je nach gewählter technischer Umsetzung die Intensität der Grundrechtsverletzung (OverblockingEffect) variieren kann und eine solche grundrechtssensible Entscheidung auch unter rechtsstaatlichen Aspekten nicht allein in der Entscheidungsgewalt der privaten Zugangsdiensteanbieter verbleiben darf. Das Zugangserschwerungsgesetz formulierte zwar nicht verpflichtend eine speziell vorzunehmende Sperrmethode, nannte über $\$ 2$ Abs. 2 jedoch: „Die Sperrung erfolgt mindestens auf der Ebene der vollqualifizierten Domainnamen, deren Auflösung in die zugehörigen Internetprotokoll-Adressen unterbleibt.“ Diese wortlautspezifisch angelegte Mindestvoraussetzung der DNS-Sperrmethode ist zutreffenderweise schon im Rahmen der Sachverständigenexpertise zum Vorgängergesetzentwurf, wie auch in einer späteren Sachverständigenbegutachtung, ${ }^{1187}$ welche nach Aussetzung des Gesetzes im Rahmen einer Rechtsausschusssitzung vorgelegt wurde, als verfassungsrechtlich nicht tragbar bezeichnet worden. Danach werde die offene Formulierung den vorzunehmenden „differenzierten Abwägungsprozessen nicht gerecht, wenn er die einfach durchzuführenden DNS-Sperrungen stets als zumutbar ansieht und als Mindestmaßnahme verlangt. Auch bei DNS-Sperrungen kann - vor allem für inhaltsreiche Domains und Subdomains mit zahlreichen Verzeichnissen - die Umsetzung der Sperrliste im Einzelfall schwierige Abwägungen erfordern und aus rechtlichen Gründen ausscheiden." 1188 Letztlich entspricht diese Aussage der obigen Herleitung in Bezug auf die grundrechtsspezifischen Berührungspunkte der Sperrmethode mit der Verfassung. Zwar führte der Gesetzgeber innerhalb der damaligen Begründung explizit aus: „Angesichts der rasanten Fortentwicklung der Technik erscheint es nicht zweckmäßig, den Zugangsvermittlern vorzugeben, wie die Sperrung technisch zu erfolgen hat. Vor diesem Hintergrund ist das Gesetz technologieneutral (...)“, „auf DNS-Ebene [liege] nach einhelliger Auffassung die geringste Eingriffstiefe. Den Diensteanbietern ist es jedoch unbenommen, sich für eine andere Sperrtechnik mit größerer Eingriffstiefe zu entscheiden." "1189 Diese gesetzgeberische Annahme entspricht jedoch nicht den tatsächlichen Gegebenhei-

1187 Sämtliche Stellungnahmen der Sachverständigen im Rechtsausschuss zur Sitzung vom 10.11.2010 einsehbar unter:

http://www.bundestag.de/bundestag/ausschuesse17/a06/anhoerungen/archiv/03_Zugangsers chwerung/04_Stellungnahmen/index.html (zuletzt abgerufen 20.5.2012).

1188 Sieber, Ausschussdrucksache 16 (9) 1559; Zusammenfassung, ders., JZ 2009, 653.

1189 BT-Drs. 16/12850, S. 6, 7. 
ten. Es kann eben nicht pauschal behauptet werden, welcher Sperrtechnik die geringste Eingriffstiefe zugrundeliegen würde, vielmehr ist zur tatsächlichen Bestimmung der Eingriffsintensität eine Unterscheidung zwischen den einzelnen Akteuren vorzunehmen. So kann die DNS-Methode für Anbieter, die bereits einen DNS-Server betreiben, in Bezug auf die Berufsausübungsfreiheit des Art. 12 Abs. 1 GG, als eine Methode mit „geringster Eingriffsintensität“ bezeichnet werden. ${ }^{1190}$ Betrachtet man hingegen die Wirkung der Methode auf den Nutzer, wird man das Ergebnis nicht ohne weiteres beibehalten können. Denn aufgrund der technischen Struktur des Internets wird unter einer Domain nicht zwangsläufig auch nur eine bestimmte Internetadresse $\mathrm{zu}$ finden sein, sondern unter der Hauptdomain auch viele andere Angebote lagern, die unter Subdomains gespeichert werden. ${ }^{1191}$ Aufgrund der unspezifisch und nicht punktuell wirkenden DNSSperre folgt ein massives Overblocking, dass starke negative Beeinträchtigungen der Informationsfreiheit aus Art. 5 Abs. 1 GG der Nutzer nachsichzieht. Fokussiert man die Betrachtung auf die Nutzer, wäre gerade die URL-ProxyFiltermethode als die Methode mit „geringster Eingriffsintensität“ zu verstehen. Diese grundrechtlich relevante Abwägungsentscheidung darf daher nicht allein in die Kompetenz der Access-Provider überstellt werden. Auch das BKA selbst wäre nach der hier vertretenen Auffassung nicht befugt, diese Entscheidung rechtsverbindlich vorzunehmen, sondern müsste die Wahl der Sperrmethode durch einen sachkundigen Richter zusätzlich überprüfen lassen. Wenn schon die bloße Überlassung der Abwägungsentscheidung nicht einmal dem BKA verfassungsrechtlich zu zugestehen ist, sondern aufgrund der Heimlichkeit und Eingriffsintensität im Verhältnis zum verfolgten Zweck auch verfahrensrechtliche Sicherungen wie ein expliziter Richtervorbehalt gefordert werden, dann kann die Überlassung der Entscheidung in die Kompetenz der Zugangsanbieter erst recht nicht als verfassungsrechtlich zulässig betrachtet werden.

b) Normbestimmtheit

Frey/Rudolph1192 wiesen in ihrem Gutachten ergänzend darauf hin, dass eine solche Formulierung auch in Anbetracht des verfassungsrechtlichen Grundprin-

1190 Hierzu Sieber/Nolde, Sperrverfügungen im Internet, 2008, S. 186.

1191 Oben 3. Teil B. I. 2. b) (bb). In die Richtung Frey/Rudolph, CR 2009, 644 (647), ausführlich Degen, Freiwillige Selbstkontrolle, 2007, S. 158; Semken in: Heermann/Ohly, Verantwortlichkeit im Netz, 2003, S. 9 (23); Sieber/Nolde, Sperrverfügungen im Internet, 2008, S. 186; Sieber, Ausschussdrucksache 16 (9) 1559, S. 10; zu „Nebenwirkungen“ des IP-Blocking, Stadler, Haftung für Informationen im Internet, 2005, Rn. 128.

1192 Frey/Rudolph, Ausschussdrucksache 16 (9) 1546, S. 5, zum Vorgängergesetzesentwurf des $\int 8$ a TMG-E; dies., Stellungnahme der Experten im Rechtsausschuss v. 7.11.2011, S. 4, abrufbar unter: http://www.bundestag.de/bundestag/ausschuesse17/a06/anhoerungen/archiv/03_Zugangsers 
zips der Normbestimmtheit ${ }^{1193}$ an ihre Grenzen traf. Der Gesetzestext gab zwar vor, anhand welcher Identifikationsmerkmale die Sperrliste vom BKA erstellt werden sollte, das Gesetz regelte aber nicht, ob die genannten Kategorien kumulativ oder einzeln zur Identifizierung eines inkriminierten Inhaltes vorliegen müssen und an die Access-Provider weitergeleitet würden. ${ }^{1194}$ In Wirklichkeit würden sich die Provider regelmäßig davon leiten lassen, diejenige Sperrmethode zu wählen, welche anhand der übermittelten Identifizierungsmerkmale am leichtesten zu implementieren ist. Würde das BKA beispielsweise nur die URL-Adresse der kinderpornographischen Webinhaltes weiterleiten, würde der Access-Provider, soweit er einen Proxy der auf URL Filterung ausgerichtet ist, besitzt, die URL Sperrmethode vornehmen, die wiederrum mit nur geringer grundrechtlicher Belastung verbunden ist. Erhält er als Identifikationsmerkmal jedoch eine IP-Adresse, würde er sich denkbarerweise keine „Mühe“ machen, die zugehörige URL oder Domain zur IP herauszubekommen, sondern würde anhand der IP-Adressierung entsprechend den Datenverkehr zur gelisteten IP unterdrücken. Eben die IP-Sperrmethode bedingt aber die größte Gefahr einer weitflächigen und von der rechtlichen Dimension des Inhaltes völlig losgelösten Sperrung. Die Unbestimmtheit der Formulierung war in der Folge nur schwer mit dem rechtsstaatlichen Bestimmtheitsgebot aus Art. 20 Abs. 3 GG vereinbar, da sich für den Normadressaten aus der Formulierung der gesetzlichen Regelung gerade nicht die rechtliche Konsequenz des Handelns kalkulieren ließ. ${ }^{1195}$

\section{c) Zwischenergebnis}

Insgesamt ist herauszustellen, dass die gesetzliche Formulierung der Sperrverpflichtung, welche die Entscheidungskompetenz für die Vornahme einer Sperrung bei den Access-Providern beließ, damit gegen rechtstaatliche Grundsätze verstieß und nicht in der Lage war, über die Erhebung der DNS-Sperre zur Mindestvoraussetzung die verfassungsrechtlichen Defizite auszugleichen.

chwerung/04_Stellungnahmen/Stellungnahme_Frey.pdf (zuletzt abgerufen 20.5.2012). Zusammenfassung dies., CR 2010, 644 (beide zum Zugangserschwerungsgesetz).

$1193 \mathrm{Zu}$ den Anforderungen einer gesetzlich formulierten Sperrverpflichtung an das Bestimmtheitserfordernis des Art. 20 GG, oben 3. Teil F. I. .

1194 Frey/Rudolph, Stellungnahme der Experten im Rechtsausschuss v. 7.11.2011, S. 8, abrufbar unter: http://www.bundestag.de/bundestag/ausschuesse17/a06/anhoerungen/archiv/03_Zugangsers chwerung/04_Stellungnahmen/Stellungnahme_Frey.pdf (zuletzt abgerufen 20.5.2012).

1195 BVerfGE 31, 255 (264); BVerfGE 83, 130 (145); BVerfGE 110, 33 (53); im Kontext zum Zugangserschwerungsgesetz Schnabel, JZ 2009, 994 (998); Spoenle, jurisAnwZert ITR 17/2009, Anm. 2; Kabl, SächsVBl. 2010, 180 (184); Sieber/Nolde, Sperrverfügungen im Internet, 2008, S. 173; Billmeier, Die Düsseldorfer Sperrungsverfügung, 2007, S. 138. 


\section{2. „Löschen vor Sperren“ ausreichend umgesetzt?}

a) Absicherung der Subsidiarität

Kernelement der Verfassungsverträglichkeit eines gesetzlichen Sperransatzes ist die begrenzte ultima-ratio Anwendbarkeit desselben. Aufgrund der breitflächigen Wirkung und mangelnden Zielgenauigkeit, sowie wegen der Inanspruchnahme der Access-Provider als Nichtstörer, sind Sperrungen nur als nachrangiges Mittel gegenüber der direkten Herausnahme des Inhaltes zulässig.. ${ }^{1196}$ Soweit eine Löschung möglich ist, ist diese aus Gründen der Verhältnismäßigkeit demnach primär heranzuziehen. In den Ausnahmefällen, in denen sich die Verantwortlichen nicht ermitteln lassen, beziehungswiese sich nach Ermittlung weigern eine Löschung des Angebotes vorzunehmen, muss dem Gesetzgeber zugebilligt werden, im rechtsstaatlich abgesicherten Rahmen, seinen Sperransatz zu verfolgen. Auch aus der Globalität der internetbasierten Verbreitung der Webinhalte ergeben sich ganz eigene Anforderungen an den Sperransatz: Ein Durchgriff inländischer Sperren auf Inhalte im Geltungsbereich der EU scheitert nicht von vorneherein am Herkunftslandprinzip, jedoch sind an die ausnahmsweise zugebilligte Durchgriffsmöglichkeit strenge Voraussetzungen zu stellen. So verlangt $\ 3$ Abs. 5 Satz 1, 2 TMG in dem Zusammenhang, dass inländische Maßnahmen, die unmittelbare Wirkung auf europäischem Staatsgebiet haben, einem speziellen Schutzziel, etwa der Verhütung, Ermittlung, Aufklärung und Vollstreckung von Straftaten einschließlich des Jugendschutzes dienen, verhältnismäßig in Hinblick auf die Erreichung dieses Ziels sind. Daneben müssen bestimmte prozedurale Anforderungen erfüllt sein, wie die Einhaltung eines vorangehenden Konsultations- und Informationsverfahrens. Der Mitgliedstaat des Sitzes des Diensteanbieters muss dementsprechend erfolglos aufgefordert worden sein, eigene Maßnahmen zu ergreifen. Zudem muss die Kommission den Mitgliedstaat des Sitzes des Diensteanbieters über die Absicht eigene Maßnahmen zu ergreifen in Kenntnis setzen. ${ }^{1197}$ Im Hinblick auf außereuropäische Inhalte ist zu verlangen, dass auch hier der subsidiäre Charakter der Sperrung nicht unterlaufen wird.

Fraglich ist, ob die erarbeiteten strengen Anforderungen an den Sperransatz im Rahmen der gesetzlichen Formulierung des Zugangserschwerungsgesetzes hinreichend eingehalten wurden. Schon auf den ersten Blick war gegenüber der Vorgängerfassung des $₫ 8 \mathrm{a}$ Abs. 1 TMG-E eine deutlichere Verbesserung im Bezug auf die Einhaltung der Anforderungen an die Erforderlichkeit erkennbar. Über $\int 1$ Abs. 2 und 3 ZugErschwG wurde ausdrücklich normiert, dass die Aufnahme in die Sperrliste und damit die Folge der Sperrverpflichtung nur greifen sollte, soweit zulässige Maßnahmen, die auf die Löschung des Angebotes abziel-

1196 Zum Herleitung der Geeignetheit des Sperransatzes oben 3. Teil B. I. 2. b) .

1197 Greiner, Die Verhinderung verbotener Internetinhalte, 2001, S. 179; Volkmann in: Spindler/Schuster, Recht der elektronischen Medien, 2011, \59 RStV, Rn. 13. 
ten, „,nicht oder nicht in angemessener Zeit erfolgsversprechend sind“. Die Formulierung lehnte damit sprachlich an die jugendmedienschutzrechtliche Generalklausel des $₫ 20$ Abs. 4 JMStV i.V.m. \59 Abs. 4 RStV, auf deren Grundlage inhaltsbeschränkende Maßnahmen stattfinden können, an und wurde als Konsequenz der vehementen Kritik im Ausschuss in die Gesetzesfassung eingearbeitet. ${ }^{1198}$ Auch die globalen Auswirkungen der Sperrung erkannte der Gesetzgeber und koppelte die gesetzliche Sperrverpflichtung im Geltungsbereich der EU im Wortlaut des Absatzes 2 Satz 2 ZugErschwG, an das Erfordernis der Einhaltung eines Konsultations- sowie Informationsverfahrens nach $₫ 3$ Absatz 5 Satz 2 TMG. In Bezug auf außereuropäische Inhalte ordnete Satz 3 an, dass Angebote sofort in die Sperrliste aufgenommen werden dürfen, „wenn nach Einschätzung des Bundeskriminalamts davon auszugehen ist, dass in dem betroffenen Staat andere Maßnahmen, insbesondere Mitteilungen an die für den polizeilichen Informationsaustausch zuständigen Stellen, nicht oder nicht in angemessener Zeit zu einer Löschung des Telemedienangebots führen.“

Auch wenn der Gesetzgeber hiermit darauf abzielte, die Verfassungsverträglichkeit des Gesetzes durch die Aufnahme des Grundsatzes „Löschen vor Sperren" zu gewährleisten, ${ }^{1199}$ konnte die gewählte Konzeption nur bedingt die Verfassungskonformität herstellen: Denn die von Verfassungswegen zu verankernde Notwendigkeit einer subsidiären Inanspruchnahme wurde durch die Formulierung "nicht in angemessener Zeit erfolgversprechend" vom Gesetzgeber selbst unterlaufen. Eine Maßnahme ist dann nicht erfolgversprechend, wenn eine vorangehende Prognose zu der plausiblen Einschätzung führt, dass sie keinen nennenswerten Erfolg zeigen werde. ${ }^{1200}$ Mit dieser Formulierung eröffnete der Gesetzgeber der handelnden Behörde die Möglichkeit, die Durchführung der Sperrung von einer subjektiven Entscheidung abhängig zu machen. Zudem bediente sich der Gesetzgeber hier des unbestimmten Rechtsbegriffs der angemessenen Zeit, ohne diesen näher zu erläutern und machte hierdurch die Norm auch in Bezug auf das Bestimmtheitserfordernis des Art. 20 GG angreifbar. ${ }^{1201}$ Die Kopplung der Zuläs-

1198 Volkmann in: Spindler/Schuster, Recht der elektronischen Medien, 2011, 1 ZugErschwG, Rn. 4.

1199 BT-Drs. 16/13411, S. 12.

1200 VG Düsseldorf, MMR 2005, 794 (797); Hartstein/Ring/Kreile/Dörr/Stettner, RStV, \59 RStV, Rn. 20; Volkmann in: Spindler/Schuster, Recht der elektronischen Medien, 2011, \59 RStV, Rn. 50; Zu dem Komplex auch Frey/Rudolph, Stellungnahme der Sachverständigen im Rechtsausschuss, S. 6 f., abrufbar unter:, abrufbar unter: http://www.bundestag.de/bundestag/ausschuesse17/a06/anhoerungen/archiv/03_Zugangsers chwerung/04_Stellungnahmen/Stellungnahme_Frey.pdf (zuletzt abgerufen 20.5.2012). Grds. zu Prognoseentscheidungen, BVerfGE 61, 1 (50); BVerfGE 50, 290 (333).

1201 Zu dem Komplex auch Frey/Rudolph, Stellungnahme der Sachverständigen im Rechtsausschuss, S. 6 f., abrufbar unter:, abrufbar unter: 
sigkeit der Sperrung an eine Prognoseentscheidung, war aber vor allem aufgrund des Verhältnismäßigkeitsgrundsatzes, der sich auch in der Anordnung einer subsidiären Inanspruchnahme des Nichtstörers widerspiegelt, nicht hinnehmbar. Eine Prognoseentscheidung beinhaltet die Möglichkeit von vorhergehenden Löschbemühungen abzusehen und ohne vorherigen Löschversuch die Maßnahme der Sperrung gegenüber den Access-Providern anzuordnen. Aufgrund der enormen Beschränkung legaler Inhalte und der demgegenüber nur bedingten Zweckerreichung im Kampf gegen internetverbreitete Kinderpornographie, muss die Löschung - als punktueller wirkendes Mittel - in jedem Fall zumindest versucht worden sein. Wegen dieser von Verfassungswegen notwendigen ultima ratioAusrichtung, hätte der Gesetzgeber auf die Formulierung „,nicht erfolgsversprechend" verzichten müssen.

Bezüglich außereuropäischer Angebote räumte der Gesetzgeber sogar in zweifacher Weise einen Prognosespielraum ein und sah die Möglichkeit der sofortigen Sperrung explizit im Gesetz vor. Zum einen wählte er auch hier die Formulierung einer „erfolgsversprechenden Maßnahme“, zum anderen wurde explizit auch die Möglichkeit eines subjektiven Beurteilungsspielraums, der ausdrücklich zur „sofortigen" Sperrung berechtige. Damit ist die Befürchtung naheliegend, dass die herkömmlichen Probleme einer internationalen Rechtsdurchsetzung zu einer „vorschnellen“ Prognose eines ineffektiven Löscherfolges und damit zu einer sofortigen Sperrung führen könnten. ${ }^{1202}$ In dem der Gesetzgeber ausdrücklich die Möglichkeit einer „sofortigen“ Sperrung bei Nicht-EU-Inhalten hervorhob, legte er schon im Wortlaut eine Differenzierungsmöglichkeit zwischen inner- und auBereuropäischen Angeboten an. Diese ist aufgrund des Grundsatzes der „Subsidiarität des Nichtstörer" gerade nicht gegeben. ${ }^{1203}$ Auch auf globaler Ebene muss stark auf die Nachrangigkeit eines Vorgehens gegen den Nichtverantwortlichen Access-Provider bestanden werden, da sonst die Verhältnismäßigkeit des gesamten Ansatzes bedroht ist.

Im Zugangserschwerungsgesetz verpflichtete der Gesetzgeber das BKA dazu, eine Liste mit „sperrungswürdigen“ Inhalten täglich an die Access-Provider weiterzuleiten. Die Kenntnisnahme der Sperrliste sollte die Sperrpflicht der Provider

http://www.bundestag.de/bundestag/ausschuesse17/a06/anhoerungen/archiv/03_Zugangsers chwerung/04_Stellungnahmen/Stellungnahme_Frey.pdf (zuletzt abgerufen 20.5.2012).

1202 Frey/Rudolph, Stellungnahme der Experten im Rechtsausschuss v. 7.11.2011, S. 8, abrufbar unter: http://www.bundestag.de/bundestag/ausschuesse17/a06/anhoerungen/archiv/03_Zugangsers chwerung/04_Stellungnahmen/Stellungnahme_Frey.pdf (zuletzt abgerufen 20.5.2012), die hier von einer ,schleppenden Behördenkommunikation“ sprechen, die dazu führen könnte, den Ansatz der Löschung nicht in Erwägung zu ziehen.

1203 In die Richtung auch Graf, Ausschussdrucksache 16 (9) 1555, S. 5. 
auslösen. ${ }^{1204}$ Eine tägliche Weiterleitungsverpflichtung ist jedoch nicht zwingend. Vielmehr muss die Sperrpflicht nur dann ausgelöst werden, wenn Löschversuche scheitern. Hierfür muss der Behörde ein Zeitraum vorgegeben werden, in welchem sie sich ab Kenntnisnahme des Angebotes intensiv um die Löschung bemüht. Erst wenn nach Ablauf der vorgegebenen Zeit eine Löschung nicht erreicht worden ist, hat die Behörde das jeweilige Angebot an die Provider zur Vornahme einer Sperrung weiterzuleiten.

Zusammenfassend ist insofern festzustellen, dass die Beachtung des Verhältnismäßigkeitsgrundsatzes zwar gegenüber dem Erstentwurf des Gesetzes durchaus positive Züge aufwies, bei näherer Betrachtung auch die neue Regelung nicht den verfassungsrechtlich gebotenen Vorgaben standhalten konnte.

\section{b) Lehren für ein Löschgesetz}

Für den Löschansatz kann aus den Problemen des Zugangserschwerungsgesetzes abgeleitet werden, dass der Gesetzgeber bemüht sein sollte eine fundierte Absicherung der Löschvariante herzustellen. Das heißt, die gesetzlich statuierte Löschung des Inhalts muss in Bezug auf die Normbestimmtheit klar und für den Rechtsanwender verständlich formuliert sein. Zur Sicherung der Verhältnismäßigkeit könnte hier dadurch erreicht werden, dass die Löschbemühungen nicht nur einer eigenständigen Stelle überlassen werden, sondern gesetzlich verpflichtend auch von externen Jugendschutzstellen Unterstützung erfahren sollen. Auf die Nachrangigkeit einer Sperrvariante muss auch innerhalb des Löschgesetzes aus verfassungsrechtlichen Aspekten nicht verzichtet werden. Allerdings muss der Anwendungsbereich der Sperrung auf ein Minimum begrenzt sein.

\section{Umleitung auf Stoppschild als wesentliches Merkmal des Gesetzes}

a) Stoppserver

Die Umleitung der Nutzeranfrage auf einen vordefinierten Stopp-Server ist in der verfassungsmäßigen Überprüfung eines gesetzlichen Sperransatzes strikt abgelehnt worden. ${ }^{1205}$ Durch eine an die Sperrmethode gekoppelte Umleitung der Nutzeranfrage auf eine Stopp-Seite, kann die gesamte Eignung des Sperransatzes in Abrede gestellt werden. Hierdurch wird auch der technisch nicht bewanderte Durchschnittsnutzer praktisch in die Richtung einer bestehenden Sperrmethode gelenkt, die es zu umgehen gilt. ${ }^{1206}$ Die Implementierung eines Stopp-Servers, der die Nutzeranfrage auf eine vordefinierte Seite umleitet, stellte entsprechend $\$ 4$ jedoch ein Grundelement des Zugangserschwerungsgesetzes dar. Danach sollten Access-

1204 Volkmann in: Spindler/Schuster, Recht der elektronischen Medien, 2011, \1 ZugErschwG, Rn. 3.

1205 Zur verfassungsmäßigen Analyse siehe 3. Teil .

1206 In die Richtung auch Sieber, Ausschussdrucksache 16 (9) 1559, S. 7. 
Provider „Nutzeranfragen, durch die in der Sperrliste aufgeführte Telemedienangebote abgerufen werden sollen, auf ein von ihnen betriebenes Telemedienangebot (Stoppmeldung)“ umleiten, „das die Nutzer über die Gründe der Sperrung sowie eine Kontaktmöglichkeit zum Bundeskriminalamt informiert.“

Die hinter der Implementierung eines Stopp-Servers stehende Intention kann als „Warn- und Abschreckfunktion“ umschrieben werden.1207 Zunächst setzt die Umleitung auf eine vordefinierte Sperr-Seite ein nach außen sichtbares Zeichen der gesellschaftlichen Ächtung von Kinderpornographie und statuiert neben der erschwerten Inaugenscheinnahme des kinderpornographischen Inhalts auch eine „Abschreckung“ des Nutzers vor dem Zugriff auf das Angebot.

In der Idealvorstellung mag die Sperrseite diese Effekte auslösen, in Wirklichkeit würde die Generierung eines Stoppseiten-Servers wahrscheinlich einen gegenteiligen Effekt aufweisen. Durch die virtuell aufgestellten Stopp-Schilder kann erst eine größere Aufmerksamkeit auf solche Webangebote gelenkt werden, die in der Weite des Internettraffic sonst leicht untergehen würden und trotz ihres Vorhandenseins völlig unbemerkt geblieben wären. ${ }^{1208}$ Zudem zeigen die obigen Ausführungen, dass nach dem heutigen Stand der Technik bei sämtlichen inhaltsbeschränkenden Maßnahmen, die sich auf die Zugriffsverhinderung zu bestimmten Webinhalten beziehen, Vollzugsdefizite und technische Hindernisse bestehen, die zwangsläufig Auswirkungen auf die Geeignetheitsbewertung der einzelnen Sperrmethoden haben. Letztlich basieren alle Sperransätze nicht auf einer Entfernung des Inhalts „an der Quelle“, sondern sind lediglich als eine Art „Sichtschutz“ konzipiert, indem sie dem einzelnen Nutzer den Zugriff auf bestimmte Seiten verwehren. ${ }^{1209}$ Soweit nicht nur ein Hinweis auf einen Verbindungsabbruch oder eine Unerreichbarkeit der angeforderten Webseite gesendet wird, sondern die Umleitung auf ein eigens vorgesehenes Stoppschild erfolgt, wird auch der technisch nicht versierte Internetuser, der gezielt nach kinderpornographischen Inhalten im Internet sucht, auf das Bestehen einer Sperrmaßnahme offenkundig hingewiesen und ihm somit die Möglichkeit eröffnet, sich detailliert mit der Umgehung dergleichen auseinanderzusetzten. Dann kann über die Zuhilfenahme von Suchmaschinen, Umgehungssoftware und Anonymisierungsdiensten leicht eine gängige Umgehungsmethode gefunden und auf die bestehende Sperrmaßnahme angewendet

1207 IE. Boecker, Stellungnahme der Sachverständigen im Rechtsausschuss v. 8.11.2010, S. 6, abrufbar unter:

http://www.bundestag.de/bundestag/ausschuesse17/a06/anhoerungen/archiv/03_Zugangsers chwerung/04_Stellungnahmen/Stellungnahme_Boecker.pdf (zuletzt abgerufen 20.5.2012); Stadler, MMR 2009, 581 (582); Sieber, JZ 2009, 653 (657).

1208 Boecker, Stellungnahme der Experten im Rechtsausschuss v. 8.11.2010, S. 6, abrufbar unter: http://www.bundestag.de/bundestag/ausschuesse17/a06/anhoerungen/archiv/03_Zugangsers chwerung/04_Stellungnahmen/Stellungnahme_Boecker.pdf (zuletzt abgerufen 20.5.2012).

1209 Sieber, Ausschussdrucksache 16 (9) 1559, S. 7. 
werden. ${ }^{1210}$ Was aber zwangsläufig die Wirksamkeit des Sperransatzes in Frage stellt. Zudem kann der explizite Hinweis auf die Unerreichbarkeit des angefragten Content auch bei dem zufälligen Zugriffsversuch auf einen kinderpornographischen Content einen „Neugiereffekt“ beim Nutzer auslösen, der ihn ebenfalls zur gezielten Suche nach einer Umgehungsmöglichkeit animiert. ${ }^{1211}$

Aus verfassungsrechtlicher Sicht muss demnach gelten: Je anonymisierter und der gesellschaftlichen Debatte entzogener ein gesetzlicher Sperransatz technisch durchgesetzt wird, umso förderlicher ist dies für die hinter der gesetzlichen Regelung stehende Intention, wie auch hinsichtlich einer verfassungsrechtlichen Überprüfung der Geeignetheit. ${ }^{1212}$ Dem kann auch nicht die positive Wirkung einer Umleitung auf die tangierte Informationsfreiheit des Nutzers aus Art. 5 Abs. 1 Satz 1, Alt. 2 GG entgegengehalten werden. Zwar würde es zu einer Aufhebung der Heimlichkeit der staatlichen Maßnahme im Nachhinein kommen, was in gewisser Weise einen positiven Effekt auf die Einschränkung der Informationsfreiheit hätte, jedoch würde dann die gesamte Eignung des Sperransatzes und damit auch dessen Anwendbarkeit bei fehlgeschlagener Löschung hinterfragt werden müssen. Wenn ausnahmsweise eine Löschung des Angebotes nicht in Betracht käme, weil die verantwortlichen Betreiber nicht zu ermitteln sind oder sich schlicht weigern die Löschung vorzunehmen, bliebe mangels Geeignetheit der Sperrung keine weitere Möglichkeit den kinderpornographischen Inhalt breitflächig zu beschränken. ${ }^{1213}$

\section{b) Lehren für ein Löschgesetz}

Hinsichtlich eines staatlich verfolgten Löschansatzes wäre zwar technisch betrachtet auch eine Umleitung auf einen vordefinierten „Stopp-Server“ denkbar, bezüglich der Verfassungsmäßigkeit eines solchen Vorgehens kann allerdings nichts anderes gelten als beim Sperransatz. Obgleich die Umgehung einer Löschmaß-

$1210 \mathrm{Zu}$ den einzelnen Umgehungsmaßnahmen bereits oben 3. Teil B. I. 2. b) (aa) (1) .

1211 iE. Boecker, Stellungnahme der Sachverständigen im Rechtsausschuss v. 8.11.2010, S. 6, abrufbar unter:

http://www.bundestag.de/bundestag/ausschuesse17/a06/anhoerungen/archiv/03_Zugangsers chwerung/04_Stellungnahmen/Stellungnahme_Boecker.pdf; Stadler, MMR 2009, 581 (582); Sieber, JZ 2009, 653 (657); Heckmann, Stellungnahme der Sachverständigen im Rechtsausschuss v. 8.11.2010, S. 16, Abrufbar unter:

http://www.bundestag.de/bundestag/ausschuesse17/a06/anhoerungen/archiv/03_Zugangsers chwerung/04_Stellungnahmen/Stellungnahme_Heckmann.pdf (jeweils zuletzt abgerufen 20.5.2012).

1212 Zur Geeignetheit bereits oben 3. Teil B. I. 2. b) .

${ }^{1213}$ Es bliebe dann nur für den Einzelfall wirkende Sperranordnung nach $\ 20$ JMStV i.V.m. $\ 59$ $\mathrm{RStV}$, was unabhängig einer Zuständigkeitsproblematik, letztlich bezüglich der Eignung des Sperransatzes keine andere Folge zulassen würde. 
nahme nicht so leicht umzusetzen ist und die Erreichbarkeit des gelöschten Inhaltes nur über ein erneutes Einstellen des gelöschten Inhaltes erreicht werden kann, sind durch die offenkundige Anpreisung der Erschwerungsmaßnahme etwaige Neugiereffekte nicht auszuschließen. Damit erhöht sich auch hier die Wahrscheinlichkeit, dass eine technische Möglichkeit gefunden wird, den herausgenommenen Inhalt entsprechend wiederzufinden. Über eine Umleitung würde folglich auch der Löschansatz in seiner Effektivität abgeschwächt und die gesamte gesetzliche Umsetzung negativ beeinträchtigt. Der Gesetzgeber sollte daher bei der Kreation eines entsprechenden Gesetzes darauf achten, die Löschvariante entweder allein, das heißt ohne eine nachrangige Sperrung umzusetzen, oder, soweit der sich doch für die Beibehaltung einer nachrangigen Sperrmöglichkeit entscheiden sollte, diese ohne Umleitung an einen vordefinierten Stopp-Server normieren.

\section{Expertengremium als Ersatz für Richtervorbehalt?}

a) Richtervorbehalt als verfahrensrechtliche Kompensation

Im Rahmen der hier zugrundgelegten Anforderungen an die Verfassungsmäßigkeit eines Sperrgesetzes wurde ein Richtervorbehalt als Kompensation der weitläufigen Einschränkungen der Kommunikationsgrundrechte gefordert. Aufgrund der grundrechtsrelevanten Folgen der Sperrung, insbesondere für die Grundrechte der Nutzer, ist es geboten, die Einordnung eines auf die Sperrliste zu setzenden Angebotes als kinderpornographisch i.S.d. \184b StGB zusätzlich durch einen unabhängigen Richter überprüfen zu lassen. Einen expliziten Richtervorbehalt sah das Zugangserschwerungsgesetz indes nicht vor.

Fraglich ist, ob eine stichprobenartige Überprüfung der Sperrliste - wie sie $\ 9$ ZugErschwG vorsah - durch ein entsprechendes Expertengremium als ein Korrektiv zur rechtsstaatlichen gebotenen Normierung eines Richtervorbehalts angesehen werden kann. Ausweislich der Begründung war die gegenüber der Vorgängerregelung neu eingeführte Bestimmung darauf bedacht, dem „Wunsch nach mehr Transparenz" nachzukommen. ${ }^{1214}$ Hierfür sah $\$ 9$ ZugErschwG die Einrichtung eines Expertengremiums beim Bundesdatenschutzbeauftragen vor. Dieses fünfköpfige Gremium sollte jederzeit zur Kontrolle der Sperrliste, folglich zur repressiven Überprüfung der Sperrvoraussetzungen berechtigt sein. Eine allgemeine Verpflichtung zur nachträglichen Überprüfung ließ sich der Norm indes nicht entnehmen. Vielmehr sollte das Expertengremium nur verpflichtet sein, mindestens einmal pro Quartal eine relevante Anzahl von Stichproben zu überprüfen.

1214 BT-Drs. 16/13411, S. 14. Dazu auch Volkmann in: Spindler/Schuster, Recht der elektronischen Medien, 2011, § 9 ZugErschwG, Rn. 1. 
Das Bundesverfassungsgericht eröffnet in seiner OnlineDurchsuchungsentscheidung ${ }^{1215}$ selbst den Weg für eine „vergleichbare verfahrensrechtliche Absicherung“" und weist darauf hin, dass die Wahrung der Verfassungsmäßigkeit einer Maßnahme nicht auf einen Richtervorbehalt beschränkt sei, sondern räumt bei der verfahrensrechtlichen Absicherung der Verfassungsmäßigkeit einer Reglung dem Gesetzgeber einen „Regelungsspielraum“ ein. Der Gesetzgeber darf eine andere Stelle aber nur dann mit der Kontrolle betrauen, wenn diese die gleiche Gewähr für ihre Unabhängigkeit und Neutralität bietet wie ein Richter. ${ }^{1216}$ Dies wird bei dem vorgeschlagenen Expertengremium bezweifelt. ${ }^{1217}$

Das Expertengremium sollte unabhängig sein und die Mehrzahl der fünf Richter musste über die Befähigung zum Richteramt verfügen. Nach Ansicht Heckmanns ${ }^{1218}$ ließe sich allein die „Befähigung zum Richteramt“, nur auf eine gewisse juristische Fachqualifikation, keineswegs gleichzeitig auch eine „Unabhängigkeit“ ableiten. ${ }^{1219}$ Grundsätzlich ist es gerade notwendig eine gewisse Unabhängigkeit, insbesondere bei einer in ihrer gesellschaftlichen Ansicht so negativ vorgeprägten Meinung zu kinderpornographischen Darstellungen, zu bewahren. Die Einordnung eines Inhalts als kinderpornographisch bedarf nicht nur eines Sachverstands aufgrund der tatbestandlichen Feinheiten, wie beispielsweise der Einbeziehung von Schein- und Fiktivdarstellungen, ${ }^{1220}$ daneben braucht es auch einer Loslösung von einer vorurteilsbehaften und gerade durch die direkte Inaugenscheinnahme eines kinderpornographischen Angebotes negativ vorgeprägten Meinung. Jedoch kann hier offenbleiben, ob sich allein aus der „Befähigung zum Richteramt“ die

1215 BVerfGE 120, 274 (332).

1216 BVerfGE 120, 274 (332).

1217 Frey/Rudolph, Stellungnahme der Experten im Rechtsausschuss v. 7.11.2011, S. 8, abrufbar unter: http://www.bundestag.de/bundestag/ausschuesse17/a06/anhoerungen/archiv/03_Zugangsers chwerung/04_Stellungnahmen/Stellungnahme_Frey.pdf; Heckmann, Stellungnahme der Experten im Rechtsausschuss v. 8.11.2010, S. 18, abrufbar unter:

http://www.bundestag.de/bundestag/ausschuesse17/a06/anhoerungen/archiv/03_Zugangsers chwerung/04_Stellungnahmen/Stellungnahme_Heckmann.pdf; Boecker, Stellungnahme der Experten im Rechtsausschuss v. 8.11.2010, S. 8, abrufbar unter:

http://www.bundestag.de/bundestag/ausschuesse17/a06/anhoerungen/archiv/03_Zugangsers chwerung/04_Stellungnahmen/Stellungnahme_Boecker.pdf (jeweils zuletzt abgerufen 20.5.2012).

1218 Heckmann, Stellungnahme der Experten im Rechtsausschuss v. 8.11.2010, S. 18, abrufbar unter: http://www.bundestag.de/bundestag/ausschuesse17/a06/anhoerungen/archiv/03_Zugangsers chwerung/04_Stellungnahmen/Stellungnahme_Heckmann.pdf (zuletzt abgerufen 20.5.2012).

1219 Heckmann, Stellungnahme der Experten im Rechtsausschuss v. 8.11.2010, S. 18, abrufbar unter: http://www.bundestag.de/bundestag/ausschuesse17/a06/anhoerungen/archiv/03_Zugangsers chwerung/04_Stellungnahmen/Stellungnahme_Heckmann.pdf (zuletzt abgerufen 20.5.2012).

1220 Hierzu oben 2. Teil A. III. 1. . 
geforderte Unabhängigkeit ableiten lässt oder erst die „Ausübung des richterlichen Berufsfeldes" die Unabhängigkeit garantiere, denn der wesentliche Unterschied zum geforderten Richtervorbehalt liegt hier in der nur stichprobenartigen Kontrolle der Sperrliste. ${ }^{1221}$ Angesichts der grundrechtlich relevanten Berührungspunkte einer gesetzlichen Sperrverpflichtung, wie sie das Zugangserschwerungsgesetz vorsah, mit den verfassungsrechtlich garantierten Rechten der am Kommunikationsprozess beteiligten Akteure und der Heimlichkeit und Eingriffsintensität der Sperrungen, dürfte diese eingeschränkte Kontrolle der Sperrliste durch das Expertengremium den verfahrensrechtlichen Anforderungen an die Verfassungskonformität des Sperransatzes nicht gerecht werden. Ziel des Richtervorbehalts ist es, eine kompensatorische Wirkung für die eingeschränkte Rechtsschutzmöglichkeit einzuräumen, ${ }^{1222}$ was über die nur stichprobenartige und quartalsmäßige Überprüfung des $₫ 9$ ZugErschwG nur unzureichend umgesetzt werden würde. Es besteht auch in einem solchen Fall keine Möglichkeit rechtlich bereits im Vorfeld gegen die Aufnahme in die Sperrliste vorzugehen. Der Nutzer kann nicht im Vorhinein eine gerichtliche Kontrolle der Maßnahme beanspruchen, um zu überprüfen, ob das Angebot tatsächlich „,kinderpornographisch“ war und deshalb gesperrt werden musste. Auch wegen der Heimlichkeit der Maßnahme wird dem Nutzer oftmals noch nicht ersichtlich sein, dass es überhaupt zu einer staatlichen Einschränkung der Kommunikation gekommen ist. ${ }^{1223}$ Um diese mangelnde Rechtsschutzmöglichkeit zu kompensieren muss daher jede Sperrmaßnahme auf ihre die Notwendigkeit hin überprüft und das ihr zugrundeliegende Gefährdungspotential für die Kommunikationsgrundrechte gegenüber der Beibehaltung des Angebotes zum freien Zugriff im Internet ins Verhältnis gesetzt und entsprechend die Notwendigkeit einer Sperrung „,bescheinigt“ werden.

\section{b) Fehlende Begründung}

Darüber hinaus sah $₫ 9$ ZugErschwG keine Begründungspflicht für Entscheidungen des Expertengremiums nach der Überprüfung der Angebote vor. Das Bundesverfassungsgericht hatte bei der Online-Durchsuchungsentscheidung jedoch

1221 Heckmann, Stellungnahme der Experten im Rechtsausschuss v. 8.11.2010, S. 19, abrufbar unter: http://www.bundestag.de/bundestag/ausschuesse17/a06/anhoerungen/archiv/03_Zugangsers chwerung/04_Stellungnahmen/Stellungnahme_Heckmann.pdf. In die gleiche Richtung Frey/Rudolph, Stellungnahme der Experten im Rechtsausschuss v. 7.11.2011, S. 9, abrufbar unter: http://www.bundestag.de/bundestag/ausschuesse17/a06/anhoerungen/archiv/03_Zugangsers chwerung/04_Stellungnahmen/Stellungnahme_Frey.pdf (jeweils zuletzt abgerufen 14.3.2011).

1222 BVerfGE 120, 274 (332), bezugnehmend auf SächsVerfGH, JZ 1996, 957 (964).

1223 Darauf weisen auch zutreffend Frey/Rudolph, Stellungnahme der Experten im Rechtsausschuss v. 7.11.2011, S. 9, abrufbar unter: http://www.bundestag.de/bundestag/ausschuesse17/a06/anhoerungen/archiv/03_Zugangsers chwerung/04_Stellungnahmen/Stellungnahme_Frey.pdf (zuletzt abgerufen 20.5.2012) hin. 
gefordert, dass die Kompensation der mangelnden Rechtsschutzmöglichkeit über einen Richtervorbehalt nur dann angenommen werden kann, wenn gleichzeitig vorausgesetzt werde, dass die Richter „die Rechtmäßigkeit der vorgesehenen Maßnahme eingehend prüfen und die Gründe schriftlich festhalten. “1224 Dabei seien die maßgeblichen Erwägungen zu dokumentieren, die zur Entscheidung geführt haben. Aufgrund der kompensatorischen Wirkung seien geeignete Formulierungen anzustellen, die im Rahmen des „Möglichen und Zumutbaren sicherstellen, dass der Eingriff in die Grundrechte [für den Grundrechtsberechtigten] messbar und kontrollierbar bleibt." ${ }^{2225}$ Mangels Begründungserfordernis genügte das Zugangserschwerungsgesetz nach diesen Maßstäben damit nicht den verfassungsrechtlichen Anforderungen. Obgleich das Bundesverfassungsgericht ausnahmsweise auch die Möglichkeit einräumte vom Begründungserfordernis Abstand zu nehmen, soweit „Gefahr im Verzug“ vorliegt, so war auch diese Voraussetzung im Falle der Rechtsmaterie des Zugangserschwerungsgesetzes nicht gegeben. ${ }^{1226}$ Für die tatsächlichen und rechtlichen Voraussetzungen der Annahme eines Eilfalls bestehen wiederum verfassungsgerichtliche Vorgaben, wonach „wegen des Ausnahmecharakters der nichtrichterlichen Anordnung“ und der „grundrechtssichernden Schutzfunktion des Richtervorbehalts“ das Merkmal „Gefahr im Verzug“" eng auszulegen ist. ${ }^{1227}$ Unter Zugrundlegung dieser Annahme wird die nur quartalsmäßig angeordnete stichprobenartige Überprüfung der Entscheidung des BKA zur Aufnahme auf die Sperrliste den Anforderungen kaum genügen können. Durch diese Regelung wird der „Eilfall“ praktisch zum „Regelfall“ umgedeutet und damit in seinem restriktiven Charakter verkehrt.

\section{c) Besetzung des Gremiums}

Das Zugangserschwerungsgesetz sah keine Regelung für die materiellen Anforderungen an die Mitglieder des Expertengremiums vor. Für Frey/Rudolph ${ }^{1228}$ deutet das auf eine „ehrenamtlich“ übernommene Tätigkeit des Gremiums hin. Dieses würde jedoch auch problematisch in Bezug auf die Effektivität der Überprüfung der Rechtmäßigkeit der Einordnung der Sperrnotwendigkeit sein, da hierdurch der kompensatorische Charakter der Maßnahme abgeschwächt werde. Auch die Verortung des Expertengremiums entsprechend $₫ 9$ ZugErschwG beim „Bundesbeauftragen für Datenschutz und die Informationsfreiheit" ist bedenklich. Wenn die

1224 BVerfGE 120, 274 (332) mit Verweis auf die bereits im Rahmen der akustischen Wohnraumüberwachung geforderte Begründungspflicht der Anordnung, BVerfGE 109, 279 (359).

1225 BVerfGE 109, 279 (359) mit Verweis auf BVerfGE 103, 142 (151).

1226 Schon BVerfGE 103, 142 (153).

1227 BVerfGE 103, 142 (153).

1228 Frey/Rudolph, Stellungnahme der Experten im Rechtsausschuss v. 7.11.2011, S. 9, abrufbar unter: http://www.bundestag.de/bundestag/ausschuesse17/a06/anhoerungen/archiv/03_Zugangsers chwerung/04_Stellungnahmen/Stellungnahme_Frey.pdf(zuletzt abgerufen 20.5.2012). 
stichprobenartige Überprüfung der Sperrliste rechtsstaatlich der Absicherung der richtigen Einordnung eines Angebotes als kinderpornographisch im Sinne des \184b StGB dienen sollte, ist es nicht nachvollziehbar, warum das Expertengremium beim Bundesdatenschutzbeauftragten für Datenschutz angesiedelt wurde. ${ }^{1229}$ Zwar sind auch datenschutzrechtliche Aspekte bezüglich der Sicherung der Liste vor Veröffentlichung und Missbrauch notwendig, um aus ihr keine katalogisierte Aufstellung kinderpornographischer Webinhalte für Pädophile herzuleiten, ${ }^{1230}$ jedoch war die primäre Aufgabe der repressiven Überprüfung, schon vom Wortlaut der Norm her, auf die Überprüfung der „Voraussetzungen der Absatzes 1 Satz 1" ausgerichtet. Auch wenn die Dienststelle des Bundesdatenschutzbeauftragten zwar beim Bundesministeriums des Innern eingerichtet ist, auf dessen Grundlage wohl die Verknüpfung zum Einsatz des Expertengremiums gründete, ${ }^{1231}$ war der Regelung nicht klar zu entnehmen, ob die angeordnete Unabhängigkeit des Gremiums auch eine Zurechnungsfreistellung für den Bundesdatenschutzbeauftragten bedeutete oder ob dieser als „Träger“ des Gremiums zur etwaigen Haftung herangezogen werden könnten. ${ }^{1232}$

\section{d) Fehlender Rechtsschutz}

Darüber hinaus mangelte es dem Zugangserschwerungsgesetz an einem effektiven Rechtsschutzverfahren. ${ }^{1233}$ Diesbezüglich sah $\ 8$ Abs. 2 ZugErschwG lediglich einen Auskunftsanspruch gegen das BKA sowie einen Verweis auf den Verwal-

1229 So auch Höbne/Dienst, jurisPR ITR 13/2009, Anm. 6; in die Richtung auch der Aufhebungsgesetzentwurf zum ZugErschwG von der SPD BT-Drs. 17/646, S. 4. In die Richtung auch schon der Bundesdatenschutzbeauftragte Peter Schaar selbst, in seinem Schreiben an dem Rechtsausschuss v. 15.6.2009, Ausschussdrucksache 16 (4) 641, danach sehe Schaar seine Unabhängigkeit als Datenschutz und vor allem als Informationsfreiheitsbeauftragter gefährdet, abrufbar unter: http://www.netzpolitik.org/wp-upload/164641-bfdi-peter-schaar-kinderpornographie-16-

13125.pdf (zuletzt abgerufen 20.5.2012).

1230 Andeutend Boecker, Stellungnahme der Experten im Rechtsausschuss v. 8.11.2010, S. 6, abrufbar unter:

http://www.bundestag.de/bundestag/ausschuesse17/a06/anhoerungen/archiv/03_Zugangsers chwerung/04_Stellungnahmen/Stellungnahme_Boecker.pdf (zuletzt abgerufen 20.5.2012).

1231 In die Richtung SPD Abgeordneter Martin Dörmann, zitiert im Interview mit Spiegel-online, Beitrag v. 16.6.2009 „Koalition einigt sich über Internetsperren“, abrufbar unter: http://www.spiegel.de/netzwelt/web/0,1518,630568,00.html (zuletzt abgerufen 20.5.2012).

1232 Hierzu Interview Bundesdatenschutzbeauftragter Peter Schaar mit taz-online v. 15.6.2009, „Schaar will nicht kontrollieren“ abrufbar unter: http://www.taz.de/1/politik/schwerpunktueberwachung/artikel/1/schaar-gegen-bka-kontrollgremium/ (zuletzt abgerufen 20.5.2012).

1233 So schon Bitkom, Stellungnahme der Sachverständigen, Ausschussdrucksache 16 (9) 1538, S. 14, noch in Bezug auf die Vorgängerregelung des $₫ 8$ a Abs. 8 TMG-E, die lediglich redaktionell an die neue Gesetzessystematik angepasst wurde. 
tungsrechtsweg in $\int 12$ ZugErschwG vor. Allerdings war keine detaillierte Begründungsverpflichtung für die Sperrmaßnahme vorgesehen. Diesbezüglich ordnete $\int 8$ ZugErschwG nur eine Dokumentations- und Nachweispflicht an, dass die Einträge auf der Sperrliste zum „Zeitpunkt ihrer Bewertung die Voraussetzungen nach $\int 1$ erfüllten“. Bereits im Gesetzgebungsverfahren wurde diese Regelung als unzureichend angesehen, weil sie nicht explizit dazu verpflichtete auch einen Nachweis darüber zu führen, ob ein bestimmtes Angebot im Zeitpunkt der Sperrlisteneintragung tatsächlich den Voraussetzungen des \ 184b StGB unterfiele. ${ }^{1234}$ Erst der entsprechende Nachweis der Sperrnotwendigkeit eröffnet den betroffenen Providern und Nutzern aber die Möglichkeit eines hinreichenden Rechtsschutzes, in dem die behördliche Entscheidung im gerichtlichen Verfahren auch im Nachhinein überprüft werden kann. Auch die Regelung des $\int 1$ Abs. 3 ZugErschwG, wonach nach Aufnahme eines Angebotes in die Sperrliste die Provider über die Gründe des Listeneintrags unterrichtet werden sollten, konnte eine Rechtsschutzmöglichkeit nicht gewährleisten. Denn soweit ein Anbieter aus Deutschland oder dem EU-Inland ermittelt werden konnte, musste das Angebot entsprechend $\int 1$ Abs. 2 ZugErschwG ohnehin gelöscht werden, so dass eine Unterrichtungspflicht in diesem Fall nicht durchgeführt werden musste. ${ }^{1235}$

\section{e) Zwischenergebnis}

Zusammenfassend ist somit festzustellen, dass das in $\int 9$ ZugErschwG vorgesehene Expertengremium kein verfassungsrechtlich vertretbares Korrektiv für die mangelnde Formulierung eines Richtervorbehaltes darstellte.

\section{f) Lehren für ein Löschgesetz}

Hinsichtlich des Löschansatzes bietet es sich folglich an eine wesentliche Verbesserung des Sicherungsmechanismus zu statuieren. Sollte der Gesetzgeber das Konzept einer Absicherung über ein Expertengremium beibehalten wollen, so müssen die Anforderungen an das Gremium gesetzlich normiert und rechtstaatlich verträglich umgesetzt werden. Neben einer explizit normierten Haftungsfreistellung im Falle einer fälschlicherweise vorgenommenen Löschung, sowohl für die Gremiumsmitglieder als auch für den Bundesdatenschutzbeauftragten, ist vor allem notwendig die Überprüfung auf der Löschvoraussetzungen nicht nur einer stichprobeartigen Begutachtung zu unterziehen, sondern jede einzelne Maßnahme über eine externe Kommission auf ihre Notwendigkeit hin zu überprüfen. Weiterhin ist die ergangene Entscheidung des Gremiums, wie die Rechtsprechung des Bundesverfassungsgerichts nahelegt, entsprechend zu begründen und das Vorlie-

1234 Noch weitergehend mitsamt eines vorformulierten Überarbeitungsvorschlages, Bitkom, Stellungnahme der Sachverständigen, Ausschussdrucksache 16 (9) 1538, S. 14.

1235 Ebenso Volkmann in: Spindler/Schuster, Recht der elektronischen Medien, 2011, \1 ZugErschwG, Rn. 8 . 
gen der Beschränkungsvoraussetzungen, mithin die Erfüllung der Tatbestandsvoraussetzungen des $₫ 184 \mathrm{~b}$ StGB entsprechend zu dokumentieren. Soweit der Gesetzgeber diese Anforderungen in der Vorschrift benennt, kann eine rechtsstaatlich verträgliche Absicherung der mit der Maßnahme einhergehenden Grundrechtseingriffe in die Grundrechte vorgenommen werden.

\section{Kompensation sonstiger Forderungen}

a) Entschädigungspflicht

Zuvorderst ist der Gesetzgeber den Forderungen nach einer Entschädigungspflicht für die in Anspruch genommenen Provider nicht nachgekommen. Zwar erkannte der Gesetzgeber den Kostenfaktor eines verbindlichen Sperransatzes und führte in der Begründung aus: „Auf die Zugangsvermittler kommen Investitionskosten für die technischen Vorkehrungen zu, die den Zugriff auf kinderpornographische Angebote im Internet erschweren. Hinzu kommen Aufwendungen für den laufenden Betrieb, für die Einrichtung der sog. Stoppmeldung sowie für die Übermittlung der Aufstellung von Zugriffsversuchen auf kinderpornographische Angebote. Diese Kosten sind nicht generell bezifferbar und hängen u. a. von dem gewählten technischen Ansatz der Zugangserschwerung, vom jeweiligen Geschäftsmodell, der Netzstruktur und der Kundenzahl eines Providers ab. Die Kosten lassen sich derzeit nicht abschätzen. Indirekte Kosten für Unternehmen und Privathaushalte durch unbeabsichtigte Einschränkungen der Internetnutzung, sowie Auswirkungen auf Einzelpreise z. B. für Dienstleistungen der Zugangsanbieter können nicht ausgeschlossen werden." Dabei sollten die entstandenen Kosten über $\$ 2$ Abs. 1 ZugErschwG kompensiert werden. Dieser sah vor, dass nur diejenigen Access-Provider von der Sperrpflicht umfasst sein sollten, die den Zugang zum Kommunikationsnetz „für mindestens 10000 Teilnehmer ermöglichen“. Diese Regelung stellte allerdings kein Äquivalent für die fehlende Entschädigungspflicht dar. ${ }^{1236}$ Verfassungsrechtlich ist die Entschädigung aufgrund unverhältnismäßiger Eingriffe in Art. 12 Abs. 1 GG geboten. Soweit die aufkommende Kostenlast zur Herstellung und Aufrechterhaltung der Sperrinfrastruktur für die berufliche Tätigkeit der Access-Provider eine erdrosselnde Wirkung einnimmt, ist der Gesetzgeber über geeignete gesetzgeberische Regelungsmechanismen zum Ausgleich verpflichtet. Die Beschränkung auf Großanbieter relativiert die Befürchtung einer erdrosselnden Wirkung hingegen nicht. Finanzielle Belastungen sind immer einzelfallabhängig vom Marktgeschehen bestimmt. Großanbieter können aufgrund eines weiten Kundenstamms oftmals die wirtschaftlichen Einbußen selbst tragen, soweit sie den Internetzugang nicht hauptberuflich oder

1236 Volkmann in: Spindler/Schuster, Recht der elektronischen Medien, 2011, 2 ZugErschwG, Rn. 2. 
nicht gegen Entgelt anbieten ${ }^{1237}$ unterfallen sie hingegen den gleichen Beeinträchtigungen wie Kleinanbieter. Um verfassungsrechtlichen Bedenken zu entgegen, müsste ein allgemeiner Kostenausgleich festgesetzt sein. ${ }^{1238}$

b) Lehren für ein Löschgesetz

Bei der Schaffung eines Löschgesetzes wäre demgegenüber zu bedenken, dass die zur Löschung Verpflichteten, anders als die Zugangsdiensteanbieter, gerade als Verantwortliche im Sinne der Gefahrenabwehr zu qualifizieren wären, so dass die miteinander in Konkurrenz tretenden Belange einer effektiven Gefahrenabwehr einerseits, und der Berufsrechte der Verantwortlichen andererseits, zu Gunsten der Gefahrenabwehr zu modifizieren wären, ohne dass es einer finanziellen Kompensation für die Inanspruchnahme bedarf. ${ }^{1239}$ Zwar würde sich die staatliche Inanspruchnahme der Provider zur Löschung gleichsam der Sperrung als eine Berufsausübungsregelung darstellen, anders als bei der Sperrung würden die verpflichteten Provider jedoch keine aufwendige und kostenintensive Sperrinfrastruktur errichten müssen, deren Investitionskosten sich auf die Ausübung des Berufsfeldes negativ auswirken würden. Vielmehr ist die Löschung als actus contrarius zur Einstellung des Inhaltes ${ }^{1240}$ gerade ohne zusätzlichen Aufwand möglich und daher leicht zuzumuten.

\section{c) Wissenschaftsfreiheit}

Überdies ist hinsichtlich der Kompensation des Eingriffs in die Wissenschaftsfreiheit aus Art. 5 Abs. 3 Satz 1, Var. 2 GG herausgearbeitet worden, dass eine ausdrückliche Beschränkung des persönlichen Anwendungsbereichs in Form einer Ausnahmeklausel für Forschungseinrichtungen verfassungsrechtlich geboten ist. Über eine solche lässt sich im Wege der praktischen Konkordanz ein schonender Ausgleich zwischen der Verfolgung jugendschützender Belange über den gewählten Ansatz der Sperrung und den daraus resultierenden Einschränkungen der Wissenschaftsfreiheit erreichen. Eine dahingehende Begrenzung enthielt die Vor-

${ }^{1237}$ Die Vorgängerfassung des $\int 8$ a Abs. 2 Satz sah noch den Klammerzusatz „in der Regel gegen Entgelt vor und beschränkte die gesetzlichen Sperrverpflichtung damit nur auf kommerzielle entgeltliche Anbieter. Der Klammerzusatz ist aber im Zugangserschwerungsgesetz entfallen. Als Begründung beschränkte sich der Gesetzgeber jedoch nur darauf, dass nunmehr alle Großanbieter umfasst sein sollen, ohne dies hinreichend zu erläutern, BT-Drs. 16/13411, S. 13.

1238 So auch Höhne/Dienst, jurisPR ITR 13/2009, Anm. 6; Frey/Rudolph, CR 2009, 644 (651). Zum Vorgängerentwurf, Bitkom, Stellungnahme der Sachverständigen, Ausschussdrucksache 16 (9) 1538, S. 17; eco, Ausschussdrucksache 16 (9) 1542, S. 10.

1239 Ausführlich zur Herleitung der Verantwortlichkeit Volkmann, Der Störer im Internet, 2005, S. 208 ff.; zuvor auch schon Greiner, Die Verhinderung verbotener Internetinhalte, 2001, S. 120 ff.

1240 Zur Vornahme der Löschung oben, unter 3. Teil B. I. 2. c) (aa) . 
schrift zur Sperrverpflichtung im Zugangserschwerungsgesetz jedoch nicht. Im Gegensatz zur Fassung des $\ 2$ ZugErschwG war noch in der Vorgängerregelung des $\int 8$ TMG-E die Beschränkung auf rein privat-rechtliche Anbieter vorgesehen. Ausweislich der Begründung sollte diese Einschränkung die Diskrepanz mit der Wissenschaftsfreiheit aufgreifen „da andernfalls [erläuternd: Ohne die Beschränkung] auch alle staatlichen Einrichtungen (Behörden, Bibliotheken, Universitäten, Schulen) erfasst wären." ${ }^{241}$ Der Gesetzgeber schien folglich die Problematik erkannt zu haben und bemühte sich diese in den Wortlaut der „alten“ Norm verfassungskonform einzuarbeiten. Allerdings war schon die vormalige Beschränkung des Anwendungsbereichs auf private Einrichtungen nicht in der Lage, dass verfassungsrechtliche Problem der Einengung der Wissenschaftsfreiheit zu kompensieren. Eine Beschränkung auf privatrechtliche Anbieter impliziert nicht immer den Umkehrschluss, dass ein Konflikt zwischen gefahrenabwehrrechtlichen Sperrungen einerseits und Wahrung der Wissenschaftsfreiheit bestmöglich umgangen wird. Wie bereits erläutert, ${ }^{1242}$ sind nicht nur die öffentlich-rechtlichen Forschungseinrichtungen Grundrechtsträger der Wissenschaftsfreiheit aus Art. 5 Abs. 3 Satz 1 GG. Auch privat-rechtliche Einrichtungen können sich auf die Wissenschaftsfreiheit berufen. Für diese privat-rechtlichen Forschungseinrichtungen würde sich daher der Konflikt in gleicher Weise stellen, wie ohne die Einschränkung der Norm. Aufgrund der hierdurch jedoch verstärkten gleichheitswidrigen Zustände ${ }^{1243}$ zwischen privaten und öffentlich-rechtlichen Access-Providern hatte der Gesetzgeber die Norm auch konsequenterweise entfernt, sich überdies jedoch nicht für eine weitergehende Beschränkung des Adressatenkreises ausgesprochen. Lediglich über $\$ 2$ Abs. 1 Satz 2, 2. Halbsatz ZugErschwG sollte eine Ausnahme von der Sperrverpflichtung für Diensteanbieter vorgesehen sein, die Internetzugänge nicht für die Öffentlichkeit anbieten, soweit diese bereits „,vergleichbar wirksame Sperrmaßnahmen“ einsetzen. Die Norm war damit nicht in der Lage die verfassungsrechtliche Diskrepanz zwischen der Verfolgung jugendschützender Belange im Internet und dem ungehinderten Informationsbedürfnis von Forschungseinrichtungen zu lösen, da sie eben keine explizite Ausnahme für wissenschaftsbetreibende Access-Provider bot. Damit war die gesetzliche Sperrverpflichtung nicht gewillt den Konflikt zur Wissenschaftsfreiheit des Art. 5 Abs. 3 Satz 2 GG in verfassungsrechtlich angemessener Weise aufzulösen und musste indes auch unter dem Aspekt zur materiell-verfassungsrechtlichen Beanstandung des Gesetzes führen.

1241 BT-Drs. 16/12850, S. 6.

1242 Dazu bereits oben unter: 3. Teil B. IV.

1243 So ausdrücklich Bitkom, Ausschussdrucksache 16 (9) 1538, S. 8. 
d) Lehren für ein Löschgesetz

In Bezug auf die zu erwartende Schaffung eines Löschgesetzes sind die Auswirkungen auf die Wissenschaftsfreiheit ebenfalls ersichtlich, wenngleich in einem grundrechtlich viel weniger einschneidendem Maße als bei der Sperrung eines Inhalts. Da die Löschung gegenüber der Sperrung viel punktueller wirkt und dadurch vermieden werden kann, dass gleichzeitig auch völlig unbedenkliche Seiten unzugänglich werden, sind die hier in Konflikt tretenden Belange zu Gunsten der Gefahrenabwehr aufzulösen. Auch wenn Forschungseinrichtungen, die selbst kinderpornographische Inhalte hosten oder gar anbieten, grundsätzlich aus Forschungszwecken auch auf diesbezügliche Primärquellenzugänglichkeit angewiesen sind, wird im Falle der Identifizierung eines dieser Inhalte als kinderpornographisch i.S.d. \184b StGB und der daran knüpfenden Löschverpflichtung, die Wissenschaftsfreiheit regelmäßig gegenüber dem mit der Löschung verfolgten Belangen zurücktreten müssen. Eine generelle Ausnahme für Forschungseinrichtungen ist aufgrund der punktuellen Wirkweise der Löschung folglich obsolet. Vielmehr reicht es aus, wenn einzelfallabhängig die Angemessenheit einer Löschung in Relation zur Einschränkung der Wissenschaftsfreiheit gestellt wird. Der Gesetzgeber würde also auch ohne einen gesetzlichen Ausnahmetatbestand den verfassungsrechtlichen Anforderungen gerecht werden.

\section{Befürchtung der Ausweitung des Gesetzes}

a) Sperrinfrastruktur universell einsetzbar

Dem Zugangserschwerungsgesetz wurde vorgeworfen, dass es praktisch das Einfallstor zur breit angelegten Internetregulierung eröffne. ${ }^{1244}$ Durch die gesetzliche Verpflichtung zur Zugangserschwerung sollten die Access-Provider gleichzeitig zum Aufbau einer Sperrinfrastruktur „gezwungen“ werden, die vom Gesetzgeber leichter dafür eingesetzt werden könnte über den Bereich der Kinderpornographie hinausgehende Sperrungen durchzusetzen. Die zur Sperrung durch die Provider benötigten technischen Gegebenheiten sind nämlich nicht spezifisch nur auf die Unterbindung bestimmter Inhalte ausgerichtet, sondern können universell auch zur Sperrung anderweitiger Inhalte eingesetzt werden. ${ }^{1245}$ Kurze Zeit nach bekannt werden der Gesetzesinitiative hinsichtlich der Unterbindung kinderpornographischer Webseiten, wurden auch tatsächlich Forderungen nach weitergehenden Sperrungen, beispielsweise von gewaltverherrlichenden Onlineseiten sowie Sperrungen im Bereich der Immaterialgüterrechte, wie Urheberrechts- und Markenrechtsverstöße, geäußert. ${ }^{1246}$ Auch nachdem das Zugangserschwerungsgesetz

1244 U.A. Begr. Aufhebungsgesetz zum ZugErschwG, BT-Drs. 17/646, S. 4.

1245 Frey/Rudolph, Ausschussdrucksache 16 (9) 1546, S. 24.

1246 Z.B. LG Hamburg, MMR 2010, 488. Darauf weist auch Höbne/Dienst, jurisPR ITR 13/2009, Anm. 6, hin; ebenso Stadler, MMR 2009, 581 (582); Greve/Schärdel, ZRP 2009, 54; Exemplarisch 
ausgesetzt war und sich die politischen Aufhebungsbemühungen aufgrund einer übereinstimmenden Abkehr vom ,ineffektiven“ Sperransatz verdichteten, wurde ein geplanter Änderungsentwurf des Glückspielstaatsvertrages vorgestellt, der ebenfalls die Möglichkeit der Sperrung solcher Inhalte vorsah. ${ }^{1247}$

Rechtlich problematisch an einer grenzenlosen Ausweitung des Sperransatzes ist, dass der verfassungsrechtlich bedenkliche Overblocking-Effect stärker ausgebreitet wird und eine unbegrenzte Ausweitung der sperrungswürdigen Inhalte zur Kontroverse mit dem Zensurgebot führen könnte.

Ebenfalls liegt der Ausweitung die Befürchtung zugrunde, dass die AccessProvider, wie schon von Frey überspitzt formuliert als „Gatekeeper des Rechts“ zu bezeichnen wären und letztlich ihre inhaltsneutrale Dienstleistung gänzlich von ihrer Funktion als staatlicher Ausführungsapparat überlagert wäre. ${ }^{1248}$

Aufgrund der Befürchtungen haben die Sachverständigen schon bezüglich der vormals angestrebten Änderung des TMG gefordert, den Anwendungsbereich des Gesetzes auf die Zugriffsunterdrückung zu kinderpornographischen Inhalten einzugrenzen. ${ }^{1249}$ Der eingeschränkte Anwendungsbereich war zwar innerhalb der gesetzlichen Begründung erkennbar, eine Fixierung innerhalb der Gesetzesstruktur fand sich allerdings nicht. Allein die Bezugnahme auf den Kinderpornographietatbestand des $\int 184 b$ StGB innerhalb der gesetzlichen Sperrverpflichtung des $\int 8 \mathrm{a}$ Abs. 1 Satz 1 TMG-E verwies auf die eingeschränkte Eingriffsbefugnis der Access-Provider.

auch heise-online, Meldung vom 6.4.2011, „Aus für „Zensursula“ und Websperren“: „Das Problem an der Wurzel packen“, abrufbar unter: http://www.heise.de/newsticker/meldung/Ausfuer-Zensursula-und-Websperren-Das-Problem-an-der-Wurzel-packen-1222817.html（zuletzt abgerufen 20.5.2012).

1247 Entsprechend $\int 9$ Abs. 1 Nr. 5 1. GlückÄndStV-E sollten Access-Provider zur Sperrung von Glücksspielangeboten verpflichtet werden. (s. Entwurfsfassung http://www.jungepiraten.de/glueckstv/GlueStV-Textentwurf-Endfassung-04042011.pdf). Nach vehemennter Kritik wurde die entsprechende Bestimmung abgeschwächt und auf das Sperrerfodernis verzichtet, vgl. Landtag SH, Drs. 17/1785. Dem geänderten Vertragsentwurf stimmten 15 Bundesländer zu (Ausnahme Schleswig-Holstein). Allerdings hat auch die Europäischen Kommission Bedenken an der Vereinbarkeit des Vertragstextes mit dem Europarecht geäußert, vgl. Stellungnahme v. 18.7.2011 - C (2011) 5319, ZfWG 2011, 325 sowie Stellungnahme im Notifizierungsverfahren 2011/0188/D, v. 20.3.2012, abrufbar unter:

http://www.gluestv.de/Gesetzesdatenbank/Staatsvertraege/Erster-

Gluecksspielaenderungsstaatsvertrag (zuletzt abgerufen 20.5.2012); Zum gesamten Komplex, Frey/Rudolph/Oster, MMR-Beil. 3/2012, S. 14.

1248 Frey, MMR 2009, 221 (222). Im ähnlichen Zusammenhang auch angeführt bei Erdemir in: Eifert/Hoffmann-Riem, Innovation, Recht und öffentliche Kommunikation, 2011, S. 27 (32).

1249 U.a. Kubnen, Ausschussdrucksache 16 (9) 1545, S. 3; Frey/Rudolph, Ausschussdrucksache 16 (9) 1546, S. 23. 
Aufgrund der geäußerten Bedenken, nahm der Gesetzgeber im Zugangserschwerungsgesetz explizit die Regelung des $\int 7$ Abs. 2 ZugErschwG auf. Danach sollten zivilrechtliche Ansprüche gegen Diensteanbieter wegen Sperrungsvornahme ausgeschlossen sein. Zur Begründung führte der Gesetzgeber aus, dass der neue Absatz neben redaktionellen Anpassungen an die neue Gesetzesstruktur sicherstellen sollte, „(...)dass das Sperrlistenverfahren und die dafür erforderliche Infrastruktur auf Grund der einzigartigen Anwendung für die Zugangserschwerung bei Seiten, die kinderpornographische Schriften im Sinne des \184b Absatz 1 StGB enthalten, nicht zur Durchsetzung etwaiger zivilrechtlicher Ansprüche gegenüber den Diensteanbietern oder sonstigen Dritten genutzt werden dürfen. Mit dieser Klarstellung wird der Befürchtung begegnet, dass Gerichte zukünftig aufgrund der durch das Sperrlistenverfahren nach diesem Gesetz vorhandenen technischen Infrastrukturen zu der Schlussfolgerung gelangen könnten, Zugangsvermittler seinen nunmehr auch im Hinblick auf andere Rechtsverletzungen (z.B. Rechte am geistigen Eigentum) zivilrechtlich zumutbar zur Sperrung heranzuziehen." Die Norm begründete nur eine zivilrechtliche Haftungsfreistellung für Access-Provider, die aufgrund der gesetzlichen Sperrverpflichtung tätig werden sollten und schloss damit eine weitergehende Haftung bei Vornahme anderweitigen Sperrungen nicht aus. Nicht ausgeschlossen wurde über die Norm beispielsweise die Nutzung der Sperrinfrastruktur für weitere öffentlich-rechtliche Sperrungen. ${ }^{1250}$ Die Möglichkeit einer grenzenlosen, verfassungsrechtlich bedenklichen Erweiterung der Sperrungsinfrastruktur droht aber - wie jüngste Berichte zum Glückspielstaatsvertrag belegen - nicht nur von zivilrechtlicher Seite, sondern kann im gleichen Maße auch bezüglich staatlich veranlasster Sperrungen.

\section{b) Lehren für ein Löschgesetz}

Für ein etwaiges Löschgesetz kann daraus abgeleitet werden, dass auch dieses explizit eine Beschränkung des Anwendungsbereichs auf Löschungen kinderpornographischer Inhalte enthalten sollte, um von Anfang an möglichen Ausweitungsbedenken und Zensurvorwürfen entgegenzutreten.

${ }^{1250}$ Dies erkennen auch Frey/Rudolph, Stellungnahme der Experten im Rechtsausschuss v. 7.11.2010, S.12, die hier von einem „Dammbruch“ der Sperrungsforderungen gegen Access-Provider sprechen, abrufbar unter:

http://www.bundestag.de/bundestag/ausschuesse17/a06/anhoerungen/archiv/03_Zugangsers chwerung/04_Stellungnahmen/Stellungnahme_Frey.pdf(zuletzt abgerufen 20.5.2012). 


\section{Nichtanwendungserlass}

Abschließend bedarf auch der so genannte „Nichtanwendungserlass“ des BMI gegenüber dem BKA, der vor in Kraft treten des Zugangserschwerungsgesetzes erlassen wurde, einer kurzen rechtlichen Begutachtung. ${ }^{1251}$

In Umsetzung der Koalitionsvereinbarungen wies das BMI das BKA über eine entsprechende Auslegungsmaßgabe an, allein den in $\int 1$ Abs. 2 ZugErschwG niedergelegten Grundsatz der Löschung durchzusetzen. Hierfür sollte das BKA darauf hinwirken, dass innerstaatliche und europäische Angebote direkt über eine Interaktion mit den entsprechenden Anbietern gelöscht, bei außereuropäischen Angeboten das jeweilige Sitzland mit der Bitte um Löschung des Inhaltes konfrontiert werde. Während der einjährigen Aussetzungsphase sollte monatlich eine Evaluierung der Löschungsmaßnahmen durchgeführt werden. Diese sollte als Grundlage für die Bewertung des Zugangserschwerungsgesetzes dienen und war letztlich mitursächlich für die Aufhebung Gesetzes. ${ }^{1252}$

\section{Rechtliche Würdigung}

Der faktische „Nichtanwendungserlass“"1253 war verfassungsrechtlich sehr bedenklich. Denn durch die Auslegungsvorgabe der Exekutive allein mittels Löschung gegen kinderpornographische Inhalte vorzugehen, wurde ein bestehender Legislativakt praktisch aussetzt und damit die verfassungsrechtlich vorgegebenen Prinzipien, die für die Entstehung und Aufhebung von Gesetzen bestimmend sind,

1251 Nichtanwendungserlass abrufbar unter: http://blog.odem.org/2010/02/19/Erlass-ZugErschwG.pdf.

1252 Entwurf eines Gesetzes zur Aufhebung von Sperrregelungen bei der Bekämpfung von Kinderpornographie in Kommunikationsnetzen, BR-Drs. 319/11. Hierzu Mitteilung des BMJ v. 6.4.2011 „Netzsperren endgültig vom Tisch“, abrufbar unter:

http://www.bmj.de/SharedDocs/Kurzmeldungen/DE/2011/20110406_Internetsperren.html? nn=1356288 (zuletzt abgerufen 13.4.2011); hierzu auch heise-online v. Meldung v. 5.4.2011, „Koalition kippt Websperren“, abrufbar unter: http://www.heise.de/newsticker/meldung/Ausfuer-Zensursula-und-Websperren-Das-Problem-an-der-Wurzel-packen-1222817.html (zuletzt abgerufen 20.5.2012).

1253 Nichtanwendungserlasse sind aus dem Steuerrecht bekannt. Sie werden dafür verwendet Entscheidungen des Bundesfinanzhofs über entsprechende Verwaltungsanweisungen nicht in die Verwaltungspraxis einfließen zu lassen. Gelten aber auch hier als umstritten. Zum Meinungsstand, ausführlich Krüger, Die Bindung der Verwaltung an die höchstrichterliche Rechtsprechung, 1987, bei Fn. 58; Kreft, Der Nichtanwendungserlass, 1989, S. 23 ff.; Leisner, Die allgemeine Bindung der Finanzverwaltung an die Rechtsprechung, 1980, 23 ff.; zusammenfassend W. Spindler, DStR 2007, 1061. In Bezug auf das ZugErschwG und dessen Nichtanwendungserlass Schnabel, K\&R 2011, 175 (176) sowie Höhne, jurisPR ITR 24/2010, Anm. 2. 
insbesondere der Gewaltenteilungsgrundsatz sowie das Rechtsstaatsprinzips des Art. 20 Abs. 2 und 3 GG umgangen.

\section{a) Verstoß gegen Rechtsstaatsprinzip}

Obgleich schon die generelle Annahme eines Beurteilungsspielraum in $₫ 1$ Abs. 2 ZugErschwG, der dahingehend interpretiert werden konnte, dass keine Sperrungen vorzunehmen seien, zu bezweifeln ist, ${ }^{1254}$ so verstieß die Verwaltungsanweisung ohnehin gegen höherrangiges Recht und war damit nicht in der Lage eine verfassungsverträgliche Nichtanwendung des Zugangserschwerungsgesetzes herbeizuführen.

Nach dem Rechtsstaatsprinzip des Art. 20 Abs. 3 Hs. 2 GG ist die vollziehende Gewalt an Gesetz und Recht gebunden. ${ }^{1255}$ Dieser so genannte Vorrang des Gesetzes bedeutet, dass die Exekutive zur Beachtung und Anwendung bestehender Gesetze verpflichtet ist und von ihrem Inhalt in der Umsetzung nicht abweichen darf. ${ }^{1256}$ Verstößt ein untergesetzlicher Rechtsakt gegen höherrangiges Recht, ist dieser im Ergebnis nichtig und darf nicht zur Anwendung kommen.

Die vom BMI vorgegebene Interpretationslinie des $₫ 1$ Abs. 2 ZugErschwG, die sich darauf richtete allein die Löschung durchzuführen, war nicht mehr vom Auslegungsspielraum der Norm gedeckt und verstieß damit gegen diesen Grundsatz der Gesetzmäßigkeit. ${ }^{1257}$ Die per Erlass bindende Auslegung der erfolgsversprechenden Maßnahme definierte diese gegenüber dem BKA, als „Benachrichtigung“ derjenigen ,ausländischen Staaten“, in welchen die identifizierten kinderpornographischen Inhalte physikalisch vorgehalten wurden. Die Benachrichtigung sollte mit der ausdrücklichen Bitte um Löschung des Inhalts korrespondieren. Eine nachrangige Sperrung war indes ausdrücklich ausgeschlossen, da weder Sperrlisten zu erstellen noch eine Weiterleitung an die Provider vom BKA vorzunehmen war. ${ }^{1258}$

1254 Kritisch zum Vorliegen eines Beurteilungsspielraums, Schnabel, K\&R 2011, 175 (176) sowie Höhne, jurisPR ITR 24/2010, Anm. 2 mwN.

1255 BVerfGE 40, 237 (248); BVerfGE 49, 89 (126); Sommermann in: v. Mangoldt/Klein/Starck, Art. 20 GG, Rn. 265; allgemein zum Vorbehalt des Gesetzes Kloepfer, JZ 1984, 685 (690).

1256 BVerfGE 25, 216 (228); Schulze-Fielitz in: Dreier, Art. 20 GG, Rn. 92; Sachs in: Sachs, Art. 20 GG, Rn. 110. Herzog/Grzeszick in: Maunz/Dürig, Art. 20 GG, Rn. 141. In Bezug auf den Nichtanwendungserlass Heckmann, Stellungnahme der Experten im Rechtsausschuss v. 8.11.2010, S. 22, abrufbar unter:

http://www.bundestag.de/bundestag/ausschuesse17/a06/anhoerungen/archiv/03_Zugangsers chwerung/04_Stellungnahmen/index.html (zuletzt abgerufen 20.5.2012).

1257 So ausdrücklich Höbne, jurisPR ITR 24/2010, Anm. 2; Scbnabel, K\&R 2011, 175 (176).

1258 So Wortlaut Nichtanwendungserlass des BMI, S. 2, abrufbar unter: http://blog.odem.org/2010/02/19/Erlass-ZugErschwG.pdf (zuletzt abgerufen 20.5.2012). 
Die vorgegebene Interpretation ließ aber den Aspekt völlig unberücksichtigt, dass der territoriale Anwendungsbereich des Gesetzes nicht auf ausländische Sperrmaßnahmen beschränkt war. Soweit man die Benachrichtigung ausländischer Staaten, in der „Hoffnung“ diese würden die entsprechenden Maßnahmen gegen die bei ihnen ansässigen Provider einleiten, stets als erfolgversprechende Maßnahme anerkannte, übersah man, dass diese Aussage, die inländischen Webangebote mit kinderpornographischem Inhalt gänzlich unberührt ließ. Für diese Angebote hätten dann die „,herkömmlichen“ Gesetzesvorgaben des $₫ 1$ Abs. 2 ZugErschwG i.V.m. $\int 1$ Abs. 1 ZugErschwG gelten müssen. Die Erlassvorgabe, wonach keinerlei Sperrlisten zu erstellen waren, stand damit im Widerspruch zur Gesetzessystematik.

Auch war die Auslegung der erfolgsversprechenden Maßnahme unter Heranziehung teleologischer Aspekte unzureichend. ${ }^{1259}$ Der gesamte gesetzliche Kontext, in dem die Norm des $₫ 1$ Abs. 2 ZugErschwG eingebettet wurde, sprach in der Tendenz für die Zulassung einer nachrangigen Sperrung. Zwar deuteten die veröffentlichten Zahlen des BKA darauf hin, dass im Ergebnis der Ansatz der Löschung in der Praxis zu Erfolgen führe, ${ }^{1260}$ der Erlass des BMI minimierte die internetbezogenen Maßnahmen aber nur auf diese „erfolgreiche“ Löschung und sah anderenfalls keinerlei Alternativen vor. Vielmehr war für den „Nichterfolgsfall“ im Erlass nur angeführt, dass soweit Erkenntnisse ergeben, dass ,in einer signifikanten Vielzahl von Fällen entweder keine Rückmeldung des benachrichtigten Staates erfolgt oder erkannt wird, dass trotz Meldung keine Maßnahmen zur Löschung der Inhalte unternommen wurden bzw. diese nicht zum Erfolg geführt haben", das BMI unter Auflistung der erfolgten Mitteilungen zu unterrichten sei und dann das BMJ um Unterstützung zu bitten wäre. ${ }^{261}$ So war aus der vorgenommenen Interpretation indes überhaupt nicht ersichtlich, ob die geäußerte

1259 Heckmann, Stellungnahme der Experten im Rechtsausschuss v. 8.11.2010, S. 22, abrufbar unter: http://www.bundestag.de/bundestag/ausschuesse17/a06/anhoerungen/archiv/03_Zugangsers chwerung/04_Stellungnahmen/index.html (zuletzt abgerufen 20.5.2012).

1260 So Antwort zur kleinen Anfrage BT-Drs. 17/3164, der Abgeordneten Sitte sowie der Fraktion DIE LINKE an die Bundesregierung, S. 2 abrufbar unter: http://blog.dielinke.de/digitalelinke/wp-content/uploads/Antwort-Loeschen-statt-Sperren.pdf (zuletzt abgerufen 20.5.2012). Zu den Löscherfolgen Bleich, heise-online, Meldung v. 18.3.2011, „Kampf gegen Kinderpornos: BKA Zahlen belegen den Erfolg von Löschen statt sperren“, abrufbar unter: http://www.heise.de/newsticker/meldung/Kampf-gegen-Kinderpornos-BKA-Zahlen-belegenden-Erfolg-von-loeschen-statt-sperren-1210432.html (zuletzt abgerufen 8.7.2011); Koch in: digitale linke, Beitrag v. 17.3.2011, „BKA Zahlen bestätigen Erfolg von „Löschen statt sperren“, abrufbar unter: http://blog.die-linke.de/digitalelinke/bka-zahlen-bestatigen-erfolg-von-loschenstatt-sperren/ (zuletzt abgerufen 20.5.2012).

1261 Wortlaut Nichtanwendungserlass des BMI, S. 3, abrufbar unter: http://blog.odem.org/2010/02/19/Erlass-ZugErschwG.pdf (zuletzt abgerufen 20.5.2012). 
(wörtlich) „Bitte“ verbindlichen Charakter haben sollte. Die Reduzierung der „angemessenen Zeit" auf die Löschaufforderung lief damit dem gesetzlichen Ziel der Bekämpfung von Kinderpornographie zuwider, da in dem Fall, wenn ausnahmsweise keine erfolgreiche Löschung stattfand, ein als kinderpornographisch erkannter Inhalt weiterhin im Internet verbleiben durfte. ${ }^{1262}$

\section{b) Gewaltenteilungsgrundsatz}

Überdies widersprach die Auslegung auch dem Gewaltenteilungsgrundsatz des Art. 20 Abs. 2 Satz 2 GG. Das Gewaltenteilungsprinzip dient als Kernelement des Verfassungs- und Rechtsstaats dazu, einer unzulässigen Machtkonzentration entgegenzuwirken und trägt dafür Sorge, dass „,staatliche Entscheidungen möglichst richtig, das heißt von den Organen getroffen werden, die dafür nach ihrer Organisation, Zusammensetzung, Funktion und Verfahrensweise über die besten Voraussetzungen verfügen. " 1263 Die wesentlichen Funktionen und Aufgabenbereiche werden daher auch per Grundgesetz den drei Gewalten und ihren Organen entsprechend zugewiesen. Aus dem Grundgesetz folgt auch eine bestimmte Loyalitätspflicht. Daraus leitet sich das Verbot des Eingriffs in den Kernbereich einer anderen Gewalt, sowie das Gebot des gegenseitigen Respekts ab, wonach jede Gewalt die Entscheidungen einer anderen Gewalt wechselseitig zu achten und bindend umzusetzen habe. ${ }^{1264}$ Der faktische Nichtanwendungserlass widersprach dieser grundgesetzlichen Wertentscheidung. Kerngehalt der Legislative ist ihre Rechtsetzungsbefugnis. ${ }^{1265}$ Von diesem Recht hatte die Legislative Gebrauch gemacht, indem sie das Zugangserschwerungsgesetz erließ. Der Exekutive wird zwar über das Grundgesetz ein gewisser Handlungsspielraum bei der Ausführung der legislatorischen Entscheidungen eingeräumt, sie darf aber im Rahmen des ihr zustehenden Handlungsspielraums bei der Ausführung der Gesetze nicht dergestalt tätig werden, als sie - wie hier - die Rolle der Legislative einnimmt, sich über ihre Vorgaben hinwegsetzt und die Gesetzesrichtung selbst vorgibt.

\section{Schlussfolgerung}

Zusammenfassend ist demnach herauszustellen, dass der faktische Nichtanwendungserlass gegen Grundwerte der Verfassung verstieß und demnach von Anfang

1262 So auch Höbne, jurisPR ITR 24/2010, Anm. 2, in die Richtung auch Schnabel, K\&R 2011, 175 (176).

1263 BVerfGE 68, 1 (86); BVerfGE 95, 1 (15), darauf bezugnehmen in Zusammenhang mit Nichtanwendungserlassen im Steuerrecht, W. Spindler, DStR 2007, 1061 (1064).

1264 Herzog in: Maunz/Dürig, Art. 20 GG, Rn. 60 sowie 115 mwN; dies anführend auch W. Spindler, DStR 2007, 1061 (1064); Herdegen in: Maunz/Dürig, Art. 79 GG, Rn. 139.

1265 So Sommermann in: v. Mangoldt/Klein/Starck, Art. 20 GG, Rn. 217; Jarass in: Jarass/Pieroth, Art. 20 GG, Rn. 26; Sachs in: Sachs, Art. 20 GG, Rn. 83 ff. 
an nichtig war. Der durch Befolgung des Erlasses durch das BKA hervorgerufene "Zustand" begründete eine mit dem Grundgesetz nicht vereinbare Situation, die folgerichtig nur durch eine formell ordnungsgemäße Aufhebung des Zugangserschwerungsgesetzes aufgelöst werden konnte.

\section{Fazit: Zugangserschwerungsgesetz und Gründe des Scheiterns}

Wie schon zynisch als „Strauß von verfassungsrechtlichen Problemen“ 1266 tituliert, litt das Gesetzesvorhaben rund um das Zugangserschwerungsgesetz in der Tat an formell wie materiell-rechtlichen Verfassungsproblemen, die durch ein ordnungsgemäßes Aufhebungsgesetz relativiert werden mussten. Auch wenn der Gesetzgeber gegenüber der Vorgängerfassung bemüht war, die verfassungsrechtlichen Reibungspunkte zu entschärfen, gelang ihm eine verfassungsrechtlich einwandfreie Umsetzung auch im Zugangserschwerungsgesetz nur bedingt.

So statuierte der Bundesgesetzgeber im Zugangserschwerungsgesetz weder verfahrensrechtliche Sicherungsmittel, welche die Eingriffsintensität des Gesetzesansatzes hätten abmildern können, noch schränkte der den Anwendungsbereich klar auf die Materie der Unterdrückung kinderpornographischer Inhalte ein. Vielmehr machte sich der Gesetzgeber durch die gewählte Ausgestaltung bezüglich formal-verfassungsrechtlicher Unstimmigkeiten angreifbar, was nicht zuletzt auf den „schnellen“ und „harschen“ Vorstoß der Regierung zur Einführung eines Regulierungskonzepts zurückzuführen war.

Für ein Löschgesetz sollte der Gesetzgeber „Lehren aus dem Zugangserschwerungsgesetz" ziehen und sich vor der Schaffung eines Löschgesetzes nicht nur mit den von der Allgemeinheit geäußerten Bedenken auseinandersetzen, sondern detailliert auf wissenschaftlichen Erkenntnissen aufbauen, um die Eignung eines Löschgesetzes für die Unterbindung von Kinderpornographie zu untersuchen. Daher ist die Empfehlung des Innenausschusses, wonach die Bundesregierung zu verpflichten ist, dem Bundestag ab dem Jahr 2013 Bericht über den Erfolg der Löschmaßnahmen zu erstatten, die einzig gangbare Lösung, um möglicherweise erneut auftretende Schutzlücken rechtzeitig erkennen zu können und nicht die gleiche Diskussion anzustacheln, wie sie durch das Zugangserschwerungsgesetz begründet wurde. ${ }^{1267}$

1266 U.A. Sieber in der Anhörung der Sachverständigen im Wirtschaftsausschuss vom 27.5.2009, Wortprotokoll S. 20; darauf bezugnehmend, Marberth-Kubicki, NJW 2009, 1792 (1795); ähnlich auch Greve/Scbrädel, ZRP 2009, 55.

1267 So Stellungnahme des Bundesrates, BR-Drs. 319/11 (Beschluss). 


\section{Teil Europäische Entwicklung}

\section{A. Vom Richtlinienvorschlag zur Richtlinie}

Parallel zur nationalen Diskussion wurde auch auf europäischer Ebene die Debatte um inhaltsbeschränkende Maßnahmen im Internet geführt. Die nachfolgende Darstellung soll die bisherigen Entwicklungen dokumentieren und einen Ausblick auf den Einfluss der europäischen Vorgaben auf die innerstaatliche Umsetzung geben.

\section{Ausgangslage - Richtlinienvorschlag vom 29.3.2010}

Wenngleich in Deutschland eine stetige Abkehr vom Sperransatz als Mittel zur Bekämpfung von Kinderpornographie erkennbar war, wurde auf europäischer Ebene zunächst eben dieser Ansatz über verbindliche Harmonisierungsvorgaben an die Mitgliedstaaten anvisiert. Hierfür stellte die Europäische Kommission am 29.3.2010 einen Richtlinienvorschlag für eine Richtlinie des Europäischen Parlaments und des Rates zur Bekämpfung des sexuellen Missbrauchs und der sexuellen Ausbeutung von Kindern sowie der Kinderpornographie und zur Aufhebung des Rahmenbeschlusses 2004/68/JI des Rates (KOM(2010)94 endg.) vor. ${ }^{1268}$

1268 Vorschlag einer Richtlinie des Europäischen Parlaments und des Rates für eine zur Bekämpfung des sexuellen Missbrauchs und der sexuellen Ausbeutung von Kindern sowie der Kinderpornografie und zur Aufhebung des Rahmenbeschlusses 2004/68/JI des 
Die Europäische Kommission war der Ansicht, dass über die innerstaatlichen Rechtsvorschriften der Mitgliedstaaten, die Probleme des sexuellen Missbrauch und der sexuellen Ausbeutung und Kinderpornographie in unzureichendem Maße gelöst würden. ${ }^{1269}$ Obgleich mit dem Rahmenbeschluss 2004/68/JI ${ }^{1270}$ bereits erste Harmonisierungsverpflichtungen umgesetzt waren, die auf eine Vereinheitlichung eines Mindestschutzstandards für Kinder und Jugendliche zielten, zeigten sich nach Ansicht der Kommission stets rechtliche Defizite, die dem Ziel eines effektiven Kinderschutzes nicht hinreichend Rechnung trügen und daher über verbindliche Vorgaben an das materielle Strafrecht an die übergeordneten Ziele der Union angepasst werden müssten. ${ }^{1271}$

Neben zahlreichen Vorgaben zur Angleichung des gesamten strafrechtlichen Rechtsrahmens für Straftaten im Zusammenhang mit der sexuellen Ausbeutung von Kindern sowie der Kinderpornographie, 1272 enthielt Art. 21 des Richtlinienvorschlags auch einen Ansatz zur technischen Verhinderung des Zugriffs auf Internetseiten mit kinderpornografischen Inhalten:

(1) ,Jeder Mitgliedstaat trifft die erforderlichen Maßnahmen, damit der Zugang von Internet-Nutzern zu Webseiten, die Kinderpornografie enthalten oder verbreiten, gesperrt wird. Die Zugangssperrung erfolgt vorbehaltlich angemessener Schutzvorschriften; insbesondere soll sichergestellt werden, dass die Sperrung auf das Nötige beschränkt wird, dass die Nutzer über die Gründe für die Sperrung

Rates zur Bekämpfung der Kinderpornographie $\operatorname{KOM(2010)94~endgültig.~Zum~Vorschlag~all-~}$ gemein Gercke, ZUM 2010, 633.

1269 So die Begründung des Richtlinienvorschlags $\operatorname{KOM}(2010) 94$ endg. v. 29.3.2010, S. 3.

1270 Rahmenbeschluss 2004/68/JI des Rates vom 22.12.2003 zur Bekämpfung der sexuellen Ausbeutung von Kindern und der Kinderpornographie, ABl. 2004 Nr. L 13, S. 44. Innerstaatliche Umsetzung durch das „Gesetz zur Umsetzung des Rahmenbeschlusses des Rates der Europäischen Union zur Bekämpfung der sexuellen Ausbeutung von Kindern und der Kinderpornographie“, BGBl. I 2008, S. 2149.

1271 Übergeordnetes Ziel ist gem. 67 AUEV die Schaffung eines hohen Maßes an Sicherheit durch Maßnahmen zur Verhütung und Bekämpfung von Kriminalität mit grenzüberschreitenden Charakter, durch die Förderung justizialer Zusammenarbeit. Art. 83 Abs. 1 Satz 2 AEUV benennt die sexuelle Ausbeutung von Kindern und Jugendlichen sowie die Computerkriminalität als ein relevantes Problemfeld innerhalb der justizialen Zusammenarbeit.

1272 Wie beispielsweise einer europaweit einheitlichen Begriffsdefinition des Kinderpornographietatbestandes (Art. 2 lit. b), einer Strafvorschrift zur Kriminalisierung des Zugriffs auf Kinderpornografie (Art. 5 Nr. 3) sowie einer grundlegenden Ausweitung der Strafbarkeit auch des Download-unabhängigen Konsums sowie der Kontaktaufnahme mit Kindern für sexuelle Zwecke (Art. 6, sog. „Grooming „); Zu den einzelnen Harmonisierungsinitiativen, Gercke, ZUM 2010, 633; Stellungnahme des Deutschen Richterbundes, „Stellungnahme des DRB zum Vorschlag für Richtlinie zur Bekämpfung des sexuellem Missbrauchs von Kindern“, abrufbar unter: http://www.drb.de/cms/index.php?id=708 (zuletzt abgerufen 20.5.2012). 
informiert werden und dass Inhaltsanbieter im Rahmen des Möglichen darüber unterrichtet werden, dass sie die Entscheidung anfechten können."

(2) „Unbeschadet des Vorstehenden trifft jeder Mitgliedstaat die erforderlichen Maßnahmen, damit Webseiten, die Kinderpornografie enthalten oder verbreiten, aus dem Internet entfernt werden."

Dieser erste Richtlinienentwurf sah über Art. 21 demnach eine obligatorische Verpflichtung der Mitgliedstaaten zur Schaffung eines legislatorischen Rechtsrahmens für technische Eingriffsbefugnisse im Internetbereich vor, um den Zugriff auf kinderpornographische Angebote zu erschweren. Im Einzelnen sollten gemäß Absatz 1, die Mitgliedstaaten die Erschwerung über eine Sperrung des kinderpornographischen Inhaltes herbeiführen und gleichzeitig auch eine korrespondierende Information der Nutzer hierüber regeln, um einen effektiven Rechtsschutz zu gewährleisten. Über Absatz 2 sollte zusätzlich zur Sperrung auch mit entsprechenden Maßnahmen auf die Entfernung des Inhaltes hingewirkt werden.

Inhaltlich benannte der Richtlinienvorschlag lediglich die Sperrung als solche, ohne diese technisch näher auszugestalten. Weitere Einschränkungen der obligatorischen Sperre - etwa ihr territorialer Anwendungsbereich - waren den europäischen Vorgaben nicht zu entnehmen. Auch die in Absatz 2 genannte Entfernung war nicht näher umschrieben. Erst unter Hinzunahme des maßgeblichen Erwägungsgrundes 13 war eine nähere Spezifizierung der Zugriffserschwerung abzuleiten: „Zur Bekämpfung der Kinderpornographie muss die Verbreitung von Kindermissbrauchsmaterial eingeschränkt werden, indem Straftätern das Laden derartiger Inhalte auf das öffentlich zugängliche Internet erschwert wird. Die Inhalte müssen an der Quelle entfernt werden, und diejenigen Personen, die sich der Herstellung, der Verbreitung oder des Herunterladens von Kindermissbrauchsinhalten schuldig gemacht haben, müssen festgenommen werden. Die EU sollte insbesondere durch verstärkte Zusammenarbeit mit Drittstaaten und internationalen Organisationen dazu beitragen, dass die zuständigen Stellen der Drittstaaten Webseiten mit Kinderpornografie, die von Servern in ihrem Hoheitsgebiet verbreitet werden, leichter entfernen können. Da sich die Entfernung von Kinderpornografieinhalten an der Quelle trotz derartiger Bemühungen aber als schwierig erweist, wenn sich das Originalmaterial nicht in der EU befindet, sollten Verfahren eingeführt werden, um den Zugang vom Hoheitsgebiet der Union zu Internetseiten, die Kinderpornografie enthalten oder verbreiten, zu sperren. Für diesen Zweck eignen sich verschiedene Verfahren: beispielsweise kann die Anordnung einer Sperre durch die zuständigen Justiz- oder Polizeibehörden erleichtert werden oder die Internetanbieter können angeregt oder dabei unterstützt werden, auf freiwilliger Basis Verhaltenkodizes und Leitlinien für die Sperrung des Zugangs zu derartigen Internetseiten zu entwickeln. Um insbesondere sicherzustellen, dass mit Blick auf die Entfernung von Kindermissbrauchsinhalten und die Sperrung des Zugangs zu derartigen Inhalten möglichst vollständige nationale Listen von Webseiten mit Kinderpornographiematerial erstellt werden, und um Doppelarbeit zu vermeiden, 
sollten die zuständigen öffentlichen Stellen zusammenarbeiten oder ihre Zusammenarbeit verstärken. Derartige Maßnahmen müssen die Rechte der Endnutzer berücksichtigen, den bestehenden Rechts- und Justizverfahren Rechnung tragen und im Einklang mit der Europäischen Konvention der Menschenrechte und der Europäischen Charta der Grundrechte stehen. Im Rahmen des Programms zur sicheren Internetnutzung wurde ein Netzwerk von Hotlines eingerichtet, deren Ziel es ist, Informationen zu sammeln und Berichte über die wichtigsten Arten von illegalen Online-Inhalten zu erstellen und auszutauschen. “1273

Erwägungsgrund 13 umschrieb die Entfernung als „Entfernung an der Quelle“, was diese gleichbedeutend mit dem technischen Instrument der Löschung des Inhaltes war. Denn für die „Entfernung“ eines Angebots an der „Quelle“ ist es notwendig, die Dateninhalte vom jeweiligen Speichermedium mittels Entfernung der Daten aus dem Zielverzeichnis zu entnehmen, was letztlich auf eine technische Löschung des Inhaltes hinausläuft. ${ }^{1274}$ Hinsichtlich der Art der vorzunehmenden Sperrmaßahme lief die Heranziehung des Erwägungsgrundes jedoch leer. Der Richtliniengeber beschränkte die nähere Umschreibung der Sperrung auf die Art und Weise, wie die technische Sperrmaßnahme verfahrenstechnisch einzubetten war. So nannte der Erwägungsgrund beispielsweise, dass die Sperre über eine Anordnung durch die zuständigen Justiz- oder Polizeibehörden oder auf Basis freiwilliger Vereinbarungen mit den Anbietern erreicht werden konnte. Nicht deutlich wurde hingegen die technische Ausgestaltung derselben. Diesbezüglich war der Vorschlag völlig offen formuliert und überließ den Mitgliedstaaten die eigenständige Auswahl der gängigen Sperrmethoden sowie die Möglichkeit, die Auswahl der Sperrmethoden verbindlich auf eine bestimmte technische Sperrvariante zu beschränken. Auch war aus der Formulierung der Verpflichtung in Art. 21 kein explizites Rangverhältnis zwischen Löschen und Sperren herauszulesen. Vielmehr sollten die Mitgliedstaaten Maßnahmen zur Löschung „unbeschadet“ der Maßnahmen zur Sperrung ergreifen. Die Formulierung ließ indes darauf schließen, dass die Sperrung und die Löschung nebeneinander Anwendung finden sollten.

Unter Gesamtbetrachtung zum Erwägungsgrund 13 war dieses Ergebnis jedoch nicht zwingend. So hieß es dort ausdrücklich, dass die verstärkte Zusammenarbeit insbesondere darauf abzielen soll, dass kinderpornographische Inhalte leichter entfernt werden können. Dabei erkannte der Richtliniengeber, dass „(...) sich die Entfernung von Kinderpornographieinhalten an der Quelle trotz derartiger Bemühungen aber als schwierig erweist [in diesem Fall] sollten Verfahren eingeführt werden, um den Zugang vom Hoheitsgebiet der Union zu Internetseiten, die Kinderpornografie enthalten oder verbreiten, zu sperren.“ Die Erwägung der Europäischen Kommission deutete indessen darauf hin, dass vorrangig Bemü-

1273 Erwägungsgrund 13 zum Richtlinienvorschlag KOM(2010)94 endg., S. 13.

1274 Zur technischen Realisierung einer Löschung, oben unter 3. Teil B. I. 2. c) (aa) . 
hungen hinsichtlich einer Entfernung erfolgen sollten und nur im Falle der missglückten beziehungsweise „schwierigen“ Löschung auch Zugriffssperren vorzunehmen wären. Eine eindeutige Tendenz war dem Richtlinienentwurf indes nicht zu entnehmen.

Noch widersprüchlicher gestaltete sich der territoriale Anwendungsbereich der Zugriffssperren. Allein aus dem Wortlaut des Art 21 Abs. 1 des Richtlinienvorschlags war keinerlei Beschränkung des Anwendungsbereichs der Sperrmaßnahmen zu folgern. Auf Basis des Art. 21 Abs. 1 wären verpflichtend Sperrmechanismen einzuführen, die Inhalte von Anbietern innerhalb des Geltungsbereichs der Mitgliedstaaten der EU beträfen, genauso wie von außereuropäischen Anbietern. Der Erwägungsgrund war diesbezüglich insofern widersprüchlich formuliert, als er die Sperrung stets im Kontext zu „Drittstaaten“ anführte. So hieß es: „Die EU sollte insbesondere durch verstärkte Zusammenarbeit mit Drittstaaten und internationalen Organisationen dazu beitragen, dass die zuständigen Stellen der Drittstaaten Webseiten mit Kinderpornographie, die von Servern in ihrem Hoheitsgebiet verbreitet werden, leichter entfernen können." Bei „Schwierigkeiten“ der Entfernung im Falle, dass sich „das Originalmaterial nicht in der EU befindet" wird erst die Bezugnahme zur Sperrung geschaffen, indem Verfahren einzuführen sind, „um den Zugang vom Hoheitsgebiet der Union zu Internetseiten, die Kinderpornografie enthalten oder verbreiten, zu sperren“. .275

Betrachtete man jedoch den Gesamtkontext des Richtlinienentwurfs, wurde die Möglichkeit der Sperrung gerade nicht territorial auf bestimmte Herkunftsländer beschränkt. Vielmehr sprach sich der Richtliniengeber faktisch für eine vom jeweiligen Herkunftsland unabhängige Notwendigkeit von Maßnahmen zur Bekämpfung von Kinderpornographie aus. Diesem Ziel hätte der Richtliniengeber selbst zuwider gehandelt, wenn er die Zugriffserschwerung mittels Sperrung nur auf Inhalte beschränken wollte, die von Anbietern außerhalb der EU stammen. Zudem betonte der Richtlinienvorschlag in dem Zusammenhang, dass alle Maßnahmen auszuschöpfen seien, die Kinder vor Gewalt und sexueller Ausbeutung „inner- und außerhalb“ der EU schützten sollen. ${ }^{1276}$

Bereits diese „missliche“ textliche Ausgestaltung des Richtlinienentwurfs lässt darauf schließen, dass der Vorschlag im nachfolgenden Rechtssetzungsverfahren stark diskutiert wurde. Anschließend sollen daher die wichtigsten Stellungnahmen verkürzt wiedergegeben werden, die maßgeblich dazu beigetragen haben, den Weg zu der endgültigen Richtlinienfassung zu ebnen.

\section{Rechtssetzungsverfahren: Die Beratungen zum Richtlinienentwurf}

Nach Zuführung des Richtlinienentwurfs in die Beratungsphase, hatten sich in allen Gremien der EU-Rechtssetzungsorgane die Diskussionen vor allem auf die

1275 Erwägungsgrund 13 zum Richtlinienvorschlag $\operatorname{KOM}(2010) 94$ endg., S. 13.

1276 Richtlinienvorschlag $\operatorname{KOM}(2010) 94$ endg., S. 3. 
in Art. 21 enthaltene Sperrverpflichtung konzentriert. Insbesondere hinsichtlich der Frage, ob die Sperrung kinderpornographischer Inhalte obligatorischer oder fakultativer Natur ausgerichtet sein sollte, bestand Uneinigkeit.

Der Europäische Wirtschafts- und Sozialausschuss legte im September 2010 seine auf Grundlage des Art. 304 AEUV erstellte Stellungnahme zum Richtlinienvorschlag vor. ${ }^{1277}$ Vor allem stimmte der Ausschuss darin der grundsätzlichen Intensivierung des europäischen Engagements zur Bekämpfung des Kindesmissbrauchs zu und lobte die Initiative, dass der bestehende Rahmenbeschluss durch eine „sachgerechtere Richtlinie“ ersetzt werden sollte. In Bezug auf die technischen Erschwerungsmaßnahmen in Art. 21 sprach sich der Europäische Wirtschafts- und Sozialausschuss eindeutig für die Einräumung der Priorität der Entfernung entsprechender Internetseiten aus. Sperrungen kinderpornographischer Angebote sollten nur angeordnet werden, falls eine Löschung derselben nicht möglich sei. Hierfür regte der Ausschuss eine Neufassung des Art. 21 an, in welcher der Entfernung explizit der Vorrang eingeräumt werde. Eine Sperrung könne allerdings als kurzfristige taktische Maßnahme parallel zur Beseitigung des Inhaltes formuliert sein, um ein größeres Schutzniveau für Kinder und unbeteiligte Nutzer zu statuieren. ${ }^{1278}$ Zudem sei es notwendig die Formulierung um die Anordnung eines „unverzüglichen“ Tätigwerdens zu ergänzen, um zu gewährleisten, dass die entsprechenden Webseiten nach ihrer Ermittlung zeitnah abgeschaltet werden. Überdies führte der Europäische Wirtschafts- und Sozialausschuss einen weiteren Aspekt an, der in dem vorliegenden Richtlinienvorschlag nur mangelhafte Berücksichtigung fand. Danach hafte dem eingebrachten Vorschlag eine Beeinträchtigung des angestrebten Kinderschutzes an, da die vorgesehenen Präventions- und Strafverfolgungsmaßnahmen nicht auch den Bereich des interaktiven Austausches in Peer-to-Peer-Netzwerken beträfen. Wegen der Zunahme des Austauschs beispielsweise in sozialen Netzwerken, müssten unverzüglich Nachbesserungen an der Richtlinie vorgenommen werden, welche auch Verfolgungsmaßnahmen für Nutzer und Diensteanbieter, die solche Seiten speichern (Host-Provider), normieren. Der Wirtschafts- und Sozialausschuss regte auf Grundlage seiner Bewertung auch eine Anpassung des maßgeblichen Erwägungsgrundes 13 an. Danach solle der gewählte Ausdruck „öffentlich zugänglich“ (i.S. öffentlich zugängliches Internet) ersetzt werden, durch „Kindesmissbrauchsmaterial in jedem Kommunikationsmedium“, um dadurch klar herauszustellen, dass auch individuelle Tauschbörsen und soziale Netzwerke von den Vorgaben des Richtlinienentwurfs umfasst

1277 Stellungnahme des Europäischen Wirtschafts- und Sozialausschusses zum Richtlinienvorschlag KOM(2010)94 endg., SOC/377 „Sexueller Missbrauch von Kindern und Kinderpornographie“ v. 15.9.2010.

1278 Stellungnahme des Europäischen Wirtschafts- und Sozialausschusses zum Richtlinienvorschlag KOM(2010)94 endg., SOC/377 „Sexueller Missbrauch von Kindern und Kinderpornographie“ v. 15.9.2010, S. 12. 
sind. Hinsichtlich der Formulierung, dass „Internetanbieter (...) angeregt oder dabei unterstützt werden [können] auf freiwilliger Basis Verhaltenskodizes und Leitlinien für die Sperrung des Zugangs derartiger Internetseiten zu entwickeln“, sprach sich der Ausschuss folglich auch für eine Nachrangigkeit dieses Vorgehens gegenüber der Löschung des Angebotes aus. Dieses sollte jedoch nicht über „freiwillige Vereinbarungen“, sondern auf Grundlage fundierter gesetzlicher Bestimmungen umgesetzt werden.

Parallel zur Vorlage des Europäischen Wirtschafts- und Sozialausschuss hatte sich auch der federführende Ausschuss für bürgerliche Freiheiten, Justiz und Inneres (LIBE) mit dem Richtlinienvorschlag zu befassen. Der Abschlussbericht ${ }^{1279}$ basierte unter anderem auf Grundlage zuvor eingeholter Stellungnahmen des Europäischen Ausschusses für Kultur und Bildung ${ }^{1280}$ sowie des Ausschusses für die Rechte der Frau und die Gleichstellung der Geschlechter. ${ }^{1281}$

Der Ausschuss für Kultur und Bildung ersuchte den Ausschuss für bürgerliche Freiheiten, Justiz und Inneres, seine Änderungsanträge in dem Abschlussbericht zum Richtlinienvorschlag zu übernehmen. Hauptaugenmerk legte der Ausschuss für Kultur und Bildung in seiner Stellungnahme auf die in Frage stehenden technischen Erschwerungsmaßnahmen des Art. 21 und kam überwiegend zu dem Ergebnis, dass große Bedenken daran bestünden, ob die mit dem Richtlinienvorschlag formulierten Ziele über eine solche Richtlinienformulierung erreicht werden können. Die Änderungsanträge der Stellungnahme gingen dabei deutlich und präzisiert über die Vorgaben des Wirtschafts- und Sozialausschusses hinaus. Zwar vertrat der Kultur- und Bildungsausschuss in Übereinstimmung zur Auffassung des Wirtschafts- und Sozialausschusses, dass die Löschung des Inhaltes als technisierte Maßnahme im Kampf gegen Kinderpornographie im Fokus stehen solle, die Stellungnahme machte überdies jedoch den Standpunkt deutlich, dass sie Zugriffssperren als uneffektiv und daher unwirksam im Kampf gegen Kinderpornographie erachtete. Aufgrund ihrer leichten Umgehbarkeit und Ungenauigkeit führen Sperren nicht zu einer Beseitigung der Inhalte, sondern nur zur „relativen Nichtverfügbarkeit“. Die Errichtung einer Sperrinfrastruktur wecke, nach Ansicht der Kultur- und Bildungsausschuss, „Begehrlichkeiten“ hinsichtlich anderer verbotener Inhalte, so dass zunehmend die Gefahr bestehe, die Sperrinfrastruktur künftig nicht nur gegen kinderpornographische Angebote einzusetzen, sondern grundsätzlich eine „Abkehr vom Grundsatz der Netzneutralität“ zu folgern sei. ${ }^{1282}$

1279 Ausschuss für bürgerliche Freiheiten, Justiz und Inneres, 2010/0064 (COD) v. 24.1.2011.

1280 Stellungnahme des Ausschusses für Kultur und Bildung des Europäischen Parlaments v. 10.11.2010,CULT_AD(2010)442976.

1281 Stellungnahme des Ausschusses für die Rechte der Frau und die Gleichstellung der Geschlechter v. 25.1.2011, FEMM_AD(2011)448743.

1282 Stellungnahme des Ausschusses für Kultur und Bildung des Europäischen Parlaments v. 10.11.2010,CULT_AD(2010)442976, S. 3. 
Ausdrücklich widerspricht der Ausschuss in seiner Stellungnahme, dem vom Wirtschaft- und Sozialausschuss präferierten Grundsatz des „Löschen vor Sperren“. Auch in diesem Fall sei die Errichtung einer Sperrinfrastruktur notwendig und somit auch die daraus zu folgernden Befürchtungen einer uferlosen Ausweitung der „sperrungswürdigen“ Angebote. Über Zugriffssperren könnten höchstens „Gelegenheitstäter“ abgeschreckt werden, was in Korrespondenz zum weitreichenden Eingriff in die Informationsfreiheit der Nutzer nicht zu rechtfertigen sei. Grundsätzlich bedarf es im Kampf gegen Kinderpornographie eines Ansatzes, der gleichermaßen Inhalte im frei zugänglichen Internet umfasse, als auch Inhalte im individualtechnischen Kommunikationsbereichen, wie E-Mail, Peer-to-Peer Netzwerken und Mobilfunk. Insgesamt sind als Kernpunkte der Stellungnahme des Kultur- und Bildungsausschuss zusammenzufassen, dass keine konkreten Vorgaben für die Errichtung von Internetsperren in die Richtlinie aufgenommen werden und die kinderpornographischen Inhalte in allem Kommunikationsmedien europaweit über den Löschansatz verfolgt werden sollen. Im Rahmen des Änderungsvorschlags für Art. 21 regte der Ausschuss eine ausdrücklichen Fokussierung auf die Entfernung in Abs. 1 und eine fakultative Überlassung weitergehender Maßnahmen in der Entscheidungsgewalt der Mitgliedstaaten. Ebenfalls seien weitergehende Maßnahmen nur zu erlauben, wenn alle Maßnahmen zur Löschung voll erschöpft wurden und auf dieser Grundlage hinreichend erwiesen ist, dass eine Löschung nicht mehr möglich wäre. Die Vornahme anderweitiger Maßnahmen soll vom Wortlaut her so ausgestaltet sein, dass die anderweitigen Maßnahmen nur über einen Richtervorbehalt vorgesehen seien und ausreichende Rechtsschutzmöglichkeiten implizieren. ${ }^{1283}$

Der Ausschuss für die Rechte der Frau und der Gleichberechtigung der Geschlechter führte in seiner Stellungnahme für den Ausschuss für bürgerliche Freiheiten, Justiz und Inneres ebenfalls das Thema der „Löschung und Sperrung“ von Inhalten aus und kam anders als etwa der Kultur- und Bildungsausschuss zu dem Ergebnis den „Löschen vor Sperren“-Ansatz europaweit verpflichtend einzuführen. ${ }^{1284}$ In einigen Mitgliedstaaten sei bislang erfolgreich mit der Sperrung gegen kinderpornographische Inhalte vorgegangen, deshalb sei es ,unerlässlich“, für den Fall, dass die Inhalte nicht gelöscht werden können, den Sperransatz nachrangig zu verfolgen. Bei Inhalten, die außerhalb der EU stammen, wäre dieser Ansatz, nach Ansicht des Gleichberechtigungsausschusses, „möglicherweise die einzig durchführbare Lösung“". Hinsichtlich des Formulierungsvorschlages lehnten die Änderungsvorschläge des Ausschusses der Ausgangsformulierung des Richtlinienentwurfs an. So sei obligatorisch eine Verpflichtung zur Entfernung einzuführen

1283 Stellungnahme des Ausschusses für Kultur und Bildung des Europäischen Parlaments v. 10.11.2010, CULT_AD(2010)442976, S. 49.

1284 Stellungnahme des Ausschusses für die Rechte der Frau und die Gleichstellung der Geschlechter v. 25.1.2011, FEMM_AD(2011)448743, S. 4. 
sowie in den Fällen, in denen die Entfernung nicht möglich sei, die Zugangssperrung „vorbehaltlich angemessener Schutzvorschriften“ zu regeln und mit einer Unterrichtungspflicht sowie einem Rechtsschutzhinweis zu versehen. ${ }^{1285}$

Der abschließende Bericht des federführenden Ausschusses bürgerliche Freiheiten, Justiz und Inneres, der auf Grundlage der Einholung der vorangegangenen Stellungnahmen erstellt wurde, nahm grundlegend eine positive Grundhaltung zu der angestrebten Harmonisierungsinitiative ein. Auch der Ausschuss für bürgerliche Freiheiten, Justiz und Inneres wies jedoch auch die Notwendigkeit einer vorrangigen Entfernung kinderpornographischer Inhalte hin und regte auf Basis dessen an, den entscheidenden Art. 21 so zu formulieren, dass der Entfernung auch im Wortlaut bereits eine Priorität gegenüber der Sperrung eingeräumt werde. Nach Ansicht des LIBE-Ausschusses sei jedes Herunterladen oder Anschauen eines kinderpornographischen Angebotes wie ein wiederholter Kindesmissbrauch zu werten und bedürfe daher einer strengen Verfolgung. Die umgehende Entfernung des Inhaltes aus dem Gesamtbestand des Internets sollte daher Hauptziel der Richtlinie sein. Daneben hält auch der LIBE-Ausschuss, in Abweichung zu dem Änderungsantrag des Bildungs- und Kulturausschusses, die Möglichkeit einer Sperrung des kinderpornographischen Angebotes nicht grundsätzlich für ausgeschlossen. Soweit es sich um Angebote handele, bei denen eine umgehende Entfernung nicht möglich sei, beispielsweise wenn sich die Provider in Drittstaaten befinden zu denen keine Kooperationsabkommen mit der EU bestehen, sollten die Mitgliedstaaten, wie auch zuvor vom Ausschuss für die Rechte der Frauen sowie dem Wirtschafts- und Sozialausschuss angeregt, die Seiten sperren dürfen. ${ }^{1286}$ Das Ergreifen dieser Möglichkeit wäre jedoch nicht als umzusetzende Verpflichtung in der Richtlinie auszugestalten, sondern sei den Mitgliedstaaten selbst zu überlassen. Sollten die Mitgliedstaten eigenständig Regelungen zur nachrangigen Sperrung in ihre Rechtsvorschriften aufnehmen, müssen sich diese im Einklang mit einzelstaatlichen Bestimmungen der Mitgliedstaaten befinden und vor allen auch aus datenschutzrechtlicher Perspektive einen angemessenen Schutzstandard bieten. Der diesbezügliche Formulierungsvorschlag des Art. 21 lehnte sprachlich zwar an den bisherigen Richtlinienentwurf an, schon innerhalb der Überschrift sollte die Neuausrichtung jedoch ersichtlich werden, indem Art. 21 anstelle der „Sperrung“ mit „Entfernung und Zugangssperrung von Webseiten, die Kinderpornographie enthalten“, überschrieben werde. Weiter sei Absatz 2 zu streichen und die dort benannte Entfernung in Absatz 1 zu überführen. Sprachlich solle der obligatorische Charakter der Löschung durch die Beibehaltung einer ermessensfreien Formulierung, wie sie bereits im Richtlinienentwurf $\operatorname{KOM}(2010) 94$ endg. angestrebt war, beibehalten werden, indem statuiert wird,

1285 Stellungnahme des Ausschusses für die Rechte der Frau und die Gleichstellung der Geschlechter v. 25.1.2011,FEMM_AD(2011)448743, S. 37.

1286 Ausschuss für bürgerliche Freiheiten, Justiz und Inneres, 2010/0064 (COD) v. 24.1.2011, S. 35. 
dass ,jeder Mitgliedstaat die erforderlichen Maßnahmen trifft um Webseiten, die Kinderpornographie enthalten an der Quelle aus dem Internet zu entfernen“. Die fakultative Sperrung wird im Änderungsvorschlag des LIBE-Ausschusses als solche ebenfalls sprachlich herausgehoben: „Um die Interessen des Kindes zu schützen können die Mitgliedstaaten in Übereinstimmung mit nationalem Recht zusätzlich Verfahren entwickeln, um in ihrem Hoheitsgebiet den Zugang von InternetNutzern zu Webseiten zu sperren““. ${ }^{287}$ Gleichzeitig zur inhaltlichen Änderung des Art. 21 bemühte sich der Ausschuss auch eine Anregung zur Anpassung des Erwägungsgrundes 13 an die neue Maßnahmeninitiative zu liefern. In diesem solle explizit die Entfernung an der Quelle als Mittel zur Bekämpfung von Kinderpornographie ausgewiesen sein, sowie klargestellt werden, dass die Mitgliedstaaten die Mittel zur Anwendung bringen könnten, „die ihnen am besten geeignete erscheinen, um ein Abrufen und Herunterladen der Bilder umgehend zu unterbinden und der weiteren Schädigung des Opfers damit Einhalt zu gebieten. " Grundlegend behielt der federführende LIBE-Ausschuss damit die bereits innerhalb der ersten Stellungnahmen favorisierte Grundlinie bei, wonach der Richtlinienvorschlag hinsichtlich der Erschwerungsmaßnahmen abzuändern und deutlich in die Richtung der primären Notwendigkeit einer Entfernung der kinderpornographischen Inhalte zu präzisieren sei. Als federführender Ausschuss fordert der LIBEAusschuss damit die EU-Kommission auf, sich erneut mit dem Richtlinienentwurf zu befassen und entsprechend die Änderungsvorschläge zu übernehmen.

In der nachfolgend im Februar 2011 stattgefunden Sitzung des Europäischen Ausschusses für bürgerliche Freiheiten, Justiz und Inneres wurde der Richtlinienentwurf beraten und der in der Sitzung erarbeitete „Kompromissvorschlag“ zur Abstimmung gebracht. ${ }^{1288}$ Im Vergleich zum Erstentwurf der Kommission

1287 Ausschuss für bürgerliche Freiheiten, Justiz und Inneres, 2010/0064 (COD) v. 24.1.2011, S. 31.

1288 Ergebnisse abrufbar unter:

http://www.europarl.europa.eu/wps-europarl-

internet $/ \mathrm{frd} / \mathrm{vod} /$ player?date=20110214\&language=de\#; hierzu auch Pressemitteilung des zuständigen Berichterstatters der Arbeitsgruppe Rechtspolitik der SPD-Bundestagsfraktion Lischka, „EU Parlament spricht sich für Löschen statt Sperren aus“ v. 15.2.2011, abrufbar unter: http://www.burkhard-lischka.de/2011/02/eu-parlament-spricht-sich-fuer-loeschen-statt-

sperren-aus/; Sawal in: golem.de, Meldung v. 15.2.2011, „EU-Parlament gegen Internetsperren“, abrufbar unter: http://www.golem.de/1102/81436.html; Benrath in: netzpolitik.org, Meldung v. 14.2.2011, „Etappensieg bei Netzsperren in der EU“, abrufbar unter:

http://www.netzpolitik.org/2011/etappensieg-bei-netzsperren-in-der-eu/.

Die europäische Ausrichtung wurde im Juli 2011 bestätigt, dass der Ansatz sich auf Löschmaßnahmen konzentrieren soll. Soweit Sperren fakultativ zur Anwendung kommen, müssen sie „transparent“ und „verhältnismäßig“ sein, zitiert nach Bendrath in: netzpolik.org, Beitrag v. 27.6.2011, „Einigung bei Internetsperren in der EU“, abrufbar unter: netzpolitik.org/2011/einigung-bei-internetsperren-in-der-eu/ (jeweils zuletzt abgerufen 20.5.2012). 
einigten sich die Beteiligten auf eine, an den Bericht des LIBE-Ausschusses angelegte Vorgehensweise: Dem Kompromissvorschlag folgend, sollten alle Mitgliedsstaaten verpflichtend ihre Bemühungen zum Löschen von kinderpornographischen Webseiten verstärken. Die darüber hinausgehende Möglichkeit anderer technischer Maßnahmen im Kampf gegen Kinderpornographie, wie die diskutierten Sperren, sollte innerhalb der Richtlinie in die Entscheidungskompetenz der Mitgliedstaaten überführt werden. Falls die Mitgliedstaaten sich für die nachrangige Methode der Sperrung entscheiden, sei in der Richtlinie herauszustellen, dass Sperren nur als ultima-ratio ausgestaltet sein dürfen und nur in dem Fall Anwendung finden, wenn sich das Löschen des Angebotes als unmöglich erwiesen habe. Der Kompromissvorschlag nahm damit wesentliche im Rechtssetzungsverfahren beratenen Änderungen auf, verzichtete hingegen auf die Aufnahme des vom Bildungs- und Kulturausschuss präferierten Richtervorbehalts zur Absicherung der Rechtschutzmöglichkeit. Vielmehr genügte danach, wie im vorgegangenen Rechtssetzungsverfahren gefordert, die Normierung einer umzusetzenden Informationspflicht und der Hinweis auf etwaige Rechtsschutzmöglichkeiten.

Letztlich mündete dieser teilweise auch informell geführte Trialog zwischen Kommission, Rat und Parlament im Juni 2011 in eine formellen Kompromissfassung, ${ }^{1289}$ die am 27.10.2011 zunächst vom Europäischen Parlament ${ }^{1290}$ und am 15.11.2011 auch vom Rat angenommen wurde. ${ }^{1291}$

III. Die endgültige Richtlinienfassung vom 13.12.2011

Die endgültige Richtlinie (2011/93/EU) ${ }^{1292}$ des Europäischen Parlaments und des Rates wurde am 13.12.2011 erlassen und am 17.12.2011 im Amtsblatt der Europäischen Union verkündet. ${ }^{1293}$ Entsprechend Art. 27 tritt die Mitgliedstaaten die Pflicht die Vorgaben der Richtlinie bis zum 18.12.2013 umzusetzen.

1289 Vgl. Rat der Europäischen Union, DROIPEN 68 JAI 441 CODEC 1091 v. 27.6.2011, hierzu Brodowski, ZIS 2011, 940 (945). Diese Kompromisslösung weicht in bezug auf die technischen Erschwerungsmaßnahmen im Wortlaut nicht von der im Februar erarbeitenen Kompormisslösung ab.

$1290 \mathrm{Zu}$ den weiteren Abstimmungergebniss vgl. Vermerk des Europäischen Rates zu den Ergebnissen der ersten Lesung des Europäischen Parlaments, DROIPEN 123 JAI 759 CODEC 1767 v. 3.11.2011.

1291 Vgl. Fassung des Ratsdokuments DROIPEN 91 JAI 601 CODEC 1398 v. 4.11.2011. Vgl. zusammenfassend zum Rechtssetzungsverfahren, Gercke, „EU: Verabschiedung der Richtlinie gegen Kinderpornographie", CR Online, abrufbar unter:

http://www.computerundrecht.de/gesetzgebungsreport_internetregulierung_24877.htm (zuletzt abgerufen 20.5.2012).

1292 Zum Namen siehe Berichtigung (ABl. 2011 Nr. L 18, S. 7), da zuvor fälschlicherweise unter der Bezeichnung 2011/92/EU verkündet.

1293 ABl. 2011 Nr. L 335, S. 1. 
Wie sich bereits frühzeitig im Rechtssetzungsverfahren herauskristallisierte, ist die Möglichkeit der Sperrung nur noch als obligatorische Pflicht an die Mitgliedstatten formuliert, die Löschung kinderpornographischer Webseiten hingegen verpflichtend. Der Wortlaut der Vorschrift des Art. 25 (ex. Art. 21 des Richtlinienentwurfs) ist wie folgt abändert:

(1) Die Mitgliedstaaten treffen die erforderlichen Maßnahmen, um sicherzustellen, dass Internetseiten, die Kinderpornografie enthalten oder verbreiten und sich auf Servern in ihrem Hoheitsgebiet befinden, unverzüglich entfernt werden, und bemühen sich, darauf hinzuwirken, dass derartige Seiten von Servern außerhalb ihres Hoheitsgebiets entfernt werden.

(2) Die Mitgliedstaaten können Maßnahmen treffen, um den Zugang zu Internetseiten, die Kinderpornografie enthalten oder verbreiten, für die Internetnutzer in ihrem Hoheitsgebiet zu sperren. Diese Maßnahmen müssen in transparenten Verfahren festgelegt werden und ausreichende Sicherheitsvorkehrungen bieten, insbesondere um sicherzustellen, dass die Einschränkung auf das Notwendige beschränkt und verhältnismäßig ist und dass Nutzer über den Grund für die Beschränkung informiert werden. Diese Sicherheitsvorkehrungen schließen auch die Möglichkeit von Rechtsmitteln ein.

Die Bedenken, die bereits hinsichtlich des Richtlinienvorschlags geäußert wurden, ${ }^{1294}$ relativiert auch die endgültige Richtlinienfassung nur unzureichend. Erneut entzieht sich der Richtliniengeber der näheren technischen Ausgestaltung der Zugangserschwerungsmaßnahmen sowie einer verfassungsmäßig gebotenen Absicherung des ultima-ratio Charakters der Sperrung gegenüber der Löschung. Der Richtliniengeber flüchtet vielmehr in eine offene Anreizgebung, deren Umsetzung den Mitgliedstaaten in freier Verantwortung obliegt. So heißt es in dem korrespondierenden Erwägungsgrund 47 (ex 13):

„Die von den Mitgliedstaaten in Übereinstimmung mit dieser Richtlinie eingeleiteten Maßnahmen zur Entfernung oder, wenn angemessen, zur Sperrung des Zugangs zu Websites mit kinderpornografischem Inhalt könnten auf unterschiedlichen öffentlichen Maßnahmen legislativer, nicht legislativer, juristischer oder anderer Art aufbauen. In diesem Zusammenhang lässt diese Richtlinie freiwillige Maßnahmen der Internet-Industrie zur Verhinderung des Missbrauchs ihrer Dienste oder jegliche Unterstützung solcher Maßnahmen durch Mitgliedstaaten unberührt. Unabhängig davon, welche Maßnahme oder Methode gewählt wird, sollten die Mitgliedstaaten gewährleisten, dass diese ein angemessenes Niveau an Rechtssicherheit und Vorhersehbarkeit für die Nutzer und die Diensteanbieter bietet."

Der Richtliniengeber verlangt den Mitgliedstaaten insofern angemessene und rechtssichere Maßnahmen ab. Mit der gewählten offenen Formulierung des Art. 26 räumt er bei der Erfüllung dieser Aufgabe, den Mitgliedstaaten selbst jedoch

1294 Bereits unter 5. Teil A. I. 
einen so starken Anwendungsspielraum ein, dass die Gefahr besteht, diese gesetzgeberische Intention von „Rechtssicherheit und Vorhersehbarkeit“ könnte durch die gewählte Offenheit ins Gegenteil verkehrt werden und damit letztlich auch dem übergeordneten Ziel der „Erreichung einer Harmonisierung“ nicht zuträglich sein. So ist von europäischer Seite noch nicht einmal das Umsetzungsmittel vorgegeben. Dieses kann nach dem Erwägungsgrund „legislativer, nicht legislativer, juristischer oder anderer Art" sein. Welche Maßnahmen sich der Richtliniengeber vorstellt, wenn er von juristischen (aber nicht legislativen) oder gar Maßnahmen „anderer Art“ spricht, lässt sich der Richtlinie nicht entnehmen. Es bleibt den Mitgliedstaaten danach möglich den Bereich der technischen Erschwerung beispielsweise über imperative staatliche Regelungen abzusichern; ebenso wäre es nach der Richtlinie zulässig, die technischen Erschwerungsmaßnahmen der reinen Selbstregulierung zu überlassen und den Rahmenprozess allein den treibenden und auf Freiwilligkeit beruhenden Durchsetzungsinteressen der Wirtschaftssubjekte zu überlassen. Letzteres wird aber gerade in dem durch Erschwerungsmaßnahmen berührten höchst grundrechtssensiblen Bereich rechtsstaatlich kaum durchsetzbar sein.

Nur geringe Verbesserungen bringt die endgültige Richtlinienfassung hinsichtlich des territorialen Anwendungsbereichs der Erschwerungsmaßnahmen. Wie schon im Richtlinienvorschlag widersprüchlich formuliert, lässt auch die endgültige Richtlinienfassung nicht hinreichend erkennen, ob die Maßnahmen lediglich auf den EU-interne Kinderpornographieangebote beschränkt werden oder darüber hinausgehend auch solche aus Drittstaaten erfassen. Der Wortlaut des Art. 26 spricht in diesem Zusammenhang davon, dass Kinderpornographieangebote aus dem „Hoheitsgebiet der jeweiligen Mitgliedstaaten“ entfernt werden sollen, der damit korrespondierende Erwägungsgrund 46 allerdings davon, dass die Mitgliedstaaten ,sich nach Kräften bemühen [sollen] mit Drittländern zusammenzuarbeiten, um die Entfernung solcher Inhalte auf deren Servern auf deren Hoheitsgebieten sicherzustellen." Letztlich wird der Richtliniengeber aufgrund des übergeordneten Ziels einer „umfassenden“ Erschwerung des Zugriffs auf kinderpornographische Angebote wohl Maßnahmen im Sinn gehabt haben, die über mitgliedstaatliche Grenzen hinaus Wirkung entfalten.

Die gleiche Widersprüchlichkeit wird auch in Bezug auf die Sperrung deutlich. Hinsichtlich der obligatorischen Sperrmaßnahmen hält sich der Richtliniengeber zwar bei Art und Weise der Umsetzung zurück, favorisiert augenscheinlich aber eine dem Zugangserschwerungsgesetz angenäherte Durchsetzungsmöglichkeit. So sollen gemäß Erwägungsgrund 47 diejenigen Mitgliedstaaten, die sich für eine Sperrungsmöglichkeit entscheiden, darauf hinwirken, dass Behörden verstärkt zusammenarbeiten um möglichst vollständige nationale „Listen“ von Webseiten mit Kinderpornographiematerial zu erstellen. Folglich sieht auch der Richtliniengeber die „Sperrlisten“ als einen notwendigen Zwischenschritt für die erfolgreiche Realisierung der technischen Erschwerungsmaßnahmen. 
Wie bereits anhand der Kompromisslösung zu erwarten war, fand der Richtervorbehalt keinen Eingang in die endgültige Richtlinienfassung. Diese sieht lediglich eine verpflichtende Verankerung einer Informationspflicht des Nutzers über die technische Erschwerungsmaßnahme vor.

\section{B. Folgerungen für die innerstaatliche Umsetzung}

Nachfolgend sollen die Folgen der europäischen Richtlinienbemühungen ins Verhältnis zur Aufhebung des Zugangserschwerungsgesetzes gesetzt werden.

I. Keine Vorwirkung des bloßen Richtlinienvorschlags

Dadurch dass der deutsche Gesetzgeber das Zugangserschwerungsgesetz erst nach Inkrafttreten der Richtlinie 2011/93/EU formell ordnungsgemäß aufgehoben hat, entging er der Problematik der sogenannten „Vorwirkung von Richtlinienvorschlägen“".

\section{Frustrationsverbot nach Inkrafttreten der Richtlinie}

Im Gegensatz zu Verordnungen, die in allen Teilen verbindlich sind und unmittelbar in jedem Mitgliedstaat gelten (Art. 288 Abs. 1 Satz 1, 2 AEUV), sind Richtlinien nach Art. 288 Abs. 3 AEUV für die Mitgliedstaaten nur hinsichtlich des zu erreichenden Ziels verbindlich. Richtlinien bedürfen daher einer zielorientierten Umsetzung in innerstaatliches Recht. Für die Anpassung der nationalen Rechtslage an die Richtlinienvorgaben steht den Mitgliedstaaten die in der Richtlinie angeordnete Umsetzungsfrist zur Verfügung. ${ }^{1295}$

Nach allgemeiner Auffassung entfaltet eine Richtlinie - nach ihrer Verkündung aber vor Ablauf der Umsetzungsfrist - für die Mitgliedstaaten eine „Vorwirkung“ im Sinne einer „Einschränkung“ der Rechtssetzungsbefugnisse der nationalen Gesetzgeber. ${ }^{1296}$

Die Mitgliedstaaten sind danach gehalten alles zu unterlassen, was die Verwirklichung der Ziele der Union ernsthaft gefährden und in Frage stellen würde.1297

1295 EuGH, Slg. 1976, I-1359, Rn. 11 f. - Kommission/Italien; EuGH, Slg. 1982, I-53, Rn. 18 Becker; grundlegend zur Richtlinienwirkung: Sydow, JZ 2009, 373.

1296 Zur Problematik ausführlich Hofmann in: Riesenhuber, Europäische Methodenlehre, 2010, \ 16, Rn. 1 ff.; Kübling, DVBl. 2006, 857; Fren₹/Wimmers, UPR 2009, 425 (429); Gronen, Die Vorwirkung von EG-Richtlinien, 2006, S. 75 ff.; Schliesky, DVBl. 2003, 631 (637 sowie 639).

1297 So Kabl in: Calliess/Ruffert, Art. 4 EUV, Rn. 97; EuGH, Slg. 1997, I-7411, Rn. 45 - InterEnvironnement Wallonie; EuGH, Slg. 2004, I-1361, Rn. 66 -Streamserve/Harmonisierungsamt für den Binnenmarkt; EuGH, Slg. 2005, I-9981, Rn. 67 - Mangold; EuGH, Slg. 2007, I-4749, Rn. 62 - Kommission/Belgien; EuGH, EuZW 2010, 183 - Zentrale zur Bekämpfung unlaute- 
Ausgangspunkt dieser Annahme ist die in Art. 4 Abs. 3 Satz 3 EUV ${ }^{1298}$ i.V.m. Art. 288 Abs. 1 Satz 3 AEUV verankerte Loyalitätspflicht der Mitgliedstaaten gegenüber Handlungen der Union. ${ }^{1299}$ Der Europäische Gerichtshof versteht diese Loyalitätspflicht der Mitgliedstaaten nicht nur in dem Sinne, als sie eine Verpflichtung zur fristgerechten Umsetzung des Richtlinienziels träfe, vielmehr beinhalte sie auch das Verbot durch zwischenzeitige Maßnahmen die Erreichung des Richtlinienziels nach Ablauf der Umsetzungsfrist zu gefährden. ${ }^{1300}$ Diese seither als „Frustrationsverbot" ${ }^{\text {"1301 }}$ bezeichnete Rechtswirkung verbietet, ab dem Zeitpunkt des Inkrafttretens einer Richtlinie bis zum Ablauf der Umsetzungsfrist, dem nationalen Gesetzgebern Vorschriften zu erlassen, die geeignet sind, das fristgerechte Erreichen des in der Richtlinie festgelegten Ziels „ernstlich“ in Frage zu stellen. ${ }^{302}$

Die Bejahung einer vorgezogenen Rechtswirkung von Richtlinien führt zwangsläufig zur Kontroverse zur grundsätzlichen Souveränität der Mitgliedstaaten: Einerseits muss es dem nationalen Gesetzgeber während des Zeitraums der Umsetzungsfrist unbenommen bleiben, seine Souveränität in Bezug auf seine Rechtssetzungsbefugnis zu wahren, andererseits muss er eben dem Richtlinienziel auf nationaler Ebene spätestens zum Zeitpunkt des Fristablaufs Geltung verschaffen. ${ }^{1303}$ Durch das Frustrationsverbot wird dieser Konflikt zwischen europarechtlichen Harmonisierungsbemühungen und mitgliedstaatlicher Eigenständigkeit daher weitestgehend auf ein zulässiges Minium gebracht. Denn der Erlass der Richtlinie entfaltet gerade keine „Sperrwirkung“ für den nationalen Gesetzgeber im klassischen Sinn, er verpflichtet lediglich zu Unterlassungshandlungen, die

ren Wettbewerbs e.V./Plus Warenhandelsgesellschaft mbH; BVerwGE 107, 1 (22); Kübling, DVBl. 2006, 857 (863 ff.); Fren₹/Wimmers, UPR 2009, 425 (429).

1298 Wenn nachfolgend nicht anders bestimmt, handelt es sich um den EUV in der Fassung seit 1.12.2009 geltenden Fassung des Vertrags von Lissabon (ABl. 2008 Nr. C 115 S. 1, ber. ABl. 2009 Nr. C 290 S.1).

1299 Vertrag über die Arbeitsweise der Europäischen Union in der seit 1.12.2009 geltenden Fassung des Vertrags von Lissabon (ABl. 2008 Nr. C 115 S. 1, ber. ABl. 2009 Nr. C 290 S.1).

1300 Begründet EuGH, Slg. 1997, I-7411, Rn. 45 - Inter-Environnement Wallonie; Fortgeführt u.a. EuGH, Slg. 2003, I-4431 - Atral; EuGH, Slg. 2005, I-9981, Rn. 67 - Mangold; EuGH, Slg. 2008, I-2533 - Impact/ Minister for Agriculture and Food; Kübling, DVBl. 2006, 857; Kabl in: Calliess/Ruffert, Art. 4 EUV, Rn. 97; Röthel, ZEuP 2009, 34.

1301 So begründet von EuGH, Slg. 1997, I-7411, Rn. 45 - Inter-Environnement Wallonie; fortgeführt u.a. Ausführlich zum gesamten Komplex, Gronen, Die Vorwirkung von EG-Richtlinien, 2006, S. 75 ff., S. 83.

1302 Kabl in: Calliess/Ruffert, Art. 4 EUV, Rn. 97; EuGH, Slg. 1997, I-7411, Rn. 45 - InterEnvironnement Wallonie; EuGH, Slg. 2004, I-1361, Rn. 66 - Streamserve/Harmonisierungsamt für den Binnenmarkt; EuGH, Slg. 2005, I-9981, Rn. 67 - Mangold; Frenø/Wimmers, UPR 2009, 425 (429); Danwitr, JZ 2007, 697 (700).

1303 So Hofmann in: Riesenhuber, Europäische Methodenlehre, 2010, § 16, Rn. 14 f. 
offenkundig das Richtlinienziel nach Fristablauf beeinträchtigen können. Ist eine Gefährdung des Richtlinienziels vom den Aktionismus des nationalen Gesetzgebers nach Fristablauf nicht zu befürchten, ist dieser auch während des Laufs der Umsetzungsfrist nicht gehindert, richtlinienwidrige Vorschriften zu erlassen beziehungsweise richtlinienkonforme Gesetze aufzuheben.1304 Die geringfügigen „Einschränkungen der Rechtsetzungsbefugnis“ sind in Anbetracht der Bedeutung der einheitlichen Anwendung des Europarechts im Hinblick auf das Harmonisierungsziel gerechtfertigt und daher hinzunehmen. ${ }^{1305}$

\section{Keine Vorverlagerung der Rechtswirkung}

Obgleich die Vorwirkung nach dem Inkrafttreten der Richtlinien in Bezug auf das Frustrationsverbot anerkannt ist, ist die Übertragung der Grundsätze auf bloße Richtlinienvorschläge nicht geboten. ${ }^{1306}$

Für eine Übertragung des Frustrationsverbots wird angeführt, dass die Europäische Union durch die Vorlage eines Richtlinienvorschlags in einen bestimmten rechtlichen Bereich erkennbar Entwicklungen einleitet und ausdrücklich signalisiert, diesen Bereich einheitlich auf europäischer Ebene regeln zu wollen. ${ }^{1307}$ Dieses stelle zudem kein einseitiges Handeln der Europäischen Union dar, dem sich die Mitgliedstaaten „hilflos“ zu unterwerfen haben. Das Initiativrecht für Gesetzgebungsakte gemäß Art. 17 Abs. 2 Satz 1 EUV stehe zwar grundsätzlich der EUKommission zu, mit dem Initiativrecht werde aber gewährleistet, dass das Unionsinteresse von Anfang an maßgeblich in den Gesetzgebungsprozess einfließt. Neben den unmittelbar beteiligten Organen und Ausschüssen sind daher durch Art.

1304 Schroeder in: Streinz, Art. 288 AEUV, Rn. 78 ff.; Wißßmann in: Erfurter Komm. zum ArbR, Vorbm. AEUV, Rn. 20; Röthel, ZEuP 2009, 34 (39); Gronen, Die Vorwirkung von EGRichtlinien, 2006, S. 98; Hofmann in: Riesenhuber, Europäische Methodenlehre, 2010, 』 16, Rn. 18.

1305 Gronen, Die Vorwirkung von EG-Richtlinien, 2006, S. 97 mit Verweis auf Klein in: FS für Everling, 1995, Bd. 1, S. 641 (645).

1306 IE. umstritten: Aus der Rechtsprechung gegen eine generelle Frühwirkung, jedoch für besondere Pflichten der Mitgliedstaaten hinsichtlich gemeinschaftlicher Rechtssetzungsvorhaben, beispielhaft EuGH, Slg. 1978, 417 (449); EuGH, Sl. 1980, 2403; EuGH, Slg. 1979, 2923 (2942); EuGH, Slg. 1981, 1045; für eine Frühwirkung Grabitz, Stillhalte-Verpflichtungen vor dem Binnenmarkt, 1988, S. 38 ff.; Bleckmann, EuGRZ 1981, 257; Ebenroth/Fischer/Sorek, BB 1989, 1566; dagegen Selmer/Brodersen/Nicolaysen, Straßenbenutzungsabgaben, 1989; Meßerschmidt, ZG 1993, 11; Arndt, DStR 1989, 471 (476); Rn. 12; Röthel, ZEuP 2009, 34 (39); Gronen, Die Vorwirkung von EGRichtlinien, 2006, S. 98; Hofmann in: Riesenhuber, Europäische Methodenlehre, 2010, \16, Rn. 6; Schliesky, DVBl. 2003, 631 (633); Neuer in: Riesenhuber, Europäische Methodenlehre, 2010, $\int 13, \mathrm{Rn} .20$.

1307 Ausführliche Darstellung des Streitstandes Gronen, Die Vorwirkung von EG-Richtlinien, 2006, S. $23 \mathrm{ff}$. 
12 EUV auch die nationalen Parlamente frühzeitig in den Gesetzgebungsprozess eingebunden. Somit baue der europäische Harmonisierungsprozess auf ständiger Verhandlung mit den Mitgliedstaaten auf und werde durch die Vorlegung eines Richtlinienentwurfs als nach außen hin abgestimmter Konsens signalisiert.

Daher können die aus dem Entwurf erwachsenen Verpflichtungen der Mitgliedstaaten im Einzelfall ausreichend sein, um eine Vorwirkung zu statuieren. ${ }^{1308}$ In dieser Einzelfallentscheidung seien Kriterien einzustellen, wie beispielsweise die voraussichtliche Dauer bis zum Erlass der Richtlinie: So kann den Mitgliedstaaten desto weniger ein Innehalten bezüglich ihrer Rechtssetzungsbefugnisse zugemutet werden, je länger die voraussichtliche Verabschiedung der eigentlichen Richtlinie dauern werde. Auch seien die Erfolgsaussichten der Richtlinie in Betracht zu ziehen, je mehr bereits ein Konsens bezüglich der in der Richtlinie enthalten Regelungen in den Mitgliedstaaten erkennbar ist, umso eher ist von einer Vorwirkung des Vorschlages auszugehen. Zudem sei auch die Dringlichkeit der Harmonisierungsbemühung zu berücksichtigen. Je geringer das Rechtsgebiet bereits harmonisiert ist und je dringender die europäische Regelung erscheint, desto weniger könne es in der Regelungsbefugnis der Mitgliedstaaten liegen, abweichende Regelungen zu treffen. ${ }^{309}$

Gegen eine Vorwirkung wird hingegen vorgebracht, dass im Zeitpunkt des Kommissionsvorschlags das weitergehende Schicksal des Entwurfs oftmals noch völlig offen sei. Denn der Rat kann in den Grenzen des Art. 293 Abs. 1 AEUV noch Änderungen am Richtlinientext vornehmen. Die EU-Kommission kann ihrerseits den Vorschlag gemäß Art. 293 Abs. 2 AEUV jederzeit abändern, ${ }^{1310}$ etwa um den Vorstellungen des Parlaments oder des Rats entgegenzukommen und damit die Akzeptanz ihres Vorgehens zu erhöhen und zu einem Interessenausgleich beizutragen. ${ }^{1311}$ Gronen ${ }^{1312}$ gibt in dem Zusammenhang zu bedenken, dass eine Vorwirkung des bloßen Richtlinienvorschlags zu einer „quasi normativem Wirkung“ des desselben führe. Eine solche sei auf europäischer Ebene jedoch nicht vorgesehen, weil sich anderenfalls die Gewichtsverteilung der Europäischen

1308 Grabitr, Stillhalte-Verpflichtungen vor dem Binnenmarkt, 1988, S. 38 ff.; Bleckmann, EuGRZ 1981, 257; Ebenroth/Fischer/Sorek, BB 1989, 1566.

1309 Ausführliche Herleitung Gronen, Die Vorwirkung von EG-Richtlinien, 2006, S. 55 ff. mwN.

1310 Hierzu König in: Schulze/Zuleeg/Kadelbach, Hdb. Europarecht, 2010, \2, Rn. 81.

1311 So in Bezug auf die frühere Rechtslage, Geiger, EUV/EGV, 2004, Art. 250 EGV, Rn. 4; Gellermann in: , 1. Aufl., 2003, Art. 250 EGV, Rn. 19; zur heutigen Rechtslage ausführlich König in: Schulze/Zuleeg/Kadelbach, Hdb. Europarecht, 2010, \2, Rn. 81.

1312 Gronen, Die Vorwirkung von EG-Richtlinien, 2006, S. 61 (bezogen auf die früheren Art. 10 EGV) mit Einschränkung der Annahme von Grabitz, Stillhalte-Verpflichtungen vor dem Binnenmarkt, 1988, S. 38 f.; der dieses Problem zwar sieht, jedoch in Bezug auf die Vorwirkung nach Inkrafttreten der Richtlinie, ohne es auch auf die vorgelagerte Fragestellung nach einer Frühwirkung zu übertragen. 
Rechtssetzungsorgane wesentlich verschieben würde. Zwar kenne die Europäische Union keine Gewaltenteilung im klassischen Sinne, jedoch werden über den Europäischen Vertrag sowie den Vertrag über die Arbeitsweise der europäischen Union den Organen entsprechende Befugnisse zugewiesen. Die Ausweitung der Vorwirkung, hinsichtlich eines Verbots der Vornahme richtlinienzielwidriger Maßnahmen, wie beispielsweise einer innerstaatlichen Aufhebung eines mit den Zielen der Richtlinie korrespondierenden Gesetzes, würde dem bloßen Richtlinienvorschlag den Charakter einer ,unabhängigen Quellen rechtlicher Verpflichtungen"1313 beimessen und die mitgliedstaatlichen Pflichten in einem zu frühen Zeitpunkt zu stark konkretisieren.

Unter Berücksichtigung dieser Problematik hätte man durchaus die Frage aufwerfen können, ob der deutsche Gesetzgeber aufgrund einer möglichen Vorwirkung des Richtlinienvorschlags ( $\operatorname{KOM}(2010) 94$ endg.) seinerzeit gehindert war, das Zugangserschwerungsgesetz formell ordnungsgemäß aufzuheben. Denn als wesentlich für die Bekämpfung von Kinderpornographie in Kommunikationsnetzen statuierte der Richtlinienvorschlag die mitgliedstaatliche Verpflichtung einer Einführung obligatorischer Sperrmaßnahmen für kinderpornographische Webinhalte. Die Aufhebung eines Gesetzes, dass gerade die Einführung solcher Maßnahmen vorsah, wäre dem Richtlinienziel diesbezüglich abträglich, so dass die Europarechtskonformität des nationalen Aufhebungsaktes ernstlich in Frage zu stellen wäre.

Dieser Problematik entging der Gesetzgeber allerdings dadurch, dass er mit der formellen Aufhebung des Zugangserschwerungsgesetzes wartete, bis die endgültige Fassung der Richtlinie verabschiedet wurde und diese in Kraft trat. Denn die finale Version der Richtlinie weicht in Bezug auf die technischen Erschwerungsmaßnahmen grundlegend von dem vorherigen Richtlinienvorschlag ab, indem Sperrmaßnahmen gerade nicht verpflichtend einzuführen sind.

Aber auch die Verfechter der Vorwirkung von Richtlinienvorschlägen hätten nach der notwendigen Einzelfallprüfung die Aufhebung des Zugangserschwerungsgesetzes wohl nicht als europarechtswidrig angesehen: ${ }^{1314}$ Denn der Richtlinienvorschlag wurde bereits im März 2010 vorgestellt und ins Rechtssetzungsverfahren überführt. Schon kurze Zeit nach Bekanntwerden der Harmonisierungsinitiative war ersichtlich, dass der Vorschlag keineswegs verfestigt war und gerade keinen Konsens bei den europäischen Organen wie auch bei den Mitgliedstaaten

1313 EuGH, Slg. 1987, I-5041 (5055); Meßerschmidt, ZG 1993, 11 (31); Gronen, Die Vorwirkung von EG-Richtlinien, 2006, S. 61.

1314 IE. wohl auch Hoffmann-Holland, Stellungnahme der Experten im Rechtsausschuss v. 8.11.2010, S. 14, abrufbar unter:

http://www.bundestag.de/bundestag/ausschuesse17/a06/anhoerungen/archiv/03_Zugangsers chwerung/04_Stellungnahmen/Stellungnahme_Hoffmann-Holland.pdf (zuletzt abgerufen 20.5.2012), jedoch ohne Herleitung und hinreichender Begründung. 
erreichte. Insbesondere war bereits frühzeitig deutlich, dass der angestrebter Kurs der EU-Kommission, speziell hinsichtlich der obligatorisch einzuführenden Sperren, nicht durchzuhalten sein werde. Im Zeitpunkt des Aufhebungsentwurfes der Bundesregierung zum Zugangserschwerungsgesetz im Juli 2011,1315 war das Rechtssetzungsverfahren bereits so weit fortgeschritten, dass erkennbar wurde, dass das eigentliche Richtlinienvorhaben nicht mehr mit dem Richtlinienvorschlag übereinstimmen würde. Der federführende Ausschuss für bürgerliche Freiheiten, Justiz und Inneres sprach sich für die Einführung einer obligatorischen Löschung und nur für eine fakultative Sperrung aus. Auch die erfolgte Abstimmung im Ausschuss zeigte deutlich, dass die Sperren, so wie sie im Zugangserschwerungsgesetz vorgesehen waren, nicht verpflichtend von den Mitgliedstaaten einzuführen sein würden. Zudem machte die Bundesregierung ihre ablehnende Ansicht bezüglich einer notwendigen legislatorischen Sperrlösung bereits vor der Bekanntgabe des Richtlinienentwurfs im Februar 2010 durch die „Aussetzung“ des Zugangserschwerungsgesetzes offenkundig. ${ }^{1316}$

Letztlich hätte die Bundesregierung das Zugangserschwerungsgesetz ungeachtet des europäischen Aktionismus bereits frühzeitig ordnungsgemäß aufheben können (und müssen) und damit den durch den Nichtanwendungsbeschluss herbeigeführten verfassungsrechtlichen Bedenken entgegentreten können.

\section{Umsetzungspflicht}

\section{Keine unmittelbare Rechtswirkung einer Ricbtlinie}

Nachdem die Richtlinie 2011/93/EU in Kraft getreten ist, ist der nationale Gesetzgeber innerhalb der in Art. 27 vorgesehenen Frist bis zum 18.12.2013 verpflichtet, die grundlegenden Vorgaben der Richtlinie ins nationale Recht zu überführen.

Über den in Art. 26 Abs. 2 der Richtlinie eingeräumten Ermessensspielraum hinsichtlich der Einführung von rechtlichen Sperrmechanismen zur Zugriffsunterdrückung kinderpornographischer Webinhalte, wird Deutschland auf Sperrmaßnahmen verzichten. Die Richtlinie verpflichtet den nationalen Gesetzgeber allerdings dazu, die Löschung dieser Angebote aus dem Gesamtbestand des Internets, herbeizuführen.

Welche einzelnen Mechanismen der deutsche Gesetzgeber hierfür auf sich nehmen muss, wird in der Richtlinie offengelassen. So kann der deutsche Gesetzgeber ein eigenes Löschgesetz erlassen, dass sämtliche Rechte und Pflichten in einem eigenständigen Gesetzgebungswerk abdeckt. Möglich wäre es auch die Löschungsverpflichtungen innerhalb der zu erwartenden Strafrechtsnovelle einzu-

1315 Entwurf eines Gesetzes zur Aufhebung von Sperrregelungen bei der Bekämpfung von Kinderpornographie in Kommunikationsnetzen, BT-Drs. 17/664.

1316 Zur Verfassungswidrigkeit des Nichtanwendungserlasses, 4. Teil C. III. 
gliedern. Letzteres würde wohl aber genauso auf Widerstand stoßen, wie die vormals anvisierte Verankerung der Sperrmaßnahme ins TMG. ${ }^{1317}$ Denkbar ist auch die bloße Herstellung rechtlicher Rahmenbedingungen innerhalb derer die Provider selbstständig Vereinbarungen zur Entfernung kinderpornographischer Inhalte treffen.

Um die „Fehler“ der Vergangenheit zu vermeiden und möglichen Bedenken an einer mangelnder Konstanz des Vorgehens entgegenzuwirken, sollte der Gesetzgeber eine eigenständige Verankerung favorisieren und die Löschung kinderpornographischer Inhalte innerhalb eines eigenständigen Regelungskonstrukt gesetzlich absichern. In einem solchen könnte der Gesetzgeber beispielsweise die Ermittlungsmöglichkeiten der Verantwortlichen verbessern, indem er eine länderübergreifende Verbesserung des „notice-and-take-down“-Verfahrens"1318 einführt. ${ }^{1319}$ Auch wäre es innerhalb eines eigenständigen Gesetzes am besten möglich, die Rechte der Nutzer und Provider zu stärken, indem umfassende Rechtsschutzmöglichkeiten bereits in die jeweilige gesetzliche Formulierung integriert würden. Zudem wäre es in Bezug auf die Rechtsicherheit und Verfassungsmäßigkeit des Vorgehens kaum umsetzbar, den Rahmenprozess der Löschung kinderpornographischer Inhalte allein den Durchsetzungsinteressen der Wirtschaftssubjekte zu überlassen. Denn nicht nur, dass bei freier Überlassung der Regulierung durch Provider stets die Gefahr droht, dass diese sich bei der Durchsetzung der Entfernung von wirtschaftlichen Aspekten leiten lassen, besteht überdies die Befürchtung, dass die gesamte Stabilität der Bemühungen bereits durch ein unbewusstes Desinteresse an der Beteiligung, beziehungsweise durch bewusste dem System widersprechende Handlungen der Provider angegriffen würde. Zudem begründet die Löschung der Inhalte ebenfalls einen grundrechtsrelevanten Bereich, weshalb der Wesentlichkeitsgrundsatz des Art. 20 Abs. 3 GG augenscheinlich für das Bedürfnis nach einer parlamentarischen Entscheidung spricht. ${ }^{1320}$

\section{Erschwerte Umsetzung durch Diskrepanz zum deutschen Recht}

Bezüglich der Verpflichtung Deutschlands die Löschung kinderpornographischer Webinhalte innerhalb eines umfassenden Regelungswerks zu formulieren, ergeben sich aus der Richtlinie Probleme, die mittelbar auf die in Art. 26 enthaltene Löschverpflichtung bezugnehmen und somit auf die nationale Umsetzung durch-

1317 Zum damaligen Gesetzesvorhaben, oben unter 4. Teil B.

1318 Hierzu bereits oben 3. Teil B. I. 2. c) (cc) .

1319 So wird die bspw. die Führung einer Täterliste und ihr Austausch zwischen den Mitgliedstaaten favorisiert.

1320 BVerfGE 46, 47 (79); Herzog/Grzeszile in: Maunz/Dürig, Art. 20 GG, Rn. 107; ausführlich Sommermann in: v. Mangoldt/Klein/Starck, Art. 20 GG, Rn. 267 ff. mwN. 
schlagen. ${ }^{1321}$ Ausgangspunkt der Diskrepanz ist die Definition in Art. 2 lit. a der Richtlinie. Danach wird als „Kind“ ,,jede Person unter achtzehn Jahren“ definiert. Als Kinderpornographie gilt gemäß Art. 2 lit. c (i) ,jegliches Material mit Darstellungen eines Kindes, das an realen oder simulierten eindeutig sexuellen Handlungen beteiligt ist, oder (ii) jegliche Darstellung der Geschlechtsorgane eines Kindes für primär sexuelle Zwecke; oder (iii) jegliches Material mit Darstellungen einer Person mit kindlichem Erscheinungsbild, die an realen oder simulierten eindeutig sexuellen Handlungen beteiligt ist oder jegliche Darstellungen der Geschlechtsorgane einer Person mit kindlichen Erscheinungsbild für primär sexuelle Zwecke; oder (iv) realistische Darstellung eines Kindes, das an eindeutig sexuellen Handlungen beteiligt ist oder realistische Darstellung der Geschlechtsorgane eines Kindes für primär sexuelle Zwecke“.

a) Anknüpfung der Löschung an strafbewehrte „Kinder-“ Pornographieinhalte

(aa) Löschvorgabe: $\$ 184 \mathrm{~b}$ StGB

Der nationale Gesetzgeber ist aus Gründen der Rechtssicherheit und Rechtsklarheit gehalten eine feste Konstante für die von der Löschpflicht umfassten Angebote innerhalb der Formulierung des Löschgesetzes vorzugeben. Im Rahmen des Zugangserschwerungsgesetzes wählte der Gesetzgeber zur Definition eines „sperrungswürdigen Inhaltes" die direkte Anknüpfung an den Straftatbestand der Kinderpornographie i.S.d. \184b StGB: „Das Bundeskriminalamt führt eine Liste über vollqualifizierte Domainnamen, Internetprotokoll-Adressen und Zieladressen von Telemedienangeboten, die Kinderpornographie nach $\$ 184 \mathrm{~b}$ des Strafgesetz-

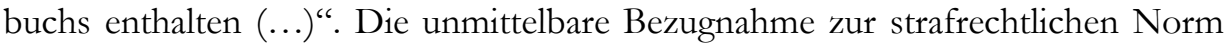
des $\ 184 \mathrm{~b}$ StGB hat den Vorzug gegenüber einer eigenständigen Definition, dass einerseits Rechtszersplitterungen durch Diskrepanzen zur anderweitigen Gesetzestexten vermieden werden können, andererseits gesetzlich feste, sowie von der Rechtsprechung überprüfbare Kriterien an das tatsächliche Vorliegen von kinderpornographischen Angeboten vorgegeben sind.

(bb) Beibehaltung der Anknüpfung vorzugswürdig

Wie bei der Sperrung so ist auch bei der Löschung aus verfassungsrechtlichen Gründen die Einordnung eines der Maßnahme unterfallenden Inhaltes nach dem geltenden Strafrechtstatbestand vorzugswürdig. Bedingt dadurch, dass die Löschung eine punktuelle und nahezu irreversible Entfernung des Inhaltes bedeutet, muss gewährleistet sein, dass diese auch tatsächlich erforderlich und die mit ihr verbundene Einschränkung der Grundrechte Dritte gerechtfertigt ist. Zwar ist innerhalb der vorzunehmenden Abwägung allein das Vorliegen eines strafrechtlich

${ }^{1321}$ In die Richtung auch die Stellungnahme des Deutschen Richterbundes zum Richtlinienvorschlag $\operatorname{KOM}(2010) 94$ endg. v. 17.3.2011. 
verbotenen Inhaltes nicht ausschlaggebend für die verfassungsmäßige Rechtfertigung des Eingriffs, jedoch kann die „Gefährlichkeit“ und „Verwerflichkeit“ des als strafrechtlich verboten attestierten Inhaltes in der Abwägung ein wesentliches Indiz für die Gewichtung sein und damit einen Eingriff in die Grundrechte der Beteiligten eher rechtfertigen, als dieses bei einer Löschung von Angeboten unterhalb des Straftatbestands der Kinderpornographie der Fall wäre. Es ist somit für die innerstaatliche Umsetzung der Löschverpflichtung vorzugswürdig, wenn der nationale Gesetzgeber, wie schon beim Zugangserschwerungsgesetz vorgesehen, die Notwendigkeit der Löschung an das Vorliegen der Tatbestandsvoraussetzungen des $\int 184 b$ StGB knüpft und nicht eigenhändig eine neue Definition für den „löschungswürdigen“ Inhalt kreiert.

(cc) Unterschiedliches Verständnis: Kind und Kinderpornographie

Die Definition des Kindes in Art. 2 lit. a der Richtlinie weicht aber von der in Deutschland geltenden Definition von „Kind“ in $\int 176$ StGB und damit auch vom Kinderpornographieverständnis des $\int 184 \mathrm{~b}$ StGB ab. ${ }^{1322}$ Die Richtlinie definiert als „Kind“ jede Person, die das 18. Lebensjahr noch nicht vollendet hat (Art. 2 lit. a). Sie unterscheidet dabei nicht zwischen Kindern auf der einen Seite und Jugendlichen auf der anderen. ${ }^{1323}$ Im nationalen Recht hingegen wird regelmäßig zwischen Kind, das heißt Person unter 14 Jahre und Jugendlicher, also Person zwischen 14 bis 18 Jahre, unterschieden. ${ }^{1324}$ Übereinstimmend unterscheidet das

$1322 \mathrm{Zu}$ dem Problem kurz auch die Stellungnahme des deutschen Richterbundes v. 17.3.2011, abrufbar unter: http://www.drb.de/cms/index.php?id=708\&L=0 (zuletzt abgerufen 20.5.2012).

1323 So schon in Bezug auf die Umsetzung des Rahmenbeschlusses des 2004/68/JI des Rates vom 22.12.2003 zur Bekämpfung der sexuellen Ausbeutung von Kindern und der Kinderpornographie, ABl. 2004 Nr. L 13, S. 44, der die gleiche Definition von Kind enthielt wie der gegenwärtige Richtlinienvorschlag, Graupner, Stellungnahme der Sachverständigen im Rechtsausschuss v. 15.6.2007, S. 4, abrufbar unter:

http://webarchiv.bundestag.de/cgi/show.php?fileToLoad=1103\&id=1118 (zuletzt abgerufen 20.5.2012).

1324 Beispielsweise gelten im Sozialrecht nach SBG VIII eigenständige Voraussetzungen für die Anwendung des Kinder- sowie Jugendhilfegesetzes. Auch die Strafbarkeit als solche steht in Abhängigkeit zu der Einordnung als Kind oder Jugendlicher. Gemäß $\ 19$ StGB sind „Kinder“, also Personen unter 14 Jahren, grundsätzlich schuldunfähig und können für Verstöße gegen das Strafgesetzbuch nicht zur Verantwortung gezogen werden. Ist der Täter zum Zeitpunkt der Begehung der Tat jedoch bereits Jugendlicher, kann er gemäß \1 i.V.m. \3 JGG strafrechtlich verantwortlich sein, wenn er zur Zeit der Tat nach seiner sittlichen und geistigen Entwicklung reif genug war, das Unrecht der Tat einzusehen und nach dieser Einsicht zu handeln. Auch im Sexualstrafrecht finden sich Vorschriften, die den sexuellen Missbrauch von Kindern unter Strafe stellen ( $\mathbb{1} 176$ StGB), der Missbrauch von Jugendlichen ist indessen eigenständig in $\ 182 \mathrm{StGB}$ normiert. 
Strafgesetzbuch auch zwischen Verbreitungsverboten von kinder- bzw. jugendpornographischen Schriften. ${ }^{1325}$ In der Konsequenz besteht eine Diskrepanz zwischen der Richtliniendefinition des Kindes und der im nationalen Recht geltenden Rechtsauffassung, was zwangsläufig zu Problemen innerhalb der Umsetzungsverpflichtung führt.

(1) Rahmenbeschluss 2004/68/JI gleiche Problematik

Bereits bei der Umsetzung des mit der Richtlinie aufzuhebenden Rahmenbeschlusses 2004/68/JI ergab sich dieselbe Problematik. ${ }^{1326}$ Der Rahmenbeschluss definierte „Kind“ in Art. 1 lit. a, entsprechend dem heutigen Richtlinienwortlaut, als „Person bis 18 Jahre“. Der Bundestag hatte seinerzeit im „Gesetz zur Umsetzung des Rahmenbeschlusses des Rates der Europäischen Union zur Bekämpfung der sexuellen Ausbeutung von Kindern und der Kinderpornographie"1327 die innerstaatliche Differenzierung zwischen Kindern und Jugendlichen beibehalten und der europäischen Forderung nach einem umfassenden Schutz von Personen unter 18 Jahren durch eigene Jugend-Sexualstrafbestände, damit auch durch Einführung einer eigenständigen Pönalisierung jugendpornographischer Schriften in $\int 184 \mathrm{c}$ StGB Rechnung getragen. ${ }^{1328}$

Explizit hatte sich der Gesetzgeber damals gegen die allgemeine Heraufsetzung der Altersgrenze von Kindern auf 18 Jahre ausgesprochen: Zwischen Sexualdelikten mit Kindern und jenen mit Jugendlichen herrsche ein unterschiedlicher

1325 Wegen der Gleichstellungsklausel des Schriftenbegriffs in $₫ 11$ Abs. 3 StGB beanspruchen die Regelungen, die ein Verbreitungsverbot in Schriften normieren auch im Rahmen der Verbreitung entsprechender Darstellungen über das Internet Rechtswirkung und werden hier als Synonym für löschfähige Wegangebote gebraucht.

1326 Rahmenbeschluss 2004/68/JI des Rates vom 22.12.2003 zur Bekämpfung der sexuellen Ausbeutung von Kindern und der Kinderpornographie, ABl. 2004 Nr. L 13, S. 44. Ausführlich zu den Änderungen im Bereich des Sexualstrafrechts, Hörnle, NJW 2008, 3521; Liesching, JMSReport 5/2008, 2; Gercke, ZUM 2009, 526 (527 ff.); Schroeder, GA 2009, 213. Umfassende kritische Stellungnahmen der Sachverständigen im Rechtsausschuss zum deutschen Umsetzungsgesetz abrufbar unter: http://webarchiv.bundestag.de/cgi/ show.php?fileToLoad=1103\&id=1118 (zuletzt abgerufen 20.5.2012).

1327 BGBl. I 2008, 2149.

1328 So war der damalige $\ 182$ StGB zwar mit „Missbrauch von Jugendlichen“ überschreiben. Im Einzelnen war dort aber nur der Missbrauch von Personen unter 16 Jahren von Personen über 18 Jahren pönalisiert, was zu Strafbarkeitslücken und Uneinheitlichkeit in der Definition von Jugendlichen führte. Zur alten Fassung und den rechtlichen Diskrepanzen Hörnle, Stellungnahme der Sachverständigen im Rechtsausschuss v. 18.6.2007, S. 2 ff., abrufbar unter: http://webarchiv.bundestag.de/cgi/show.php?fileToLoad=1103\&id=1118 (zuletzt abgerufen 20.5.2012). 
Unrechtsgehalt, der anderenfalls nicht hinreichend Berücksichtigung finde. ${ }^{1329}$ Dies gründe darin, dass die sexuelle Selbstbestimmung als verfassungsrechtliches Kernelement des Allgemeinen Persönlichkeitsrechts des Art. 2 Abs. 1 i.V.m. Art. 1 Abs. 1 GG bei Jugendlichen viel weiter ausgereift ist als bei Kindern. ${ }^{1330}$ Während der Schutzgedanke hinter der Unterbindung von klassischen kinderpornographischen Darstellungen, offensichtlich sei, müssen bei Ablichtung sexueller Handlungen mit Jugendlichen nicht zwangsläufig strafbare Handlungen vorliegen. ${ }^{1331}$ Wenn die Ablichtung und das Verbreiten sexueller Handlungen im gegenseitigen Einvernehmen der jugendlichen Sexualpartner vorliegen, kann das Verhalten nicht genauso unterbunden werden, wie bei Kindern. ${ }^{1332}$

Im Rahmen des Umsetzungsgesetzes zum Rahmenbeschluss hatte der Gesetzgeber den Konflikt durch die eigenständige Formulierung von Jugendstraftatbeständen mit geringeren Strafmaß und teilweisen Ausnahmen aufgelöst und die Rahmenbeschlussvorgaben europarechtskonform in nationales Recht transformiert. ${ }^{1333}$ So ist beispielsweise der Tatbestand des $\int 184 \mathrm{~b}$ Abs. 1, 2 StGB mit einer Freiheitsstrafe von drei Monaten bis zu fünf Jahren, der Tatbestand des $\int 184 \mathrm{c}$ Abs.1, 2 StGB mit einer Freiheitsstrafe bis zu drei Jahren oder mit Geldstrafe bestraft.

(2) Probleme für das Löschgesetz

Der nationale Gesetzgeber ist entsprechend Art. 288 AEUV nicht zur wortlautgetreuen Umsetzung der Richtlinienvorgaben verpflichtet, sondern muss nur die hinreichende Umsetzung des jeweiligen Richtlinienziels gewährleisten. ${ }^{1334}$ Daher

1329 BT-Drs. 16/3439 S. 9.

1330 Darauf wiesen übereinstimmend viele Sachverständige während des Rechtssetzungsverfahrens zum nationalen Umsetzungsgesetz des Rahmenbeschlusses im Rechtsausschuss hin, Stellungnahmen abrufbar unter:

http://webarchiv.bundestag.de/cgi/show.php?fileToLoad=1103\&id=1118 (zuletzt abgerufen 20.5.2012).

1331 So die Argumentation von Hörnle, Stellungnahme der Sachverständigen im Rechtsausschuss v. 18.6.2007, S. 7, abrufbar unter:

http://webarchiv.bundestag.de/cgi/show.php?fileToLoad=1103\&id=1118 (zuletzt abgerufen 20.5.2012); dem iE. folgend BT-Drs. 16/3439, S. 9.

1332 Graupner, Stellungnahme der Sachverständigen im Rechtsausschuss v. 15.6.2007, S. 3, abrufbar unter: http://webarchiv.bundestag.de/cgi/show.php?fileToLoad=1103\&id=1118 (zuletzt abgerufen 20.5.2012).

1333 Hörnle, NJW 2008, 3521 (3523); Fischer, \ 184 StGB, Rn. 2; andeutend kritisch Kübl in: Lackner/Kühl, \184c StGB, Rn. 1, der wohl allein den Altersaspekt als ausschlaggebenden Aspekt für den unterschiedlichen Unrechtsgehalt nicht anerkennt.

1334 EuGH, Slg. 1976, I-497 (498); EuGH, Slg. 2002, I-6325; Ruffert in: Calliess/Ruffert, Art. 288 AEUV, Rn. 27. 
ist es grundsätzlich möglich die Differenzierung zwischen Kind und Jugendlicher im nationalen Recht beizubehalten, ohne in Kontroverse mit den Richtlinienvorgaben zu geraten. Problematisch ist allerdings, dass die im Strafrahmen der

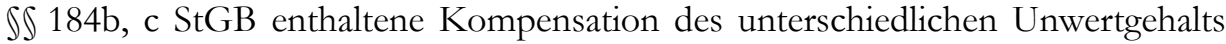
zwischen Kinder- und Jugendpornographie bei der Löschverpflichtung gerade nicht möglich ist. Löschen als irreversible, endgültige Maßnahme lässt keine der abgestuften Strafbarkeit vergleichbare Differenzierung zu. Die europäische Vorgabe bestimmt demgegenüber jedoch sehr klar: Die Inhalte müssen gelöscht werden. Die Richtlinie eröffnet dem nationalen Gesetzgeber dabei keinen Spielraum hinsichtlich einer Abstufung nach dem Alter der Beteiligten der ,kinderpornographischen" Darstellung im Sinne der Richtlinie. Der nationale Gesetzgeber kann also nicht eigenhändig von der Löschung jugendpornographischer Inhalte absehen, ohne eines Vertragsverletzungsverfahren wegen mangelhafter Umsetzung fürchten zu müssen. Folglich werden sich diesbezüglich Probleme in der Umsetzung stellen.

(dd) Tatmodalitäten der Kinderpornographie

Nicht nur die Definition des Kindes in Art. 2 lit. a stößt auf Umsetzungsprobleme, auch die damit einhergehende Definition der Kinderpornographie kann zu weiteren Umsetzungsschwierigkeiten führen. In Art. 2 lit. c (iii) ist Kinderpornographie als ,jegliches Material mit Darstellungen einer Person mit kindlichen Erscheinungsbild, die an realen oder simulierten eindeutig sexuellen Handlungen beteiligt ist (...)" definiert. Eine ähnliche Formulierung enthielt auch schon der Rahmenbeschluss 2004/68/JI in Art. 1 lit. b (ii). Seit der Umsetzung des Rahmenbeschlusses ins nationale Strafrecht wurde das Erfordernis des „kindlichen Erscheinungsbildes“ im Rahmen der „Scheinkindlichkeit" und Scheinjugendlichkeit" in die Straftatbestände der $\$ \int 184 \mathrm{~b}$, c StGB involviert und wird von der Rechtsprechung angewendet. ${ }^{1335}$ Jedoch waren in Bezug auf das damalige Umsetzungsgesetz bereits Zweifel daran geäußert worden, ob die Einbeziehung von Scheinjugendlichkeit in den Tatbestand des $₫ 184$ c StGB überhaupt zulässig sei. Dies gründete auf der Erwägung, dass die Einbeziehung von Scheinjugendlichen regelmäßig zu einer ausufernden Strafbarkeit führen kann, da die Kriterien, wann eine Person lediglich ,jugendlich“ anmutet nicht hinreichend bestimmbar sind. ${ }^{1336}$ Zudem sei allen pornographischen Angeboten immanent, dass sie regelmäßig

1335 BVerfG, MMR 2009, 178; dem anschließend VGH München, Urt. v. 23.03.2011 - 7 BV 09.2517 n.v.

1336 Zur Anwendbarkeit der Strafbarkeit auf den Fall der Scheinvolljährigkeit, BGHSt 47, 55 (61); eingehend Liesching, JMS-Report 5/2008, S. 3; Hörnle, NJW 2008, 3521 (3524); Eisele in: Schönke/Schröder, $\int 184 c$ StGB, Rn. 4. 
junge Darsteller enthielten und dadurch das Kriterium der Scheinjugendlichkeit besonders oft entscheidend für die Strafbarkeit wäre. ${ }^{1337}$

Es ist folglich davon auszugehen, dass auch bei der Umsetzung des Richtlinienvorhabens die gleiche Diskussion wieder auflebt, insbesondere in Anbetracht der an die Kinderpornographie gekoppelten Löschverpflichtung.

Im politischen Rechtssetzungsverfahren zur Richtlinie ist diese Problematik zwischenzeitig ebenfalls erläutert worden. Im Ratsdokument der Arbeitsgruppe „Materielles Strafrecht“ vom 26.11.2010 eröffnete der Rat über Art. 5 Nr. 8 die Möglichkeit, es den Mitgliedstaaten freizustellen, strafbare kinderpornographische Handlungen auf Personen mit kindlichem Erscheinungsbild auszuweiten. ${ }^{1338}$

Die damals geforderte fakultative Überlassung der Maßnahme in die Regelungsgewalt der nationalen Mitgliedsstaaten hätte die beste Lösung dargestellt, dem nationalen Gesetzgeber die Möglichkeit zu geben, die Notwendigkeit der Einbeziehung der Scheinjugendlichkeit in den Straftatbestand zu hinterfragen und entsprechende Nachbesserungen vorzunehmen. Auf die Einführung einer solchen ist in der endgültigen Richtlinienfassung allerdings verzichtet worden.

\section{b) Fiktivpornographische Darstellungen}

Bereits der Rahmenbeschluss 2004/68/JI nahm über die Definition von Kinderpornographie in Art. 1 lit. b (iii) auch fiktive kinderpornographische Darstellungen in die Regelungsmaterie auf. Entsprechend den europäischen Vorgaben wurde der Tatbestand des $\int 184 b$ StGB angepasst und um die fiktiven Darstellungen ergänzt. ${ }^{1339}$ Auch die Richtlinie knüpft an die Vorgaben des Rahmenbeschlusses an und zielt auf die verbindliche Einbeziehung der Fiktivpornographie in die nationalen Rechtsordnungen ab. Gemäß Art. 2 lit. c (i) ist Kinderpornographie als ,jegliches Material mit Darstellungen eines Kindes, das an realen oder simulierten eindeutig sexuellen Handlungen beteiligt ist", definiert.

$1337 \int 184$ StGB normiert nur ein Verbot für unter 18-Jährige. Erwachsenen ist der Konsum, die Weitergabe sowie das Zugänglichmachen von „normaler“ Pornographie grundsätzlich erlaubt. Zum Pornographieverbot des Strafrechts eingehend, Erdemir, Filmzensur und Filmverbot, 2000, S. 135 ff.; Schreibauer, Das Pornographieverbot des \ 184 StGB, 1999, S. 71 ff.

1338 Rat der Europäischen Union, 16958/10 DROIPEN 139 JAI 998 CODEC 1368; kritisch deutschen Richterbundes, Stellungnahme zum Richtlinienvorschlag $\operatorname{KOM}(2010) 94$ endg. v. 17.3.2011, abrufbar unter: http://www.drb.de/cms/index.php?id=708\&L=0 (zuletzt abgerufen 20.5.2012), die darüber hinaus anmerken, dass eine aus der Formulierung heraus lesbare Beweislastumkehr mit dem deutschen Strafrecht nicht zu vereinen wäre.

1339 Dies geschah, wie auch innerhalb der Norm des $\int 184$ c StGB, nicht über eine unmittelbare Fixierung der Fiktivpornographie in den Tatbestand, sondern über eine systematische Auslegung zum Gesamtkontext der Norm. Hierzu bereits oben 2. Teil A. III. 1. a) . 
Im gesamten Gesetzgebungsprozess zum Zugangserschwerungsgesetz wurde die Thematik der fiktionalen Darstellungen nicht angetastet. Der Gesetzgeber wählte vielmehr die direkte Bezugnahme zum Straftatbestand des \184b StGB und überließ die Fragestellung nach einer Einbindung fiktionaler Darstellungen der Strafrechtslehre. Diese sieht in Bezug auf $\int 184 b$ StGB im Kontext zum Umsetzungsgesetz des Rahmenbeschlusses, sowie aufgrund des geschützten Rechtsguts, die Einbeziehung von fiktionalen Darstellungen in den Straftatbestand als gegeben. Diesbezüglich würde die Richtlinienvorgabe für den nationalen Gesetzgeber damit keinen erneuten Handlungsbedarf ergeben. Im Rahmen des Löschgesetzes wäre es jedoch wünschenswert, wenn der deutsche Gesetzgeber aus Klarstellungsgesichtspunkten ausdrücklich die fiktionalen Darstellungen in den Löschtatstand aufnimmt und diesbezüglich Rechtssicherheit schafft.

\section{Schlussfolgerung}

Die offenkundige Abkehr von der Möglichkeit der Sperrung hin zur Löschung kinderpornographischer Inhalte ist auf europäischer Ebene gegenüber der national präferierten Linie deutlich abgemildert. Anders als der deutsche Gesetzgeber nimmt die europäische Vorgabe eine Sperrung nicht gänzlich aus dem Maßnahmenkatalog zur Bekämpfung kinderpornographischer Inhalte heraus, sondern gestaltet diese lediglich als fakultative Maßnahme aus. Die Löschung ist hingegen als obligatorische Maßnahme in allen Mitgliedstaten einzuführen und bildet einen wesentlichen Grundpfeiler der Harmonisierungsmaßnahmen.

Die innerstaatliche Transformation der europäischen Vorgaben, welche die nationalen Gesetzgeber zum Einführen einer Löschpflicht für kinderpornographische Inhalte verpflichtet, ist nicht unproblematisch. Zwar hat der nationale Gesetzgeber durch das deutsche Umsetzungsgesetz des Rahmenbeschlusses 2004/68/JI bereits viele rechtliche Grundsteine gelegt, die einen erneuten Umsetzungsbedarf obsolet machen, jedoch birgt auch die Richtlinie, wie damals schon der Rahmenbeschluss, viele Diskrepanzen zum geltenden Recht, welche rechtspolitischen Handlungsbedarf begründen.

\section{Europäisches Vorgehen am Beispiel Frankreichs}

Das Thema Löschen und/oder Sperren kinderpornographischer, wie allgemein rechtsverletzender Inhalte führt auch in anderen europäischen Ländern zu zahlreichen Gesetzesvorhaben, die ähnlich der nationalen Kontroverse stark im Fokus der Öffentlichkeit stehen. Besonders Frankreich nimmt bei der Thematik eine Art Vorreiterstellung ein. In den vergangenen Jahren sind immer wieder Gesetzesvorhaben angestrebt sowie Gesetze erlassen worden, die rechtsgebietsübergreifend die administrativen Rechte der französischen Behörden im Bereich der inhaltsbe- 
schränkenden Maßnahmen im Internet stärken sollen. ${ }^{1340}$ So verwundert es auch nicht, dass Frankreich im jüngsten Bericht der Organisation „Reporter ohne Grenzen“ als einziger Mitgliedsstaat der Europäischen Union „unter Beobachtung" gestellt wurde und damit vergleichbar mit Ländern wie Libyen, Türkei, Thailand, Ägypten sowie Süd Korea gesellschaftlich im Mittelpunkt der Diskussion hinsichtlich einer zensurartigen Beschränkung der Internetkultur steht. ${ }^{1341}$ Die neuste Entwicklung der französischen Gesetzgebung insbesondere mit Fokus auf die Unterbindung kinderpornographischer Inhalte soll hier zum Anlass genommen werden, einen kurzen Einblick über die Neuerungen der französischen Rechtsordnung zu geben und einen vergleichenden Exkurs zur deutschen Debatte um das ,gescheiterte“ Zugangserschwerungsgesetz wagen.

\section{Einführung}

\section{Ermächtigungsgrundlage nach französischen Recht}

„Lorsque les nécessités de la lutte contre la diffusion des images ou des représentations de mineurs relevant de l'article 227-23 du code pénal le justifient, l'autorité administrative notifie aux personnes mentionnées au 1 du présent I les adresses électroniques des services de communication au public en ligne contrevenant aux dispositions de cet article, auxquelles ces personnes doivent empêcher l'accès sans délai. Un décret fixe les modalités d'application de l'alinéa précédent, notamment celles selon lesquelles sont compensés, s'il y a lieu, les surcoûts résultant des obligations mises à la charge des opérateurs."

Die Norm entspricht Art. 4 des französischen Gesetzes Loi n 2011-267 „Loi d'orientation et de programmation pour la performance de la sécurité intérieure“ (so genanntes „Loppsi $\left.2^{“ 6-G e s e t z)}\right)^{1342}$ und stellt die Ermächtigungsgrundlage der

1340 Beispielhaft Loi n ${ }^{\circ} 2009-669$ du 12 juin favorisant la diffusion et la protection de la création sur internet (gen. Hadopi 2) sowie Loi no 2011-267 du 14 mars 2011 d'orientation et de programmation pour la performance de la sécurité intérieure (gen. Loppsi 2).

1341 Reporter ohne Grenzen ist eine Menschenrechtsorganisation die sich gezielt für die Meinungsund Pressefreiheit einsetzt und weltweit Verstöße dokumentiert. Als Nichtregierungsorganisation ist Reporter ohne Grenzen weltweit anerkannt und nimmt beratende Tätigkeiten u.a. beim Europarat ein, Informationen abrufbar unter: http://www.reporter-ohne-grenzen.de/ueberuns.html (zuletzt abgerufen 20.5.2012). Die Organisation „Reporter ohne Grenzen“ veröffentlicht jährlich einen umfassenden Bericht zur Kontrolle, Überwachung und Zensur des Internets, der verschiedene Länder kritisch begutachtet und in die Kategorien „Internet-Feinde“ sowie „unter Beobachtung“ hinsichtlich der zensurartigen Beschränkung von meinungs- und Pressefreiheit einteilt.

1342 Loi n ${ }^{\circ}$ 2011-267 du 14 mars 2011 d'orientation et de programmation pour la performance de la sécurité intérieure, Journal officiel de la République française, (JORF) Nr. 0062 v. 15.3.2010, 
französischen Verwaltungsbehörden dar, Sperrverfügungen gegen Internetprovider zu erlassen, um kinderpornographische Abbildungen nach Art. 227-23 des französischen Strafgesetzbuches unzugänglich zu machen. Gemäß der Gesetzesfassung soll eine Regierungsbehörde (genauer l'Office central de lutte contre la criminalité liée aux technologies de l'information et de la communication) ${ }^{1343}$ auf Basis einer noch zu erlassenden Verordnung befugt sein, Internetprovider zum Sperren kinderpornographischer Inhalte zu verpflichten. Die Verordnung legt dabei die genaue Umsetzung des Verfahrens fest, insbesondere die Bedingungen eines finanziellen Ausgleichs von eventuell bestehenden Mehrkosten, die den Providern im Falle der Umsetzung der gesetzlichen Verpflichtung entstehen. ${ }^{1344}$

Art. 4 Loi n $2011-267$ beruht auf einem breiten Maßnahmenpaket, das über die Änderung geltender Rechtsvorschriften, die internetbasierten Eingriffsbefugnisse der staatlichen Behörden erweitern soll. ${ }^{1345}$ Es setzt das bereits entwickelte Maßnahmenpaket des Loi n ${ }^{\circ}$ 2002-1094 „Loi d'orientation et de programmation pour la Sécurité Intérieure“ (Loppsi 1) ${ }^{1346}$ fort, zielt anders als das erste Paket aber nicht auf die Verbesserung der organisatorischen Strukturen zur Gewährleistung der inneren Sicherheit ab, sondern bezweckt vordergründig die Schaffung neuer Kompetenzbereiche mit zugehörigen Eingriffsermächtigungen für die französischen Polizeibehörden sowie die Gendarmerie Nationale, um eine effektive Bekämpfung der Kriminalität tatsächlich durchsetzten zu können. Neben der Ermächtigung der Behörde zur Sperrung kinderpornographischer Webangebote, enthält Loi n 2011-267 auch Regelungen, die eine gezielte Online-Durchsuchung, die Zulassung und den Einsatz von technischer Spyware und Ganzkörperscan-

S. 4582, abrufbar unter: http://www.senat.fr/petite-loi-ameli/2010-2011/262.html (zuletzt abgerufen 20.5.2012), nachfolgend Loi n 2011-267 oder Loppsi 2 genannt.

1343 Die sog. OCLCTIC ist eine nationale Behörde die im Rahmen von Kriminalität in Zusammenhang mit Informations- und Kommunikationstechnologien eingesetzt wird. Die Behörde ist angegliedert an die Generaldirektion der französischen Polizei und Teil der nationalen Kriminalpolizei. Im Wesentlichen unterteilen sich die Aufgaben der OCLCTIC auf operative Tätigkeiten, wie die technische Untersuchungen im Rahmen von Straftaten und strafrechtlichen Ermittlungen im Kommunikationsmedien sowie organisatorische Tätigkeiten, wie die Organisation länderübergreifender Tätigkeiten sowie Schulungen und Fortbildungen. Informationen zum Tätigkeitsbereich abrufbar unter: http://www.securiteinfo.com/legal/OCLCTIC.shtml (zuletzt abgerufen 20.5.2012).

1344 Überblicksartig, Sottet, MMR-Aktuell 2010, 309015.

1345 Im Einzelnen soll Art. 4 Loi n 2011-267, Art. 6 des Loi n 2004-575, du 21 juin 2004 pour la confiance dans l'économie numérique est ainsi modifié (Gesetz über das Vertrauen in die digitale Wirtschaft) ergänzen.

${ }^{1346}$ Loi n 2002-1094, du 29 août 2002 d'orientation et de programmation pour la sécurité intérieure, Journal officiel de la République française, (JORF) Nr. 202 v. 30.8.2002, hierzu MMR 9/2007, XXXII. 
nern sowie die Erweiterung von polizeilichen Datenbanken zur Täterermittlung um genetische Informationen, erlauben. ${ }^{1347}$

\section{Conseil Constitutionnel im Kontext jüngerer Rechtsprechung}

a) Conseil Constitutionnel-Entscheidung vom 10.3.2011

Der politische Werdegang des Loppsi 2-Gesetzes war - wie die Breite der verfolgten Maßnahmen bereits erahnen lässt - seit Anbeginn der Gesetzesinitiative massiver Kritik ausgesetzt. Insbesondere die hier im Fokus stehende Vorschrift des Art. 4 wurde nahezu spiegelbildlich zur innerstaatlichen Diskussion um das Zugangserschwerungsgesetz in den politischen Lagern der französischen Regierung stark umkämpft, ehe das Gesetz letztlich am 15.3.2011, nach Prüfung durch den französischen Verfassungsrat Conseil Constitutionnel in Kraft treten konnte. ${ }^{1348}$

Im Mai 2009 reichte die französische Regierung einen ersten Entwurf des Gesetzes ein. ${ }^{1349}$ Die erste Fassung enthielt bereits die in Art. 4 normierte Ermächtigungsgrundlage der Verwaltungsbehörden zur Anordnung einer Sperrung kinderpornographischer Inhalte durch die Provider. Diese Anordnung war jedoch an eine vorherige richterliche Überprüfung der Sperrnotwendigkeit geknüpft. Die Kritik am Gesetzesvorhaben nahm weiter zu, als der französische Senat die richterliche „a-priori-Kontrolle“ innerhalb des zweiten Gesetzesentwurfs verwarf: Seither reicht eine frei von gerichtlicher Prüfung ergangene Verwaltungsanordnung an die Internetprovider aus, um die Sperrverpflichtung auszulösen. Im Einzelnen erstellt hierfür das l'Office central de lutte contre la criminalité liée aux technologies de l'information et de la communication eigenmächtig eine geheime „Blacklist" mit identifikationsmerkmalen kinderpornographischer Webseiten, welche die Behörde in regelmäßigen Abständen allen in Frankreich ansässigen

1347 Überblicksartig, Subuc in: wbs-law.de, Beitrag v. 29.3.2011, „Loppsi 2 - Netzsperre ohne richterliche Kontrolle ist in Frankreich verfassungsgemäß“, abrufbar unter: http://www.wbslaw.de/internetrecht/loppsi-2-netzsperre-ohne-richterliche-kontrolle-ist-in-frankreichverfassungsgemas-6945/\#more-6945 (zuletzt abgerufen 20.5.2012).

1348 Con. const., Décision n² 2011-625 DC du 10 mars 2011, abrufbar unter: http://www.conseilconstitutionnel.fr/conseil-constitutionnel/francais/les-decisions/acces-par-date/decisions-

depuis-1959/2011/2011-625-dc/decision-n-2011-625-dc-du-10-mars-2011.94924.html (zuletzt abgerufen 20.5.2012).

1349 Entwurfsfassung Loi n 1697 abrufbar unter: http:/ /www.assemblee-nationale.fr/13/projets/pl1697.asp (zuletzt abgerufen 20.5.2012); kurzüberblick Sottet, MMR-Aktuell 2010, 301044. Zur Kritik zusammenfassend Pany, telepolis, Beitrag v. 28.5.2009, „Loppsi und der Franzosentrojaner“, abrufbar unter: http://www.heise.de/tp/artikel/30/30416/1.html (zuletzt abgerufen 20.5.2012). Zum Gesetzgebungsverfahren Sottet, MMR-Aktuell 2010, 301044; Buron, MMR-Aktuell 2011, 313762; dies., MMR-Aktuell 2011, 316290. 
Internetprovidern zuleitet und diese daraufhin die in der Liste aufgenommenen Webseiten mittels technischer Sperrmaßnamen im Zugriff beschränken.

Nach langwierigen politischen Auseinandersetzungen stimmte im Dezember 2010 zunächst die Assemblée Nationale (Nationalversammlung) sowie im Januar 2011 anschließend auch der Senat dem Gesetzesvorhaben in seiner novellierten Fassung zu. Bereits unmittelbar nach der Verabschiedung des Gesetzes durch den Senat haben die französischen Oppositionsparteien eine Überprüfung vor dem französischen Verfassungsrat gefordert und das Gesetz zur Prüfung gemäß Art. 61 Abs. 2 der französischen Verfassung „la Constitution de octobre 1958“ vorgelegt. ${ }^{1350}$

Der französische Verfassungsrat erklärte in seiner daraufhin ergangenen Entscheidung vom 10.3.2011 insgesamt dreizehn Artikel des Gesetzespakets als mit der französischen Verfassung unvereinbar. ${ }^{1351}$ Bezüglich des umstrittenen Art. 4 Loi no 2011-267 befand das Conseil Constitutionnel die Vorschrift über die Zugriffsbeschränkung zu kinderpornographischen Webseiten jedoch als verfassungsgemäß. Die Opposition rügte die Verfassungswidrigkeit der Regelung vor allem deshalb, weil die durch die Verwaltungsbehörde anzuordnende Sperrverpflichtung keiner richterlichen Kontrolle unterliege sowie die grundsätzliche Eignung der Sperre im Kampf gegen Kinderpornographie nicht als gesichert gelte. Auch sei die Tatsache verfassungsrechtlich bedenklich wäre, dass die Provider im Falle der

1350 Der Conseil Constitutionnel ist im Wesentlichen zu vergleichen mit dem Bundesverfassungsgericht. Er fungiert als unabhängiges Rechtsprechungsorgan, wobei seine Entscheidungen Gesetzeskraft entfalten. Entsprechend Art. 61 Abs. 2 de la Constitution de octobre 1958 kann ein vom Parlament verabschiedetes Gesetz vor dessen Verkündung fakultativ zur Überprüfung auf seine Verfassungsmäßigkeit dem Conseil Constitutionnel vorgelegt werden. Antragsberechtigt ist der Präsident der Republik, der Premierminister, der Präsidenten der Nationalversammlung, der Präsidenten des Senats oder die Abgeordneten oder Senatoren, soweit diese das vorgeschriebene Quorum von 60 Personen erreicht haben. Zum Verfahren im Einzelnen, Jan, Le Procès Constitutionnel, 2010; Roussillon, Le Conseil Constitutionnel, 2008,

Erläuterung abrufbar unter:

http://www.conseil-constitutionnel.fr/conseil constituti-

onnel/deutsch/verfassungsrat/verfassungsrat.25770.html (zuletzt abgerufen 20.5.2012). Nähere

Einzelheiten zur Arbeitsweise regelt entsprechend Titel VII, Art. 63 de la Constitution de octobre 1958 ein Gesetz.

1351 Con. const., Décision n 2011-625 DC du 10 mars 2011, abrufbar unter: http://www.conseilconstitutionnel.fr/conseil-constitutionnel/francais/les-decisions/acces-par-date/decisionsdepuis-1959/2011/2011-625-dc/decision-n-2011-625-dc-du-10-mars-2011.94924.html (zuletzt abgerufen 20.5.2012). Darunter u.a. die Regelungen zum Verbot des Onlineverkaufs von Tickets für Kultur- und Sportveranstaltungen, wie auch die Vorschriften über eine umfassende Videoüberwachung öffentlicher Plätze durch private Sicherheitsfirmen, sowie die Reglungen zur Verschärfung des Jugendstrafrecht sowie des Versammlungsrechts. 
Erfüllung der gesetzlichen Verpflichtung nicht notwendigerweise finanziell zu entschädigt würden. Der Verfassungsrat verwarf diese Argumentation jedoch innerhalb einer kurzen Begründung: Nach Ansicht des Rates sei nicht festzustellen, dass das gewählte Mittel der Sperrung zur Erreichung der gesetzgeberischen Ziele, offensichtlich ungeeignet sei. Auch liege kein offensichtlicher Beurteilungsfehler seitens des Gesetzgebers vor, wenn die Mehrkosten der Internetprovider, die mit der Bereitstellung der notwendigen Sperrinfrastruktur zusammenhängen, nicht finanziell ausgeglichen würden. Hinsichtlich der Frage nach einem verfassungsrechtlichen Erfordernis einer vorhergehenden richterlichen Überprüfung der Sperrnotwendigkeit einer Webseite, sprach sich das Gericht dafür aus, dass die angegriffene Norm auch diesbezüglich mit der Verfassung in Einklang stehe. Eine generelle gerichtliche a-priori-Überprüfung sei von Verfassungswegen nicht vorgesehen. Die Entscheidung der Verwaltungsbehörde eine Sperrung anzuordnen, könne vielmehr jederzeit von jeder interessierten Person vor dem zuständigen Gericht in Frage gestellt werden und gegebenenfalls im einstweilligen Rechtsschutzverfahren überprüft werden. Die Regelung des Art. 4 Loi n 2011-267 stehe somit insgesamt im Einklang mit der Verfassung. Sie wahre vor allem das Verhältnis zwischen dem verfassungsrechtlichen Ziel der Einhaltung der öffentlichen Ordnung zur Beschränkung der Freiheit der Kommunikation, welche in Artikel 11 der Erklärung der Menschenrechte und Bürgerrechte von 1789 verankert ist und der Beschränkung der Provider, im verfassungsrechtlich zulässigen Maße. ${ }^{1352}$

1352 Cons. const., Décision n 2011-625 DC, Erwägungsgrund 6 ff. : „Considérant que les requérants font valoir, dune part, que l'institution d'un dispositif de blocage des adresses électroniques donnant accès à certains sites internet constitue une mesure inappropriée voire contreproductive et d'un coût excessif au regard de l'objectif poursuivi de lutte contre la diffusion d'images pédopornographiques ; que, d'autre part, en l'absence d'autorisation judiciaire, l'atteinte portée à la liberté de communication par l'impossibilité d'accéder à ces sites serait disproportionnée; - Considérant, en premier lieu, que le Conseil constitutionnel na pas un pouvoir général d'appréciation et de décision de même nature que celui du Parlement ; qu’il ne saurait rechercher si les objectifs que s'est assignés le législateur auraient pu être atteints par d'autres voies, dès lors que les modalités retenues par la loi ne sont pas manifestement inappropriées à l'objectif visé ; qu'en instituant un dispositif permettant d'empêcher l'accès aux services de communication au public en ligne diffusant des images pornographiques représentant des mineurs, le législateur n’a commis aucune erreur manifeste d'appréciation ; qu'en prévoyant que les surcoûts résultant des obligations mises à la charge des opérateurs seraient, s’il y a lieu, compensés, il na pas méconnu lexigence constitutionnelle du bon usage des deniers publics; - Considérant, en second lieu, que les dispositions contestées ne confèrent à l'autorité administrative que le pouvoir de restreindre, pour la protection des utilisateurs d'internet, l'accès à des services de communication au public en ligne lorsque et dans la mesure où ils diffusent des images de pornographie infantile; que la décision de l'autorité administrative est susceptible d'être contestée à tout moment et par toute personne intéressée devant la juridiction compé- 
Die Ausführungen des Conseil Constitutionnel beschränkten sich hinsichtlich der Prüfung der Verfassungsmäßigkeit des Art. 4 Loi n 2011-267 damit auf eine kurze Widerlegung der oppositionellen Argumentation. Ausführliche Erläuterungen, die ähnlich einem obiter dictum generalisierenden Charakter hätten und auf zukünftige Fallgestaltungen übertragbar wären, sucht man innerhalb der vorgenommenen Begründung vergebens. Vielmehr beschränkt sich der Verfassungsrat bei der Frage nach einer grundsätzlichen Eignung der Sperrtechnik als Mittel zur Unterdrückung von Rechtsverletzungen im Internet auf die Ausführung, dass es selbst nicht darüber befinden könne, ob andere Maßnahmen, so etwa auch die technische Möglichkeit der Löschung, erfolgreicher im Kampf gegen Kinderpornographie wären. Der Gesetzgeber hätte seine diesbezüglich zugestandene Einschätzungsprärogative zumindest nicht offensichtlich überschritten, als er sich im Gesetz für die Möglichkeit der Sperrung ausgesprochen hatte. ${ }^{1353}$

\section{b) Conseil Constitutionnel-Entscheidung im Falle Hadopi}

Der Rat hatte in einer jüngeren Entscheidung aus dem Jahr 2009 das umstrittene Loi $n^{\circ}$ 2009-669 „Loi favorisant la diffusion et la protection de la création sur internet “"1354 (so genanntes Hadopi 1-Gesetz), ${ }^{1355}$ welches ein mehrstufiges Verwarnsystem für urheberrechtliche Rechtsverletzungen im Internet mit der endgültigen Sanktion der Zugangssperrung regelt, seinerzeit wegen eines mangelnden Vorbehalts einer richterlichen Überprüfung verworfen. ${ }^{1356}$ Das im Hadopi-Gesetz

tente, le cas échéant en référé ; que, dans ces conditions, ces dispositions assurent une conciliation qui n'est pas disproportionnée entre l'objectif de valeur constitutionnelle de sauvegarde de l'ordre public et la liberté de communication garantie par l'article 11 de la Déclaration des droits de l'homme et du citoyen de 1789.“

1353 Hierzu überblicksartig, Krempl in: heise-online, Meldung v. 11.3.2011, „Websperren in Frankreich sind verfassungsgemäß“, abrufbar unter:

http://www.heise.de/newsticker/meldung/Websperren-in-Frankreich-sindverfassungsgemaess-1206781.html (zuletzt abgerufen 20.5.2012).

${ }^{1354}$ Loi n 2009-669 du 12 juin 2009 favorisant la diffusion et la protection de la création sur internet, Journal officiel de la République française, (JORF) Nr. 135 v. 13.6.2009, S. 9666, abrufbar unter :

http://www.legifrance.gouv.fr/affichTexte.do?cidTexte=JORFTEXT000020735432\&dateTexte = (zuletzt abgerufen 20.5.2012). Dazu Spies, MMR 2009, 437; Geiger, IIC 2011, 457.

1355 Hadopi ist die Kurzform von Haute Autorité pour la diffusion des oenvres et la protection des droits sur l'Internet und bezeichnet die durch das Art. 19 Loi 2009-669 neu einzurichtende Behörde, die gegen Urheberrechtsverletzungen nach dem im Gesetz vorgeschriebenen Verfahren vorgeht.

1356 Con. const., Décision n 2009-580 DC du 10 juin 2009, abrufbar unter: http://www.conseilconstitutionnel.fr/conseil-constitutionnel/francais/les-decisions/acces-par-date/decisionsdepuis-1959/2009/2009-580-dc/decision-n-2009-580-dc-du-10-juin-2009.42666.html (zuletzt abgerufen 20.5.2012). Hierzu ausführlich Geiger, IIC 2011, 457 (466 f.). 
niedergelegte Konzept wird oftmals mit dem „Three-Strikes-Verfahren“ umschrieben. ${ }^{1357}$ Das Konzept folgt im Wesentlichen einem dreistufigen Verwarnverfahren, an dessen Abschluss die Sperrung des Internetzugangs angeordnet werden darf. Nachdem dem Anschlussinhaber auf erster Verwarnstufe per E-Mail von der Hadopi-Behörde mitgeteilt wird, dass sein Internetzugang vermutlich für urheberrechtswidrige Handlungen benutzt wurde und entsprechende Sanktionen nach Art. L. 335-7 und L. 335-7-1 des französischen Gesetzesbuches zum Schutz des geistigen Eigentums (Urhebergesetz) „Code de la propriété intellectuelle“ (CPI) angedroht wurden, erfolgt auf zweiter Stufe eine wiederholte Verwarnung mittels Einschreiben, soweit der Anschlussinhaber weiterhin Urheberrechtsverletzungen im Internet begeht. Sollte auch die zweite Stufe nicht vor weiteren RechtsverstöBen abhalten, kann in der abschließenden dritten Stufe des Verfahrens eine völlige Sperrung des Internetzugangs angeordnet werden. ${ }^{1358}$

Der Verfassungsrat hielt die erste Fassung des Gesetzes vor allem deshalb für verfassungswidrig, weil eine Behörde, anstelle eines Richters, über die dritte Sanktionsstufe einer endgültigen Sperrung und damit auch über die Einschränkung von Grundrechten entscheiden durfte. Der Conseil Constitutionnel hatte in der Entscheidung deutlich ein „Recht auf Zugang zum Internet“ herausgearbeitet und dieses der Entscheidungsfindung zugrunde gelegt. ${ }^{1359}$ Das Recht des Zugangs zum Internet leitete der Verfassungsrat aus Art. 11 der Menschen- und Bürgerrechtserklärung von 1789 her: Danach sei die „freie Mitteilung der Gedanken und Mei-

1357 Das „Three-Strikes and you’re out“ ist grundsätzlich eine Redewendung, die im Fachgargon des Baseballs verankert ist und bedeutet, dass der Spieler nach dreimaligen Fehlschlag vom Platz muss. Seit Bekanntwerden des französischen Gesetzesvorhabens wird sie Umgangssprachlich für das dreistufige Verwarnsystem nach dem Hadopi-Gesetz gebraucht. Grds. liegt dem Ansatz ein Prinzip der abgestuften Erwiderung „réponse graduée“ zugrunde, hierzu Nérisson, GRUR-Int. 2010, 637 bei Fn. 5; Solmecke/Sebastian/Sabuc, MMR-Aktuell 2011, 316298; kurz auch Spindler in: Eifert/ Hoffmann-Riem, Innovation, Recht und öffentliche Kommunikation, 2011, S. 67 (86); Greve/Schärdel, ZRP 2009, 54; zur Vereinbarkeit eines Three-Strikes-Verfahrens mit deutschen Verfassungsrecht, Fink in: carta-online, Beitrag v. 13.8.2009, „Internet-Zugangssperren: Wäre Three-Strikes in Deutschland verfassungsgemäß?“, abrufbar unter: http://carta.info/13113/ (zuletzt abgerufen 20.5.2012).

1358 Allgemein hierzu Greve/Schärdel, ZRP 2009, 54; Nérisson, GRUR-Int. 2010, 637 bei Fn. 5; Solmecke/Sebastian/Sabuc, MMR-Aktuell 2011, 316298; kurz auch Spindler in: Eifert/Hoffmann-Riem, Innovation, Recht und öffentliche Kommunikation, 2011, S. 67 (86); Geiger, IIC 2011, 457; Spies, MMR 2009, 437.

1359 Con. const., Décision n ${ }^{\circ}$ 2009-580 DC, Erwägungsgrund 12, abrufbar unter: http://www.conseil-constitutionnel.fr/conseil-constitutionnel/francais/les-decisions/acces-pardate/decisions-depuis-1959/2009/2009-580-dc/decision-n-2009-580-dc-du-10-juin2009.42666.html (zuletzt abgerufen 20.5.2012). Hierzu Geiger, IIC 2011, 457 (466 ff.); ders., Recueil Dalloz Sirey 2011, 773. 
nungen (...) eines der kostbarsten Menschenrechte. Jeder Bürger kann also frei schreiben, reden und drucken unter Vorbehalt der Verantwortlichkeit für den Missbrauch dieser Freiheit in den durch das Gesetz bestimmten Fällen“. Aus dieser verfassungsrechtlichen Gewährleistung folgerte der Rat, dass aufgrund des gegenwärtigen Standes der Kommunikationsmittel und in Anbetracht der allgemeinen Verbreitung von Online-Kommunikationsdiensten, sowie der Bedeutung, die diese Dienste für die demokratische Mitwirkung und den Ausdruck von Gedanken und Meinungen besitzen, das in Artikel 11 gewährleistete Recht auch darauf gerichtet sei, freien Zugang zu diesen Diensten zu erhalten. ${ }^{1360}$ Um die Wichtigkeit des Rechts zu wahren, dürfen Beschränkungen nicht allein der Entscheidung einer Exekutivbehörde überlassen werden, sondern müssen zusätzlich von einem unabhängigen Rechtsprechungsorgan auf ihre Notwendigkeit hin überprüft werden. Die daraufhin überarbeitete Fassung Loi n 2009-1311 „Loi relative à la protection pénale de la propriété littéraire et artistique sur internet"1361 (bekannt als „Hadopi 2“-Gesetz), griff den im ersten Gesetzesentwurf niedergelegten Ansatz der Internetsperren für urheberrechtliche Verletzungshandlungen erneut auf, bindet, entsprechend der Vorgaben des Verfassungsrates, jedoch die Gerichte verstärkt in die Beurteilung der Sperrnotwendigkeit ein, wobei sich das Gesetz auf ein schnelles Rechtsschutzverfahren beschränkt. Nach Maßgabe der Entscheidung des Conseil Constitutionnel entscheidet nunmehr ein Einzelrichter im Eilverfahren auf Antrag der Hadopi-Behörde über die abschließenden Sanktionen: Zur Auswahl stehen neben der gewöhnlichen Bußgeldstrafe für Urheberrechtsverletzungen, auch eine totale Aufhebung des Internetzugangs für den Zeitraum von höchstens einem Jahr gekoppelt mit dem Verbot während der Geltungszeit der Sperre einen zusätzlichen Vertrag mit einem Online-Diensteanbieter abzuschlieBen. Dem Anschlussinhaber wird die Entscheidung des Richters schriftlich mitgeteilt, gegen die der Anschlussinhaber innerhalb von 45 Tagen Einspruch erheben kann. ${ }^{1362}$ Diesen Ansatz hatte das französische Conseil Constitutionnel in einer

1360 Con. const., Décision n 2009-580 DC, Erwägungsgrund 16, abrufbar unter:

http:/ / www.conseil-constitutionnel.fr/conseil-constitutionnel/francais/les-decisions/acces-pardate/decisions-depuis-1959/2009/2009-580-dc/decision-n-2009-580-dc-du-10-juin-

2009.42666.html (zuletzt abgerufen 20.5.2012).

1361 Loi n 2009-1311 „Loi relative à la protection pénale de la propriété littéraire et artistique sur internet", Journal officiel de la République française, (JORF) Nr. 251 v. 29.10.2009, S. 18290, abrufbar unter :

http://www.legifrance.gouv.fr

/ affichTexte.do;jsessionid=EFD10EF57A3F4B5C6220F16A4E343588.tpdjo03v_2?cidTexte=J ORFTEXT000021208046\& dateTexte=\&oldAction=rechJO\&categorieLien=id) (zuletzt abgerufen am 20.5.2012).

1362 Als gesetzlich normierter Gegenbeweis, den der Anschlussinhaber im Falle der Verteidigung anführen kann, benennt das Gesetz lediglich das Vorhandensein einer von der Hadopi empfoh- 
erneuten Vorlage als verfassungsgemäß gebilligt, woraufhin das Gesetz in Kraft trat. ${ }^{1363}$

c) Kontext beider Entscheidungen

Dem ersten Anschein nach steht diese Entscheidung im Fall Hadopi damit im Widerspruch zur Entscheidung des Conseil Constitutionnel im Falle des LoppsiGesetztes, welche gerade keine vorherige Prüfung der Inhaltssperre durch einen unabhängigen Richter forderte. Für eine unterschiedliche Beurteilung des Conseil Constitutionnel bezüglich der Notwendigkeit einer vorherigen richterlichen Kontrolle der Sperrung sprechen im Vergleich der beiden Fallgestaltungen zueinander jedoch eindeutige Erwägungen:

In beiden Fällen ist, wie der Verfassungsrat deutlich macht, mit dem angeordneten technischen Eingriff eine Einschränkung der Kommunikationsfreiheiten des Art. 11 der Erklärung der Menschenrechte und Bürgerrechte von 1798 verbunden. ${ }^{1364}$ Es ist jedoch nicht allein die Einschränkung der Kommunikation, die zu einer a-priori-Kontrolle durch eine unabhängige Instanz verpflichtet. Vielmehr ist die Eingriffsintensität entscheidend: Nach dem Hadopi-Gesetz handelt es sich um eine nutzerseitige Beschränkung, Loppsi hingegen veranlasst zu einer Inhaltssperre: Während nach dem Hadopi-Gesetz die nutzerseitige Beschränkung über eine völlige Zugangssperrung des gesamten Internetzugangs erfolgen darf, berechtigt Art. 4 des Loppsi-Gesetzes nur zur Zugriffserschwerung bestimmter Webinhalte. Obgleich mit der Sperrung eines einzelnen kinderpornographischen Inhaltes auch weitere, unter anderem auch völlig rechtmäßige Inhalte gleichzeitig gesperrt werden (Overblocking-Effect), ${ }^{1365}$ ist der Internetnutzer im grundsätzlichen Zugang zum Internet nicht beschränkt. Besonders die vom französischen Verfassungsrat hervorgehobene „Wichtigkeit der ungestörten Onlinenutzung für die

lenen Sicherungsmaßnahme an seinem Computer oder seinem Internetzugang, die vor unberechtigter Nutzung des Anschlusses durch Dritte schützt.

1363 Con. Const., Décision n 2009-590 DC du 22 Octobre 2009, abrufbar unter :

http://www.conseil-constitutionnel.fr/conseil-constitutionnel/francais/les-decisions/acces-pardate/decisions-depuis-1959/2009/2009-591-dc/decision-n-2009-591-dc-du-22-octobre-

2009.45973.html (zuletzt abgerufen 20.5.2012).

1364 Con. const., Décision $\mathrm{n}^{\circ}$ 2009-580 DC, Erwägungsgrund 16, abrufbar unter: http://www.conseil-constitutionnel.fr/conseil-constitutionnel/francais/les-decisions/acces-pardate/decisions-depuis-1959/2009/2009-580-dc/decision-n-2009-580-dc-du-10-juin-

2009.42666.html (zuletzt abgerufen 20.5.2012). Sowie Con. const., Décision n 2011-625 DC, Erwägungsgrund 8, abrufbar unter:

http:/ / www.conseil-constitutionnel.fr/conseil-constitutionnel/francais/les-decisions/accespar-date/decisions-depuis-1959/2011/2011-625-dc/decision-n-2011-625-dc-du-10-mars-

2011.94924.html (zuletzt abgerufen 20.5.2012).

1365 Hierzu bereits ausführlich oben 3. Teil B. I. 2. b) (bb) . 
Demokratie“ machen es unabdingbar, die Notwendigkeit einer so grundrechtssensiblen und schwer einschränkenden Maßnahme vor ihrer Verhängung überprüfen zu lassen. Zudem wird in Frankreich oftmals das Abonnement eines Internetvertrages im Rahmen eines Mehrdienstevertrages angeboten wird. Anschlussinhaber können über das Internetabonnement neben dem Internetzugang, gleichzeitig auch Telefonanschluss sowie Fernsehprogramme empfangen und im Rahmen einer Flaterateabrechnung, alle Dienste im Rahmen einer festgesetzten monatlichen Zahlung pauschal begleichen (sog. Triple Play). ${ }^{1366}$ Neben der wirtschaftlichen Problematik, die im Falle einer totalen Zugangssperrung mit der Weiterzahlung des Abonnements, trotz Beschränkung der Nutzens verbunden ist, ist vor allem rechtlich relevant, dass die Zugangssperrung damit nicht nur einen klassischen Eingriff in die Informations- und Kommunikationsgrundrechte in Bezug auf den Internetzugang bedeutet, sondern auch zu einer Kontroverse zu sonstigen Kommunikations- und Informationsgrundrechten des Nutzers führt und technisch nur schwer auf einzelne Dienstleistungen beschränkt werden kann.

Wesentlicher Unterschied der beiden Entscheidungen ist darüber hinaus, dass mit der Zugriffssperrung nach Hadopi eine verfassungsrechtliche bedenkliche Umkehrung der Unschuldsvermutung einhergeht. ${ }^{1367}$ Vergleichbar der deutschen Rechtsordnung bestimmt Artikel 9 der Erklärung der Menschenrechte und Bürgerrechte von 1798, dass jeder Mensch so lange als unschuldig zu gelten hat, bis seine Schuld bewiesen ist. Über Hadopi wird dieser Grundsatz wesentlich angetastet. Das Gesetz bestraft nämlich nicht den Download von urhebergeschützten Werken durch eine bestimmte Person, sondern dass die Internetverbindung für unzulässiges Filesharing verwendet wurde (Art. L336-3 UrhG). Um die Kontroverse zur Unschuldsvermutung zu entschärfen und die verfassungsrechtlichen Bedenken dieses Vorgehens zu kompensieren, hatte das Conseil Constitutionnel eine zusätzliche richterliche Kontrolle vor Vollstreckung der Nutzersperrung angeordnet.

1366 Fink in: carta-online, Beitrag v. 13.8.2009, „Internet-Zugangssperren: Wäre Three-Strikes in Deutschland verfassungsgemäß?“, abrufbar unter: http://carta.info/13113/ (zuletzt abgerufen 20.5.2012). Der neue L. 335-7 Satz 2 enthält deshalb ausdrücklich die Formulierung, dass soweit „dieser Dienst [Online-Kommunikationsdienst] im Rahmen eines Gesamtangebots erworben wird, welches auch andere Arten von Diensten umschließt, wie beispielsweise Telefon oder Fernsehen, sind diese anderen Dienste von der Zugangssperre nicht betroffen.

1367 Con. const., Décision n 2009-580 DC, Erwägungsgrund 17, abrufbar unter:

http://www.conseil-constitutionnel.fr/conseil-constitutionnel/francais/les-decisions/acces-pardate/decisions-depuis-1959/2009/2009-580-dc/decision-n-2009-580-dc-du-10-juin-

2009.42666.html (zuletzt abgerufen 20.5.2012). In die Richtung Spies, MMR 2009, 437 (438). 
d) Fazit

Es bestehen grundsätzliche Unterschiede hinsichtlich einer Sperrung vereinzelter Webinhalte (Loppsi) und einer totalen Sperrung des gesamten Internetzugangs (Hadopi). In Anbetracht der unterschiedlichen Intensivität der Grundrechtseingriffe und der weitergehenden Probleme, welche mit dem Hadopi-Ansatz verbunden sind, ist die unterschiedliche Beurteilung des Verfassungsrates hinsichtlich der Notwenigkeit einer vorherigen richterlichen Genehmigung nachvollziehbar.

\section{Art. 4 Loppsi 2 im Vergleich zum deutschen Recht}

Nach Maßgabe des Conseil Constitutionnel ist nach französischem Recht ein Gesetz, dass die Sperrung eines kinderpornographischen Inhaltes im Internet anordnet folglich ohne richterliche Kontrolle verfassungsgemäß. Die nachfolgende Analyse soll zunächst die Rechtsgrundlage des französischen Rechts mit der Rechtsgrundlage vergleichen, wie sie im Zugangserschwerungsgesetz vorgesehen war, um anschließend aufzuzeigen, dass die französische Regelung den Anforderungen an eine verfassungsverträgliche Sperrgrundlage nach deutschem Recht nicht genügen würde.

\section{Rechtsgrundlage im Vergleich}

a) Anknüpfung an strafrechtliches Verständnis

Im Vergleich ist Ausgestaltung der Rechtsgrundlage des Art. 4 Loi n ${ }^{\circ}$ 2011-267 ähnlich der im Zugangserschwerungsgesetz über $\int 1$ Abs. 1 i.V.m. \ 2 Abs. 1 u. 2 normierten Eingriffsbefugnis der Behörde: In beiden Fällen ist die Ermächtigung darauf gerichtet kinderpornographische Angebote, welche die Tatbestandsvoraussetzung des strafrechtlichen Kinderpornographieverbotes erfüllen, mit einer Zugriffserschwerung zu belegen. Im Zugangserschwerungsgesetz wählte der Gesetzgeber die unmittelbare Bezugnahme zum strafrechtlichen Verbot der Verbreitung kinderpornographischer Schriften nach \184b StGB. In Art. 4 Loi n 2011-267 verlangt der französische Gesetzgeber für die Sperrpflicht, dass Angebote den Straftatbestand des Art. 227-23 Code Pénal (französisches Strafgesetzbuch) erfüllen.

Aufgrund eines unterschiedlichen Rechtsverständnisses von „Kind“, sind die zu sperrenden Inhalte nach beiden Rechtsgrundlagen damit nur faktisch gleichlaufend: Während nach deutschem Rechtsverständnis „Kinder“ und damit auch die Beteiligten einer kinderpornographischen Darstellung i.S.d. \184b StGB, Personen unter 14 Jahren sind, ${ }^{1368}$ wird nach französischen Verständnis der Begriff der „Minderjährigen“, also „mineur“ verwendet, welcher entsprechend dem Umkehr-

$1368 \mathrm{Zu}$ den Tatbestandsmerkmalen des $\int 184 \mathrm{~b}$ StGB bereits 2. Teil A. III. 1. a) . 
schluss zu Art. 227-23 Satz 2, Personen bis 18 Jahre einschließt. ${ }^{1369}$ Damit geht die Sperrverpflichtung des Art. 4 Loi $\mathrm{n}^{\circ}$ 2011-267 weiter als die Sperrverpflichtung, die im $\ 1$ Abs. 1 i.V.m. $\ 2$ Abs. 1 u. 2 ZugErschwG angelegt war.

b) Konsequenz für europäischen Umsetzungsbedarf

Im Bezug auf die europäischen Harmonisierungsbemühungen hinsichtlich einer Richtlinie des Europäischen Parlaments und des Rates zur Bekämpfung des sexuellen Missbrauchs und der sexuellen Ausbeutung von Kindern sowie der Kinderpornographie besteht bei der französische Regelung insofern kein Umsetzungsbedarf. Auch das von der Richtlinie vorgegebene europäische Verständnis von „Kind“ und „Kinderpornographie“ entsprechend des Art. 2 lit. a des Richtlinienvorschlags ( $\mathrm{KOM}(2010) 94$ endg.) ist darauf ausgerichtet ist, den Kreis der schutzbedürftigen Personen auf Kinder bis 18 Jahre auszuweiten. ${ }^{1370}$ Gleiches gilt auch in Bezug auf die explizite Einbeziehung von Personen „mit kindlichen Erscheinungsbild“ in den strafbewehrten Tatbestand des Art. 227-23 Code Pénal. Über die Formulierung „Les dispositions du présent article sont également applicables aux images pornographiques d'une personne dont l'aspect physique est celui d'un mineur, sauf s'il est établi que cette personne était âgée de dix-huit ans au jour de la fixation ou de l'enregistrement de son image" bestimmt die französische Strafnorm, dass auch solche kinderpornographischen Angebote den Straftatbestand erfüllen, die Personen abbilden, die in ihrem äußeren Erscheinungsbild minderjährig anmuten, soweit nicht das erwachsene Alter der Beteiligten erwiesen ist. Eine vergleichbare Formulierung findet sich in der deutschen Strafnorm des $\$ 184 \mathrm{~b}$ StGB nicht, obgleich die Rechtsprechung bisweilen von einer Einbeziehung des kindlichen Erscheinungsbildes innerhalb der deutschen Strafnorm ausgeht. ${ }^{1371}$

1369 Art. 227-23 Code Pénal: „Le fait, en vue de sa diffusion, de fixer, d'enregistrer ou de transmettre l'image ou la représentation d'un mineur lorsque cette image ou cette représentation présente un caractère pornographique est puni de trois ans d'emprisonnement et de $300000 \mathrm{~F}$ d'amende. Le fait de diffuser une telle image ou représentation, par quelque moyen que ce soit, de l'importer ou de l'exporter, de la faire importer ou de la faire exporter, est puni des mêmes peines. Les peines sont portées à cinq ans d'emprisonnement et à $500000 \mathrm{~F}$ d'amende lorsqu'il a été utilisé, pour la diffusion de l'image ou de la représentation du mineur à destination d'un public non déterminé, un réseau de télécommunications. Les dispositions du présent article sont également applicables aux images pornographiques d'une personne dont l'aspect physique est celui d'un mineur, sauf s'il est établi que cette personne était âgée de dix-huit ans au jour de la fixation ou de l'enregistrement de son image."

1370 Zum Richtlinienvorhaben ausführlich 5. Teil A. .

1371 Zur Problematik einer Einbeziehung des kindlichen Erscheinungsbildes in den Tatbestand in Bezug auf das Bestimmtheitsgebot des Art. 103 GG oben 2. Teil A. III. 1. a) . 
c) Verfahren im Vergleich

Weitestgehende Kongruenz besteht hingegen hinsichtlich des gesetzlich vorgeschriebenen Verfahrens. Beide Ermächtigungsgrundlagen sind auf die gesetzliche Verpflichtung aller inländischen Access-Provider durch eine Verwaltungsbehörde ausgerichtet. Während das BKA über $\int 1$ ZugErschwG für die Einordnung des Angebotes als kinderpornographisch sowie die Erstellung und Weiterleitung der Sperrliste zuständig sein sollte, ist im französischen Art. 4 Loi n ${ }^{\circ} 2011-267$ die Einordnungs- und Weiterleitungsbefugnis dem l'Office central de lutte contre la criminalité liée aux technologies de l'information et de la communication) zugewiesen. ${ }^{1372}$ Nach Übermittlung einer „Sperrliste“ mit Webadressen kinderpornographischer Angebote, müssen die Provider die in der Liste genannten Angebote unverzüglich sperren. Es handelt sich in beiden Fällen damit um eine Inanspruchnahme der Access-Provider für staatliche Zwecke. ${ }^{1373}$

Nähere Angaben über die technische Ausgestaltung der vorzunehmenden Sperrmaßnahme enthalten beide Regelungen nicht. Während über $\int 2$ Abs. 2 ZugErschwG zumindest eine weitere Erläuterung der technischen Realisierung und die Nennung einer Mindestvoraussetzung für die Sperrung vorgegeben war: „Für die Sperrung dürfen vollqualifizierte Domainnamen, Internetprotokoll-Adressen und Zieladressen von Telemedienangeboten verwendet werden. Die Sperrung erfolgt mindestens auf der Ebene der vollqualifizierten Domainnamen, deren Auflösung in die zugehörigen Internetprotokoll-Adressen unterbleibt." Finden sich nähere Bedingungen zur Realsiering der Verpflichtung nach Art. 4 Loi n ${ }^{\circ} 2011$ 267 entsprechend Satz 2 lediglich in einer ,noch zu erlassenden Verordnung“. Damit ist die Ausgestaltung der Sperrung nach französischem Recht der Exekutive überlassen und im Zeitpunkt des Inkrafttretens des Gesetzes noch nicht fixiert. Welche näheren Bedingungen die zukünftige Verordnung enthalten wird, ist zum jetzigen Zeitpunkt nicht abzuschätzen, es darf jedoch vermutet werden, dass auch der französische Verordnungsgeber sich auf eine technologieneutrale Formulie-

1372 Die sog. OCLCTIC ist eine nationale Behörde die im Rahmen von Kriminalität in Zusammenhang mit Informations- und Kommunikationstechnologien eingesetzt wird. Die Behörde ist angegliedert an die Generaldirektion der französischen Polizei und Teil der nationalen Kriminalpolizei. Im Wesentlichen unterteilen sich die Aufgaben der OCLCTIC auf operative Tätigkeiten, wie die technischen Untersuchungen im Rahmen von Straftaten und strafrechtlichen Ermittlungen in Kommunikationsmedien sowie organisatorische Tätigkeiten, wie die Organisation länderübergreifender Tätigkeiten sowie Schulungen und Fortbildungen. Informationen zum Tätigkeitsbereich abrufbar unter: http://www.securiteinfo.com/legal/OCLCTIC.shtml (zuletzt abgerufen 20.5.2012).

1373 Zur Inanspruchnahme der Provider für staatliche Zwecke der Sperrung von Webangeboten bereits oben 3. Teil A. II. 
rung beschränken wird, um die Aktualität des Gesetzes auch bei fortschreitender technischer Entwicklung zu wahren. ${ }^{1374}$

d) Kreis der Verpflichteten im Vergleich

Unterschiede bestehen jedoch hinsichtlich des Kreises der Verpflichteten. Zwar handelt es sich in beiden Fällen um eine staatliche Inpflichtnahme der AccessProvider, im \2 Abs. 1 ZugErschwG war jedoch eine Beschränkung auf diejenigen Provider vorgesehen, „die eine Nutzung von Informationen über ein Kommunikationsnetz für mindestens 10000 Teilnehmer oder sonstige Nutzungsberechtigte ermöglichen“. Die gesetzliche Intention einer Beschränkung des Adressatenkreises beruhte auf der Annahme, dass große Provider, die mit der Sperrung verbundenen finanziellen Lasten besser tragen, als Provider mit kleinem Nutzerkreis. ${ }^{1375}$ Eine kongruente Einschränkung findet sich innerhalb der französischen Regelung des Art. 4 Loi n 2011-267 hingegen nicht. Die Frage nach einer eventuellen Notwendigkeit einer finanziellen Ausgleichspflicht für die Inanspruchnahme der Provider überlässt der Gesetzgeber ebenfalls den näheren Bestimmungen der noch zu erlassenden Verordnung.

Anders als nach der deutschen Intention des $\int 4$ ZugErschwG ist die Sperrung des kinderpornographischen Angebotes nach Art. 4 Loi n 2011-267 nicht an das Erfordernis einer gleichzeitigen Umleitung des Internetnutzers an einen vordefinierten Stopp-Server, der auf die Gründe und Notwendigkeit der Sperrmaßnahme sowie Kontaktmöglichkeiten im Falle eventueller Rückfragen aufmerksam macht, gekoppelt. Dagegen mangelt es der französischen Sperrverpflichtung, im Gegensatz zum Gesetzesversuch des Zugangserschwerungsgesetzes, an der Normierung einer Bezugnahme zur Löschung. Während nach deutschen Verständnis die Sperrung nur ultima-ratio bei erfolgloser Löschung eingreifen durfte, ist die Sperrung nach Art. 4 Loi n 2011-267 ohne vorhergehende Löschversuche zulässig.

e) Fazit

Festzustellen bleibt demnach, dass sich die Rechtsgrundlagen zur Sperrung kinderpornographischer Inhalte nach französischen Recht im Vergleich zum deutschen Versuch des Zugangserschwerungsgesetzes im ihren Grundzügen ähneln. In beiden Fällen wählte der Gesetzgeber eine unmittelbare staatliche Verpflichtung der Access-Provider zur Sperrung kinderpornographischer Angebote, die den jeweiligen Straftatbestand des Kinderpornographieverbotes erfüllen. Als we-

1374 So die gesetzgeberische Intention bei Formulierung des Zugangserschwerungsgesetzes, BT-Drs. 16/12850, S. 6.

1375 BT-Drs. 16/12850, S. 6; hierzu Volkmann in: Spindler/Schuster, Recht der elektronischen Medien, 2011, \ 2 ZugErschwG, Rn. 2. 
sentlicher Unterschied ist herauszustellen, dass die französische Norm keinen Subsidiaritätsgrundsatz für die Sperrung vorsieht.

\section{Verfassungsmäßigkeit der Norm nach deutschem Recht?}

Obgleich die Ausgestaltung der französischen Eingriffsbefugnis in den Internetbestand zur Unterbindung kinderpornographischer Inhalte dem deutschen Gesetzesversuch des Zugangserschwerungsgesetzes ähnelt, finden sich vereinzelt Unterscheide, welche sich grundlegend auf die Verfassungsmäßigkeit einer solchen Bestimmung nach deutschen Grundrechtsverständnis auswirken würden.

Grundsätzlich würden in Übertragung der französischen Rechtsgrundlage des Art. 4 Loi n 2011-267 ins deutsche Recht, die auf Grundlage dessen durchgeführten Sperren in Grundrechte der am Sperrprozess Beteiligten, wie der AccessProvider, der Nutzer sowie der Content-Provider eingreifen. ${ }^{1376}$ Die gesetzliche Regelung wäre, als ein die Grundrechte einschränkendes Gesetz somit dem Grundsatz der Verhältnismäßigkeit unterworfen und müsste einen legitimen Zweck erfüllen, geeignet, erforderlich und angemessen sein. ${ }^{1377}$ Hinsichtlich des legitimen Zwecks und der Geeignetheit ergeben sich keine Unterschiede. Der französische Verfassungsrat stellt in Übereinstimmung mit der Rechtsprechung des Bundesverfassungsgerichts ${ }^{1378}$ hinsichtlich der Geeignetheit der Maßnahme auf die weite Einschätzungsprärogative ab, die nur bei offensichtlicher Ungeeignetheit verletzt ist. ${ }^{1379}$

a) Mangelnde Erforderlichkeit

Wenngleich die Regelung des Art. 4 Loi n 2011-267 bezüglich ihrer Geeignetheit nach deutschem Recht nicht verfassungsrechtlich zu verwerfen wäre, so würde die Norm jedoch hinsichtlich ihrer Erforderlichkeit dem nationalen Verfassungsverständnis nicht genügen. Im verfassungsmäßigen Element der Erforderlichkeit findet das Prinzip des geringstmöglichen Eingriffs seinen Ausdruck. ${ }^{1380}$ Danach ist nur dasjenige staatliche Mittel rechtstaatlich „erforderlich“, dass bei gleicher Ge-

\footnotetext{
1376 Im Einzelnen zu den tangierten Grundrechten insgesamt 3. Teil B.

1377 BVerfGE 19, 342 (347 f.); BVerfGE 43, 242; BVerfG, NVwZ 2006, 1282; BGH, NStZ, 2009, 324;BVerfGE 44, 353; allgemein zum Verhältnismäßigkeitsgrundsatz und seinen rechtlichen Ausgestaltungen, Stern in: Isensee/Kirchhof, Hdb. StaatsR, 2002, Bd. V, J 20 IV, Rn. 7b; Hirschberg, Der Grundsatz der Verhältnismäßigkeit, 1981, S. 26 ff.

1378 BVerfGE 77, 84 (104); BVerfGE 90, 145 (173 ff.); BVerfGE 109, 279 (336 ff.).

1379 BVerfGE 77, 84 (104); BVerfGE 90, 145 (173 ff.); BVerfGE 109, 279 (336 ff.).

1380 Lerche, Übermaß und Verfassungsrecht, 1961, S. 19; darauf bezugnehmend Billmeier, Die Düsseldorfer Sperrungsverfügung, 2007, S. 117.
} 
eignetheit, die relativ mildeste Maßnahme darstellt. ${ }^{1381}$ Innerhalb der Ermächtigungsgrundlage des Art. 4 Loi $n^{\circ}$ 2011-267 ist nur die Sperrung als Mittel zur Bekämpfung von Kinderpornographie vorgesehen. Nach deutschem Verfassungsrecht würde sich eine alleinige Normierung der Sperrmöglichkeit allerdings verbieten. ${ }^{1382}$ Aufgrund der punktuellen Wirkweise und der geringeren grundrechtlichen Belastungen muss in jeden Fall die Maßnahme der Löschung primär zur Anwendung kommen und auch als solche innerhalb der gesetzlichen Ermächtigungsgrundlage angeführt sein. Verfassungsrechtlich nicht zu beanstanden ist es daher, wenn die Sperrung zur Absicherung des Schutzziels als subsidiäres Mittel zur Anwendung kommt. Der Exklusivitätscharakter der Sperrung gegenüber der Löschung muss in einem solchen Fall bereits innerhalb der gesetzlichen Formulierung hinreichend abgesichert sein, um die verfassungsrechtlichen Anforderungen an die Erforderlichkeit der gesetzlichen Maßnahme zu wahren. ${ }^{1383}$ Die französische Regelung des Art. 4 Loi n ${ }^{\circ}$ 2011-267 wird diesen Anforderungen nicht gerecht, da sie zur sofortigen Sperrung des kinderpornographischen Inhaltes ermächtigt.

b) Verhältnismäßigkeit im engeren Sinn - Angemessenheit

In Gegenüberstellung zu den innerstaatlichen Kriterien an die Angemessenheit ist die französische Regelung in vielen Punkten unzureichend.

c) Kommunikationsgrundrechte - fehlender Richtervorbehalt

Zunächst fehlt die Normierung eines gesetzlich angeordneten Richtervorbehalts der als verfahrensrechtliches Kompensationsmittel, die Verfassungsmäßigkeit der Regelung vor dem Hintergrund der mangelnden Rechtsschutzmöglichkeit beim heimlichen und intensiven Eingriff in die Kommunikationsgrundrechte sicherstellen könnte. Zwar ist ein solcher Richtervorbehalt nach der Rechtsprechung des französischem Verfassungsrates nicht zwangsläufig vorgeschrieben, nach deutschen Recht sind die Kommunikationsgrundrechte, aufgrund ihrer enormen Bedeutung für die Demokratie nur unter besonderen Voraussetzungen einschränkbar. Art. 4 Loi n 2011-267 würde zwar den abstrakten Anforderungen an die zusätzliche Voraussetzung eines „allgemeinen Gesetzes“ im Sinne des Art. 5 Abs. 2 GG genügen, überdies wäre die Einschränkung des Grundrechts wegen der ausufernden Wirkweise der Sperrung nur über eine zusätzliche verfahrensrechtliche Kompensation eines Richtervorbehalts zu vertreten. Hierdurch kann ein

1381 BVerfGE 67, 157 (176); Huster/Rux in: Epping/Hillgruber, Art. 20 GG, Rn. 183; Grzeszile in: Maunz/Dürig, Art. 20 GG, Rn. 113, 114; Sommermann in: v. Mangoldt/Klein/Starck, Art. 20 GG, Rn. 304; Jarass in: Jarass/Pieroth, Art. 20 GG, Rn. 85; Reuter, JURA 2009, 511 (513).

1382 Zur Diskussion um die Notwenigkeit des Grundsatzes „Löschen vor Sperren“, 3. Teil B. I. 2. c)

1383 Zur Herleitung der verfassungsrechtlichen Anforderungen an eine Sperrvorschrift für kinderpornographische Inhalte vgl. gesamter 3. Teil . 
schonender Ausgleich zwischen der weitläufigen Einschränkung der Kommunikationsgrundrechte und dem Ziel der Sperrmaßnahme sichergestellt werden. Auch wenn der Verfassungsrat die Notwendigkeit eines Richtervorbehalts nach französischen Recht nur für den Fall einer totalen Zugangssperrung, wie sie das HadopiGesetz vorsieht, fordert, ist nach der bisherigen Tendenz der nationalen Rechtsprechung davon auszugehen, dass auch für die „mildere Beschränkung“ der Zugriffssperrung einen Richtervorbehalt erfordern würde. ${ }^{1384}$

\section{d) Einhaltung rechtsstaatlicher Prinzipien}

Die gesetzliche Ausgestaltung des Sperrverfahrens wäre nach deutschem Verfassungsrecht unzureichend. So beschränkt sich die gesetzliche Formulierung des Art. 4 n 2011-267 lediglich auf die Anordnung einer Sperrung, während nähere Bedingungen der Maßnahme innerhalb einer Verordnung zu regeln sind. Diese Formulierung würde nach deutschem Rechtsverständnis mit dem Bestimmtheitsgrundsatz kollidieren und in Kontroverse zum Wesentlichkeitsgrundsatz des Art. 20 Abs. 2, 3 GG treten. Aufgrund der hohen Grundrechtsrelevanz, die jeder internetbasierten Sperrmaßnahme zugrundeliegt, besteht grundsätzlich ein Bedürfnis nach einer parlamentarischen Entscheidung. ${ }^{1385}$ Der Gesetzgeber muss also die Auswahl der anzuwendenden Sperrtechnologie selbst in der Formulierung der gesetzlichen Sperverpflichtung festlegen und darf diesbezüglich nicht auf eine zukünftige Verordnung verweisen. ${ }^{1386}$

\section{e) Entschädigungspflicht}

Darüber hinaus mangelt es der Regelung an der Normierung einer angemessenen Entschädigung als Ausgleich für die Inanspruchnahme der Provider zur Gefahrenabwehr und damit an der Verhältnismäßigkeit des Eingriffs in Art. 12 GG sowie hinsichtlich Art. 14 Abs. 1 Satz 2 GG. Zwar schreibt die französische Formulierung hier vor, dass die Notwendigkeit einer finanziellen Ausgleichzahlung ebenfalls in der Verordnung geregelt werden soll, nach deutschem Rechtsver-

1384 So in der Tendenz das Bundesverfassungsgericht im Fall der Online-Durchsuchung, BVerfGE 120, 274.

1385 BVerfGE 46, 47 (79); Herzog/Grzeszile in: Maunz/Dürig, Art. 20 GG, Rn. 107; ausführlich Sommermann in: v. Mangoldt/Klein/Starck, Art. 20 GG, Rn. 267 ff. mwN.

1386 In die Richtung ebenso in Bezug auf das Zugangserschwerungsgesetz Heckmann, Stellungnahme der Sachverständigen im Rechtsausschuss v. 8.11.2010, S. 18, abrufbar unter: http://www.bundestag.de/bundestag/ausschuesse17/a06/anhoerungen/archiv/03_Zugangsers chwerung/04_Stellungnahmen/Stellungnahme_Heckmann.pdf (zuletzt abgerufen 20.5.2012); ebenfalls Schnabel, JZ 2009, 996 (998); Spoenle, jurisAnwZert ITR 17/2009, Anm. 2; Frey/Rudolph, CR 2009, 644 (647), wobei letztere 3 Autoren die Wesentlichkeitsaspekte mit Aspekten der Bestimmtheit gleichsetzen. 
ständnis wäre eine solche Formulierung aber nicht verfassungsrechtlich ausreichend:

Es steht aufgrund der Budgethoheit des Parlaments allein dem Gesetzgeber zu über Art und Ausmaß der Entschädigung zu bestimmen. ${ }^{1387}$ Im Art. 4 Loi n ${ }^{\circ}$ 2011-267 ist die Frage der Entschädigung jedoch in die Entscheidungsbefugnis der Exekutive übertragen. Das Bundesverfassungsgericht hat im Hinblick auf die ausgleichspflichtige Enteignung nach Art. 14 Abs. 3 GG sowie auch für die ausgleichspflichtige Inhalts- und Schrankenbestimmung des Art. 14 Abs. 1 Satz 2 GG herausgestellt, dass „Inhalt und Schranken des Eigentums zu bestimmen (...) grundsätzlich Sache des Gesetzgebers [ist]. Er ist gehalten, die verfassungsrechtlichen Grenzen inhaltsbestimmender Gesetze zu wahren, und darf, wenn er ein zwingendes Verbot ausspricht, nicht darauf vertrauen, daß die Verwaltung oder die Gerichte Verletzungen der Eigentumsgarantie gegebenenfalls durch ausgleichende Vorkehrungen oder Geldleistungen vermeiden. Soweit kompensatorische Entschädigungsansprüche begründet werden sollen, kann dies ohnehin, auch mit Rücksicht auf das Budgetrecht des Parlaments, nur durch ein Gesetz geschehen. “1388 Im Kern dient diese vom Bundesverfassungsgericht herausgearbeitete Pflicht, die Entschädigung innerhalb eines Parlamentsgesetzes festzulegen, einer „Kompetenzwahrung des Parlaments“: 1389 Allein dem Parlament kommt die Verantwortung über den staatlichen Haushalt zu, denn nur das Parlament kann besten überschauen, welche laufenden und zukünftigen Belastungen der Staatskasse zu erwarten sind und in welcher Höhe öffentlichen Gelder zur Verfügung stehen. ${ }^{1390}$ Deshalb wäre nach innerstaatlichem Rechtsverständnis nur eine unmittelbare Formulierung einer Entschädigungspflicht innerhalb desselben oder eines anderen Parlamentsgesetzes verfassungsrechtlich zulässig, um den Eingriff in die Berufsund Eigentumsfreiheit der Access-Provider auszugleichen und die Angemessenheit der Rechtsgrundlage zu wahren.

\section{f) Wissenschaftsfreiheit}

Überdies wäre die Regelung des Art. 4 Loi n 2011-267 auch hinsichtlich der Einschränkung der Wissenschaftsfreiheit nicht ausreichend. Dadurch dass der französische Gesetzgeber den Adressatenkreis der Regelung auf sämtliche AccessProvider ausbreitet und keinerlei Ausnahmen für Forschungseinrichtungen vor-

1387 BVerfGE 46, 268 (287); BVerfGE 100, 226 (245); Depenheuer in: v. Mangold/Klein/Starck, Art. 14 GG, Rn. 437; Wieland in: Dreier, Art. 14 GG, Rn. 108 f.; Papier in: Maunz/Dürig, Art. 14 GG, Rn. 592 ff.

1388 Ausdrücklich BVerfGE 100, 226 (245).

1389 Depenheuer in: v. Mangold/Klein/Starck, Art. 14 GG, Rn. 437.

1390 Wieland in: Dreier, Art. 14 GG, Rn. 37 mwN; Zu den Anforderungen an eine verfassungsverträgliche Sperrregelung hinsichtlich der Wissenschaftsfreiheit des Art. 5 Abs. 3 GG sowie die Kritik an der Fassung des Zugangserschwerungsgesetzes, 4. Teil C. II. 5. c) . 
sieht, würde die Norm einen unangemessenen Eingriff in die Wissenschaftsfreiheit des Art. 5 Abs. 3 Satz 1, Var. 2 GG bedeuten und höchstwahrscheinlich einer verfassungsrechtlichen Prüfung durch das Bundesverfassungsgericht nicht standhalten.1391

\section{g) Mangelnde Gesetzesstruktur}

Im Allgemeinen würde es der Regelung des Art. 4 Loi n 2011-267 nach deutschem Verfassungsverständnis vor allem an der notwendigen Transparenz des Verfahrens mangeln. Die Formulierung einer Sperrpflicht für kinderpornographische Inhalte, welche lediglich innerhalb einer einzelnen Rechtsvorschrift verankert ist, birgt die Gefahr einer Übertragung auf andere Rechtsgebiete und verleiht ihr den Charakter einer Generalermächtigung zum staatlichen Eingriff in den Internetbestand. Diesbezüglich sollte eine Regelung gewählt werden, die den Sperransatz innerhalb eines eigenständigen Gesetzes festlegt. Hierbei könnte neben der Normierung von Rechtsschutzmöglichkeiten sowie Sanktionen bei Zuwiderhandlungen auch ausdrücklich der Exklusivitätscharakter der Maßnahme herausgestellt werden, um eine Überleitung auf andere Bereiche zu verhindern.

\section{h) Europäische Vorgaben}

Auch im Lichte der Richtlinie des Europäischen Parlaments ist die französische Regelung in ihrer derzeitigen Ausgestaltung unzureichend. ${ }^{1392}$ Auch wenn die derzeitige Regelung des französischen Loppsi 2-Gesetzes der Prüfung durch den französische Verfassungsrat standhielt, ist der französische Gesetzgeber aufgrund der europäische Harmonisierungsbemühungen verpflichtet die Regelung des Art. 4 Loi n ${ }^{\circ}$ 2011-267 nachzubessern und an die europäischen Vorgaben anzupassen. Aufgrund der bereits erfolgten Angleichung des strafrechtlichen Tatbestandes der Kinderpornographie gemäß Art. 227-23 Code Pénal an die Richtlinienvorgaben, ${ }^{1393}$ würde der französische Gesetzgeber, anders als Deutschland, dabei nicht vor der Problematik unterschiedlichem Kinderpornographieverständnisses unterstehen. ${ }^{1394}$ Indessen müsste die Norm des Art. 4 Loi n 2011-267 aber um die explizite Einbeziehung der Löschung des kinderpornographischen Inhalts ergänzt werden sowie eine eigenständige Formulierung eines möglichen Rechtsschutzes beinhalten. Die Angleichung der französischen Norm an die Harmonisierungs-

$1391 \mathrm{Zu}$ den Anforderungen an die Wahrung der Wissenschaftsfreiheit der „forschenden“ AccessProvider, oben 3. Teil B. IV.

1392 Zur Richtlinie oben 5. Teil .

1393 Die Angleichung beruht auf der Umsetzung des Rahmenbeschluss 2004/68/JI des Rates vom 22.12.2003 zur Bekämpfung der sexuellen Ausbeutung von Kindern und der Kinderpornographie, ABl. 2004, Nr. L 13, S. 44, der maßgeblich bereits die gleichen Definitionen von Kind und Kinderpornographie enthielt, wie die gegenwärtige Richtlinie, bereits 5. Teil B. II. 2. a) (cc) .

1394 Zur Diskrepanz der Richtlinienvorgaben zum deutschen Recht, 5. Teil B. II. 2. 
vorgaben würde freilich auch eine Angleichung an die Verfassungsverträglichkeit nach deutschen Recht bedeuten, da die Erforderlichkeit der Maßnahme dadurch nicht von vorneherein auszuschließen wäre.

Insgesamt bleibt folglich herauszustellen, dass nach deutschem Rechtsverständnis eine vergleichbare Regelung in ihrer derzeitigen Form verfassungswidrig wäre.

\section{Fazit}

Betrachtet man die Sperrungen aus rechtlicher Perspektive so finden sich starke Überschneidungen in der Wahl des legislatorischen Mittels. Beide Rechtsgrundlagen sind auf die staatliche Inanspruchnahme der Access-Provider zur Vornahme technischer Sperrungen von kinderpornographischen Webangeboten ausgerichtet. Während Frankreich über Art. 4 Loi n 2011-267 die Norm tatsächlich als geltendes Gesetz in die Rechtsordnung integriert hatte, hat Deutschland durch die Aussetzung des Zugangserschwerungsgesetzes von einem entsprechendem legislatorischen Ansatz Abstand genommen.

Vor allem die mangelnde Bezugnahme zum technischen Mittel der Löschung im französischen Recht ließe den gewählten Ansatz nach deutschem Recht an der Erforderlichkeit der Maßnahme scheitern. Der französische Gesetzgeber übersieht in dem Zusammenhang völlig, dass die Entfernung des kinderpornographischen Inhaltes das primäre Mittel sein muss, um einen als kinderpornographisch attestierten Inhalt aus dem Internet zu entfernen. Zudem wäre die Übertragung der näheren Bedingungen der Anwendung der Norm in die Verordnungsbefugnis der Exekutive nach nationalem Verfassungsverständnis problematisch. 



\section{Teil Gesamtwürdigung}

Festzustellen ist, dass die Frage nach der Notwendigkeit staatlicher Eingriffsbefugnisse im Internet zur Unterbindung kinderpornographischer Angebote zu einer kontroversen Debatte geführt hat. Einigkeit besteht darin, dass der Staat aus Art. 2 Abs. 1 GG i.V.m. Art. 1 Abs. 1 GG verpflichtet ist, alle Maßnahmen zu ergreifen, um den Kindes- und Jugendschutz zu garantieren. Ob der Jugendschutz auch zu technischen Eingriffen in den Internetbestand über gesetzliche Sperrverpflichtungen für Access-Provider zur Unterbindung kinderpornographischer Webinhalte berechtigt, führt zu zahlreichen Diskussionen. Auch wenn der Gesetzgeber letztlich eine Abkehr vom Sperransatz favorisiert und ausschließlich die Löschung der Inhalte verfolgt, ist ein legislatorisches Sperrkonzept allerdings nicht per se als verfassungswidrig anzusehen. Für eine verfassungsverträgliche Sperrlösung ist der Gesetzgeber verpflichtet legislatorische Sicherungsmittel festzusetzen, um den Anwendungsbereich der Sperrmaßnahme sowie die Beeinträchtigung der Grundrechte Dritter zu beschränken. Im Vordergrund muss hierbei die ultima-ratioAusrichtung stehen. Ein Sperransatz ist nur dann verfassungsrechtlich zulässig, wenn er zur Absicherung der Löschmaßnahme eingesetzt wird. Zur Kompensation der wirtschaftlichen Nachteile der verpflichteten Provider müssen finanzielle Entschädigungsklauseln vorgesehen sein.

Mit dem zunächst favorisierten Zugangserschwerungsgesetz versuchte der Gesetzgeber eben jenen Ansatz gesetzlich zu fixieren. Die tatsächliche Umsetzung blieb jedoch weit hinter den von der Verfassung gestellten Anforderungen zurück und musste folgerichtig zur ordnungsgemäßen Aufhebung führen. So wies das 
Gesetz erhebliche materielle Mängel auf, indem es die Wahl der Sperrmaßnahme in die Entscheidungsbefugnis der Access-Provider stellte, nur unzureichende verfahrensrechtliche Kompensationen für die Grundrechtseingriffe vorsah und den subsidiären Charakter der Sperrmaßnahme nicht hinreichend sicherstellte. Auch die Einräumung eines effektiven Rechtsschutzes sowie ausreichende Haftungsfreistellungen waren im Gesetz nicht vorgesehen. Zudem mangelte es an einer ausgleichenden Entschädigungspflicht für die Inanspruchnahme der Provider. Daneben wies auch das formelle Gesetzgebungsverfahren wesentliche Schwächen auf. Letztlich sind es diese Gründe, die zu einer Abkehr vom Gesetz veranlassten, die eigenmächtige Aussetzung des Gesetzes durch die Exekutive war indes kein verfassungsrechtlich verträglicher Akt, um den geäußerten Bedenken des Gesetzes entgegenzuwirken.

Auch die europäische Debatte um die Notwendigkeit von inhaltsbeschränkenden Maßnahmen zur Unterbindung von Kinderpornographie war seit dem Richtlinienentwurf $\mathrm{KOM}(2010) 94$ endg. parallel zur innerstaatlichen Diskussion von der Frage bestimmt, ob Löschen und Sperren einzuführen sind. Obgleich dieser Entwurf auch die verpflichtende Einführung von Sperrmaßnahmen vorsah, ist es nach der endgültigen Richtlinienfassung notwendig eine obligatorische Löschung einzuführen, indes nur fakultative Sperrmaßnahmen vorzusehen. Folglich wird der deutsche Gesetzgeber in der Pflicht sein, die derzeitigen Löschbemühungen auch gesetzlich abzusichern. Es ist zu erwarten, dass in Korrespondenz zur legislatorisch einzuführenden Löschung vor allem die europäische Definition des Kindes und der Kinderpornographie die größten Probleme der Umsetzung darstellen wird. Parallel zur innerstaatlichen Diskussion um die Verfassungsmäßigkeit des Zugangserschwerungsgesetzes hat der französische Conseil Constitutionnel eine vergleichbare Regelung des Art. 4 Loi n 2011-267 für verfassungsgemäß erklärt. Eine derartige Regelung wäre mangels Subsidiarität der Sperrung mit dem deutschen Verfassungsrecht unvereinbar. 


\begin{abstract}
ie Art und Weise wie dem Missbrauch des Internets als Verbreitungsmedium für Kinderpornographie Einhalt geboten werden kann, wird auf nationaler wie auch europäischer Ebene stark diskutiert. Im Mittelpunkt steht die Frage, ob auch unmittelbare Eingriffe in die Internetstruktur zwecks Unterbindung des Zugriffs auf kinderpornographische Webinhalte gerechtfertigt sind. Damit sind in erster Linie die Internetsperren von Access-Providern angesprochen und die Problematik, ob diese tatsächlich eine effektive Maßnahme in der Bekämpfung von Kinderpornographie verheißen.
\end{abstract}

Die Autorin untersucht dieses Thema primär anhand einer verfassungsrechtlichen Würdigung eines legislatorischen Sperransatzes zur Verhinderung des Zugriffs auf diese kinderpornographischen Webinhalte, bezieht aber auch die europäische Entwicklung mit ein. Neben der Herleitung allgemeiner verfassungsrechtlicher Anforderungen wird auch ein Überblick über das Zugangserschwerungsgesetz gegeben, das in den Jahren 2009/2010 als erster ernstzunehmender gesetzlicher Ansatz zur Inhaltsregulierung galt, letztlich jedoch praktisch nicht angewandt wurde. 